


\title{
Sustainability in Urban Planning and Design
}

\author{
Edited by Amjad Almusaed, \\ Asaad Almssad and Linh Truong - Hong
}



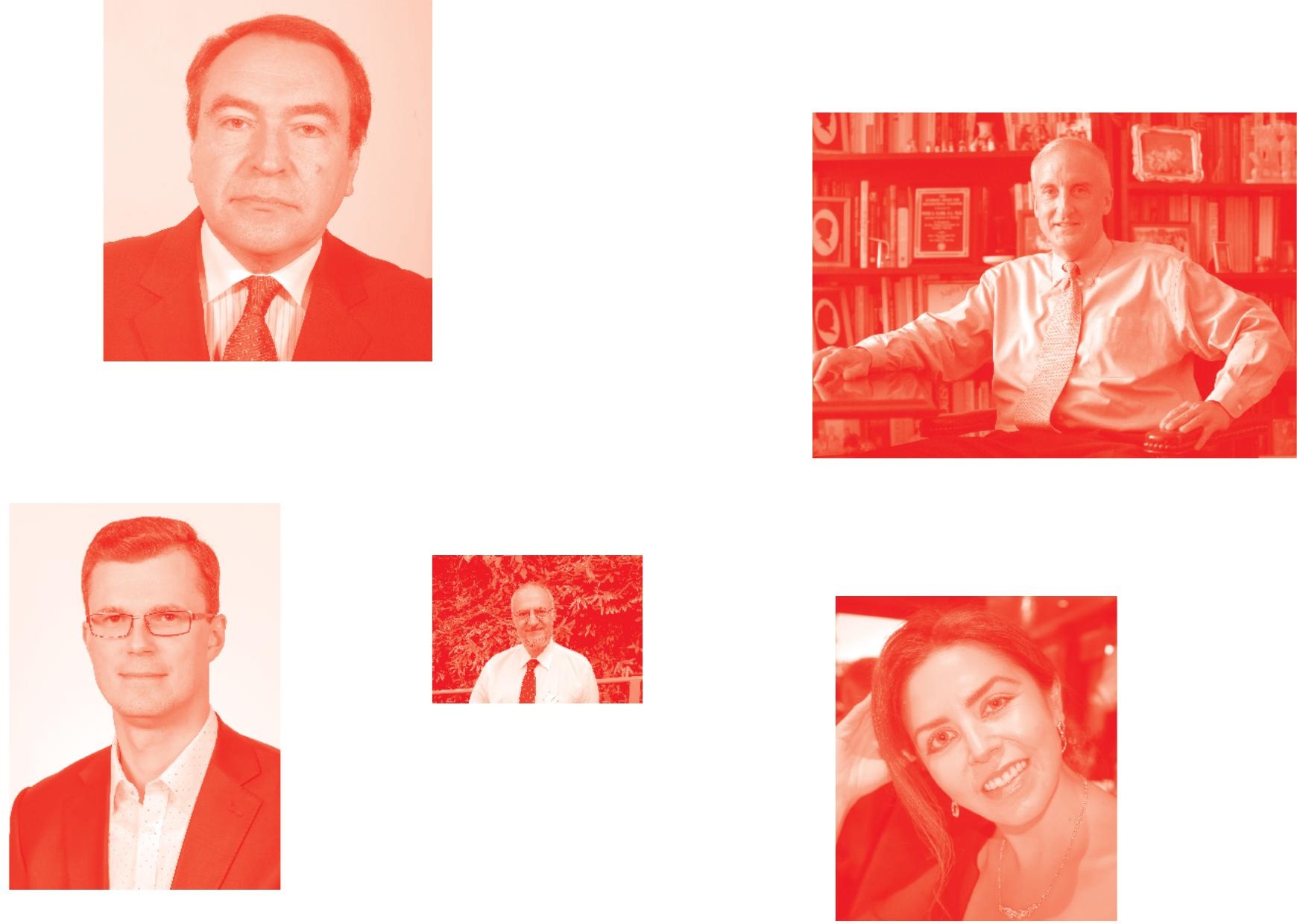

Supporting open minds since 2005
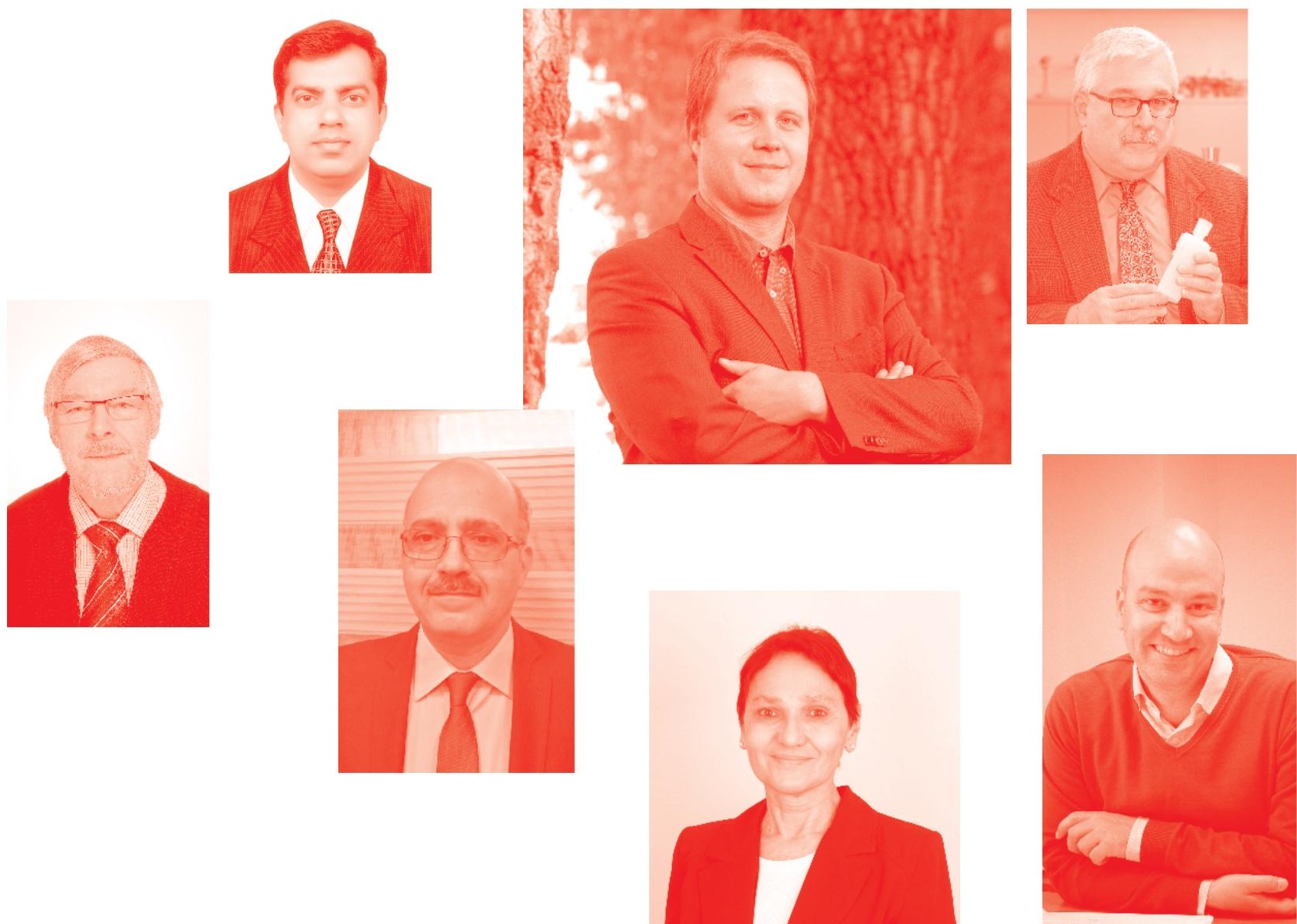
Sustainability in Urban Planning and Design

http : //dx. doi . org/10.5772/intechopen. 77648

Edited by Amjad Almusaed, Asaad Almssad and Linh Truong - Hong

\section{Contributors}

Bahareh Kalantar, Maruwan Salih Abu Bakr Amazeeq, Shattri Manosr, Mohammed Oludare Idrees, Husam Abdulrasool H. Al-Najjar, Hossein Mojaddadi Rizeei, Yuan Gao, Sara Shirowzhan, John Trinder, Paul Osmond, Qaaid Al-Saraify, David Grierson, Eleanna Panagoulia, Corina Shika Kwami, Nick Tyler, Le Anh Tu, Haider Jasim Essa Al-Saaidy, Vincent Onodugo, Nkeiru Ezeadichie, Jose Gerardo Carrillo Gonzalez, Jacobo Sandoval Gutiérrez, Francisco Pérez Martínez, Nurul Shakila Khalid, Sabirah Hilal, Yang Liu, Ning Li, Abdul Razak Mohamed, Ebenezer Owusu-Sekyere, Samuel Twumasi Amoah, Umut Doğan, Dávid Földes, Csaba Csiszár, Yinying He, Jana Moravcová, Jiri Pecenka, Denisa Pekna, Vendula Moravcova, Nikola Novakova, Carol Archer, Marvin Reid, Nadine Freeman-Prince, Brian Williams, Oluseyi Fabiyi, Amjad Zaki Almusaed, Asaad Almssad, Amir Shakibamanesh, Bita Ebrahimi, Balamurugan Paramasivam, Arumugavelu Illanthirayan, Peter Newman, Jeffrey Kenworthy, Sabirah Hilal, Colette CunninghamMyrie, Tamika Royal Thomas

(-) The Editor(s) and the Author(s) 2021

The rights of the editor(s) and the author(s) have been asserted in accordance with the Copyright, Designs and Patents Act 1988. All rights to the book as a whole are reserved by INTECHOPEN LIMITED. The book as a whole (compilation) cannot be reproduced, distributed or used for commercial or non-commercial purposes without INTECHOPEN LIMITED's written permission. Enquiries concerning the use of the book should be directed to INTECHOPEN LIMITED rights and permissions department (permissions@intechopen.com).

Violations are liable to prosecution under the governing Copyright Law .

\section{(cc) BY}

Individual chapters of this publication are distributed under the terms of the Creative Commons Attribution 3. 0 Unported License which permits commercial use, distribution and reproduction of the individual chapters, provided the original author(s) and source publication are appropriately acknowledged. If so indicated, certain images may not be included under the Creative Commons license. In such cases users will need to obtain permission from the license holder to reproduce the material. More details and guidelines concerning content reuse and adaptation can be found at http : //www . intechopen. com/copyright-policy. html.

Notice

Statements and opinions expressed in the chapters are these of the individual contributors and not necessarily those of the editors or publisher. No responsibility is accepted for the accuracy of information contained in the published chapters. The publisher assumes no responsibility for any damage or injury to persons or property arising out of the use of any materials, instructions, methods or ideas contained in the book.

First published in London, United Kingdom, 2021 by IntechOpen

IntechOpen is the global imprint of INTECHOPEN LIMITED, registered in England and Wales, registration number: 11086078 , 5 Princes Gate Court, London, SW7 2QJ, United Kingdom Printed in Croatia

British Library Cataloguing-in-Publication Data

A catalogue record for this book is available from the British Library

Additional hard and PDF copies can be obtained from orders@intechopen.com

Sustainability in Urban Planning and Design

Edited by Amjad Almusaed, Asaad Almssad and Linh Truong - Hong

p. cm.

Print ISBN 978-1-83880-351-3

Online ISBN 978-1-83880-352-0

eBook (PDF) ISBN 978-1-83969-414-1 


\section{We are IntechOpen, \\ the world's leading publisher of Open Access books}

\section{Built by scientists, for scientists}

\section{$5,100+$}

Open access books available

156

Countries delivered to
$126,000+$

International authors and editors

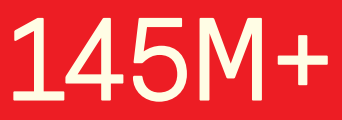

Downloads

Our authors are among the

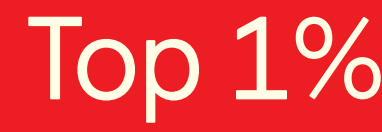

most cited scientists

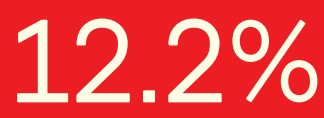

Contributors from top 500 universities

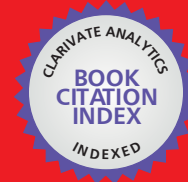

WEB OF SCIENCE ${ }^{\mathrm{TM}}$

Selection of our books indexed in the Book Citation Index in Web of Science ${ }^{\mathrm{TM}}$ Core Collection (BKCI)

Interested in publishing with us?

Contact book.department@intechopen.com

Numbers displayed above are based on latest data collected.

For more information visit www.intechopen.com

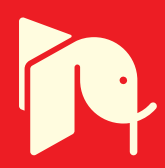





\section{Meet the editors}

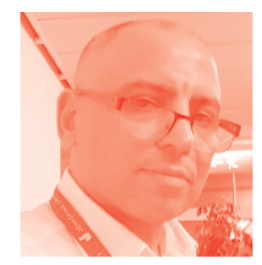

Amjad Almusaed Phd was born on January 15, 1967. He holds a $\mathrm{PhD}$ degree in Architecture (Environmental Design) from Ion Mincu University, Bucharest, Romania. He completed postdoctoral research in 2004 on sustainable and bioclimatic houses, from the School of Architecture in Aarhus, Denmark. His research expertise is sustainability in architecture and urban planning and design. He has carried out a great deal of research and technical survey work and has performed several studies in the above-mentioned areas. He has edited many international books and is an active member of many worldwide architectural associations. He has published more than 170 international academic works (papers, research, books, and book chapters) in different languages.

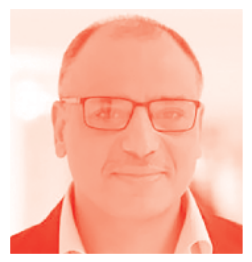

Asaad Almssad has more than 30 years of experience in the industry as well as teaching and research, inter alia, Umeå University, Karlstad University and both European and non-European institutions. His research focuses on building structures, materials, sustainable building, and energy efficiency in building systems. His viewpoint of the building and its components is that the orientation of new researchers tends to move the human actions under the building roof toward energy efficiency and healthy living spaces. He has authored and co-authored more than 50 research papers and many books. Now, he is employed as a docent at Karlstad University, Karlstad, Sweden.

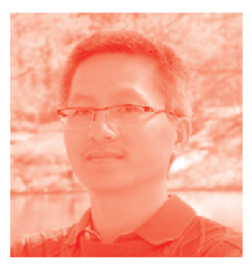

Dr. Linh Truong-Hong is a Marie Curie Fellowship at the Department of Geoscience \& Remote Sensing, Delft University of Technology. He obtained his BEng. and MEng. from Ho Chi Minh City University of Technology and a PhD degree from the University College Dublin. He has been a researcher at Dublin Institute of Technology (2011-2013) and University College Dublin (2013-2018). His research interests are to develop integrated frameworks to deploy LiDAR and photogrammetry in 3D objection reconstruction and change detection for infrastructure inspection and assessment, construction management, and a smart city. Dr. Truong-Hong has published more than 50 scientific papers and filed 2 patents. His research activity has been recognized through 4 peer-reviewed international awards. His research projects have been funded by Ireland and the European Research Council. 



\section{Contents}

Preface

Section 1

Theories of Sustainable Urban Planning and Design

Chapter 1

City Phenomenon between Urban Structure and Composition by Amjad Almusaed and Asaad Almssad

Chapter 2

Future Planning of Global South Cities with Inclusive Informal

Economic Growth in Perspective

by Vincent Aghaegbunam Onodugo and Nkeiru Hope Ezeadichie

Chapter 3

New Metrics for Spatial and Temporal 3D Urban Form Sustainability Assessment Using Time Series Lidar Point Clouds and Advanced GIS Techniques

by Sara Shirowzhan, John Trinder and Paul Osmond

Chapter 4

Reshaped Urban Mobility

by Csaba Csiszár, Dávid Földes and Yinying He

Chapter 5

Improving Feature Map Quality of SOM Based on Adjusting the Neighborhood Function

by Le Anh Tu

Chapter 6

Procedure to Prepare and Model Speed Data Considering the Traffic Infrastructure, as Part of a Cyber-Physical System by José Gevardo Carrillo-González, Jacobo Sandoval-Gutiérrez and Francisco Pérez-Martínez

Chapter 7

The Role of Public Spaces in Small Municipality by Jana Moravcová, Jiri Pecenka, Denisa Pekna, Vendula Moravcova and Nikola Novakova 
Human-Centered Approaches in Urban Analytics and Placemaking

by Eleanna Panagoulia

Chapter 9

Urban Sprawl

by Balamurugan Paramasivam and Illanthirayan Arumugavelu

Chapter 10

Toward Practical Criteria for Analyzing and Designing Urban Blocks by Amir Shakibamanesh and Bita Ebrahimi

Chapter 11

Adaptive Governance as an Avenue for Delivering Public Purpose in the Wake of Financialization

by Corina Shika Kwami and Nick Tyler

Chapter 12

Sustainable Design in Urban Green Space

by Ning Li and Yang Liu

\section{Section 2}

Lessons from Sustainable Urban Planning and Design - Practical Cases

Chapter 13

Urban Planning Using a Geospatial Approach: A Case Study of Libya by Bahareh Kalantar, Husam A.H. Al-najjar, Hossein Mojaddadi Rizeei, Maruwan S.A.B. Amazeeq, Mohammed Oludare Idrees, Alfian Abdul Halin and Shattri Mansor

Chapter 14

Digital Urban Administration Model for a Traditional City

(Case Study of Ibadan, Nigeria)

by Oluseyi O. Fabiyi

Chapter 15

The Rise and Decline of Car Use in Beijing and Shanghai

by Yuan Gao, Peter Newman and Jeffrey Kenworthy

Chapter 16

Exploring the Prescriptive and Descriptive Lost Space in the Setting of Urban Fabrics of Kuala Lumpur

by Nurul Shakila Khalid

Chapter 17

Integrated Approach towards Participatory Development of Urban

Neighborhood Spaces: Chennai, India

by Abdul Razak Mohamed

Assessing the Urban Design Quality of Turkish Cities

by Umut Doğan 
Jamaican Universities Aiding the Design of an Urban Public Space by Carol Archer, Colette Cunningham-Myrie, Nadine Freeman-Prince, Marvin Reid, Brian Williams and Tamika Royal Thomas

Chapter 20

Approaching Urban Design through the Analysis of Structural

Differences within Three Neighborhood Typologies in Basra City

by Qaaid Al-Saraify and David Grierson

Chapter 21

Lessons from Baghdad City Conformation and Essence

by Haider J.E. Al-Saaidy

Chapter 22

Urban Social Sustainability - Case Study; Gellerupparken-Denmark by Amjad Almusaed and Asaad Almssad

Chapter 23

Urban Design, Space Economy and Survival in the City:

Exploring Women's World of Work in Kumasi, Ghana

by Ebenezer Owusu-Sekyere and Samuel Twumasi Amoah 



\section{Preface}

The current population growth is putting pressure on urban areas, resources, housing prices, and public services. Also, the increase in traffic volume results in poorer air quality and congestion-related problems. At the same time, there is also an increasing tendency to the social division between population groups in big cities. The development of sustainable cities is one of the biggest global challenges right now. Cities face a wide range of social, environmental, and economic challenges that need to be considered. Population influx raises new demands of physical infrastructures and management. Thus, there is a need to think across disciplines and sectors. All over the world, cities face major challenges that call for solid urban planning. There must be sustainable urban planning and design that captures the city as a whole and that delivers concrete, high-quality solutions. The requirement is to design cities that people like to look at and move to, cities that work, cities where you can easily get from place to place, and cities that are environmentally balanced and that are healthy and safe to live in. Our cities must have space for everyone and involve as many people as possible.

Sustainable Urban Planning and Design is a form of study that takes into consideration the active interaction between the built environment domain and social, economic, and influential forces. Urban planning in a sustainable framework represents a technical and political process that seeks to organize and design land use and built environments, including air, water, and the infrastructure passing to and from urban areas such as transport, communications, and distribution networks.

Usually, urban planning has followed a top-down approach to master planning for the physical location of settlements. The main concern was public welfare, which included considerations for efficiency, sanitation, environmental protection, and use, and the impact of master plans on social and economic performance. The environment has a strong interaction with human health. The health status of the population depends not only on the quality of the established care system but also on the living conditions, where an obvious reduction in harmful environmental exposures can improve population health and may contribute to health disparities. Urban planning and urban design are related but different in fundamental ways. Urban planning is the act of planning the structures of a city, including its policies, infrastructure, neighborhoods, building codes, and regulations. On the other hand, urban design is the creation of city features based on plans. Historically, city function and urban planning as an activity have been defined by architects and engineers in various shadows, but today there are also geographers, sociologists, and the like. Urban design originated from the multidisciplinary composition of urban planning, and it aims to provide a more holistic, practical approach to the solution for questions about urban planning and design that the classical disciplines could not individually provide. Frequently, there are situations when these strategies do not work, and some groups remain marginalized and socially excluded without fully benefiting from the advantages and resources offered by living in the urban environment. In turn, contemporary urban living presents several challenges for local administrations. Sometimes, the generally accepted social order is challenged within urban social movements, which propose their solutions to various unsolved urban problems and a new approach to the concept of social order. Different groups and places in the world have been studied by social researchers since the nineteenth century. In those studies, various methods, techniques, concepts, explanations, 
and sub-disciplines have been developed, which help us to explore and gain more understanding about the complexity of urban life. Cities have very different and distant origins. The first cities appeared, apparently, in the more advanced countries in terms of technical rationality, in the regions that knew how to organize an irrigation system. A certain number of cities were formed somewhat spontaneously, responding to a need, and their installation took place around a predestined point or which offered favorable conditions (monasteries, medieval castles, garrisons, villages near a spread, coves). To make cohabitation possible, all such groups develop coexistence strategies and respect a particular social order. The concept of "design of the urban environment" replaced the term "small architectural forms", which was widespread in the second half of the last century and was familiar to all of us, and interpreted elements of street furniture and equipment only as separate architectural details of the city's public spaces. Many cities are due to external causes, which happened unexpectedly (mining, oil, gas deposits, factories, tourism development, or political expansion). The design of the urban environment is a complex topic, that is related to creating a positive space for humans and building a specific climate in the city, which is located at the level of the first floors of the building and ensuring the vital activity of the city.

The contraction was, through appropriate extension, to create a coherent hierarchy of squares, smaller squares, and street spaces where, at any level, the degree of public/private situation or locality could be ascertained. At the same time, the importance of adapting the visuals of the areas of the human scale and not passing vehicle traffic at full speed was emphasized. In another part, the topic of the urban design represents an interdisciplinary subject area that deals with the planning and design of the city as a whole, taking into account relevant functional, aesthetic, and societal conditions. Urban design is directly associated with several disciplines of planning-mainly architecture, landscape architecture, and urban planning. However, urban planning has a wider scope than "design". There are several methods of urban planning, with differences in intentions, scales, time, the nature of the interventions, and the actors. The urban design focuses on the location and design of major civic buildings (city hotels, operas, museums, etc.), and their relationship with the open space. At one point, there may be two very similar spaces that we can consider isotopic spaces, only that in the existence of the city something can happen to lead to modification. In another spirit, one or both so that they become heterotopic spaces; or two identical spaces, one remains empty. Also, there is a special activity generating agglomeration, which causes that, at that moment, its character as opposed to the character of the other space changes. This fact must be taken into account when obtaining spatial differentiation, in the sense that one space can be sufficiently well-differentiated from another space by introducing training elements related to the rhythm, activity, and movement of people within it.

Today's city is not an accident. It is the product of decisions made for single, separate purposes, whose interrelationships and side effects have not been fully considered. The future of our cities is dependent on the action of today. In particular, achieving sustainable cities is imperative in our rapidly urbanizing world. By definition, the city in a sustainability context represents a fascinating, complex, and very dynamic object of study, despite its great stability. This offer as a study laboratory aroused the interest of general fundamental sciences, such as physics, mathematics, and biology. On the one hand, it offers new elements that help these sciences to substantiate their basic theories, and on the other, it constitutes an ideal framework for validating other previously issued theories. For geographers, contact with the disciplines involved in the analysis of the city is beneficial to detect more clearly the niche of specific research, but also to know better the intimate processes that take place in the urban organisms. The urban 
compositions are determined by operations regarding the creation, extension, or replacement of some urban spaces, having very different conditions of conception and implantation. Urban forms may have stronger or more erased geometric compositions, continuous or discontinuous from the topological point of view. A composition, to be continued, must be not only strong or continuous but also interpretable and acceptable. Given the complexity of the challenges, there is a need for an overall urban policy framework for how they are addressed and the potentials are exploited. By thinking about social conditions, the environment, and the economy together, the probability of being able to implement coherent solutions is improved. Sustainable buildings must be economically viable, while taking into account climate adaptation, energy, and resource efficiency, the environment, architectural quality, and social security. The economy and the environment can thus generate added values when they think of holistic considerations. Urbanization can contribute to a more sustainable society, e.g. by linking different urban functions in urban development strategies. Urban planning and design in sustainable reading are, on a general level, about construction and in many cases, reconstructions of the city space. Where before, in old districts, smaller squares and squares emerged closely integrated into city life, especially during functionalism; they were watered down and surrounded by randomly placed moderniststyle buildings. It is important to become better at dealing with these contradictory interests so that they do not turn into regular variances. Therefore, the work of making big cities more sustainable also consists of developing the best tools for planning and involving the various stakeholders so that there are constructive solutions.

This book aims to present the reader with examples of the latest research into the reading of urban planning and design. This book goes behind the scenes and reveals the variety of tools in the metropolitan studies toolbox. A proper understanding of its application is vital to all those involved in city research. This book presents some of the diverse aspects that are inextricably bound up with, and strongly influence, the scope of urban planning and design. To end, I would like to express my sincere sense of appreciation and thankfulness to all the co-editors Dr. Asaad Almssad and Dr. Linh Truong Hong, and the authors for their valuable contributions. At the same time, I would like to thank Ms. Kristina Kardum from IntechOpen's Publishing Process Manager for her assistance and efficiency in the management of this book and her cooperation at various phases of the book publication.

Amjad Almusaed Jönköping University, Jönköping, Sweden

Asaad Almssad Karlstad University, Karlstad, Sweden

Dr. Linh Truong-Hong

Optical and Laser Remote Sensing Group, Department of Geoscience and Remote Sensing, Faculty of Civil Engineering and Geosciences, Delft University of Technology,

Netherlands 

Section 1

\section{Theories of Sustainable \\ Urban Planning and Design}





\title{
City Phenomenon between Urban Structure and Composition
}

\author{
Amjad Almusaed and Asaad Almssad
}

\begin{abstract}
Cities are not just a sum of buildings, but especially a set of social relations that their inhabitants develop. Cities are characterized by a wide variety of social groups and lifestyles. An urban composition represents a form of the city in which it gets a formal order, so that the shape of any urban ensemble is not linked to a random phenomenon, but to an intervention mastered and understood as such. For the city, the urban composition represents what the architectural composition represents for a building. This concept regarding the composition is common both to the architecture and to the city. The main property of the composition is that it transforms a possibly dispersed ensemble into a whole, resolving the contradictions that arise when the requirements and conditions of the project are numerous. Spatial forms and urban compositions are built over time, longer than that of architectural composition. On the other hand, "design of the urban environment" is understood by us as a complex formation of public spaces of the city, located on the ground floor level of the city building and ensuring the vital activity of the urban community. This chapter will study the city phenomenon on a large scale.
\end{abstract}

Keywords: urban structure, urban composition, urban design, urban space, public space, city image, city phenomenon

\section{Introduction}

Cities cannot be defined only by their administrative boundaries, and urban policies can no longer target only administrative units at the city level. The importance of multilevel governance has been strongly emphasized by the European Parliament and the Committee of the Regions. This is in full accordance with the conclusions of this report: policies at European, national, regional, and local levels must be correlated with each other [1]. In any urban development and expansion plan, it must be taken into account that natural systems have a limited capacity to respond and adjust to changes produced by man. From the perspective of urban sustainable development, any impact of urban activities on the environment must be minimized. The idea of sustainable urban development was born in the 1970s, as a result of deep concern about a development model that threatened the environment and the vitality of the planet. There is a strong belief that, apart from government programs and the private sector initiative, local communities need to be actively involved in this process. This concept is at the basis of formulating sustainable policies, which try to harmonize the relationship between population, environment, and industrial development. Controlled urban expansion is also known as smart growth. The experience of the states of the European Union shows 
that metropolitan areas, well managed, reach economic competitiveness quickly (economic policies can effectively attract funds and investors and can energize the construction, services, and tourism sectors), and their future development is sustainable (economic, cultural, social, ecological, and policies are harmonized). Such a project aims at decongesting large cities, establishing unitary architectural development, accessing European funds for regional development, and, thereby, creating civilized living conditions for all inhabitants of metropolitan areas. More than two-thirds of Europe's population lives in urban areas [2]. Cities are places where problems arise and solutions are found. They represent a fertile ground for science and technology, for culture and innovation, for individual and collective creativity, as well as for mitigating the effects of climate change. However, cities are also places where problems such as unemployment, discrimination, and poverty are concentrated [3].

The objective of the Thematic Strategy for the urban environment, adopted in 2006, at European level, "to contribute to a better quality of life through an integrated approach to urban areas," in conjunction with the effort to contribute to "a higher level of quality of life and social well-being of citizens, by ensuring an environment in which the level of pollution does not generate harmful effects on human health and the environment and by encouraging the sustainable urban development," defined, for the next years, the priorities, the direction, and the means by which this strategy to be applied [4]. It follows from this strategy that most cities face a common set of basic problems, such as those related to air quality, heavy traffic, high noise levels, low-quality construction, abandoned land, greenhouse gas emissions, non-systematic areas, generation of waste and wastewater, and providing public services to the population. Among the causes of these problems is the increase in the use of resources per inhabitant, the increase in the number of individual households, the demographic changes, and the increase in the number of personal property machines. The solutions must be forward-looking, taking into account aspects of risk prevention, the anticipation of climate change, or the progressive reduction of dependence on fossil fuels. The activities in the urban environment are sources of pollution for all environmental factors. Therefore, they must be controlled and managed to minimize the impact on the environment.

- What are the five challenges for urban planning theory?

Urban planning deals with the design of building groups, settlements, neighborhoods, and in particular public spaces. Urban design can be understood as a term for the visible and creative aspects of urban planning. According to a broader understanding, the concept of urban planning encompasses the totality of planning and construction measures for urban and rural spatial planning aimed at creating the prerequisites for the coexistence of people in an environment appropriate to them in the pursuit of sociopolitical goals. In conclusion, urban design is a product of the collaboration on site of elements of the urban framework, determined functionally within the configuration spatial structure. It can be understood as a term for the visible and creative aspects of urban planning. Traditionally it has been referred to a discipline within urban planning, landscape architecture, or more simultaneously linked to emerging disciplines such as landscape urbanism.

\section{The urban phenomenon and city morphology}

The form of the urban process is a form of evolutionary procedure, which is connected directly to the concept of urban society. It takes dynamic 
contradictions from the inside to the outside of urban phenomena. The phenomenon takes an evolutionary process which means that the urban form is the concretization in time and space of the urban phenomenon. The definition of urban phenomenon performs clear in support on highlighting of urban functions, urban growth, and urban shape/image. Another area which must be clearly defined is determining the urban phenomenon which starts from the corroboration of internal and external functions of the city [5]. The urban phenomenon is in a continuous transformation process. There are several directions of structural determination:

- Morphological-functional structure

- Volumetric spatial structure

The urban phenomenon is different from the form it dresses in the city because the shape and structure can be viewed from several points of view (plastic, mathematical-geometric, topological). It is embodied in three typescripts:

1. Centrality, where it manifests itself through a grouping of objects, actions, and phenomena in a more or less delimited space

2. Conflictuality, where it associates with consumption and production

3. Simultaneity, where all these elements associated with the urban phenomenon take place simultaneously

A clear example for this case is a street, which represents the place of manifestation of the urban phenomenon in time and space; it reveals it on a certain plane of its complexity, because 1, 2, and 3 are expressed on several levels of specialty and several directions of interest (economic, social, political, material, spiritual). The urban phenomenon reflects the same signification of global reality. An urban existing is presented by:

- Material and spiritual expression of the urban phenomenon.

- Resembles: built frame, people there at one point, cars, and plantations.

- It is a complex, obvious concretization of a certain urban structure.

In conclusion, the urban phenomenon has a continuous and infinite development through the typological, spatial, and temporal multitude of its phenomenological successions. However, the urban form has moments of stagnation and discontinuity. The urban phenomenon has a double reference:

a. A reference to the logic of the form, which refers to all quantifiable aspects of the urban phenomenon (population growth, surface area, stretches, openings of space, densities). It is a form of the geometrical logic, which refers to specialist-spatial configuration, topology, the form of the built volumes, and directions of interest.

b. A reference to the dialectic of content-the so diverse components of the urban phenomenon are the result of a conflict or lead to conflict (e.g., with the neighbors). There is certain independence between form and content. 


\subsection{The city as an urban phenomenon}

References of the urban phenomenon to the logic of form and to the dialectic of content justify its understanding as a system. These references impose relationships between the components of the urban phenomenon, so that they are realized in systems and subsystems. The urban phenomenon can be:

- Units/less unitary

- Dense/less dense

- Intense/less intense

The urban phenomenon as a system is defined only through the urban form, the fact that leads us to the idea of knowing and directing the urban phenomenon (of its processes and acts) through careful, corroborated analysis of the manifestations of any kind of urban form [6]. The urban form has a dialectic character, which reflects the evolution of the urban phenomenon, it has:

a. The ability to express itself very differently either:

○ In particular: within a certain urban existence, through image, movement, and sound

$\circ$ In abstract: imaginative-within the representation of the pre-existing or post-existing urban existence

b. Graphically: by mathematical-geometric, technical, and plastic means

c. Verbally: by the psychosociological or mathematical-statistical concept

The urban form has the capacity to move from a logical, but an abstract manifestation (through a certain language), into a form of effective actions, which results in a certain urban existence. It had an active character which can highlight three sides:

- Selectivity with histories and character: any urban form, any urban existence, is the result of historical evolution. The urban form has the capacity to evolve, selecting over time the various values within the respective urban existence.

- A capacity of reunification: of old or new contents in a totality.

- A possibility to create an urban strategy at the conception and decision levels, which represent a reflection for a certain city existence.

\subsubsection{Spatiotemporal of determination of the urban form}

The urban form is not indifferent to space-time, but not taken as such, because they are transformable elements, imprinting on the urban existence a succession of states. The spatiotemporal determination of the urban form lies between innovation and tradition. The urban form does not have to be shaped at any given moment by acquiring space, time, or a conventional model. 


\subsection{City as a social-human settlement}

The city represents a multifaceted structure of social organization, which involves a number of social institutions and a typical configuration of social relations. A sustainable city is organized so as to enable all its citizens to meet their own needs and to enhance their well-being without damaging the natural world or endangering the living conditions of other people, now or in the future $[3,7]$. This makes the users of the city, the social relations they develop in cities, the ways in which they live, the problems they face, and the urban space in general the object of research of modern urban studies. A human being in urban composition means to get yourself on a doctrinal position. The composition in urban scale is based on both the structure and the doctrine (ideology). In urban composition, esthetics remains just one aspect, where the urban form is read as a static instance. It is a concrete land, inscribed in history, having a memory and therefore not completely subordinating to the needs or the will of a class, preserving morphological landmarks that illustrate this resistance. At the same time, the memory of the place, a notion determined historically and socially, plays an important role in the permanence of the significance of some urban spaces; it illustrates: "what one epoch finds worthy of attention in another." It is considered an artifact because it is the physical result of the aspirations of the urban society, created by its reference elements, the public buildings. Architecture always expresses and illustrates the social and cultural potential of an era. A city includes rights and freedoms for all its inhabitants, promotes social and political participation, informs its citizens, and makes democratic decisions. Economic inclusion refers to public policies to support the poor and to provide equal opportunities in business and equal access to the labor market. Cultural inclusion: an inclusive city promotes social integration and celebrates diversity. It respects the cultural rights of individuals, recognizes human capital in all segments of society and strives to increase it by promoting creative artistic expression and preservation of traditions. The concept of "the city for all" and "the right to the city" refers to the access of social and economic benefits by all the inhabitants, promoting social equality and access to the benefits of urban living, for each inhabitant. A city must dig even on the social, political, economic, and cultural levels, if no efforts are made in this respect, and then continue promoting the exclusive development and sharing of benefits, marginalization, and discrimination. The city administration must be well aware of the sociocultural realities that make up the social life of the respective city; they must strive to build and promote inclusive strategies and policies and then integrate these strategies into the daily lives of the population. The city has been and remains a land of negotiation between various social groups; harmonious cohabitation in cities is a difficult process, which is often punctuated by various urban social movements. In general, these movements challenge the social order and the existing public policies, fighting for visibility on the social scene and for a fair distribution of resources. Cities in their evolution have undergone a permanent territorial extension and intense remodeling. The forms of evolution and urban concentration are different from one area to another and from one region to another. They differ in both genesis and size. Depending on these two elements, several forms of urban concentration can be distinguished. Therefore, the city does not only mean buildings, roads, parks, fences, abandoned corners, water pipes, and cable networks, but especially interactions between citizens, contacts, social relations, and communication situations, direct and indirect [8]. All these make up the complexity of urban social life and give life to cities. In another view of this subject, the urban habitat expresses the synthesis of the conditions of human life, of the social-economic reality existing at one point. At the global scale, the 
population is divided into two major types of habitat: rural and urban, between which there are similarities, but also fundamental differences. The urban habitat or the city is a form of human settlement superior of the village, which is distinguished by a higher density of population and constructions, superior technical-urban equipment, mainly secondary and tertiary economic activities, a specific way of life, and with a higher demographic potential. Although these criteria are clear enough to distinguish the village from the city, they are not necessarily the same for everyone. Depending on the region and the age, the idea we make about the city changes. Each civilization has a different conception of the city. Certain ancient cities, populated mostly by cultivators, cannot be considered cities in our view. Difficulties in differentiating the village and town arise from the lack of accuracy of the vocabulary. The city is a space that is defined by a series of metric properties, by dimensions, surfaces, and densities. It is an intensely populated space, with a high degree of concentration, production, and social and cultural organization, which develops under certain conditions of space and time, thanks to the convergence of the forces of production and in permanent opposition to the village. Urban social studies analyze urban life in all its complexity. Through explanations and information provided in urban studies, we can better understand the reality and social, cultural, and economic phenomena that are happening in the urban environment around us; we can understand the causes of these phenomena; we can understand the sociocultural diversity; and we can find new opportunities to live together and creatively use urban spaces.

\subsection{City as a form of human life in the context of a complex dynamic system}

A city is not just a place to live, but a complex and dynamic system that unites a certain community of people and is called upon to ultimately improve the quality of life of every person. Urban spaces are formed under the influence of many factors and over long periods. When designing an urban environment, the designer must take into account the compositional. The idea that heterotopia does not inevitably mean a state of urban chaos can be retained here, that distant order can, in many cases, be particularly subtle. One of the most complicated and, at the same time, very topical issues regarding the urban form is that of spatial differentiation as a way of explaining the existence in any urban situation of different spaces between them. First, the aspect of understanding spatial differentiation appears in the sense of a dialectical result in the process of constituting the urban form, namely, in the sense that the urban form is the expression for the purpose of the urban phenomenon. However, this understanding must not be inclined toward the metaphysical, that is, it must not be considered in the sense that a certain expression of the urban form is completely and definitively recognized as a final expression, beyond which nothing can appear. It continues to evolve over a period of time greater or less, in which it remains in the same form (unitary or non-unitary), until, undergoing a new transformation process, it reaches another form, constituting itself as the new existence that can be considered as a new moment of finality [9]. This is why we can say that the urban form as a finality of the urban phenomenon is in the process of continuous perfection. It is noteworthy that precisely this process creates spatial differentiation, this differentiation occurring either within the same urban space (frame, element for an urban existence) from one moment to another of its evolution, or within the city, when an urban space arrives. At a time, a purpose that is different from that of other urban space at the same time. So, within the city, we have to deal with a spatial differentiation to be analyzed either in a horizontal temporal section (without neglecting the constitution overtime of the respective urban spaces) or in a vertical temporal section (insisting on the evolutionary character of the respective urban space). Although, at least in the first situation, the 
differentiation can be caught only through a structural analysis of urban spaces; it cannot ensure the depth of our conclusions, especially if, at the level of detail or, on the contrary, at the level of the whole, they are necessary for defining aspects which characterize the urban form in a certain area, in a certain time. The urban form concerns the morphological characteristics of the urban framework both in general, at the scale of the entire city (extension, perimeter, street network, watercourses, etc.), and in detail, the relation of a building with the surrounding urban framework, a group of buildings, ensemble, and neighborhood structure of the urban framework [9]. The transformation of the living environment, including the design of the urban environment, is one of the most urgent problems solved by the modern designer-an active participant in creating the environment of the environment, educator, and exponent of the culture and esthetic taste of society. The urban design is oriented to interpret the form and public space with physical-estheticfunctional criteria, seeking to meet the needs of urban communities or societies, within a consideration of collective benefit in an existing or future urban area, until reaching the conclusion of an urban structure to follow. Therefore, the urban design performs physical planning at analysis levels, such as the region, the urban center, the urban area, and even the urban furniture itself.

\subsection{City as an urban utopian and empathy space}

Utopian space has a special feature. It is defined as combining both the close order and the distant order, at the concept level, between urban isotope and heterotopy. But if these are characteristics that address the material existence, therefore exclusively to what is perceived (in volumetric, color, movement, noise), the space considered as utopian has a deep subjective potential, its appreciation being closely related to the psychic. Heterotopic spaces are spaces that reveal different places, each supported by different functional, spatial, and encompassing characteristics. But also within the same urban space-the more complex it is, the more obvious this observation is - we can also find isotopic states or heterotopic states, which gives the space a homogeneity or heterogeneity. Symbols are commonly applied to formal iconographic representations. Symbolism encompasses complex conceptual codes and pictorial representations of a worldview that operates on multiple levels and scales [10]. Differentiation in the sense of heterotopy isotope, in the context of an urban situation, is not fixed. Urban symbolism is commonly associated with the enhancement of formal urban figures, objects, or pieces of the collection and landmarks [11]. The utopian space is, in general, a symbolic space, and what the architects forget, a space with imaginary availability not for themselves, but for those who cross it as ignorant of a survey methodology of analysis, but directly and perhaps impressively primitive. For example, a utopian space can be, within the city, an organized market, but extremely wide, whose limits come out of the natural perception, the image retaining the volumetric, but also a passage of the outer space. Then our psyche, as well as our imaginary, intervenes in determining a certain environment, a certain impression at that moment and in that place. As a utopian space, any urban space may appear during the night, when a number of aspects of its configuration fade, even though during the day it may be an isotopic or heterotopic space. The significance of urban space, obviously determined by its functionality and geometrical-spatial appreciation, cannot be achieved except for a small but constructive, utopian value. The monumental, like the enchanting, are features that serve the significance of the urban space; however, there are traits that constitute a spatial approach/recognition/perception, at least in part utopian. 
An important type of urban space is empty space, which represents a space that attracts and even ends up being filled (both personally and figuratively), in the sense that it attracts people at a certain time in relation to a certain activity located here temporarily, so it attracts certain interests to confront here and, as such, can even find a symbolic "filling," finds a certain content. It is wrong to argue that such a space should be conceived, in the context of urban modernization, as a neutral space, because, when it is accidentally occupied, it expresses the beginning of a new phase of spatial expansion, and when it is periodically occupied, it expresses a need, of organized space [10]. And in one case, and in the other, the permanence of his occupation as a mono- or polyvalent space imposes a configuration that can no longer be left as an indifferent space in relation to the neighborhood. There is a natural tendency of the urban phenomenon that, gradually, by decommissioning some previously occupied spaces, they will become indifferent spaces in the urban structure, which leads to some unfavorable situations for the city: an increase of the affected territories, thus the deterioration of the qualities of the urban framework, the deterioration the balance of spatial differentiation in the territory, and the loss of features that particularized the respective places. Mastering this process, be easy to talk about the neutralization of some urban existences, thus presents a special significance, making it difficult for a direct intervention on the existing built fund: finding the possible values, monitoring the state, maintaining them, and properly completing them.

The urban form is defined by the physical characteristics of the urban framework, customized by:

- The geometry of space and construction template

- The relationships between the elements of the urban framework

The urban form represents the morphological component of the urban framework. It is displayed by a great diversity of morphological compositions, capable of individualizing and customizing various areas of the city or the city as a whole, depending on:

- Various stages of its development (temporal dimension)

- The destination of the buildings and spaces (functional dimension), of the importance of the buildings, and of the material resources of investors/owners (economic-social dimension)

It is required to put more attention to the city as a territorial and social entity, countless works being focused on increasing social polarization, which is increasingly evident in the internal structure of cities. The effects of poverty and marginalization of social groups and ethnicities are more and more manifested in urban spatial structures. Today the application by postmodernism in urban geography remains problematic, and it is necessary to adopt relativism in science. Postmodernism should be the final point in a millennial evolution of art and science. Is it true that science has reached this level above which it is no longer possible to go categorically; therefore, the postmodernist stage in the evolution of thinking in the field of urban geography should be regarded as a temporary one, improperly named, because of the progress made by registered so far; it shows that future changes will be quite astonishing. The contemporary urban evolution leads to an increase in the power of urban control over human activities and, at the same time, an increase of the vulnerability of cities and urban systems. This vulnerability must be treated in light of the sustainable development of the city in general. 


\section{Design concept between urban composition, visual form, and human life}

Today, when the history of design as an independent field of art history and scientific discipline has acquired quite specific features, it becomes relevant to pay attention to the historical development of individual local areas of design. One of them and the young ones are the design of the urban environment or urban design. The term "urban design," as noted by a professor of Sydney University, John Lang, appeared in the 1950s. He, as well as his synonym for the "designing city environment," has firmly entered the professional vocabulary of the designer which is used to designate nominations for competitions and exhibitions of design festivals and to name specializations in design education. A design feature is that each thing is considered not only from the point of view of benefit and beauty but also from the point of view of the functioning process, that is, taking into account how the item will be transported, how to pack, where and what place it will occupy in the apartment, what care should be taken, how to be included, etc. In the design domain, visual design tools are common for plastic arts: point, line, texture, texture, color, shape, volume, proportion, mass, and space. These components are combined based on the principles of composition: symmetry, asymmetry, balance, rhythm, movement, etc. The design has widespread use and such means as the proportion of the golden ratio. Harmony and contrast as a universal means of art are systemically important in design. It is especially important for the art design to take into account the dependence of the shape of the object on the materials used, structures, and production technology. Design plays an important role in human creativity products. Design areas are household appliances, dishes, furniture, machine tools, vehicles, graphics, clothes, and more.

\section{- Why design and build something that will not solve the problem without creating bigger problems?}

The designer is looking for the optimal shape of each element, taking into account how it depends on the work function (purpose) of the product and its relationships with the person. Design is a special product of specific, abstract, and, at the same time, imaginative thinking. It is also created based on fundamental knowledge: philosophy, esthetics, anthropology, the foundations of visual literacy, and psychology. It involves the study of engineering, technology, ergonomics, ecology and system design, etc. The professional activity of the designer, both developing on social grounds and based on the natural qualities of a person (esthetic, emotional and intellectual), established the role and place of design in public life. The meaning of designing is to become a unique, powerful, and effective means of influencing the esthetic and the ennobled activity of society. Thus, the design is a rather specific and significant sphere of activities of people, which by its nature is as human as, say, education, science, and healthcare. Design functions are not only the creation of appropriate products but also advisory, methodological, and coordinating; the design is a special branch of people's life. The functions, structure, place, the role of design, as well as its evolution are not sufficiently studied in philosophical and cultural literature, in which the appeal to these topics is only partial. To date, there is not even a generally accepted definition of the phenomenon of "design" [9]. Moreover, meanwhile, this phenomenon causes increased practical and theoretical interest in our society. Today the contemporary cities are marked by invisible borders, which delimit areas and "territories," separating the inhabitants. This social fragmentation is best reflected in the way resources are distributed, 
opportunities for a good life and even urban space-often unequal distributionbenefiting certain socioeconomic categories, living in certain "territories," and disadvantaging others living in separate "territories." For example, certain areas of a city can be taken care of, with large spaces, well-maintained parks and gardens, and with quality residential areas, while other areas are characterized by poverty, poor housing, poor public services, lack of access to recreational and cultural facilities, decay, reduced investments in public infrastructure, and unequal opportunities and freedoms. Usually, economic and social exclusion leads to cultural and political exclusion. In a divided sense, inequalities are exacerbated, which contributes to stratifying the population into social categories marked by social segregation; the poor, along with immigrants and other individuals lacking social esteem or "undesirables," are usually part of the same category. The increasing role of modern design is associated with the growth of global problems, and its tasks depend on solving environmental, esthetic, and humanistic problems of culture. In general, the design is not only a graphic and decorative activity; in many areas of management and economy, especially where research is carried out, specialists-engineers, designers, and technologists - are always faced with the need to draw. The ability to draw and the related ability to feel the harmony of the world open up new possibilities. A design product has a positive impact on the general social atmosphere; it forms an esthetic taste, inspires people, raises their working capacity, creates conditions for productive and creative activity, increases respect for the immediate environment of human existence, and makes it more human. By urban design process, human being becomes a part of an innovative study environment with project-oriented teaching in a creative and idea-developing community, and we go the step further in collaboration with different companies. We also go on study trips across the years in the field of study, and you come from an internship abroad, where you are linked to a small company.

- What is the real concept of urban design?

In narrow scope: urban design represents the form of human settlements, physical features at scales larger than a single building. It can be done through the manipulation of the concrete elements of distance, material, scale, view, vegetation, land area, water features, road alignment, building style, and numerous other items that create the natural landscape and the built environment [12]. Urban design seems to be the profession that determines the spatial shape or physical environment. Different approaches for urban design are as follows:

1. Good form: To define an axis of movement, the designer may strategically place small and large buildings to create scale linkages receding in space or insert in the landscape an arch or a gate.

2. Legibility: A legible city is one whose constituent parts "are easily identifiable and are easily grouped into an overall pattern."

3. Vitality: A bustling street life is essential to a good city, and main streets need "a most intricate and close-grained density of uses that give each other mutual support."

4. Meaning: In reaction to modernism that focused on building forms, a new generation of thinkers has stressed [the city's] capacity to exhibit history, tradition, nature, nationality, or other themes that heighten the meaning and solidify the identity. 
In broad scope: urban design is the field that engages the human experience of the built environment - the sense of understandability, congeniality, playfulness, security, mystery, or respect that lands and built form evoke [11].

\section{Urban design missions and the process}

An urban designer mission has all the analytical approach as an engineer and, therefore, always does much in-depth analysis before drafting a solution to the problem. He also has the creative approach as the architect and can sometimes have multiple walls pasted with sketches that are subsequently sent through the "control" that the analysis has contributed to. Urban design deals with the spatial configuration, appearance, and functionality of the elements of cities or other settlements. Urban planning is a discipline at the junction, synthesizing the approaches of urban planning, landscape design, and architecture. Urban planning requires an understanding of political, social, and economic factors. The term urban design was proposed in 1956 at an international conference at the Harvard Graduate School of Design (GSD). In another view the urban social studies are not only useful in the academic environment: they provide important data and materials to those who decide on the urban level and conceive the strategies for the development of cities [13]. Apart from these aspects, urban studies are useful to all of us, in the sense that it helps us to understand each other better and to improve our daily lives. Urban social researchers closely analyze the impact of contemporary political and economic systems on people's lives in the urban environment. Their studies highlight the problematic issues arising from this impact but also possible solutions.

\subsection{Legibility and readability in urban evaluation}

In an urban city, it is required to focus on two factors in the creation process, those are Legibility and readability, where are different. Readability is the ease with which a reader can recognize words, sentences, and paragraphs. Legibility (clearness) is a component of readability. Other typographic factors that affect readability include font choice, point size, kerning, tracking, line length, and justification. Legibility is "the degree of individuality that enables the viewer to understand or categorize the contents of a scene the greater the legibility the greater the preference" [14]. According to Lynch's definition, legibility can enhance the identity, structure, and the meaning of environmental surroundings. The city may have a strong identity and character but still be confusing and unclear because of confusion of its path system. The quality of an object depends upon its shape, color, and arrangement. This quality determines the degree of legibility. Imageability has physical and cultural components; the first one defines two attributes: location (a real location, spatial relationship, prominence, and scope) and appearance (shape, color, age, size, construction material, etc.). The second component has two sides also: meaning (economical, political, social, historical, religious, functional, etc.) and association (familiarity, atmosphere, and affinity) [15]. Particular attention is paid to the development of the configuration of common areas in which the daily activities of citizens are carried out (streets, squares, parks, public infrastructure).

\subsection{Urban design and human lifestyle and requirement}

A city supports its inhabitants to stay with other people, to realize social behaviors through partnership in urban life. People are attracted to cities by an attractive offer 
of urban buildings, public spaces, and characteristic landscapes. The urban composition is a human product in an urban area which resulted in effective collaboration between different elements of the urban framework, which have to be determined functionally within the configuration spatial structure. The urban composition represents a work of art, where the content is an essential topic that reflects the city functionality translated into activities. In this area a proposition is precisely the totality of the coherent means of expression. At the level of the form;

- The speech is constituted as a state of composition.

- The statement is constituted as spatial compositional values.

Surrounding is an act with three-polar meaning (Figure 1).

\subsubsection{City and a need for existences}

In order to survive, plants need air and water, as well as heat and light. Can they meet their own needs? People's needs are endless. Fortunately, from all our essential needs, from the beginning of our life from the womb to death, someone is able to fulfill them and who chooses to do so. When human beings come to this world, we find everything prepared to satisfy all the needs of the senses, mental and spiritual. Everything is contingent, because it is as possible that they exist or do not exist. Anything can exist anytime, anywhere, in any form, and with any character. Nothing and no one has a role in determining the manner, time, and place in which it occurs, its character and characteristics. Therefore, there must be a power to choose between the existence of a thing and its nonexistence, which confers unique characteristics on it.

\subsubsection{City and a moral requirement}

Building a relationship with a city is like when you are in a relationship with someone-just as cities can be generous or inspirational, so can they be dangerous and impenetrable. The city is a moral universe in which helpfulness is extended beyond kinsfolk to strangers. In a modern city, public institutions aspire to provide solace or uplift to all, often with a cool efficiency that is rewarding in its way as is the warmth usually credited to small communities. A close reading of the city scene reveals inconspicuous artifacts of consideration such as telephone booths and wheelchair ramps on sidewalks that symbolize the principles of communication and

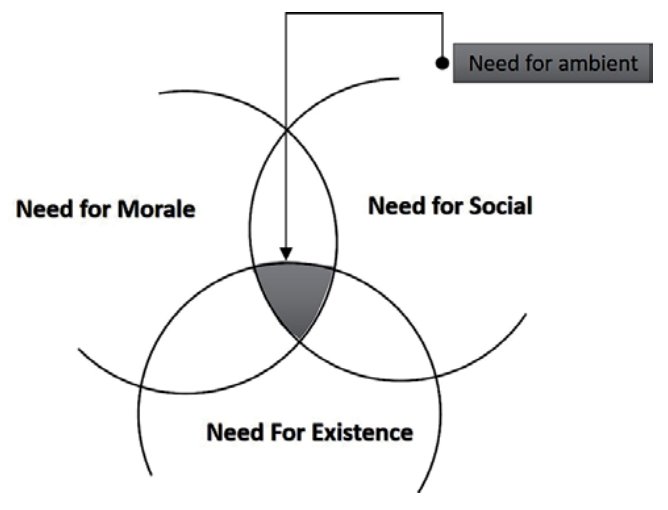

Figure 1.

City design and the three-polar meaning. 
access [16]. It is required to feel the city in order to understand it. He does not tell us how to do this, but he shows us how to walk the streets with eyes wide open so we can explore everything the city has to offer.

\subsubsection{City and a need for social}

As Lynch says: "the city is in itself the powerful symbol of a complex society" [17]. To understand the different actions of people in the city, the changes that occur in the city, the gratifications and dissatisfactions of the inhabitants, and the diversity of ways of life in the city requires a wealth of information and data. Urban researchers are trying to obtain such data through various methods. These methods of obtaining data fall into two categories:

- Quantitative-methods for obtaining information focused on a particular topic, from a large number of people (e.g., population census, opinion barometers, electoral surveys, etc.)

- Qualitative-methods for obtaining rich information from a small number of people

The social order is one of the most difficult concepts to explain, related to social life: how it is formed, how it is preserved, how it is challenged, and how it is violated-all these are questions on which thousands have written, in books and studies. Of course, there are exceptions and special occasions; there are times when the social order is challenged or violated, such as during a street carnival or during street riots. Social researchers have always been interested in the ways in which people come to accept or challenge or violate this order. In addition, they were interested in the ways and conditions in which this order is changed or negotiated, between groups located in opposite positions. It is important to remember that social researchers are trying to understand the views, motives, and visions of all people, without judging them and dividing them into "bad people" and "good people." It is the role of the legal system to decide whether certain facts that violate the social order are to be condemned and which is the proper conviction. On the other hand, the legal system adapts to the social changes produced over time, precisely because of the individuals who challenge the social order. For example, the slave trade was legal in the nineteenth century, while it is now illegal; women's voting was illegal in Switzerland until the 1970s and is now legal. The social order is strong but flexible over time. The social order is not an immutable concept, the meanings of which never change; on the contrary, it is a concept in permanent transformation or negotiation. Therefore, social researchers look at respecting, challenging, or violating the urban social order first and foremost as a proof of the diversity of urban ways of life.

\section{Public spaces in city function}

Public place represents, by its nature and destination, an area accessible to the public even if no person is present; any place accessible to the public, the main features chosen by the public spaces consist in the fact that they are public (not private), they have free access and are used by several people in a common area. Public spaces have played an important role throughout history. From the time that humans first defined private spaces, public spaces have served as places where people have come together to exchange ideas, becoming centers for free speech and 
public discourse. Defined as an environment of simple reciprocal observability, a practical intersubjectivity among people in order to make possible their ability of communication and socialization, or an ensemble of scenes where a group of organized and politically oriented actions is exposed, the public space defines the place where all the constituent activities of the political fact take place [18]. The form of contemporary public space is the reflection of the evolution of the political aspects, because it is based on the opposition between the private spaces, which belongs to families and the public space, which do not belong to practically anyone, but which, on the contrary, is available to all and in which social actors interact. In this public space, therefore, practices, discourses, and activities are constituting the political fact taking place. However, is this idea of public space open to everyone? Is there any reality? Isn't there any potential for domination of certain groups? Nowadays, the public space is regarded as a conflict and contested battleground for power too. Accessible, but filtered, public markets are essential. Physically, they are easily accessible, at the intersection of the streets and the "hubs" of the transport flows, of people, of goods, and of the lights of the streets. However, they are filtered and bounded in an invisible, but rigorous way. The market is not accessible to everyone: camcorders, police, and security are watching and selecting who "deserves" to have access to these spaces. Moreover, yet, it is threatened by privatization, but by individualism. In the interest of someone, the public interests are for private interests; for example, business, another tendency is the lack of interests of the divisions vis-à-vis public employment. "The individual is the most diligent citizen of the citizen." That required for securing clarity with reference to the lifestyle of moderating the market relations and marketing which is reflected in the total moving of social-consequences on the esthetics and visual appearance of the publicsector premises. The markets, as the decency of the public space, have undergone significant transformations and have become the subject of "passive waiting"- the subject of looking, not living, which is called as "Allocation space." In passage space, in any case, there is a resistance to total marketing. For example, some public spaces remain dedicated to cultural and identity expression, while others are taken over by youth and subcultures. The markets still have some space for leisurely walks, not related to consumption.

\subsection{Urban space in history}

Dialectically justified, it is difficult to specify a clear limit of separation between character and specific, with a permanent overlap area. We cannot speak of their total overlap, because, in relation to the motivations stated above, the distinction between character and specificity is evident not only conceptually but also practically. The possibility, however, of the reciprocal crossing of the general and the singular (in the sphere of character and specific features) from one to the other, during the evolution of the urban phenomenon, should not be neglected. Through the process of topic selection, the general features have been polished, gradually becoming character traits that, retained over time, are today constituted as elements of specificity. There are also numerous examples of cases in which traits initially giving specificity to an urban space, considered valid and taken over as a model, later became character traits, tending even to a broader generality-an aspect involving today, in a way. In particular case, it is a requisite to discuss the topic of industrialized urban construction. But not only temporally but also spatially, an interference between character and specificity is possible, meaning that what is characteristic of a confined space may be a specific element for a larger territory-for the city. In general, however, the singular elements conferring specificity to an urban space are revealed as elements of specificity and for all other possible 
territorial framings-remaining within the respective framing of a specific singular presence (Campanile from San Marco Square in Venice) or registering in an also generalizer with specific value. It is shown from the above that, in order to detach the character and specificity of an urban space, it is necessary to pay attention to the space and time and regarding the mastering of the modernization process in relation to understanding the particular value of the urban space (of the city as a whole), it is necessary to recognize the valid behaviors of that generalizer with a specific value. Thus the risk of losing the specific is higher. However, we do not have to imagine the specificity of an exclusive space as a postcard image. As a surprise of the urban form, it refers not to a metaphysically understood form, but a totality of manifestations wearing a multitude of static and dynamic expressions. The behaviour of using the space which has to answer to the following questions (how it responds to the requirements how it adapts), as well as the behavior in that space, intervene in defining the specificity, but, at the same time, also being positioned as an object of its influence. Acquired in human consciousness through perception and sensation, the particularity of urban space also encapsulates a series of values of chance, because as Kevin Lynch notes: "always in a city at any moment you can see or hear something new, unmarked until that time, and these things often depend also on the environment, and on the continuation of the events that led us here, and on the memory of past experiences. It can also be thinking of a random determination of the specificity, a possible determination considering that it supports the spatial differentiation-results to some extent and from what happens within the respective spaces, so by chance.

\subsection{The public spaces and the city social life}

Urban space represents the spatial concentration of the economic, social, cultural, and political activities, different from the nonurban/rural spaces by the population density or the characteristics of the way of life. Urban spaces embody a general reading of many factors; it presents the social life of the city is closely linked to the urban space. The relations between social life and urban space are the object of study of the urban disciplines. In the urban space, people interact and develop their social relations, enjoy or be scared, have or take possession of certain urban spaces, develop feelings of affection for some, or have memories related to others. Urban space is a term characterized by polysemy, flexibility, but also ambiguity. Therefore, it is difficult to reach a unique definition of urban space, generally accepted in all socio-human sciences. However, we will try to provide some main coordinates. It is important to understand the urban space take importance from public space, where the public space includes all the spaces freely used in the day to day by the general public, such as streets, squares, parks, and public infrastructure. Some aspects of privately possessed spaces, such as the facades of buildings or domestic gardens, also contribute to public space and are therefore considered by urban design theory. Some of the writers on this discipline are Gordon Cullen, Jane Jacobs, Christopher Alexander, William H. Whyte, Kevin Lynch, Aldo Rossi, Robert Venturi, Colin Rowe, Peter Calthorpe, and Jan Gehl. Public spaces are frequently subject to the overlapping responsibilities of multiple agencies or authorities and interests of nearby owners, as well as the requirements of multiple and sometimes competent users [19]. The public space is associated with "sociability," with the potential of meeting and communication between strangers. This implies that people come to the public space and remain there for the meeting with others; they use the space for meetings as a stage for specific social interactions. However, today, the "space of the move" is being replaced more and more with the "space of passage." Public spaces became places full of people 
from elsewhere, who go elsewhere. Meetings, in contemporary cities, are temporary and replaced by events. The markets become spaces of the grocery store; the culprits are not to be together; they can wait for their friends to hang out at the mall or a public space.

- Why should public spaces be considered permanent, in the context of housing and stability?

- Could it become temporary, flexible, mobile, remaining public?

- Can we link to these new concepts of space and living with the original notion of public space?

Some of the writers whose lawyer and a treatise on this discipline are Gordon Cullen, Jane Jacobs, Christopher Alexander, William H. Whyte, Kevin Lynch, Aldo Rossi, Robert Venturi, Colin Rowe, Peter Calthorpe and Jan Gehl. Public spaces are frequently subject to the overlapping responsibilities of multiple agencies or authorities and interests of nearby owners, as well as the requirements of multiple and sometimes competent users [20].

\section{Urban image and components}

The imageability and urban readability (Kevin Lynch) are concepts proposed by Kevin Lynch, which refers to the degree of decipherability of the urban landscape at the level of each individual. Every city has an urban image; like any image, as presented in Lynch's sense, it must be readable, decipherable. A well-thought out and the well-planned city is easy to read, meaning it is legible. Readability is a result of urban design and urban space organization. A readable city provides us with emotional security, while an unreadable city awakens feelings of fear and insecurity. The imageability would be the quality of a city to stimulate the perception of a viewer and to cause strong mental images; more precisely, it refers to the feeling that a city manages to generate (e.g., good places/bad places). Images can generate different perceptions, which means that each of us relates differently to space. A good urban space is a space where people find it meaningful to spend time and experience something. Related to the urban image mechanism [18], there are three connection systems (see Figure 2).

- The physical space system (reality)

- The reference space system

- The reflected space system

\subsection{Integration and the specific in urban image}

Formal integration as a cohesive element in spatial differentiation proves to be a certainty in that, in such situations, the space formalized during a long topical selection is nothing more than the sum of the qualities of the component elements taken apart and, at the same time, that it always carries a meaning (civic, esthetic, ethical, etc.), and so it is itself functional. Considered thus, within the limits of its possibilities of affirmation, the association between new and old can no longer start from the (pseudo) idea of principle comparability, in fact envisaging a state 


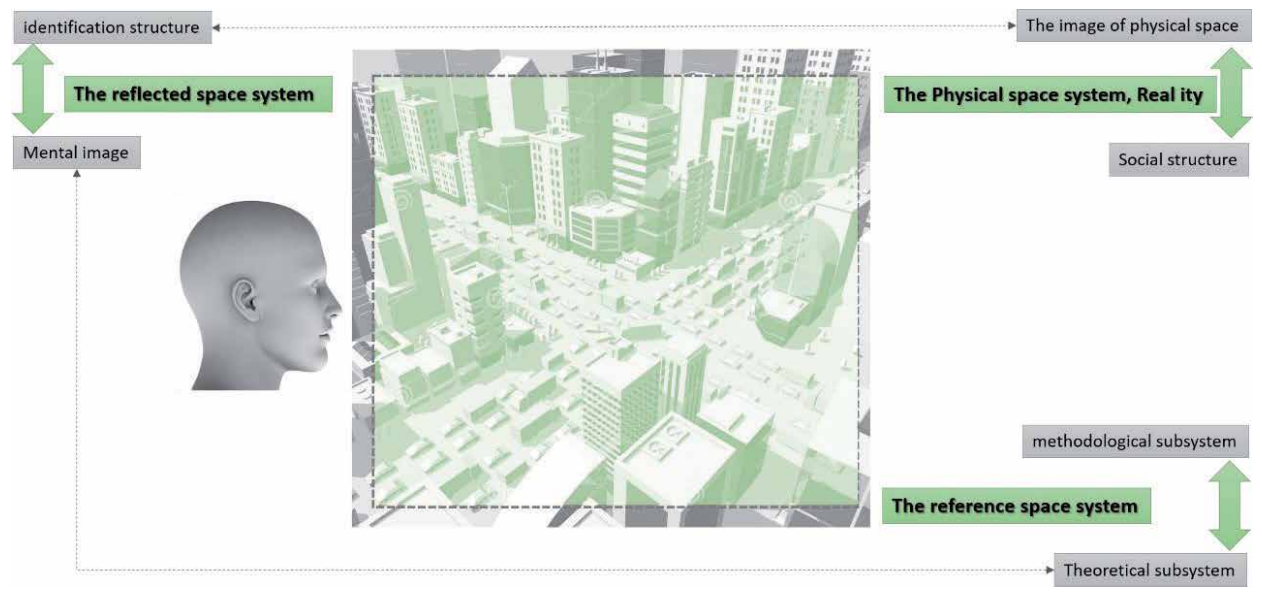

Figure 2.

Image of urban space in the connection system.

without comparability relations (because they cannot exist when everything is "at kind"), but from the idea of the natural coexistence of different elements in a state that, without being tired, requires us intensely in defining comparability relationships. By increasing combinatorial solutions, so does the diversity of urban spaces; the spatial differentiation evolves unitary, discovering, restoring, or completing the particular features of the different urban spaces and, at the same time, confirming or perfecting each time their unitary character. The particular value of urban space thus constitutes its qualitative determination, its individuality, incorporating the general-a reflection of the essence-into its own form that can be expressed and can be appreciated by character and specificity.

\section{- Can a differentiation of concept be made between the character and specificity?}

It is necessary to recognize the differentiation, because, diverse art, in general, is linked to the quality of the urban space; besides the effect, it is particularly interested in the cause, the means of realization - on which we act, not to forget, a directly objective determination through functionality and possibilities of realization, adaptation to an existing material that causes both the inventiveness, as well as the capacity to assimilate the previous experience and the time as a wrapper and space as a place of the limited selection that tends toward an increasingly complex urban space formation. It should be added here that, in defining the urban space, we do not always have to deal with a single (in the sense of capacity) creative personality, which intervenes more than in art-taken in general-tradition and behavioral habit as a reflection of the requirements of the major. In these conditions, the particular value of the urban space is a result of the interference in the context of the functional generality and the significant forms of some participations of the nature of a restricted generality, conferring character, and of participations of the singular nature, conferring specificity. For the San Marco ensemble and the whole of Venice, the Campanile is an element that gives the ensemble and the urban body, respectively specificity. However, it is unique, and it is precisely through this unique presence that he completes a summit of specificity in a framework that otherwise cannot be accused of being non-specific, and yet, when collapsed, it was restored by the commune's effort, not the functional considerations dictated in this operation, but the subjective significant ones, to which the specificity is in principle related. The central area of Bologna, on the other hand, is specific through the succession of 
porches along the streets, from the ground floor of the buildings. This is a common element of a multitude of constructions, and it confers specificity precisely through this repetition. Moreover, in one case, and in the other, the specificity elements, unique or common and repeatable, prove for the respective assemblies an efficient common factor (Figure 3).

The urban image makes architectural objects to take high values by reading of the urban composition by the harmony between Human being, all site elements, site functions and urban or site framework, which determines urban spaces, configuration, and structure. One of the major problems facing us is how to establish and

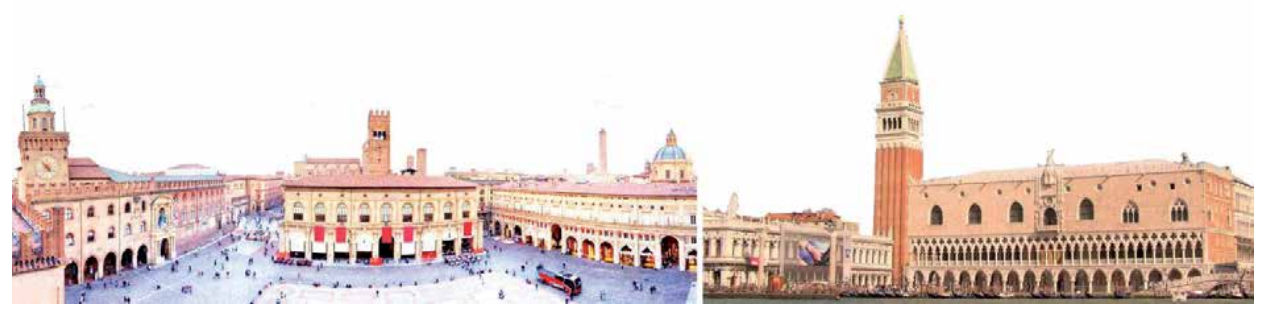

Figure 3.

San Marco ensemble.

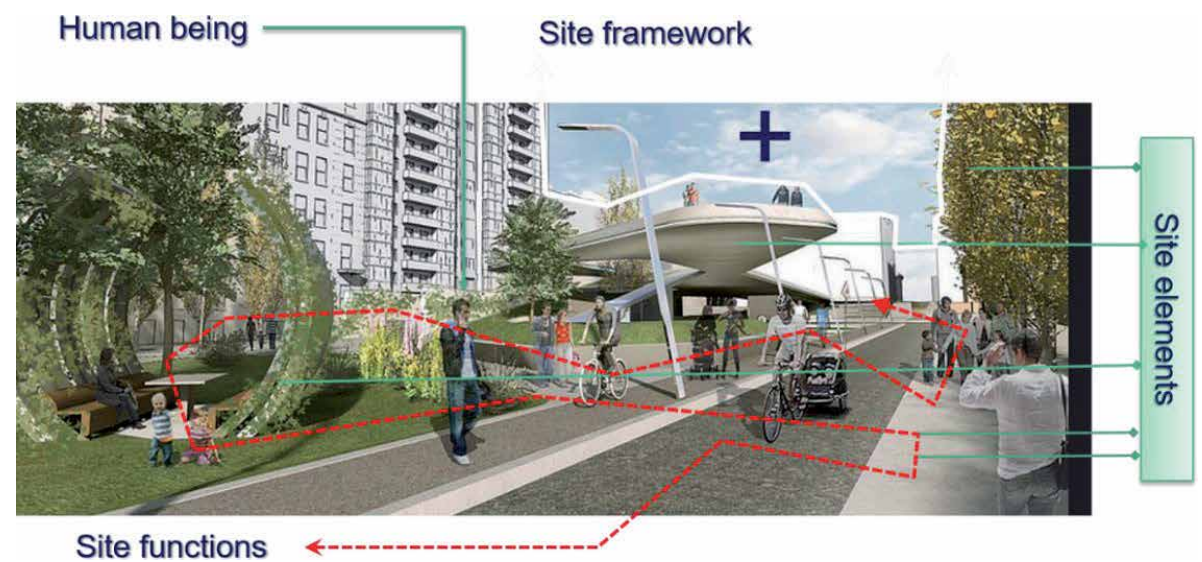

Figure 4.

Urban image and site components.

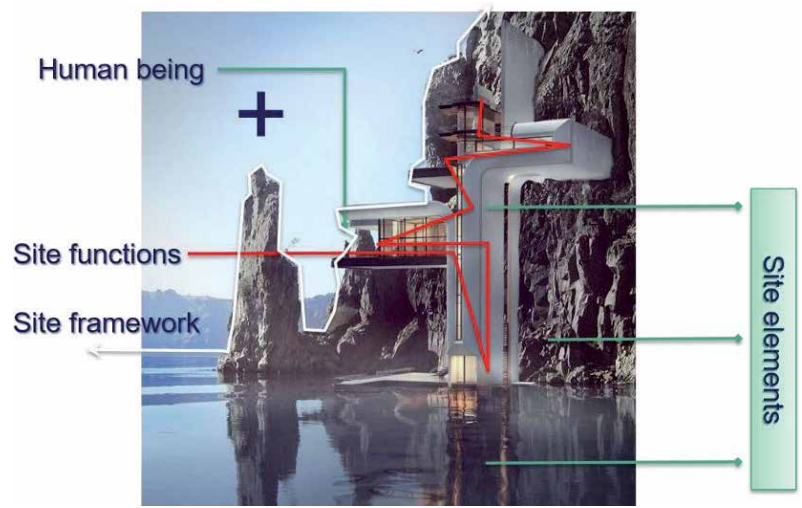

Figure 5.

Urban image and site components in a special case. 
maintain environments that support human health and at the same time are ecologically sustainable. Green areas seem too important to people. Most people today believe that the green world is beautiful [21]. Green areas are essential for people, where most people believe that it represents a high value in the city configuration (Figure 4) [22].

Urban design search for the human experience which contributes to building environment within private properties or public areas (Figure 5).

Between the elements of the site and the image reader position a relationship that takes time to be significant and increase the quality of the image which is seen at a given time-space-isotopic-unitary, continuous and-heterotopic diversified space, differentiated but not necessarily discontinuous or lack of unity. A utopian image can be isotopic or heterotopic when something "fabulous, fantastic" is created (e.g., night lighting accentuates or deletes specific characteristics).

\section{Urban image and structural composition and characteristics}

The urban image represents an essential element in the organization of the space and triggers in new, unexpected resorts regarding the appreciation of the urban reality. It represents also a vital element in the conformation of the public space process within the theoretical and practical analysis (therefore, also fundamental and applied research) of the concept of urban image and its role in the organization of the urban space. The theoretical dimension of the concept consists in its analysis, both in individual (interpretive) value and in the context of the current principles of thinking that have marked the dynamics of urban geography as a science, realizing an entire framework and conceptual context for deepening the urban image [23]. By identifying the typical typologies of the urban image, it can determine their viability and also possibilities of individualizing and customizing them, in order to define strategies to be followed and to establish the specific priorities and attitudes to find the appropriate ways to ensure the natural development, without constraints and contradictions, of the city. The characteristics determined by the precise relations between buildings or plots, courtyards, gardens, streets, and markets define urban pieces' type: grouping of series of buildings and the relationship between buildings and the private or public un-built space. The specific perspectives, their depth, are also characteristic elements that generated the urban space at a given time and which write it down as a consecrated type, with permanence urban value and it represents a good premise for its personalization, for the creation of a new urban identity, either in conformity with the existing one or by replacing it according to the functional approach. Homogeneous parts of urban tissue form a morphological point of view; the sectors have specific compositions of parcels or buildings in identifiable relationships with each other or with the land on which they arise. The analysis of the urban sectors facilitates the appreciation of the elements of physicalspatial identification characteristic of a city, coherent from the urban and architectural point of view, which can become a reference and highlighting elements. This procedure allows the detection of attitudes necessary and possible to be taken means the organization of urban development, the elements of continuity as well as the polarizing ones of the urban image are determined, the coherence of the city structure is ensured (Figure 6).

\subsection{The human being and objectives in urban space}

The city is a relatively numerous, dense, and permanent settlement of heterogeneous individuals from a social point of view. It differs from the rural world by: 


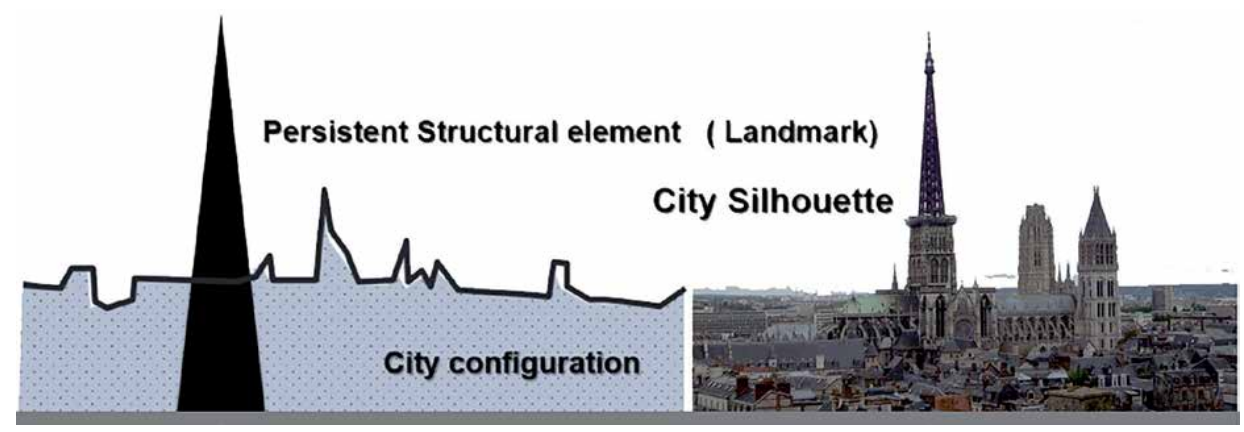

Figure 6.

The persistence of the structural element in the urban image "Ulm Minster, Germany."

- The positive aspects that they generate-economic activities (commercial, industrial), transport and telecommunications infrastructure (increasingly developed), and good quality of urban services. All this has the effect, ultimately, of creating new jobs and determines an increased quality of life of the citizens.

- The negative effects it implies for the environment (increasing air pollution, but also noise pollution-mainly due to heavy traffic, diminishing green spaces in favor of the construction, or implantation of new businesses) and for a large part of the urban population (IE about social inequities) [21, 24].

The objectives on the site-the comment is carried out on the characteristics of the objective but also of the environment of the site such as:

- Characteristics regarding volume, color, silhouette, size, etc.

- The building form which in a certain picture constitutes an image-an object with an important character in the image-of average performance-frame which it is interested in:

- The dimensions and characteristics

- The linearity of the myth (exists or not)

- The characteristic of the environment processing (the volume accents in the image)

- The color

The role of architectural composition, through its complex activities, is to create the framework material, of the organized space, with a view to satisfy the material and spiritual needs of the person and society [25]. Tall buildings are neither an object of love nor an object of hatred; they are necessary objects in the urban composition, and thus they are subject to a court of architectural value and a court of urban value. In the drawings of Ulm Minster, Ulm, Germany (161.5 m), the tallest cathedral in the world, for example, churches are presented to us with a silhouette in which the churches, unique in size, were still "tall buildings," having a meaning, although not one could speak of an urban composition. In the modern city, the tall building must be considered, on the one hand, in the immediate context (adjacent 
neighborhood), when its own architecture is important and, on the other, in the remote context, when the silhouette is important, the architectural-urbanistic "cut." Already there is a disjunction, in the judgment it was referring to, which imposes the option for a priority in evaluating such a presence in the urban space. The transformation of the static approach form of the dynamic approach is not arbitrated by elevation, especially when it comes to an important building. The elevation is real in its volume and presence, but it is unreal in its image. According to Kevin Lynch, in urban imaging mechanism, it is required to include the building in context, which is represented by:

- Visible points

- The places where the building can be viewed

Space perception is the procedure through which humans and other creatures become alert of the relative locations of their individual bodies and objects around them. It offers indications, such as depth and distance, which are important for movement and orientation to the environment (Figures 7, 8).

In this domain it is required to take in evidence:

- Observation position: in this situation, it is necessary to take in as evidence distance, height (terrain configuration), and opening (in space).

- Observing conditions: in this situation, it is necessary to take in as evidence conjuncture and weather conditions (night-day, winter-summer, cloudy-sunny).

The observatory is characterized by:

- Visual acuity of perception-all senses are required, not just the visual but also the complexity of perception which varies from one individual to another (e.g. in Austria_clean, fresh air-you feel purity; in Paris the street is fragrant. The smell participates in the image that remains afterwards; Germany-the smell of perfumed gasoline, the special smell. It is of superior quality olfactory perception).

- The movement of the space that can be perceived static or dynamic.

- Movement-work in perception.

Every city has a form, called an urban form (plan metric image or top view), expressing in a geometric configuration of urban distribution, social relations, and ideological hierarchies [26]. The urban form is physically expressed through the urban structure, both are historically determined, and they are formed by a succession of reactions and evolutions starting from a previous state.

a. Viewing-designates the physical process through which the visual contact between the observer and the observed object is realized.

- The view from that is performed under particular conditions (e.g. the terraces at the last levels of the skyscraper-Sears Tower, Chicago-above the city_fabulous) - from the level of the bird's flight - it is a perception that has a philosophical meaning, demiurgic, "divine look." 

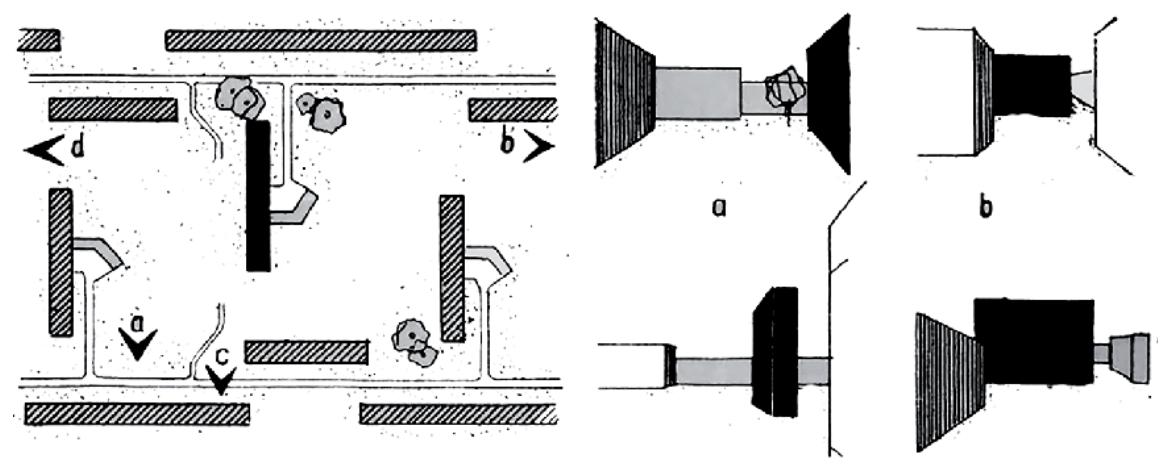

Figure 7.

The connection between observation position and image impression.

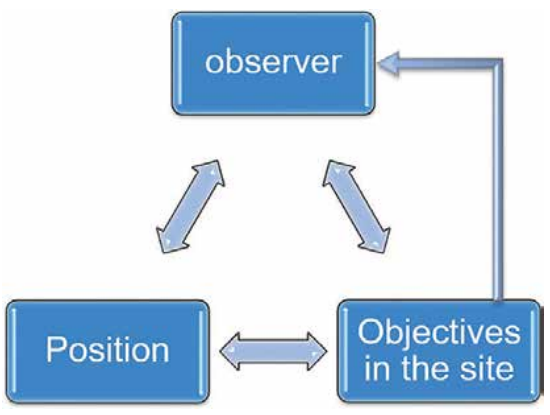

Figure 8.

Relationship system that physically defines the urban relationship.

- Bottom view is typical

- Look-a process actually determined physically. It is not reduced to front registration.

b.Vision is beyond the physical process of gazing. It also associates the mental processing of the physically determined ones; it is completed by understanding, reporting, learning, and rejection (when you like a certain thing, architectural object, etc. or on the contrary) [27].

\subsection{City images and structural element}

A structural element represents the factor motor to creating a consistent city image, which creates an equilibrate urban image by relationships and proportions.

The structural element can be as follows:

\subsubsection{City image with one structural element}

It dominates the city silhouette, with convenient effective distances required for acting positively in a city configuration.

During the preparation of the plans, regardless of what power or even the landmark will reflect, it must be understood that it is an element and a device that will orientate the development [27] (Figure 9). 

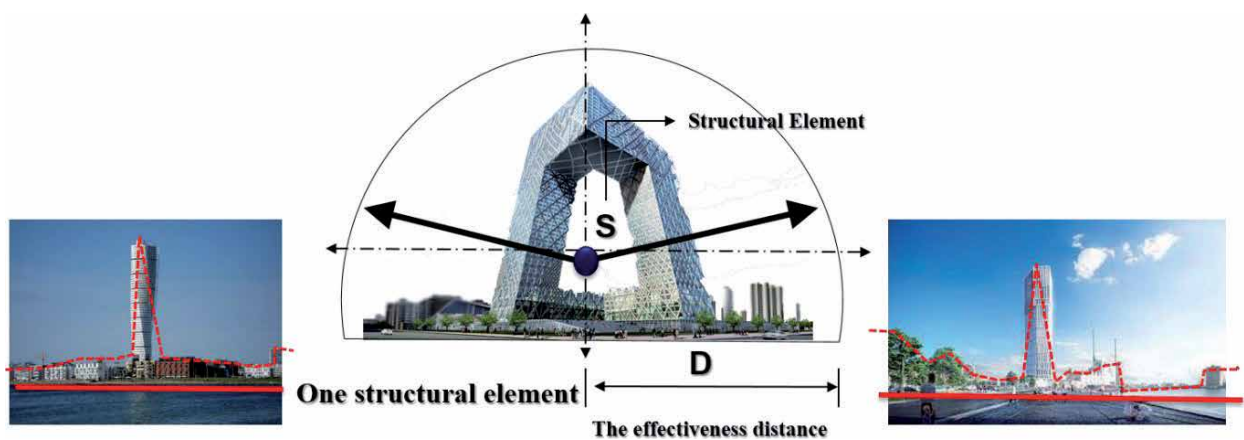

Figure 9.

Urban image with one structural element.

\subsubsection{City image with two structural elements}

There appear two dominant elements in city image. The effectiveness of viewer distance that can labour harmoniously with the city silhouette. The structural field of the building systems which can be positive or negative. The structural elements $(1,2)$ working, harmonious, see Figure 10.

The distance between two different architectural dominant elements.

\subsubsection{City image with many structural elements}

The city can contain many structural elements that collaborate together to create the city image (Figure 11).

Several structural fields create unity throughout an integrated urban image.

\subsection{Dynamic city image}

This image is used in descriptions. It refers to the movement, creating at the same time different emotions and moods for the reader. The integrate image configuration is dominant and has to work as an organic unit. The city silhouette has to be presented creatively and unitary [28]. The urban design takes into consideration the following aspects:

- Urban structure: How places are positioned together and how the parts interrelate with each other.

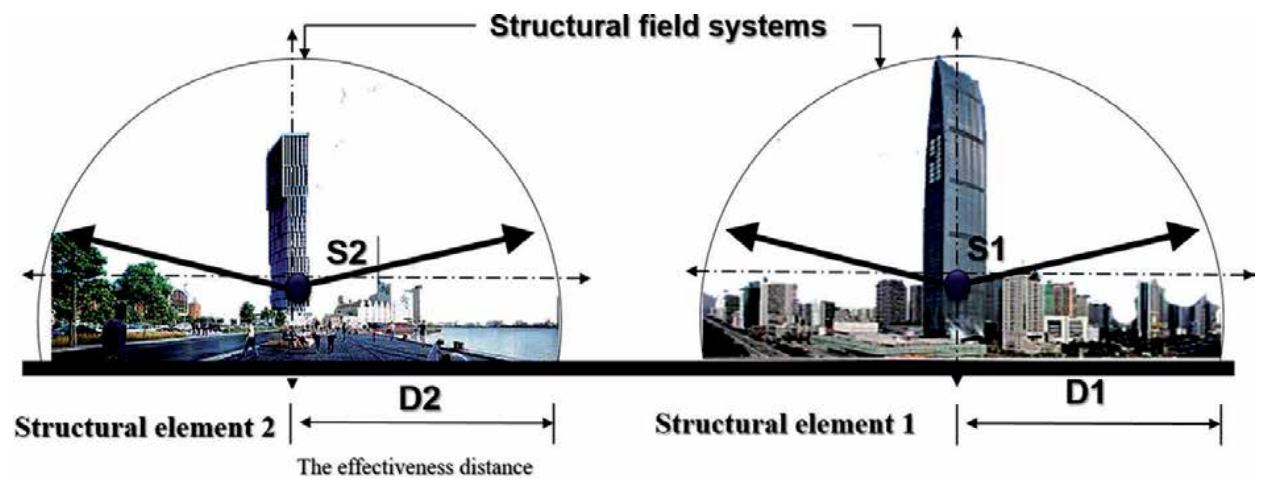

Figure 10.

Urban image with two structural elements. 


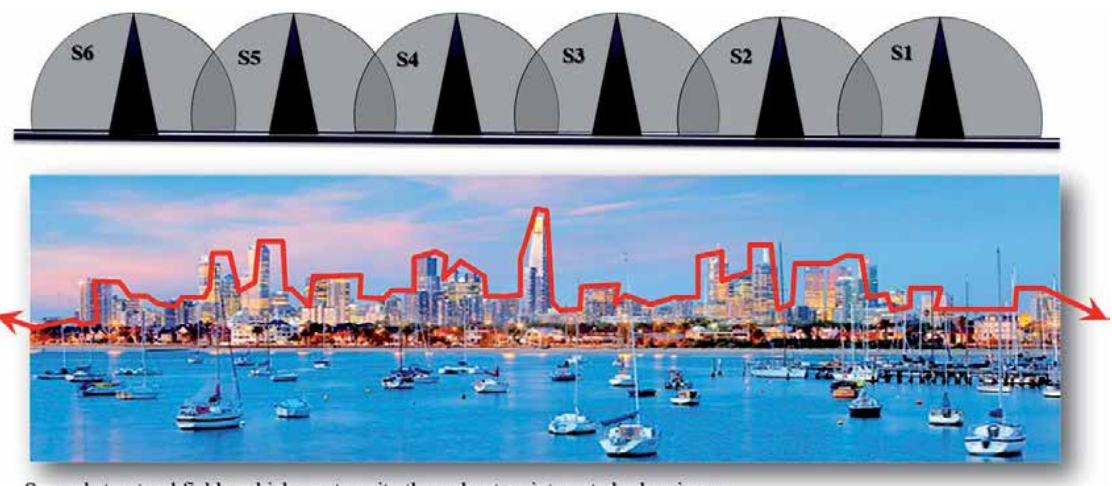

Several structural fields, which create unity throughout an integrated urban image

Figure 11.

Urban image with many structural elements.

- Types of spaces and morphologies related to the intensity of use, resource consumption, production, and maintenance of viable communities.

- Accessibility: Provide an easy and safe option to move between spaces.

- Readability and guidance: Help people find their way and understand how space works.

- Animation: Design spaces to simulate a public activity.

- The mix of complementary uses: Location of activities that allow constructive interaction between them.

- Characterization and significance: Recognize and assess the differences between one space and another.

- Civil society: Make spaces where people are free to meet each other as civic equals, an important component in the construction of social capital [13, 18] (Figure 12).

Architecture in urban composition can take many functions:

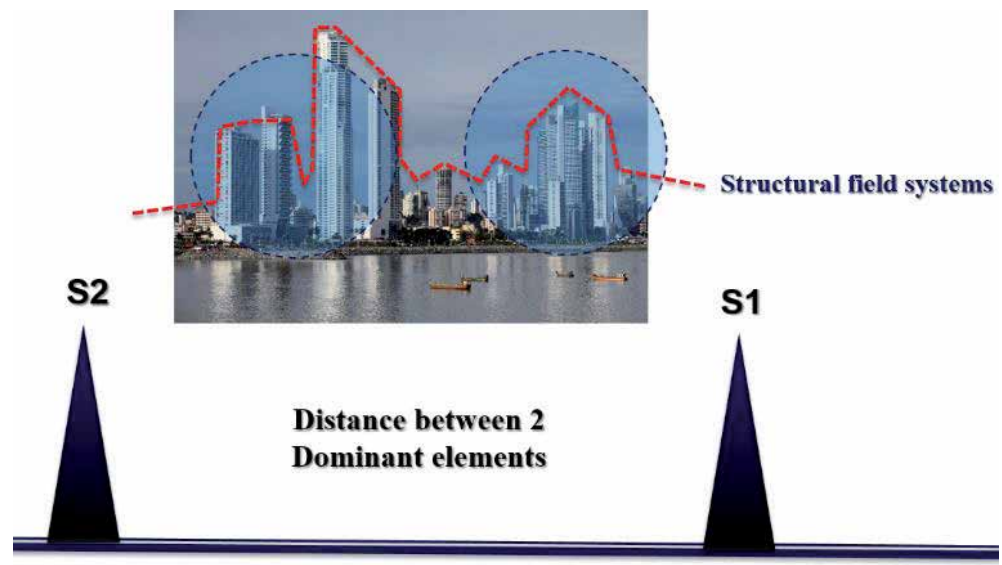




\subsubsection{Architecture as a human product}

Architecture elements have many readings form regarding the art of building, painting, sculpturing and technique using which called the beautiful illustrations from the ancient times. The architecture works in shape and mass like sculpture art, and it works with color like paint art. However:

- It is a functional art.

- It solves realistic tasks.

- It creates tools for a human being.

\subsubsection{Architecture as commodity}

To commodify an object is to make it tradable and consumable on markets:

- Ordinary goods and services are commodities and traded on markets.

- Nature or natural and built environment is resistant to commodification, yet it happens:

○ The environment turns into the land.

- Human being turns into the labor commodity.

- The consequences are environmental degradation and human suffering.

A right architecture can be described as that where thinking and human feelings come into play and create an entire harmonic, which ensembles structure and possesses significance.

In urban space analysis, the strategy of marketing and the policy of research become essential for combining the relation between architectural creation and potential user positively. That required to understand the meaning of profitable building design, which is influenced by a series of more general economic aspects such as people's living standards. The architectural product is characterized by a life cycle similar to traditional products (Figure 13).

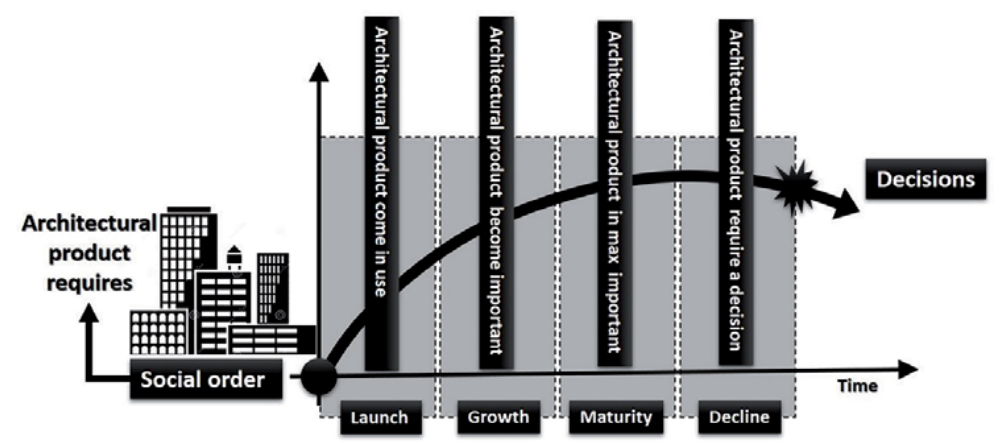

Figure 13.

The life cycle of an architectural product. 
Urban design is a creative and technological field of study that works with a long-life human product that is oriented nationally and internationally. Urban space has signified elements like a landmark. Landmarks as reference signs orient the people. Landmarks are defined as an external point of reference that helps to orient in a familiar or an unfamiliar environment [29]. Landmarks are a kind of signals of urban space [10]. The question is how people orient themselves in urban space considering reference points. People choose the points in the city for their orientation. In the city, same natural or man-made elements are seen as signs giving the sense of wayfinding [27].

\section{The conclusion}

The problem of organizing the urban space has aroused great interest due to its practical importance. There are several models and theories that try to clarify these issues and cover the whole variety of existing situations, thus having a high degree of applicability. The main objective of the study of the urban structure is the formation of an own system of coherent urbanistic thinking in the sense of developing the capacity of interdisciplinary approaches in the field and of the understanding of the city as a complex urban body, functional-configurative, clarifying both problems of terminology and problems of method, developing the readiness to form logical analytical or synthetic conclusions regarding specific states, phenomena, or working methods. Their complexity is determined by three main elements: land, population, and urban activities, which by their configuration, dimensions, and profile, respectively, generate specific forms of territorial organization. The urban spaces of some small countries are simply structured, while in the big countries, they present structures of great complexity, as a result of the stepped development and the permanent intensification of the internal relations. Within the transformations that characterize the evolution of human societies, one of the means by which this process manifests itself is the qualitative and quantitative change of the living environment, and the city belongs to both fields of manifestation. Urban agglomerations such as metropolises or conurbations were born through the continuous development of relative cities close to each other in space, between which there was sufficient buildable or usable land to allow new connections and housing. The evolution of the society, the demographic growth, and the economic developer determined the creation of dynamic urban space, in continuous expansion and growth. The arrangement of the territory changes from year to year due to the accelerated development of the society and its requirements, and the population generates the value of territory but also its deterioration over time. In the context of the current urban development, the field of urbanism is confronted with phenomena described by the dynamics of complex systems, which are becoming increasingly difficult to predict, but not impossible to manage. The sense of strategic planning is changing; the methods of forecasting and adapting to the urban phenomenon must be understood in the sense of such complexity. Urban configuration takes in evidence developing the capacity for functional-configuration analysis and definition of a possible urban image as a support for the process of architectural-urban creation in the urban space, development of the formulation capacity, and development of a value judgment on the configuration of the space organization. 


\section{Author details}

Amjad Almusaed ${ }^{1 *}$ and Asaad Almssad ${ }^{2}$

1 Department of Construction Engineering and lighting science, Jonkoping University, Sweden

2 Department of Construction Technology, Karlstad University, Sweden

*Address all correspondence to: amjad.al-musaed@ju.se

\section{IntechOpen}

(C) 2019 The Author(s). Licensee IntechOpen. This chapter is distributed under the terms of the Creative Commons Attribution License (http://creativecommons.org/licenses/ by/3.0), which permits unrestricted use, distribution, and reproduction in any medium, provided the original work is properly cited. (cc) BY 


\section{References}

[1] Dijkstra L, Poelman H. A Harmonized Definition of Cities and Rural Areas: The New Degree of Urbanization, Regional Working Paper. European Commission; 2014. p. 6

[2] Carmona M, Tiesdell S, editors. Urban Design Reader. Amstedam Boston other cities: Architectural Press of Elsevier Press; 2007

[3] Aapo Huovila Peter B, Miimu A. Comparative analysis of standardized indicators for smart, sustainable cities: What indicators and standards to use and when? Cities. 2019;89:141-153

[4] Caragliu A, Del Bo C, Nijkamp P. Smart cities in Europe. Journal of Urban Technology. 2011;18(2):65-82. DOI: 10.1080/10630732.2011.601117

[5] Yanga T, Lib M, Shenb Z. Between morphology and function: How syntactic centers of the Beijing city are defined. Journal of Urban Management. 2015;4(2):125-134. DOI: 10.1016/j. jum.2015.11.001

[6] Middel A et al. Urban form and composition of street canyons: A human-centric big data and deep learning approach. Landscape and Urban Planning. 2019;183:122-132. DOI: 10.1016/j.landurbplan.2018.12.001

[7] Amjad A, Asaad A. Urban Biophilic Theories upon Reconstructions process for Basrah City in Iraq. 30th International Plea Conference 16-18 December 2014, CEPT University, Ahmedabad, Available from: https://www.researchgate. net/publication/311861845_ Urban_Biophilic_Theories_ uponReconstructions_process_ for_Basrah_City_in_Iraq [Accessed: 12-10-2019]

[8] Amjad A, Asaad A. Introductory Chapter: Housing Policy Matters,
Housing, Amjad Almusaed and Asaad Almssad, Intechopen; 2018, Available from: https://www.intechopen.com/ books/housing/introductory-chapterhousing-policy-matters

[9] Curtis S, Acuto M. The foreign policy of cities. The RUSI Journal. 2018;163(6):8-17. DOI: 10.1080/03071847.2018.1562014

[10] Bala H. Landmarks in urban space as signs. Current Urban Studies. 2016;4:409-429. DOI: 10.4236/Cus. 2016.44027

[11] Zappulla C, Suau C, Fikfak A. The pattern making of Megaslums on semantics in slum urban cultures. Journal of Architecture and Urbanism. 2014;38:247-264. DOI: $10.3846 / 20297955.2014 .987368$

[12] Rydin Y et al. Shaping cities for health: Complexity and the planning of urban environments in the 21st century. Lancet. 2012;379(9831):2079-2108. DOI: 10.1016/S0140-6736(12)60435-8

[13] Krieger A, Saunders WS, editors. Urban Design. USA: University of Minnesota Press; 2009. Available from: www.jstor.org/stable/10.5749/j. ctttspsh

[14] Bell N, Koch D, Shindell D. Impacts of chemistry-aerosol coupling on tropospheric ozone and sulfate simulations in a general circulation model. Journal of Geophysical Research. 2005;110:D14305. DOI: 10.1029/2004JD005538

[15] Broadbent DE, Cooper PJ, Fitz Gerald PF, Parkes KR, et al. British Journal of Clinical Psychology. 1982;21:1-16

[16] Tuan Y-F. The City as a moral universe. Geographical Review. 1988, 1988;78(3):316-324 
[17] Lynch K. The Image of the City. The MIT Press; 1960. pp. 23-25

[18] Călin sinescu, Spațiul public al comunicării politice; 2009. Avilable from: http://www.sferapoliticii.ro/ sfera/141/art08-sinescu.html\#to

[19] Gehl J. Life between Buildings: Using Public Space. WashingtonCovelo-London: Island Press; 1987/2011

[20] Cruz SS, Roskamm N, Charalambous N. Inquiries into public space practices, meanings and values. Journal of Urban Design. 2018;23(6):797-802. DOI: 10.1080/13574809.2018.1525289

[21] Amjad Almusaed. Introductory Chapter: A General Reading Process on Landscape Architecture, Landscape Architecture-The Sense of Places, Models and Applications, Amjad Almusaed, IntechOpen; 2018. Available from: https:// www.intechopen.com/books/ landscape-architecture-the-senseof-places-models-and-applications/ introductory-chapter-a-general-readingprocess-on-landscape-architecture

[22] Almusaed A. Biophilic and Bioclimatic Architecture, Analytical Therapy for the Next Generation of Passive Sustainable Architecture. UK: Springer; 2011. p. 173. [December 21, 2010]

[23] Stevens Q. The shape of urban experience: A reevaluation of Lynch's. Environment and Planning. B, Planning \& Design. 2006;33:803-823

[24] Bala HA. Landmarks or structural element in urban space as signs. Current Urban Studies. 2016;4:409-429. DOI: 10.4236/cus.2016.44027

[25] Almusaed A, Almssad A. Biophilic architecture, : The concept of healthy, sustainable architecture. In: PLEA 2006: 23rd International Conference on
Passive and Low Energy Architecture. Geneve: Universite de Geneve; 2006. pp. 383-387

[26] Böcekl B. Investigating the Effects of Nodes and Landmarks in City Planning Practice, A Dissertation Submitted to the Graduate School in the Partial Fulfillment of the Requirements for the Degree of Master of Urban Design. İzmir, Turkey: İzmir Institute of Technology; 2003. p. 9

[27] Roger M, Bonnardel N, Le

Bigot L. Improving navigation messages for Mobile guides: Effects of the Guide's interlocutor model, spatial abilities and use of landmarks on route description. International Journal of Industrial Ergonomics. 2004;39:509-515. DOI: 10.1016/j.ergon.2008.10.009

[28] Larice M, MacDonald E, editors. The Urban Design Reader. New York, London: Routledge; 2007

[29] Heth CD, Cornell EH, Alberts, DM. Differential use of landmarks by 8 - and 12-year-old children during route reversal navigation. Journal of Environmental Psychology. 1997;17:n199-213. DOI:10.1006/ jevp.1997.0057 



\title{
Future Planning of Global South Cities with Inclusive Informal Economic Growth in Perspective
}

Vincent Aghaegbunam Onodugo and Nkeiru Hope Ezeadichie

\begin{abstract}
Current urbanization trends and projections clearly indicate that the global South cities, especially of Asia and Africa, would be at the receiving end of about $80 \%$ of the expected 2.7 billion increase in urban population between 2010 and 2050. These trends and projections make it imperative for the future planning of the global South cities to step out of the box, away from the traditional planning systems, and begin to adopt inclusive and innovative planning approaches that would efficiently tackle the current and emerging urban realities in these cities rather than sticking to rigid planning standards that ignore realities, generate continuous conflict, and fail to take advantage of the potentials of these urbanization consequences, especially the resilient informal economy. The chapter examines the urbanization trends and one of its major challenges in global South cities; informal economic activities, the planning implications of these informal economic activities, various approaches that have been adopted by different governments and the effectiveness or otherwise of the approaches in tackling the challenges of informal economy. The chapter also focuses on the successful planning approaches that have been implemented with a view to portraying the key lessons that can ensure its applicability in other global South cities facing similar challenges.
\end{abstract}

Keywords: planning, informal economy, global South cities, inclusive

\section{Introduction}

The global dichotomy between the global North and global South is not a mere fiction but a fact that actually plays out in many spheres of life [1]. The current position of many nations in the global South is involuntary, however, the derogatory characteristics of a global South nation can change when there is a sincere, determined resolution by all stakeholders to make the nation functional and efficient. The much needed functional cities in the global South cannot be achieved without deliberate, effective and apt urban planning. A clog in the wheel of progressive change in urbanization trend of these cities is hinged on the unrelenting position of many global South planners who cling to their colonial-master-bequeathed planning approaches without consideration of current realities, with the results that these cities evolve and grow without circumspective direction and proper management of urbanization trends.

In the light of the above scenario, the characterization of global South cities as informal-economy-cities has not only just persisted but is expanding and taking 
new dimensions. Consequently, this chapter briefly discusses the trend of planning at different epochs in history; examined urbanization, and its major consequence in global South cities, which is informal economy. It further explores the Neo-liberal thinking and trends, which underpins and sustains the perpetration of informal economy, and details and interrogates the predominance of informal economy in global South cities. The Chapter specifically devotes sections to discuss the relationship between urban planning and informal economy; the need for adjustment in global south urban planning standards to meet current realities, with lessons drawn from successful story of Singapore, a global South city that has become a model for other global South cities, showing that being an informal-economy-city is not a permanent status but can be transformed when necessary actions are taken by all stakeholders. Finally, the chapter proposes innovative and inclusive urban planning design as the path to economic growth in global South cities.

\section{Traditional planning system in the global south cities}

The discussion on the trend of urban planning will be incomprehensive without retrospection on the trends of human settlements/development. In fact, each stage of urban planning can only be effectively discussed within the context of the prevailing development era and so a better chronological order is to discuss the type and level of planning that prevailed in each human development era. The focus of this section though on planning in global South cities, needs to first discuss planning globally since most global south planning systems are bequeathed by their colonial masters especially in African cities and their contemporary planning practices still have its foundation on the inherited system. The following section therefore focuses on planning during the six major historical human development eras before the contemporary period.

The human settlement is an organized grouping of human habitation. The first stage of prehistoric human era known as the Paleolithic era was characterized by trial and error of the stone age-man. The Stone Age man at the experimental period had no definite settlement and moved from one place to another, it was a period of experimentation in virtually every facet of life [2]. At this point, planning was non-existent and actually irrelevant since man lived a nomadic life and the only moment of temporary abode was during very harsh weather and security threats in caves and cliffs. The next human development era was the Neolithic era which started around $6000 \mathrm{BC}$ and was characterized by initial settlements first as temporary and gradually to permanent settlements. In this era, the first attempts at planning were identified where the people settled at different locations based on some criteria and definite situational $l$ advantages. Planning at this point was informal but was obvious as the location of settlements was based on clearly defined advantages that such locations provided for the settlers. Some of the choice locations for settlements in the Neolithic era included near water bodies and cultivable lands. The next stage is called Bronze Age also known as Urban Revolution was an era when agriculture was the major source of income and so most planning attempts were to organize the available land for effective agriculture as well as set standards for the few towns that had come into existence then. The Bronze Age was a remarkable period and can actually be described as the real starting point of planning. The fourth epoch was called Classical Age. It comprises mainly Greek city-States and Classical Romans. It was at this stage that saw the laying of the many foundations for urban planning especially by Hippodamus regarded as the father of urban planning. The Medieval Age was a time of regression both for the planning and other aspects of life then and as such 
no progress was made. The Renaissance era, saw to the revival of planning and some more steps of progress made in the cities that existed then (mainly in the current global North). The features of Renaissance town planning include radial concentric town layout, carriage-way development and landscape planning ([2], p. 50). The Nineteenth century/Industrial Age had a lot of challenges for urban planning and gave the opportunity for planning to thrive and became a very relevant profession especially with the contributions of Robert Owen and Ebenezer Howard.

In the global South, most of the locations known today as cities started as rural areas and had some form of informal planning. Typical examples are some communities in Nigeria (which are part of the global South cities) as Ile-Ife, Kano, Oyo and Bini. The planning practice then was characterized by the ordering of the community features in a radial form with the prime feature such as the King's palace or place of worship at the centre [3].

The contemporary urban planning is traced to the planning standards introduced by the colonial masters in many global South cities. In Nigeria, the 1932 Town and Country Planning Act of the United Kingdom formed the basis for the 1946 Nigerian Town and Country Planning Ordinance (No. 4) [3]. The current Urban and Regional Planning Law (1992) is also rooted in the former existing laws. Many other countries formally colonized in the global South share the same experience of Nigeria. Singapore is another typical example; its planning legislation was based on the British Town and Country Planning Act of 1947 [4]. The impact of colonial planning laws on the colonized global South cities is quite obvious in the physical organization of the cities right from the colonial era till date. The underlying factors that influenced the colonial planning legislations especially that of the 1930s and 1940s in Britain/Europe are no longer tenable even in the originating nations but unfortunately the colonized nations that were bequeathed with these planning legislations still hold tenaciously to them even in contemporary divergent situations [5]. Also the planning standards practiced in the colonial era had some design issues that were elitist, yet contemporary planning systems in the global South have rigidly upheld these standards till date. The Contemporary planning system is vividly captured by Watson ([6], p. 2261).

Remarkably, much of the global South, as well as part of the North, still use variations of an approach to urban planning which emerged in Europe and the US in the early part of the $20^{\text {th }}$ century, adapted to forms of government and urban conditions which have changed significantly.

The traditional forms of planning that have persisted in global South cities are opined to somewhat be driven by some forces [6] even the current trend of global South cities' urbanization reveals their inadequacy and ineffectiveness.

\section{Urbanization and its effects on the global south cities}

The global population reached the 7 billion mark in 2011 and is expected to get to the 9 billion mark by 2050. Urbanization, which is the influx of people from rural to urban areas, is a global concern. Globally, urban population reached the $50 \%$ mark in 2007 and has continued to increase ever since then with a projected $70 \%$ by 2050. Urbanization is a process predominant in the global North in the nineteenth century and has currently shifted to the global South [7]. It is predicted that $80 \%$ of the expected $70 \%$ urban population by 2050 would be resident in Asian and African cities [8]. The urbanization of the global North was accompanied by many positive effects such as new employment opportunities and poverty reduction. However, 
global South urbanization is fraught with many challenges in virtually every facet of the society due to its rapid rate and the governments' unpreparedness for the challenges. The urbanization challenge focus of this work is on the urban economy and its effect on the urban environment. Urbanization in the global South has had a great toll on the economy. The influx of people to urban areas in the South has led to constant increase in the level of unemployment. As the population increase has not been matched with commensurate growth in gross national product (GDP) and employment provisions both by the government and the private sector resulting in high level of unemployment with many urban residents resorting to the informal economy. The urban informal economy characterized by unregistered and unregulated businesses, has become the sole resort for many urban residents. This informal economy has been traced to some government policies and international economic policies which have affected the global South nations more than the developed global North nations. One of the major policies that have influenced and sustained the informal economy is neo-liberalism. Going through history, one can glean insights on how humankind and their groups have identified and reacted to threats and openings which were embedded in their natural settings. Urbanization, in this case, is seen as one of three fundamental approaches in history employed by humans towards problem solving. This particular approach involves movement of people from areas of scarcity and lack to areas of available resources. As for the actual timing of when urbanization started, it is believed to date back as far as the pre-historic period of 2350-1800 B.C.

Urbanization is not restricted to any particular region of the world; however, the rate at which urbanization is taking place is seen to be fastest in global south cities of Africa, Latin-America, Asia, the Pacific and the Caribbean. The United Nations (UN) projection is that higher than 4 billion or $77 \%$ of urban residents of the world will be in less developed regions in 2025. This figure will translate to a total increase of $186 \%$ or an equivalent of 2.61 billion new urbanities in Latin America, Asia and Africa starting from 1990. The State of World Population indicates that in year 2009, urbanization level in less developed countries stood at 45 and $29 \%$ in least developed countries. The growth rate of urban population in the same report indicates $2.6 \%$ for less developed countries and $4.1 \%$ for least developed countries annually.

A greater percentage of people who move from rural to urban areas find themselves living in harsh or extreme conditions, more often than not, in the worst areas of cities. Such areas are often characterized by slums and squatter settlements. Houses in these areas are mostly shacks and cheap self-made apartments of mud, wood and zinc, corrugated iron sheets, etc. The most unfortunate ones are completely homeless or just manage to put up anywhere possible in global South cities like in Nigeria.

\subsection{Effects of urbanization}

Urbanization has both negative and positive effects on global South cities, though, discussions in this respect often tilt towards the negative effects. The negative effects will be addressed along two broad areas of environment and economy.

\subsubsection{Environment}

Urbanization effects on the environment of global South cities come in two major ways: air and water pollution. The hallmark of cities and towns is the existence of automobiles and factories. As more people move into cities, larger quantities of dangerous gases such as carbon-dioxide, carbon-monoxide and 
nitrogen oxides, and smoke are emitted into the atmosphere. These gases present severe threats to our health and are known to cause serious respiratory challenges. What is more it is generally responsible for depleting the ozone layer with the many adverse consequences. The next immediate environmental challenge is water pollution. Increase in the population of the cities makes it difficult to manage water generated for use. Most times, waste generated find its way into streams and rivers or onto the streets. Sometimes, solid and other waste from factories is dumped into water bodies. As this happens, the water sources become polluted and dangerous for use. In consequence, city dwellers are presented with more difficulty in assessing clean water.

\subsubsection{Management of waste and sewage (sanitation issues)}

It has already been pointed out that slums and squatter settlements are unavoidable fallouts of urbanization, management of waste and sewage is a major problem in these areas. One of the reasons is that official health and sanitation arrangements do not adequately cater for these areas. In as much as the city dwellers are not directly involved, any outbreak of diseases or epidemics will definitely not spare city dwellers. Most of the residents of these settlements indulge in open defecation with the attendant health hazards associated with it.

\subsubsection{Other types of pollution}

There are a number of other types of pollution which urbanization brings in its wake. They include traffic congestion which comes with the inevitable increase in various kinds of automobiles such as pedicabs; noise pollution which result from extra noise from small production units established by the migrants; inconvenience to pedestrians as they struggle with hawkers and street vendors; and a host of other types of environmental pollution. Another ancillary urbanization issues is the emergence of urban sprawls. This requires special mention as a form of environmental adverse effect of urbanization. The reason is that urban sprawls are not part of the original urban planning policy of any city. A sprawl indicates an increase in space or adjoining area of a city. Sprawls provide a haven for a plethora of informal economic activities which put pressure on the facilities meant for formally planned segments of the cityscape.

\subsubsection{Economic}

The economy of global South cities are affected by urbanization in several ways:

\subsubsection{Unemployment}

Generally urbanization comes with it a spillover effect of hands that are not engaged in productive activities. The unemployment among developing countries of the global south cities have been a thing of worry. For instance, the official figure of Nigerian unemployment is put at $23 \%$, while youth unemployment figure is put to about $52 \%$ as at 2018 [9]. The immediate side effect of this high level of unemployment is unrestrained increase level of poverty. As at 2017, Nigeria with a population estimated at about 200 million people had about 86 million in extreme poverty. This made her exceed India as the highest destination of poor people globally. On the wheels of this growing incidence of poverty is increased spate of criminal activities such as banditry, kidnapping, bribery and corruption among many other crimes. The basic explanation is that man is self-preservative, and in the 
absence of a genuine means of livelihood, resorts are made to criminal activities for survival. This fits into the age-long proverbial saying; that an idle hand/mind is a devil's workshop.

\subsection{Loss of natural ecosystem}

The springing up of urban sprawls is attended with the destruction of forests and natural reserves for squatter settlements. This leads to the loss of farm land which ordinarily would have been available to city dwellers for farming.

\subsection{Benefits of urbanization}

In as much as urbanization has negative effects on global South cities, however, there are immense benefits that accrue when cities get urbanized. Urban cities enjoy delivery of services in terms of supply of basic amenities such as water, electricity, and health attention. This flows from the fact that administrations of cities are usually planned. Different activities of city life are allotted to specific areas and are carefully monitored to ensure compliance. In comparative terms, life in the city is much more sophisticated and advanced than the rural areas. It boasts of better transport, communications, educational and health facilities. There is much more convenience and comfort in the city. Finally, products of different types both local and foreign normally find their way into the city. Larger markets are cited in the city and these attract buyers and sellers from diverse places. This result to growth in commercial activities much more than what obtains in the rural areas. Other benefits include: growth in economy, social and cultural integration, efficient use of resources.

\section{Neo-liberal trends and effects on global South cities}

The word Neo-liberalism etymologically is an amalgam of two words, namely 'Neo' which means 'new' and 'liberalism.' which connotes 'freedom and without let'. The simple literal translation is that it is a new and revived form of liberal political economic thinking. Impliedly, this definition suggest that there was a time liberal ideology ruled the political-economic thinking of the world; and with time got replaced by other ideological thinking, and has come back into the political-economic thinking with the new christened name- Neo-liberalism [10-13]. Proponents of this perspective see Neo-liberalism as a revived form of liberalism.

Another perspective of looking at Neo-liberalism is akin to the concept of 'Neoconservatism' which descended from and shares a lot of similarities with conservatism but represent a different thoughts altogether [14-16]. The implication of this school of thought is that neo-liberalism, albeit, share the same roots and similarities with liberalism it comes with a lot of embellishments to give it an independent school of thought. The key question is what is the essential thrust of Neo-liberalism thinking? What are its trends and how does it affect global south cities?

\subsection{What is neo-liberalism?}

The concept of neo-liberalism is fraught with polemics and varying interpretations in the literature that it defies uniform and integrated definition. These divergent opinions inhere from the fact that most literature discourse of neo-liberalism is largely approached from the point of critiques rather than an attempt at definition, description and postulations. The heterogeneity of opinions notwithstanding, 
neo-liberalism shares certain coherent characteristics, strands of thought and ideology that give it a unique characterization in the literature.

The roots of Neo-liberalism can be traced to the realm of political-economy. As a successor to classical liberalism, it shares the belief that the best way to efficiently allocate resources is to leave it in the hands of free market forces. As Munck [17] rightly observes, neo-liberalism is an economic philosophy which believes that the best way to allocates resources is to give free reign to market forces and individual liberty to economic pursuit. Consequently, neo-liberals advocate for less government interference in economic activities as it undermines the fine logic of distributional efficiency of the market. A more concise definitions of Neo-liberalism were given by Harvey [18] and Blomgren [19] thus:

\begin{abstract}
Neo-liberalism is in the first instance a theory of political economic practices that proposes that human well-being can best be advanced by liberating individual entrepreneurial freedoms and skills within an institutional framework characterized by strong private property rights, free markets and free trade ([18], p. 2).
\end{abstract}

Neo-liberalism is commonly thought of as a political philosophy giving priority to individual freedom and the right to private property ([19], p. 224).

Implicit in these definitions is that Neo-liberalism advocates for and promotes the freedom and liberty of individuals to pursue entrepreneurial activities, free exchange of goods and services and own private property. Inherent in these definitions is that the state should act as umpire and provide the necessary enabling environment for the individuals to actualize their potentials. Given this ensuing analysis, it is axiomatic therefore to conclude that modern day capitalism and the accompanying democratic philosophy is underpinned by Neo-liberal ideology.

It is pertinent to note that neo-liberal thinking has evolved overtime with various prototypes at display in its shelf. These varying typologies descend from the literature polarization of the understanding of the role of the state in economic activities and the degree to which it should intervene. From the time of Adam Smith, who was the proponent of classical liberalism (believes that the state should steer clear from meddling into economic activities) and John Maynard Keynes, who is the father of macroeconomics and a firm believer that state should run the economy, other economists pitch their tents in between these polar ends. In the same vein, Neo-liberalism has various categorizations according to the limit of state's role in economic activities. Some extreme Neoliberals believe that the state should be abolished completely, they are referred to as 'anarcho capitalism,' while some others believe that there is need for a strong state whose role is to safeguard individual liberty and property rights [20-22]. The latter is referred to as classical liberalism.

In a nutshell, Neo-liberalism is a political ideology that believes in the free reign of market forces as a best means of allocating resources with the role of state being to provide the enabling environment to protect individual freedom to economic pursuit and property rights.

\title{
4.2 What are Neoliberal trends and effects in global South?
}

There is no doubt that we live in a globalized world, with various nation states linked together in such a way that the world is seen as a global village $[23,24]$. The implication is that what happens in one region generate in some ways a ripple effects in other regions of the world. The neo-liberal thinking which was developed in the global west has since permeated and shaped the political and economic thinking in other regions especially in the global south. For instance, the major institutional 
frameworks that drive neo-liberal thinking are capitalism (economic mode of production) and democracy (political ideology). Prior to the era of neo-liberalism of the nineteenth and twentieth century, various countries of the global South cities adopted various types of political-economic ideological formation. In sub-Saharan African countries for instance, depending on their historical experiences, there were divergent political experimentations. While some practiced various forms of western democratic type of government, others practiced eastern type of communism and yet others experimented on domesticated forms of African socialism. At some point, military type of centralized totalitarian government became the vogue among many countries in the global south nations. However, with the increased specter of neo-liberal thinking there is an overwhelming convergence in the adoption of western democracy as the best form of political ideology. The tenets and values of western democracy has become so internationalized that there is instant global rejection of any overthrow of any democratically elected government by way of coup d'état. Fascism and totalitarian government in any form, including apartheid regime were denounced and repudiated. As a result, what you see, albeit there are various shades, is the enthronement and respect of democracy as the dominant global political thinking; many thanks to neo-liberalism.

The question is how did this neo-liberal thinking permeate the political thinking of these global south cities? The answer to the question takes us back to the nature of the relationship between the global south nations and their previous colonial or trading masters. During and after colonialism the relationship between these developing countries and their colonial masters continued in the form of dependence of the former on the latter. This subservient relationship shifted from direct political and administrative dependence during colonialism to economic dependence during post-colonial dispensation. For instance, most advanced western countries used loans and grants conditionalities to compel these nations to politically align to liberal democracy and to deregulate their economy. The Breton woods institutions (IMF and World Bank) that are used to supervise many of these credit handouts would usually require the beneficiary nations to structurally adjust their economy to align to neoliberal thinking before the deal is struck.

Another manifest influence of Neo-liberal thinking in the global South economies is the unprecedented bilateral, multilateral and international growth in trade relations between and among countries of the various geographical divides. Neo liberalism has supported the removal of barriers and inhibitions to global trade to the extent that most global south cities are net importers of basic necessities of life. Several institutions such as World Trade Organization (WTO), United Nations Conference on Trade and Development (UNCTAD) and a plethora of regional and sub-regional trade agencies were conceived to facilitate international trade. The implications are that the specter of neo-liberalism has left in its wake a clear dismantling of the structural inhibitions to international trade. This move is further supported by credit, aid and donor granting agencies that insists that these barriers would be removed as a condition for continuous financial aid to these countries. The anticipated and sometimes unintended consequences of these unequal economic relations are the growing huge indebtedness of these developing countries to international financial institutions.

The concluding remark of this section is that neoliberalism provides the theoretical context that explains the spiraling growth of informality in the global South cities. Neo-liberalism supports a milieu that promotes free economic enterprise with minimal, if any interference from the state. The implication of the tenets of neoliberal theory is the roll back of the state and by extension, the reduction of formal sector which unfortunately, contemporary formal urban planning in developing countries superintends $[25,26]$. The growth of urbanization and complimentary 
deregulation of the economy as supported by neoliberal thinking and forces provides theoretical explanation of the growth of informal sector in developing economies of the global South.

\section{Predominance of the informal economy in global South}

Defining informal economy or informal sector has attracted much research within academic circles. In literature, hence, there is a plethora of definitions and perspectives of informal economy. Many more definitions and re-definitions are still on-going. For this study, however, two definitions are trite: (i) The last general discussions of informal economy by the ILO tripartite constituents in 2002 International Labour Conference... define informal economy to include "all economic activities that are-in law or practice-not covered or insufficiently covered by formal arrangements"; and (ii) Employment in the informal sector was defined by the 15th International Conference of Labour Statisticians as "including all jobs in informal sector enterprises, or all persons who, during a given reference period, were employed in at least one informal sector enterprise, irrespective of their status in employment and whether it was their main or a supplementary job”.

Researchers have attempted to delineate the main threads that run in the several definitions. For instance, Kasarda and Grenshaw [27] after synthesizing several works submitted that the conceptualization of informal economy were hinged on four main characteristics namely: (i) size of firm; (ii) source of financial and material resources; (iii) the degree of linkages between regulated and unregulated sectors and (iv) the extent to which firms comply with government regulations. With regards to the main characteristics of enterprises that operate in the informal sector, Becker [28] presented the following characteristics; (a) start-up and conditions are minimal; (b) activity level is normally small with a number of workers; (c) normally, formal education does provide the expertise required for business operations, and (d) goods and services produced require a lot of labour.

\subsection{Origin of informal economy}

The informal economy or sector had existed in various forms in the pre-historic times. In literature, however, two research works are credited with popularizing the concept. The honor of "discovering" the concept has frequently been given to Keith Hart, a British Anthropologist, as a result of the work he did in Ghana from the mid-to-late 1960s [29]. The second work was the research by the International Labour Organization (ILO) alongside the United Nations Development Programme (UNDP) Employment Mission to Kenya in 1972 [30]. These research efforts are believed to have greatly popularized the use of the term and as a result triggered off much research in that field. Going through literature, however, reveals that each bloc/country within the economies in the global south regions have their peculiar version as regards the origin of informal economy.

\subsection{Predominance of informal economy in Global South: Statistical evidence}

Evidence is rife in research literature concerning the prevalence of informal economy in the Global South. On a global scale, World Bank [31] observed that an equivalence of two-thirds of the entire workforce is employed in the informal sector. On the African continent [32] observe that a good junk of economic activities are taken-up by the informal sector notably in mining, finance, commerce and manufacturing. Xaba et al. [33], in his sub-Saharan African countries' study has 
shown that the informal economy has shown to be the single practical option in the face a drop in rise of formal employment and has effectively functioned as a shock absorber, remained consistent across period and got enlarged in operations. Gali and Kucera [34] in agreement assert that the informal economy has repeatedly acted as a shock absorber for official employment, whereas, the informal sector accounts for $93 \%$ of jobs created in the African continent in the 1990s [35]. Comparably, whereas, the portion of formal economy recorded a reduction in the total workforce, the informal economy recorded an increase [33].

More statistics on the prevalence of informal economy in the global South was presented by ILO [36] and; Williams and Nadin [37]. When the incidence of informal sector vis-a-vis the formal sector is disaggregated across the various regions of the world in terms the percentage of the self-employed, we have the following data: $70 \%$ in sub-Saharan Africa (SSA); 62\% in North America; 60\% in Latin America and $59 \%$ in Asia. Horn (cited in [38]) notes that: $72 \%$ of non-agricultural employment in sub-Saharan Africa is informal; 84\% of women non-agricultural workers are informally employed in sub-Saharan Africa and the greater part of recent employment in Africa are in the informal economy. Across the continent of Africa, reports that the informal sector provides between 50 and $75 \%$ of jobs, and $72 \%$ of non-agricultural employment. The portion of non-agricultural employment rises to $78 \%$ with the exclusion of South Africa. The informal economy has the following portions out of some countries' labour force in Africa: more than 50\% in Kenya and Uganda; about 43\% in South Africa and Zambia; and 89\% in Ghana [35]. Nigeria's informal economy is believed to have contributed greater than $50 \%$ to both the entire country's labour force as well as its GDP, estimated to have gone up from about $50 \%$ in the 1970 s to about $65 \%$ in the 1980 s [39-41]. Estimate of Nigeria's average portion of informal economy relative to the nation's GDP was put at $56 \%$ within 1999 to 2005 [42]. A third of Nigeria's urban labour is believed to come from the informal economy [33].

\subsection{The role informal economy in global South}

Informal economy plays a vital role in transition and developing countries in facilitating successful adjustment to globalization and structural reforms. It provides a means of survival to a large number of poor and extremely poor workers in a society and also plays a vital role in unlocking entrepreneurial potentials which could become lost in the bureaucracy of formality.

\section{Urban planning and informal economy in global South}

Urban planning in the global South is established as founded and inherited from the global North $[6,43,44]$. The global South surely appreciates this offer, however, instead of moving ahead to re-examine what has been received and practiced for decades based on current urban realities, many global South cities' planners have stuck to the traditional planning system, which Watson ([6], p. 2262) has aptly captured as dinosaur in contemporary era. The dogmatic attitude of global South planners in the midst of glaring current urban realities is very much exemplified in planners' reaction to the informal economy which is obviously the ONLY available alternative for many urban residents based on the dwindling formal economy.

One of the descriptions of informality in Duminy ([45], p. 1) as a range of behaviours and practices unfolding within cities has been very much overtaken as many researchers have realized that informality and precisely informal economic 
ventures have come to stay [46]; a fact that many planners in global South cities have refused to accept [43]. The stance of urban planners in relation to informal economy in the global South is mainly of three categories; suppression (which is the most common), compassionate disregard $[47,48]$ and the recently growing positive responses [26]. Earlier descriptions of informal economy as illegal activities no longer holds in many instances as some governments in the global South have realized the role of informal economy and started having a rethink, however many have adopted alternative terms for it such as small-scale enterprises, entrepreneurs, etc., probably to suit some class of the society. The indispensability of informal economy in the global South is not debatable as many governments do not have any tenable alternative formal employment for the growing unemployed in the cities. The realization of this fact has actually motivated the inclusion of entrepreneurship as a compulsory course in some institutions. Apart from the internal forces that are driving informal economy in the global South, there are external forces; economic globalization, neoliberal urban policy responses coupled with the 2008 global economic/financial crisis [46]. These turn of events re- iterate that informal economy (then traditional sector) is not a phenomenon that is about to fade off soon as earlier speculated by Lewis [49] rather it has not only come to stay in many global South cities, it has actually become the convention rather than the exception.

Despite these obvious relevance and permanence of informal economy, many urban planners are yet to view it from a positive perspective resulting in constant conflict between urban planners and informal economy operators. The non-acknowledgement of the role of informal economy operators has also caused planners not to key-into contemporary trends of maximizing the potentials of this group in some global South cities. Urban planners have been alleged to use the very planning instruments in their custody like the master plan and zoning as instruments to dispossess the urban poor among the informal economy operators of their property and source of livelihood many times without compensation or alternative livelihoods. This is particularly peculiar to Nigerian cities. Some governments in the global South are argued to be promoting informal activities by their policies and yet penalize the urban residents caught-up by these policies [50]. However, it's not all negative attitudes, Onodugo et al. ([26], p. 97) has some of the success stories on positive attitudes of planners/government towards informal economy while Yuen [44] tells the success story of Singapore.

\section{The need for adjustment in global south urban planning standards to meet current realities}

The dogmatic stance of many urban planners in global South cities has aggravated the challenges of many urban areas. Instead of working towards solving the problems, they are concerned with ensuring 'ordered' cities at the expense of livelihood, economic growth and accomplishment of many other sustainable development goals. However, Watson [6] has described the reason for the ineffectiveness of global South planners as a complex issue which in some cases lies beyond the powers and will of the planners and linked to some local political ideologies and beyond, to the international policies. One of the tools of traditional urban planning is the master plan, a very powerful tool that has been used by planners to affect the urban rich and the poor in different ways. For the rich, it's a tool that helps them to maintain their properties at strategic locations of the city while the urban poor have been marginalized using the master plan. The master plan of earlier years concentrated on physical development without much consideration of other aspects of life like economic and 
social. The continuous use of the traditional planning systems by global South planners especially in African cities to manage contemporary cities has been described as an impossible task ([51], p. 4 in [43]). This is due to Colonial-based urban planning systems adopted by these planners instead of contextual-based planning systems that take cognizance of the current urban realities in the global South. Another reason for the adjustment of the global South planning standards is that, the challenges of informal economic activities, were believed to be a problem characteristic of informal/unplanned settlements in global South cities and so did not constitute much challenge to urban planners' areas of jurisdiction, however, recent researches have shown that since the Structural Adjustment Programme of the 1990s, the 2008 global economic recession and more recently, the international neoliberal policies, the proliferation of informal economic activities has extended to the formal/planned layouts of high and medium density and surprisingly to the low density areas [52], the very domain of the rich in our cities. This is thought provoking and calls for urgent action by planners rather than the dogmatic refusal to acknowledge informal economy. Another reason for planners to reconsider their planning standards is that many governments of the global South cities have found solace for unemployment challenge by setting up skill-acquisition centres, entrepreneurship centre and smallscale training and empowerment centre, no matter the nomenclature adopted, the bottom line is that the possible form of empowerment and employment that most global South governments can offer to the teeming unemployed youths and adults is in the informal economy. Yet urban planners have no plan for accommodating these growing entrepreneurs in most global South cities. This scenario will very soon make the planning profession in the global South obsolete, inefficient and irrelevant to the contemporary city-residents. It is therefore a wakeup call for urban planners in the global South to rise up to the current challenge to ensure a continued relevance. It is expected that planners should step up from the traditional planning systems that laid the foundation of global south planning and step into current urban realities of the global South by producing innovative and inclusive urban plans.

\section{Innovative and inclusive urban planning design: The path to economic growth in global South cities}

Innovative refers to featuring new methods; advanced and original, introducing new ideas; original and creative in thinking. Inclusive means including all the services or items normally expected. Innovative and inclusive urban planning designs therefore refer to planning designs that reflect steps ahead of the foundational planning systems to contextually-effective planning approaches that reflect current Global South urban realities. The innovative design should not be a copy and paste design that is a mere replica of the received planning standards rather it's a design that takes into account what is currently happening and considering a projected future condition. For the design to be effective, every sector of the city needs to be given some consideration-ensuring that it is all-inclusive. The innovative and inclusive urban planning design, if proposed by the planner may not get to the point of implementation with other stake-holders and so is not solely dependent on the urban planner but the planner needs to conceive and propose the idea and should show adequate evidence of the design being implementable that can convince other stakeholders to key-into the design.

An innovative and inclusive planning design should not also be a one-size-fit all design, the fact that a particular design worked in a city does not mean it will wholly work out in another city. The important point to note however is the need for there to be a willingness to accept a workable design and then the design can be adapted 
to suit the prevailing context. One of the limitations of the traditional planning standards is its focus on physical planning, ordering of land uses to accomplish an esthetic city without adequate balance in terms of economic and social life of residents. An innovative design must give due consideration to economic growth which will sustain the design when implemented and improve the standard of living of the residents to ensure affordability of provided infrastructure. The need for urban designs that give consideration to economic growth in addition to the usual ordering of land uses in global South cities cannot be over emphasized given that most global South cities have already been condemned to the position of informal economy cities. Without a conscious plan that includes economic growth and considers the urban poor which is expanding in global South cities, the cities will continue in their status quo. The change in our planning approaches and designs must start with the mind set of first the urban planner who proposes the design and that of all other stakeholders. The short-lived Warwick Junction case [53] from 1995 to 2010 is an example that planners can actually step out of the box and get planning to work and maximize the potentials of informal economy in Africa, the briefness of this South African case makes it an incomprehensive case for a model. However, a better and vivid case of a global South nation that has stepped ahead of the rudimentary traditional planning standards and clearly succeeded is Singapore.

Singapore, the smallest nation (area-wise-700 sq km) in Southeast Asia, one of the least urbanized regions of the world like Africa; gained her independence from Britain on the 9th of August, 1965 after it was colonized in 1819. The economic success of Singapore from the 1980s saw it having its unemployment rate reduced to as low as $3 \%$ while its GDP growth averaged 8\% up till 1999. The March 2019 unemployment figure is 3.2\% [54]. The success story of Singapore's urban planning is detailed in Yuen [44] and would be briefly discussed here. Singapore like other colonized global South cities had its Singapore Master Plan set out in the 1959 Planning Ordinance, which was a 20-year statutory planning for land use with the major objective of urban growth control and implementation of spatial improvements. This major objective depicts the general picture of British-inherited master plans. In a brief analysis of the objective; urban growth control in the global South cities is currently a very difficult; and almost impossible task especially when it has to do with rural-urban migration, the international urban growth control may be possible but not intra-national. The second part of the objective on implementation of spatial improvement is like dealing with a superficial outcome of an issue while neglecting the root-cause, implying that if the root-cause is not dealt with, the issue will keep resurfacing until the root-cause is adequately treated. Based on these two scenarios, the master plan has become an incompetent tool for current urban challenges. After Singapore's independence, by 1971, they improved on the master plan by adopting the Concept plan-the nonstatutory, strategic planning framework and the same year the Singapore Institute of Planners was established. In her description of the concept plan, Yuen noted that;

it embodies a planning approach that is more agile and collaborative across all urban aspects. Reflecting goal-oriented strategic urban planning, its emphasis is on defining the emergent vision of the city and strategies to effect flexibility and responsive shifts to solve big urban problems and meet growing needs, changing circumstances and available opportunities as they arise. The approach is influenced by pro-growth politics, seeking to describe what a city should have rather than what it can have... ([44], p. 153).

The 1971 concept plan was reviewed in 1991 and 2001 and is planned for a regular 10-year review. Some key lessons to be gleaned from Singapore's planning approach-Concept plan are as follows: 
The concept plan is not all about physical planning but went a step further to give real consideration to the economy and even quality of life. Also the Concept plan entailed an integrated planning process that includes all agencies involved in all facets of development coming together to take a consensus decision on the development of the nation. The Concept plan was prepared to align with the twenty-first century globalization while the strategies are contemporary approaches such as urban greenery and new regional centres with the maximization of the scarce land in perspective. Two key words noted in the Singapore minister for finance's speech ([55] c.f. [44]) are constant learning and adaptation these we believe are the secrets of Singapore's planning and general success and unfortunately are the very elements lacking in the dogmatic, traditional planning approach of many global South cities that has kept them static and even in retrogression in some cases. The planning and development of cities have been opined to have effects on the urban challenges and possible resolution [44]. This chapter therefore advocates that other global South city planners and stakeholders should learn from Singapore and adopt innovative and inclusive planning approaches that will lead to effective planning and management of other global South cities.

\section{Conclusion}

The key problem that provided impetus for this study is the unprecedented population growth of most developing cities of the global South. This is so much that it is estimated that by 2050 it will provide haven for most of the world's additional population. The immediate sequel to this is that urbanization trend in these countries has and will continue to overwhelm the formal sector of these cities. Consequently, the unplanned informal sector will fester across the formally planned and inherited urban cities, distorting the original master plan in its wake. Underpinned by neo-liberal thinking that promotes protection of individual's right to free enterprise and private property ownership, coupled with limited labour absorptive capacity of the formal sector, informal sector will continue to thrive and grow.

This chapter views as anachronistic, moribund and counter-productive, the current rigid top-down exclusive planning approach by conventional urban planners that refuses to appreciate context specific changes in the socio-economic landscape of these global south cities. Insisting on an urban planning that refuses to integrate the views of more than half of the labour market (that operates in the informal market) in the cities is at best shadow boxing and at least an exercise in motions without movement as evidence point to colossal failure.

The import of, and perhaps the contribution of this chapter is the proposal that there should be a reversal of the present planning model that only sees to the formal sector. We propose that modern urban planning should be both innovative (finding new, context specific and creative ways of doing old assignments) and integrative. The latter implies admitting the changes that has occurred in the socio-economic and demographic landscape of urban development and incorporating all the stakeholders in the planning process. Inter alia, people tend to comply with policies that they made inputs in designing. 
Future Planning of Global South Cities with Inclusive Informal Economic Growth in Perspective DOI: http://dx.doi.org/10.5772/intechopen.89145

\section{Author details}

Vincent Aghaegbunam Onodugo ${ }^{1 *}$ and Nkeiru Hope Ezeadichie ${ }^{2}$

1 Department of Management, University of Nigeria, Enugu Campus, Enugu State, Nigeria

2 Department of Urban and Regional Planning, University of Nigeria, Enugu Campus, Enugu State, Nigeria

*Address all correspondence to: vincent.onodugo@unn.edu.ng

\section{IntechOpen}

(C) 2019 The Author(s). Licensee IntechOpen. This chapter is distributed under the terms of the Creative Commons Attribution License (http://creativecommons.org/licenses/ by/3.0), which permits unrestricted use, distribution, and reproduction in any medium, provided the original work is properly cited. (cc) BY 


\section{References}

[1] Odeh LE. A comparative analysis of global north and global south economies. Journal of Sustainable Development in Africa. 2010;12(3):338348. Clarion University of Pennsylvania, Clarion, Pennsylvania

[2] Adinnu IF. Physical Planning in History. Bida: Jube-Evans Books and Publications; 2005

[3] Ogbazi JU. Historical development of urban planning in Nigeria. In: $\mathrm{Mba} \mathrm{H}$, Ogbazi J, Efobi K, editors. Principles and Practice of Urban and Regional Planning in Nigeria. Awka: Mekslink; 1992

[4] Yuen B. Guiding spatial changes: Singapore urban planning. In: Lall S, Freire M, Yuen B, Rajack R, Helluin JJ, editors. Urban Land Markets: Improving Land Management for Successful Urbanization. New York: Springer; 2009

[5] Yuen B. Revisiting Urban Planning in East Asia, Southeast Asia and the Pacific, UN-HABITAT Global Report on Human Settlements 2009. 2009. Available from: http://www.unhabitat. org/grhs/2009

[6] Watson V. Seeing from the south: Refocusing urban planning on the Globe's central urban issues. Urban Studies. 2009;46(11):2259-2275

[7] United Nations, Department of Economic and Social Affairs (UNDESA). Population Division, World Population Prospects 2011: The 2011 Revision

[8] United Nations Department of Economic and Social Affairs (UN DESA). World Population Prospect 2017: The 2017 Revision

[9] NBS. Nigerian gross domestic report (Q4 \& full year 2017). Abuja: National Bureau of Statistics; 2018
[10] Hayek FA. The Road to Serfdom.

London: Routledge; 1944

[11] Röpke W. Civitas Humana-

Grundfragen der Gesellschafts- und Wirtschaftsreform. Erlenbach-Zürich: Eugen Rentsch; 1944

[12] Röpke W. Die Deutsche Frage.

Erlenbach-Zürich: Eugen Rentsch; 1945

[13] Hayek FA, Pierson NG,

Mises LV, Halm G, Barone E. Collectivist Economic Planning - Critical Studies on the Possibilities of Socialism. London:

Routledge; 1935

[14] Fukuyama F. America at the Crossroads: Democracy, Power and the Neoconservative Legacy. New Haven, Connecticut: Yale University Press; 2006

[15] Kristol I. Reflections of a

Neoconservative: Looking Back, Looking Ahead. New York: Basic Books; 1983

[16] Wolfson A. Conservatives and neoconservatives. The Public Interest. 2004;150:32-48

[17] Munck R. Neoliberalism and politics, and the politics of neoliberalism. In: Saad-Filho A, Johnston D, editors. Neoliberalism-A Critical Reader. London: Pluto Press; 2005. pp. 60-69

[18] Harvey D. A Brief History of Neoliberalism. Oxford: Oxford University Press; 2005

[19] Blomgren A. Nyliberal Politisk Filosofi. En Kritisk Analys av Milton Friedman, Robert Nozick och F. A. Hayek. Nora: Bokförlaget Nya Doxa; 1997

[20] Hayek FA. Law, Legislation and Liberty: A New Statement of the Liberal Principles and Political Economy. 
Volume III: The Political Order of a Free People. London: Routledge; 1979

[21] Mises L. The Free and Prosperous Commonwealth: An Exposition of the Ideas of Classical Liberalism. Princeton, New Jersey: Van Nostrand; 1962

[22] Nozick R. Anarchy, State and Utopia. Oxford: Blackwell; 1974

[23] Chaykowski RP. Globalisation and Canadian labour policy. Canadian Public Policy. 2002;28(1):81-91

[24] Onodugo VA, Nwoji SC. Widening the breadth of knowledge diffusion among Nigerian employees: The upsides of globalization. International Journal of Management and Sustainability. 2013;2(6):113-124

[25] Ezeadichie N, Jiburum U, Onodugo V, Onwuneme C, Attama K. Integrating home-based enterprises in Urban Planning: A case for providing economic succour for women of Global South. Berkeley Planning Journal (Department of City and Regional Planning, University of California, USA). 2018;30(1):84-104

[26] Onodugo V, Ezeadichie N, Onwuneme C, Anosike E. The dilemma of managing the challenges of street vending in public spaces: The case of Enugu City, Nigeria. Cities. 2016;59:95-101

[27] Kasarda JD, Grenshaw EM. Third world urbanisation: Dimensions, theories and determinants. Annual Review of Sociology. 1991;17:467-501

[28] Becker KF. The Informal Economy: Fact Finding Study. Swedish International Development Cooperation Agency (SIDA). 2004. Available from: http//www.sida.se/English/About-us/ Publication_database

[29] Hart K. Informal income opportunities and urban employment in
Ghana. The Journal of Modern African Studies. 1973;11(1):61-89

[30] ILO. Employment, Income and Equality: A Strategy for Increasing Productive Employment in Kenya. Geneva: International Labour Office; 1972

[31] World Bank. Urban Strategy. Washington, DC: World Bank; 2009

[32] Sparks LD, Barnett ST. The Informal Sector in Sub-Saharan Africa: Out of the Shadows to Foster Sustainable Employment and Equity? International Business \& Economics Research Journal. 2010;9(5):1-12

[33] Xaba J, Horn P, Motala S. The informal sector in sub-Saharan Africa, ILO Working Paper on the Informal Economy, No. 2002/10; 2002

[34] Gali R, Kucera D. Informal Employment in Latin America: Movements over Business Cycles and the Effects of Worker Rights. Discussion Papers No. 145. Geneva: ILO; 2003.

Available online: www.ilo.org

[35] Verick S. The Impact of Globalisation on the Informal Sector in Africa. Conference Papers; 2006. Available from: www.iza.org/ conference_files/worldb2006/

[36] ILO. Decent Work and the Informal Economy, Report VI, Conference General Discussion Paper; Geneva, Switzerland; 2002

[37] Williams C, Nadin S.

Entrepreneurship and the informal economy: An overview. Journal of Developmental Entrepreneurship. 2010;15(4):361-378

[38] Blaauw D. The informal sector: An African Perspective Presentation prepared for the 2011 DTI Small Business Summit; October 10-12; Bloemfontein; 2011 
[39] Sethuraman SV editor. The Urban Informal Sector in Developing Countries: Employment, Poverty, and Environment. Geneva: ILO; 1981

[40] Meagher K, Yunusa MB. Passing the buck: Structural adjustment and the Nigerian urban informal sector. UNRISD Discussion Paper no. 75. Geneva: United Nations Research Institute for Social Development (UNRISD); 1996

[41] Yusuff OS. A theoretical analysis of the concept of informal economy and informality in developing countries. European Journal of Social Sciences. 2011;20(4):624-636

[42] Schneider F, Buehn A, Montenegro C. Shadow economies all over the World; New Estimates for 162 Countries from 1999 to 2007, Policy Research Working Paper 5356, the World Bank Development Research Group; Poverty and Inequality Team and Europe and Central Asia Region, Human Development Economics Unit; 2010

[43] Kamete AY. On handling urban informality in southern Africa. Geografiska Annaler: Series B, Human Geography. 2013;95(1):17-31

[44] Yuen B. Urban planning in Southeast Asia: Perspectives from Singapore. Town Planning Review. 2011;82(2):147-149

[45] Duminy J. Literature survey: Informality and planning. African Centre for Cities, University of Cape Town, South Africa, June, for WIEGO; 2011

[46] Watson V. The Planned City sweeps the poor away. Urban planning and $21^{\text {st }}$ century urbanization. Progress in Planning. 2009;72:151-193

[47] Ezeadichie NH. Home-based enterprises in urban space: An obligation for strategic planning? Berkeley Planning Journal (Department of City and Regional Planning, University of California, USA). 2012;25(1):44-63. Available from: http://escholarship.org/ uc/item/8857741x

[48] Onyebueke VU. Incidence of informal sector enterprises in the urban residential zone: Analysis of the pattern and determinants in Enugu. Journal of the Nigerian Institute of Town Planners. 2000;13:12-25

[49] Lewis WA. Economic development with unlimited supplies of labour. Manchester School of Economics and Social Studies. 1954;22:139-191

[50] Fernandes E. Illegal housing: Law, property rights and urban space. In: Harrison P, Huchzermeyer M, Mayekiso M, editors. Confronting Fragmentation: Housing and Urban Development in a Democratising Society. Cape Town: University of Cape Town Press; 2003. pp. 228-243

[51] Bauman Z. Modernity and Ambivalence. Cambridge: Polity; 1993

[52] Okosun AE, Ezeadichie NH. Towards sustainable urban environment: A case study of urban poverty and land-use conversion in Owerri, Imo State, Nigeria. In: Okowole A et al, editors. The Built Environment: Innovation; Policy and Sustainable Development. Canaan Land, Ota, Nigeria: Department of Architecture, College of Science and Technology, Covenant University; 2006. pp. 260-265

[53] Dobson R, Skinner C. Working in Warwick: Integrating Street Traders into Urban Plans. Durban: University of KwaZulu-Natal; 2009. Available from: http://www.inclusivecities. org/research/Working-in-Warwick [Accessed: November 03, 2015]

[54] Ministry of Manpower. 2019. Available from: https://www. 
Future Planning of Global South Cities with Inclusive Informal Economic Growth in Perspective DOI: http://dx.doi.org/10.5772/intechopen.89145

channelnewsasia.com/news/singapore/ mom-total-employment-growth-

q1-retrenchments-similar-11480756

[Accessed: July 24, 2019]

[55] Ryntjes D. Tharman on "Immense

Challenge” of Smart Urban Planning.

Channel News Asia. 9 October 2010 



\title{
New Metrics for Spatial and Temporal 3D Urban Form Sustainability Assessment Using Time Series Lidar Point Clouds and Advanced GIS Techniques
}

\author{
Sara Shirowzhan, John Trinder and Paul Osmond
}

\begin{abstract}
Monitoring sustainability of urban form as a 3D phenomenon over time is crucial in the era of smart cities for better planning of the future, and for such a monitoring system, appropriate tools, metrics, methodologies and time series 3D data are required. While accurate time series 3D data are becoming available, a lack of 3D sustainable urban form (3D SUF) metrics, appropriate methodologies and technical problems of processing time series 3D data has resulted in few studies on the assessment of 3D SUF over time. In this chapter, we review volumetric building metrics currently under development and demonstrate the technical problems associated with their validation based on time series airborne lidar data. We propose new metrics for application in spatial and temporal 3D SUF assessment. We also suggest a new approach in processing time series airborne lidar to detect three-dimensional changes of urban form. Using this approach and the developed metrics, we detected a decreased volume of vegetation and new areas prepared for the construction of taller buildings. These 3D changes and the proposed metrics can be used to numerically measure and compare urban areas in terms of trends against or in favor of sustainability goals for caring for the environment.
\end{abstract}

Keywords: point cloud, voxel, time series lidar, 3D spatiotemporal changes, urban remote sensing, machine learning, 3D urban form, support vector machine (SVM) 3D change detection, smart cities

\section{Introduction: 3D sustainable urban form}

Urban form is defined as a composite of the patterns of land use, transportation network and urban design [1]. It is also defined as the spatial pattern of the "large, inert and permanent physical objects" ([2], p. 47). Anderson et al. [3] defined urban form as the "spatial pattern of human activities". Aggregation of repetitive elements determines a form and urban form is a result of urban patterns [4]. Indeed, these urban patterns are the results of the repetition and combination of undifferentiated elements [4]. Considering the scale of analysis, Tsai [5] classified 
the levels of urban form analysis into neighborhood, city and metropolitan area together with three variables of density, diversity and spatial structure. These variables for different scales of analysis may carry different meanings. Therefore, firstly, the scale of analysis needs to be determined, and then the meaning of the variable for that scale needs to be found. While plot and urban block are the terms implying local scale, urban form is used for a range of scales from local to regional (i.e. neighborhood, city and metropolitan area).

Sustainability of urban form is a crucial topic that needs to be carefully considered for future cities. ${ }^{1}$ The need of sustainable cities was recognized by the United Nations (UN) in setting up the UN Sustainable Development Goals [6], in which the 11th goal aims to "Make cities and human settlements inclusive, safe, resilient and sustainable". According to the UN, city populations are growing with about $54 \%$ of the global population,or about 3.9 billion people, now living in cities [6]. One of the issues facing future cities centers around climate change. Land use has been known as one of the major factors affecting the level of heat in urban areas at a large scale. If we think about cities in three dimensions, we see that the height and bulk of buildings are also important factors in local climate phenomena, in particular the urban heat island (UHI) effect defined by the temperature difference between urban areas and their surrounding rural areas. Building height and geometry affect the distribution patterns of shade, wind speed and wind direction. Urban canyon geometry (orientation plus aspect ratio, the ratio of average building height to street width) affects street ventilation and the dispersion of air pollution. In turn, these factors interact with the urban heat islands effect to create a unique urban microclimate.

Knowledge of three-dimensional (3D) urban growth including changes in human formed and natural objects requires accurate monitoring systems that are able to identify areas with greater changes that are unsustainable and therefore can be prioritized areas for greater attention for intervention policies and activities. In this way, the monitoring system helps to build a more resilient urban form that should maintain adequate levels of the natural environment in built-up areas.

In addition, urban vegetation cover has positive effects on microclimate since it helps to reduce carbon emissions though absorbing $\mathrm{CO}_{2}$ as well as mitigating other gaseous and particulate air pollution. Additionally, it helps to minimize soil erosion, retain soil moisture and reduce the generation of dust.

Current urban change studies focus on land use change detection occurring in decades or annually at large scales and ignore short-term changes of vegetation within built-up areas. Also, detected urban changes are generally two-dimensional; for example, rarely changes within an area of lawn or area of trees have been noticed. The differential effects of trees and grass areas on microclimate can be easily understood in terms of shading and evapotranspiration. Also in Shanahan et al. [7], the benefits of tree cover in a city in the UK one in Australia, were estimated by 'Nature Relatedness', in which tree cover varied from less than $10 \%$ to more than $60 \%$. The Natural Relatedness scale correlates well with attitudes toward nature and distinguishes between those who are enthusiastic about nature and those who are not. The chapter demonstrates the benefits of tree cover including reduced stress and asthma and 'psychological restoration'. 'Nature dose intensity' in the form of trees taller than $2 \mathrm{~m}$ was assessed using airborne lidar and NDVI from Landsat 8 images [8].

This raises a critical question about how vegetation cover changes compared to $3 \mathrm{D}$ changes in built form in urban areas. Through exploring fine resolution 3D

\footnotetext{
${ }^{1}$ In this chapter more or less 'sustainable' refers to the dynamic relationship between vegetation and built form in the city
} 
changes within a built up area and to answer the above research question, this work reviews and discusses existing 3D metrics for defining sustainable urban form (3D SUF), proposes some new 3D metrics and develops a new approach to processing time series airborne lidar for monitoring 3D SUF, to support decision-making in favor of a more resilient and sustainable urban form for future generations.

The rapid growth of high-rise urban development has created an urgent need for new methods for characterizing the trends and patterns of these developments, including changes in time series 3D data sets. Repeated airborne lidar data coverage can provide accurate 3D data revealing changes of building heights over time. Integration of information derived from remote sensing acquisition systems with new digital technologies, such as GIS-based applications, provides a unique opportunity to the users for interactive accessibility to the magnitude of change.

In this research, we use the advanced remote sensing technology of Light Detection and Ranging (lidar) to acquire time series airborne data to detect 3D morphological changes in inner city locations and visualize the outcomes in a GIS-based application in which the end-user can readily access information about these changes.

\section{Developing conceptual approaches of urban growth modeling toward 3D}

There are two major conceptual approaches at metropolitan scale for the analysis of spatial and temporal urban patterns, namely, traditional and modern perspectives. These approaches are illustrated in Figure 1 adapted from Herold [9]. Herold explains that processes produce structures in the traditional top-down view (i.e. from process to structure), whereas two-dimensional spatial arrangements of urban elements such as open and public spaces (i.e. structures) are representative of socioeconomic activities or policies and strategic plans to achieve a certain type of urban pattern (i.e. process) in the modern bottom-up view (i.e. from structure to process). Demand for land, master plans and economic forces are major drivers

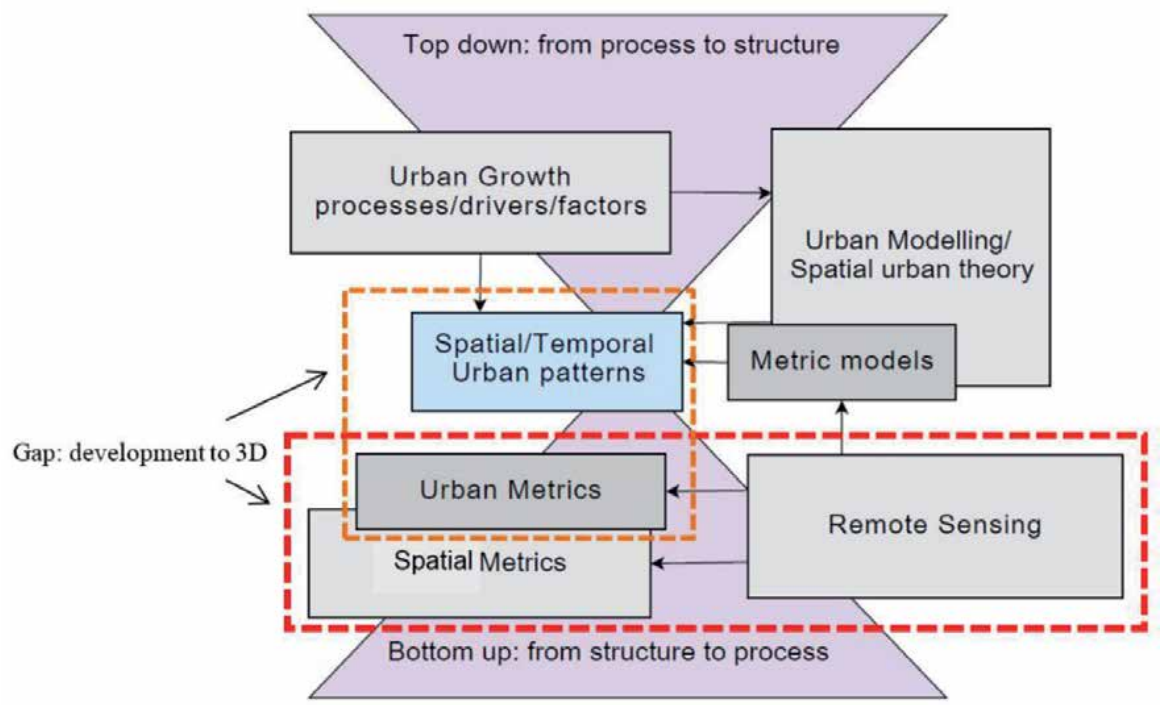

Figure 1.

Developing conceptual approaches for studying 3D urban dynamics (adapted from Herold et al. (2005)). 
and factors that affect urban change over time. Indeed, the question is how a type of pattern for change in urban structures results from these processes. As shown in Figure 1, urban metrics are applied to remote sensing data to derive spatial and temporal patterns of urban structure and development in the bottom-up view known as modern perspective. Then the derived structure becomes the subject for analysis and investigation of the underlying processes. In contrast, it can be argued that the processes are the major drivers of the existing patterns of urban form and structure [9] in the traditional perspective.

While two-dimensional information on urban development patterns is typically derived from the modern approaches, they have not been applied to investigate 3D knowledge of urban patterns. This gap is noted in Figure 1, and the aim of this research is to fill the gap of vertical urban development pattern analysis by proposing new 3D metrics and employing 3D remote sensing data (i.e. airborne lidar).

The motivation for proposing new 3D compactness metrics in this study is the current lack of appropriate metrics. Two commonly used metrics in urban planning are building coverage ratio (BCR) and floor area ratio (FAR). BCR is defined as the building coverage area divided by the area of the land lot (plot). This metric is also known as the building-to-land ratio (BTL). FAR refers to the ratio of the combined area of building floors to the total area of the land lot. As seen, BCR and FAR are $2 \mathrm{D}$ and $3 \mathrm{D}$, respectively. While FAR has been calculated using remote sensing data such as airborne lidar, it suffers from the problem of uncertainty, because FAR is calculated based on assumptions about each floor height. This metric is subject to uncertainty because floor height is definitely higher for a retail land use in a large shopping center than for low-density residential land use (Yu et al. [10]). Also, the threshold of floor height differs from city to city.

Past and current practices in urban form studies focus on themes such as the two-dimensional growth of urban form or horizontal development in space and time $[11,12]$ as shown by the following:

- growth of built up areas as a 2D phenomenon [13];

- using 2D landscape metrics for analysis of sustainable development of urban form over time [14];

- using temporal remote sensing data for assessment of urban form and morphology changes over time for considering sustainability [15];

- claiming to address sustainability aspects, but the study only focuses on 2D urban form study over time [16];

- analysis of 2D expansion of cities using remote sensing data [17], considering compactness as a sustainable urban form and other relevant studies [18];

- sustainable 2D brownfield development [19];

- change of 2D land use considering compact the urban form paradigm as a claimed sustainable urban form [20, 21].

There are also studies on the effect of urban form on energy consumption for a sustainable city [22]. 


\section{Problems of 3D urban development studies in literature}

Nowadays the use of 3D building models focuses on visualization, which also have high "potential for supporting the 'smart city' concept" [23]. 3D city models are often managed by using CityGML that is an information model for storing, representing and exchanging of virtual 3D city models. While there are methods in CityGML that demonstrate the 3D changes to buildings [24] in urban areas, there are some problems with these methods that are listed below:

- Studying time series 3D models is a very time-consuming task.

- Such studies usually only consider cities as places of buildings, whereas cities consist of buildings, infrastructure, trees and other vegetation cover established on terrain with various topographical characteristics across different locations.

- This kind of change detection using existing 3D city models is not appropriate for applications of disaster monitoring, as the 3D models are not representative of real situations and as well they require a lot of time to produce.

Indeed, the as-built city models derived from airborne lidar data are closer to reality than those 3D models created from cadastral layers and building height information which usually ignores detailed height information of the different parts of a building. Also, advanced remote sensing airborne lidar data captured over urban areas is an accurate source of 3D data from which to derive 3D city models. Change detection from time series airborne lidar data is a preferred approach as it does not include the above-mentioned problems. As well, advanced data collection methods such as using remote piloted aerial system (RPAS) can be used for collection of data immediately after rapid changes consequent on disaster events such as floods or earthquakes. There are several algorithms for detection of these changes from time series airborne lidar data. One of the major problems in urban change detection studies of airborne lidar data is that the pixel-based algorithms that are more appropriate for calculation of volumetric changes suffer from either lack of height change information or a high level of noise.

There are other problems relevant to 3D metrics for assessment of the sustainability of urban form. While there are 3D metrics for comparison of different urban forms or to characterize 3D cities, there is a lack of appropriate metrics for application into the assessment of the sustainability of urban form over time, as defined in the Introduction. Koziatek and Dragicevic (2019) proposed 3D indices for spatial and temporal urban analysis of 3D urban expansion, but one of the major problems of their studies is that they do not use time series 3D remote sensing data for exploration of the real changes of the buildings over time. There is a problem of uncertainty in their 3D models because various sources of building height data are used to create time series 3D city models. For example, the number of floors is one source of building height data, but as discussed before, heights between floors for buildings with different functionalities vary; therefore, estimation of building heights for an urban area with various building uses based on number of floors is very inaccurate.

All in all, a thorough review of the urban form literature and metrics [25] shows that even though urban form analysis has a long history in the literature, there are deficiencies in metrics development including (a) a lack of 3D studies using remote sensing for sustainability assessment of urban form and (b) a lack of studies on 3D urban growth assessment for sustainability. 
Considering current rapid urbanization and the above-mentioned lack of studies on sustainable 3D urban development, there is an urgent need to numerically characterize how 3D urban development affect the sustainability goals of caring for the environment, including maintaining (and ideally, enhancing) vegetation.

\section{Proposing novel methodology and 3D metrics for sustainable urban form assessment over time}

\subsection{Airborne lidar and technical methods}

Light detection and ranging (lidar) measures ranges from an airborne scanner which scans at right angles to the flight direction, to the terrain surface using a pulsed laser and generates rich 3D point clouds about the terrain surface and objects on the surface. The round trip time of the laser pulses from aircraft to the ground allows the determination of the distance from the laser scanner to the terrain or objects. Together with known positions and attitude of the scanner derived from a global navigation satellite system (GNSS) receiver for the determination of instantaneous positions of the aircraft and an inertial measuring unit (IMU) for the determination of instantaneous velocities and orientations of the aircraft this also enables determination of accurate 3D coordinates of points representing the terrain or any visible objects on the terrain. After pre-processing, the data can be used for a wide range of applications such as urban growth monitoring, biomass estimation and object measurements. Figure 2 illustrates the summary of the entire process of data acquisition and applications.

A digital surface model (DSM) is generated from airborne lidar data elevation values projected on a raster data format.

Figure 3 represents a flowchart of our tested time series airborne lidar data processing and the method for application of the proposed 3D metrics. Ground, vegetation and building classes can be extracted from temporal airborne lidar data sets which are Digital Surface Models (DSM). The difference between the ground elevation and elevations of buildings and vegetation, provides the height of these objects above ground. Also, voxelization of the buildings and vegetation classes would be advantageous to overcome the problem of different point density and sampling of the time series airborne lidar data. Comparison of the buildings and vegetation changes over time from either approaches (i.e. the approach of

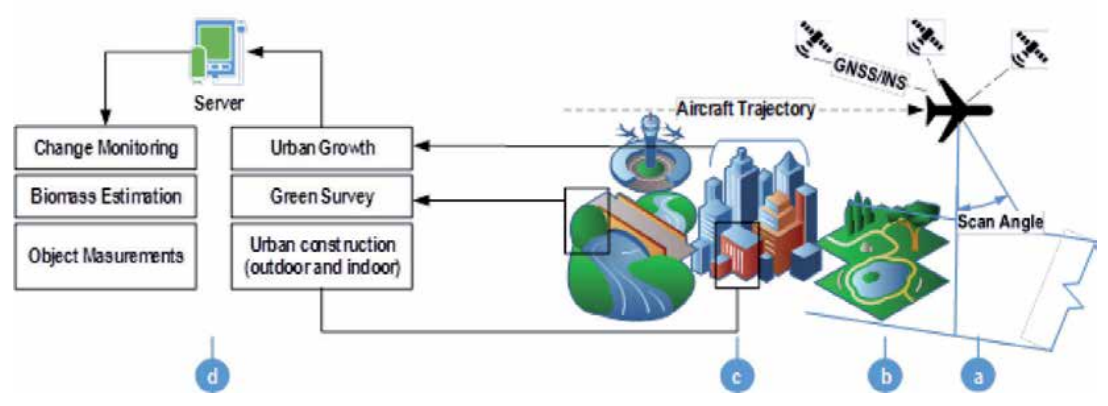

Figure 2.

Generating big data for urban growth and construction change analysis, (a) airborne lidar; $(b)$ biomass survey; (c) dimensions of buildings; $(d)$ data collection and processes. 


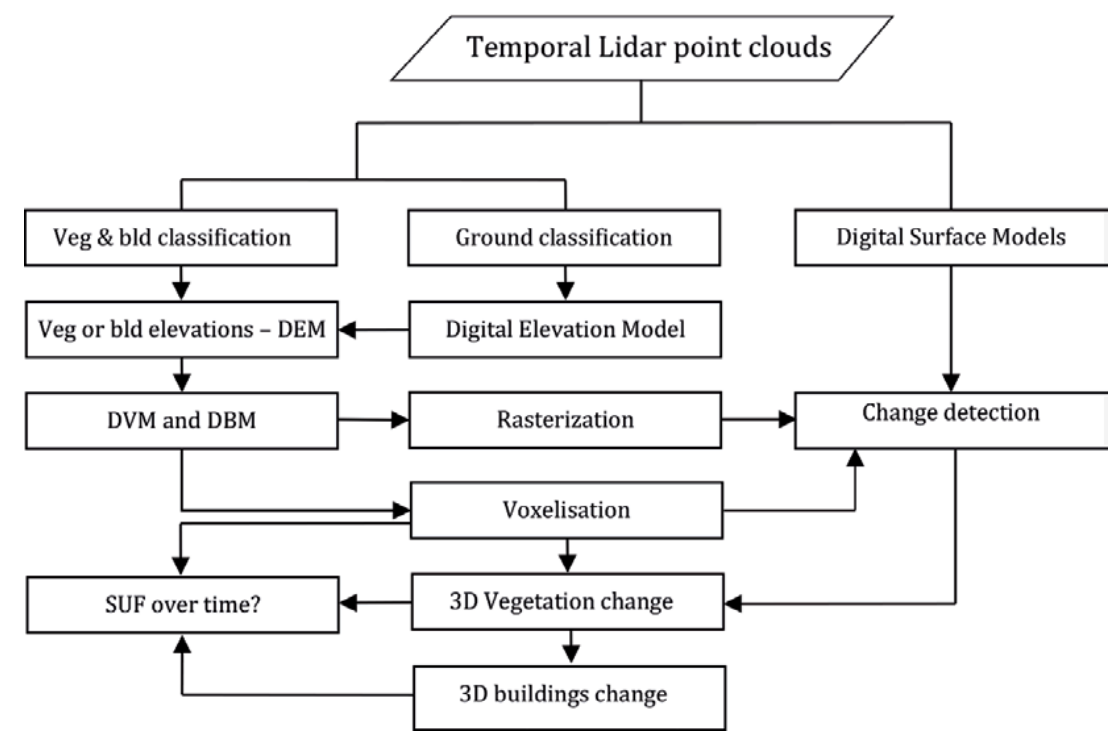

Figure 3.

The flowchart of the proposed procedure of airborne lidar data processing for the calculation of $3 D$ metrics of sustainable urban form. Note: UFS: Urban form sustainability; DBM: Digital building model; DVM: Digital vegetation model; bld: Building; veg: Vegetation.

classification then detecting changes or the approach of change detection) can be used in a SUF study so as to see how the volumes of buildings change compared to the volume of vegetation, as one indicator of sustainability.

One of the challenges regarding various change detection algorithms is that, especially for time series airborne lidar, the performances of these algorithms are not evaluated for large data sets covering vast urban areas. In addition, the results of these algorithms are not compared to identify the most appropriate one for determining three-dimensional changes of urban developments. Matikainen et al. [26] have also confirmed that there have been limited studies on change detection over large urban areas.

A lack of criteria on which to base comparisons of change detection methods for characterizing vertical urban development is also another problem. In this study, two criteria for the evaluation of change detection algorithms have been developed; namely, determination of the range of height changes; and differentiation between new or increased heights, as against demolished or decreased heights in the building class.

\subsubsection{Study extents}

Time series airborne lidar data for the University of New South Wales are considered as spatiotemporal 3D test data to quantify 3D changes of buildings compared with vegetation. Figure 4a-c illustrates these data sets, and areas of 3D changes can be seen by comparing them. Details of these data sets are summarized in Table 1.

\subsection{Building and vegetation metrics}

As discussed before, there is a lack of metrics for assessment of sustainability of urban form as a $3 \mathrm{D}$ phenomenon over time. We propose the following metrics to be added for this purpose. 


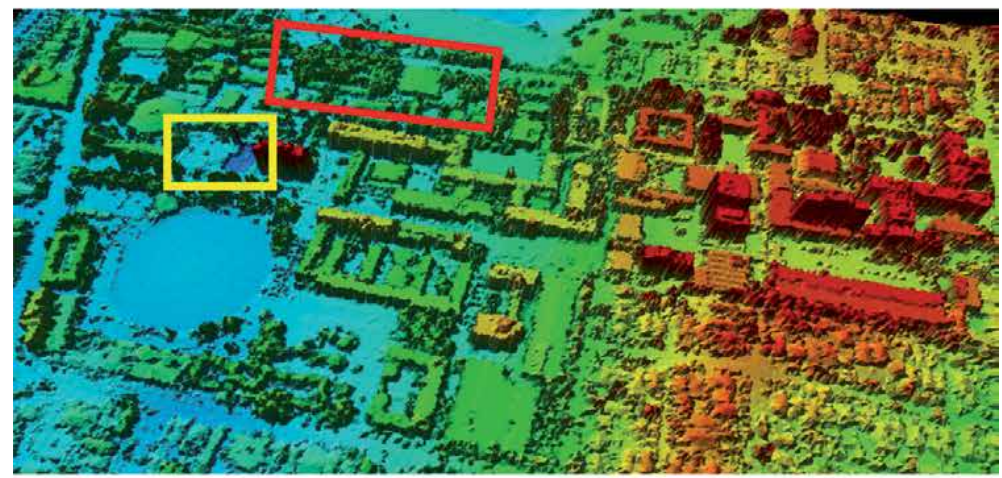

(a)

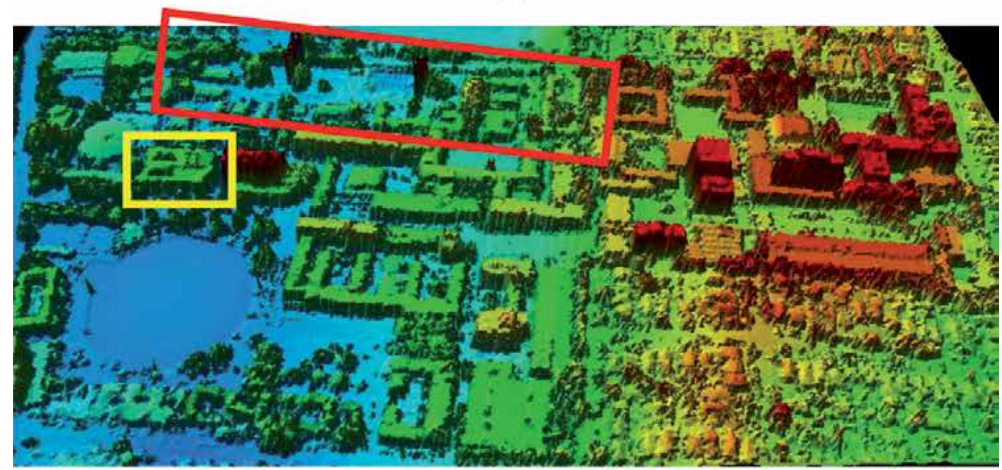

(b)

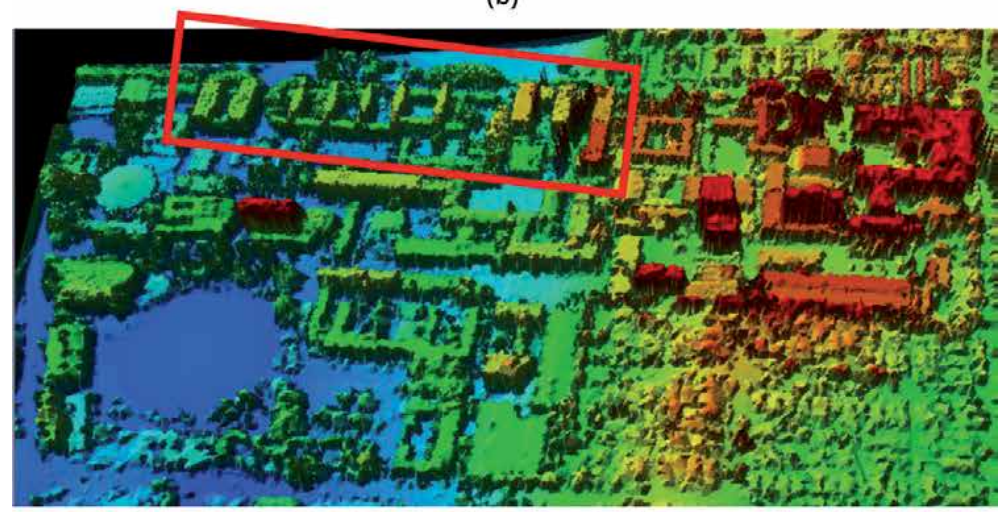

(c)

Figure 4.

Time series airborne lidar data over the selected area of Sydney, Australia and demonstrated areas of changes in yellow and red rectangles: (a) lidar data collected in 2005; (b) lidar data collected in 2008 and (c) lidar data collected in 2013.

\begin{tabular}{lccc}
\hline & 2005 UNSW & 2008 UNSW & 2013 UNSW \\
\cline { 2 - 4 } & $\begin{array}{c}\text { Optech ALTM } \\
\mathbf{1 2 2 5}\end{array}$ & $\begin{array}{c}\text { Optech ALTM 3100, Optech } \\
\text { ALTM 3025 }\end{array}$ & $\begin{array}{c}\text { Leica } \\
\text { ALS50-II }\end{array}$ \\
\hline Vertical accuracy (m) & 0.10 & 0.15 & 0.3 \\
\hline Horizontal accuracy (m) & 0.5 & 0.5 & 0.8 \\
\hline Density (points $/ \mathrm{m}^{2}$ ) & 1 & 1.3 & 1.57 \\
\hline
\end{tabular}

Table 1.

Detailed information of airborne lidar data sets used in this study. 
New Metrics for Spatial and Temporal 3 D Urban Form Sustainability Assessment Using Time... DOI: http://dx.doi.org/10.5772/intechopen.89617

\subsubsection{Ratio of volume change $\left(R_{V C}\right)$}

For comparison of the changes of new and demolished buildings, a volumetric descriptor of ratio of volume change $\left(\boldsymbol{R}_{V C}\right)$ is proposed in (1):

$$
R_{V C}=\frac{\sum_{i=1}^{k} n \times h_{i n}}{\sum_{i=1}^{l} d \times h_{i d}}
$$

where $\boldsymbol{n}$ demonstrates the area of a pixel on detected new buildings and $\boldsymbol{h}_{\text {in }}$ demonstrates the height of that pixel above ground, $\boldsymbol{d}$ represents the area of a pixel in demolished buildings and $\boldsymbol{h}_{i d}$ is its corresponding height value. This ratio can be calculated using the results of image differencing.

One of the limitations of DSM differencing method is the selection of the appropriate thresholds for the unchanged class. Lu et al. [27] proposed thresholds to be $[m-\gamma \sigma, m+\gamma \sigma]$ in the histogram of the resultant difference image (i.e. $D S M_{d}$ ), where $m$ is the mean of the distribution and $\sigma$ represents the standard deviation. Shirowzhan [28] tested different values between 2 and 4 for the thresholds of $\gamma$ in this study area and found that $\gamma=3$ is an appropriate value.

The next step for this 3D metric is a careful visual inspection to determine whether the areas of change belong to buildings because the result of image differencing includes both buildings and vegetation changes. If this ratio is more than 1 , it means that the volume of new buildings is greater than the volume of demolished buildings. However, this metric cannot show whether the development is of vertical form. Therefore, complementary descriptors are necessary to recognize whether the urban form change is vertical growth. For example, if this ratio is greater than 1 and the new buildings are higher than the demolished ones, it can be concluded that an infill vertical development is occurring in a study area.

\subsubsection{Mass and space index}

Other volumetric descriptors for spatial and temporal 3D urban growth can be proposed which use improved concepts of 3D mass and space in urban planning. Examples of a 3D mass index and a 3D space index are defined in (2) and (3) as the ratio of the volume of buildings (or vacant space if applicable) to the total volume of an assumed cube, whose footprint is the ground surface area including all buildings, and its height equals the tallest building height in the study extent. For a study extent, after calculation of the volume of new and demolished buildings, an increase in the 3D mass index will represent a trend toward more compact 3D urban form. The assumption for the cube is that it only contains buildings.

$$
\begin{gathered}
\text { 3D MassIndex }=\frac{V b}{V c}=\frac{\sum_{i=1}^{n} b \times h_{b}}{V c} \\
\text { 3D Space Index }=\frac{V s}{V c}=\frac{V c-\sum_{i=1}^{n} b \times h_{b}}{V c}
\end{gathered}
$$

where $V_{b}$ is the volume of buildings, $V_{c}$ is the volume of the containing cube and $V_{s}$ represents the volume of vacant space. In a pixel-based method, $b$ is the area of a pixel representing built form and $h_{b}$ is the corresponding height of the pixel.

\section{Results}

Temporal point clouds of the selected case study were analyzed based on the developed procedure (refer to Figure 3 ). The purpose of the analysis was vegetation 
and building classification, ground classification and creating a DSM. Each of these objectives is presented in the following sections:

\subsection{Building and vegetation classification from airborne lidar}

For classification of buildings using ERDAS Imagine software, various thresholds are tested for the parameters of minimum slope, minimum area, plane offset, minimum height, maximum height and roughness and we came up with the optimum values to be $30,100,1,2.5,10,000$ and 0.3 for each of the parameters, respectively (see Figures 5 and 6). The results show misclassifications between ground and buildings, building boundaries and vegetation. In addition, some of the buildings with multi-level attachments to the rooftops are classified as vegetation. These misclassifications can be overcome through postprocessing by careful manual adjustment.

\subsection{Change detection and calculation of the 3D metrics}

The results of change detection using an integrated approach of SVM and together with DSM differencing are presented in Figure 7. Figure 8 also shows the profile views of an excavated site in 2005 that was changed to a tall building in 2008. As seen in Figures 6 and 7, the level of noise is very low for the integrated approach compared with when DSM differencing only is used and the magnitude

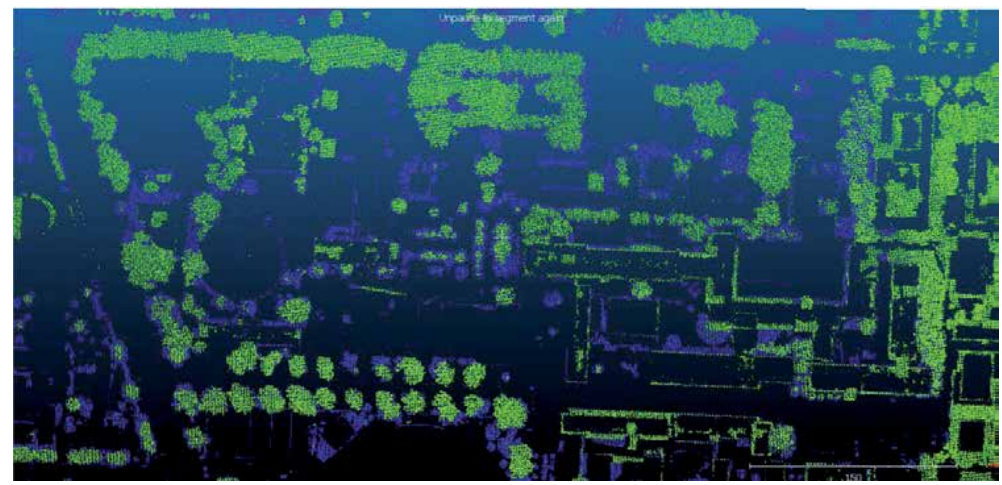

Figure 5.

Vegetation classification.

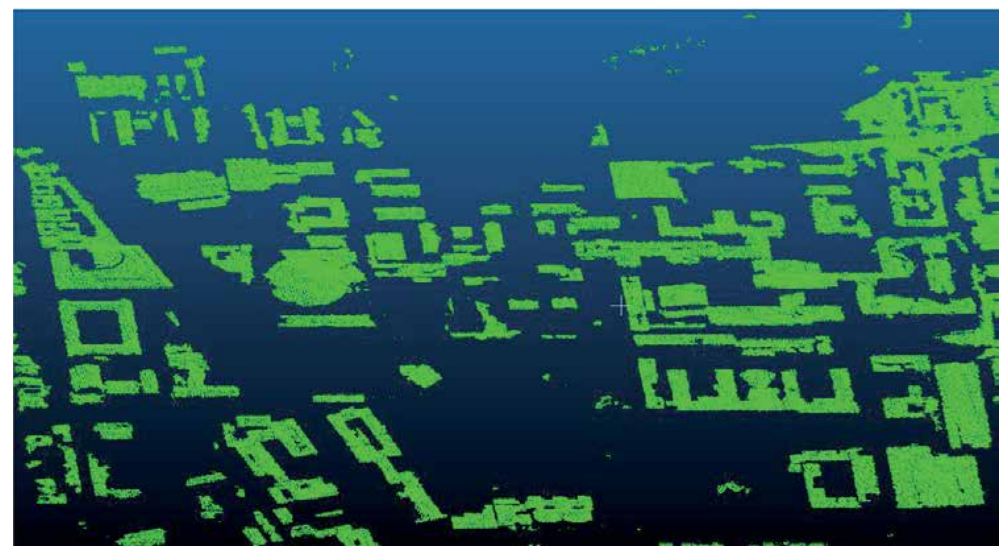

Figure 6.

Building classification. 


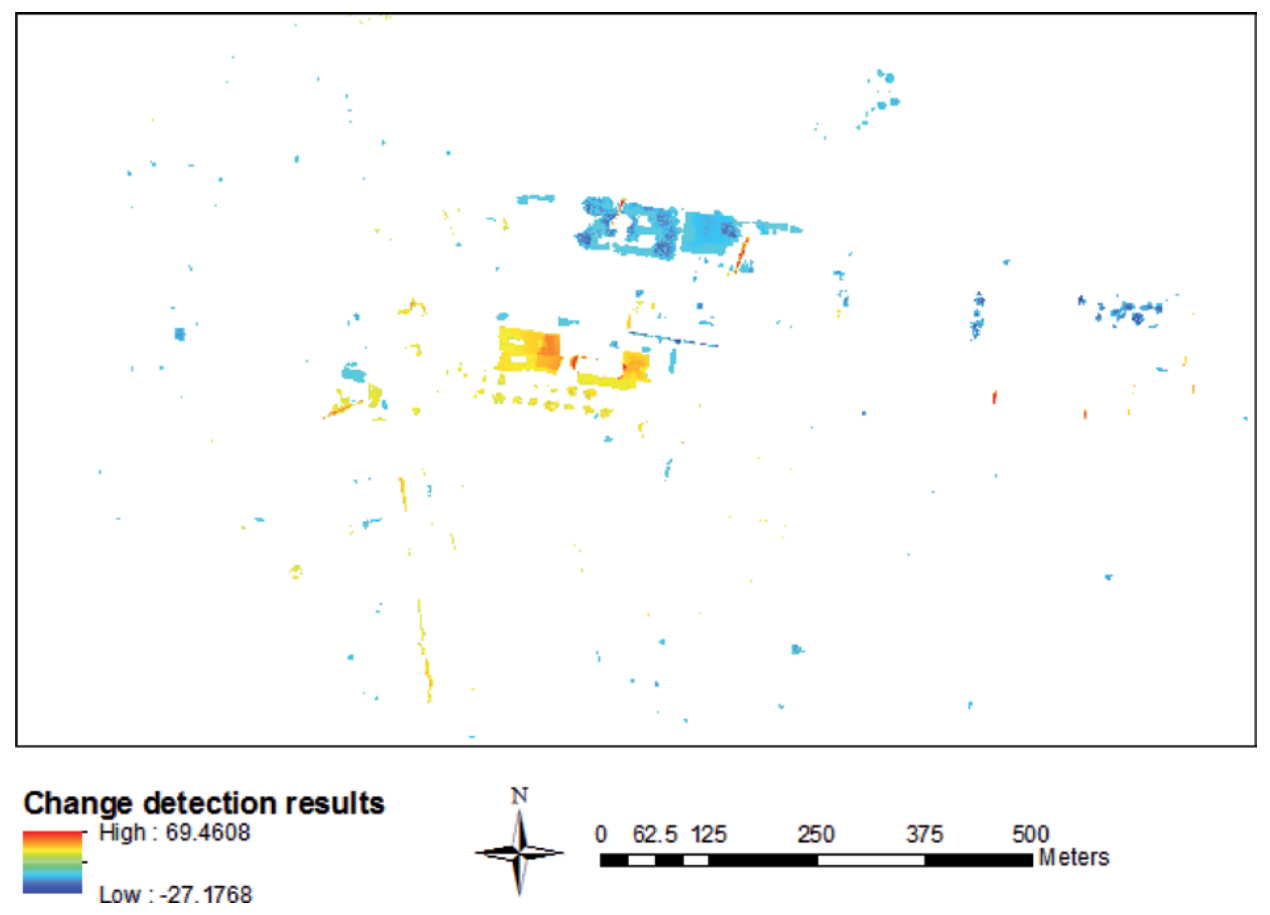

Figure 7.

Results of $3 D$ change detection between 2005 and 2008 from the integration of DSM differencing and SVM.

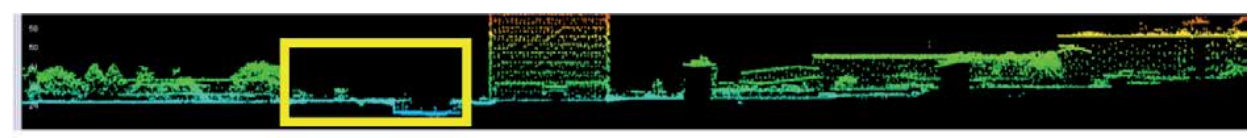

(a)

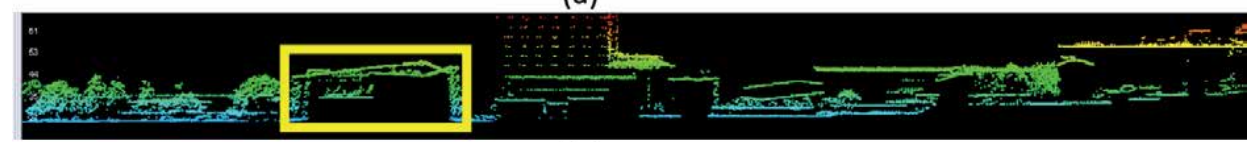

(b)

Figure 8.

Changes of profiles views for an excavation site to a new tall building from 2005 to 2008. (a) excavated site, (b) the new tall building.

of change can be accessed for each pixel. Having these values for each pixel gives a major advantage for the calculation of 3D metrics as proposed in Section 4.2. While this method is recommended in this research, there are other problems which need to be resolved before developing it further. One problem is to differentiate between buildings and trees in the changed results. For the problem of occlusions among trees and building points, it seems that separation of these two classes of objects in the change detection result is very challenging. The approach of classifying buildings first and then determining change detection second, is also challenging as the differences of lidar point densities impact the results [29].

\section{Discussion}

The analysis of the changes of urban form including buildings and trees in 3D space is important because contributions of changes in tree canopy cover compared 
with changes in grass cover have significantly different effects related to the reduction of air pollution and also evapotranspiration levels that affect the microclimate conditions. This information will result in better data driven decision making for smart solutions for future 3D developments of cities, as well as demonstrate 3D green spaces in cities if land conversion from tree cover to built-up areas occurs. Having the changes of height data, urban planners can make better decisions for smart changes of urban form for future developments, considering the negative impacts of buildings on the natural environment of the cities. Smart changes of urban form refer to data driven decision making on the areas within cities with higher potential of change.

This research introduced a robust method for exploring 3D changes of cities to see whether these changes can be considered as being toward or away from a more sustainable 3D urban form, based on the relationship between built up and vegetated areas, in particular tree canopy. Future work will focus on the speed of change in different urban areas for the vegetation and building classes.

Similar metrics can be proposed for vegetation or a combination of vegetation and buildings. However, current technical problems of data collection and also extraction of individual trees using airborne lidar need to be resolved. The data collection problem here refers to the separation of tree canopy from vegetation, as well as the loss of many lidar points in tree structures below canopy level, that affects the extraction of the complete shape of a tree crown. The incompleteness of tree shape reconstruction necessarily affects the results of the calculation of the volume of trees. In addition, the pixel-based approach in tree volume calculation may be affected by the lidar sampling density and distribution, since a tree sampled by multi-temporal airborne lidar will be represented by totally different sets of points in each epoch. As well, depending on the scattering characteristics of the lidar laser, we could see differences in the heights of pixels representing the trees in each epoch.

In the previous work, the authors found that for monitoring of 3D building changes over time, a change detection approach is preferred compared to a process of building classification of time series lidar data [29]. In this study, we found that change detection is not sufficiently accurate for vegetation classes, therefore, we recommend voxelization of the classified vegetation for future studies.

These sampling problems impact on the voxelization of the tree points. In addition, a further problem for the voxelization of lidar point clouds is that tree trunks may not be sampled leading to gaps between tree crowns and the ground which are not registered in the rasterization process.

So far, we have found that for the calculation of volumetrics of vegetation, the change detection approach is not sufficiently reliable as unchanged trees are sometimes detected as changed trees (cut trees or new trees) from the sampling of airborne lidar data. To alleviate this problem and to overcome the problem of inconsistency of classified time series lidar data, we have tested voxelization of classified buildings and vegetation. In addition, change detection of vegetation to identify growth is not sufficiently accurate. Therefore, future work should focus on development of methods for detection of vegetation growth as another class of change in urban areas. This should be possible as future lidar systems will provide much higher densities of sampling, which together with multispectral lidar systems will enable more accurate height measurement of trees.

Vegetation cover as a valuable component of a healthy built environment within cities motivates us to ask a critical question for future studies. Indeed, the question is whether $3 \mathrm{D}$ vegetation cover change could be a more influential factor in changing the local climate and affecting health and wellbeing than grassed areas. So far, we know that the observation of the trees in providing shade and the mechanism of photosynthesis in absorbing $\mathrm{CO}_{2}$ confirm that preserving trees within built-up 
areas is crucial for caring for the environment leading toward more sustainable urban forms for future generations.

Our work is intended to provide fundamental information for "wise management of natural resources" ([30], p.6) in which we provide information on the location of changes in the natural and human-made resources within cities.

From an urban planning and design perspective, this work provides a pathway to the development of rapid assessment protocols for estimating the directions in which our precincts and cities are trending in terms of sustainable development. Such an approach would take the increase (or decrease) of vegetation, in particular tree canopy, as a proxy for a rising or falling level of sustainability in an urban location. Of course, sustainability, particularly in the urban context, is far more complex than this, including such factors as climate change mitigation and adaptation, consumption of renewable and non-renewable resources, biodiversity protection and so on. But an increase or decline in urban vegetation over time represents a fundamental trend, which can indicate a great deal about other aspects of urban sustainability.

\section{Conclusions}

The lack of appropriate metrics and methodologies for the assessment of the sustainability of urban form over time motivated us to conduct this research. In this chapter, we proposed novel 3D metrics and potentially appropriate methodologies and tested these methods. Our tests results show that while airborne lidar data is a very accurate and promising source of data for detection of changes of the volume of buildings, there are areas requiring improvement in 3D reconstruction of trees and vegetation from airborne lidar, to enable its use in an urban change detection studies. We found integration of SVM and DSM differencing appropriate for the building change detection and proposed a voxelization approach for vegetation change detection in future research.

We observed a trend of decreasing volume of vegetation and increasing the volume of buildings using three of epochs airborne lidar data from 2005 to 2013 in a developing urban area in Sydney, Australia. This implies a trend against sustainability goals and suggests a need for intervention policies for preserving the natural objects such as trees in a built environment. 


\section{Author details}

Sara Shirowzhan ${ }^{1 *}$, John Trinder ${ }^{2}$ and Paul Osmond ${ }^{1}$

1 Faculty of Built Environment, The University of New South Wales, Sydney, Australia

2 School of Civil and Environmental Engineering, The University of New South Wales, Sydney, Australia

*Address all correspondence to: s.shirowzhan@unsw.edu.au

\section{IntechOpen}

(C) 2019 The Author(s). Licensee IntechOpen. This chapter is distributed under the terms of the Creative Commons Attribution License (http://creativecommons.org/licenses/ by/3.0), which permits unrestricted use, distribution, and reproduction in any medium, provided the original work is properly cited. (cc) BY 


\section{References}

[1] Handy S. Methodologies for exploring the link between urban form and travel behavior. Transportation Research Part D: Transport and Environment. 1996;1:151-165

[2] Lynch K. Good City Form. MIT Press; 1984

[3] Anderson WP, Kanaroglou PS, Miller EJ. Urban form, energy and the environment: A review of issues, evidence and policy. Urban Studies. 1996;33:7-35

[4] Jabareen YR. Sustainable urban forms. Journal of Planning Education and Research. 2006;26:38-52

[5] Tsai Y-H. Quantifying urban form: Compactness versus 'sprawl'. Urban Studies. 2005;42:141-161

[6] United Nations. Sustainable development goals. In: Goal 11: Sustainable Cities and Societies. 2015. Available at: https://www. un.org/sustainabledevelopment/ sustainable-development-goals/

[7] Shanahan DF, Cox DTC, Fuller RA, Hancock S, Lin BB, Anderson K, et al. Variation in experiences of nature across gradients of tree cover in compact and sprawling cities. Landscape and Urban Planning. 2017;157:231-238

[8] Cox DT, Shanahan DF, Hudson HL, Fuller RA, Gaston KJ. The impact of urbanisation on nature dose and the implications for human health. Landscape and Urban Planning. 2018;179:72-80

[9] Herold M. Remote Sensing Derived Mapping to Support Urban Growth Theory. 2005.

[10] Yu B, Liu H, Wu J, Hu Y, Zhang L. Automated derivation of urban building density information using airborne LiDAR data and object-based method.
Landscape and Urban Planning. 2010;98(3-4):210-219

[11] Höjer M, Gullberg A, Pettersson R. Images of the Future City: Time and Space for Sustainable Development. London: Springer Science \& Business Media; 2011

[12] Zhou L, Shen G, Wu Y, Brown R, Chen T, Wang C. Urban form, growth, and accessibility in space and time: Anatomy of land use at the parcel-level in a small to medium-sized American City. Sustainability. 2018;10(12):4572

[13] Aburas MM, Ho YM, Ramli MF, Ash'aari ZH. Monitoring and assessment of urban growth patterns using spatio-temporal built-up area analysis. Environmental Monitoring and Assessment. 2018;190(3):156

[14] Pili S, Grigoriadis E, Carlucci M, Clemente M, Salvati L. Towards sustainable growth? A multi-criteria assessment of (changing) urban forms. Ecological Indicators. 2017;76:71-80

[15] Nor MM, Noor NBM. Urban morphology analysis by remote sensing and GIS technique, case study: Georgetown, Penang. In: 35th Asian Conference on Remote Sensing 2014, ACRS. Sensing for Reintegration of Societies; 2014

[16] Irwin EG, Jayaprakash C, Munroe DK. Towards a comprehensive framework for modeling urban spatial dynamics. Landscape Ecology. 2009;24(9):1223-1236

[17] Kasanko M, Sagris V, Lavalle C. Analysing the compactness of urban areas by using indicators derived from data acquired by remote sensing. In: 2007 Urban Remote Sensing Joint Event. IEEE; 2007. pp. 1-7

[18] Abdullahi S, Pradhan B. Land use change modeling and the effect of 
compact city paradigms: Integration of GIS-based cellular automata and weights-of-evidence techniques. Environmental Earth Sciences. 2018;77(6):251

[19] Abdullahi S, Pradhan B. Sustainable brownfields land use change modeling using GIS-based weights-of-evidence approach. Applied Spatial Analysis and Policy. 2016;9(1):21-38

[20] Abdullahi S, Pradhan B, MojaddadiH.Citycompactness:Assessing the influence of the growth of residential land use. Journal of Urban Technology. 2018;25(1):21-46

[21] Chen SS, Yan Y, Gao Q, Liu D. Quantifying circular urban expansion patterns of compact Chinese cities: The case of Yangtze River Delta, China. Environment and Planning. B, Planning \& Design. 2015;42(2):279-299

[22] Ye H, He X, Song Y, Li X, Zhang G, Lin $\mathrm{T}$, et al. A sustainable urban form: The challenges of compactness from the viewpoint of energy consumption and carbon emission. Energy and Buildings. 2015;93:90-98

[23] Toschi I, Nocerino E, Remondino F. Geomatics makes smart cities a reality. GIM International. 2017;31(10):25-27

[24] Pédrinis F, Morel M, Gesquière G. Change detection of cities. In: 3D Geoinformation Science. Cham: Springer; 2015. pp. 123-139

[25] Shirowzhan S, Sepasgozar SM, Li H, Trinder J. Spatial compactness metrics and constrained voxel automata development for analyzing 3D densification and applying to point clouds: A synthetic review. Automation in Construction. 2018;96:236-249

[26] Matikainen L, Hyyppä J, Ahokas E, Markelin L, Kaartinen H. Automatic detection of buildings and changes in buildings for updating of maps. Remote Sensing. 2010;2:1217-1248
[27] Lu D, Mausel P, Batistella M, Moran E. Land-cover binary change detection methods for use in the moist tropical region of the Amazon: A comparative study. International Journal of Remote Sensing. 2005;26(1):101-114

[28] Shirowzhan S. Spatial and temporal pattern analysis of 3D urban development using airborne Lidar, $\mathrm{PhD}$ thesis. Sydney, Australia: University of New South Wales; 2017

[29] Shirowzhan S, Trinder J. Building classification from lidar data for spatiotemporal assessment of 3D urban developments. Procedia Engineering. 2017;180:1453-1461

[30] Abdoullaev A. A smart world: A development model for intelligent cities-The trinity world of trinity cities. In: The 11th IEEE International Conference on Computer and Information Technology, The 11th IEEE International Conference on Scalable Computing and Communications, Pafos/Cyprus. 2011 http://www.cs.ucy. ac.cy/CIT2011 


\title{
Chapter 4
}

\section{Reshaped Urban Mobility}

\author{
Csaba Csiszár, Dávid Földes and Yinying He
}

\begin{abstract}
The application of novel solutions in vehicle and information technologies and the need for sustainability result in significant change in urban mobility. Moreover, autonomous vehicles (AVs) are expected to contribute to this alteration as well. The mobility is considered not only a single trip from A to B anymore but a comprehensive service. Shared and demand-driven services are more and more available besides traditional transportation modes. Modes are presented, evaluated, and compared, giving a realistic scenario for upcoming changes and opportunities. The development of the passenger transportation system requires an integrated approach considering user expectations. It is facilitated by the concept of Mobilityas-a-Service (MaaS), in which improvement of the quality has higher relevance than before. The impacts of the alteration are also summarized.
\end{abstract}

Keywords: autonomous vehicles, demand-driven, future mobility, impacts, Mobility-as-a-Service, passenger transportation system, shared urban mobility

\section{Introduction}

Passenger transportation, accessibility, land use, and activities interact with each other. On the one hand, passenger transportation provides the adequate circumstances of every movement. On the other hand, its effect on the environment is negative (e.g., traffic accidents, energy consumptions, pollution, land use).

Mobility is the complexity of transportation processes derived from the spatial characteristics of human needs and activities. It includes the flow of persons, goods, and information, as well as information processes related to them. In cities, the demands are concentrated resulting in a high volume of traffic.

Sustainable mobility means a long-term and balanced relationship among environment, economy, society, and transportation system. Accordingly, substantial alteration is required by introducing such innovative solutions that provide the adaptivity of the system. During the development, the aim is to apply such solutions that manage the resources efficiently while satisfying travelers' preferences [1].

In this chapter, we summarize the knowledge related to the reshaping of urban passenger mobility based on literature review and our previous studies. The topic is discussed by a transportation engineering point of view. We focus both on management- and traveler-related issues, highlighting social effects instead of technical details.

The chapter proceeds as follows: Section 2 provides a thorough overview and comparison of current traditional and novel urban transportation modes and mobility services. In Section 3, the alteration in mobility services is discussed with a special focus on automation and autonomous vehicles (AVs). Section 4 describes the planning principles of novel mobility services highlighting user expectations. In Section 5, Mobility-as-a-Service (MaaS) concept is detailed with special regard 
to quality. Section 6 presents the major impacts of novel mobility services on the urban environment. In the last section, the research is concluded, emphasizing the key findings, and the future research directions are given.

\section{Mobility services}

Transportation modes are defined as the means of transportation and their attributes. Individual and collective modes are distinguished. Besides them, socalled transitional modes are spreading. The attributes of transitional modes are to be defined between that of individual car use and traditional public transportation. Typically, either the time frame of a vehicle or the available seats of a vehicle are shared. The sharing facilitates the efficient allocation of the available sources. Either demand-responsive or demand-driven (on-demand) mobility services are provided. In demand-responsive services, flexible schedules are applied, and the capacity reflects the demands [2]. Demand-driven services are operated only if any demand arises. The routes and schedules are not predetermined [3]. At these modes, the ordering (demand announcement) in advance is usually mandatory. The real-time demand-capacity coordination and management of the services are based on an advanced infocommunication system. Several transitional modes are available only via a smartphone application. Mobility services can be defined as joint activities that provide the transportation capacities, technological processes, and related (information) services (e.g., seat reservation). Description of typical urban transportation modes and services is summarized in Table $\mathbf{1 .}$

Walking is incorporated into every trip. Access to the departure point and egress from the destination point, as well as transfer between the modes, require walking. It is competitive for a short range. The so-called soft mobility forms cover micromobility, namely small-sized (one or two seats) human or electric-driven vehicles (e.g., bicycle, pedelec, Segway, scooter). They are used for the last miles. These vehicles are operated in shared mobility services as well.

Transportation modes and mobility services can be categorized according to several attributes. The knowledge of these attributes is necessary to sufficiently serve the travel demand and remain competitive. The most important categorization aspects of transportation modes are as follows (Figure 1):

- Modality of vehicle use (individual or collective)

- Vehicle proprietor (service company or private person)

- Driver (traveler or professional driver)

The selection of a mobility form for a specific trip is influenced by several aspects at the same time. Transportation modes can be compared, among others, according to travel distance, the regularity of traveling, the number of passengers, and flexibility. Detailed flexibility analyses focus on the following attributes:

- Spatiality-e.g., departure and destination point, coverage, availability, travel distance, and the fixity of the routes

- Temporality-e.g., accessibility (operation time), timetable, waiting time, service time, time units of the use, and the minimum time of use

- User target group 
Reshaped Urban Mobility

DOI: http://dx.doi.org/10.5772/intechopen.89211

\begin{tabular}{ll}
\hline Transportation modes & Description \\
\hline Public transportation & $\begin{array}{l}\text { Supply-based services which are accessible for anyone at a specified location } \\
\text { (stop), at a specified time (according to timetable), on a specified route } \\
\text { (line), according to the specified terms and conditions, for a specified fee }\end{array}$ \\
\hline $\begin{array}{l}\text { Demand-responsive } \\
\text { transportation }\end{array}$ & $\begin{array}{l}\text { Flexible mobility service in space and/or in time which can be used only after } \\
\text { request, often with the same tariff as the traditional public transportation } \\
\text { has. It is operated typically in a sparsely populated area or in time periods } \\
\text { when travel demand is low }\end{array}$ \\
\hline Vehicle-sharing & $\begin{array}{l}\text { Shared use (in time) of a publicly or privately owned vehicle. The vehicles } \\
\text { are available for anyone for a (time-based) fee. It is typically used for a short- } \\
\text { range, urban ride, for a short term }\end{array}$ \\
\hline Ride-sharing & $\begin{array}{l}\text { Capacity (seat) sharing of a privately owned vehicle to share the travel cost. } \\
\text { Typically, a slightly regulated, nonprofit transitional mode for a long-range } \\
\text { travel. The driver offers the free seats of the vehicle }\end{array}$ \\
\hline Taxi & $\begin{array}{l}\text { Strongly regulated profit-oriented transportation mode typically for a short- } \\
\text { range, urban ride. It provides a door-to-door, high-quality ride for a high fee }\end{array}$ \\
\hline Ride-sourcing & $\begin{array}{l}\text { Application-based ride management. Travel demand and capacity are } \\
\text { coordinated automatically. The mode is preferred for a short-range, urban } \\
\text { ride, like the taxi service. It provides door-to-door service with slight } \\
\text { regulation, applying dynamic tariff system }\end{array}$ \\
\hline Individual car/motorcycle/ & $\begin{array}{l}\text { Traveling in our own car as a passenger with a "hired" driver. Typically, it is } \\
\text { used for the sake of convenience, usually at night, when the traveler is not } \\
\text { capable of driving or wishes to do other activities during the travel }\end{array}$ \\
$\begin{array}{l}\text { Using a privately owned vehicle for an individual trip; neither the vehicle nor } \\
\text { the seat is shared with unknown travel mates }\end{array}$ \\
\hline Chauffeur service
\end{tabular}

Table 1.

Description of transportation modes (source: based on [4]).

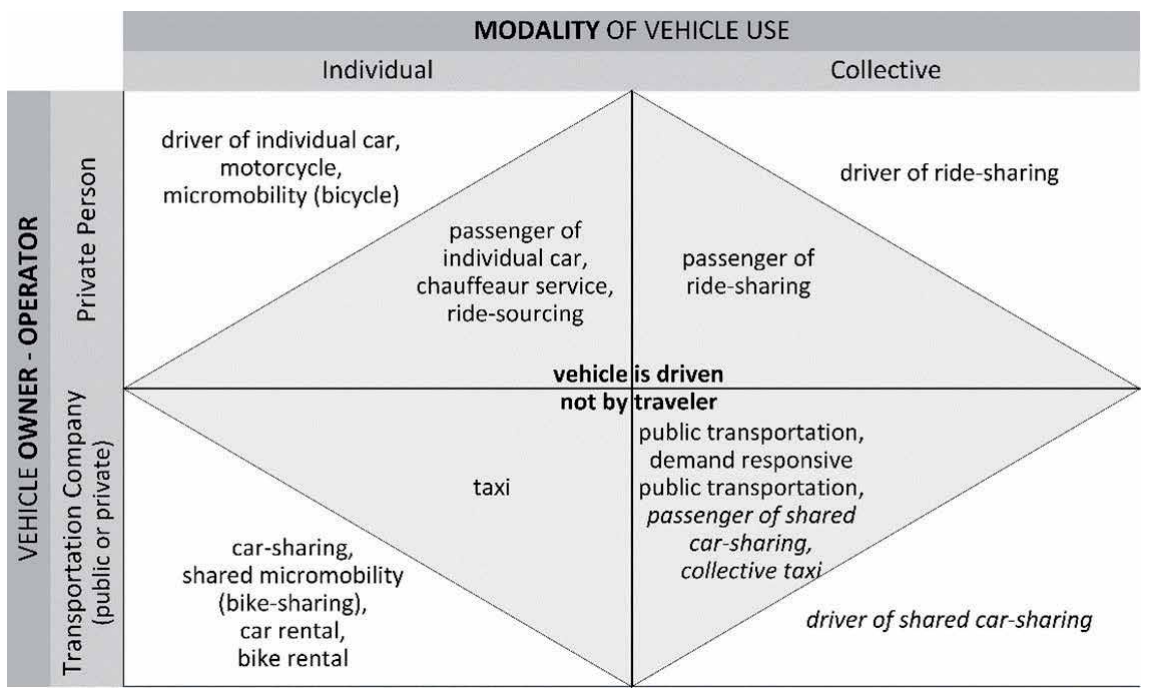

Figure 1.

Classification of current passenger transportation modes (source: based on [4]).

\section{- Attributes of ordering}

- The degree of spread 
- Type of the applied infocommunication system and services

- Attributes of the fee collection system-e.g., method of fee calculation and payment

- Need for additional tasks-e.g., maintenance and repair

- Type of operation-e.g., publicly or privately owned vehicles [4]

The attributes influence modal share and travel chains. Modal share is a set of indicators which show the percentages of travelers using particular transportation modes in terms of either the number or the length of the trips. Usually walking, cycling, car use, and public transportation are considered. Although the use of transitional modes is constantly increasing, their modal share is still exiguous.

Travel chain is defined as the combined use of different modes and services during a trip. The aims of forming travel chains are:

- To extend the supply of passenger transportation

- To combine the partial advantages of transportation modes

During the formation of an integrated travel chain, the combination of transportation modes is to be planned to provide similar mobility opportunity and service level than that of individual transportation. If a travel chain including a public transportation service provides favorable mobility opportunity according to flexibility and service quality, the share of public transportation can be enhanced. The "weakest link" determines the "strength" of a travel chain. The transfer is the critical part of a chain. The transfers between means and modes are performed at stops and in stations as well as at intermodal junctions. The quality of the mobility service is influenced by, besides the quality attributes of each mode, the design of the intermodal junctions (e.g., walking distances) and the quality of the available supplementary services (e.g., information provision). The common targets during the combination of transportation modes are to minimize the time spent in the system and the fee to be paid while maximizing the perceived service quality.

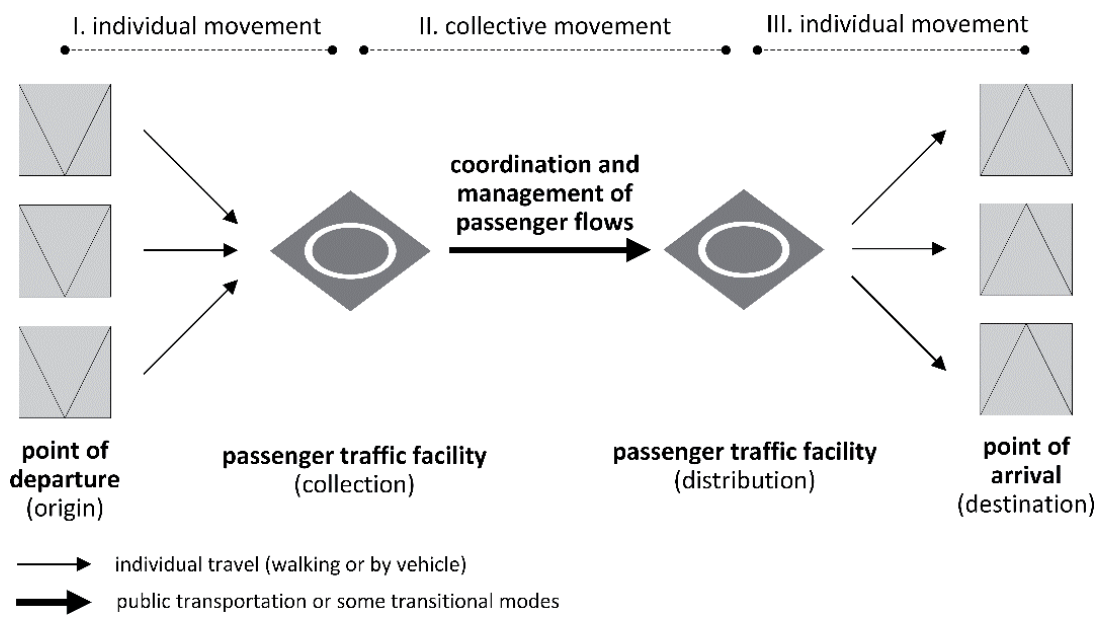

Figure 2.

Model of travel chain (source: [4]). 


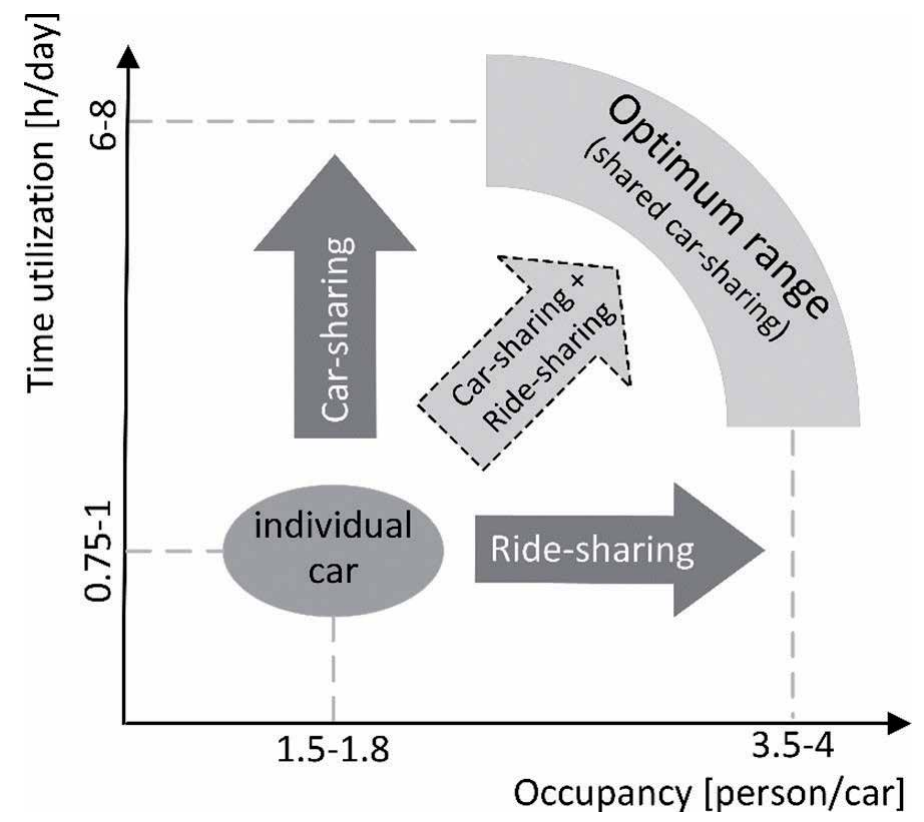

Figure 3.

Enhancement of capacity utilization of individual cars (source: based on [4]).

Travelers' movements should be managed in the network considering these targets. The coordination of passenger flows is represented in Figure 2 [4].

Shared or transitional modes provide services complementing traditional public transportation. So, new alternatives to individual vehicle use are established. The relevance of that is high as the individual cars are used for only 0.75-1 hour per day and only 1.5-1.8 travelers sit in a car on average during a trip in the European Union. However, the utilization of a vehicle can be enhanced by car-sharing and ridesharing. The daily utilization of a car can be enhanced to 6-8 hours by car-sharing and the seat capacity utilization to 3.5-4 travelers by ride-sharing. In an ideal case, car-sharing and ride-sharing are to be combined (Figure 3), which is a significant potential for the application of AVs.

\section{Alteration of mobility services}

In the early days, walking and animal-powered (mainly horses) transportation meant the only way of transportation. The individual serve of increasing travel demand was not efficient over a specific volume. Thus, public transportation services were implemented. In an urban environment, the horse-drawn omnibus, later the electric (e.g., tram, subway) and internal combustion engine-powered vehicles (e.g., bus), meant the base of transportation. The use of electric drivetrain remained significant in guided public land transportation, namely, electric locomotive, tram, subway (metro), and trolleybuses. Public transportation may significantly contribute to the decrease of fossil fuel dependency [5]. Furthermore, nowadays electric vehicles are getting more and more attention in the field of road transportation.

Because of economic growth, changing lifestyle, and technological development, mobility demand is increasing. Private car ownership and private car use have grown by leaps and grounds. The increasing number of road vehicles made imperative the management of traffic flow. High-quality public transportation and 
the spread of transitional modes can reverse the tendency. Where the road network, mainly in the European cities with historical urban structure, cannot serve the huge volume of private car use or where the economic growth was not sufficient, the nonmotorized and public transportation become widespread.

At early stages, mobility service providers managed the processes independently without cooperation. In the second half of the twentieth century, many transportation centers have been established to coordinate the public transportation services in urban areas (e.g., common tariff and information system, fee collection). The integration is an expectation from travelers as well.

Innovation in the transportation system is motivated by altering traveler expectations and technical developments $[6,7]$. The adoption of novel technologies is a solution to several challenges albeit the shift in technology causes difficulties during the implementation phase and the fears around new technologies are significant. As a result of technology development, the characteristic of vehicles and traffic management alter. Furthermore, the attributes of mobility demand and quality expectations are also altering. The travelers increasingly wish short preparation and travel times, pleasant circumstances during travel, as well as reliable and personalized information services. Intelligent and smart systems are available. Smart systems "know" more than intelligent systems because they are able to learn. The learning ability is programmed into them. With learning ability smart systems can respond not only predetermined situations.

Vehicle automation generates alterations in planning, operational management, and passenger handling functions. The current transportation modes are usually operated under human control, while the back-end functions are more and more automated. In general, automated and autonomous systems are distinguished:

- The automated system is controlled by computers following predetermined, step-by-step rules which were programmed into them, respectively. The algorithms cover potential situations and their consequences.

- The autonomous system is controlled by computers which make individual decisions using cognitive capabilities and learning capacities to manage the situations that have not been known before.

Automated and autonomous vehicles can be considered as moving computers. Several pieces of hardware and software are required for the operation. The operation of these components is simpler if the propulsion of the vehicle is electric. Moreover, the control functions needed for driver-less operation can be adopted easier in an electric vehicle. The main development areas in automotive technology are vehicle control, communication system, validation, and verification of components [8]. In the automotive industry, SAE levels are commonly used for describing only the vehicle control [9].

Several types of public transportation means are already automated, especially in track-based services (e.g., subways). Personal rapid transit (PRT) and group rapid transit (GRT) are relatively new mobility services operated mostly by automated vehicles. The comfortable, exclusive, either feeder or point-to-point services are available in small-scale areas in order not to give up the advantages of individual travel [4].

The entire mobility system is expected to be reshaped due to the widespread use of fully autonomous vehicles. According to the expectations, a high proportion of road vehicles becomes automatized. Currently, the developments of AVs focus on most types of road vehicles such as car, small bus (so-called pod), as well as even air vehicles (drone). 
Current transitional modes are merging into a new mode-so-called shared AV. This mode is infocommunication-based, highly personalized, shared, and available via mobile application and provides mostly on-demand or demand-responsive service. Small capacity vehicles, so-called pods, are applied. The seat or trip reservation is mandatory, which supports capacity planning, and so results in efficient transportation. The reservation, especially in urban transportation, requires additional action from the traveler. Since the large one-directional travel demands cannot be served efficiently by any other modes, the high-capacity, arterial public transportation lines remain important in the future too. Different scenarios are made for the type of this mode:

- Door-to-door, shared service [10]

- Feeder service to high-capacity public transportation $[11,12]$

- Combination of the previous types $[13,14]$

Personalized, flexible, door-to-door service can be provided mostly in rarely built-up areas because of the road capacity limitations. Consequently, in densely populated and highly urbanized areas, feeder service should be provided [13, 15]. The demands can be influenced by the application of dynamic tariff structures. In this way, the traveler is motivated to use the feeder and shared services.

Based on the scenarios, we defined the types of shared AVs:

- Taxi provides individual door-to-door service between any departure and arrival points without sharing the seat capacity.

- Shared taxi provides door-to-door service between any departure and arrival points with sharing of the seat capacity.

- Feeder pod provides feeder service from any departure points in a zone to the stop of an arterial, high-capacity line; transfers are guaranteed by semi-fixed timetable. The operation is symmetric in the opposite direction (from the stop of an arterial line to any arrival points).

- Fixed route pod provides mostly feeder service on fix route. The departure and arrival points are fix stops. It is operated according to fix timetable, but additional departures may be inserted according to current demands [4].

This mode can serve a significant rate of demand derived from individual car use. The individual, private AVs are used only for the most flexible travel purposes. The proportion of soft mobility forms, i.e., walking, and micromobility remain significant in the cases of both individual and shared use. However, the circumstances of soft mode use should be improved, especially in the downtowns.

Future transportation modes are represented in Figure $\mathbf{4}$ according to the modality of vehicle use, vehicle owner-operator, and the driver. The modality of the vehicles tends to collective modes due to shared AVs. Furthermore, most of the vehicles are to be owned by a company. The mobility services are managed by an integrated mobility service provider, while vehicles are owned and maintained by either a transportation company or a private person. Especially the smallest capacity vehicles used for taxi and shared taxi service may be owned by a private person. These vehicles can be publicly used when they are not used by the owner (i.e., ride-sourcing service with $\mathrm{AVs}$ ). 


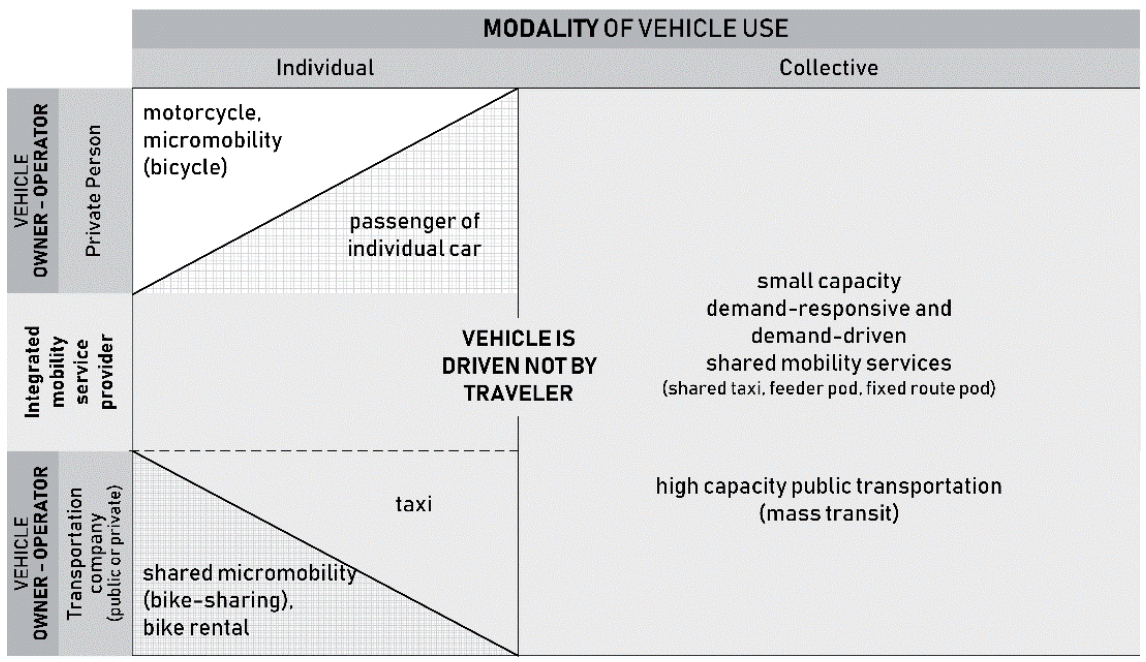

Figure 4 .

Classification of future transportation modes.

The future categories of passenger transportation are:

- Individual transportation

$\circ$ Nonmotorized: walking and cycling

$\circ$ Motorized: individual AV, motorcycle, and micromobility

- Public transportation (mobility services)

○ Small capacity

○ Nonmotorized: bike-sharing

○ Motorized: shared AV, other shared micromobility

- High capacity (mass transit) based on AVs (e.g., bus, tram) or highly automated vehicle (e.g., subway) [4]

\section{Planning principles}

The new mobility services require new approaches in planning. Especially, knowledge about mobility services based on AVs is still lacking as vehicle developments are still at an early stage. However, the various and combined service types require novel comprehensive planning and operational methods. Traditional methods [16] should be altered as the consequence of the following factors:

- Complex system architecture (e.g., the vehicle becomes an independent system component, and the number of operational functions is increasing)

- New and unknown technology 
- Increasing dynamism of data management

- Altering user preferences and expectations toward a higher quality of service

The traveler needs to learn completely new tasks, and the existing ones should be managed in a different way (e.g., ordering, open/close the vehicle, payment). Because of AVs, the role of human staff can be reduced, and drivers' work regulations are not to be considered anymore. But the lack of staff attendance implies several new challenges both in management (e.g., electric energy charging) and passenger handling (e.g., safety, information). Moreover, the vanishing driver as a job will cause a societal challenge.

Most of the functions can be automated either partially or entirely. The most relevant challenges are revealed in the following functions:

- Real-time demand-capacity coordination

- Planning vehicle runs with and without passengers; furthermore, shared runs are to be introduced

- Customization of mobile application and supplementary services

- Automatic real-time, personalized, and location-based push information provision

- Automatic vehicle charging

In advance mobility services, both data collection and planning functions are supported by software. The planning and operation of the novel, transitional services and shared AVs require a high amount of real-time data. But, as the technology is new, operational data are unavailable. The collection and consideration of user expectations are inevitable. The acceptance and easy adoption of a new service or technology, like AVs, can be significantly enhanced by a highly personalized mobility service considering the user expectations.

Not every traveler group can be served by the new mobility services. For instance, the ride-sourcing services are used by mostly youngers with high education background and for short distance [17]. The acceptability can be measured before the use (as an expectation), whereas the acceptance itself is to be measured after the use (as a revealed preference) [18]. Numerous publications deal with the measurement of expectations toward services based on AVs mostly by stated preference questionnaires $[10,19]$ or in some cases by revealed preference questionnaires $[20,21]$. Measuring the acceptance is rather difficult as bare experience is available. Consequently, the expectations can only be measured according to the stated preferences. But the acceptability is predominantly influenced by the perceived usefulness, expected effort, ease of use, and social influence [12].

In our previous studies [22, 23], we performed a questionnaire survey to reveal user expectations. The main findings were:

- The preferred service type is influenced by motivation and current mode use. The less-flexible (pod-like) types are preferred for less-flexible motivation (e.g., work/school), whereas the flexible (taxi-like) types are more likely preferred for the ad hoc travel motivation (e.g., leisure activity). Current car users prefer flexible types, while public transportation users accept less-flexible service types. 
- Higher spatial coverage is expected from the shared AV mode. Namely, the willingness to walk is less in general than in the case of a traditional bus service. But it depends also on the current mode choice preference, the size of the city, and age. Young generations living in big cities and using public transportation have a higher willingness to walk.

- The more flexible the service is, the higher the acceptable fee level is. The younger generation's willingness to pay is higher.

- Mobile application functions that help the use of the mobility service are the most important (ticketing, entitlement checking, fee calculation, display travel-related information).

- Services providing travel-related information, along with the services supporting the use of individual smart devices (free Wi-Fi, chargers), are the most important onboard services.

- Activities which are limited or impossible to do during driving become more popular in the future (looking around, surfing on the Internet/chatting, working).

\section{Mobility-as-a-Service}

The integration facilitates the establishment of the concept of Mobility-as-aService. It provides a wide range of personalized mobility packages in an integrated way that consists of shared, transitional, and mass (public) transportation modes. Instead of tickets and passes, the traveler purchases mobility packages. The mobility package or "monthly plan" consists of rides on various transportation modes (e.g., public transportation, bike-sharing, car-sharing, etc.) provided by several providers. Thus, MaaS establishes the interoperability of transportation subsystems. The combination of travel modes highlights the advantages and eliminates the drawbacks of the various transportation modes. Passenger handling functions (e.g., journey planning, booking, payment) for an entire multimodal journey are operated through a single interface (mainly smartphones). The operational model is presented in Figure 5. Traditional MaaS consists of the following modes: bus, tram

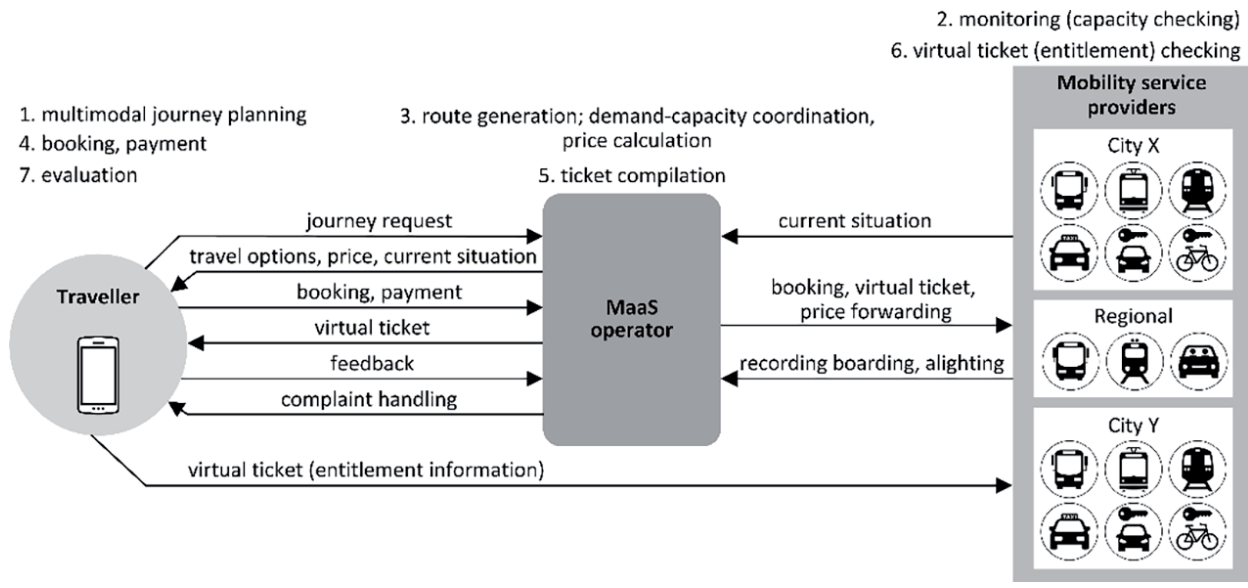

Figure 5.

MaaS operational model (source: [4]). 
(light rail), metro (subway), taxi, car-sharing, ride-sharing, and bike-sharing. The operational area of the MaaS is mostly cities, but regional travels can also be managed [4]. The aim is to reach the international and global MaaS operation [24].

The so-called MaaS operator coordinates the processes and connects passengers and mobility service providers. Contracts are made on two levels. On the one hand, a contract is made between the MaaS operator and the traveler when the mobility package is compiled and purchased. On the other hand, a contract is made between the MaaS operator and mobility service provider to permit sub-sale of services. The quality aspects, the minimum level of services, as well as the cooperation-related issues are declared in the contracts (bonus-malus system).

The quality of a mobility service is a complex and partially subjective term which depends on several attributes of the mobility service. Its objectivity is to be enhanced by the application of norms. The quality is an important aspect to facilitate passenger's satisfaction.

The traditional MaaS is defined as a semipublic transportation service. Thus, the quality assessment criteria of both public and private transportation are taken into consideration. Real-time information management among subsystems (e.g., service providers, travelers) is the backbone of this service. The accessibility and availability of transfers are highlighted; the transfer connection both in spatial and temporal senses should be ensured. As shared services are also incorporated, the interior facility of small or medium-sized vehicles may significantly affect traveler's satisfaction (e.g., cleanness).

MaaS can be fully adopted with the application of AVs [24]. The differences between the MaaS provided by traditional and autonomous vehicles are as follows:

- The composition of mobility services (high-capacity public transportation, shared AV, bike-sharing, and other shared micromobility forms)

- Integrated operational control

- Driving

- Passenger handling

The MaaS based on AVs is defined as a public transportation service, where highly automated transportation processes are considered. Namely, the AVs are fully incorporated, and the real-time task coordination process is managed by machine-tomachine components automatically. Service types are highly fused, and the transitional modes are replaced by the service of shared AVs. Assessment criteria of MaaS based on AVs is established on the basis of public transportation [25]. Since MaaS is a smartphone application-based and traveler-centric service, the infocommunication background is tightly related to quality. Travelers interact with "two computers (smartphone and AV)" in real time. Thus, passenger handling functions (e.g., journey planning, booking, payment), as well as seat reservation function, are to be assessed as the specialties of this service. In the case of MaaS based on AVs, the aim of MaaS operator is to enhance the quality, while sustainability is attained in all senses at.

\section{Impacts of alteration}

Reshaped urban mobility implies several impacts. Due to shared and demanddriven services, it is expected that the individual car use will decrease. However, the change in the travelers' mindset is needed. In an urban area, individual car use 
and car ownership are to be eliminated. Necessarily, efficient public transportation and introduction of shared and transitional transportation modes are required. In developed countries, the intention to own a car is decreasing among the younger generation.

Significant benefits can be gained by dynamic assignment of shared vehicles for different service types [26]. The benefits are relevant for passengers (e.g., reduction of travel time and fee) and operators (enhanced utilization rate). However, the utilization of shared services is not efficient without adequate management. For instance, the capacity utilization of a taxi service is not efficient without seatsharing [27]. The mileage of taxis can be reduced by $40 \%$ by seat-sharing [28].

Moreover, if shared, demand-driven services are too convenient, the share of high-capacity public transportation decreases, which may cause further problems (e.g., increasing traffic jams). For instance, at least half of the ride-sourcing trips replace traditional public transportation trips [17].

The application of AVs has impacts on society and the environment too. The length of trips is expected to grow as travel time is spent in a more efficient and pleasant manner. In this way, daily commuting distance can be even longer. Furthermore, travel time can be reduced as a result of better drivability of the vehicles and advanced traffic control. Vehicle design and passenger compartment also alter. The individual total utility of travel increases, because onboard activities may replace activities performed at home or the workplace. All in all, the number of travels is expected to increase.

However, individual car use decreases by the introduction of a flexible shared AV service because similar service quality can be provided as by an individual car. Current car users' willingness to shift is the highest, as bikers' and pedestrians' willingness to shift are the lowest according to our previous study [29]. The number of cars decreases as less vehicle is enough to meet the needs. Furthermore, the capacity utilization and useful mileage of the vehicles increase because of the shared use. However, the number and length of empty runs may increase due to dissimilar pickup and drop-off points of passengers.

The vehicles communicate with each other, with the infrastructure and with other road users. Consequently:

- The number of road accident decreases [30], and traffic safety increases.

- Traffic parameters alter, for instance, smaller headway and higher speed.

- Traffic control alters [31], for instance, less traffic sign is enough, but a complete replacement of them is not expected as they are needed by soft mobility users.

The public places in cities are utilized in a different way which causes a paradigm shift in urban design as well. The number and extension of road infrastructure elements are also expected to be altered. For instance, less parking lots are enough. Accordingly, the available space for pedestrians and micromobility users or other, non-transportation-related functions (e.g., green areas) can be increased. The time base of road infrastructure elements is to be shared between the functions:

- Shared parking lots:

○ At night or daytime, residents or shared AVs park and recharge.

$\circ$ In daytime shared AVs use them as virtual stop. 
○ In dedicated time intervals, freight AVs serving neighborhood shops, restaurants, etc. park and recharge during loading.

- Shared traffic lanes: in the peak hours for moving traffic, in the off-peak hours for parking

Though the AVs may serve any point, they cannot stop "anywhere." Therefore, allocation of virtual stops is needed. Virtual stops are points where passengers can board and alight an AV in a safe way and the traffic is not hindered. Virtual stops can be established without any special infrastructure.

The energy consumption becomes more efficient as a result of energy-efficient vehicle control. Thus, the environmental impact of transportation is also reduced. Pollution decreases further if electric and renewable energy sources are applied.

The traveler groups alter as well. Current car drivers become passengers. Demand-driven mobility services provide better spatial coverage and time availability as they usually serve door-to-door rides on demand. Accordingly, some pedestrians become also passengers as the use of a demand-driven service can be faster and more comfortable than walking. The small AVs may be also considered as an accessory of a building. While the elevators support the vertical movements, the small AVs connect the locations with horizontal movements. The travelers can enter the building with them (e.g., during shopping). Thus, the concept of smart vehicle and smart mobility is related to the concept of smart home or building, and from a wider perspective, these all are part of the smart city concept. However, all in all, the share of pedestrians and micromobility users is expected to increase as soft mobility modes are promoted, especially in urban areas (e.g., pedestrian zone). Accordingly, both soft mobility modes and the shared use of AVs as a feeder service are needed in order to avoid the significant increment of motorized road traffic.

\section{Conclusion}

In this chapter, reshaping urban mobility was discussed in a transportation engineering point of view with a special focus on automation. The main contribution of the chapter was the description of transportation modes and current mobility services, as well as the detailing alteration in urban mobility. Moreover, planning principles of such mobility services and MaaS as a concept was overviewed, and the impacts of alteration were summarized.

The border between the individual and public transportation modes is blurring. Novel shared and on-demand, so-called transitional transportation modes are spreading in cities which can provide similar service level as individual car use but in a more efficient way as either the vehicle in time or the seats are shared.

New mobility services based on AVs are expected soon. We found that the transitional transportation modes and, even more, most of the individual car use can be replaced by a new, shared, demand-driven mobility service based on small capacity AVs which is accessible only with advance ordering via a mobile application. However, we highlighted that as the capacity of the built infrastructure is limited, the travel demands can be served efficiently only by shared and feeder mobility services. Additionally, promotion of walking, public transportation, and/ or micromobility use is also required. Mobility-as-a-Service concept contributes to achieving these aims. Moreover, the shared use of vehicles causes significant alteration in cities, e.g., the function of public places alters. 
Since the current shared services are novel, and the mobility services based on AVs are at the very early stage, only assumptions can be made about the impacts. Considering the user expectations during the planning of these services is inevitable. In that way, the acceptance and adoption of new services can be facilitated.

Possible future intentions are to be the elaboration of novel, complex evaluation and comparison methods for mobility services. The evaluation covers service quality, flexibility, features of integrity and automation, as well as customization. Furthermore, planning and operational methods of mobility services based on AVs are to be developed, and travelers' expectations are to be analyzed.

\section{Acknowledgements}

The research reported in this chapter was supported by the Higher Education Excellence Program of the Ministry of Human Capacities in the frame of Artificial Intelligence research area of the Budapest University of Technology and Economics (BME FIKP-MI/FM).

\section{Author details}

Csaba Csiszár, Dávid Földes* and Yinying He

Department of Transport Technology and Economics, Faculty of Transportation Engineering and Vehicle Engineering, Budapest University of Technology and Economics, Budapest, Hungary

*Address all correspondence to: foldes.david@mail.bme.hu

IntechOpen

(C) 2019 The Author(s). Licensee IntechOpen. This chapter is distributed under the terms of the Creative Commons Attribution License (http://creativecommons.org/licenses/ by/3.0), which permits unrestricted use, distribution, and reproduction in any medium, provided the original work is properly cited. (cc) BY 


\section{References}

[1] Pribyl O. Transportation, intelligent or smart? On the usage of entropy as an objective function. In: Smart Cities Symposium Prague 2015, SCSP 2015. Czech Republic: Prague; 2015. DOI: 10.1109/SCSP.2015.7181564

[2] Cordeau J-F, Laporte G, Potvin J-Y, Savelsbergh MWP. Transportation on demand. Transportation.

2007;14:429-466. DOI: $10.1016 /$ S0927-0507(06)14007-4

[3] Davison L, Enoch M, RyleyT, Quddus C, Wang A. A survey of demand responsive transport in Great Britain. Transport Policy. 2013;31:47-54. DOI: 10.1016/j.tranpol.2013.11.004

[4] Csiszár CS, Csonka B, Földes D. Innovative Transportation Systems. Budapest: Akadémia Kiadó; 2019. online book. DOI: $10.1556 / 9789630599412$

[5] Milojevic S, Skrucany T, Milosevic H, Stanojevic D, Pantic M, Stojanovic B. Alternative drive systems and environmentally friendly public transport. Applied Engineering Letters. 2018;3(3):105-113. DOI: 10.18485/ aeletters.2018.3.3.4

[6] Gerike R, Koszowski C. Sustainable urban transportation. In: Abraham MA, editor. Encyclopedia of Sustainable Technologies. Sustainable Built Environment \& Sustainable Manufacturing. Amsterdam, The Netherlands: Elsevier; 2017. pp. 403-413. DOI: $10.1016 /$ B978-0-12-409548-9.10176-9

[7] Cass N, Schwanen T, Shove E. Infrastructures, intersections and societal transformations. Technological Forecasting and Social Change. 2018;137:160-167. DOI: 10.1016/j. techfore.2018.07.039 2018

[8] Szalay Z, Tettamanti T, EsztergárKiss D, Varga I, Bartolini C. Development of a test track for driverless cars: Vehicle design, track configuration and liability considerations. Periodica Polytechnica Transportation Engineering. 2018;46(1):29-35.

DOI: 10.3311/PPtr.10753

[9] Society of Automotive Engineers (SAE). Taxonomy and Definitions for Terms Related to On-Road Motor Vehicle Automated Driving Systems [Internet]. 2018. Available from: https://www.sae. org/standards/content/j3016_201806/ [Accessed on: 05 July 2019]

[10] Krueger R, Rashidi T-H, Rose JM. Preferences for shared autonomous vehicles. Transportation Research Part C: Emerging Technologies. 2016;69: 343-355. DOI: 10.1016/j.trc.2016.06.015

[11] Alessandrini A, Alfonsi R, Site PD, Stam D. Users' preferences towards automated road public transport: Results from European surveys. Transportation Research Procedia. 2014;3:139-144.

DOI: 10.1016/j.trpro.2014.10.099

[12] Madigan R, Louw T, Dziennus M, Graindorge T, Ortega E, Graindorge M, et al. Acceptance of automated road transport systems (ARTS): An adaptation of the UTAUT model. Transportation Research Procedia. 2016;14:2217-2226. DOI: 10.1016/j.trpro.2016.05.237

[13] Owczarzak L, Zak J. Design of passenger public transportation solutions based on autonomous vehicles and their multiple criteria comparison with traditional forms of passenger transportation. Transportation Research Procedia. 2015;10:472-482.

DOI: 10.1016/j.trpro.2015.09.001

[14] International Transport Forum (ITF). Shared Mobility Simulations for Helsinki [Internet]. 2017. Available from: https://www.itf-oecd.org/sites/ default/files/docs/shared-mobilitysimulations-auckland.pdf [Accessed on: 05 July 2019] 
[15] International Transport Forum (ITF). Urban Mobility System Upgrade: How shared self-driving cars could change city traffic [Internet]. 2015. Available from: https://www.itf-oecd.org/sites/default/ files/docs/15cpb_self-drivingcars.pdf [Accessed on: 05 July 2019]

[16] Ibarra-Rojas OJ, Delgado F, Giesen R, Muñoz JC. Planning, operation, and control of bus transport systems: A literature review. Transportation Research Part B: Methodological. 2015;77:38-75. DOI: 10.1016/j. trb.2015.03.002

[17] Rayle D, Dai N, Chan R, Cervero R, Shaheen S. Just a better taxi? A surveybased comparison of taxis, transit, and ridesourcing services in San Francisco. Transport Policy. 2016;45:168-178. DOI: 10.1016/j.tranpol.2015.10.004

[18] Merat N, Madigan R, Nordhoff S. Human Factors, User Requirements, and User Acceptance of Ride-Sharing in Automated Vehicles. Paris, Discussion Paper: International Transport Forum; 2017

[19] Kockelman KM, Bansal P, Singh A. Assessing public acceptance of and interest in the new vehicle technologies: An Austin perspective. Transportation Research Part C:

Emerging Technologies. 2016;67:1-14. DOI: 10.1016/j.trc.2016.01.019

[20] Christie C, Koymans A, Chanard T, Lasgouttes J-M, Kaufmann V. Pioneering driverless electric vehicles in Europe: The city automated transport system (CATS). Transportation Research Procedia. 2016;13:30-39. DOI: 10.1016/j. trpro.2016.05.004

[21] Nordhoff S, de Winter J, Payre W, van Arem B, Hapee R. What impressions do users have after a ride in an automated shuttle? An interview study. Transportation Research Part F: Traffic Psychology and Behaviour. 2018;63: 252-269. DOI: 10.1016/j.trf.2019.04.009
[22] Földes D, Csiszár CS. Framework for planning the mobility service based on autonomous vehicles. In: Smart Cities Symposium Prague SCSP2018. Prague, Czech Republic; 2018. pp. 24-25. DOI: 10.1109/SCSP.2018.8402651

[23] Földes D, Csiszár CS, Zarkeshev A. User expectations towards mobility services based on autonomous vehicle. In: 8th International Scientific Conference CMDTUR2018. Zilina, Slovakia; 2018

[24] Li Y, Voege T. Mobility as a service (MaaS): Challenges of implementation and policy required. Journal of Transportation Technologies. 2017;7(2):95-106. DOI: 10.4236/

jtts.2017.72007

[25] He Y, Csiszár CS. Quality assessment method for mobility-as-aservice based on autonomous vehicles. In: International Conference for Traffic and Transport Engineering. Belgrade, Serbia; 2018

[26] Atasoy B, Ikeda T, Song X, Ben-Akiva ME. The concept and impact analysis of a flexible mobility on demand system. Transportation Research Part C: Emerging Technologies. 2015;56: 373-392. DOI: 10.1016/j.trc.2015.04.009

[27] Dimitriou L, Kourti E, Christodoulou C, Gkania V. Dynamic estimation of optimal dispatching locations for taxi services in mega-cities based on detailed GPS information. IFAC-PapersOnLine. 2016;49(3):197-202. DOI: 10.1016/j.ifacol.2016.07.033

[28] Santi P, Resta G, Szell M, Sobolevsky S, Strogatz SH, Ratti C. Quantifying the benefits of vehicle pooling with share ability networks. PNAS. 2014;111(37):13290-13294. DOI: $10.1073 /$ pnas. 1403657111

[29] Földes D, Csiszár CS. Operational model and impacts of mobility service based on autonomous vehicles. 
In: International Conference for Traffic and Transport Engineering. Belgrade, Serbia; 2018

[30] Waldrop MM. Autonomous vehicles: No drivers required. Nature. 2015;518(7537):20-23. DOI: $10.1038 / 518020 \mathrm{a}$

[31] Pereira AM, Anany H, Pribyl O, Prikryl J. Automated vehicles in smart urban environment: A review. In: Smart City Symposium 2017, SCSP 2017. Prague, Czech Republic; 2017. DOI: 10.1109/SCSP.2017.7973864 



\title{
Improving Feature Map Quality of SOM Based on Adjusting the Neighborhood Function
}

\author{
Le Anh Tu
}

\begin{abstract}
This chapter presents a study on improving the quality of the self-organizing map (SOM). We have synthesized the relevant research on assessing and improving the quality of SOM in recent years, and then proposed a solution to improve the quality of the feature map by adjusting parameters of the Gaussian neighborhood function. We have used quantization error and topographical error to evaluate the quality of the obtained feature map. The experiment was conducted on 12 published datasets and compared the obtained results with some other improving neighborhood function methods. The proposed method received the feature map with better quality than other solutions.
\end{abstract}

Keywords: quantization error, topographical error, self-organizing map, feature map, projection quality, learning quality

\section{Introduction}

SOM is a very useful neural network for visualization and data analysis. Among SOM's application areas, urban design is a potential area. Many of SOM's applications can be included in urban design such as: analysis of growth factors in urban design proposal [1], consider urban spatial structure [2], analysis of city systems [3], city data mining [4], predicting accessibility demand for healthcare infrastructure) [5], etc. However, for SOM's calculation results to be more accurate, improving the quality of feature map is a problem to solve.

SOM creates a map of the input data in the multi-dimensional space to the less dimensional space that is usually two-dimensional space called by the feature map of the data. To evaluate the quality of feature map, people mainly use two indicators: learning quality and projection quality [6-9]. The learning quality indicator is determined through measurement of quantization error (QE) $[10,11]$. The projection quality indicator is determined through measurement of topographical error (TE) [12-14]. If the values of the QE and TE are small, feature map will be assessed with good quality.

Many studies have shown that the quality of feature map is affected greatly by the initial parameters of the network, including map size, numbers of training and neighborhood radius $[11,15-18]$. Beside that, a feature map achieving with a set of fit parameters is not considered as the best quality map. Therefore, improving the feature map quality of SOM is concerned by many researchers. 
To achieve good quality map for each dataset in traditional method is "trying error" with different parameters of the network. These parameters, creating a map with the smallest error measurement are suitable for the dataset [11]. According to Chattopadhyay et al. [19], with a specific dataset, the size of the map is selected by "trying error" until reaching value of QE, TE small enough. Polzlbauer [20] indicates the technical correlation between $\mathrm{QE}$ and TE, which TE often arises when $\mathrm{QE}$ reduces. In case of increasing the size of Kohonen layer, QE may reduce but TE increases (i.e., the large size of the Kohonen layer can distort the shape of the map), and vice versa when the size of Kohonen layer is too small, TE is not trust. The use of a small neighborhood radius leads to reduced QE. If the neighborhood radius is the smallest value, $\mathrm{QE}$ will reach a minimum value [21].

Besides the method of "trying error" to determine a suitable network configuration, the study on improving the algorithm of SOM to enhance the quality of feature map is also interested by researchers. Germen [22, 23] optimized QE by integrating "hit" parameter when updating the weight vector of the neurons, the term "hit" means the number of excitation to a neuron (or BMU counter). The "hit" parameter will determine adjusting weight vector of neuron, i.e., the neurons representing for many samples are adjusted less (to ensure not lose information) than neurons representing for less samples.

Neme $[24,25]$ proposed SOMSR model (SOM with selective refractoriness), which allows reducing TE. In this model, the neighborhood radius of the BMU did not reduce gradually in the learning process. In every training times, every neuron in the neighborhood radius of the BMU will decide itself whether being affected by the BMU or not in the next training.

Kamimura [26] has integrated the "firing" rate in the distance function to maximize information input. The "firing" rate identifies the important degree of each feature comparing to the remaining features. This method can reduce both $\mathrm{QE}$ and TE; however, with each dataset, it needs to "trying error" in several times to determine the appropriate value of "firing."

Lopez-Rubio [27] describes the topographical error of the map as a state of "selfintersections." If it detects a "self-intersections" state between neurons after each learning times, it will redo that learning times. This solution can reduce the TE, but increase QE.

Another approach is to adjust the scope and the learning rate of the neighborhood neurons. Kohonen [11] homogenised learning rate of all the neurons in the neighborhood radius to learning rate of the BMU by using the "bubbles" neighborhood function. He concluded that the bubbles function is less effective than the Gaussian function.

Aoki and Aoyagi [28] and Ota et al. [29] published an asymmetric neighborhood function. The essence of this function is extending the neighborhood radius towards one direction and shrinking the opposite one. Theoretically, this could "slide" down the topographical error out of the map. However, his experiment has been limited in the certain situations and not really convinced.

Lee and Verleysen [30] replaced the neighborhood function by "fisherman" rule. "Fisherman" rule updates the neurons in neighborhood radius following the recursive principle, which BMU is adjusted following input sample and the BMUadjacent neurons (adjacent level 1) is governed by the BMU (unadjusted by input samples), moreover, each adjacent neuron in level 2 is adjusted by the previous adjacent neuron in level 1 . The remaining neurons in the neighborhood radius are adjusted in the same rule. However, the way to determine the order of the adjacent neurons when they are organized in a rectangular or a hexagonal grid is not shown in his article. In addition, he concluded that the Gaussian function has better results than the rule of "fisherman". 
It can be recognized that achieving a feature map with good quality according to many criterion is a difficult problem. So far, there has not any solution, reducing simultaneously both QE and TE that is well-applied for every dataset.

In this chapter, we improved Gaussian neighborhood function by adding the adjusting parameter in order to simultaneously reduce the $\mathrm{QE}, \mathrm{TE}$ of the map. The next contents of the chapter include: Section 2 presents an overview of SOM and assessment measures of the quality of feature map; Section 3 presents our studying on adjusting the parameter of the Gaussian neighborhood function; Section 4 indicates the empirical results and the conclusion of the proposed method.

\section{Self-organizing map neural network}

\subsection{Structure and the algorithm}

SOM includes input and output Kohonen layer. Kohonen layer is usually organized under the form of a two-dimensional matrix of neurons. Each unit $i$ (neuron) in the Kohonen layer having a weight vector $w_{i}=\left[w_{i, 1}, w_{i, 2}, \ldots, w_{i, n}\right]$, with $n$ is the size of the input vector; $w_{i, j}$ is the weight vector of neuron $i$ going with input $j$ (Figure 1). SOM is trained by unsupervised algorithm. The process is repeated many times, at time $t$ doing three steps:

- Step 1. Finding BMU: randomly select sample $x(t)$ from dataset (with $t$ is training times), search for a neuron $c$ of the Kohonen matrix containing the minimum dist distance (frequently use functions of Euclidean, Manhattan or vector dot product). Neuron $c$ is called by Best Matching Unit (BMU).

$$
\text { dist }=\left\|x(t)-w_{c}\right\|=\min _{i}\left\{\| x(t)-w_{i} \mid\right\}
$$

- Step 2. Calculating neighborhood radius of BMU: using the interpolation function (reduce gradually following the times of iterations)

$$
N_{c}(t)=N_{0} \exp \left[-\frac{t}{\lambda}\right]
$$

where $N_{c}(t)$ is the neighborhood radius in the $t$ training time; $N_{0}$ is initial neighborhood radius; $\lambda=\frac{K}{\log \left(N_{0}\right)}$ is time constant, with $K$ is the total number of iterations.

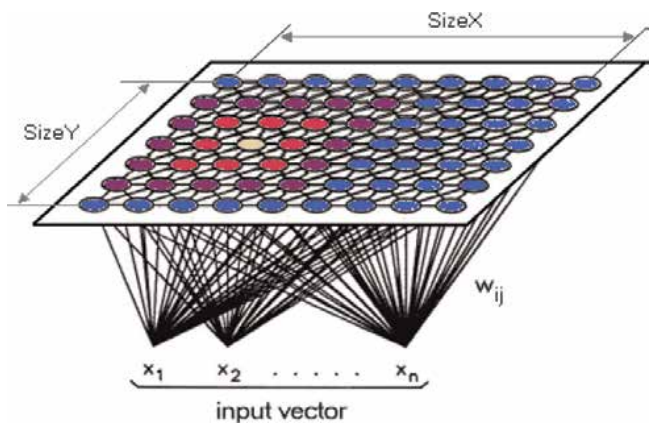

Figure 1.

Illustrates the structure of SOM. 
- Step 3. Updates weight vector of neurons in the neighborhood radius of BMU towards being near to sample $x(t)$ :

$$
w_{i}(t+1)=w_{i}(t)+L(t) h_{c i}(t)\left[x(t)-w_{i}(t)\right]
$$

where $L(t)$ is the learning rate at the iteration $t$, (the learning rate is reduced simply along with time similar to neighborhood radius, with $0<L(t)<1) . L(t)$ could be a linear function, exponential function ...; $h_{c i}(t)$ is a neighborhood function, showing the impact of distance on the learning process calculated by the formula (4)

$$
h_{c i}(t)=\exp \left[-\frac{\left\|r_{c}-r_{i}\right\|^{2}}{2 N_{c}^{2}(t)}\right]
$$

where $r_{c}$ and $r_{i}$ are the positions of neuron $c$ and neuron $i$ in Kohonen matrix.

\subsection{The quality of feature map}

Quantization error and topographical error are main measurements to assess the quality of SOM. Quantization error is the average difference of the input samples compared to its corresponding winning neurons (BMU). It assesses the accuracy of the represented data, therefore, it is better when the value is smaller [11].

$$
Q E=\frac{1}{T} \sum_{t=1}^{T}\left\|x(t)-w_{c}(t)\right\|
$$

where $x(t)$ is the input sample at the training $t$; $w_{c}(t)$ is the BMU's weight vector of sample $x(t)$; T is total of training times.

Topographical error assesses the topology preservation $[13,14]$. It indicates the number of the data samples having the first best matching unit $\left(\mathrm{BMU}_{1}\right)$ and the second best matching unit $\left(\mathrm{BMU}_{2}\right)$ being not adjacent. Therefore, the smaller value is better.

$$
T E=\frac{1}{T} \sum_{t=1}^{T} d(x(t))
$$

where $x(t)$ is the input sample at training times $t ;(x(t))=1$ if $\mathrm{BMU}_{1}$ and $\mathrm{BMU}_{2}$ of $x(t)$ not adjacent, vice versa, $d(x(t))=0$; $T$ is total of training times.

\section{Adding adjust parameter for Gaussian neighborhood function}

Formula 3 shows the learning ability of SOM depends on two components: learning rate $L(t)$ and neighborhood function $h_{c i}(t)$.

Because the learning rate decreases simply over time, it should define the general learning rate of SOM over the training time. Therefore, the quality of feature map will be influenced mainly by neighborhood function $h_{c i}(t)$. The adjustment of the neighborhood function will affect directly to the learning process and the quality of the feature map of SOM.

Neighborhood function $h_{c i}(t)$ defines the influence level of input sample on neurons in the neighborhood radius $N_{c}(t)$ of BMU (Figure 2). 


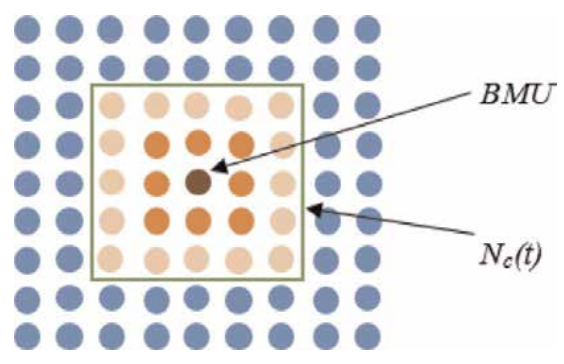

Figure 2.

Illustrates the influencing of input sample on the neurons in the neighborhood radius at training times $t$.

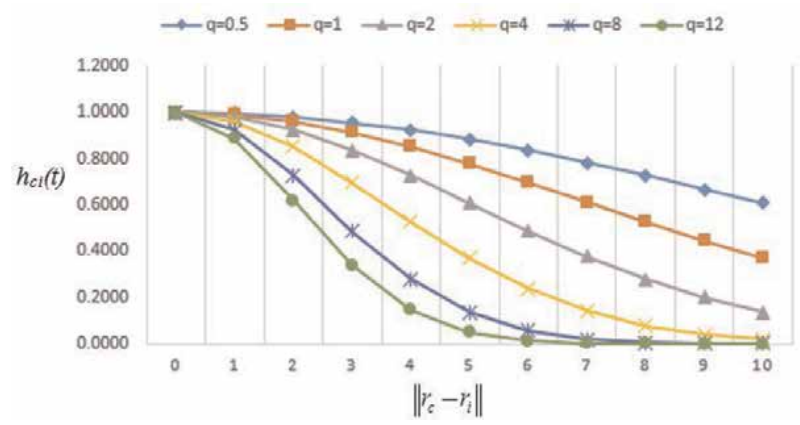

Figure 3.

Illustrates function $h_{c i}(t)$ after changing the value of $q$.

The formula (4) is rewritten in the following general form:

$$
h_{c i}(t)=\exp \left[-q \frac{\left\|r_{c}-r_{i}\right\|^{p}}{N_{c}^{p}(t)}\right]
$$

where $q$ and $p$ are two adjustable parameters, with $q \geq 0$ và $p \geq 0$.

It shows that the value of $h_{c i}(t)$ depending on the distance from the position of the being assessed neuron $\left(r_{i}\right)$ (neuron $i$ ) to the position of BMU $\left(r_{c}\right)$ and parameters $q, p$, specifically:

- If $\left\|r_{c}-r_{i}\right\|=0$ (BMU is neuron being assessed), $h_{c i}(t)=1$.

- If $\left\|r_{c}-r_{i}\right\|=N_{c}(t)$ (the being assessed neuron in the farthest position in neighborhood radius $N_{c}(t)$ ), the value of the neighborhood function depends on parameter $q$, with:

$$
h_{c i}(t)=\exp [-q]
$$

The formula (8) shows the minimum value of function $h_{c i}(t)$ depends on parameter $q$.

Figure 3 illustrates the neighborhood function $h_{c i}(t)$ in case of the neighborhood radius $N_{c}(t)=10$, where $p=2$ and $q=0.5,1,2,4,8,12$.

\subsection{Parameter $q$}

In principle, the bigger adjusting level of neurons's weight vector in the current learning times, the higher their difference with other input patterns in other learning times is. This is the cause of increasing the quantization error. Therefore, to 
reduce the $\mathrm{QE}$, we must reduce the level and scope of the influencing of input sample, i.e., the increase of the value of $q$ will reduce $Q E$.

However, if $q$ is too large, the learning ability of the map is restricted, i.e., the topography of map changes less, and partly depends on the initialization of the neural's weight vector. On the other hand, neighborhood radius $N_{c}(t)$ can be shrunk, due to $h_{c i}(t) \approx 0$ with neurons in remote positions of neighborhood radius (i.e., neurons in remote positions in the neighborhood radius are not adjusted or adjusted negligibly by input sample). Therefore, to ensure that all the neurons in the neighborhood radius $N_{c}(t)$ are adjusted by the input sample, the parameter $q$ is not allowed to be too large. For example, the case of $q=8$ and 12 , function $h_{c i}(t) \approx 0$ when the value of $\left\|r_{c}-r_{i}\right\|$ reaching to $N_{c}(t)$.

In case of $q \approx 0$, Gaussian function has the same result as bubble function, i.e., $h_{c i}(t) \approx 1$ with all neurons in the neighborhood radius $N_{c}(t)$. As a result, if the neighborhood radius $N_{c}(t)$ is bigger, the feature map will be more likely to change locally following input sample $x(t)$. This reduces the remember ability the previous learning times of the network.

Therefore, TE may depends on initializing the weight vector of neurons if $q$ is too large or depends on the order of the input samples if $q$ is too small. It is notable that the initial weight vector of neurons and the order of the input sample are selected randomly. Therefore, the topographic learning ability of network is best when parameter $q$ is not too small or too large.

\subsection{Parameter $p$}

When the parameter $q$ is fixed, if the parameter $\mathrm{p}$ increases, the value of function $h_{c i}(t)$ of the neurons that near the BMU will increase gradually to 1, i.e., the number of neighbors around the BMU that are adjusted similar with BMU will extend. This is the cause of QE increasingly. If the parameter $p$ is too large, the feature map tends to change locally according to the input sample from the closest training times (similar to the case that parameter $\mathrm{q}$ is too small). However, TE may vary slightly because $\mathrm{TE}$ is conducted by $\mathrm{BMU}_{1}$ and $\mathrm{BMU}_{2}$.

Figure 4 illustrates original neighborhood function $h_{c i}(t)$ (with $q=0.5$ and $p=2$ ) and adjusted neighborhood function $h_{c i}(t)$ (with $q=4$ and $p=1,2,3,4,5,6$ ) in case of $N_{c}(t)=10$.

In case of $p=1$, the graph $h_{c i}(t)$ is similar to the case of $q=8,12$ in Figure 3, i.e., the smallest QE compared to the case of $p>1$, but $T E$ is unreliable due to depend on initializing the weight vector of neurons.

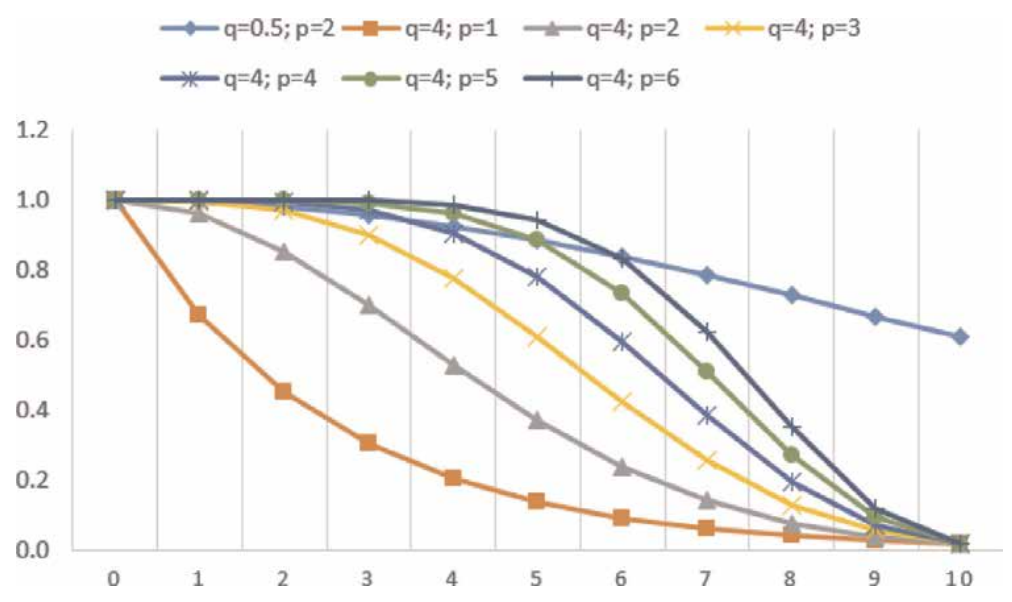

Figure 4.

Illustrates function $h_{c i}(t)$ after changing the value of $p$. 
Therefore, the adjustment of parameter $p$ has no significant impact on improving the quality of the feature map of SOM, but the parameter $q$ has positive significance in improving the quality of the feature map of SOM. The bigger the parameter $q$ is, the smaller $Q E$ is. However, $q$ reaches the most appropriate value when $T E$ is the smallest. Therefore, we recommend the neighborhood function $h_{c i}^{\prime}(t)$ with an adjustable parameter as follows:

$$
h_{c i}^{\prime}(t)=\exp \left[-q \frac{\left\|r_{c}-r_{i}\right\|^{2}}{N_{c}^{2}(t)}\right]
$$

with the parameter $q$ can be adjusted depending on each the dataset to achieve better quality of feature map.

\section{Experiments}

We have conducted experiments for 12 published datasets, including: XOR (data samples are distributed within the XOR operation), Aggregation, Flame, Pathbased,

\begin{tabular}{|c|c|c|c|c|c|c|}
\hline$q$ & 0.5 & 1 & 2 & 4 & 8 & 12 \\
\hline \multirow[t]{2}{*}{ XOR } & 0.1890 & 0.1585 & 0.1299 & 0.1129 & 0.0902 & 0.0810 \\
\hline & 0.0318 & 0.0223 & 0.0273 & 0.0427 & 0.0705 & 0.0925 \\
\hline \multirow[t]{2}{*}{ Aggregation } & 5.9702 & 5.0643 & 4.0276 & 2.9340 & 2.2819 & 1.8472 \\
\hline & 0.0549 & 0.0362 & 0.0294 & 0.0245 & 0.0424 & 0.0678 \\
\hline \multirow[t]{2}{*}{ Flame } & 2.1839 & 1.9512 & 1.5194 & 1.1822 & 0.9129 & 0.8206 \\
\hline & 0.0700 & 0.0567 & 0.0407 & 0.0393 & 0.0479 & 0.0833 \\
\hline \multirow[t]{2}{*}{ Pathbased } & 4.5859 & 4.0427 & 3.2618 & 2.4779 & 1.9392 & 1.7401 \\
\hline & 0.0561 & 0.0433 & 0.0373 & 0.0315 & 0.0434 & 0.0794 \\
\hline \multirow[t]{2}{*}{ Spiral } & 4.7595 & 4.1719 & 3.4675 & 2.9239 & 2.2975 & 2.0085 \\
\hline & 0.0543 & 0.0404 & 0.0284 & 0.0364 & 0.0413 & 0.0564 \\
\hline \multirow[t]{2}{*}{ Jain } & 5.2745 & 4.4829 & 3.5726 & 2.3559 & 1.6236 & 1.5234 \\
\hline & 0.0513 & 0.0395 & 0.0313 & 0.0269 & 0.0443 & 0.0637 \\
\hline \multirow[t]{2}{*}{ Compound } & 4.4205 & 3.7595 & 3.1508 & 2.5672 & 1.8323 & 1.7744 \\
\hline & 0.0624 & 0.0299 & 0.0349 & 0.0400 & 0.0630 & 0.0690 \\
\hline \multirow[t]{2}{*}{ R15 } & 2.2226 & 2.0212 & 1.8005 & 1.4606 & 1.0730 & 0.9562 \\
\hline & 0.0722 & 0.0631 & 0.0368 & 0.0274 & 0.0613 & 0.1162 \\
\hline \multirow[t]{2}{*}{ D31 } & 4.7676 & 4.1204 & 3.3943 & 2.4569 & 2.0055 & 1.6793 \\
\hline & 0.0479 & 0.0352 & 0.0284 & 0.0207 & 0.0332 & 0.0394 \\
\hline \multirow[t]{2}{*}{ Iris } & 0.7709 & 0.6430 & 0.5353 & 0.4403 & 0.3773 & 0.3494 \\
\hline & 0.0739 & 0.0548 & 0.0689 & 0.0940 & 0.1196 & 0.1566 \\
\hline \multirow[t]{2}{*}{ Vowel } & 2.7459 & 2.5736 & 2.3755 & 2.2005 & 1.9150 & 1.7468 \\
\hline & 0.0537 & 0.0436 & 0.0412 & 0.0448 & 0.0494 & 0.0497 \\
\hline \multirow[t]{2}{*}{ Zoo } & 1.5841 & 1.4421 & 1.2468 & 1.0912 & 0.9790 & 0.9156 \\
\hline & 0.0343 & 0.0254 & 0.0169 & 0.0104 & 0.0162 & 0.0208 \\
\hline
\end{tabular}

Table 1.

Experiment results when fixed parameter $p=2$, change parameter $q$. 
Spiral, Jain, Compound, R15, D31, Iris, Vowel and Zoo. The parameters were used in the experiment as follows: network size: $10 \times 10$; initial neighborhood radius: 10 ; initial learning rate: 1 ; number of training times: 20,000 .

The experiments were conducted in two cases: case 1-fixed parameter $p$, changed parameter $q$; case 2-fixed parameter $q$, changed the parameter $p$.

Note: The results in Tables 1 and 2 are the average value of 10 experiment times. The result of each dataset presented in two rows: the first row shows $Q E$ and the second row displays $T E$.

Case 1: Parameter $p$ is fixed, parameter $q$ changed.

Table 1 shows the experimental results with parameter $p=2$ and change the value of parameter $q=0.5,2,4,8,12$.

We can see that $Q E$ is in a reverse ratio to $q$, when $q$ is bigger, $Q E$ is smaller, while $T E$ reaches the minimum value with $q=1,2,4$. This is especially true with the proposed analysis in Section 3.

The values in bold are the best results, in which: $T E$ is the smallest, $Q E$ is also smaller than the case of using the original neighborhood function $(q=0.5)$ (column 2, Table 1).

\begin{tabular}{|c|c|c|c|c|c|c|}
\hline$p$ & 1 & 2 & 3 & 4 & 5 & 6 \\
\hline \multirow[t]{2}{*}{$\operatorname{XOR}(q=1)$} & 0.1754 & 0.1587 & 0.1546 & 0.1518 & 0.1525 & 0.1513 \\
\hline & 0.0534 & 0.0203 & 0.0225 & 0.0244 & 0.0238 & 0.0255 \\
\hline \multirow[t]{2}{*}{ Aggregation $(q=4)$} & 2.7895 & 3.0003 & 3.2722 & 3.6436 & 3.6100 & 3.8718 \\
\hline & 0.0850 & 0.0300 & 0.0277 & 0.0273 & 0.0316 & 0.0282 \\
\hline \multirow[t]{2}{*}{ Flame $(q=4)$} & 1.1858 & 1.2105 & 1.2306 & 1.3158 & 1.4010 & 1.4209 \\
\hline & 0.1438 & 0.0405 & 0.0284 & 0.0304 & 0.0331 & 0.0330 \\
\hline \multirow[t]{2}{*}{ Pathbased $(q=4)$} & 2.5458 & 2.4759 & 2.7586 & 2.8462 & 2.9400 & 2.9928 \\
\hline & 0.1300 & 0.0313 & 0.0363 & 0.0351 & 0.0349 & 0.0304 \\
\hline \multirow[t]{2}{*}{ Spiral $(q=2)$} & 3.5976 & 3.4319 & 3.4334 & 3.4603 & 3.4926 & 3.5797 \\
\hline & 0.0690 & 0.0290 & 0.0265 & 0.0290 & 0.0261 & 0.0264 \\
\hline \multirow[t]{2}{*}{ Jain $(q=4)$} & 2.3664 & 2.3519 & 2.7136 & 2.9018 & 3.1494 & 3.3035 \\
\hline & 0.0896 & 0.0263 & 0.0270 & 0.0306 & 0.0402 & 0.0403 \\
\hline \multirow[t]{2}{*}{ Compound $(q=1)$} & 4.2063 & 3.7575 & 3.6224 & 3.4969 & 3.5082 & 3.4913 \\
\hline & 0.0666 & 0.0291 & 0.0337 & 0.0340 & 0.0373 & 0.0398 \\
\hline \multirow[t]{2}{*}{$\mathrm{R} 15(q=4)$} & 1.3161 & 1.4406 & 1.5544 & 1.6498 & 1.6972 & 1.7376 \\
\hline & 0.1055 & 0.0294 & 0.0367 & 0.0390 & 0.0454 & 0.0548 \\
\hline \multirow[t]{2}{*}{$\mathrm{D} 31(q=4)$} & 2.3832 & 2.4769 & 2.8137 & 2.9886 & 3.0686 & 3.1960 \\
\hline & 0.0803 & 0.0199 & 0.0227 & 0.0238 & 0.0259 & 0.0284 \\
\hline \multirow[t]{2}{*}{ Iris $(q=1)$} & 0.7140 & 0.6382 & 0.6166 & 0.6002 & 0.5880 & 0.5849 \\
\hline & 0.0665 & 0.0518 & 0.0555 & 0.0560 & 0.0572 & 0.0598 \\
\hline \multirow[t]{2}{*}{ Vowel $(q=2)$} & 2.3938 & 2.3715 & 2.4186 & 2.4310 & 2.4529 & 2.4627 \\
\hline & 0.0635 & 0.0410 & 0.0416 & 0.0414 & 0.0429 & 0.0455 \\
\hline \multirow[t]{2}{*}{$\operatorname{Zoo}(q=4)$} & 1.1817 & 1.0912 & 1.1780 & 1.1954 & 1.2015 & 1.2131 \\
\hline & 0.0366 & 0.0104 & 0.0182 & 0.0188 & 0.0176 & 0.0180 \\
\hline
\end{tabular}

Table 2.

Experiment results when change parameter $p$, fixed parameter $q$. 
Case 2: Parameter $q$ is fixed, parameter $p$ changes.

Table 2 shows the experimental results when fixes parameter $q$ of each dataset corresponding to the best value of $T E$ in Table 1 and respectively change the value of $p=1,2,3,4,5,6$.

When $p=1$ : both $Q E$ and $T E$ increase high.

When $p \geq 2$ : TE tends to be stable or increase slightly when $p$ rises. This shows that the parameter $p$ is negligibly significance in improving the topographical quality when identifying suitable parameter $q ; Q E$ tends to increase with the majority of datasets while increasing $p$ (excepting for the dataset XOR, Compound and Iris, $Q E$ tends to decrease, but $T E$ tends to increase). This suggests that, $p=2$ is the best value.

From Figures 5 to $\mathbf{1 6}$ are charts comparing the values of $Q E, T E$ when changing the parameters $q$ and $p$, in which: figures on the left (a) are the results when fixing $p=2$ and changing $q$; figures on the right (b) are the results when fixing $q$ and changing $p$. Parameter $q$ is selected by the corresponding value to achieve the smallest value of $T E$ in figure (a).

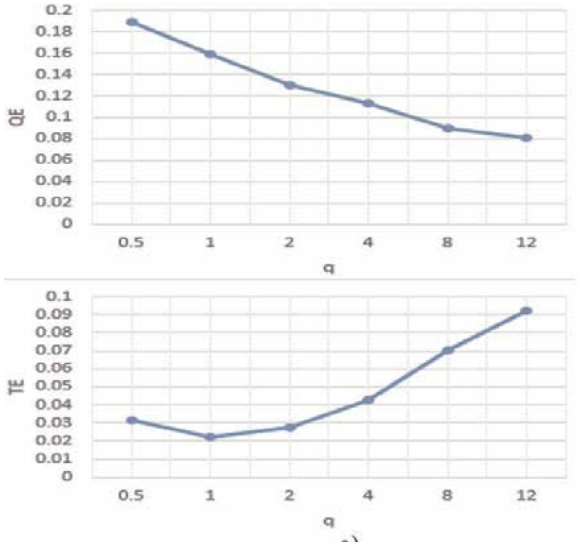

a)
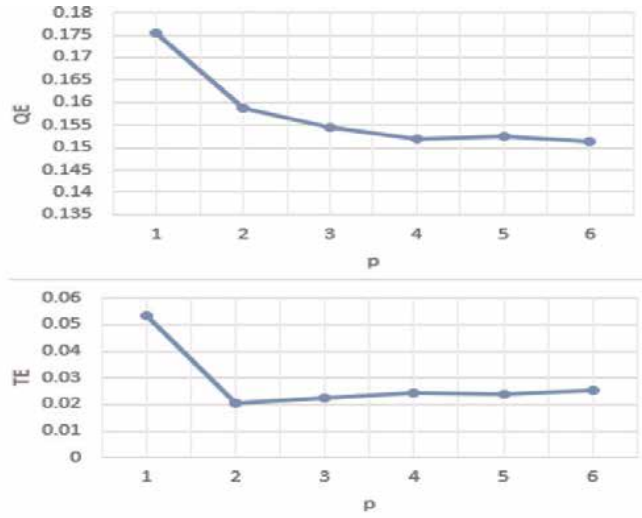

b)

Figure 5 .

$X O R$ dataset. (a) $p=2$ and $q$ changes and (b) $q=1$ and $p$ changes.
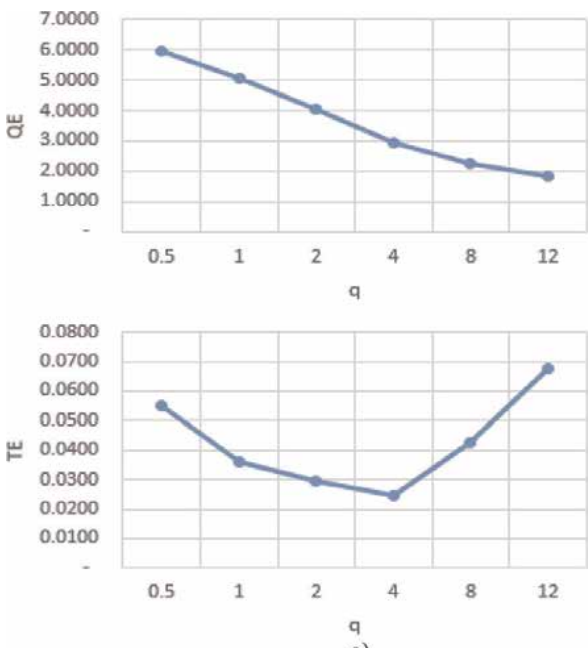

a)
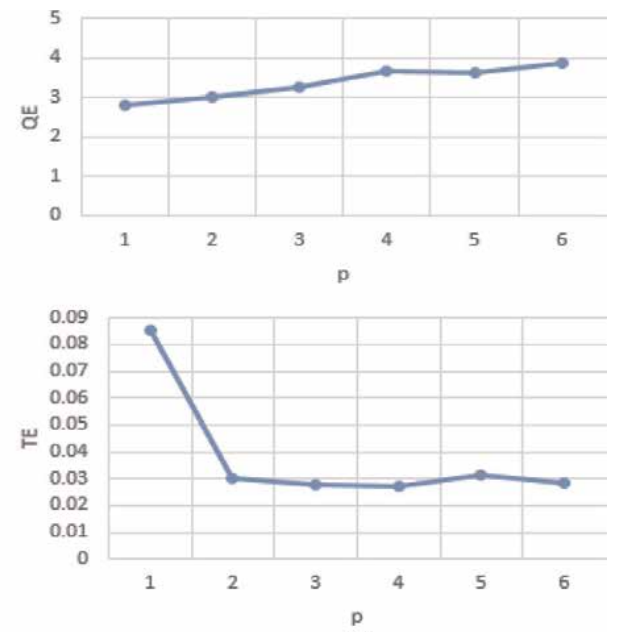

b)

Figure 6.

Aggregation dataset. (a) $p=2$ and $q$ changes and (b) $q=4$ and $p$ changes. 

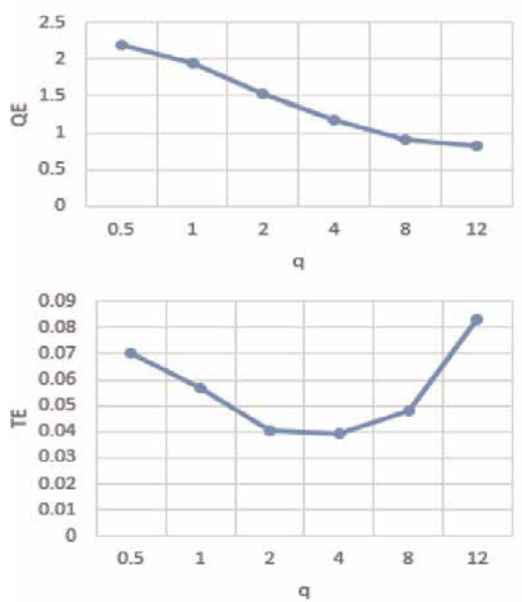

a)
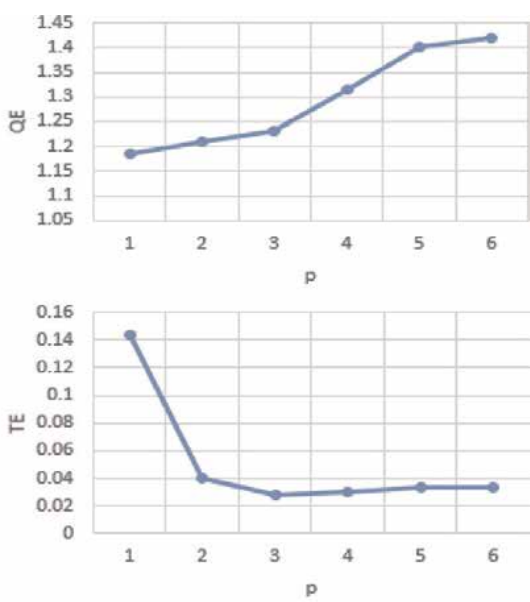

b)

Figure 7.

Flame dataset. (a) $\mathrm{p}=2$ and $\mathrm{q}$ changes and $(b) \mathrm{q}=4$ and $\mathrm{p}$ changes.
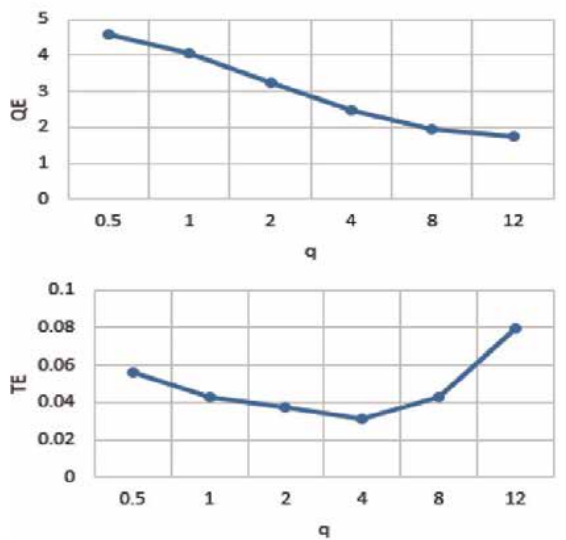

a)
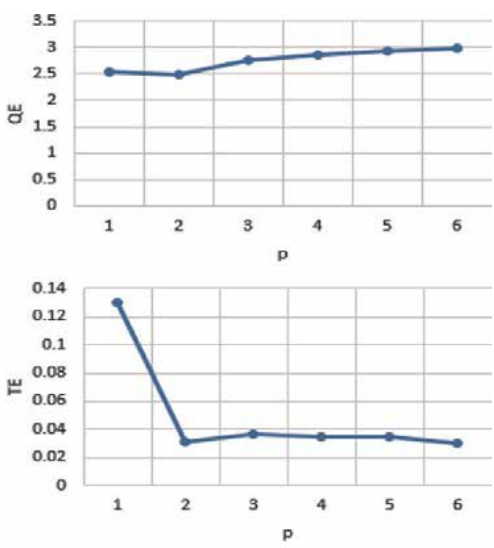

b)

Figure 8.

Pathbased dataset. (a) $p=2$ and $q$ changes and (b) $q=4$ and $p$ changes.
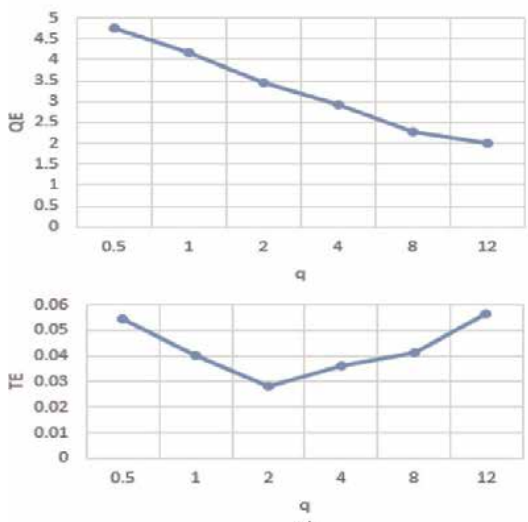

a)
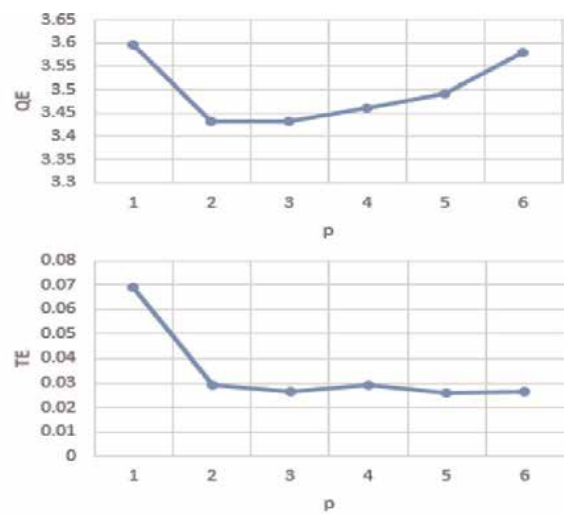

b)

Figure 9.

Spiral dataset. (a) $p=2$ and $q$ changes and b) $q=2$ and $p$ changes. 
Improving Feature Map Quality of SOM Based on Adjusting the Neighborhood Function DOI: http://dx.doi.org/10.5772/intechopen.89233
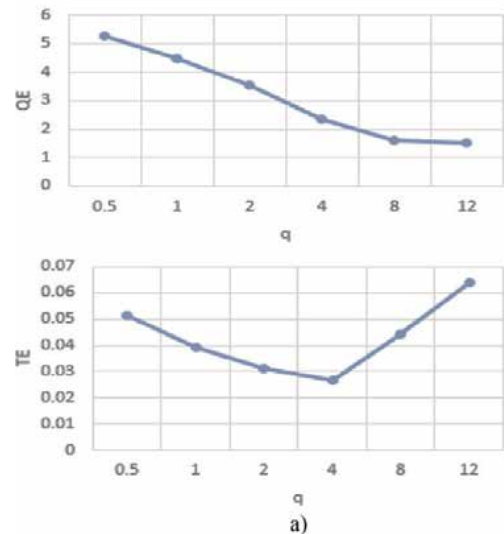
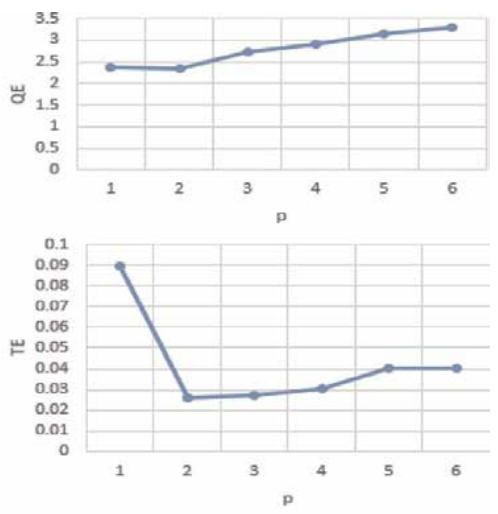

b)

Figure 10.

Jain dataset. (a) $p=2$ and $q$ changes and (b) $q=4$ and $p$ changes.
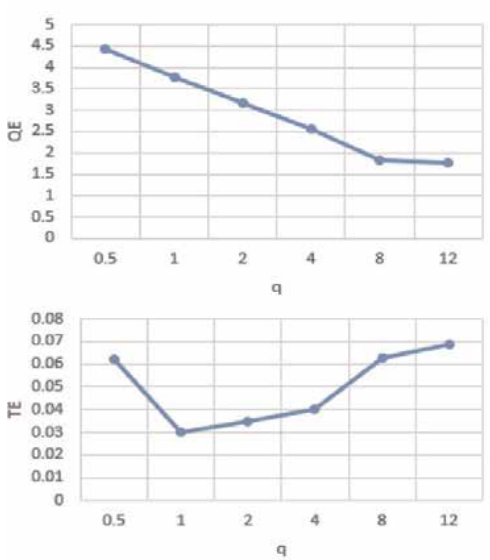

a)
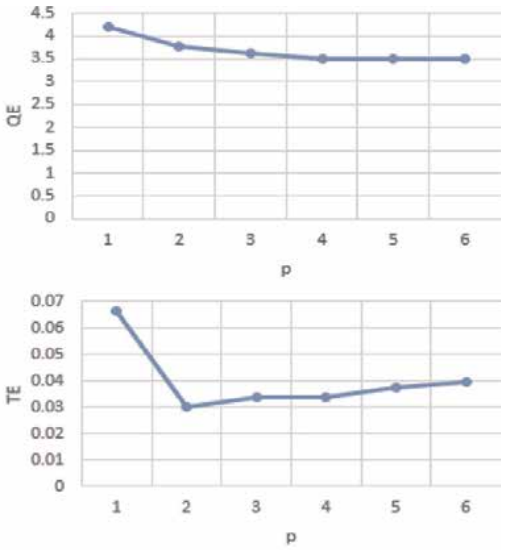

b)

Figure 11.

Compound dataset. (a) $p=2$ and $q$ changes and (b) $q=1$ and $p$ changes.
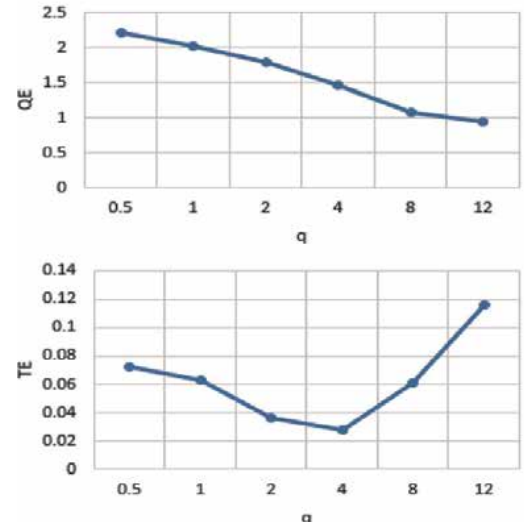

a)
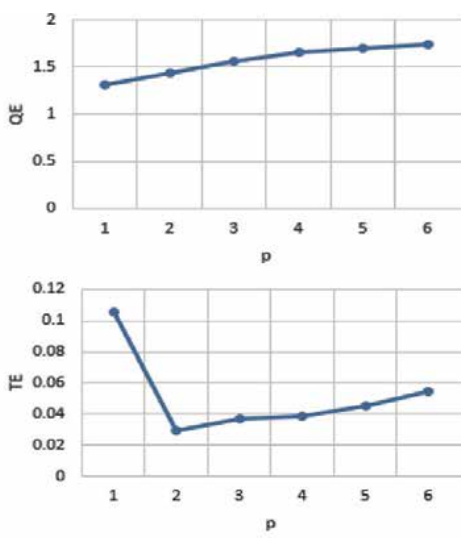

b)

Figure 12.

R15 dataset. (a) $p=2$ and $q$ changes and (b) $q=4$ and $p$ changes. 

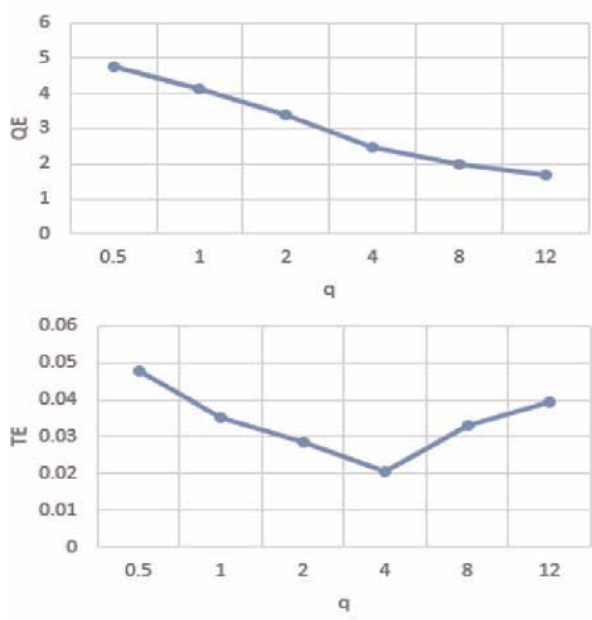

a)
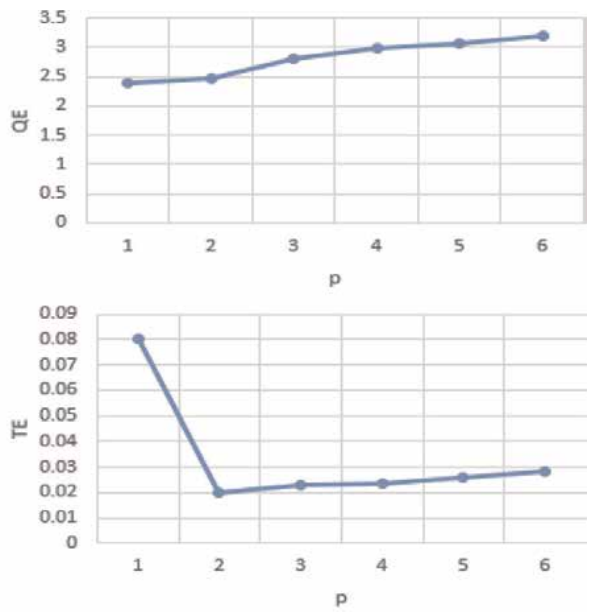

b)

Figure 13.

D31 dataset. (a) $p=2$ and $q$ changes and (b) $q=4$ and $p$ changes.
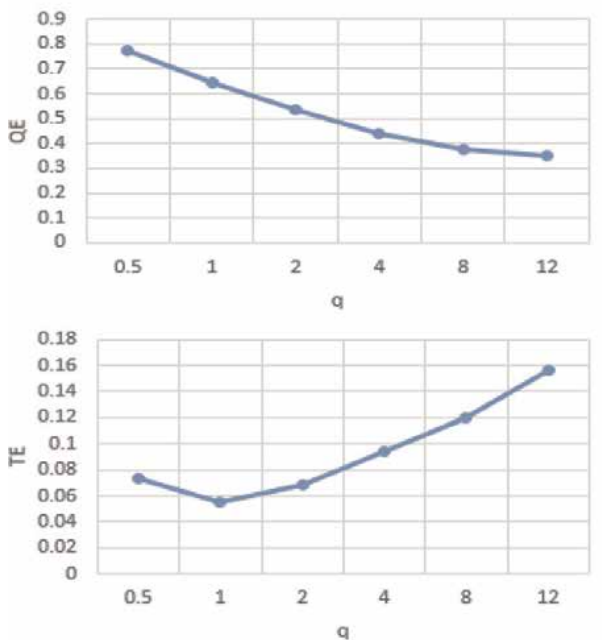

a)
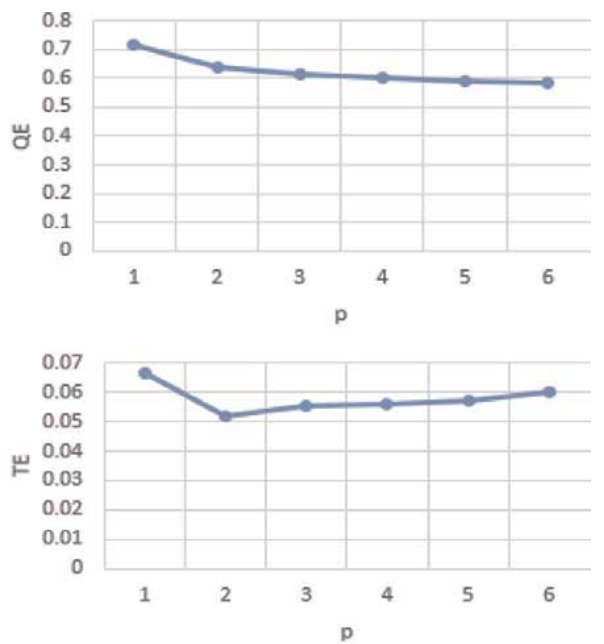

b)

Figure 14.

Iris dataset. (a) $p=2$ and $q$ changes and (b) $q=1$ and $p$ changes.

When putting parameter $p=2$ and changing parameter $q$, we see that the charts are similar (figure (a)—on the left), with $Q E$ is reduced gradually, $T E$ reduced at first, then increased inversely with $Q E$ when parameter $q$ increased gradually. $T E$ reaches the lowest value when $q \in[10,28]$.

When fixing parameter $q$ and changing the parameter $p$, the charts also have similarities (figure (b) —on the right), including: $T E$ is highest when $p=1$; both graphs of $Q E$ and $T E$ tend to stabilize or increase gradually with $p \geq 2$.

Conclusion: With $p=2$ (default value), the adjustment of the parameter $q$ has significantly impacted on the quality of the feature map. If $q$ is bigger, the $Q E$ is smaller. However, TE is lowest when $q$ is not too small or too large. Therefore, with $p=2$, parameter $q$ is the most suitable when its value is large enough to achieve the lowest value of TE. Conversely, if we have identified the most appropriate value of 
the parameter $q$, the parameter $p$ has little significant impact on improving the quality of the feature map.

Table 3 shows the results of $Q E, T E$ when using neighborhood function $h_{c i}^{\prime}(t)$ (with parameter $p=2$ and $q$ is determined for each dataset shown in Table 2) and some other neighborhood functions. Results show that the neighborhood function $h_{c i}^{\prime}(t)$ achieved $Q E, T E$ smaller than the original Gaussian function, Bubbles function and asymmetric neighborhood function.

Note: The results in Table 3 are the average value of 10 experiment times. The result of each dataset present in two rows: the first row shows $Q E$ and the second row displays $T E$.
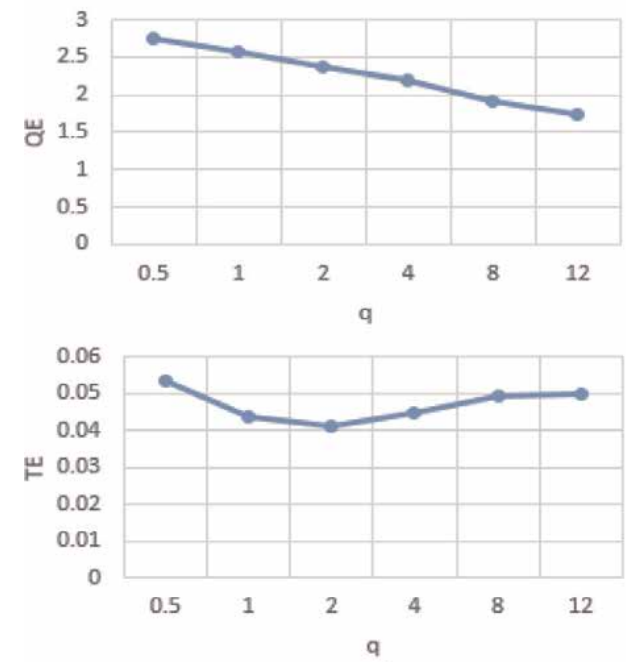

a)
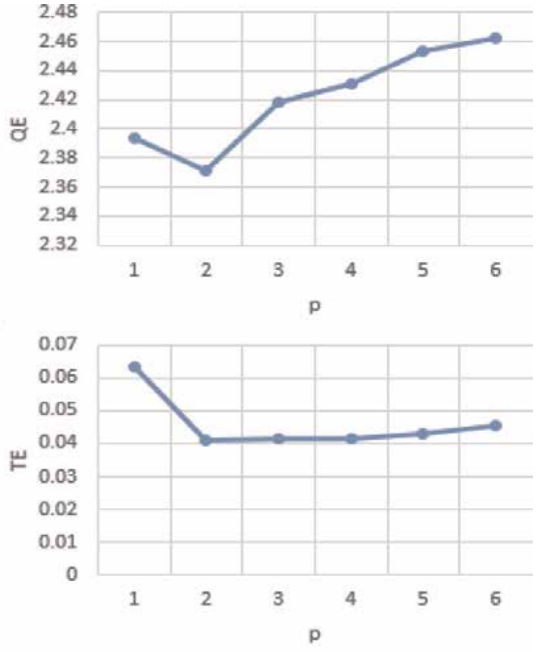

b)

Figure 15.

Vowel dataset. (a) $p=2$ and $q$ changes and (b) $q=2$ and $p$ changes.
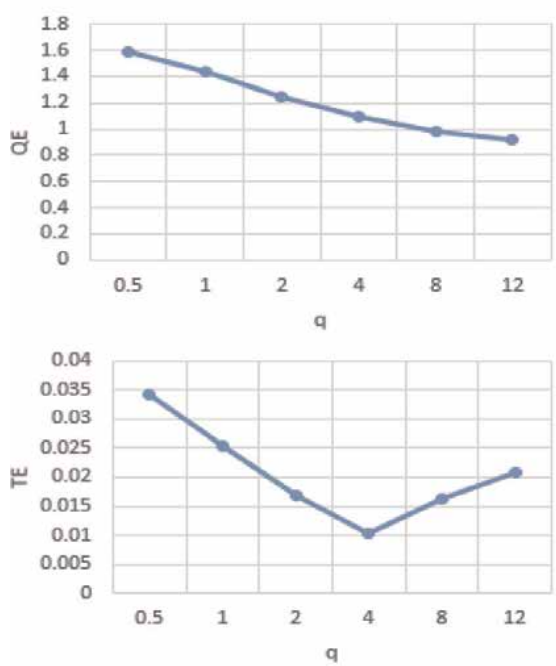

a)
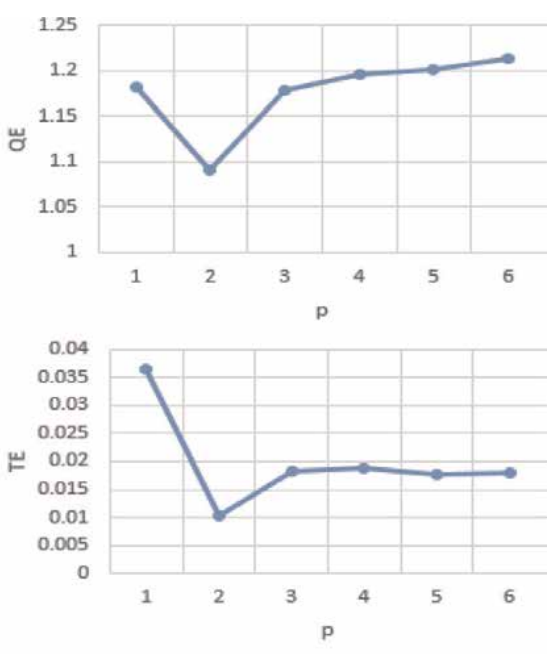

b)

Figure 16.

Zoo dataset. (a) $p=2$ and $q$ changes and (b) $q=4$ and $p$ changes. 


\begin{tabular}{|c|c|c|c|c|}
\hline Dataset & $h_{c i}(t)$ & $h_{c i}^{\prime}(t)$ & Bubble function & Asymmetric neighborhood function \\
\hline \multirow[t]{2}{*}{ XOR } & 0.1890 & 0.1585 & 0.2572 & 0.1808 \\
\hline & 0.0318 & 0.0223 & 0.2708 & 0.4635 \\
\hline \multirow[t]{2}{*}{ Aggregation } & 5.9702 & 2.9340 & 7.3092 & 4.9466 \\
\hline & 0.0549 & 0.0245 & 0.1794 & 0.4476 \\
\hline \multirow[t]{2}{*}{ Flame } & 2.1839 & 1.1822 & 2.6352 & 2.1916 \\
\hline & 0.0700 & 0.0393 & 0.1642 & 0.6828 \\
\hline \multirow[t]{2}{*}{ Pathbased } & 4.5859 & 2.4779 & 5.524 & 5.3888 \\
\hline & 0.0561 & 0.0315 & 0.1981 & 0.2715 \\
\hline \multirow[t]{2}{*}{ Spiral } & 4.7595 & 3.4675 & 5.6515 & 4.3775 \\
\hline & 0.0543 & 0.0284 & 0.1502 & 0.6306 \\
\hline \multirow[t]{2}{*}{ Jain } & 5.2745 & 2.3559 & 6.3026 & 5.4962 \\
\hline & 0.0513 & 0.0269 & 0.2024 & 0.3172 \\
\hline \multirow[t]{2}{*}{ Compound } & 4.4205 & 3.7595 & 5.5663 & 3.5529 \\
\hline & 0.0624 & 0.0299 & 0.2199 & 0.4349 \\
\hline \multirow[t]{2}{*}{ R15 } & 2.2226 & 1.4606 & 2.5017 & 1.8911 \\
\hline & 0.0722 & 0.0274 & 0.1384 & 0.6337 \\
\hline \multirow[t]{2}{*}{ D31 } & 4.7676 & 2.4569 & 5.6095 & 5.958 \\
\hline & 0.0479 & 0.0207 & 0.2054 & 0.3506 \\
\hline \multirow[t]{2}{*}{ Iris } & 0.7709 & 0.6430 & 1.001 & 0.9284 \\
\hline & 0.0739 & 0.0548 & 0.2312 & 0.2610 \\
\hline \multirow[t]{2}{*}{ Vowel } & 2.7459 & 2.3755 & 3.1022 & 2.8808 \\
\hline & 0.0537 & 0.0412 & 0.1872 & 0.3965 \\
\hline \multirow[t]{2}{*}{ Zoo } & 1.5841 & 1.0912 & 1.7182 & 1.7179 \\
\hline & 0.0343 & 0.0104 & 0.2182 & 0.2210 \\
\hline
\end{tabular}

Table 3.

Compares measures $Q E, T E$ of some neighborhood functions.

\section{Conclusion}

This chapter proposes the parameter for adjustment of the Gaussian symmetric neighborhood function. Our parameter adjusting method can reduce both $Q E$ and $T E$ of the feature map. However, the value of parameter must be determined individually for each specific dataset. The improved Gaussian function is better than the original Gaussian function and some other neighborhood functions like Bubble function, asymmetric neighborhood function. 
Improving Feature Map Quality of SOM Based on Adjusting the Neighborhood Function DOI: http://dx.doi.org/10.5772/intechopen.89233

\section{Author details}

Le Anh Tu

Halong University, Vietnam

*Address all correspondence to: anhtucntt@gmail.com

\section{IntechOpen}

(C) 2019 The Author(s). Licensee IntechOpen. This chapter is distributed under the terms of the Creative Commons Attribution License (http://creativecommons.org/licenses/ by/3.0), which permits unrestricted use, distribution, and reproduction in any medium, provided the original work is properly cited. (c) BY 


\section{References}

[1] Lonsway B, Mulky AR. A selforganizing neural system for urban design. In: Proceedings of the Twenty First Annual Conference of the Association for Computer-Aided Design in Architecture; 11-14 October 2001; Buffalo (New York). pp. 386-391

[2] Arribas-Bel D, Schmidt CR. Selforganizing maps and the US urban spatial structure. Environment and Planning B: Urban Analytics and City Science. 2013;40(2):362-371

[3] Kropp J. A neural network approach to the analysis of city systems. Applied Geography. 1998;18(1):83-96

[4] Neme O, Pulido JRG, Neme A. Mining the city data: Making sense of cities with self-organizing maps. In: WSOM 2011: Advances in SelfOrganizing Maps. Springer; 2011. pp. 168-177

[5] Mayaud JR, Anderson S, Tran M, Radić V. Insights from self-organizing maps for predicting accessibility demand for healthcare infrastructure. Urban Science. 2019;3(1):33. DOI: 10.3390/urbansci3010033

[6] Bauer H, Pawelzik K. Quantifying the neighborhood preservation of self organizing feature maps. IEEE

Transactions on Neural Networks. 1992; 3(4):570-579

[7] Kahraman C. In: Kahraman CE, editor. Computational Intelligence Systems in Industrial Engineering. 1st ed. Vol. 6. Atlantis Press; 2012. pp. 295-315

[8] Polani D. Measures for the organization of self-organizing maps. In: Studies in Fuzziness and Soft Computing. Vol. 78. Springer; 2002. pp. 13-44

[9] Uriarte E, Martín DF. Topology preservation in SOM. International
Journal of Applied Mathematics and Computer Science. 2005;1(1):19-22

[10] Berglund E, Sitte J. The parameterless self-organizing map algorithm. IEEE Transactions on Neural Networks. 2006;17(2):305-316

[11] Kohonen T. Self-Organizing Maps. 3rd ed. Springer-Verlag; 2001

[12] Bauer H, Herrmann M, Villmann T. Neural maps and topographic vector quantization. Neural Networks. 1999;12 (4-5):659-676

[13] Kiviluoto K. Topology preservation in self-organizing maps. In: Neural Networks, IEEE International Conference on (ICNN96), Volume 1; June 3-6 1996; Washington, DC: IEEE; 1996. pp. 294-299

[14] Mwasiagi JI, XiuBao H, XinHou W, Qing-dong C. The use of K-means and Kohonen self organizing maps to classify cotton bales. In: Beltwide Cotton Conferences (BWCC'07); 9-12 January 2007; New Orleans, Louisiana; 2007

[15] Flanagan JA. Self-organization in Kohonen's SOM. Neural Networks. 1996;9(7):1185-1197

[16] Germen E. A novel approach for learning rate in self orginizing map (SOM), anadolu University. Journal of Science and Technology - Application of Science and Engineering. 2018;19(1): 144-152

[17] Mulier F, Cherkassky V. Statistical analyses of self-organization. Neural Networks. 1995;8(5):717-727

[18] Wang S, Wang H. Knowledge discovery through self-organizing maps: Data visualization and query processing. Knowledge and Information Systems. 2002;4(1):31-45 
[19] Chattopadhyay M, Dan PK, Mazumdar S. Application of visual clustering properties of self organizing map in machine-part cell formation. Applied Soft Computing. 2012;12(2): 600-610

[20] Polzlbauer G. Survey and comparison of quality measures for selforganizing maps. In: Paralic J, Polzlbauer G, Rauber A, editors. In: Proceedings of the Fifth Workshop on Data Analysis (WDA-04); 24-27 June 2004; Sliezsky dom, Vysoke Tatry, Slovakia: Elfa Academic Press; 2004. pp. 67-82

[21] Sun Y. On quantization error of selforganizing map network.

Neurocomputing. 2000;34(1-4):169-193

[22] Germen E. Increasing the topological quality of Kohonen's self organizing map by using a hit term. In: Neural Information Processing, Proceedings of the 9th International Conference on (ICONIP'02), Volume 2; 2002. pp. $930-934$

[23] Germen E. Improving the resultant quality of Kohonens self organizing map using stiffness factor. In: Advances in Natural Computation, Lecture Notes in Computer Science (First International Conference, ICNC 2005), Volume 3610; August 27-29 2005; Changsha, China: Springer, Berlin, Heidelberg; 2005. pp. 353-357

[24] Neme A, Chavez E, Cervera A, Mireles V. Decreasing neighborhood revisited in selforganizing map. In: Artificial Neural Networks-ICANN 2008, Volume 5163; 3-6 September 2008; Prague, Czech Republic: Springer, Berlin, Heidelberg; 2008. pp. 671-679

[25] Neme A, Miramontes P. Selforganizing map formation with a selectively refractory neighborhood. Neural Processing Letters. 2014;39(1): 1-24
[26] Kamimura R. Input information maximization for improving selforganizing maps. Applied Intelligence. 2014;41(2):421-438

[27] Lopez-Rubio E. Improving the quality of self-organizing maps by selfintersection avoidance. IEEE

Transactions on Neural Networks and Learning Systems. 2013;24(8):1253-1265

[28] Aoki T, Aoyagi T. Self-organizing maps with asymmetric neighborhood function. Neural Computation. 2007;19: 2515-2535

[29] Ota K, Aoki T, Kurata K, Aoyagi T. Asymmetric neighborhood functions accelerate ordering process of selforganizing maps. Physical Review. 2011; 83(2-1):1-9

[30] Lee JA, Verleysen M. Selforganizing maps with recursive neighborhood adaptation. Neural Networks. 2002;15:993-1003 



\title{
Procedure to Prepare and Model Speed Data Considering the Traffic Infrastructure, as Part of a Cyber-Physical System
}

\author{
José Gerardo Carrillo-González, \\ Jacobo Sandoval-Gutiérrez and Francisco Pérez-Martínez
}

\begin{abstract}
This chapter investigates the relationship between traffic control infrastructure (traffic lights and speed bumps) and the vehicles' travel speeds, for certain hours and days of the week. The authors propose the following procedures: (1) street segmentation, (2) clustering and categorization of speed data, (3) histograms' comparison analysis, (4) outlier detection, (5) modeling, and (6) delivering info to the users. Comparing speed histograms, segments with matching infrastructure presented similarities, regardless of the day of the week. Two techniques to model data were employed: polynomial regression and multinomial logistic regression. The algorithms to predict the travel speed category were also developed. The first technique yields on average $91.3 \%$ of data categorized correctly, and the second gets $90.09 \%$. The traffic lights and speed bumps, located on the street segments under consideration, were identified as variables causing different travel speeds. The procedure allows to incorporate more traffic elements and can also be applied to other geographical locations.
\end{abstract}

Keywords: cyber-physical system, speed bumps, street segments, traffic lights, travel speed

\section{Introduction}

Traffic conditions have a profound effect on population's quality life. The TomTom traffic index states that in 2017, Mexico City had a travel delay of $66 \%$ when compared with normal times of uncongested traffic, placing it as the first in the world rank. The wasted time per day was $59 \mathrm{~min}$, or $227 \mathrm{~h}$ per year, with delays in the morning and evening peaks of about $100 \%$. Of the 23 million private cars in Mexico, $72 \%$ correspond to metropolitan areas [1]. As a result, those areas are a suitable choice to analyze traffic behavior. In 2010, with a population of 20,116,842 and 0.3 cars per habitant (about 6,035,052 cars), the Mexico City Valley is the most crowded of the country. The number of operating vehicles in a city reduces the average traveling speed and increases pollution $[2,3]$ and the number of car accidents $[4,5]$. The zone under study in this work is located between Mexico City and 
Toluca, a region that is part of the Mexico City megalopolis, which makes the area a suitable candidate for analyzing traffic conditions. In this research we developed a procedure to analyze speed tendencies (by comparing histograms) and prepare (set clusters and remove anomalies) and model speed data to be used in an application example: speed prediction. The procedure answers the following question: what is the pathway to generate new information when speed data is available?

Recently, there has been a great effort in studying and analyzing traffic data from different world locations. Travel speed is one way to measure traffic conditions, as is travel time. In [6], the travel time distribution for different kinds of roads is estimated for Beijing. The time intervals to analyze data were set to $15 \mathrm{~min}$, and it was concluded that the best-fitting distribution depends on the congestion level and that the average travel time of all road segments (for all days) can be estimated with acceptable precision using the normal distribution (compared with the log-normal, gamma and Weibull). In [7], travel time prediction is pursued. The variables considered were flow, concentration, and higher order auto-regression, concluding that local linear regression is preferable than global modeling. Characterization of the daily temporal variation of congestion is presented in [8], where a fitted model and live data are combined in a ten-parameter exponential smoothing equation. With the purpose of analyzing historical traffic data, a query processing method with timeline information is proposed in [9], along with an analysis of the congestion dependency along roads. The work presented in [10] estimates the average link speed with vehicles equipped with GPS, and therefore the quantity of equipped vehicles required for estimating the speed was established.

Using traffic data to make predictions is a current challenge, as Google maps traffic and Waze are doing. The purpose in [11] is to use information from Bing Maps to analyze, visualize, and predict traffic jams in Chicago. In addition, a prediction model to correct flow intensities with logistic regression was proposed, where the independent variables were day, hour, street number, and number of pixels (red, yellow, and green). In this work, a tool was developed to extract the roads' traffic intensity from a GIS map service, where colors represent flow intensity: red as congested, green not congested, and yellow in between. In [12], the properties of a community-driven mapping service (Waze) are characterized. Additionally, the authors discuss the use of traffic data to identify traffic accidents and potholes. In [13], a four-phase traffic approach is proposed: (1) data collection and representation, (2) traffic prediction, (3) vehicle selection for re-routing, and (4) alternative route assignment. In our work, we focus our contribution in the first two phases.

The traffic infrastructure elements (such as traffic lights, speed bumps, potholes) involved in driving situations influence driver's behavior, which in turn affects speed and number of accidents. The intention in [14] is the development of statistical models to predict accidents. These models correlate highway characteristics with traffic accidents. The variables considered were classified in groups: section identifiers, cross section related, location, traffic related (e.g., the percentage of trucks on a highway section), alignment, horizontal curvature, and accidents. The regression methods used were Poisson and negative binomial. The statistically significant variables were number of lanes, horizontal curvature, speed limit, tangent length, section length, average annual daily traffic, and peak hour. In addition, accidents are predicted with equations that consider roadway elements such as average daily traffic, commercial and residential units, intersections, speed limits, lane width, and number of lanes.

The work presented in [15] classifies traffic control elements (infrastructure) into three groups according to their effect on accidents. In Group 1 are those elements that reduce the number of accidents, such as speed limit signs, 
speed-reducing devices, signalized pedestrian crossings, urban play streets, pedestrian streets, traffic-calming areas, traffic signals at intersections, bus lines and bus stops, parking control, and access control. Group 2 has no statistical effect on accidents: road markings, one-way streets, reversible lanes, traffic control for pedestrians and cyclists, priority control, and yield signs at intersections. Group 3 increases accidents: right turn on red, pedestrian crossing without signs, blinking traffic light, and increasing speed limits. According to [16], the presence of traffic control elements with the purpose to reduce speed or simplify the road users' tasks (e.g., traffic signs) tends to reduce accidents. An obvious consequence of the presence of speed-reducing devices (humps, rumble strips, narrow road width, bollards) is the increase of travel time [17] and the decrease of the average travel speed. One of the conclusions in [15] is that the traffic control elements that reduce accidents also reduce mobility.

Traffic elements such as signals and traffic lights are important in human driving decisions. The work presented in [18] intends to determine the relevance of the static road elements in driving situations using Markov logic networks (MLNs). The information considered to determine the relevance of speed limits and supplementary signs were the position in relation to lanes, vehicle type, date, time, and weather. Then, with first-order logic rules, the relevance of each was inferred. To determine the relevance of traffic lights, the following variables were considered: navigation system, environment perception, spatial relations, and the traffic light state.

The speed changes in the presence of speed bumps were analyzed in [19]. The speed limit on the streets under study is $50 \mathrm{~km} / \mathrm{h}$. The speed results measured at the bump location are as follows: about $30 \%$ of the cases show an 85 th percentile speed higher than the posted limit speed, $26 \%$ lie in the range $45-50 \mathrm{~m} \mathrm{~km} / \mathrm{h}$, and the rest is under $45 \mathrm{~km} / \mathrm{h}$. The 85 th percentile speed (measured after $20-25 \mathrm{~m}$ of the bumps' location, at the crosswalk area) tends to increase in $50 \%$ of the tested sites, similar result for the 50th percentile case (45\%). Nevertheless, for both cases the speed change was not significant, according to the statistical analysis. Another result was obtained comparing the speed at bumps and $100 \mathrm{~m}$ away: in most sites, the 85th percentile speed decreases in the range of $1-18 \%$ (with respect to the zone without bumps). The statistical analysis concludes for both percentiles that speed values do not change significantly.

The use of cyber-physical system in traffic is a current topic in the literature. In [20], a simulated vehicular cyber-physical system (VCPS) is designed for delivering warnings to the driver and to avoid accidents. With this end, the predicted vehicle motion/location, the driver behavior and the road geometry were considered. Then, the short-term motion of the objective vehicle and the surrounding vehicles are predicted. With the objective vehicle location and the traveled distance among vehicles, the collision risk is estimated, and the driver is notified. In [21], a perceptual Control Architecture of Cyber-Physical Systems (CPSs) is proposed, taking as example a traffic incident management system. The intelligent behavior of this is characterized by the physical-reflex space and cyber-virtual space. In the physicalreflex space, the sensing actuation of the objective scenario is constructed on four levels of traffic infrastructure. In the cyber-virtual space, the decisions (through Bayesian reasoning network) are defined according to three levels: principles, interrelated factors, and situation assessment. In [22] the potential participation of smartphones (equipped with GPS) is discussed to build a traffic information system (to inform the entire transportation network) that is part of the cyber-physical infrastructure system. In [23] a cloud-based cyber-physical system is presented, with the end to find fast routes for the users. The system is presented in four steps: (1) the GPS on taxis are used as mobile sensors to measure the traffic status in the 
physical world; (2) the info generated by the taxis is sent to the cloud (cyber world) and mined, and then knowledge is acquired about the taxis' preferred directions and traffic patterns on the roads; (3) the knowledge in the cloud is sent to the users with the Internet; and (4) the recommendations for a specific user are improved using its driving behavior and preferred routes. In [24], a short-term traffic prediction model (combining fuzzy theory with Markov progress) is presented, which is part of a vehicular cyber-physical system; the prediction results are expressed in terms of traffic flow and speed. A proper discussion about the definition of a cyberphysical system, and its relationship with transportation, is in [25].

From a cyber-physical system point of view, in the procedure presented in this work, the cyber part corresponds to the elements in charge to acquire and mine data for generating knowledge and the process to communicate that Intel to the users. The user (a biological entity) and intelligent devices (e.g., the user smartphone, the vehicle computer) reacting in response of the knowledge correspond to the physical part.

The aim of the present work is to introduce a method for analyzing speed data measured on streets where the traffic infrastructure is assumed to be the cause of low speeds. Then, we develop models and algorithms that, working with our data, allow to make predictions. The procedure presented in this work is summarized in the following steps:

- Street segmentation is performed considering traffic control elements (speed bumps and traffic lights).

- Clustering speed data, validated with the silhouette metric.

- With the Chi-Square distance $\left(\chi^{2}\right)$, the travel speed histograms of weekdays are compared and also the histograms of segments.

- Mahalanobis distance is used to detect outliers.

- Two techniques (polynomial and logistic regression) were used to develop the models that describe speed data. An algorithm for each modeling technique was developed to predict travel speed.

- Communicate the generated knowledge to the users.

This chapter is organized as follows: Section 1 Introduction; Section 2 Method, which includes theoretical frame (data, clusters, histograms, outliers) and procedure (street segmentation, clustering, comparative analysis of histograms, outlier detection, mathematical models, connecting Intel with users); Section 3 Results (with discussion); and Section 4 Conclusions (with future work).

\section{Method}

\subsection{Theoretical frame}

\subsubsection{Data}

The zone under study is comprised of two streets located in Lerma de Villada, Mexico: Av. Miguel Hidalgo and Av. Reolin Barejon. Data was obtained using the Google Maps Directions API. The time for a vehicle to traverse each segment was 
recorded every $15 \mathrm{~min}$, after [6]. We found this time interval to be highly efficient for incorporating relevant data while ignoring redundant information. In this way, the average travel speed on each segment was measured. Three weeks $\left(w_{1}, w_{2}\right.$, and $w_{3}$ ) of data were considered: $w_{1}$ from Dec 27, 2016 to Jan 03, 2017; $w_{2}$ from Jan 03, 2017 to Jan 10, 2017; and $w_{3}$ from Jan 20, 2017 to Jan 27, 2017. The time interval to acquire data was from 6 a.m. to 11:59 p.m. (an interval of $18 \mathrm{~h}$ per day) and only in weekdays, i.e., between Monday and Friday.

\subsubsection{Clusters}

The $k$-means technique [26] was selected (because it is easy to implement and is commonly used in distinct traffic problems [27-29]) to cluster the speed data of any of the 3 weeks; since these are close in time, it is expected a similar travel speed from 1 week to another, and then we select $w_{1}$. In simple terms, the $k$-means technique consists in calculating the centroid of each cluster as the mean of the data in the corresponding cluster and is recalculated until convergence.

We apply the $k$-means technique selecting a number of clusters in the range 3-6; for each case we calculate the silhouette score [30], given in Eq. (1), where $a(i)$ is the average distance from $i$ with the data in the same cluster, $b(i)$ is the minimum average distance from $i$ with the data of each other's cluster, and $i$ is the data index. The silhouette score is in the range -1 to +1 ; a value close to 1 indicates that the speed data is well matched in the selected clusters, while a value close to -1 indicates the opposite situation:

$$
s s(i)=\frac{b(i)-a(i)}{\max \{a(i), b(i)\}}
$$

\subsubsection{Histograms}

Analyzing the speed frequency, by comparing speed histograms of certain locations (special selection) and certain time (temporal selection), we expected to find spatial and temporal relationship about the weekdays when the speed is similar (dissimilar) and the segments where the speed is similar (dissimilar).

The metric employed to compare a pair of histograms is the Chi-Square $\left(\chi^{2}\right)$ histogram distance [31], given in Eq. (2), where P and $\mathrm{Q}$ are the histograms to be compared and $P_{i}$ and $Q_{i}$ contain the speed frequency of the $i$ bin ( $i$ is the bin index, the selected bin width is 1 ):

$$
\chi^{2}(\mathrm{P}, \mathrm{Q})=\frac{1}{2} \sum_{i} \frac{\left(P_{i}-Q_{i}\right)^{2}}{\left(P_{i}+Q_{i}\right)}
$$

This metric has the advantage of reducing the importance of the result when bins with large count are compared, as in many natural histograms, the difference of bins with high values is less important [31]. If the metric gets a 0 result, then there is no difference between the compared histograms; as the result value becomes larger, the difference in terms of the speed frequency also becomes higher.

\subsubsection{Outliers}

We filtered the speed data using the Mahalanobis distance (MD) [32] to detect outliers, i.e., atypical speed not belonging to normal driving behavior, since we are not interested in including this data for modeling. The MD is presented in Eq. (3), 
where $x_{i}$ is a vector containing the time and speed, $\bar{x}$ is a vector with the means, and $C_{x}^{-1}$ is the covariance matrix:

$$
M D_{i}=\sqrt{\left(x_{i}-\bar{x}\right)^{T} C_{x}^{-1}\left(x_{i}-\bar{x}\right)}
$$

\subsection{Procedure}

\subsubsection{Street segmentation}

The avenues under study were divided into segments: each segment is denoted $s_{k}$, with $k$ as the segment index. On each segment, we have number of speed bumps $c_{1}$, number of traffic lights $c_{2}$, and landmarks $c_{3}$. A segment's length $l$ is set to approximately $500 \mathrm{~m}$, and then on each segment there are specific traffic elements: $s_{k}=\left\{c_{1}, c_{2}, c_{3}, l\right\}$, as shown in Table 1 .

\subsubsection{Clustering}

The silhouette score, considering three clusters, is better evaluated, with $s s=0.7360$. For four, five, and six clusters, we calculated a $s s=0.7331, s s=0.7194$, and $s s=0.7105$, respectively. As we were interested in communicating in a simple way the speed category at which is possible to travel, three options (as slow, medium, and normal) seem adequate. A similar approach in Google Maps (traffic option), where the speed is represented considering four options, from fast to slow.

The resultant average speed (in $\mathrm{km} / \mathrm{h}$ ) range of each cluster (or category) is category 1 (5.4112-18.1455), category 2 (18.1455-23.4234), and category 3 (23.4234-36.0750). For $w_{2}$ and $w_{3}$, values smaller than 5.4112 fall into category 1 , and those larger than 36.0750 fall into category 3 .

The percentage of a segment's speed data (from $w_{1}$ ) in a cluster is shown in

Table 2. It is interesting to note that for all segments, there is a specific cluster that

\begin{tabular}{|c|c|c|c|c|c|c|}
\hline$s_{k}$ & $c_{1}$ & $c_{2}$ & $c_{3}$ & $l(\mathbf{m})$ & $\begin{array}{l}\text { GPS start } \\
\text { coordinate }\end{array}$ & $\begin{array}{l}\text { GPS end } \\
\text { coordinate }\end{array}$ \\
\hline$s_{0}$ & 2 & 0 & None & 501 & $\begin{array}{l}19.284512 \\
-99.500927\end{array}$ & $\begin{array}{l}19.285725 \\
-99.505498\end{array}$ \\
\hline$s_{1}$ & 2 & 0 & $\begin{array}{c}\text { School, museum, gas station, government } \\
\text { offices }\end{array}$ & 500 & $\begin{array}{c}19.285725 \\
-99.505498\end{array}$ & $\begin{array}{l}19.286330 \\
-99.510221\end{array}$ \\
\hline$s_{2}$ & 0 & 1 & $\begin{array}{c}\text { Banks, center square, school, fast-food } \\
\text { restaurants }\end{array}$ & 500 & $\begin{array}{l}19.286330 \\
-99.510221\end{array}$ & $\begin{array}{l}\text { 19.286711, } \\
-99.514964\end{array}$ \\
\hline$s_{3}$ & 3 & 2 & $\begin{array}{l}\text { Cultural center, hospital, school offices, } \\
\text { kindergarten }\end{array}$ & 501 & $\begin{array}{c}19.286711 \\
-99.514964\end{array}$ & $\begin{array}{l}19.286477, \\
-99.519630\end{array}$ \\
\hline$s_{4}$ & 3 & 0 & Telecom company offices, shopping mail & 499 & $\begin{array}{l}19.286477 \\
-99.519630\end{array}$ & $\begin{array}{l}19.285784 \\
-99.514944\end{array}$ \\
\hline$s_{5}$ & 2 & 1 & $\begin{array}{l}\text { Hospital, government offices, cultural } \\
\text { forum }\end{array}$ & 500 & $\begin{array}{c}19.285784 \\
-99.514944\end{array}$ & $\begin{array}{l}19.284943 \\
-99.510282\end{array}$ \\
\hline$s_{6}$ & 4 & 1 & School, supermarket, hospital & 500 & $\begin{array}{l}\text { 19.284943, } \\
-99.510282\end{array}$ & $\begin{array}{l}\text { 19.284500, } \\
-99.505561\end{array}$ \\
\hline$s_{7}$ & 2 & 0 & None & 481 & $\begin{array}{l}19.284500 \\
-99.505561\end{array}$ & $\begin{array}{l}19.284403 \\
-99.500993\end{array}$ \\
\hline
\end{tabular}

Table 1.

Segments' characteristics. 
Procedure to Prepare and Model Speed Data Considering the Traffic Infrastructure, as Part... DOI: http://dx.doi.org/10.5772/intechopen.88280

\begin{tabular}{cccc}
\hline Segment & Cluster 1 (\%) & Cluster 2 (\%) & Cluster 3 (\%) \\
\hline$s_{0}$ & 0.55 & 9.9 & 89.53 \\
\hline$s_{1}$ & 11.84 & 80.71 & 7.43 \\
\hline$s_{2}$ & 88.98 & 11.01 & 0 \\
\hline$s_{3}$ & 93.66 & 6.33 & 0 \\
\hline$s_{4}$ & 14.04 & 85.95 & 0 \\
\hline$s_{5}$ & 79.61 & 20.38 & 0 \\
\hline$s_{6}$ & 83.47 & 16.52 & 0 \\
\hline$s_{7}$ & 4.13 & 3.85 & 92.01 \\
\hline
\end{tabular}

Table 2.

Percentage of speed data in a cluster.

contains a high percentage of data (at least 79.61\%), which validates our clustering results.

\subsubsection{Comparative analysis of histograms}

First, we consider all segments as a single road, and then the histograms of the speed frequency (from 6 a.m. to 11:59 p.m.) happening on weekdays (in $w_{1}$ ) are compared in pairs, with the Chi-Square metric presented in Eq. (2). The results are shown in Table 3, starting with the lowest $\chi^{2}$ value, i.e., the similar histograms among weekdays, with $\mathrm{D}_{1}=$ Monday, $\mathrm{D}_{2}=$ Tuesday, and so on .

Second, the speed data throughout weekdays, but individual segments, was used to conform the histograms of the speed frequency happening on each segment for 5 days (the weekdays of $w_{1}$ ). These histograms were compared in pairs with the $\chi^{2}$. Table 4 shows the results starting with the lowest $\chi^{2}$. We found that if the compared segments share similar traffic elements, the speed frequency also is similar, and therefore a low $\chi^{2}$ is obtained.

\begin{tabular}{|c|c|c|c|c|c|c|c|c|c|}
\hline $\mathrm{D}_{2}-\mathrm{D}_{3}$ & $\mathrm{D}_{4}-\mathrm{D}_{5}$ & $\mathrm{D}_{3}-\mathrm{D}_{4}$ & $\mathrm{D}_{2}-\mathrm{D}_{4}$ & $D_{1}-D_{3}$ & $D_{1}-D_{2}$ & $D_{1}-D_{5}$ & $\mathrm{D}_{3}-\mathrm{D}_{5}$ & $\mathrm{D}_{2}-\mathrm{D}_{5}$ & $D_{1}-D_{4}$ \\
\hline 7.77 & 10.758 & 10.936 & 11.139 & 14.097 & 15.168 & 16.347 & 16.827 & 17.609 & 20.653 \\
\hline
\end{tabular}

Table 3.

Chi-Square distance between histograms with weekdays' data.

\begin{tabular}{|c|c|c|c|c|c|c|}
\hline $\boldsymbol{s}_{2}-\boldsymbol{s}_{5}$ & $s_{3}-s_{6}$ & $s_{5}-s_{6}$ & $s_{1}-s_{4}$ & $s_{2}-s_{6}$ & $s_{0}-s_{7}$ & $\boldsymbol{s}_{2}-\boldsymbol{s}_{3}$ \\
\hline 20.37 & 34.17 & 39.01 & 45.57 & 46.05 & 73.75 & 88.591 \\
\hline$s_{3}-s_{5}$ & $s_{4}-s_{5}$ & $s_{4}-s_{6}$ & $s_{1}-s_{5}$ & $s_{2}-s_{4}$ & $s_{3}-s_{4}$ & $s_{1}-s_{6}$ \\
\hline 98.59 & 167.65 & 185.37 & 198.5 & 212.47 & 220.04 & 226.01 \\
\hline$s_{1}-s_{2}$ & $s_{0}-s_{1}$ & $s_{1}-s_{3}$ & $\boldsymbol{s}_{1}-\boldsymbol{s}_{7}$ & $s_{0}-s_{4}$ & $s_{4}-s_{7}$ & $s_{6}-s_{7}$ \\
\hline 238.39 & 269.15 & 271.36 & 303.87 & 321.89 & 337.16 & 337.43 \\
\hline $\boldsymbol{s}_{2}-\boldsymbol{s}_{7}$ & $\boldsymbol{s}_{5}-\boldsymbol{s}_{7}$ & $s_{0}-s_{5}$ & $s_{0}-s_{6}$ & $s_{0}-s_{2}$ & $\boldsymbol{s}_{3}-\boldsymbol{s}_{7}$ & $s_{0}-\boldsymbol{s}_{3}$ \\
\hline 339.58 & 340.24 & 342.78 & 344.59 & 346.80 & 350.76 & 356.21 \\
\hline
\end{tabular}

Table 4.

Chi-Square distance between histograms with segments data. 


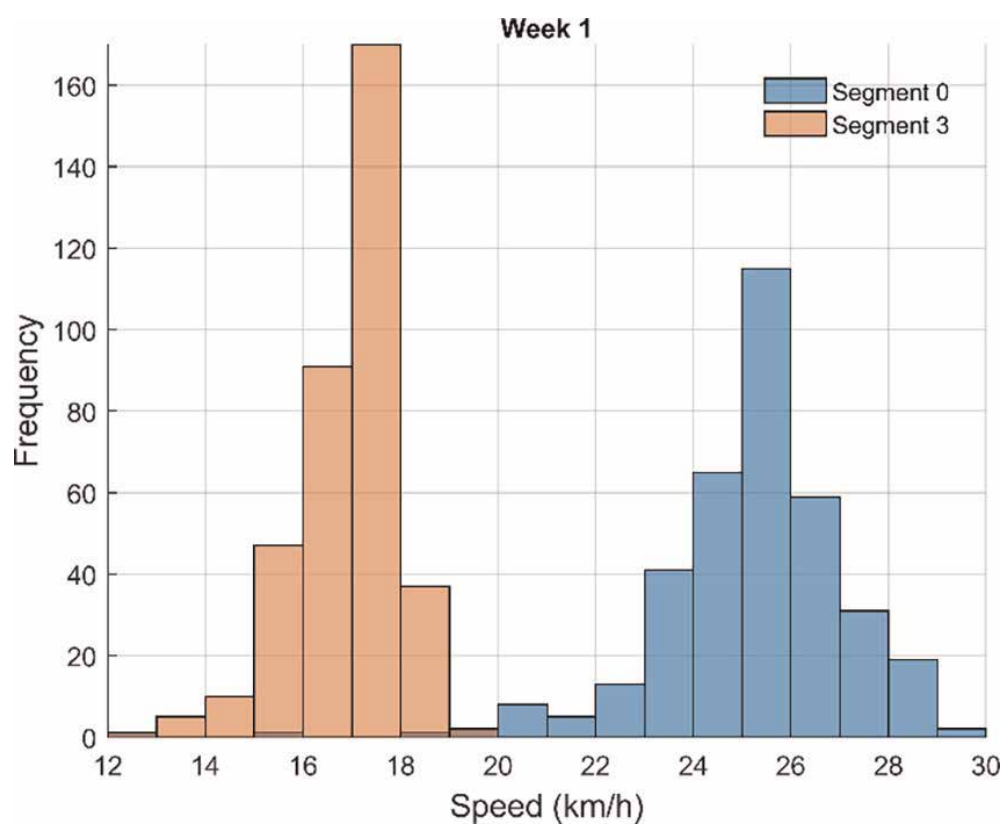

Figure 1.

Dissimilar histograms ( $s_{0}$ and $\left.s_{3}\right)$.

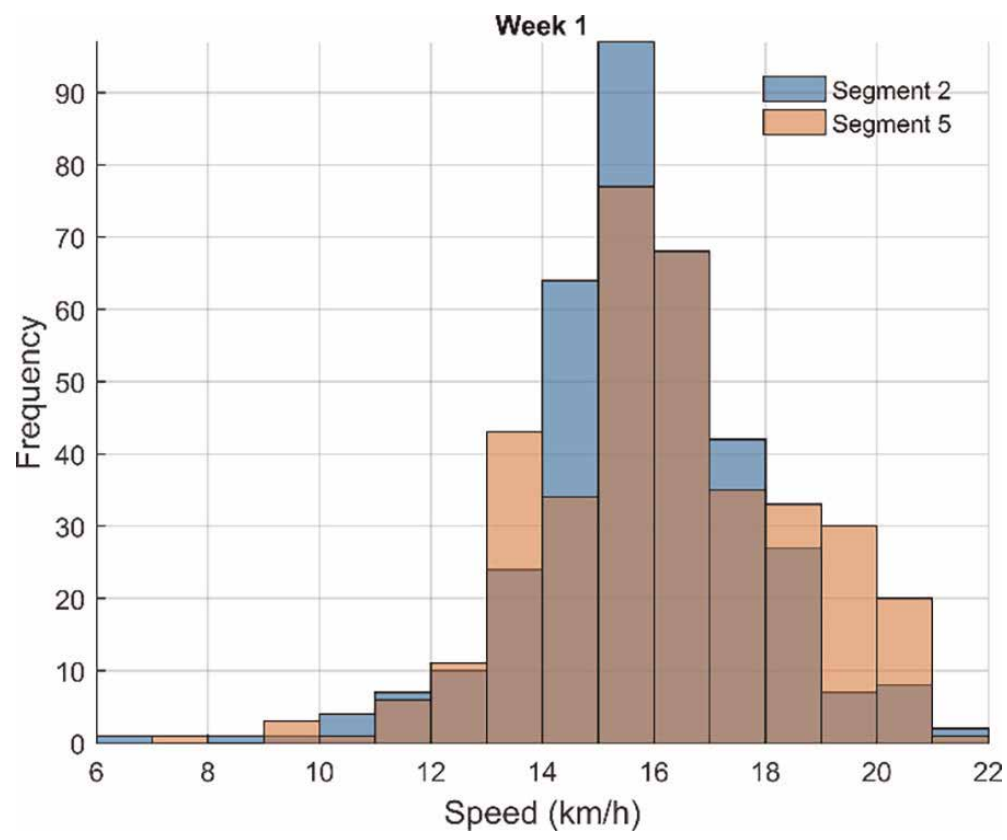

Figure 2.

Similar histograms $\left(s_{2}\right.$ and $\left.s_{5}\right)$.

Figure 1 shows the most dissimilar histograms, $s_{0}$ and $s_{3}$. Table 1 shows that $s_{0}$ has two speed bumps and no traffic lights, while $s_{3}$ has three speed bumps and two traffic lights; because the traffic lights on $s_{3}$, we will expect a lower speed in this segment, and this conclusion can be corroborated by looking at Figure 1.

Figure 2 shows the most similar histograms, $s_{2}$ and $s_{5}$. Segments $s_{2}$ and $s_{5}$ share the same number of traffic lights; however, there are two speed bumps in $s_{5}$ and 0 in $s_{2}$, then a slight superior speed is expected in $s_{2}$ (see Figure 2). 
Tables 3 and 4 show that comparing histograms with the speed frequency of individual days (and all segments) are evaluated with a lower $\chi^{2}$ (the lower value is 7.77, the higher is 20.653) than the observed comparing histograms with the speed frequency of individual segments (and all days), where the lower value is 20.37 and the higher is 356.21 . Then, it appears that the travel speed is weakly influenced by the day of the week, since the traffic control elements of the whole road, from day to day, are the same. However, it seems that the segment strongly influences the travel speed, since the traffic control elements, which characterize each segment, modify the speed at which is possible to travel.

To corroborate the abovementioned statement, we use the speed frequency of $w_{2}$. Figure 3 shows the histograms of the speed frequency of each day (and all segments), where it can be observed the histograms' similarity. Figure $\mathbf{4}$ shows the histograms of the speed frequency of each segment (and all days), where it can be observed the histograms' dissimilarities.

\subsubsection{Outlier detection}

To put an example, the speed data of $s_{0}$ and $w_{1}$ is presented in Figure 5. We calculate the MD of this data (Figure 5), and then the probability density of the MD is presented in Figure 6, which has mean $=1.2331$ and standard deviation $\mathrm{SD}=0.6894$. From Figure 6, a point with value $\mathrm{MD}>\left(2^{*} \mathrm{SD}+\right.$ mean $)=2.6119$ corresponds to a red point in Figure 5 and is considered an atypical point. The inequality value, i.e., $\left(2^{*} \mathrm{SD}+\right.$ mean $)$, was established through trial and error.

The speed data from $w_{1}$ and $w_{2}$, for all segments, is filtered the same way as the example. The data used in the polynomial regression satisfy $\mathrm{MD}<=\left(2^{*} \mathrm{SD}+\right.$ mean $)$ and in the logistic regression $\mathrm{MD}<=\left(3^{*} \mathrm{SD}+\right.$ mean $)$.

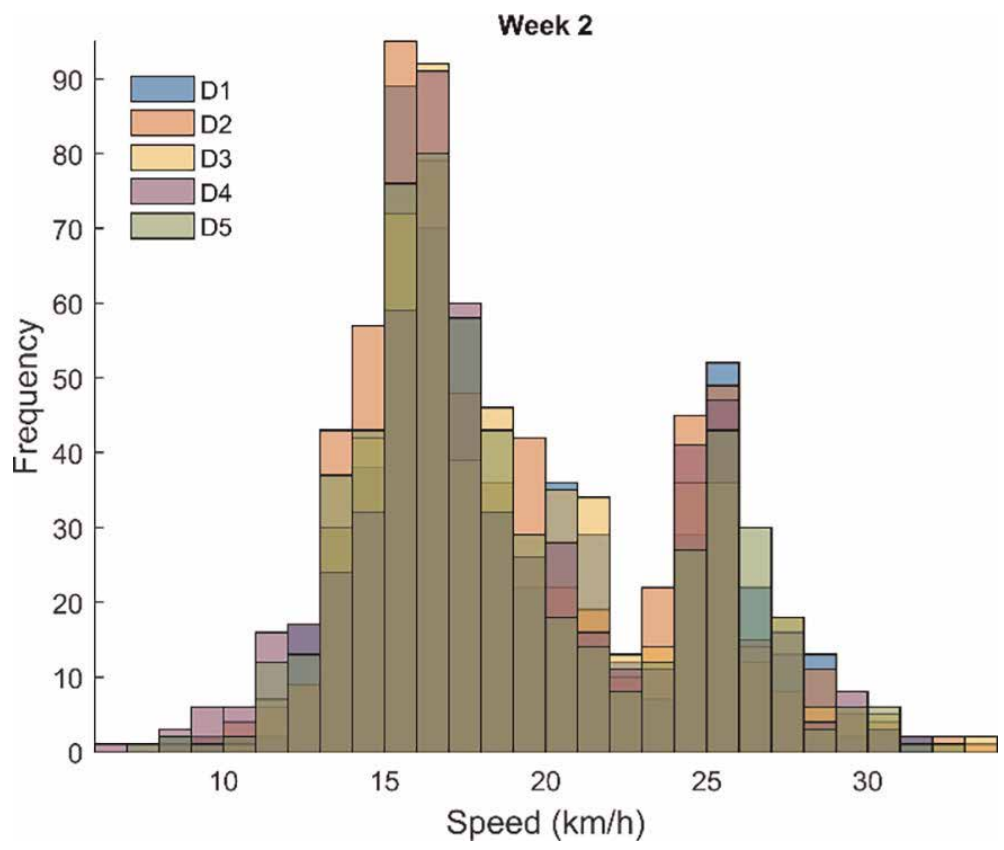

Figure 3.

Seed frequency of days. 


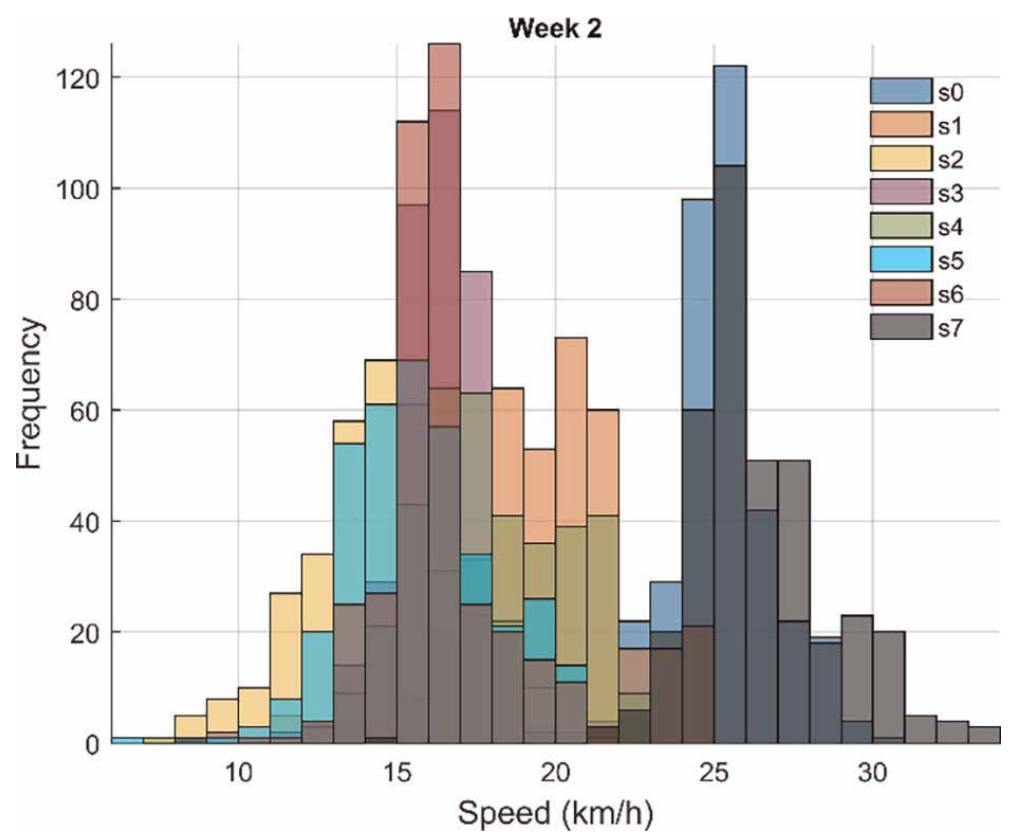

Figure 4.

Speed frequency of segments.

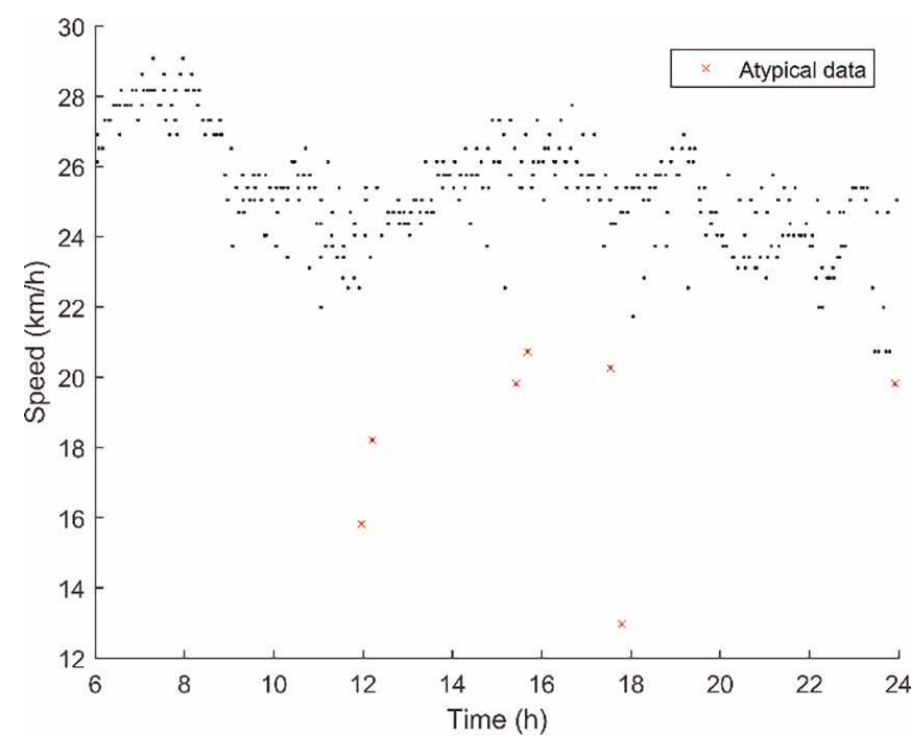

Figure 5 .

Time vs. speed: Data of $s_{0}$ and $w_{1}$.

\subsubsection{Mathematical models}

Polynomial: The data of each segment, with time as the independent variable and travel speed as the dependent variable, is modeled with a five-degree polynomial, enabling four-speed trend changes (the common requirement from the observations). The coefficients are calculated with the least-squares regression technique. 


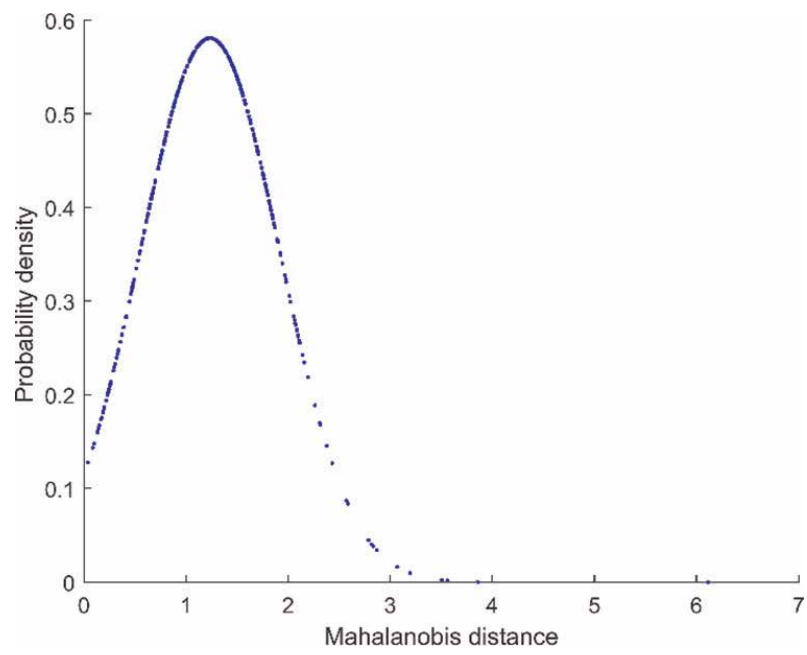

Figure 6.

Mahalanobis distance vs. probability density.

The following terminology is used to describe the model: the data size of all segments is $N=\sum_{k=0}^{k=7} N_{k}$, with $N_{k}$ referring the data size of the $k$ segment. The observed $i$ speed is denoted by $y(i)$, while time is $t(i)$. The speed model of segment $k$ and week $q$ is denoted by $M_{k}^{q}(i)$, with $k=\{0,1,2,3,4,5,6,7\}$ and $q=\{1,2\}$. The model is presented in Eq. (4), where coefficients $\varphi_{1} \ldots \varphi_{6}$ were calculated with speed data of the corresponding week $(q)$ and segment $(k)$ :

$$
M_{k}^{q}(i)=\varphi_{1}+\varphi_{2} t(i)+\varphi_{3} t(i)^{2}+\varphi_{4} t(i)^{3}+\varphi_{5} t(i)^{4}+\varphi_{6} t(i)^{5}
$$

Multinomial logistic: The number of speed bumps and traffic lights (see Table 1) are used to explain the speed. With multinomial logistic regression [33], we obtained the logistic model presented in Eq. (5), with $\psi=\{a, b\}$ :

$$
E_{\psi}^{q}(i)=\psi_{1}+\psi_{2} v_{1}(i)+\psi_{3} v_{2}(i)+\psi_{4} v_{3}(i)+\psi_{5} v_{4}(i)+\psi_{6} v_{5}(i)
$$

The coefficients are denoted by $\psi_{1} \ldots \psi_{6}$, and $q=\{1,2\}$ refers again to the data from $w_{1}$ and $w_{2}$, respectively. The explanatory variables are $v_{1}=$ day weight, $v_{2}=$ number of speed bumps, $v_{3}=$ number of traffic lights, $v_{4}=$ segment weight, and $v_{5}=$ time. The weight of a specific day is calculated as the day average speed (of the speed measured from 6 a.m. to 11:59 p.m.) divided by the sum of the speed average of each weekday. A segment's weight is calculated as the segment's average speed (during weekdays) divided by the sum of the speed average of each segment.

In Eq. (5), $E_{a}^{q}$ calculates the relative risk of being in cluster 1 vs. cluster 3 (the reference), and $E_{b}^{q}$ calculates the same but for cluster $2 v s$. cluster 3 . The conversion to probability is given in Eqs. (6)-(8), where $R_{j}^{q}$ is the probability belonging to the $j$ category, with $j=\{1,2,3\}$ :

$$
\begin{gathered}
R_{1}^{q}(i)=e^{E_{a}^{q}(i)} /\left(1+e^{E_{a}^{q}(i)}+e^{E_{b}^{q}(i)}\right) \\
R_{2}^{q}(i)=e^{E_{b}^{q}(i)} /\left(1+e^{E_{a}^{q}(i)}+e^{E_{b}^{q}(i)}\right) \\
R_{3}^{q}(i)=1-\left(R_{1}^{q}(i)+R_{2}^{q}(i)\right)
\end{gathered}
$$




\subsubsection{Connecting Intel with users}

With the developed procedure, knowledge is acquired about the speed at which is expected to travel on the segments under the study. The architecture design (and the implementation) to connect the Intel with the users is out of the scope in this work (planned as future work); nevertheless we present in this section the basic idea.

The algorithms developed (in Appendix A and Appendix B) were programmed in a regular computer; according the procedure presented, the data acquired (from the zone under study) is modeled, and the models are used in the algorithms to generate knowledge. The link between this knowledge and the users could be established through a cell phone app (via the Internet). When a driver is in the proximity of a street segment, the cell phone (with GPS) detects the current location and acquires information for the driver, as the number of bumps and traffic lights, and also the expected travel speed calculated with the proposed algorithms; this info is presented to the driver in a proper way to not distract him, and then the driver can decide the more convenient route. A more challenging design is to communicate the cell phone with the vehicle (assuming that an intelligent system is part of it and can control some functions) and, for example, when the vehicle is approaching a speed bump, it automatically decelerates (if the driver is not reacting adequately).

The program running in a computer, in charged to acquire and mine data for generating knowledge and to establish communication with the responsive elements, conforms the "cyber" part of the system. The elements reacting with intelligence to the Intel delivered, as the driver, the cell phone, and the vehicle, conform the "physical" part of the system. Finally, the cyber and physical parts combined conform a cyber-physical system.

\section{Results}

\subsection{Polynomial regression model and Algorithm 1}

The error between the modeled data, with Eq. (4), and the observed data, was calculated with the mean absolute error (MAE) (see Eq. (9)) [34]. Here, $n=N_{k}$, $y(i)$ and $\hat{y}(i)$ are the observed and modeled data, respectively. Table 5 shows the

\begin{tabular}{ccccc}
\hline & \multicolumn{2}{c}{$\mathbf{M}_{\boldsymbol{k}}^{1}$} & \multicolumn{2}{c}{$\mathbf{M}_{\boldsymbol{k}}^{2}$} \\
\hline Segment & MAE $(\mathbf{k m} / \mathbf{h})$ & SD $(\mathbf{k m} / \mathbf{h})$ & MAE $(\mathbf{k m} / \mathbf{h})$ & SD $(\mathbf{k m} / \mathbf{h})$ \\
\hline$s_{0}$ & 0.8269 & 0.6802 & 0.7895 & 0.6321 \\
\hline$s_{1}$ & 1.0101 & 0.9630 & 1.1939 & 0.9916 \\
\hline$s_{2}$ & 0.9523 & 0.7622 & 1.1754 & 1.0670 \\
\hline$s_{3}$ & 0.6198 & 0.4628 & 0.6701 & 0.5917 \\
\hline$s_{4}$ & 0.8435 & 0.6882 & 0.9765 & 0.7416 \\
\hline$s_{5}$ & 0.8971 & 0.6826 & 0.9234 & 0.7408 \\
\hline$s_{6}$ & 0.8438 & 0.7297 & 0.7737 & 0.6680 \\
\hline$s_{7}$ & 0.9376 & 1.0762 & 0.7894 & 0.6653 \\
\hline
\end{tabular}

Table 5 .

$M A E$ and $S D$. 
MAE, and its standard deviation (SD), with the data of $w_{1}$ and $w_{2}$, and the respective modeled equations:

$$
M A E=\frac{1}{n} \sum_{i=1}^{n}|y(i)-\hat{y}(i)|
$$

An algorithm (Appendix A, Algorithm 1) is designed to predict the speed of $w_{3}$ using the modeled equations $\left(M_{k}^{1}\right.$ and $\left.M_{k}^{2}\right)$ and historical data, i.e., the data available from $w_{3}$ before the current time. The error between the observed (from $w_{3}$ ) and predicted (with Algorithm 1) travel speeds is calculated with Eq. (9). The MAE, SD, and hits (percentage of data categorized correctly) for $w_{3}$, using Algorithm 1, are shown in Table 6.

Figure 7 shows, as example, the observed speed data (in black circles) of $w_{3}$ and segment $s_{0}$, the modeled data with $w_{1}$ (model $M_{0}^{1}$, in blue dots) and $w_{2}$ (model $M_{0}^{2}$, in green dots), and the estimated speed with Algorithm 1 (in red plus signs).

\subsection{Multinomial logistic regression model and Algorithm 2}

Algorithm 2 (see Appendix B) is used to predict the speed category of the observed data from $w_{3} . H_{1}(i)$ and $H_{2}(i)$ are two data sets obtained from $w_{1}$ and $w_{2}$, respectively. These sets save the associated category of the average speed in a time interval from $t(i)-0.5$ to $t(i)+0.5(0.5 \mathrm{~h}=30 \mathrm{~min})$ and centered on $t(i)$, of the day and segment under evaluation. $H_{3}(i)$ is the category speed of $w_{3}$ (which is only available for previous data, i.e., prior to $(i)$, with $i \ldots N$ being the data index. The probability most likely to occur is $P_{q}(i)=\max \left\{R_{1}^{q}(i), R_{2}^{q}(i), R_{3}^{q}(i)\right\}=R_{x}^{q}(i)$ and the category is stored in $S_{q}(i)=x$, where subindex $q=\{1,2\}$ refers to the week. A threshold value, selected through trial and error, is used to discard the result in $S_{q}(i)$ if $P_{q}(i)<$ threshold. Algorithm 2 predicts the speed category for $w_{3}$, which is stored in $S_{3}(i)$. Choosing threshold $=0.9$ gives $90.09 \%$ of correct evaluations. This percentage is the summation of cases, where $S_{3}(i)$ was categorized correctly divided by the total data $\mathrm{N}$.

Afterward, we attempted to predict the speed category of the observed speed in $w_{3}$ under the assumption that set $H_{2}(i)$ is composed only with the average speed of each segment, and not including $H_{1}$. The optimum result was found if threshold $=\sim 0.85$, with $85.62 \%$ of correct predictions. If the threshold value is reduced, the positive prediction decreases (because the model fails to predict accurately with that threshold value). Similarly, if the threshold is increased, it becomes more

\begin{tabular}{cccc}
\hline Segment & MAE $(\mathbf{k m} / \mathbf{h})$ & SD $(\mathbf{k m} / \mathbf{h})$ & Hits $(\%)$ \\
\hline$s_{0}$ & 0.7757 & 0.7142 & 92.4 \\
\hline$s_{1}$ & 0.9353 & 1.0061 & 85.2 \\
\hline$s_{2}$ & 0.8641 & 0.7537 & 89.5 \\
\hline$s_{3}$ & 0.7749 & 0.7658 & 94.8 \\
\hline$s_{4}$ & 1.0053 & 1.0903 & 85.2 \\
\hline$s_{5}$ & 0.8051 & 0.7942 & 93.5 \\
\hline$s_{6}$ & 0.6968 & 0.6639 & 96.5 \\
\hline$s_{7}$ & 0.7994 & 0.9391 & 93.5 \\
\hline
\end{tabular}

Table 6.

Algorithm 1 prediction results: MAE, SD, and hits. 


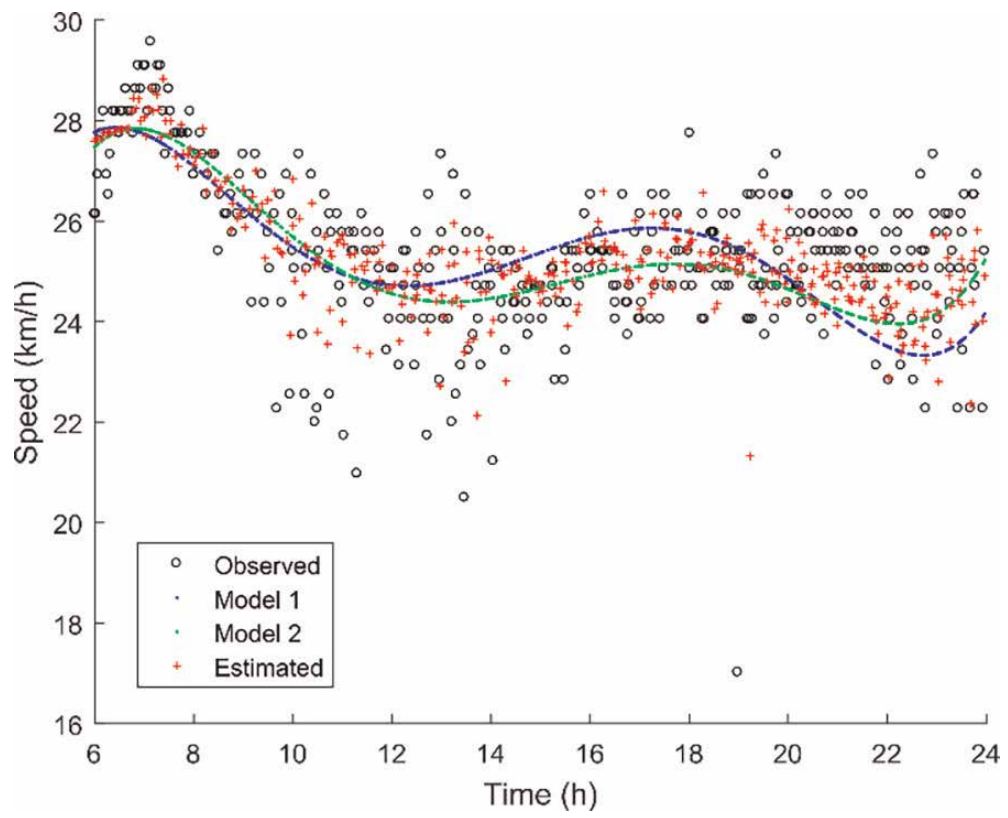

Figure 7.

Time vs. speed: data of $s_{0}$ and $w_{3}$.

difficult to satisfy the condition $P_{q}(i) \geq$ threshold, and then the positive prediction also drops because now the set $H_{2}(i)$ (with the limitation mentioned before) contributes more. Table 7 shows the percentage of speed data categorized correctly with different threshold values.

\subsection{Discussion}

A series of steps are employed in a numerical example that, in combination, constitute a new method for speed prediction. The first step, street segmentation, divides an avenue in such a way that distributes different traffic elements on different segments. These elements are number of speed bumps, traffic lights, and landmarks, which in turn leads to different speed behavior on each segment. The second step, clustering, selects intervals which better fit the travel speed observed, resulting in three categories. Depending on the segment, most of the speed data (approximately at least $80 \%$ ) is within a specific cluster (category). For example, we infer that the speed behaviors in $s_{2}$ and $s_{5}$ are similar, since most of the speeds for both fall inside cluster 1 . Moreover, speed behaviors of $s_{0}$ and $s_{3}$ are dissimilar, since most of the speeds belong to different clusters ( 3 and 1 , respectively). In the third step, comparative analysis of histograms, we corroborate that for each segment, the

\begin{tabular}{lc}
\hline Threshold & Prediction (\%) \\
\hline 0.75 & 81.69 \\
\hline 0.80 & 83.10 \\
\hline 0.85 & 85.62 \\
\hline 0.90 & 84.24 \\
\hline 0.95 & 83.97 \\
\hline
\end{tabular}

Table 7.

Algorithm 2: threshold values and $w_{3}$ prediction results. 
speed behavior is related to the traffic elements involved. It was observed that the speed histograms of two segments get a low Chi-Square distance if the segments share approximately the same number of speed bumps, traffic lights, and landmarks, independent of the day of the week. A high Chi-Square distance implies the opposite situation, i.e., segments with different number of traffic elements. The fourth step, outlier detection, removes atypical speed behavior, e.g., a vehicle circulating slower or faster than the usual. In step five, mathematical models, the models explain the speed. From steps 2 and 3, it is already known that on each segment, speed behaves according to the traffic elements involved, and hence the speed data of each segment is modeled independently with a polynomial model, with time as the independent variable. The multinomial logistic model uses as independent variables the number of speed bumps, traffic lights, the time, and two weights. The weights are calculated based on the average of the measured travel speeds considering segments and days. Finally, in step 6, connecting Intel with users, the drivers are properly informed about the travel speed expected on the surrounding segments, helping them to continuously adjust their route.

\section{Conclusions}

The procedure presented in this chapter proposes street segmentation; on each segment, there are traffic elements that we infer may be related with the observed speed frequency. By comparing speed histograms, we found that the speed frequency of all segments is similar among weekdays, and then the speed frequency of a specific segment is similar regarding the day. Considering the speed frequency of all weekdays, and individual segments, the segments with different traffic elements (speed bumps, traffic lights, and landmarks) yield dissimilar traveling speeds. From this observation, two techniques were considered for modeling speed: (1) polynomial regression, where the data of each segment is modeled independently, using time as the independent term, and (2) logistic regression, with several independent variables-number of speed bumps and traffic lights, time, and two weights (from the observed speeds on street segments and weekdays). The models were implemented in algorithms, which use the modeled and historical data. With the polynomial model and Algorithm 1, it was possible to categorize correctly the travel speed in the range from 85.2 to $96.5 \%$, depending on the segment. The multinomial logistic model and Algorithm 2 correctly predict the speed category in $90.09 \%$ of the evaluated cases. With these results, we conclude that the proposed procedure is suitable to prepare and model speed data and then to predict the speed category at a low computer processing cost. The procedure is useful to establish the relationship between traffic infrastructure and travel speed.

\subsection{Future work}

We contemplate as future work the development of the architecture to communicate the expected travel speed (obtained with the proposed procedure) with the users, as well as convert this knowledge in suggestions and decision-making.

\section{Appendix A}

In Algorithm 1, if $i \leq$ deep (line 3), the modeled speed of $w_{1}$ and $w_{2}$ contributes the same (each multiplied by 0.5 ). The case $i \geq$ deep +1 (line 6 ) enables the 
estimation of $\bar{y}(i-1)$ and $\bar{y}(i)$ with known data from $w_{3}$. Variables $h_{1}$ and $h_{2}$ (see lines from 9 to 14) store the average of the absolute difference between historical and modeled data, from $w_{1}$ and $w_{2}$, respectively. $h_{3}$ (line 15) stores the absolute difference of the historical and estimated data, from $w_{3}$ and index $i-1$. The condition in line 16 verifies that the $y(i-3)$ to $y(i-1)$ speeds are nonempty, i.e., available. $h_{1} \ldots h_{3}$ are normalized and converted to weights, named $W_{1} \ldots W_{3}$. Because $h$ carries the error, a greater $h$ results in a smaller $W$, and so forth. In line 18, the predicted speed is calculated using the weights, the modeled speed with $w_{1}$ and $w_{2}$, and the estimation with previous data of $w_{3}$. If the condition in line 16 is not true, then in line 21 the speed prediction is calculated with the modeled data and new weights, without the $w_{3}$ data.

\section{Algorithm 1}

Initial conditions: deep $=3$;

1. for $k=0$ to $k=7$

2. for $i=1$ to $i=N_{k}$

3.if $i \leq$ deep

4. $\hat{y}(i)=M_{k}^{1}(i) * 0.5+M_{k}^{2}(i) * 0.5$

5.end if

6. if $i \geq$ deep +1

7. $\bar{y}(i-1)=y(i-2)+(y(i-2)-y(i-3))$

$8 . \bar{y}(i)=y(i-1)+(y(i-1)-y(i-2))$

9. $h_{1}=0 ; h_{2}=0$;

10. for $j=1$ to $j=$ deep

11. $h_{1}=h_{1}+\left|y(i-j)-M_{k}^{1}(i-j)\right|$

12. $h_{2}=h_{2}+\left|y(i-j)-M_{k}^{2}(i-j)\right|$

13.end for

14. $h_{1}=h_{1} /$ deep $; h_{2}=h_{2} /$ deep

15. $h_{3}=|y(i-1)-\bar{y}(i-1)|$

16.if $y(i-1) \notin \varnothing \wedge y(i-2) \notin \varnothing \wedge y(i-3) \notin \varnothing$

17. $h_{1}=\frac{h_{1}}{h_{1}+h_{2}+h_{3}} ; h_{2}=\frac{h_{2}}{h_{1}+h_{2}+h_{3}} ; h_{3}=\frac{h_{3}}{h_{1}+h_{2}+h_{3}} ; W_{1}=\frac{1-h_{1}}{1-h_{1}+1-h_{2}+1-h_{3}} ;$

$W_{2}=\frac{1-h_{2}}{1-h_{1}+1-h_{2}+1-h_{3}} ; W_{3}=\frac{1-h_{3}}{1-h_{1}+1-h_{2}+1-h_{3}}$

18. $\hat{y}(i)=M_{k}^{1}(i) * W_{1}+M_{k}^{2}(i) * W_{2}+\bar{y}(i) * W_{3}$

19.else

$20 . h_{1}=\frac{h_{1}}{h_{1}+h_{2}} ; h_{2}=\frac{h_{2}}{h_{1}+h_{2}} ; W_{1}=1-h_{1} ; W_{2}=1-h_{2} ;$

21. $\hat{y}(i)=M_{k}^{1}(i) * W_{1}+M_{k}^{2}(i) * W_{2}$

22. end if

23.end if

24.end for

25.end for

\section{Appendix B}

From Algorithm 2, in lines 3 to 10 it is compared the modeled and historical speed category (from $w_{1}$ and $w_{2}$ ), with the historical from $w_{3}$, to determine which is 
the accurate. The number of hits of the model and the historical (for weeks 1 and 2) is stored in score with sub-index from 1 to 4 , for the four cases. In line 12, if the probability $P_{2}(i)$ is greater or equal than the selected threshold and, if score $_{2} \geq$ score $_{1}$, then $S_{2}(i)$ is the predicted speed category. In line 14, if $P_{1}(i) \geq$ threshold and, if score $_{1} \geq$ score $_{2}$, then the predicted speed category is $S_{1}(i)$. If previous conditionals (line 12 and 14) are not evaluated to true, in lines from 16 to 18, the historical with the greater score, $\mathrm{H}_{2}$ or $\mathrm{H}_{1}$, is the selected to predict the speed category.

\section{Algorithm 2}

Initial conditions: score $_{1}=0 ;$ score $_{2}=0 ;$ score $_{3}=0 ;$ score $_{4}=0$; threshold $\in[0.75,0.95]$;

$$
\begin{aligned}
& \text { 1. for } i=1 \text { to } i=N \\
& \text { 2. if } i>1 \\
& \text { 3. if } H_{3}(i-1)==S_{1}(i-1) \\
& \text { 4. } \text { score }_{1}++ \text {; end if } \\
& \text { 5. if } \mathrm{H}_{3}(i-1)==S_{2}(i-1) \\
& \text { 6. } \text { score }_{2}++ \text {; end if } \\
& \text { 7.if } H_{3}(i-1)==H_{1}(i-1) \\
& \text { 8. } \text { score }_{3}++ \text {; end if } \\
& \text { 9.if } \mathrm{H}_{3}(i-1)==\mathrm{H}_{2}(i-1) \\
& \text { 10. } \text { score }_{4}++ \text {; end if } \\
& \text { 11.end if } \\
& \text { 12. if }\left(P_{2}(i) \geq \text { threshold } \wedge\left(\text { score }_{2} \geq \text { score }_{1}\right)\right. \\
& \text { 13. } S_{3}(i)=S_{2}(i) \text {; else } \\
& \text { 14. if }\left(P_{1}(i) \geq \text { threshold } \wedge\left(\text { score }_{1} \geq \text { score }_{2}\right)\right. \\
& \text { 15. } S_{3}(i)=S_{1}(i) \text {; else } \\
& \text { 16.if } \text { score }_{4} \geq \text { score }_{3} \\
& \text { 17. } S_{3}(i)=H_{2}(i) \text {; else } \\
& \text { 18. } S_{3}(i)=H_{1}(i) \text {; end if } \\
& \text { 19.end if } \\
& \text { 20.end if } \\
& \text { 21. end for }
\end{aligned}
$$




\section{Author details}

José Gerardo Carrillo-González ${ }^{1,2 *}$, Jacobo Sandoval-Gutiérrez ${ }^{2}$ and Francisco Pérez-Martínez ${ }^{2}$

1 CONACYT, Consejo Nacional de Ciencia y Tecnología, Ciudad de México, México

2 Department of Information and Communications Systems, Universidad Autónoma Metropolitana, Estado de México, México

*Address all correspondence to: jgcarrilo@conacyt.mx

\section{IntechOpen}

(c) 2019 The Author(s). Licensee IntechOpen. This chapter is distributed under the terms of the Creative Commons Attribution License (http://creativecommons.org/licenses/ by/3.0), which permits unrestricted use, distribution, and reproduction in any medium, provided the original work is properly cited. (cc) BY 
Procedure to Prepare and Model Speed Data Considering the Traffic Infrastructure, as Part... DOI: http://dx.doi.org/10.5772/intechopen.88280

\section{References}

[1] ONU-Hábitat. Reporte Nacional de Movilidad Urbana en México 2014-2015. 2015

[2] Marr LC, Grogan LA,

Wöhrnschimmel H, Molina LT, Molina MJ, Smith TJ, et al. Vehicle traffic as a source of particulate polycyclic aromatic hydrocarbon exposure in the Mexico city metropolitan area. Environmental Science \& Technology. 2004;38(9): 2584-2592

[3] Jiang M, Marr LC, Dunlea EJ, Herndon SC, Jayne JT, Kolb CE, et al. Vehicle fleet emissions of black carbon, polycyclic aromatic hydrocarbons, and other pollutants measured by a mobile laboratory in Mexico City. Atmospheric Chemistry and Physics. 2005;5(12): 3377-3387

[4] Híjar M, Vazquez-Vela E, ArreolaRisa C. Pedestrian traffic injuries in Mexico: A country update. Injury Control and Safety Promotion. 2003;10 (1-2):37-43

[5] Ramos A, Silva E, Aguirre A. Fatal car accidents in the metropolitan zone of Mexico City: A geographical and temporal perspective. Papeles de Poblacion. 2015;21(86):253-282

[6] Li R, Chai H, Tang J. Empirical study of travel time estimation and reliability. Mathematical Problems in Engineering. 2013;2013:1-9

[7] Rupnik J, Davies J, Fortuna B, Duke A, Clarke SS. Travel time prediction on highways. In: Computer and Information Technology; Ubiquitous Computing and Communications; Dependable, Autonomic and Secure Computing; Pervasive Intelligence and Computing (CIT/IUCC/DASC/PICOM), 2015 IEEE International Conference on. 2015. pp. $1435-1442$
[8] Chacon S, Kornhauser AL. Analysis, Characterization, and Visualization of Freeway Traffic Data in Los Angeles. 2012

[9] Imawan A, Indikawati F, Kwon J, Rao P. Querying and extracting timeline information from road traffic sensor data. Sensors. 2016;16(9):1340

[10] Long Cheu R, Xie C, Lee D-H. Probe vehicle population and sample size for arterial speed estimation. ComputerAided Civil and Infrastructure Engineering. 2002;17(1):53-60

[11] Tostes AIJ, de LP Duarte-Figueiredo F, Assunção R, Salles J, Loureiro AAF. From data to knowledge: City-wide traffic flows analysis and prediction using Bing maps. In: Proceedings of the 2nd ACM SIGKDD International Workshop on Urban Computing. 2013. p. 12

[12] Silva TH, de Melo POSV, Viana AC, Almeida JM, Salles J, Loureiro AAF. Traffic condition is more than colored lines on a map: Characterization of Waze alerts. In: International Conference on Social Informatics. 2013. pp. 309-318

[13] Pan J, Popa IS, Zeitouni K, Borcea C. Proactive vehicular traffic rerouting for lower travel time. IEEE Transactions on Vehicular Technology. 2013;62(8): 3551-3568

[14] Milton J, Mannering F. The relationship among highway geometrics, traffic-related elements and motor-vehicle accident frequencies. Transportation. 1998;25(4):395-413

[15] Kinderyte-Poškiene J, Sokolovskij E. Traffic control elements influence on accidents, mobility and the environment. Transport. 2008;23(1): 55-58. Available from: http://www.tandf 
online.com/doi/abs/10.3846/

1648-4142.2008.23.55-58

[16] Peden M, Scurfield R, Sleet D, Mohan D, Hyder AA, Jarawan E, et al. World Report on Road Traffic Injury Prevention. Geneva: World Health Organization; 2004

[17] Baum HM, Wells JK, Lund AK. Motor vehicle crash fatalities in the second year of $65 \mathrm{mph}$ speed limits. Journal of Safety Research. 1990; 21(1):1-8

[18] Nienhüser D, Gumpp T, Zöllner JM. Relevance estimation of traffic elements using Markov logic networks. In: Intelligent Transportation Systems (ITSC), 2011 14th International IEEE Conference on. 2011. pp. 1659-1664

[19] Pau M, Angius S. Do speed bumps really decrease traffic speed? An Italian experience. Accident; Analysis and Prevention. 2001;33(5):585-597

[20] Wu C, Peng L, Huang Z, Zhong M, Chu D. A method of vehicle motion prediction and collision risk assessment with a simulated vehicular cyber physical system. Transportation Research Part C: Emerging Technologies. 2014;47:179-191

[21] Wang Y, Tan G, Wang Y, Yin Y. Perceptual control architecture for cyber-physical systems in traffic incident management. Journal of Systems Architecture. 2012;58(10): 398-411

[22] Work DB, Bayen AM. Impacts of the mobile internet on transportation cyberphysical systems: Traffic monitoring using smartphones. In: National Workshop for Research on High-Confidence Transportation CyberPhysical Systems: Automotive, Aviation, \& Rail. 2008. pp. 18-20

[23] Yuan J, Zheng Y, Xie X, Sun G. Driving with knowledge from the physical world. In: Proceedings of the

17th ACM SIGKDD International

Conference on Knowledge Discovery

and Data Mining. 2011. pp. 316-324

[24] Chen C, Liu X, Qiu T, Sangaiah AK. A short-term traffic prediction model in the vehicular cyber-physical systems. Future Generation Computer Systems. 2017. In press

[25] Jianjun S, Xu W, Jizhen G, Yangzhou $C$. The analysis of traffic control cyber-physical systems. Procedia - Social and Behavioral Sciences. 2013;96:2487-2496

[26] Jain AK. Data clustering: 50 years beyond K-means. Pattern Recognition Letters. 2010;31(8):651-666

[27] Montazeri-Gh M, Fotouhi A. Traffic condition recognition using the k-means clustering method. Scientia Iranica. 2011;18(4):930-937

[28] Fotouhi A, Montazeri-Gh M. Tehran driving cycle development using the $\mathrm{k}$ means clustering method. Scientia Iranica. 2013;20(2):286-293

[29] Saunier N, Sayed T. Clustering vehicle trajectories with hidden Markov models application to automated traffic safety analysis. In: The 2006 IEEE International Joint Conference on Neural Network Proceedings. 2006. pp. $4132-4138$

[30] Rousseeuw PJ. Silhouettes: A graphical aid to the interpretation and validation of cluster analysis. Journal of Computational and Applied Mathematics. 1987;20:53-65

[31] Pele O, Werman M. The quadraticchi histogram distance family. In: Daniilidis K, Maragos P, Paragios N, editors. Computer Vision - ECCV 2010: 11th European Conference on Computer Vision, Heraklion, Crete, Greece, September 5-11, 2010, Proceedings, Part 
Procedure to Prepare and Model Speed Data Considering the Traffic Infrastructure, as Part... DOI: http://dx.doi.org/10.5772/intechopen.88280

II. Berlin, Heidelberg: Springer Berlin Heidelberg; 2010. pp. 749-762

[32] De Maesschalck R, Jouan-Rimbaud D, Massart DL. The Mahalanobis distance. Chemometrics and Intelligent Laboratory Systems. 2000;50(1):1-18

[33] Hutcheson G. The Multinomial Logistic Regression Model. Manchester: Sage Publications; 2009

[34] Willmott CJ, Matsuura K.

Advantages of the mean absolute error (MAE) over the root mean square error (RMSE) in assessing average model performance. Climate Research. 2005; 30(1):79-82 



\title{
The Role of Public Spaces in Small Municipality
}

\author{
Jana Moravcová, Jiri Pecenka, Denisa Pekna, \\ Vendula Moravcova and Nikola Novakova
}

\begin{abstract}
Public spaces are a subspace of municipality space: they are its physical type, closely linked to permanent settlements, especially to cities. There are both social communication and movement of people, things and goods. These are classic, usually architecturally designed spaces between buildings: squares, agora, streets and parks. Public spaces in small municipalities have been crucial to the functioning of the community, their social, historically, and also economic life. In various types of rural municipalities, the function and formation of public spaces have changed over the course of history, often in relation to the geographical location of the municipality in terms of location or local conditions and customs. Nowadays, the tourist attraction of the place is also an important driving element in the form of public spaces. This chapter should show how public spaces have changed over time using examples of different types of municipalities and show examples of good and somewhat worse care for them.
\end{abstract}

Keywords: public space, history, small municipality, urban planning

\section{Introduction}

\subsection{What is the public space: definition}

Public spaces are all squares, streets, marketplaces, sidewalks, public greenery, parks and other areas accessible to everyone without restriction, thus serving general use, regardless of ownership of this space. Public spaces are part of public infrastructure as defined by the Building Act. Public space is an area defined by urban resources, i.e. mainly the surrounding development. It may also be delimited by greenery (trees) or other spatial elements and methods (water surface, watercourse, etc.) [1].

We distinguish two quite different groups of public spaces, namely a group consisting of squares, streets, marketplaces or sidewalks (public spaces where mostly paved areas predominate) and a group of public green spaces (parks, small parks, park squares, other publicly accessible areas and areas with prevailing green areas) [2].

A public space can also be defined as a space for public use without restriction and regardless of ownership of the space [3].

Public space can be viewed in terms of its physical form, i.e. space, and in terms of its activities-the functions it performs [4]. 
The spatial characteristics of the public space consist of the following elements:

- size and shape;

- proposal of public space solution and quality of its implementation;

- the nature of the area, e.g. the proportion of paved and grass areas and the use of water;

- type and quality of greenery and its maintenance;

- the character of the development that defines the public space (closed-block, terraced, etc.; loose-free-standing houses, etc.), or buildings that are part of the public space (in their area), their height, volume and scale;

- architectural quality, esthetic standards, construction and technical condition of buildings and other surrounding buildings;

- The parterre and everything that is perceptible in the walking eye horizon [1].

The following parameters describe the content and meaning characteristics of the public space:

- availability;

- accessibility - a public space must be a place where people can walk freely or stay freely without restrictions;

- ability to bring people together-public spaces are meeting places;

- ability to keep people present-space must be friendly to stay and people stop at points of interest or lines [5];

- liveliness, variety and diversity-the presence of people and the associated plenty of different objectives, as well as the diversity and interestingness of the street, square or park space itself, their division, opening and closing of views and the presence of greenery;

- safety-good lighting and order and action in public spaces contribute to the sense of security of those present;

- comfort and convenience-public spaces should provide the opportunity to relax and include places to rest or stop;

- climate comfort-temperature on hot summer days is largely reduced by grown trees, street alleys and water features, especially fountains; they reduce space overheating and improve air quality in public areas;

- continuity and interconnection with other areas-interconnection of public spaces and fluency of pedestrian movement (without barriers and unnecessary bypassing of obstacles) are important in terms of their use, both on streets and squares, and on green areas [3]. 
The characteristics of a public space affect and limit its functions, i.e. the possibilities of pursuing activities. Outdoor activities related to public space can be divided into necessary, optional and social. This division is related to the basic functions of public spaces:

- service-providing passage, transit to destinations outside the public area and further ensuring access to users of public areas and facilities that make up the public area (especially civic amenities and housing), including access to supply, health services and firefighters, technical infrastructure service, and maintenance;

- social-meeting friends and residents to strengthen relationships (it is important nowadays when contacts using communication technologies replace personal contact);

- social-meetings of residents and visitors at social events, including cultural events;

- residential (recreational and relaxing) — mainly provided by types of public spaces with a predominant share of greenery, especially parks [5].

The perception of areas or private land lying outside the public space, which is viewed from the public space-courtyards of houses, gardens of houses, etc. is the part of the overall operation of the public space. The quality of space and function of space interact. An example of the interaction of space and function is already evident in the basic function of most public spaces, i.e. as a space intended for movement beyond a certain target. Whether a citizen or visitor uses the public space and for how long depends on the quality of the space, its characteristics, and other functions that it performs. Public spaces are currently faced with many other problems in addition to traffic pressure. These relate to the priorities of society, lifestyle, economic opportunities and many other conditions that affect public spaces. The following are some of the most pressing problems of public spaces [4].

\subsection{Types of villages in the Czech Republic}

This study deals with public space in small municipalities, i.e. in municipalities of the village category. The village is the basic settlement unit in the rural area, which as the administrative unit is called rural village. The village is then usually defined by a maximum number of inhabitants, between 2000 and 5000 inhabitants [6]. It is usually a specific social community with traditional own material and spiritual culture and functions. The actual form of today's village is influenced by long-term development, both in functional and geographical and spatial terms [7].

From a spatial point of view, several different types of rural settlements can be distinguished. The most common classification is based on works [2, 8-12].

The publication of Ref. [11] defines the basic seven types of municipalities, including:

- A scattered courtyard village characteristic for mountainous terrains;

- Natural type of village otherwise described as a type of mass village with irregular ground plan, characteristic especially for the oldest inhabited areas; 
- Line villages characterized by their elongated linear arrangement;

- Road villages characterized by tight arrangement of individual dwellings and buildings along the road;

- A street, i.e. a road village intersected by a road of local character, which can subsequently grow into a street or wide street, when the area is secondary to the local extension of the road;

- A rope village, where objects are typically arranged irregularly mostly along a stream or path;

- Square type of villages characterized by the arrangement of objects around a differently shaped square (square, triangular, round or irregular).

The second possible classification according to Černý [8] involves a total of nine categories of villages, namely:

- Natural type of village, bound to local geographical conditions without regular structure, which is mostly a mountain type of mass villages;

- Norm villages, i.e. villages mostly established in the late Middle Ages according to a well-defined plan;

- Forest field villages founded during the late Great Colonization with the arrangement of houses in rows in wooded terrain;

- Short forest field villages characterized by one or two rows of houses with a maximum village length of up to $500 \mathrm{~m}$;

- Forest square villages typically arranged in a circular shape with radial land around;

- Road village characterized by two rows of houses along the perimeter of the road;

- Roadside labels typical of the local extension of the road in the middle of the village, where the extension forms a small square;

- Street villages typically accessible only from one side, with houses perpendicular to the entire road and at its dead end;

- Square villages, i.e. a typical settlement with a generously designed village area with the location of a church, chapel, pond or school.

The third classification according to Frolec and Vařeka [9] defines only six separate types of village, including:

- A mass village typical of late-colonized mountain forested areas;

- Terraced village, mostly double-row in flat terrain with a burrowing land;

- A row village, arranged linearly along roads, watercourses and areas; 
- A woodland village typical of the terraced order of the individual colonies from the Great Colonization era;

- Forest village, a circular settlement in later populated parts of the country;

- Village with a closed trailer area of different shapes and uses.

The last classification according to Pešta [12] includes a total of seven types of village. Particularly speaking about:

- Villages, which are regularly based on norms based on the given ground plan;

- Bulk burial villages, which, unlike the previous type, do not have a regular ground plan arrangement;

- Growing road villages, which usually arose spontaneously along the road;

- Linear communication villages that originated linearly according to any remote element such as communication or watercourse;

- Rope village, created as a grouping of settlements with a sprout along a linear element or a round square;

- Row or row villages located in one or two rows around roads in the eighteenth century;

- A chain village based on the Moravian-Slovak border with an irregular ground plan.

\section{Description of individual types of villages}

For the purpose of this study, municipalities representing individual characteristic groups of rural settlements within the Czech Republic were selected, with greater regard to the area of interest of the South Bohemian Region, or Šumava and its foothills. For such a set of municipalities, basic characteristics were always found and both current and historical materials depicting maps and real public spaces in municipalities were obtained.

For the purposes of the map comparison, the online database of the Czech Office for Surveying, Mapping and Cadastre, specifically the stable cadastre map from the beginning of the nineteenth century and the current orthophoto map from 2017 to 2019 were freely accessible.

\section{Village with concentrated ground plan and fragmented land around}

\subsection{Village road}

These municipalities are always characterized by an elongated shape around a significant communication line. The houses turn into the gutter road, i.e., longer side and form a continuous row of buildings without gaps. This type of rural settlement does not occur within the area of interest, most often it can be found in the territory of South Moravia. The public space in these municipalities has been 
reduced from the beginning only to the edges of roads and municipalities usually have no other common areas. In history, so much typical areas for common grazing were, if possible, delimited in the space behind the barns. Extensive public space in these villages, at least in visual form, was made possible by frequent front gardens of terraced houses.

The example of the municipality Loděnice (district Brno-Venkov) was chosen as an example of this way of organization of the municipality. To compare a similar type of municipality within the South Bohemian Region, it is possible to use the example of the municipality of Dobrá (Prachatice district).

Village Lodenice comes from the pre-colonization period from the end of the twelfth century. Over time, the village has developed into its present form, when most houses were built as a row brick gutter development. The common public areas of the municipality were, like other road municipalities, reduced to empty areas of roads and part of the undeveloped space between two rows of houses. There is also an early Gothic church of St. Margaret, whose close surroundings also served the inhabitants as a public space. The available preserved map from the beginning of the nineteenth century (Figure 1) also shows typical front gardens in front of residential buildings, which create an extension of public spaces and separate public and private space. The map of the stable cadastre from this period also shows a very low representation of public green areas and the complete absence of common municipal pastures or permanent grasslands and orchards.

Since that time, the public spaces in the village have not undergone any significant development and their state is essentially unchanged. In some cases, they were reduced due to expanding development. In most cases, however, they have been preserved, although their purpose has largely changed. Similar to most municipalities of this type, public and semi-public green areas have undergone a significant change. The public areas were partially reduced, in the village virtually absent significant areas of greenery. The semi-public greenery in the form of front gardens near houses was often rebuilt or completely abolished. Areas often no longer fulfill their function and are used as parking spaces. If the area of greenery was preserved, there were often changes in the composition of green areas to a more modern form. In the case of other areas, development is due to changes in the needs

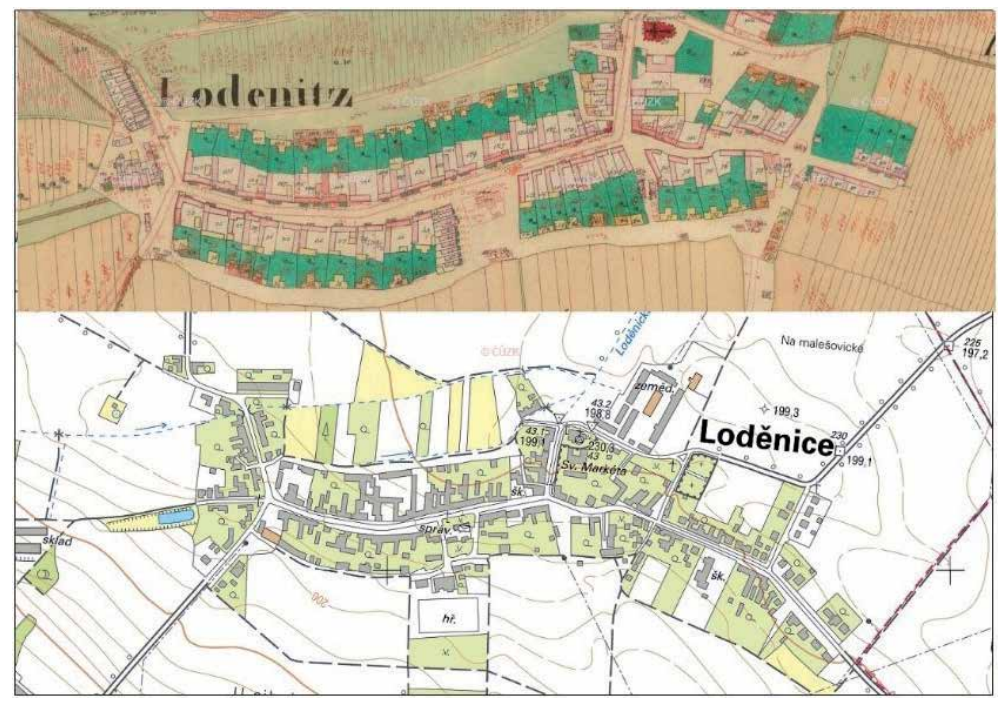

Figure 1.

Historical and contemporary map of the village Lodènice (district Brno-Venkov). 
of the population and to general technical developments. Public areas in the village were supplemented with facilities for public transport as well as collection points for waste sorting. In recent years, a historical monument with a statue of John of Nepomuk has also been restored (Figure 2).

The municipality continues to develop its public spaces in the area beyond the former village borders. There are sports facilities and a cemetery. However, there is no greater background for the children's population of the village.

A not very typical representative of this category of municipalities, as already indicated, is the settlement Dobrá. This village was founded very late in the first quarter of the nineteenth century as a timber settlement in the estate of the princes of Schwarzenberg (Figure 3).

From the beginning, the village was situated around a local road without significant common areas. The village itself had no common land, and all surrounding areas were owned by the owner of the estate. Individual houses stand in isolation surrounded by small gardens with private greenery of individual dwellings. The village virtually from the beginning had no public space or equipment, and there was no church building. After 1945, the village was partially displaced and some houses were destroyed. There were virtually no changes in terms of public spaces. The village has kept its terraced development without any common areas, despite the fact that there are pensions in the village and it is a touristly exposed area (Figure 4).

The reason for the absence of public spaces and insufficient maintenance of greenery around the settlement is probably the absence of a larger number of land owned by the municipality. A large part of the land in the vicinity of the development is nowadays administered by the National Park Šumava, which has no reason to create common areas. The same applies to the land of private owners. Places for the collection of sorted waste are virtually the only public areas that the municipality manages for residents.

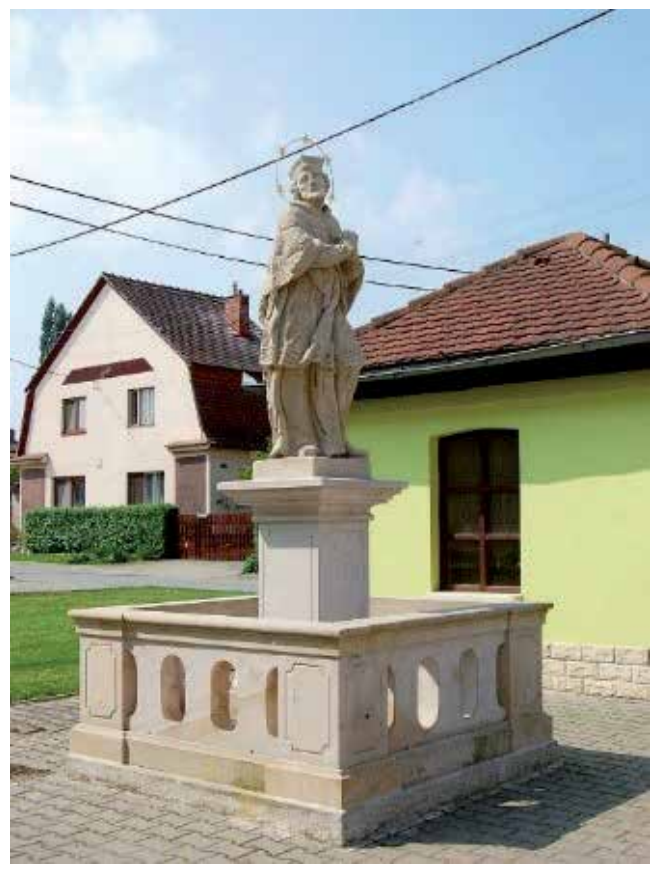

Figure 2.

Restored public space with the statue of St. John of Nepomuk. 


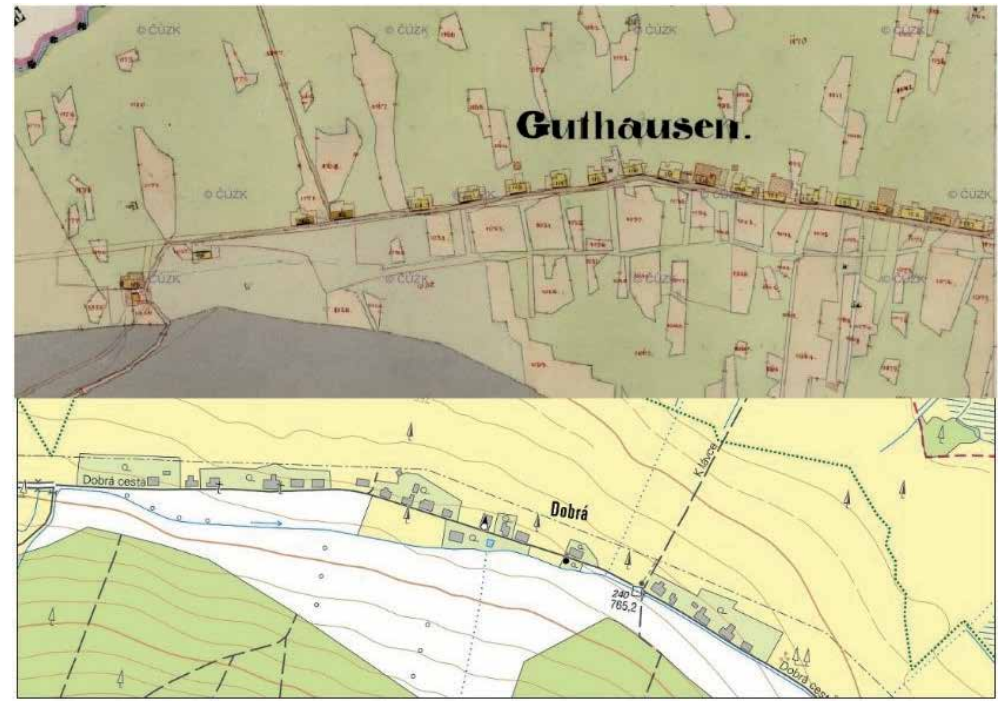

Figure 3.

Historical and contemporary map of the village Dobrá (Prachatice district).

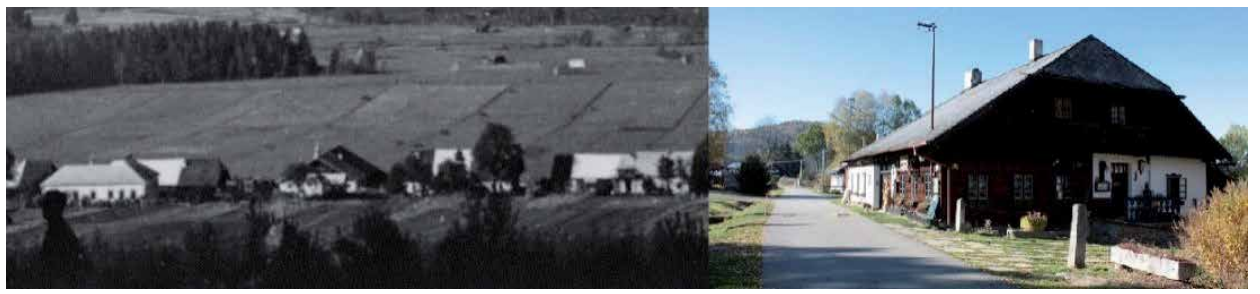

Figure 4.

Comparison of the area of the village Dobrá at the beginning of the twentieth century and today.

\subsection{Road square village}

A special case of road municipalities are the so-called road square villages. These are municipalities or settlements, which, although they also originated around the communication route, there was a slight expansion and created a space functioning as a village square in their central part. These villages also do not have to be typically built by gutter terraced houses; the houses are often turned towards the village green and the gable road (a settlement with a long square passing through a long distance or local road). These municipalities often originated around important market routes, where the extended square area often served as a market venue. These villages originated across all periods of village formation. The settlements on the most important market routes originated in the pre-colonization period, while the settlements in most mountainous areas are from the time of the great colonization. These are then typical of the prevailing German population. Public spaces in these municipalities are mostly represented by a large open space, which was used for holding markets or gathering moving merchants. On the contrary, in these municipalities, there is usually no public greenery in public space.

Mountain villages Kvilda (district Prachatice), Nový Svět (district Prachatice) and Horní Vltavice (district Prachatice) were chosen as representatives of this group of municipalities.

The settlement of Kvilda was founded in the sixteenth century as a seat of lumberjacks working in the surrounding forests. The basis of the village is a road 
forming the backbone of the entire settlement. Individual wooden buildings, including the church, gradually grew around the road. Part of the village forming the square was extended around the church. According to the map from the beginning of the nineteenth century (Figure 5), the municipality as such has virtually no common public space at all in the form of public greenery or common pastures, grasslands or orchards.

The current state of public spaces is largely influenced by the fact that the municipality is very busy. Public spaces thus include rest areas, bicycle stands, benches, etc. At the same time, free parking spaces are left in the open spaces left after the demolished houses of the original German inhabitants. Due to the massive development of tourism and many free areas, the village has also created public green spaces in the form of a small park (Figure 6).

Of course, there are also areas designated for public transport, waste collection and sorting, playgrounds, sports facilities, swimming pools, etc.

A completely different formation of public spaces can be observed at another elected representative of the linear village with the extension of the village square, Nový Svět. Although it is a village that was also founded quite late as Kvilda in the seventeenth century, public spaces are minimal and poorly maintained. Historically, the village formed similarly, and it was mostly a timber settlement (Figure 7).

Historically, this village did not have common agricultural land, in the form of grasslands or orchards. Public areas surrounded the church and the nearby cemetery. The village after Second World War was largely destroyed because of the large percentage of inhabitants that were relocated back to Germany. At present, it serves mainly for recreational and tourist purposes. However, unlike Kvilda, the municipality did not adapt its public areas for these purposes. In the centre of the settlement, there are practically only public transport stops, but without shelters, only in the form of signs, and containers for waste sorting. The municipality does not invest or maintain any areas of permanent greenery in other public areas (except for seasonal cutting of grass edges of roads).

Another representative of this type of village is Horní Vltavice. This municipality represents a completely different type of settlement. The village was founded along the trade route already in the fourteenth century. Historically, the village had

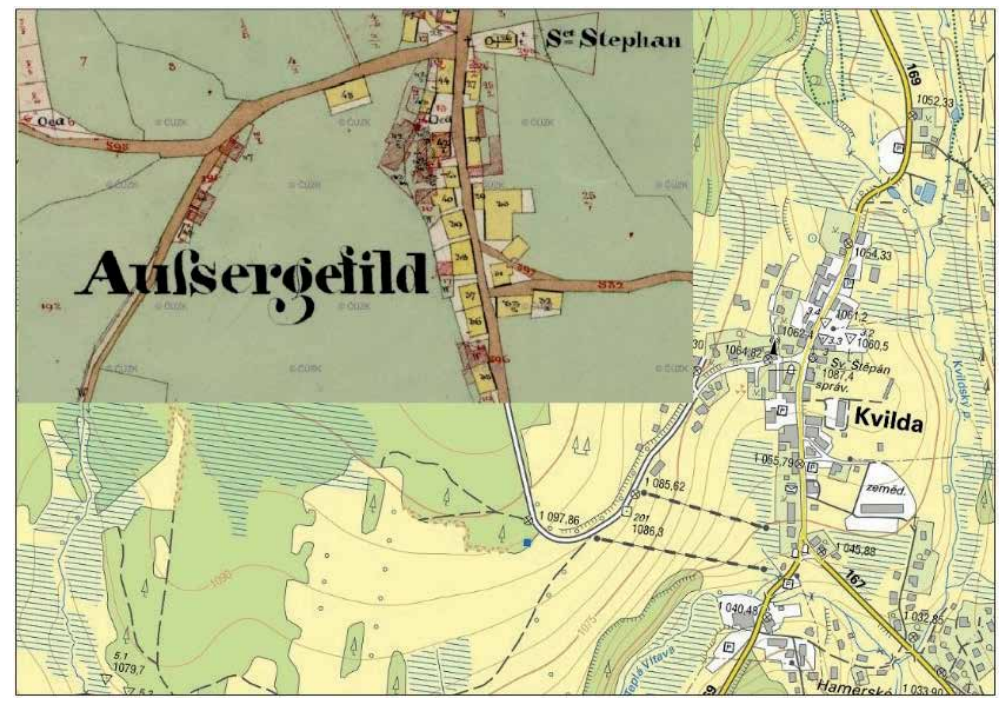

Figure 5.

Historical and contemporary map of Kvilda (Prachatice district). 


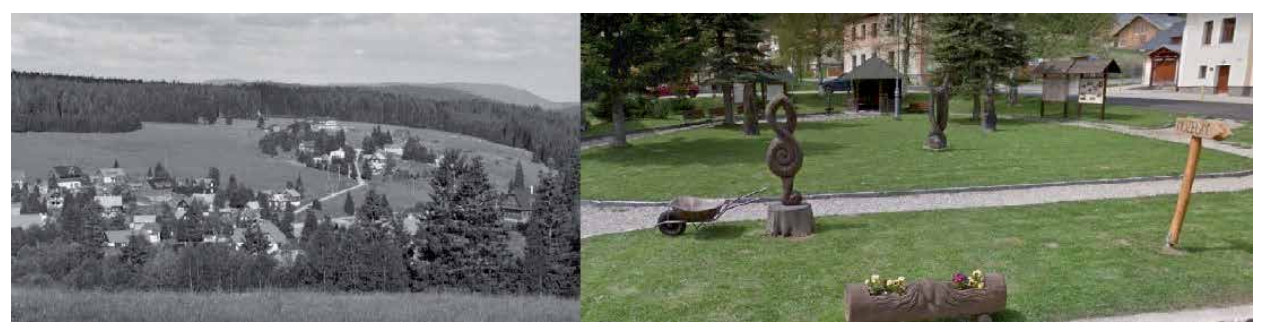

Figure 6.

Comparison of the area of Kvilda at the beginning of the twentieth century and today.

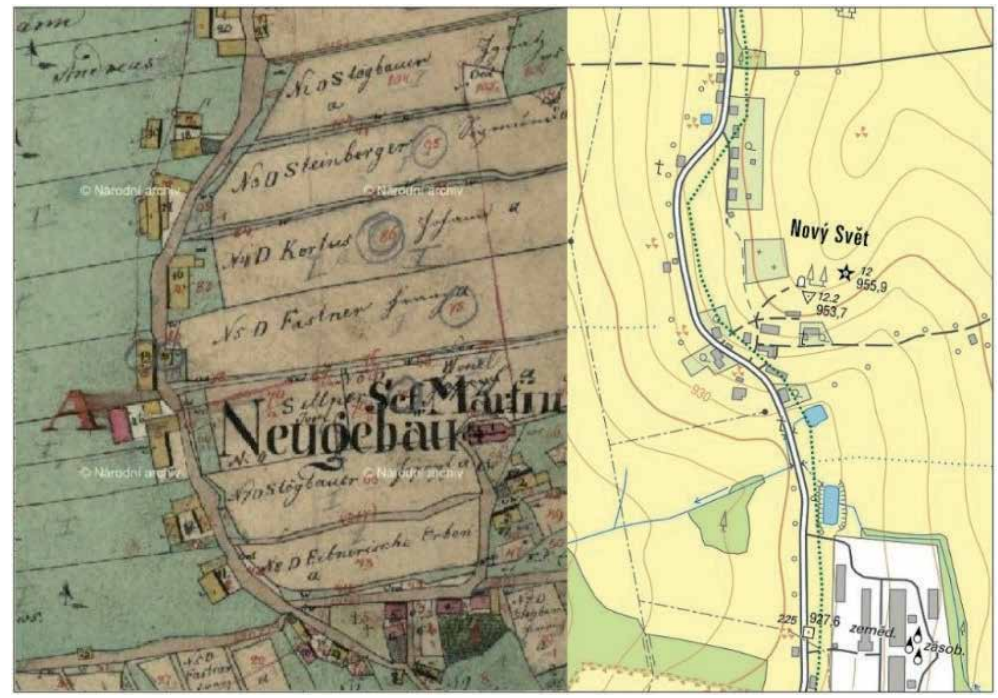

Figure 7.

Historical and contemporary map of Nový Svět (Prachatice district).

a small village square near the church with a cemetery and inn No. 3 (today No. 10). The extension of the main road also served passengers on one of the branches of the Golden Salt Route (Figure 8). The municipality also used meadows in the wider centre of the village as a common public pasture. At present, the key first class road is still going through the village, but the importance of the village no longer corresponds to the historical importance. Public areas of the village are very limited and do not serve their original purpose and do not correspond to their location. The village has created a secondary public area near the ski area from the second half of the last century and near school buildings with a small playground. At the same time, the municipality still uses grassland in the meander of the watercourse as a public space. Today, there are no pastures, but outdoor sports facilities are built this year. The municipality has basically most of public spaces in the form of green grassy areas with sporadically occurring trees in a maintained state corresponding to the importance of the municipality and the number of permanent inhabitants of the municipality.

The quality and facilities of the public areas are not too great and, surprisingly or not, positively influenced by the presence of the ski area and tourism. Of course, in the village, there are public transport stops, but without shelters, and space for containers for sorted waste. It can be stated that the road, which previously brought prosperity to the municipality and increased the quality of public spaces, is today rather harmful and the municipality is burdened with excessive traffic. It can also be an obstacle to greater expansion and improvement of common areas in the village. 


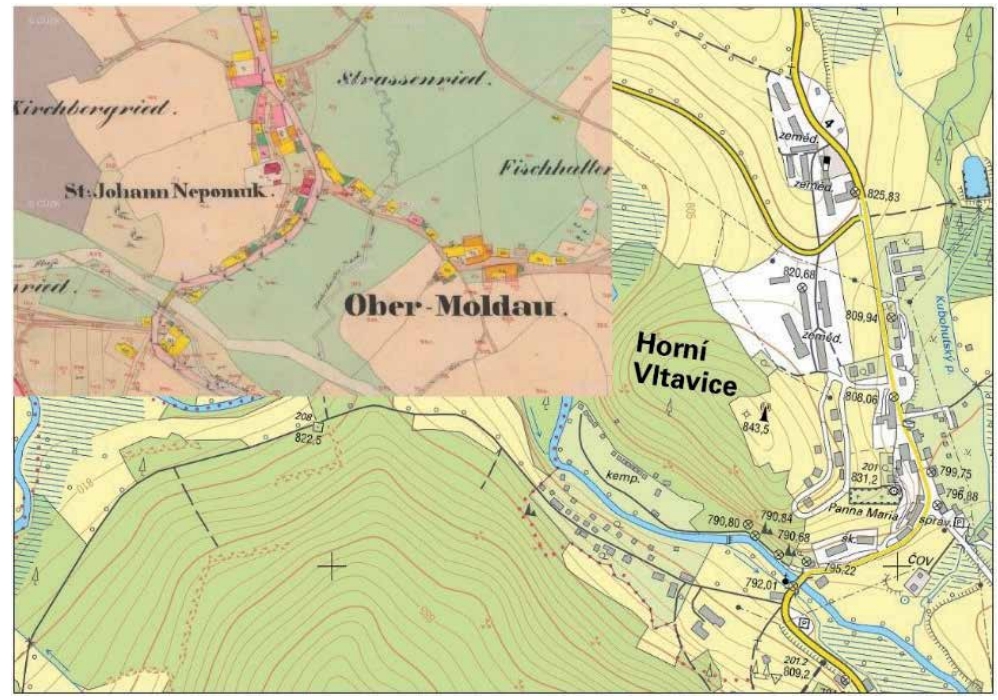

Figure 8.

Historical and contemporary map of the village Horní Vltavice (Prachatice district).

\subsection{Squared village (triangular or rectangular square)}

Squared villages are practically the most common type of villages in the Czech Republic, or in the South Bohemian Region. It is mostly an older type of settlement from the pre-colonization and colonization times, i.e. from the tenth to fourteenth centuries. Squared villages are characterized by a more or less closed village square, into which roads converge from the periphery of the village. The green areas were typically public buildings, religious buildings, ponds, common municipal pastures or open public spaces. These were areas important for the economic and social life of the whole community. Squares can have different shapes, mostly regular, and rectangular, triangular or even circular. There are also municipalities with irregular or otherwise rugged village squares or with several adjoining village areas.

The municipalities of Vyšovatka (Prachatice district) representing the village with a typical rectangular square, Nebahovy (Prachatice district) with a rounded square, Zdenice (Prachatice district) with a triangular square and Ktiš (Prachatice district) with a double square were chosen as representatives of this type of village.

The village Vyšovatka is a typical fourteenth century colonization village with a typical German population. The village was designed from the beginning as a village with a large rectangular space in the middle of the village. This space served as a public space from the beginning (Figure 9).

A chapel was built here and the rest of the space served as a communal pasture. A peculiarity of the village was the location of small equally large gardens, each belonging to one homestead built around the perimeter of the village square. Since its inception, this municipality has practically not changed in terms of the layout of public spaces. Unlike other similar municipalities, the generous village area has not been built up. At present, there is a maintained grassland with sporadic trees in the village square. In this area, there is also a playground, sports facilities and other areas and facilities for meeting residents of the village near the replica of the original chapel. A major change from the past is the absence of private gardens in the village square. At present, the whole square is used as a public space (Figure 10).

Another municipality that was analyzed is called Nebahovy in the Prachatice district (Figure 11). This is another typical colonization village this time with a rounded village square. However, this village has undergone significant changes 


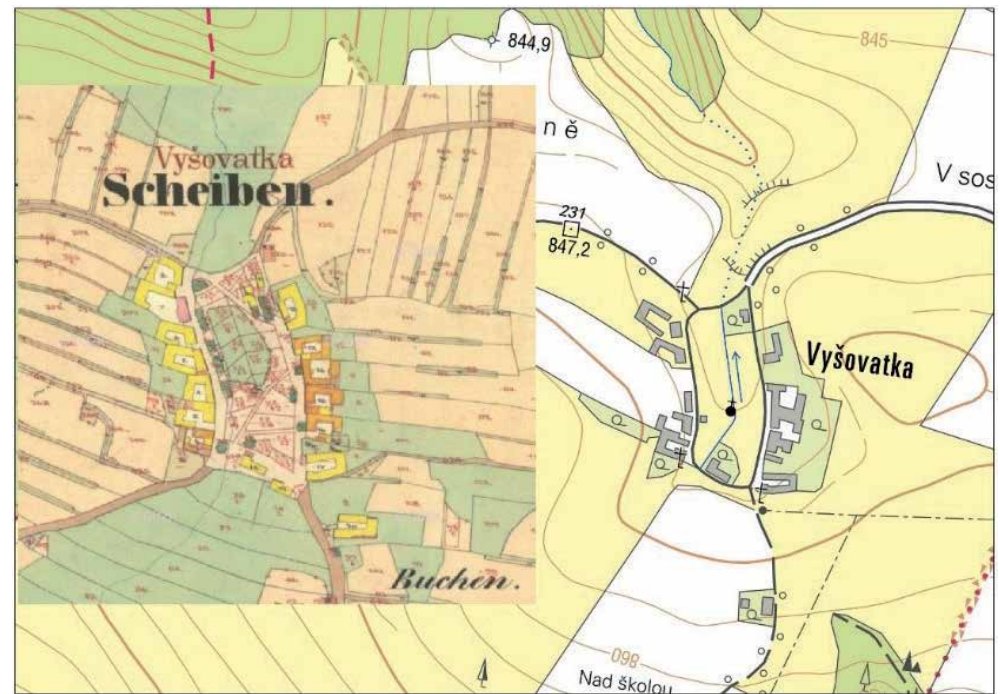

Figure 9.

Historical and contemporary map of village Vyšovatka (Prachatice district).

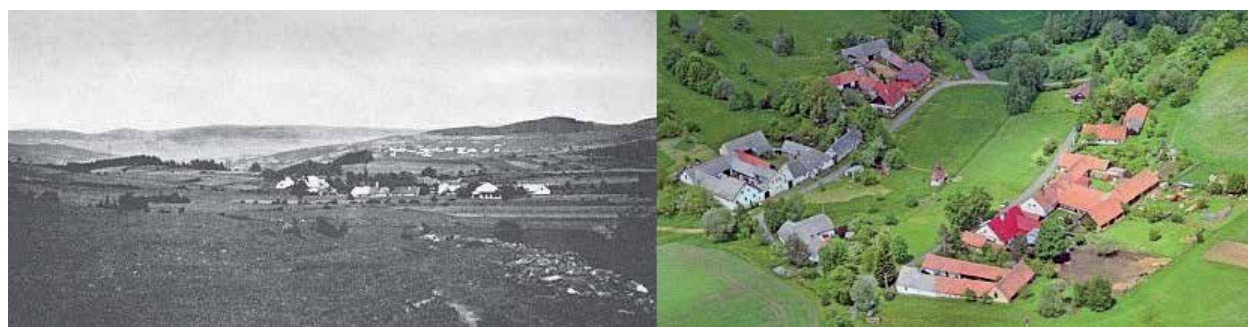

Figure 10.

Comparison of the area of Vyšovatka in the early twentieth century and today.

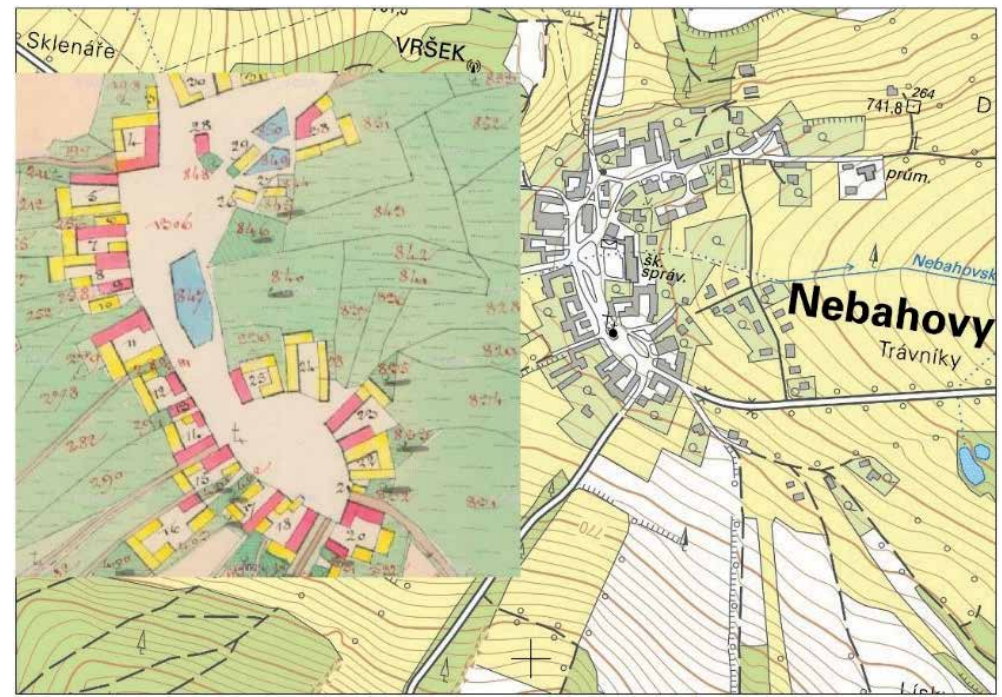

Figure 11.

Historical and contemporary map of Nebahovy (Prachatice district). 
over time in the formation of public spaces in the central part of the village.

According to the original arrangement, the village had a large vacant village square, in which there were a total of three small water reservoirs originally intended for breeding water poultry. There was also a grassy area for grazing small farm animals around these ponds.

Over the last hundred years, the layout of public spaces and buildings has undergone significant changes. The most significant change was the abolition of all three water areas that occurred on the square and the construction of other buildings either along the perimeter or directly in the square. The most prominent objects are the hospitality building and the village chapel. At present, a significant feature of the public space is also a memorable tree in the form of a linden tree and the village is complemented by other new trees. The municipality also has a public transport stop including a shelter, resting places for residents and also nowadays common places for the collection of sorted waste.

By contrast, the neighboring village Zdenice (Figure 12) is a typical representative of the village with a triangular village square. This village also originates from the colonization period, but its square area representing public spaces has not changed much since that time.

The village has an equally shaped triangular square, into which only a village chapel has been added, and during the last century also a shelter for a public transport stop, a tree stands and small furniture. The peculiarity is that even though the village is near the previous village Nebahovy, maintenance of public space is minimal and does not even significantly renewed.

The last analyzed representative of the squared village group is the village of Ktiš (Figure 13). This village differs from the previous not only in the arrangement of the village square, which is divided into two separate parts, but also in size and significance characteristics. Ktiš has always been a centre municipality with a greater importance than in the previous analyzed municipalities. Ktiš is also a village from the beginning of the fourteenth century, i.e. from the time of the great colonization. Atypically, the municipality has two separate green spaces representing virtually the only public space in the municipality, given the fact that the municipality has

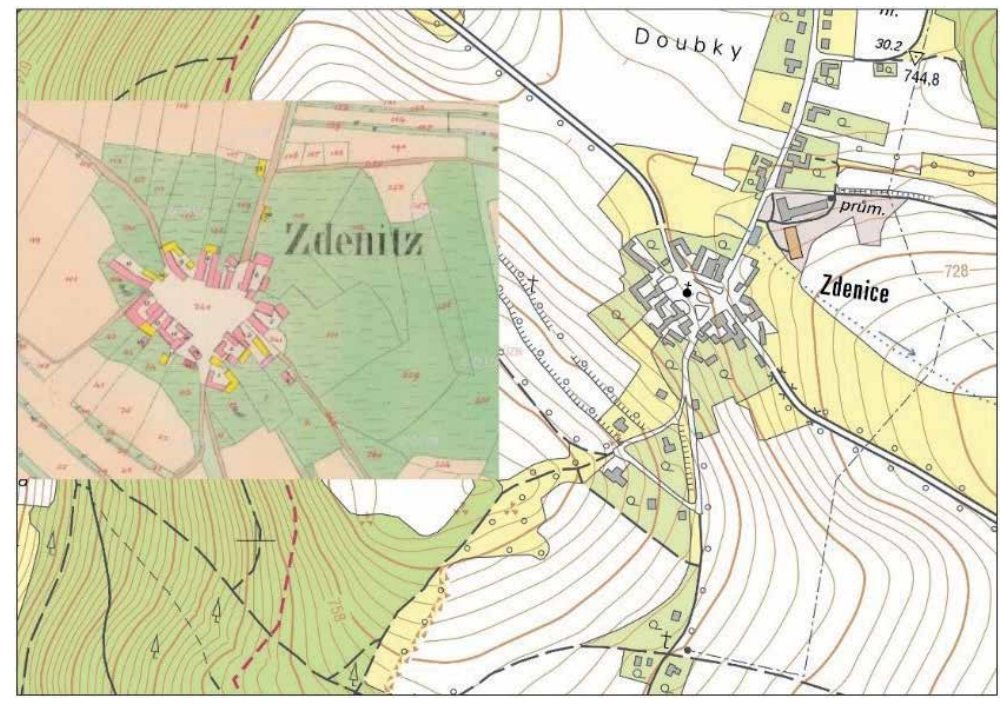

Figure 12.

Historical and contemporary map of Zdenice (Prachatice district). 


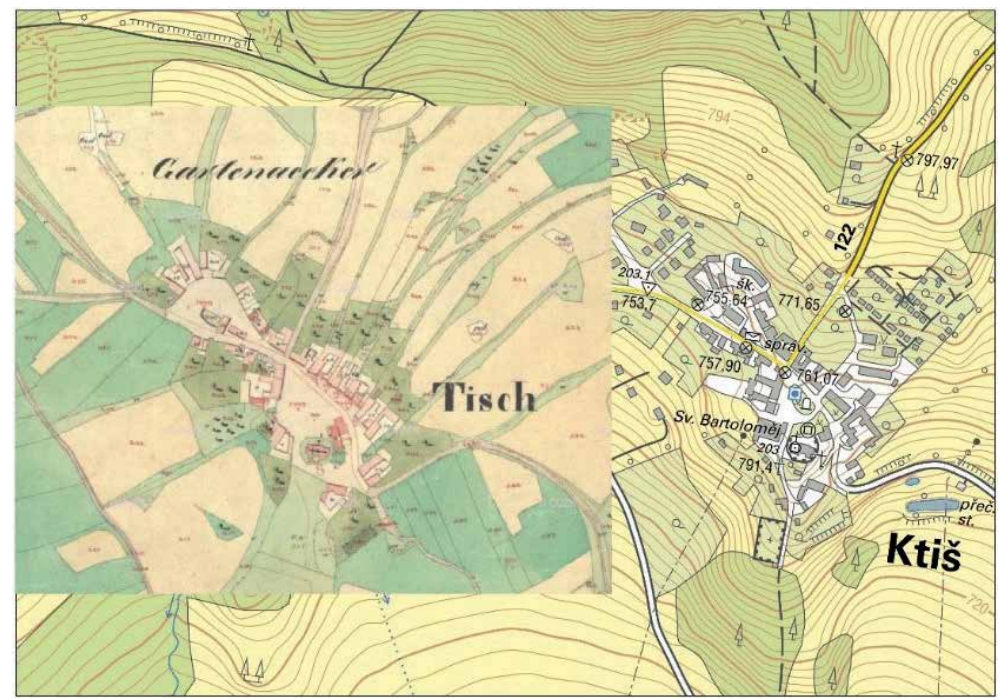

Figure 13.

Historical and contemporary map of Ktiš (Prachatice district).

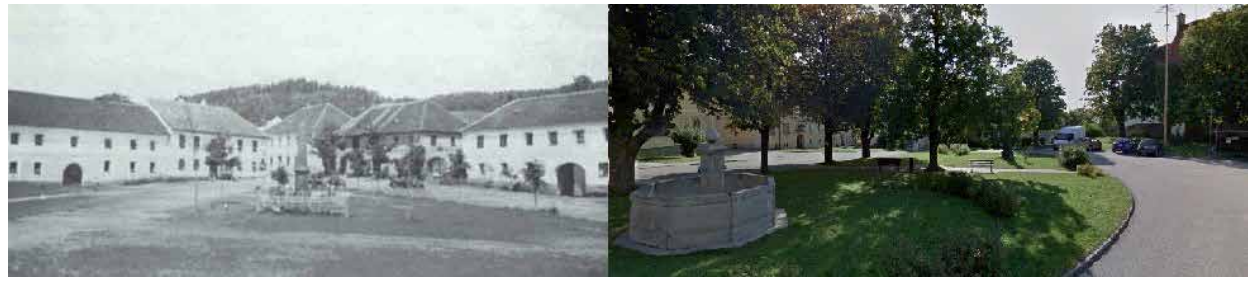

Figure 14

Comparison of the area of Ktiš at the beginning of the twentieth century and today.

virtually no common land in the form of common pastures, grasslands or orchards. Similar to the village of Nebahovy, there was a village pond in the upper part of the village green, which formed the centre of the northern part of the village public areas, while the centre of the southern part was a naturally elevated church with the surrounding cemetery.

Also in this village, public spaces underwent a significant change during the second half of the last century, which included drying the village water reservoir in the northern part of the village square and adding municipal buildings in the close vicinity of the southern part of the village square. In the northern part of the square, the building in the neighborhood of the pond was transformed into a municipal office and a mixed goods store was built on the site of the former water reservoir. In the southern part of the square, there was a cultural house. A new natural centre of public space was the area of public greenery in front of the culture house and church, complemented by a memorial to the victims of the war and a fountain (Figure 14).

The municipality also has public areas designated for transport services and for the collection of sorted waste. However, what the village lacks is a larger area for sports and children's enjoyment. Despite its undeniable importance, the municipality does not pay as much attention to its public space as it deserves. The reason may be the low tourist interest in this location, which does not force the municipality to invest more money into the adjustment and expansion of public spaces. 


\section{Village with free ground plan and compact land}

Another historic type of villages are villages with a free ground plan and solid plots around a characteristic feature such as a stream.

\subsection{Terraced villages}

Terraced villages are the most widespread in this category. These are characterized by one or two rows of houses along a path or stream, mostly in mountain terrain, also known as forest field villages or field villages. These villages are typical for the period of great colonization since the thirteenth century and occur mostly in mountain areas in the border areas of the Republic. Unfortunately, very few of these villages have survived to this day, due to extinction in the second half of the last century, mostly after the displacement of the majority German population. However, some typical representatives can be found that have been preserved either in their original extent or at least partially.

For the purposes of this publication, the municipalities of Dlouhá Stropnice (district of České Budějovice), Chlupatá Ves (district of České Budějovice) or Jenín (district of Český Krumlov) were analyzed. A typical feature of these municipalities was the absence of a significant public space that would serve as a village square. Most of the municipalities used only common land in the central part, usually formed by the floodplain of the brook or around the local road, which formed the axis of the settlement.

The village of Dlouhá Stropnice (Figure 15) is a typical colonization village from the turn of the thirteenth and fourteenth centuries. Individual farmsteads were built on the first river terrace, which allowed the middle of the river meanders to lead not only communication but also to create a large number of common lands serving as pasture and forage source for farm animals of individual farmers. The village did not own any other land in the area and did not create any other public spaces.

The village has practically no public space, which could be used by more than 60 permanent residents and tourists, for whom the location is increasingly attractive. Of course, as in all other municipalities, waste collection bins, a sheltered public

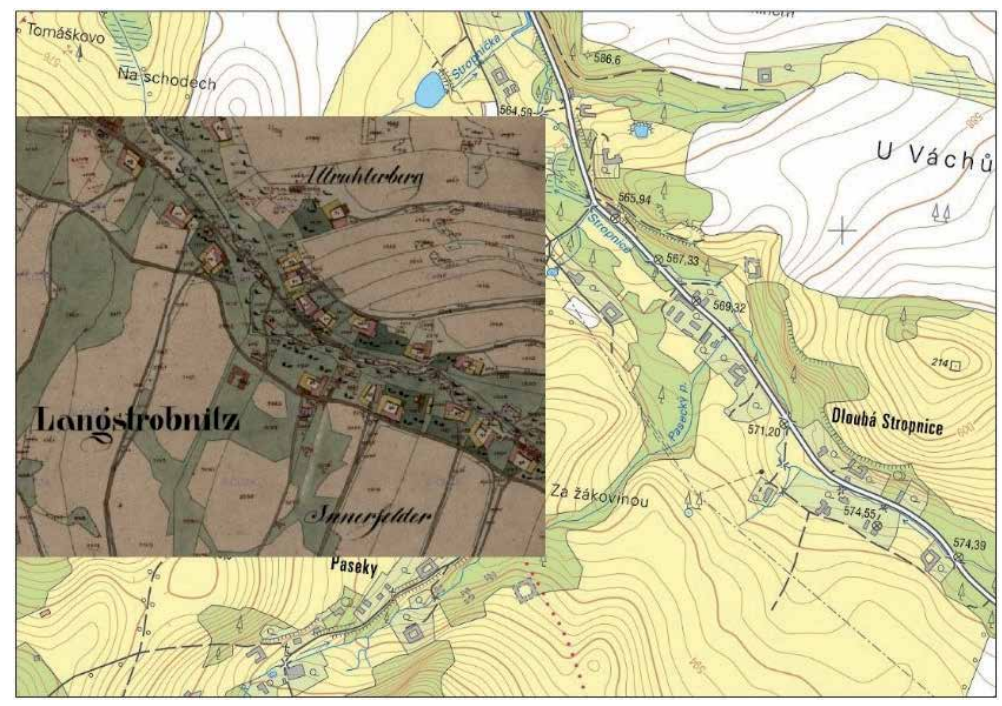

Figure 15.

Historical and contemporary map of the village Dlouhá Stropnice (district České Budējovice). 
transport stop and a public message board can be found in publicly accessible places. The vast plots of the floodplain with green vegetation are not maintained today and are only a landscape feature in the middle of the village.

Similarly, there is another of the analyzed municipalities, namely the village of Chlupatá Ves (Figure 16), which lies near the previous settlement. Furry Village is also a typical German colonization village from the end of the fourteenth century. The settlement had practically the same features as the previous village of Dlouhá Stropnice and was characterized by a large valley floodplain in the middle of the village serving as a pasture area. Unlike Dlouhá Stropnice, the current situation is somewhat different.

Although the village also does not show any large public spaces with significant equipment in the form of furniture, playground, etc., common areas between the individual farms are in good condition and the floodplain is maintained as a large mowed grassland, despite the fact that the village today has only six permanent residents and is also a party of attractive tourist routes.

This shows that the interest of local residents, whether permanent or holidaymakers, who often take over the care of public areas in their own places, is also a significant factor in the state of public spaces (Figure 17).

The last analyzed municipality is the settlement Jenín (Figure 18). As in previous cases, it is also a village from the time of great colonization, founded in the fourteenth century exclusively by German colonists. The village was spread on both sides of the Jenínský creek, in whose valley floodplain was a road and municipal pastures, making up the.

Individual farmhouses were again located on the first terrace above the stream to protect them from the onslaught of large water. A primary school was also located among the farms. It is practically the only public building in the centre of the village. This village again largely disappeared in the second half of the last century after the expulsion of the German population, and currently, 30 people are still living here. In the village there, was in 2007 a new tourist site under the name “Cyklostanice Jenín” (Figure 19).

It is an accommodation and catering facility that not only makes extensive use of the facilities of former farm and residential buildings but also of former municipal

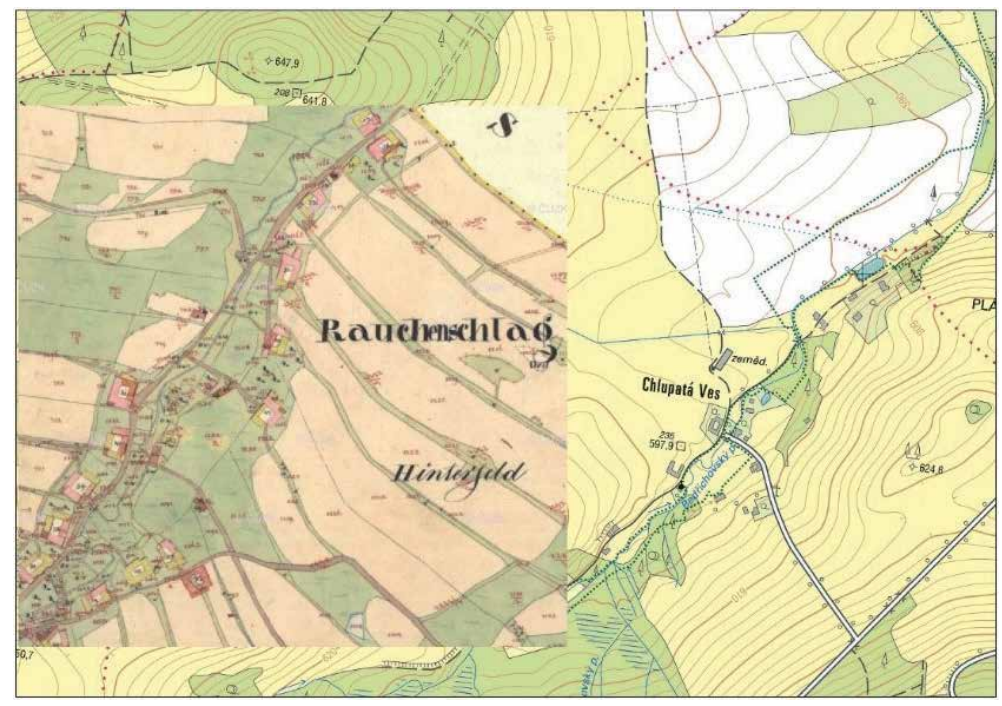

Figure 16.

Historical and contemporary map of the village of Chlupatá Ves (district České Budējovice). 
The Role of Public Spaces in Small Municipality DOI: http://dx.doi.org/10.5772/intechopen.89881
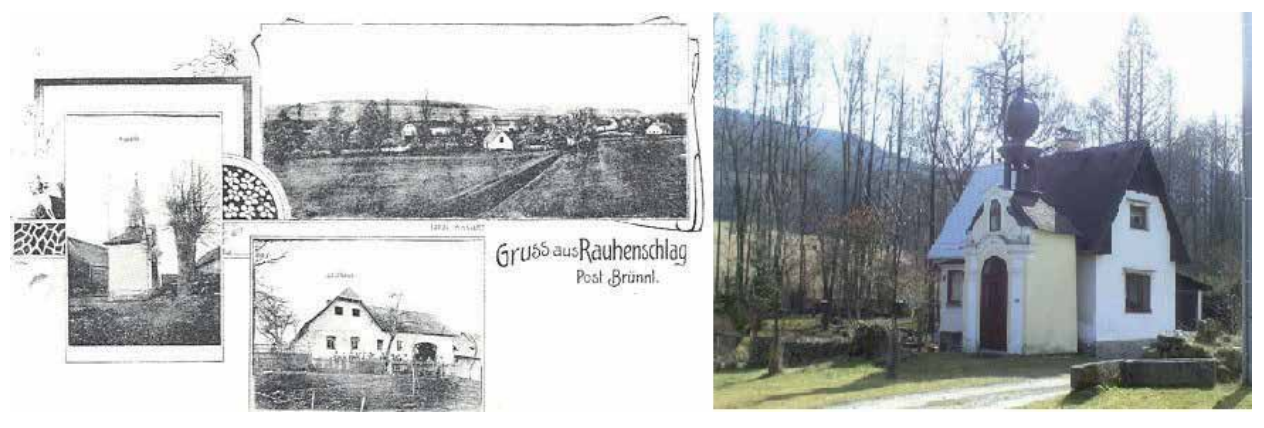

Figure 17.

Comparison of the area of the village Chlupatá Ves at the beginning of the twentieth century and today.

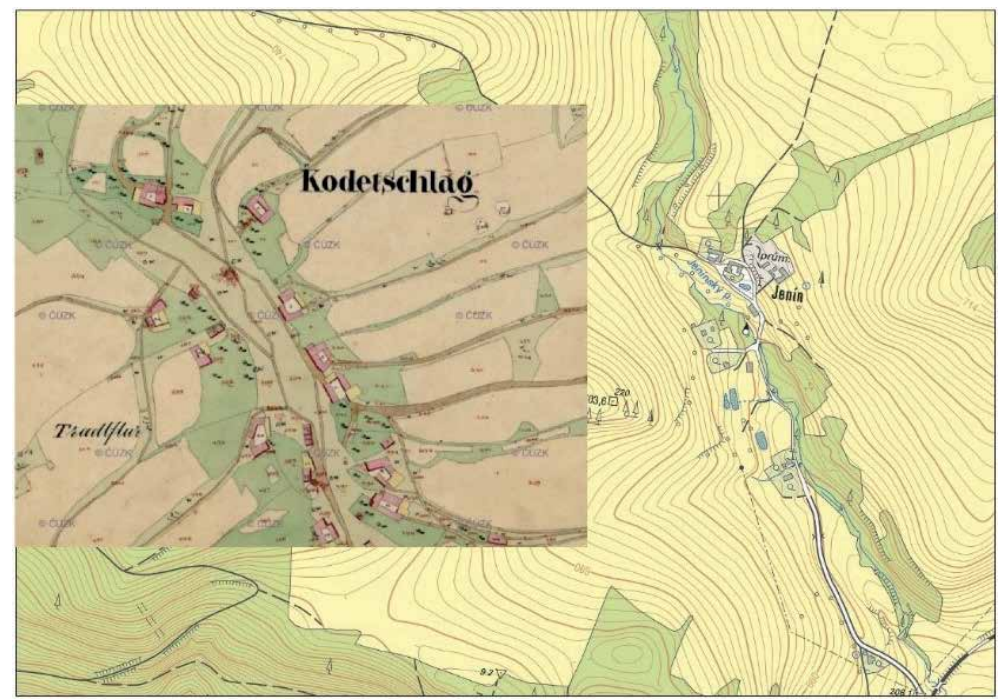

Figure 18.

Historical and contemporary map of the village Jenín (district Český Krumlov).

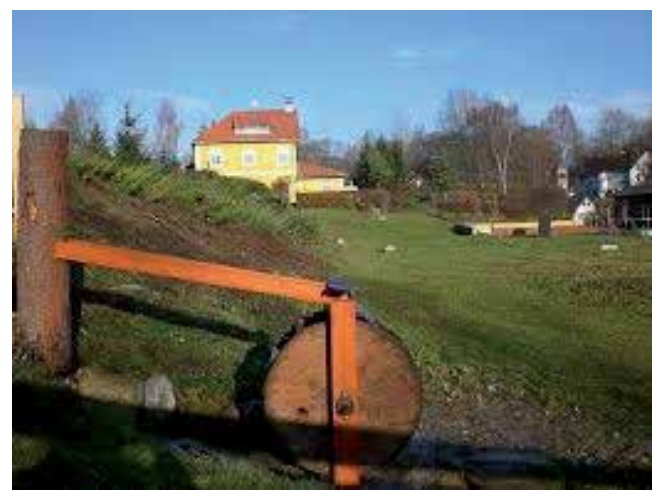

Figure 19.

Example of the area around Cyklostanice Jenin.

public spaces. Since the establishment of this facility, there has been a significant shift in the care of land forming the centre of the former municipality. The land is partly used again as a grazing area for small farm animals (sheep, goats, donkey, llamas, etc.) but also sports grounds, a fish pond and a playground were created. 
Due to the increasing interest of tourists, as well as locals and holidaymakers, the areas representing the village have undergone a significant change. Of course, well-kept ornamental foliage and suitably built-in elements of the technical infrastructure, including containers for sorted waste, as well as minor elements of sacral architecture and historical landmarks, have become a natural part of public spaces. In recent years, even public roads have been reconstructed, which until recently were the only significant defect in the appearance of public spaces due to their poor technical condition.

\subsection{Mass and court villages}

The last two characteristic types of villages in our region are mass villages without a clear plan, irregularly distributed especially in the mountain terrain, respectively, farmyard villages characterizing scattered settlements freely in the terrain. These settlements originated relatively late in terms of establishing villages in our territory, mainly as a result of economic activities such as logging, glassmaking and metallurgy. These settlements usually lack significantly shaped common land in the form of public areas, and these areas usually do not form today. Unfortunately, a large part of these villages and settlements were destroyed in the second half of the twentieth century, both because of the displacement of German residents, who were virtually exclusive residents of these settlements, and also by establishing a border zone when settlements disappeared because of their inaccessibility. Most of these places were then demolished, only isolated buildings subsequently served as part of the border guards. Such settlements included, for example, Knížecí Pláně (Prachatice district) or Bučina (Prachatice district) (Figure 20). An example of an existing settlement can be Horská Kvilda (Klatovy district).

The first written mention of the settlement of Horská Kvilda (Figure 21) dates back to the second half of the sixteenth century. Settlement was probably related to the movement of people on the trade Golden Salt Trail. From the beginning, the local development had the character of scattered settlements and only a few places along the main road were the buildings more concentrated. Settlement for a long time consisted of only a few settlements and the population increased only in the eighteenth and nineteenth centuries in connection with the development of glass and woodworking in the surrounding forests. At that time, scattered solitude arose in the surrounding forests. The decline in population occurred with the expulsion of the German population after the end of World
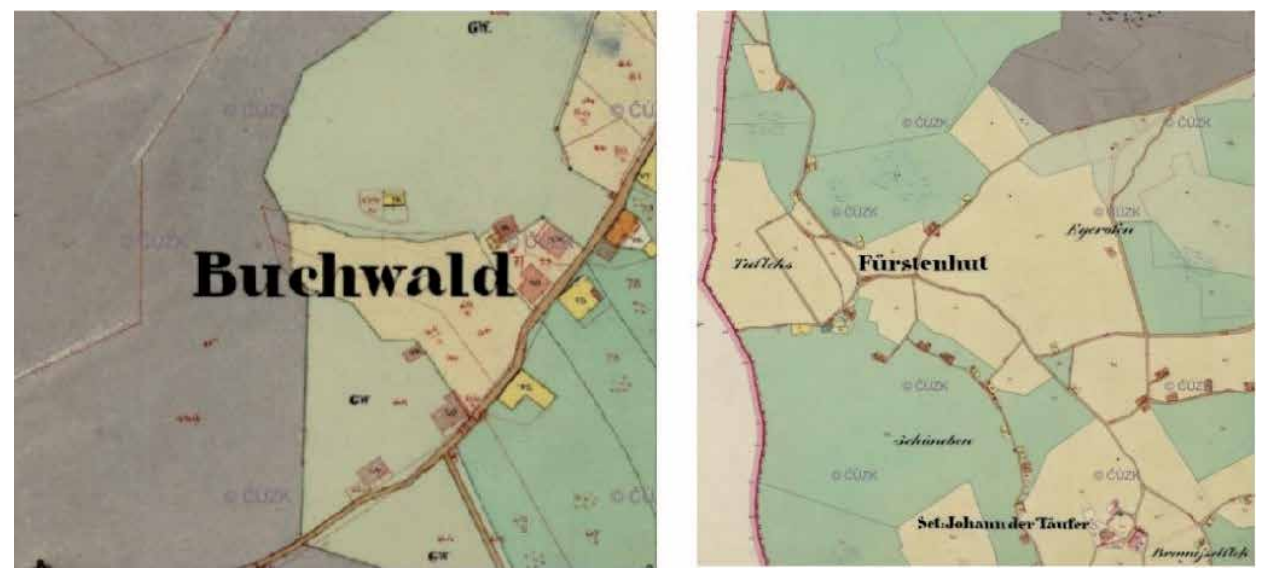

Figure 20.

Historical map of extinct villages Bučina and Knížecí Pláně (district Prachatice). 


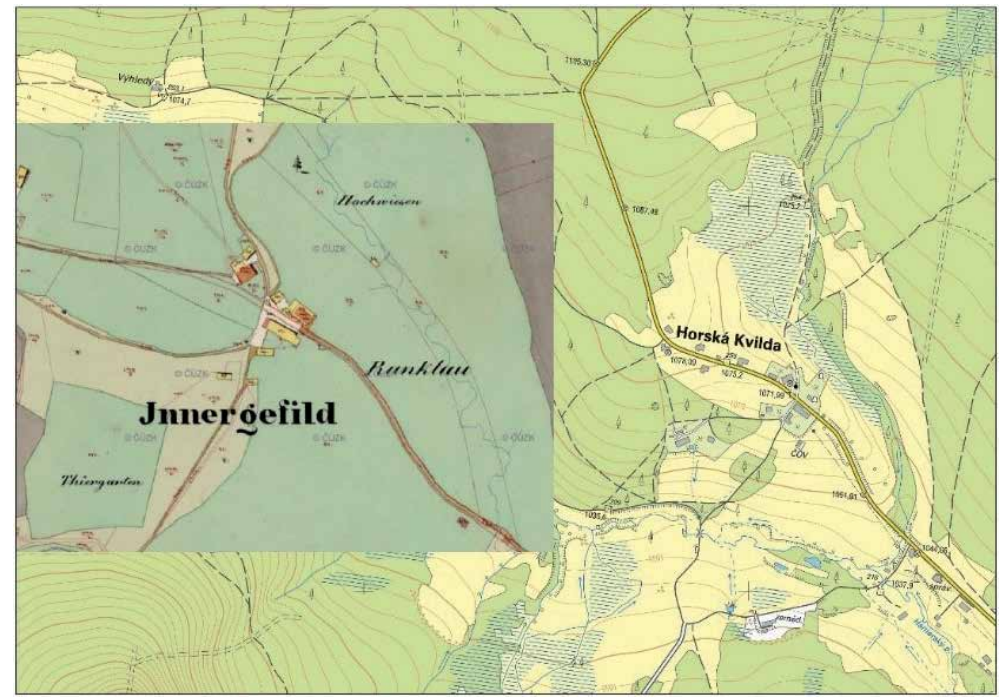

Figure 21.

Historical and contemporary map of Horská Kvilda (district Klatovy).

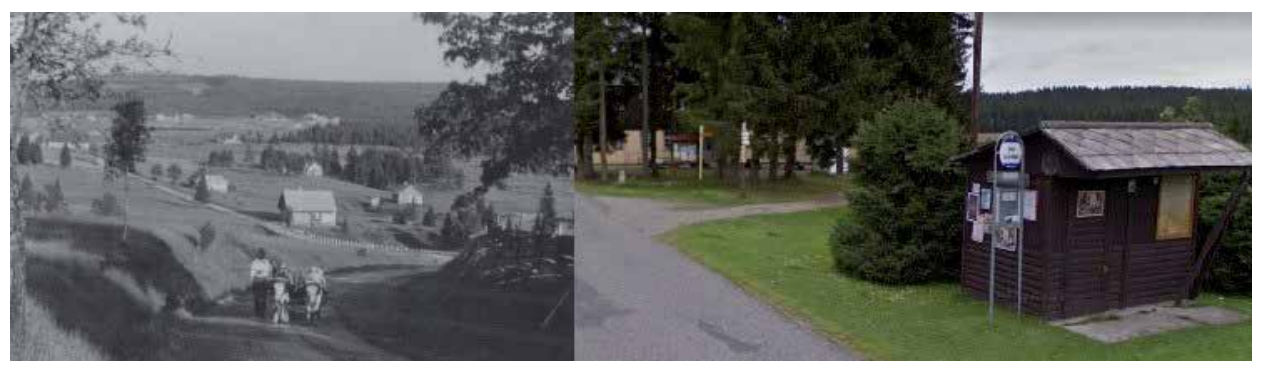

Figure 22.

Comparison of the area of Horská Kvilda at the beginning of the twentieth century and today.

War II and then continued until the end of the 1980s. Currently, there are 31 buildings, of which 19 are still inhabited by 73 people.

The municipality practically never had any public spaces serving economic or social activities. The same situation persists in the village to this day, when practically the only area serving as a public space is a small area of public greenery in front of the municipal office, where there is also a message board and classic park furniture in the form of benches (Figure 22). It is interesting that the village has no need to create and maintain no public spaces, although it is a highly exposed tourist site, both in summer and winter. In winter, the village only participates in the maintenance of ski trails around the village.

The absence of public spaces only proves and documents the strength of the traditional arrangement of this type of village, although tradition was severed in the last century by the displacement of indigenous peoples.

\section{Conclusions}

In conclusion, it is possible to state that the various types of public spaces in municipalities are largely influenced by the historical formation and geographical conditions in the place where the municipality was founded. The development of 
public spaces was reflected in the entire historical development, especially in the last 100 years, when there were major changes in the structure of municipalities in both social and economic terms. There have been many changes in the equipment of municipalities, development and use of open spaces, very often in response to changes in the mindsets and needs of rural residents. Especially in traditional agricultural areas, changes are minimized and reduced only to changes in population needs. The location of public spaces and their care (financing of maintenance, etc.) as well as their equipment is also strongly reflected in the exposure of the localities from the point of view of tourism. As has been documented on many examples, neighboring municipalities with different attractiveness for tourists have a completely different approach to public spaces and these are also widely used.

\section{Acknowledgements}

The publication was funded by the project of Technological Agency of the Czech Republic Nr. TL02000322 Thermal comfort in villages: feeling of inhabitants, physical reality, role of greenery and by the project of South Bohemian University in Ceske Budejovice GAJU Nr. 045/2019/Z Influence of landscape management on ecosystems, landscape function and organisms.

\section{Author details}

Jana Moravcová*, Jiri Pecenka, Denisa Pekna, Vendula Moravcova and Nikola Novakova

Faculty of Agriculture, Department of Landscape Management, University of

South Bohemia, Ceske Budejovice, Czech Republic

*Address all correspondence to: moravcova.janca@seznam.cz

IntechOpen

(C) 2020 The Author(s). Licensee IntechOpen. This chapter is distributed under the terms of the Creative Commons Attribution License (http://creativecommons.org/licenses/ by/3.0), which permits unrestricted use, distribution, and reproduction in any medium, provided the original work is properly cited. (cc) BY 


\section{References}

[1] Ambrožová Z. Veřejné prostory malých měst-teoretická východiska. Urbanismus a územní rozvoj. 2010;13:14-20

[2] Krykorková Z. Veřejné prostranstvísoučást kvalitního života. Sborník Asociace pro urbanismus a územní plánování České republiky. Veřejná prostranství: veřejné prostory, sídelní zeleň, krajina v územním plánování. 2008;1:23-25

[3] Pondělíček M. Zeleň v urbánním prostoru jako indikátor kvality života města. Regionální rozvoj mezi teorií a praxí 2010. Regionální rozvoj v době krize; 6th May 2010; Pardubice, Czech Republic; 2010

[4] Vacek L. Veřejná prostranství a jejich plánování. Urbanismus a územní rozvoj;16:66-70

[5] Madden K, Filáková B. Utváření místa: př́ručka k vytváření kvalitních veřejných prostranství. Nadace Partnerství: Brno; 2003. 99 p

[6] Pešta J. Encyklopedie českých vesnic. Praha: Libri: Díl II.-Jižní Čechy; 2004. $450 \mathrm{p}$

[7] Vařeka J, Scheybal JV. Lidová architektura: encyklopedie. Praha: Grada Publishing a.s; 2007. 428 p

[8] Černý E. Zaniklé středověké osady a jejich plužiny: metodika historickogeografického výzkumu v oblasti Drahanské vrchoviny. ČSAV: Praha; 1979. 167 p

[9] Frolec V, Vařeka J. Lidová architektura a lidové stavitelství. SNTL/ Alfa: Praha; 1983.360 p

[10] Máčel O. Základní problematika urbanistické struktury vesnice $\mathrm{v}$ Čechách a na Moravě: část prvá. Výzkumný ústav výstavby a architektury: Brno; 1954. 221 p
[11] Máčel O. Základní problematika urbanistické struktury vesnice $\mathrm{v}$ Čechách a na Moravě: část druhá. Výzkumný ústav výstavby a architektury: Brno; 1955.30 p

[12] Pešta J. Plošný průzkum lidové architektury a venkovských sídel. Praha: Národní památkový ústav, územní odborné pracoviště středních Čech v Praze; 2014. $170 \mathrm{p}$ 



\title{
Human-Centered Approaches in Urban Analytics and Placemaking
}

\author{
Eleanna Panagoulia
}

\begin{abstract}
Planning for resilience and enabling positive design outcomes require combinatory methods of working with data, in order to assist decision-makers to develop evidence-based methodologies and to communicate new knowledge. The staggering rise of technology and the integration of data-aided analysis tools in urban planning not only facilitates our understanding of socioeconomic flux but also attempts to actively involve users to participate in the creation of environments that are responsive and appropriate to their needs. This chapter aims to contribute to the discourse on user involvement in design-oriented fields, and specifically in urban planning, by analyzing two different approaches of user participatory design, those of indirect and direct participation.
\end{abstract}

Keywords: user-centric design, open-data, data-aided analysis, participation, evaluation, 'reblock'

\section{Introduction}

Planning for resilience and enabling positive design outcomes requires combinatory methods of working with data, in order to assist decision-makers to develop evidence-based methodologies and easily communicated scenarios. To accomplish this, we need to bring together data and information sets from disparate and vastly divergent disciplines and sources. The impactful rise of technology in urban planning has allowed for the extensive integration of data analysis tools, which promote a better understanding of socioeconomic fluctuation, as well as the active involvement of users in the planning process. In this way, users can participate and impact the planning process toward outcomes, which are more appropriate to their needs [1]. Evaluating urban environments is not only important from the planners' perspective but also has larger implications for the residents themselves. This shifts our thinking toward democratic environments, where users engage designers by expressing their preferences on how an idea could become part of their lives. This chapter aims to contribute to the discourse on user involvement in design-oriented fields, in our case, urban planning, by analyzing two different approaches of participatory design. The first approach addresses user participation as a research method or an analysis tool and the second as an urban design method. The key aspect to both approaches is open data platforms, as they allow access to the intended audience, researcher, or average user. Both approaches are presented through example case studies that are analyzed and compared based on the type of user participation, amount of user involvement, and type of context they are applied to. The two case studies represent different stages of participatory design, 
where the first focuses on the integration of human perspective in neighborhood evaluation and the other on active, contextualized user participation in placemaking and neighborhood reformation. Both processes address human perception as an effective means in capturing the dynamics of space, as well as a mean to drive the change itself. User participation is the agency upon which, local resilience is formed by balancing the power between stakeholders and community members. We support that user-centric approaches improve society well-being and user satisfaction, toward more democratic and sustainable urban environments.

\section{Participatory design}

In order to improve policy-making and the health of communities, collaborations often extend beyond the level of academic research, to that of the user level. Recent research suggests that researchers create more innovative concepts when taking advantage of user input than working purely with existing data sets. Humans are positioned as the major contributors to changing environments [2]; therefore, human factor should be addressed and included when conceptualizing urban analysis methodologies. This approach has a political dimension of user empowerment and democratization, and it is called participatory design approach. Participatory approaches link together all stakeholders (e.g. employees, researchers, customers, citizens, end users), in an attempt to improve human well-being, user satisfaction, accessibility, sustainability, and livability. As participatory processes are more and more supported by information technology, this enables both sides, users, and researches to understand and collect diverse knowledge, for example, opinions, ideas, objectives, statements, etc.; however, it increases the complexity and the handling of information when it comes to decision-making. Regarding user participation, the possibilities of digitalization should be regarded as an opportunity to accompany the social transformation toward a digital society in the information age of the twenty-first century [3]. A participatory process involves the side of the researcher or organizer and the side of the participants. In this chapter, we present two different directions of the above relationship: indirect user participation and direct user participation. In the first case, the users seek no personal interest in the process; however, they state their opinion regarding a real matter, which is proven useful in understanding urban dynamics. This process involves two stages that depict different processes. The results are then combined in a series of maps. The second case is a deliberate process in which the interested party (citizens) is involved in the policy-making toward the satisfaction of their needs. The process involves the construction of a digital platform that is user driven. This approach builds upon participatory action research by moving beyond participants' involvement and producing solutions to problems rather than documenting the results as a resource database. Further stages may then focus on community brainstorming, modeling and prototyping, and implementation in community spaces.

\section{Challenges of central urbanism methodologies}

Urbanism during the twentieth and beginning of twenty-first century was formed by large-scale centrally planned developments. In the 1960 s until early 2000s, several urban analytics models incorporated computational tools that introduced automation and standardization, in order to visualize and understand the urban space. One of the most widespread used tools that revolutionized mapping since the 1960s was geographic information system (GIS), which enabled the 
association of geo-location with information. GIS systems are able to visualize time and space paths as static models using models of space and time that show the entire path within a geographic space and a fixed domain of time [4]. This has greatly lowered the cost of data accumulation and improved the accuracy of the results [5]. The main data source employed in central urban model is census data from government databases, which with the use of GIS tools can be visualized and mapped.

Central urbanism presents certain challenges, which derive from two sources: the first is related with technical aspects of data sets and data handling and the second with socioeconomical aspects that influence the fluctuation of capital and investments related to urban space and infrastructure.

1. Centrally planned urbanism refers mainly to the broad picture of the urban environment; as a result, it does not address local details adequately. Centralized, top-down approaches do not derive in resilient conditions as they usually favor certain economic interests. In contradiction to bottom-up approaches, central-based urbanism does not rely on evidence-based methodologies, and therefore they do not involve user participation.

2. In addition to the above, centralized approaches involve money-oriented developments, which do not respond to local citizens' needs; in fact, they usually undermine them. As they largely follow the dictates of social and economic elites, they are based around uneven development and exclusion, increasing economic segregation.

3. Centrally planned urbanism is based on limited data sets and assumptions, which fail to address cities as arrays of social complex relations. Such assumptions engendered vehicular domination over walkability, maximized urban density, and homogenized urban districts all at the expense of residents' quality of life. It appears that there is hardly any empirical data or residents' input that provide insight into most central-based master plan developments. Central urban models are guided by a set of specified constraints that perform in a simplified environment disconnected from real facts; thus, they may not capture complex dynamics of socioeconomic flux. One explanation for this is the difficulty of adequately incorporating the breadth of social theory needed to account for the range of urban mechanisms. For instance, even the analysis of the relationships that occur in a park of a business district neighborhood during day and nighttime quickly becomes a complicated problem to describe through census data. These models are constrained by their inability to theoretically ground mechanisms of neighborhood change and translate them into a data set. They are limited by a lack of empirical detail, in their specifications of data attributes.

The challenges listed above derive from the fact that the processes employed mask a great deal of heterogeneity between urban areas. This resulted from deficiencies in the data sets and short time-scale of the analysis, factors that designated the low predictive capacity of the models, and the insufficiency to fully understand neighborhood dynamics, which remain ambiguous and conflicting.

As cities are becoming more instrumented and networked, more data is being generated about the urban environment and its residents, allowing urban designers to access the local scale fabric of the city, opening up new research directions for understanding the city. Going beyond traditional data sources, such as census, which is fairly static and updated only every, designers are encouraged to engage with other types of data that capture the ephemeral side, such as, people's desires, problematic, trends, etc. It is important for designers and planners to recognize the 
opportunities for making better sense of public space through technology. One of the key benefits of adopting a data-driven approach to urban analytics surveys is the ability to see a combination of datasets in context with each other and to detect temporal and spatial patterns.

\section{Challenges of participatory design}

A new generation of researchers has been deriving evidence-based rules for urbanism, which benefits from user participation [6]. These rules replace outdated working assumptions that have created dysfunctional urban conditions. Recent methodologies in urban research validate human scale urbanism and collaborative approaches. In order to provide a better understanding of the contradictory approaches, we will list some of the main challenges of centralized urbanism. Moving beyond the form-oriented framework of centrally based urbanism, we should also refer to certain challenges that the participatory approach entails.

The growing desire of involving participants in the process represents certain challenges that need to be addressed for successful decision-making [7]. Building user participation systems in response to the complexity requires a combination of data, which is fit for use and decision support tools. We list some of the key barriers that are present in user participation approaches.

1. Complex data user inputs. User data inputs are usually complicated data types. For example, natural language text, descriptions, sketches are a challenge for computers to interpret and also for researchers to translate them into a binary or measurable form. This type of data is also difficult to store, categorize, and visualize in a proper way for future interpretation.

2. The translation of miscellaneous forms of data input is a labor intense, manual analysis and might result in potentially obscuring part of knowledge that can be drawn from the raw user data.

3. Ensuring that the user understands the request and is able to provide useful feedback. Abstract requests could result in user distraction, which can complicate the feedback data previously described in the first point. Moreover, researchers will need to consider that the user input should not rely heavily on the users technical skills and prior knowledge of the tools, as this would limit the target user group to a very small pool of people, which would have the expertise.

4. Citizens are often a resource of small-scale ideas that could improve the livability of their immediate environment. However, it is hard for local people to coordinate and produce visualized results that they could communicate with the authorities. Even so, such proposals are likely to be discarded as they do not represent the stakeholders' benefits and moreover, large-scale developers make it impossible for citizens to have any influence in urban development.

Based on the above, opening a channel for sharing knowledge and opinions is not necessarily sufficient for building a system that takes the most advantage of user input. The objective is to achieve a balanced relationship between extensive information and clarity, in order to ensure that all the data and their interconnections are handled to their entirety. We need to build human-computer interaction in a way that it facilitates user orientation and comprehension of the framework, defines the 
scopes of the user and the researcher, and translates the user input into a quantifiable entity. Therefore, we refer to a software workflow/application that ingrates user input in a form of binary data that can be easily quantified, categorized, and visualized. To avoid oversimplification of the process, the insight of the researcher is crucial, in order to extract valuable, subjective information in a simple format.

\section{Case study 1: urban analytics through crowdsourcing methodologies}

\subsection{Introduction}

The first example is a mapping process of the gentrification and displacement rate and livability levels in the neighborhoods of Oakland in the San Francisco Bay Area. Before analyzing the methodology of the example, we should first understand the notions of neighborhood and gentrification as addressed in this chapter, which will provide clarity regarding the reasoning behind the example methodology.

The neighborhood is often understood as the physical building block of the city for both social and political organization [8] and thus combines physical and nonphysical characteristics. Early scholars have described neighborhoods as defined, closed ecosystems, characterized only by their physical elements, such as size, density, demographics, etc. that would get disrupted by external factors, such as new residents. Moreover, neighborhood change has been regarded as a natural process of population relocation and competition for space, until a state of equilibrium could be reestablished. Based on these ideas, neighborhoods were presented as a deterministic model and categorized based on simplified criteria such as their residents' financial status, etc. However, neighborhoods are not introverted, autonomous clusters, and the mechanisms of neighborhood change do not rely on exclusively external factors. According to Jacobs [1], nowadays, people identify a neighborhood by a landmark in the city because it has become intimate from daily use or encounter. The key that creates the notion of a neighborhood is diversity and identity. She argues that people tend to avoid visiting places that do not represent any variation either in function or esthetics [1]. Although the modern way of living has urged people to be more mobile than previously, people tend to pay attention to district that surrounds their home if it meets the certain criteria that fit their lifestyle. The stability of a neighborhood relies on its capacity to absorb opportunities and sustain its diverse character. In this paper, the term neighborhood can be described as an instance of organized complexity [1].

The notion of gentrification can be described as one category of neighborhood change and is broadly defined as the process of improving and renovating previously deteriorated neighborhoods by the middle or upper class, often by displacing low-income families and small businesses. The first documented use of the term "gentrification" [9] describes the influx of a "gentry" in lower income neighborhoods. Owens identifies nine different types of neighborhoods that are experiencing upgrading: minority urban neighborhoods, affluent neighborhoods, diverse urban neighborhoods, no population neighborhoods, new white suburbs, upper middle-class white suburbs, booming suburbs, and Hispanic enclave neighborhoods [10]. Gentrification does not only rely on a singular cause, as it may emerge when more than one condition is present. It is a complicated process that does not rely on binary and linear explanations. Early studies identified two main categories that cause gentrification: private capital investment for profit-seeking and people flow that refers to individual lifestyle preferences [11]. Gentrification does not necessarily result in negative effects, as it can also operate as a tool for revitalization. When revitalization occurs from existing residents, who seek to improve their 
neighborhood conditions, the result can be constructive in enforcing the neighborhood stability. This condition is called incumbent upgrading or "unslumming' as Jacobs [1] defines it. However, when revitalization causes the displacement of current residents and a decline in neighborhood diversity, then neighborhoods gradually become segregated by income, due in part to macrolevel increases in income inequality as well as decline of job opportunities. Hence, neighborhood stability is compromised because the opportunities have been narrowed down to a very limited range of financial status and lifestyle. Displacement, however, is identified as the biggest negative impact of concern resulting from neighborhood revitalization and gentrification. Displacement occurs when any household is forced to move from its residence, usually because of eviction and unaffordable rent increase [12]. However, tracking unwilling displacement can be challenging to categorize, as researchers have faced limitations regarding data availability and data comprehension.

In this case study, we carefully selected and analyzed the various, specific data sets that relate to gentrification and are associated with livability, from authoritative census data categories, such as income, crime, education level, employment rate, urban infrastructure, etc. to more ephemeral and subjective data classifications related to human perception and user input. In order to go beyond the conventions in understanding the dynamics that drive socioeconomic phenomena and construct lived space, we attempted to implement methods that although they are considered disassociated with urban analytics, they offer a strong potential in contributing to this study as it will be analyzed in detail in the following paragraphs.

This case study involves three methods of data accumulation and analysis; the first method is a preliminary census data classification of key GIS data sets that are available from the government and other certified public resources. The second method uses data resources that derive from open data platforms (data that is freely accessible), such as Google API, Google Places, and collective, open-data platforms where users post all kinds of requests (sell and buy, real estate, etc.), such as "craigslist.org", while the third uses human perception and subjectivity as a qualitative source of data that can unveil qualities that could not appear otherwise and enrich the outcome with a diverse layer of data. This enrichment leads to a more informed decision-making and a more qualitative image of the city that reflects subjective aspects of urban planning [13].

Although the methods differ significantly in the types and source of data being used, it is important to mention that each perspective provides a different lens through which to view transition toward more or less livable and gentrified environments. The data sets collected from the three methods operate at different scales, some at urban scale for the entire San Francisco Bay Area, some at neighborhood scale, and some at street level scale. Each method presents certain advantages and altogether provide a calibrated understanding of the multiple grains of constructed space through top-down and bottom-up methods, as well as to offer a tool of visualizing dynamical characteristics of the urban environment. For example, using a human-based perspective alone may lead us to commit to something, which is entirely subjective, by ignoring holistic factors that emerge at aggregate levels and vice versa. The census data analysis provides an overview of the context over a significant time span (2000-2012) and helps us understand major socioeconomic shifts that affect tenure, which then affects the local market and the standards of living in the area in terms of public infrastructure. The open data analysis depicts the ephemeral layer of relationships that take place in the urban environment, which is impossible to be described by authoritative data; however, it is more relevant to the actual conditions, revealing virtual changes and dynamics for the near future. The third method enriches the process with user personal feedback about ranking the environment of a neighborhood as it currently stands. 
Across all three studies, the data has been visualized based on a few basic rules. Changes of degree in a factor are displayed with a gradient of the same color, changes of type are displayed with different colors, and the general vocabulary of visual styles is communicated with dots, lines, and areas [14]. The tools used for the data visualization are "Microsoft Excel" for calculation of delta, median, and average values, "Grasshopper" for processing data input in ".json," ".csv," or ".shp" file formats, "Rhinoceros" for processing the output data from "Grasshopper," "Processing" as a geo-located three-dimensional virtual space, where multiple data sets can be displayed and overlaid at the same time, in order to assess their relationship and "Adobe Suite" for final printed output.

\subsection{Method 1: preliminary census data analysis}

The initial method, which defines the preliminary step of the research, refers to the use of GIS census data analytics. This method aims to depict the urban areas that have undergone changes on authoritative parameters that are associated with the phenomenon of gentrification, such as tenure status, median household income, land value, and employment rate. Moreover, this method queries the livability levels based on parameters related to public infrastructure and the urban quality, such as pedestrian network continuity and status, transportation, walkability, and car dependency street trees and parks, schools, education points, medical and religious spaces. The objective of these data sets integration is to assess whether the built environment is evolving toward an equal state of services and other opportunities or in favor of certain socioeconomic groups over others.

The "Geographic Information System", or GIS, tools enable the accelerated gathering of data sets of multiple categories. As this method focuses solely on census data and basic population characteristics, the data sets that are useful to the execution of the survey are population, median household income, level of education, transport network, and infrastructure.

Initially, the survey began with a high-level analysis of the San Francisco Bay Area natural morphology and broad population characteristics; therefore, the first data sets that were visualized were green areas, wetlands, urban areas, total population, and land value (Figure 1). Before analyzing more thoroughly the city of San Francisco, we collected some data related to the homeless population community in the city as it is a very apparent phenomenon that appears to be getting aggravated. As the core of the research is focused on depicting and tracing the dynamics of gentrification, we believe that information associated with the homeless population community and then compared with the census data regarding tenure status and land value could provide useful insight (Figure 1).

The second stage of the survey focused solely in the county of San Francisco, as it was considered a suitable context to trace the main changes in demographic characteristics. The data sets that were visualized at this stage of the survey were the range of household income, range of home value, owner-occupied housing, vacant lots, and the ratio of unemployed population against the total population (Figure 2). Green areas in the San Francisco Bay Area that are accessible to the public, such as parks, plazas, etc, were excluded from the calculation as they do not relate to the targeted data sets, and they would have affected the results of the survey.

Although the previously described survey did reveal information on the transition of some neighborhoods in San Francisco, at the next stage of the research, it became apparent that the most applicable scale for census data display would be that of the entire San Francisco Bay Area. The reason for this is that census data has low spatial resolution and therefore refers to large-scale surveys. Hence, the data was recollected for the San Francisco Bay. The census data collected consists of data sets that range 


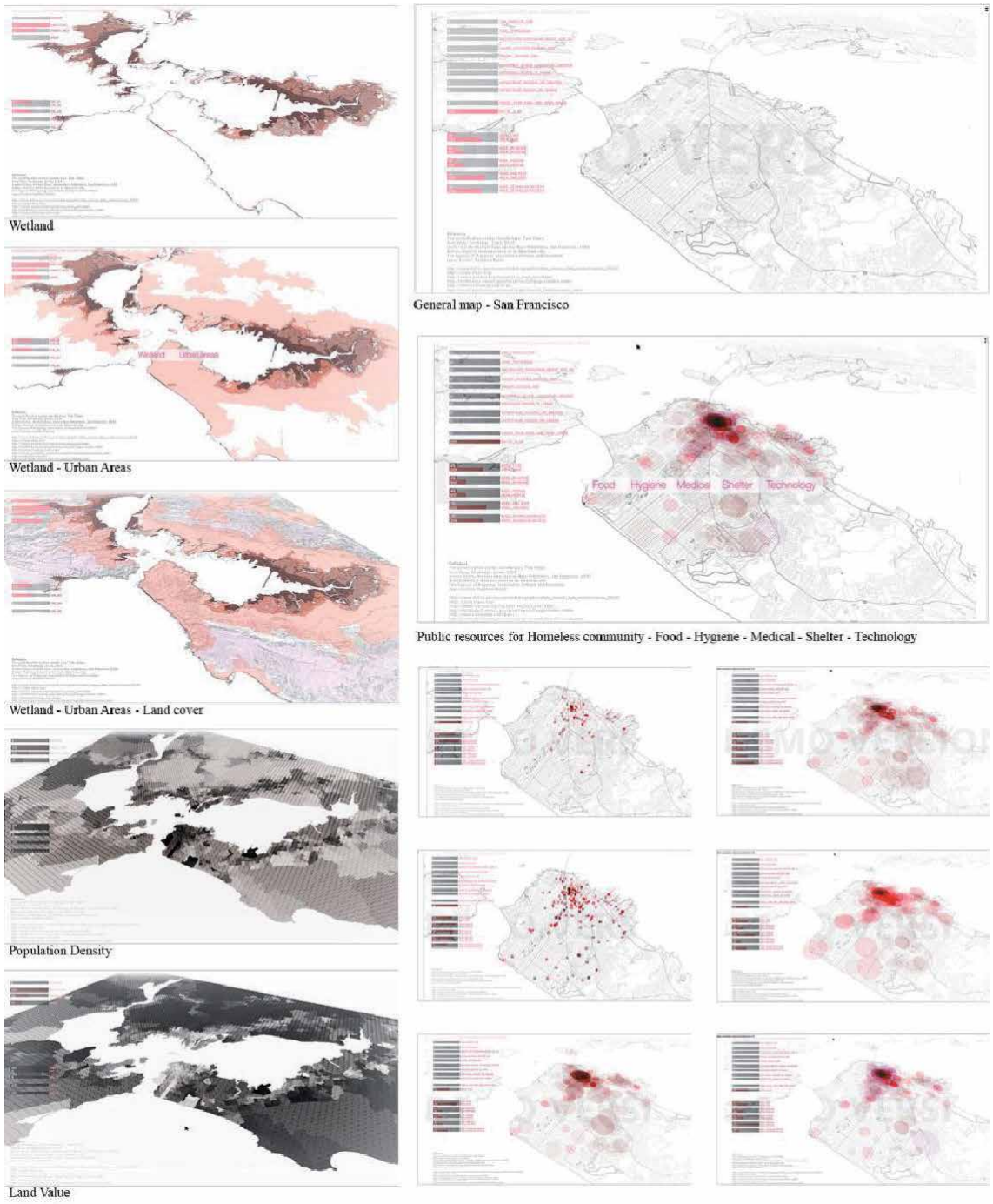

Figure 1.

Geo-located $3 D$ space in the software processing. Natural elements and census data for San Francisco Bay Area. Public resources for homeless population for the city of San Francisco (figure was created by the author) [20, 21, 22].

from 2000 to 2012 and is related to tenure status, median household income, median home value, and employment rate. For every data set of the above, we calculated the delta value (amount of change or difference) between the years 2000 and 2012 and remapped the values to a numerical range between 0 and 1 , which corresponded to a gray scale ranges from white $(255,255,255)$ to black $(0,0,0)$. White color represents no change, whereas black color represents the highest amount of change. The delta value was plotted in the context of San Francisco Bay Area, and the result is four maps, each for one data set. The four maps, which derived from the process described above, represent the amount of change in tenure, median household income, median home value, and employment rate were weighted and integrated into a single map that represents the amount of change of all four data sets (Figure 3).

In addition to the data sets related to tenure status, we included the census data of artists' employment rate as it is considered a key indicator of the early stages of a gentrification process. Surveys in the field of urban renovation have established 

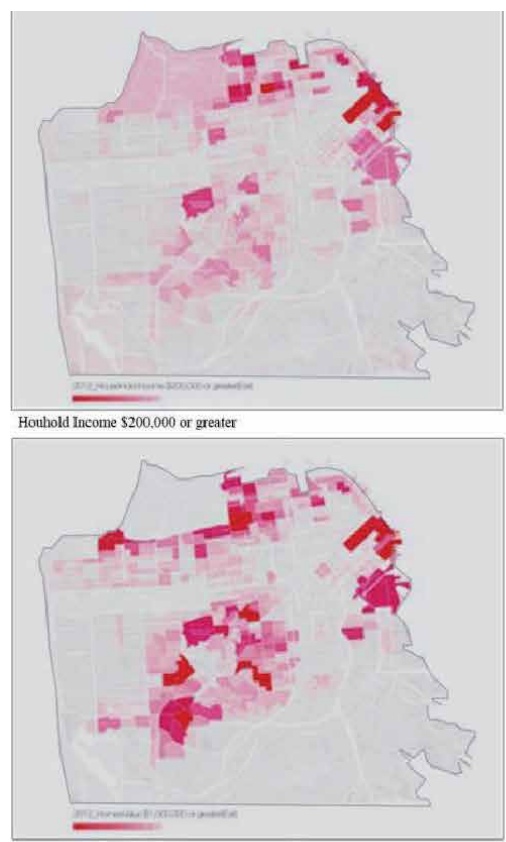

Home value $\$ 100,000$ or greater
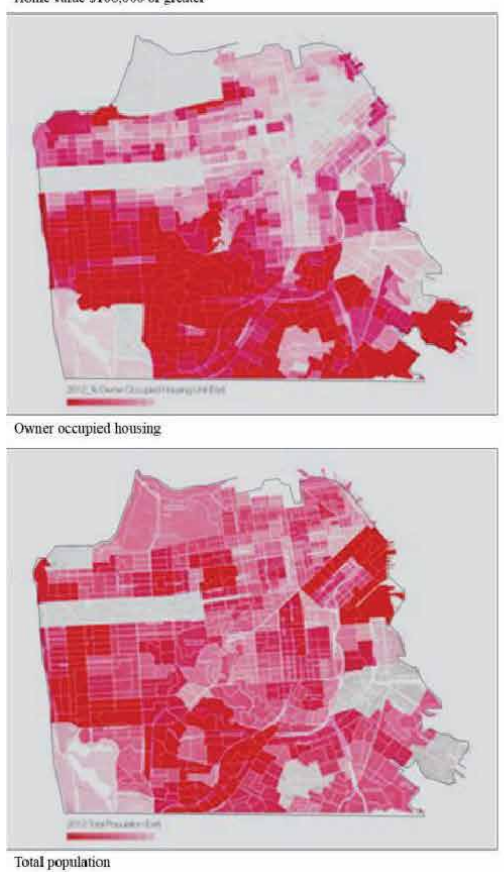
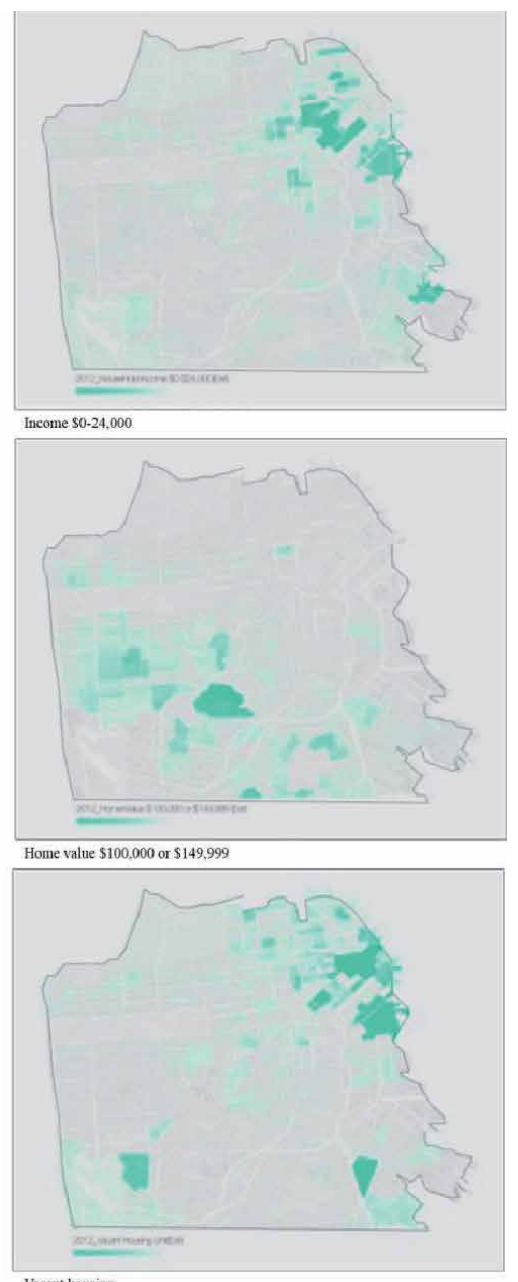

Vacant housing

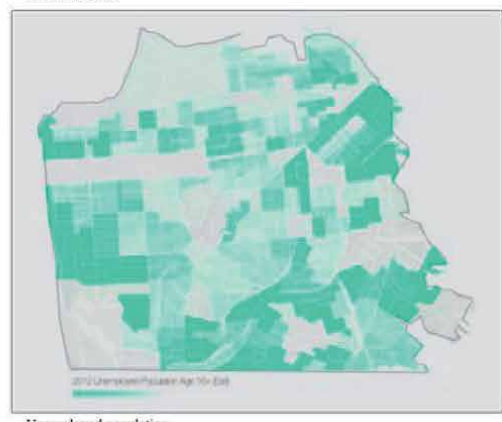

tnemployed population

Figure 2.

Census data for the city of San Francisco, total population, income, vacant housing, home value, unemployed population (figure was created by the author) [18].

the artists community as an agent of urban gentrification, for the reason that low-income artists tend to revalorize unproductive spaces because they are affordable and, as a result, increase the attractiveness of the neighborhood. Artists make the first move into post-industrial, post-welfare neighborhoods, and soon they attract the hipster movement before, eventually, being displaced by them and their new middle-class neighbors. Both participate in the cycle of exploring, developing 

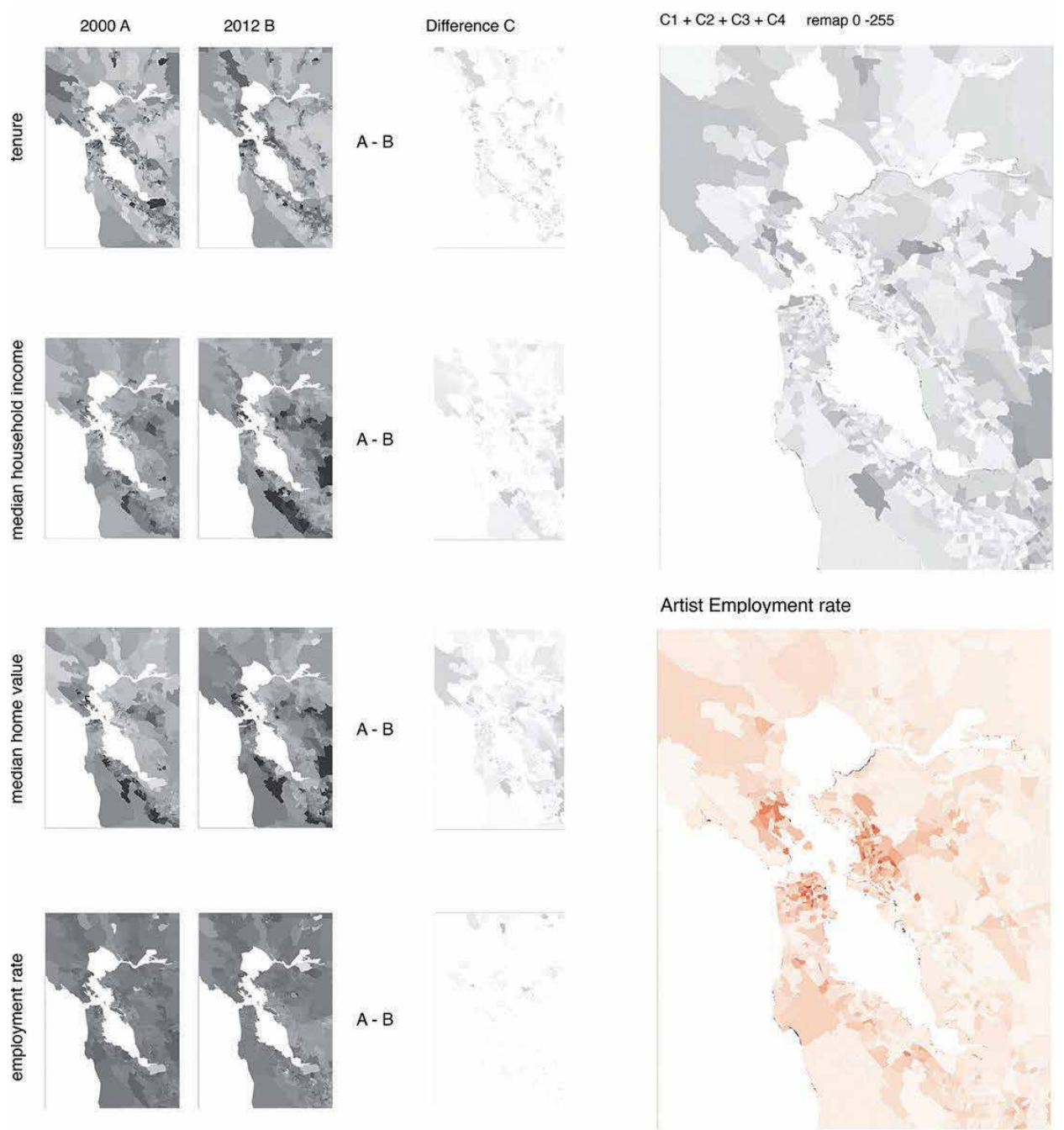

Figure 3.

San Francisco Bay Area, census GIS data comparison of tenure, median household income, median home value, and employment rate from 2000 to 2012 overlapped with artists' employment rate (figure was created by the author) $[19,20,22]$.

new potential sites for capital investment. Hence, the combined data set of the four census categories is overlapped with artists' employment rate census data set (Figure 4). Regarding the services that are directly related to the urban quality, such as accidents and pedestrian network continuity and status, transportation, walkability, and car dependency street trees and parks, schools, education points, medical and religious spaces, the data sets are divided in two categories. The first depicts amenities such as access to education, religion, health, and green areas, as well as the street trees that definitely improve the urban environment in terms of walkability, microclimate, and aesthetic. The second depicts car dependency zones, reported car injuries location, pavement condition, and parking spaces (Figures 5-7). The source of the data sets mentioned above was mainly government websites, and the data were provided in.csv format. Data were imported to Microsoft Excel, in order to calculate and process the key indicators that derive from more than one data set and the delta values from the comparison of the data set over a period of time. After the calculation, the information was then imported in grasshopper and processing for visualization in context, as a series of maps. 


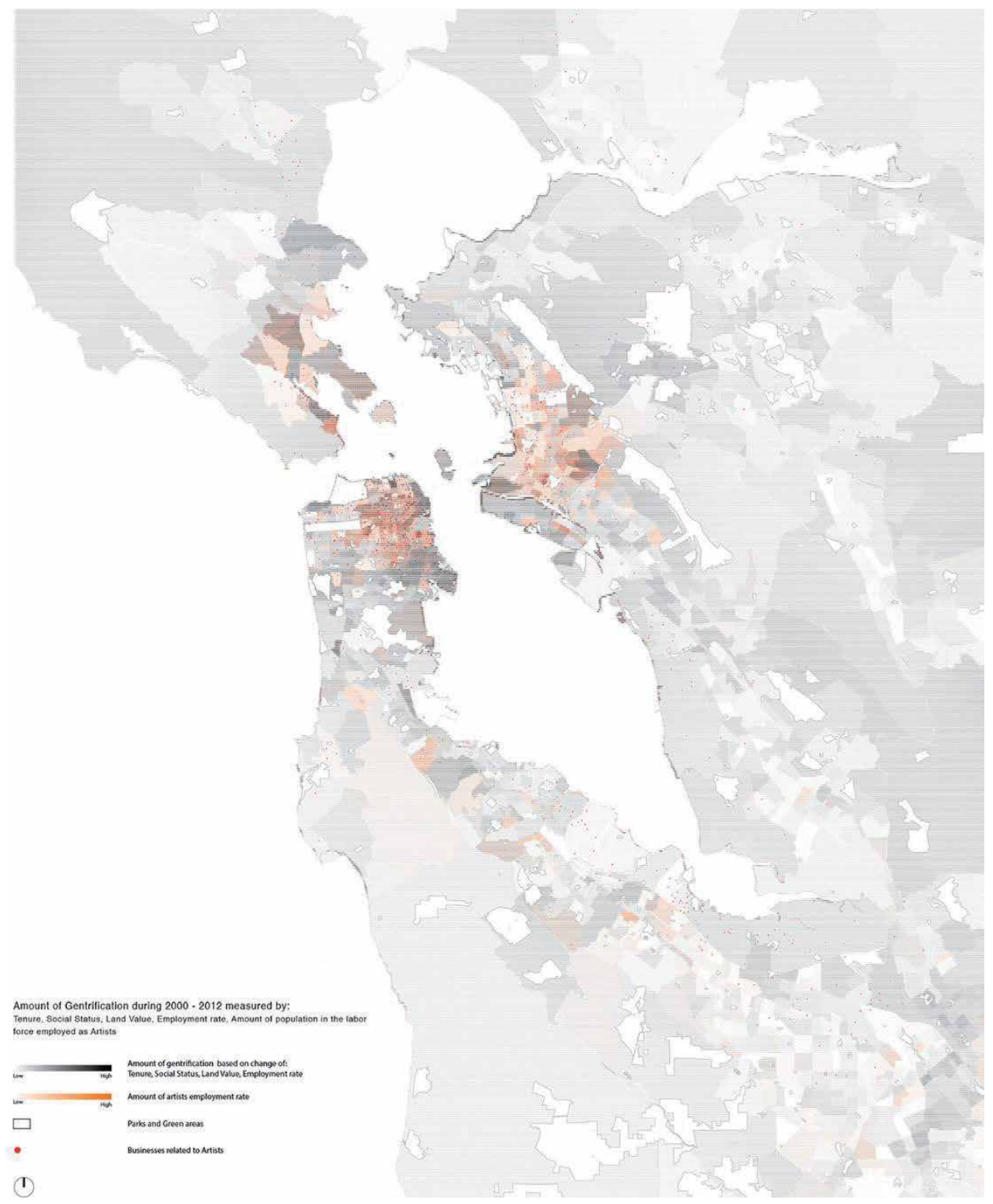

Figure 4 .

San Francisco Bay Area, census GIS data comparison from 2000 to 2012 overlapped with businesses related to artists from Google places (figure was created by the author) [19, 20, 22].

\subsection{Method 2: open-data}

The database is articulated by tracing certain populations and services categories that reflect activity and flux of the built environment. The targeted data sets involve artists and their recent activity in Oakland, industrial buildings, loft residencies, yoga and fitness studios, fashionable cafes, as well as crime reports from 2010 to 2013 (Figures 8 and 9). The data accumulation derives from open data platforms by defining an equivalent keyword query. The artist population is considered as the frontline of gentrification [2]; therefore, tracing their activity would provide useful insight, combined with a survey on loft residencies, which usually attract the artist community and on certain amenities that appeal to the same target group. The survey on industrial buildings helps in the formation of a forecast model of potential 


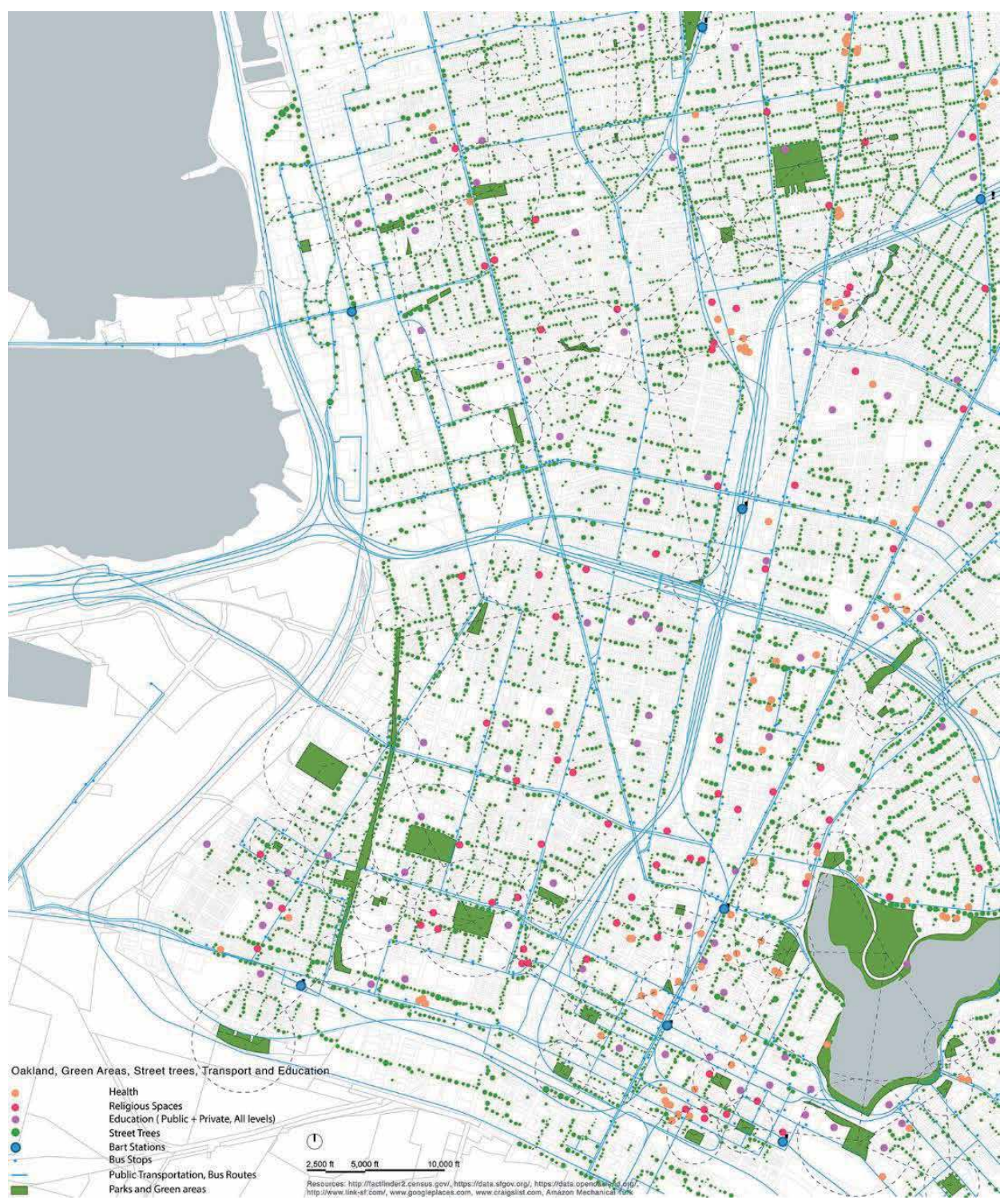

Figure 5.

Oakland green areas, street trees, transport, and education (figure was created by the author) [17].

transformation of industrial building envelopes to loft residencies. The chosen data sets describe adequately the artists community in the sense that it is commonly known that upcoming artists are mostly freelancers or seeking for a job, and in order to settle their studio, exhibition space, etc, they actively pursue real state, as well as specific lifestyle preferences. This activity regarding real estate hunting cannot be described by census data, simply because it is volatile and constantly shifting. Methods that employ open data platforms such as Google Places and "craigslist.org," however, can capture the activity of such groups very accurately as every activity is geo-located. The key difference between the census data analysis and this method is that the data derives from open-data platforms by defining a key word query. Despite the fact that the two methods are referring to the same target group, in this case, artists, the data are a result of a significantly different process and source. The open-data method, using Google API and "craigslist.org," involved multiple requests at a daily basis, in order to collect all the necessary data. The keyword queries were related to temporal 


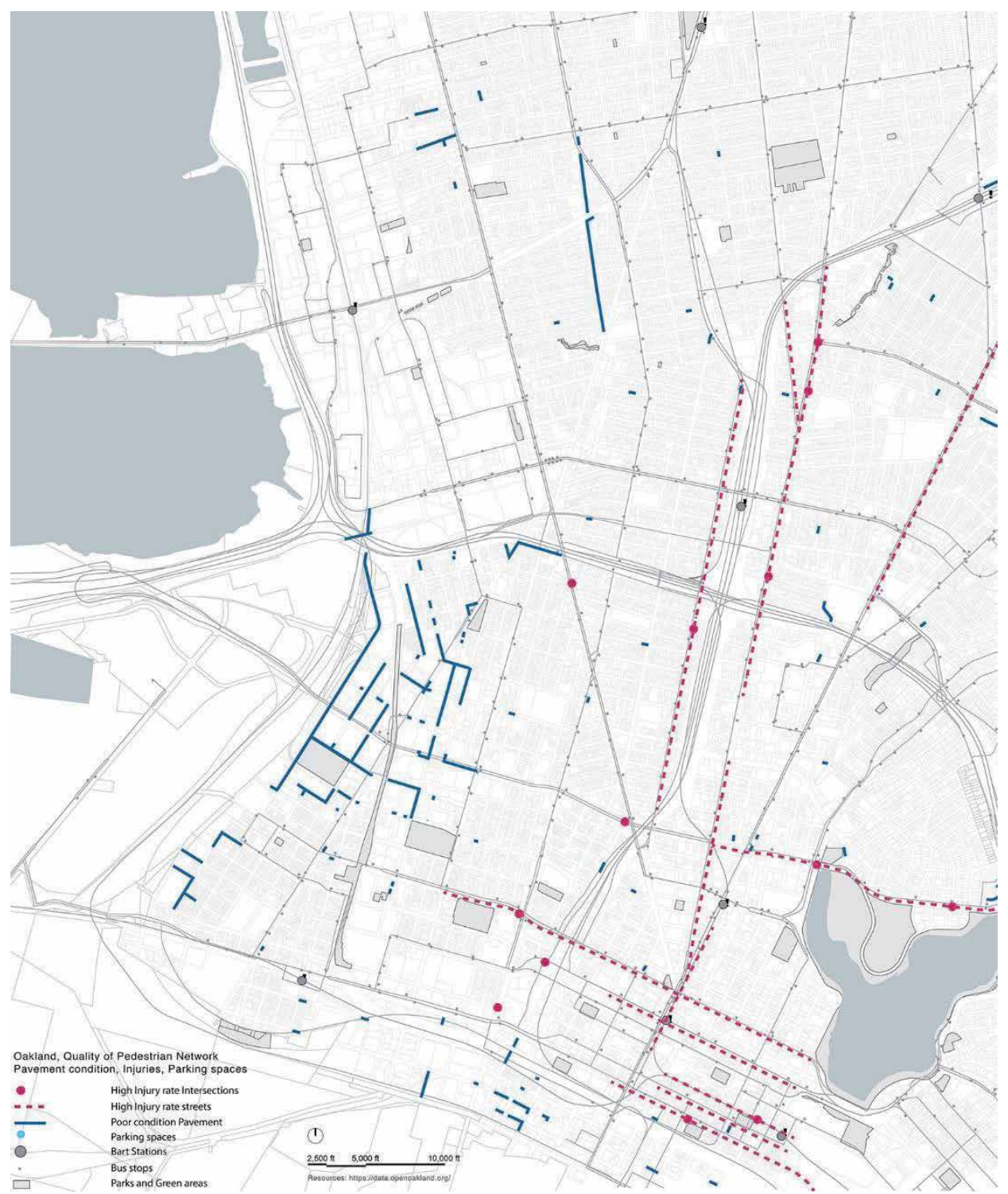

Figure 6.

Oakland, quality of pedestrian network, pavement condition, injuries, and parking spaces (figure was created by the author) [17].

requests and offers regarding real estate for artists' studios, gallery spaces, events, artists' resources, artwork sale, exhibitions, FAQ, etc. The second set includes crime reports posted from civilians for the years 2010 and 2013, depicting a significant decrease in reported crimes during that period. The data accumulated was formatted in.csv format and visualized as nodes on the same context (Figures 8 and 10).

\subsection{Method 3: crowdsourcing}

The second method involves a human-based approach, as a crowdsourcing process. In this method, the crowdsourcing process was achieved via a human-based outsourcing platform called "Amazon Mechanical Turk." The "Amazon Mechanical Turk" platform is a crowdsourcing Internet marketplace, operated by “Amazon," which enables individuals to coordinate the use of human intelligence and perform 


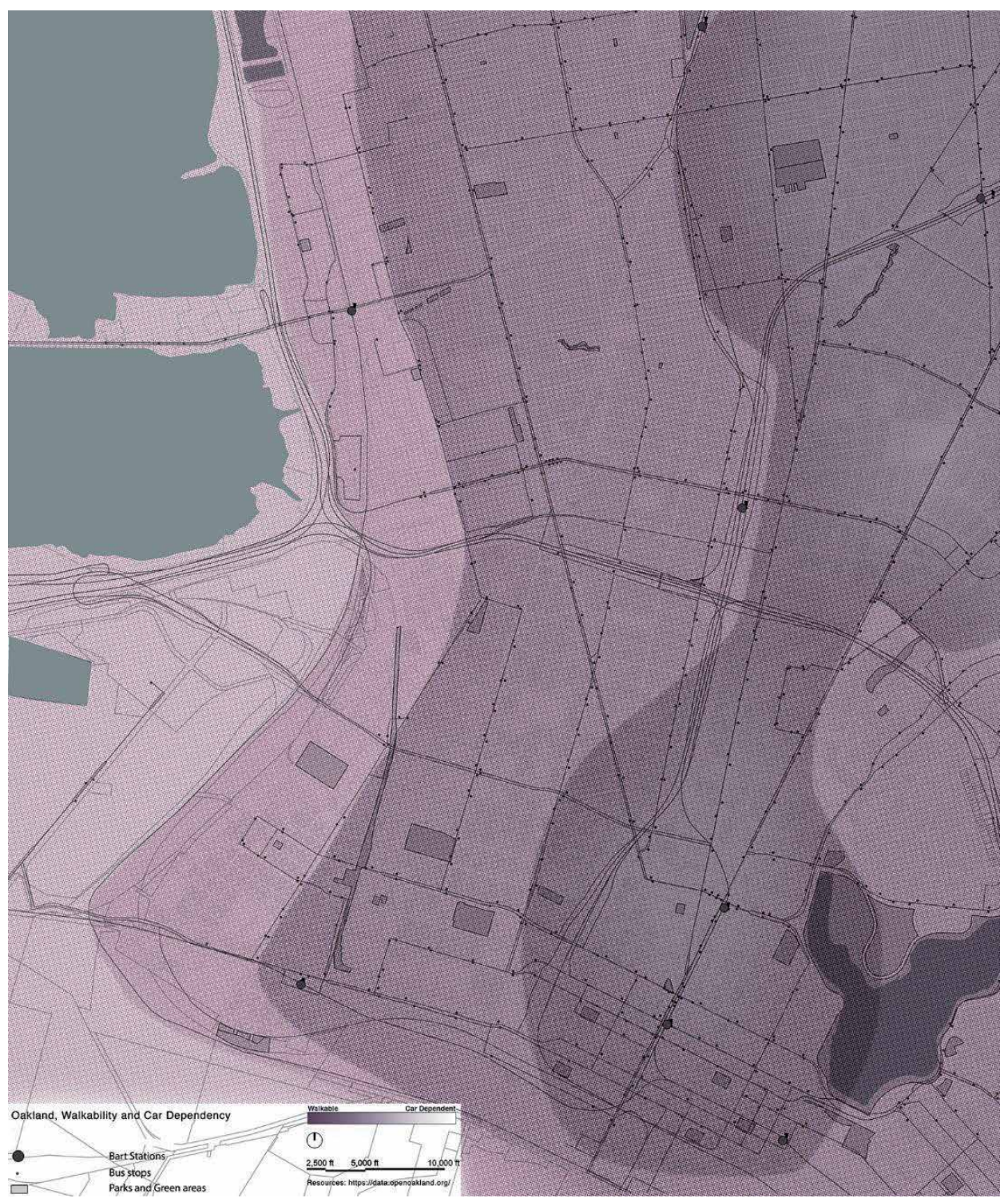

Figure 7.

Oakland, walkability, and car dependency (figure was created by the author) [17].

tasks that computers are currently unable to perform successfully. It is an on-demand sample of users that executes simple assignments over an agreed period of time. The "Amazon Mechanical Turk" can be associated with the term "Human Computing."

Initially, and in order to test the feasibility of this method, we processed only few blocks in Emeryville, Oakland, and the questions posted to Amazon Mechanical Turk were very simple and required identification of certain elements and whether they appear in the images. Example elements that were queried are bicycles, lofts, abandoned buildings, and industrial buildings (Figure 11). In the next stage, a large group was given two different sets of questions. The first set of questions is related to human subjectivity, which implies that the users were given a set of subjective questions that were related to the qualitative rating of selected neighborhoods in the San Francisco Bay Area. The questions were communicated in a simple way, by extracting Google Street viewpoints as images and submitting 


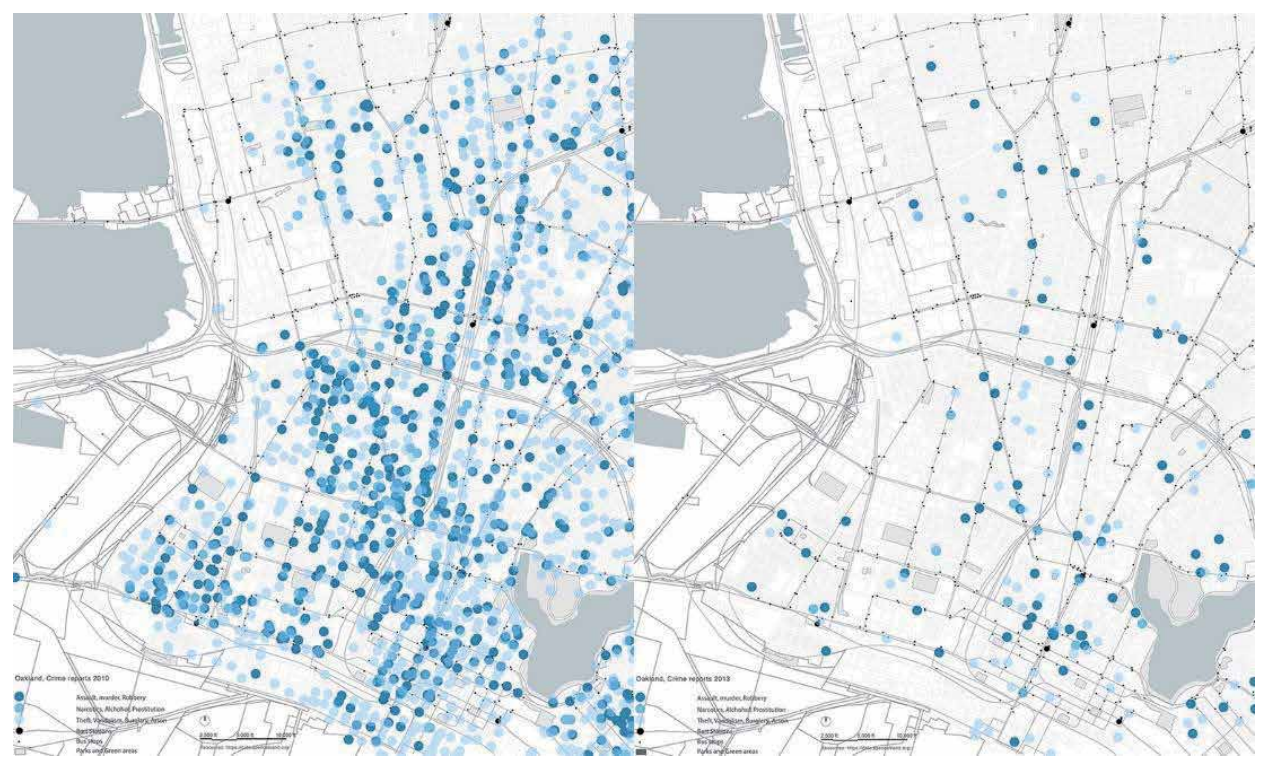

Figure 8.

Oakland crime reports, 2010 (left), Oakland crime reports 2013 (right) (figure was created by the author) [23].

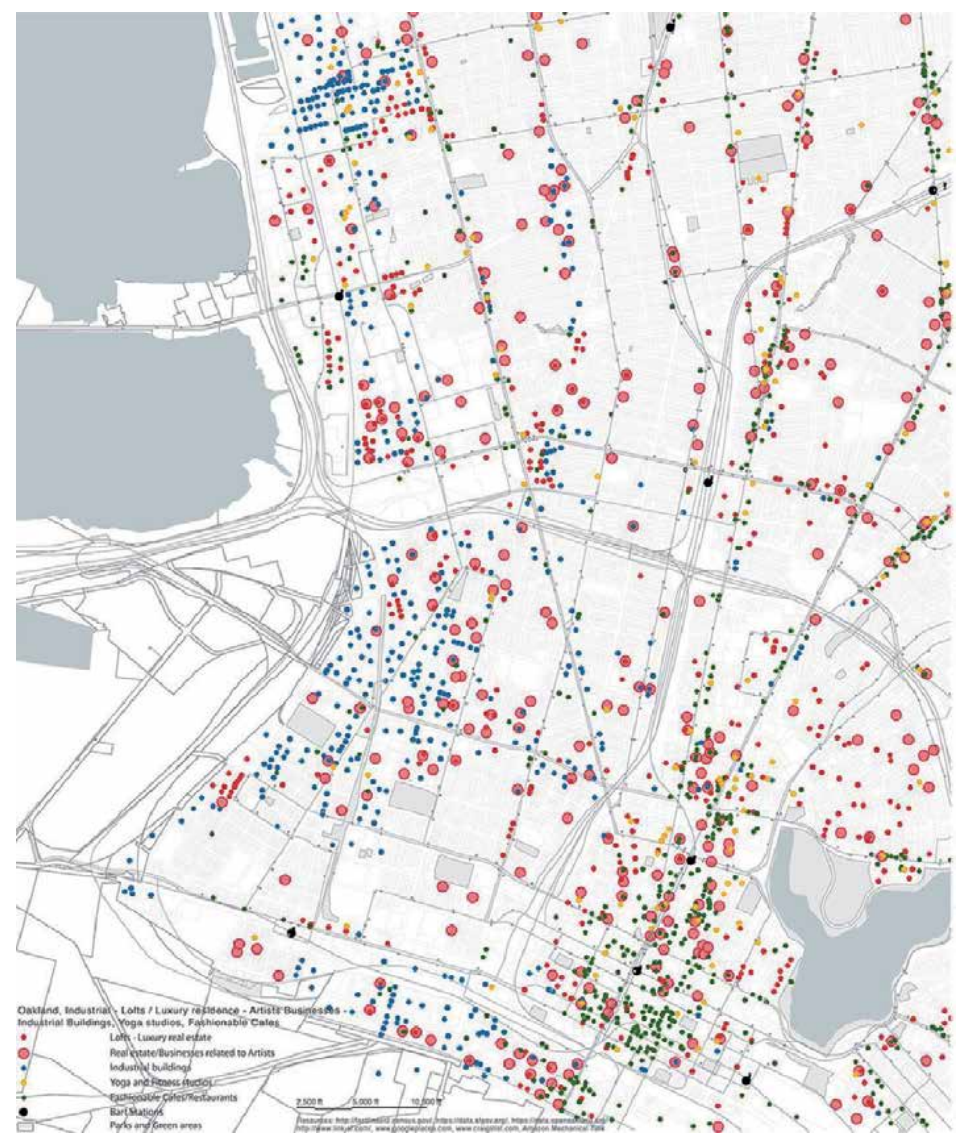

Figure 9.

Oakland, industrial buildings, lofts/luxury residence, businesses related to artists, yoga and fitness studios, fashionable cafes (figure was created by the author) [23-25]. 


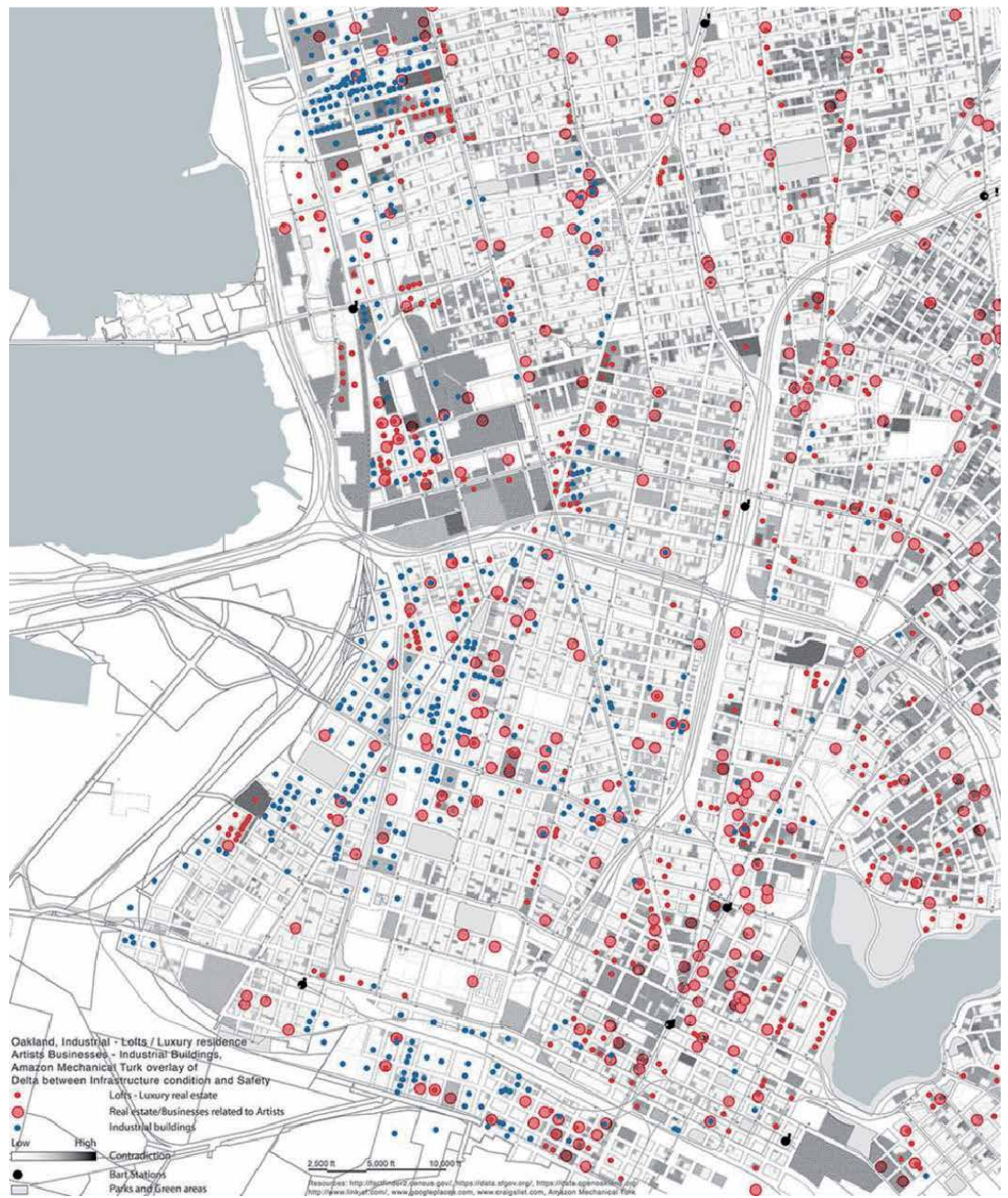

Figure 10.

Oakland, industrial buildings, lofts/luxury residence, businesses related to artists overlaid with Amazon Mechanical Turk Delta between infrastructure condition and safety (figure was created by the author) [23, 25].
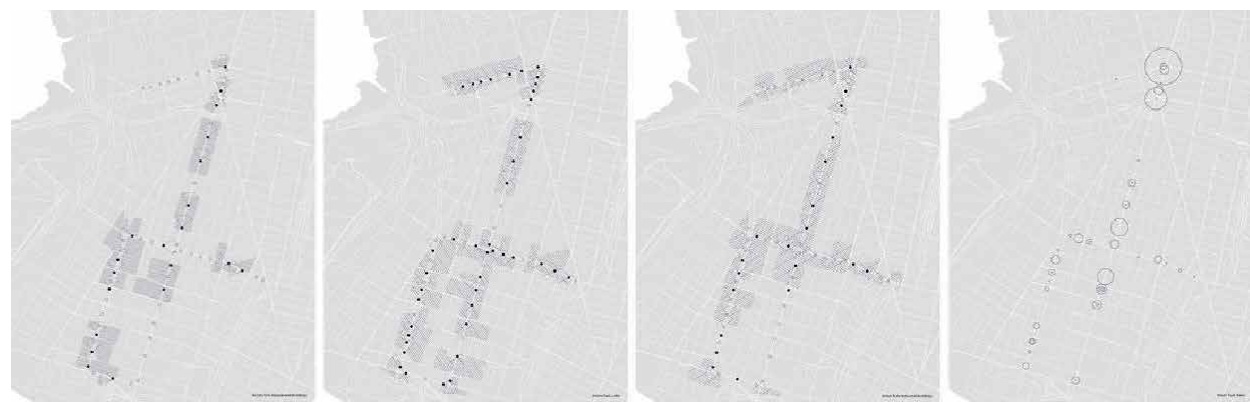

Figure 11.

Amazon Mechanical Turk Oakland example maps of bicycles, lofts, abandoned buildings, and industrial buildings (figure was created by the author).

them to the "Amazon Mechanical Turk" system for rating along with a series of questions regarding the content shown in the images. This process takes advantage of human subjectivity when it comes to rating an area based on someone's personal 
Human-Centered Approaches in Urban Analytics and Placemaking DOI: http://dx.doi.org/10.5772/intechopen.89675

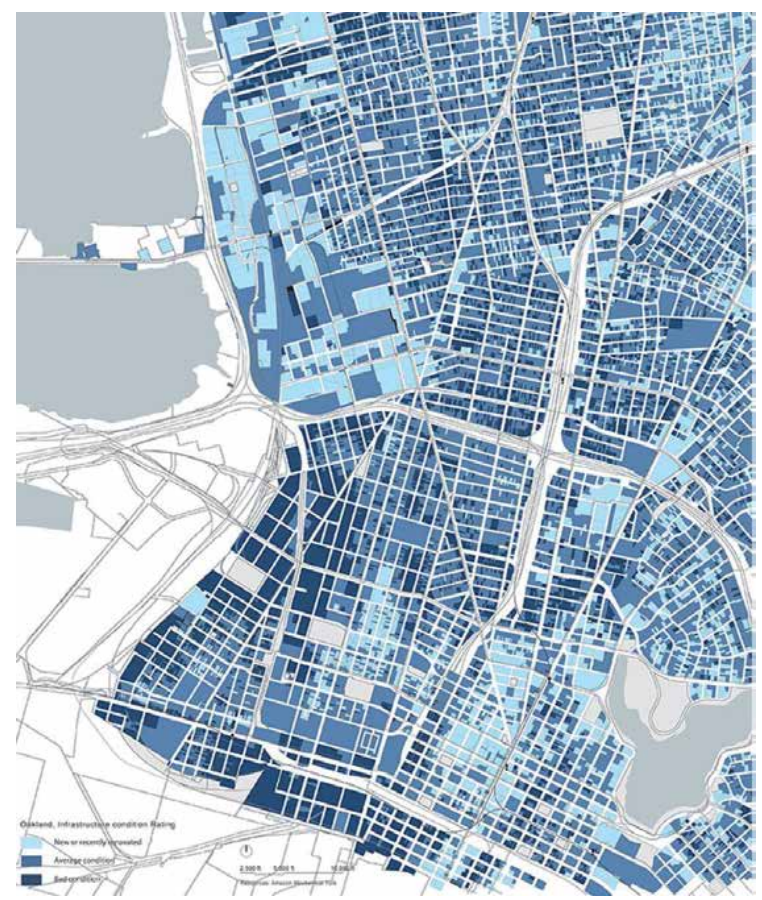

Figure 12.

Amazon Mechanical Turk neighborhood rating: neighborhood infrastructure evaluation (figure was created by the author) [25].

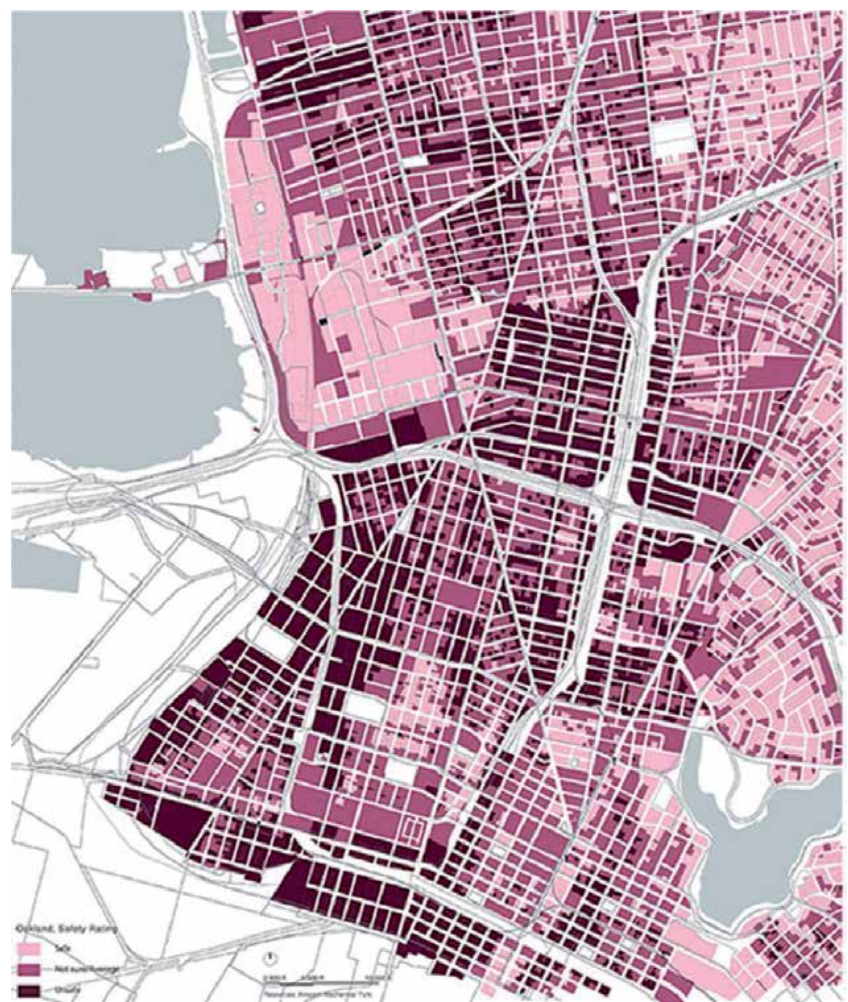

Figure 13

Amazon Mechanical Turk neighborhood rating: neighborhood safety evaluation (figure was created by the author) [25]. 
infrastructure condition (Figure 12), interpretation of safety (Figure 13) and affordability (Figure 14), qualities that vary significantly even among neighboring blocks; however, the amount or the frequency of variation may have a significant role in the overall research. The second set of questions is related to the collection of detail features, such as the presence of expensive loft housing, abandoned buildings, industrial buildings, trees, fitness studios, contemporary and stylish coffee shops. This process is utilizing the same strategy as the first one, by using Google Street viewpoints in order for the participants to identify the presence of any of the feature elements in the content of the images. The identification of these features would be extremely time consuming to collect manually; therefore, this method is proven highly efficient on this aspect. The areas of interest for both sets of questionnaires are Oakland and Emeryville, which were chosen because they are transforming from high concentrated crime areas into urban, entertainment, and commercial attractor points. The questions were submitted to "Amazon Mechanical Turk" as a file in ".json" format and were structured in a way that the answers would be easy to process and to visualize. In particular, the answers to the question would have to be represented either as a numerical scale from 1 to 10 , as a binary yes or no option, or

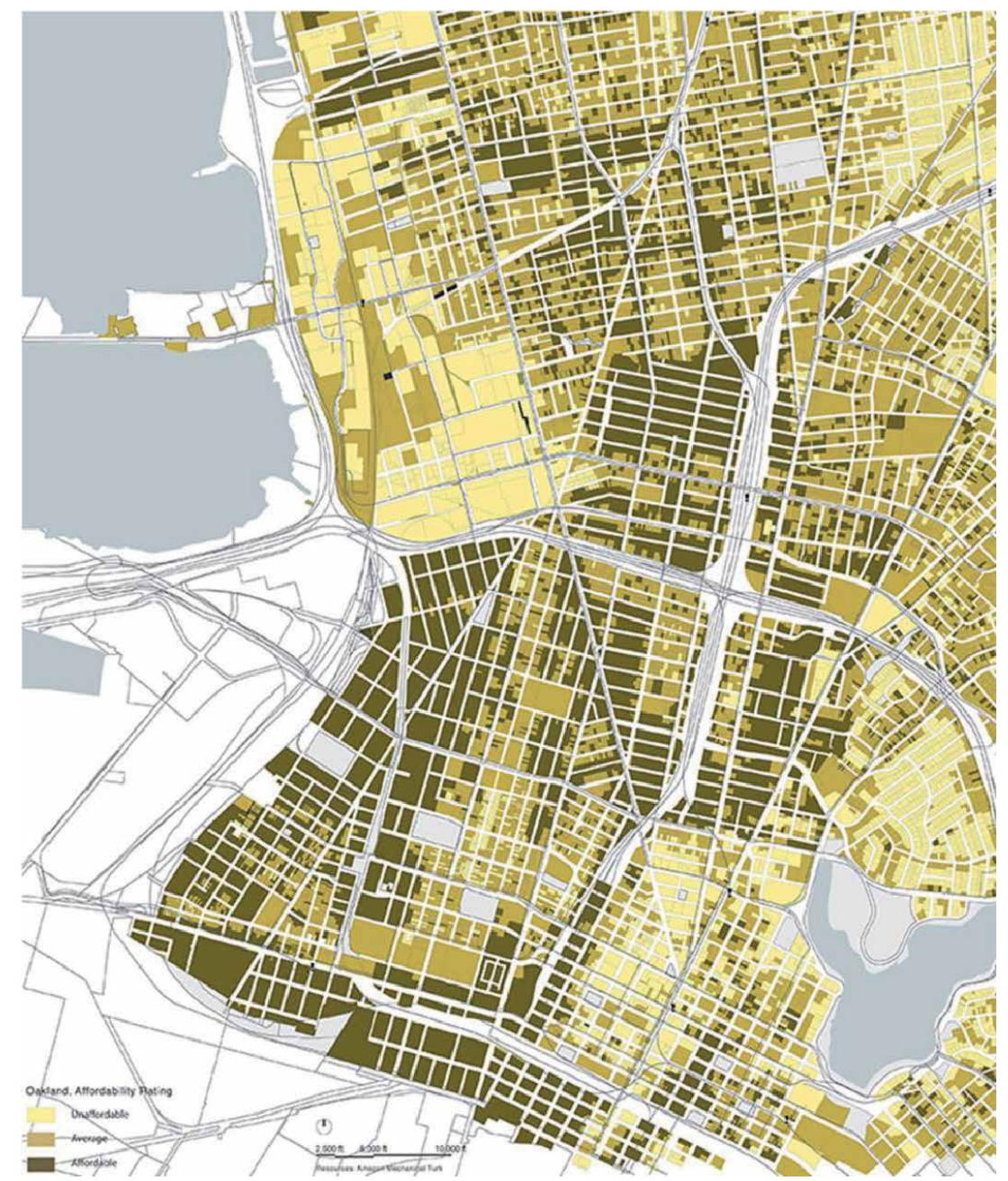

Figure 14 .

Amazon Mechanical Turk neighborhood rating: neighborhood affordability evaluation (figure was created by the author) [25]. 

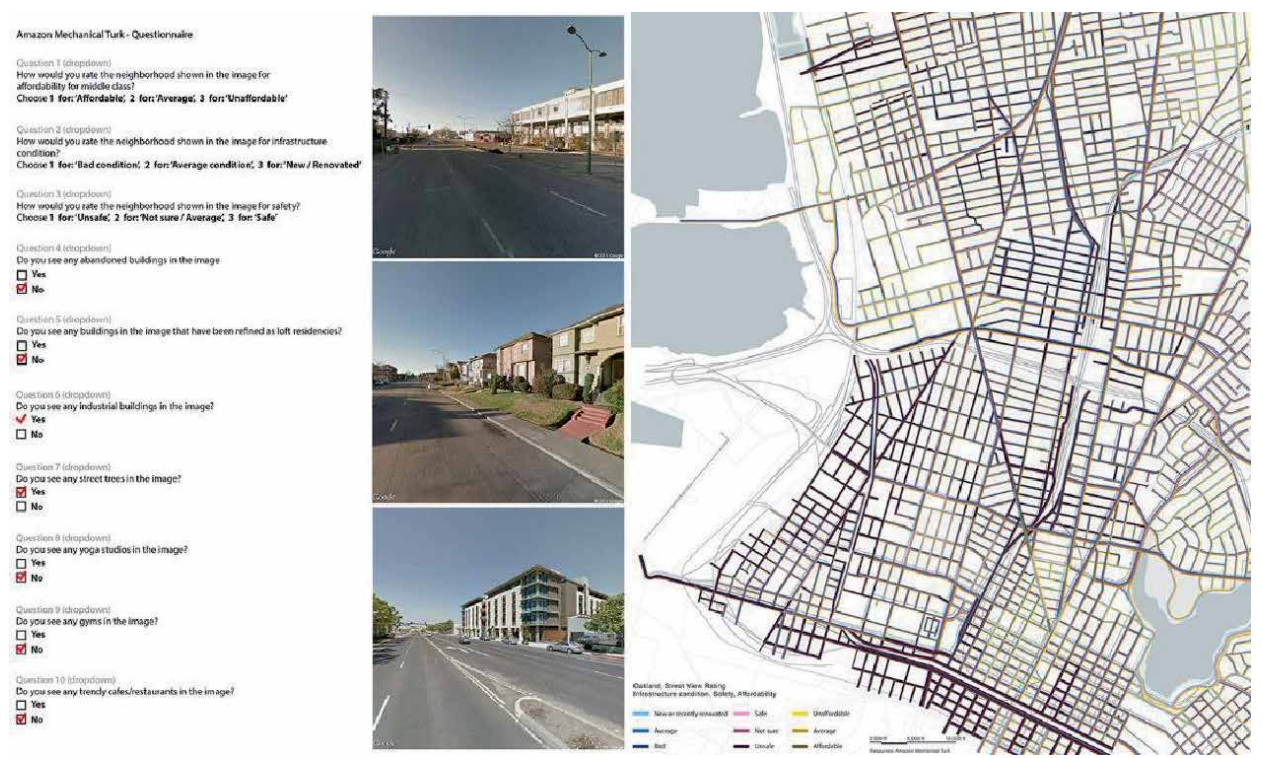

Figure 15.

Amazon Mechanical Turk submitted questionnaire (left) Amazon Mechanical Turk street rating (right) (figure was created by the author) [25].

a multiple choice (tick the box). We avoided completely answers that would require the user to write lengthy texts (Figure 15). The received answers were in ".json" format, so they were transformed into ".csv" format as in the previous method.

All data layers were combined and provided the context for a more fine-grained understanding of neighborhood characteristics, conflicts, and relationships that reveal the heterogeneous characteristics of the city [15]. Mapping here is not only addressed as a visualization tool but also as a platform based on which we can make faster and factual assessments [16].

\section{Case study 2: urban placemaking through user input}

\subsection{Introduction}

Moving away from the expert urbanist model, which determines the form and functionality of the built environment based on central rules, we argue that engagement with democratic participation can lead to more sustainable and resilient built environments. "Openreblock" platform is an open-ended approach to social justice that offers users active participation and opportunities to reform their immediate environment (Figure 16). By encouraging participatory planning via community mapping by its own citizens, it contributes in improving slum communities and their integration in the broader urban fabric. Some of the immediate benefits are land regularization and security of land ownership, allowance for public services, and connectivity.

As urban planning should be understood as a communicative, pragmatic, social practice, this tool facilitates intercultural dialog and implementation. "Openreblock" enables users to reorganize slum communities that lack significant public infrastructure, such as access to a public street. The idea of the tool is that citizens have the right to affect the design of their local neighborhood and have access to an open-source methodology for doing so. It is a web-based service for an open-source platform that proposes the least disruptive reformation of the existing street network 


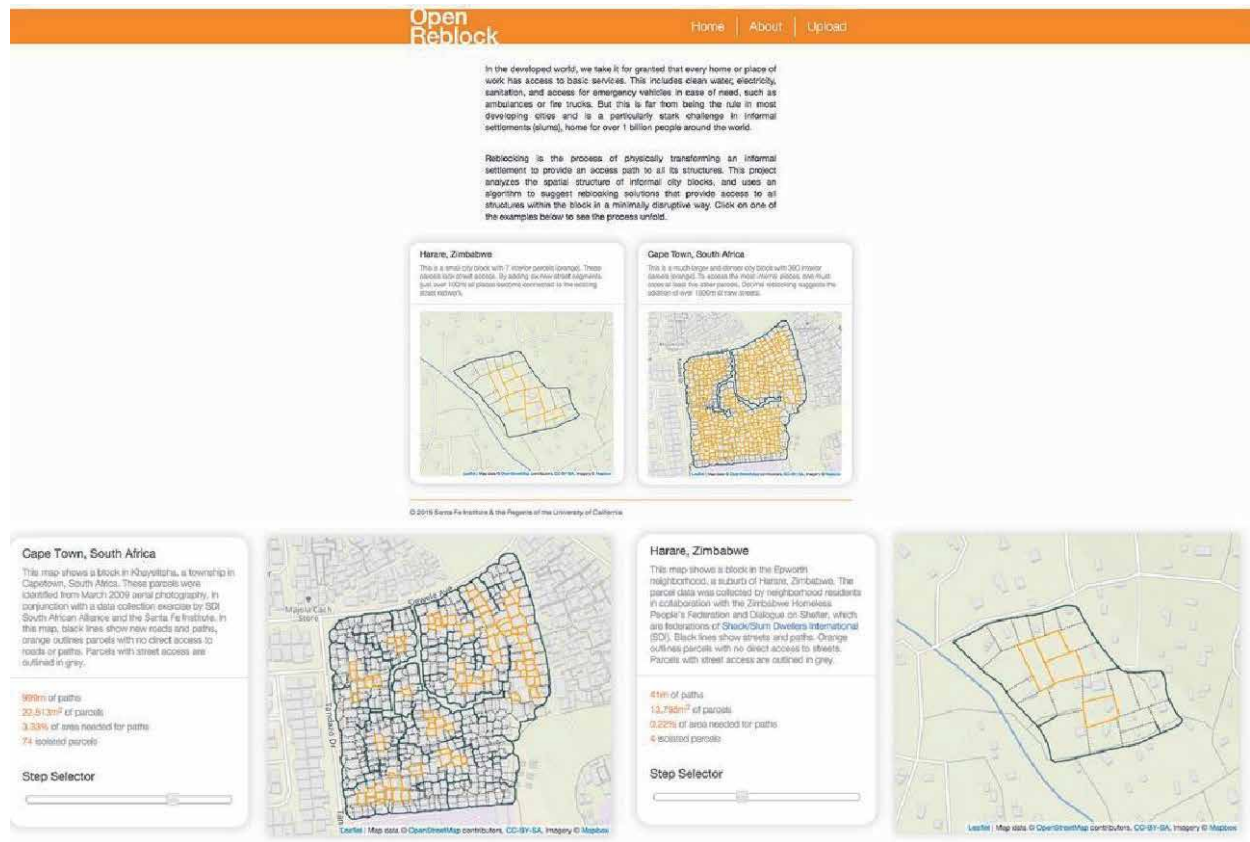

Figure 16.

"Openreblock": website main page, interface, graphics (graphic design by Stamen design).

in order to interconnect slum building blocks that lack access to a public street. This sets the basis for land formalization and property stability, so that urban slum communities become more resilient to future exploitation and natural disasters.

Funded through OpenIDEO, it is the product of major research collaboration by the Santa Fe Institute, Sam Houston State University, UC Berkeley, and Shack/ Slum Dwellers International, a global network of community-based organizations representing the urban poor. Shack/Slum Dwellers International is a network of community-based groups from 33 countries representing and communicating the needs of the urban poor, engaging international agencies, and operating on the global stage in order to support and advance local struggles for the last 20 years.

"Openreblock" combines the knowledge of slum communities' inhabitants with data analytics worldwide to enable each citizen to become an agent of information with the objective to enrich local knowledge and empower their community to pursue faster and more sustainable development outcomes from the local governments.

\subsection{Topology of street network}

In order to be able to formalize a strategy on how to evaluate and classify urban fabric typologies, we need to identify some key characteristics that define the character of the urban space. These characteristics should correspond to physical characteristics and relationships between the elements of space, in order to become a quantifiable set of parameters. In our case, the morphology of space that we need to analyze is that of a slum urban block. Although slum communities are diverse in physical appearance, context parcel population, and opportunities, they share common characteristics of organic typology and aggregation of parcels that are a result of unplanned, spontaneous expansion. In most cases, this type of urban development across time results in isolated parcels that do not have access to the street network at all and therefore to any services. 


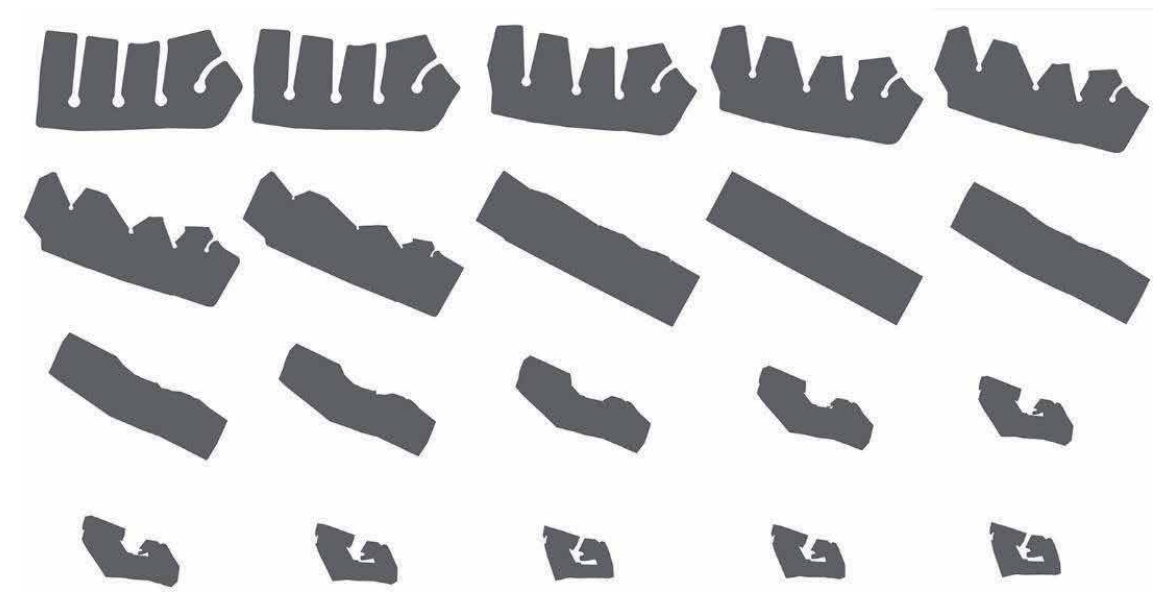

Figure 17.

Topology of a building block-morphing process between three building blocks that share the same topology (figure was created by the author).

The lack of infrastructure appears to be common to most poor or informal neighborhoods, and some of the challenges that these communities are facing derive partially form this fact. Streets are not only used for transportation, they carry all the necessary infrastructures such as drainage, electrical and communication services that interconnect the neighborhoods.

Based on the above, the key quantifiable set of parameters is the topology of the parcels, which reveals parcels with "blind" sides to a public street. In comparison with normal city block that is accessible from all sides, an isolated block would share a common side with one or more of its neighboring blocks. Thus, we can classify the urban fabric quality of any community block from maps that include spatial parcels and access networks in a way that can be automated. We demonstrate an example below of a morphing procedure between three different typologies of urban blocks that have the same topology (same number of parcels and no isolated parcels, common number of nodes), where we can mathematically transform the parcels from one block typology to the other. The third block typology is the output of the "reblocking" procedure of a slum block in Epworth, Zimbabwe, while the other two are from New York and Cape Town. This small example reflects the concept of urban topology evaluation, as the morphing process would have failed if the Epworth block had isolated parcels (Figure 17).

Thus, by evaluating the topology of the street network, we can assess more effectively the quality of the neighborhood in terms of public services, connectivity, and social and economic justice in general.

\section{3 “Openreblock” platform}

"Openreblock" visualizes access to essential services like water, energy, and sanitation at a neighborhood parcel level. This web-based platform requires user input, in order to operate and uses an algorithm to evaluate the topology of the blocks and the continuity of the street network, identify the parcels that do not have access to a public street, and then propose the least disruptive reorganization of a cluster of slum blocks, so that each parcel gets access to a street. It provides the missing connectivity that reduces travel distances and essentially transforms the parcels configuration to commonly known patterns of city building blocks that have access to streets on all sides. The resulting map reflects the changes in the physical 
layout of the blocks. The solution corresponding to the absolute minimum number of new streets could be impractical for the citizens themselves for the reason that it does not offer enough flexibility; however, it offers a good basis that is easily perceived by the users, in which they can develop and customize further. The process has been enriched by additional functionality that allows the users to exclude streets from the calculation and customize their priorities prior to the calculation based on what reflects their needs best. This is the kind of local knowledge that emerges from processes that allow active user engagement, and its value is immense for the reformation of the community.

The input required is a map of the properties in the community in a shape file format (.shp). The design system is articulated by specific front-end and back-end processes (Figure 18). The front-end processes are related to the display of the website based on user demand, which constitute the User Interface, and the back-end processes are related to the background processes needed for the calculation, such as reclustering calculation, queuing of tasks being performed, registering a user in a database, and creating a user profile. As the calculations could potentially demand a

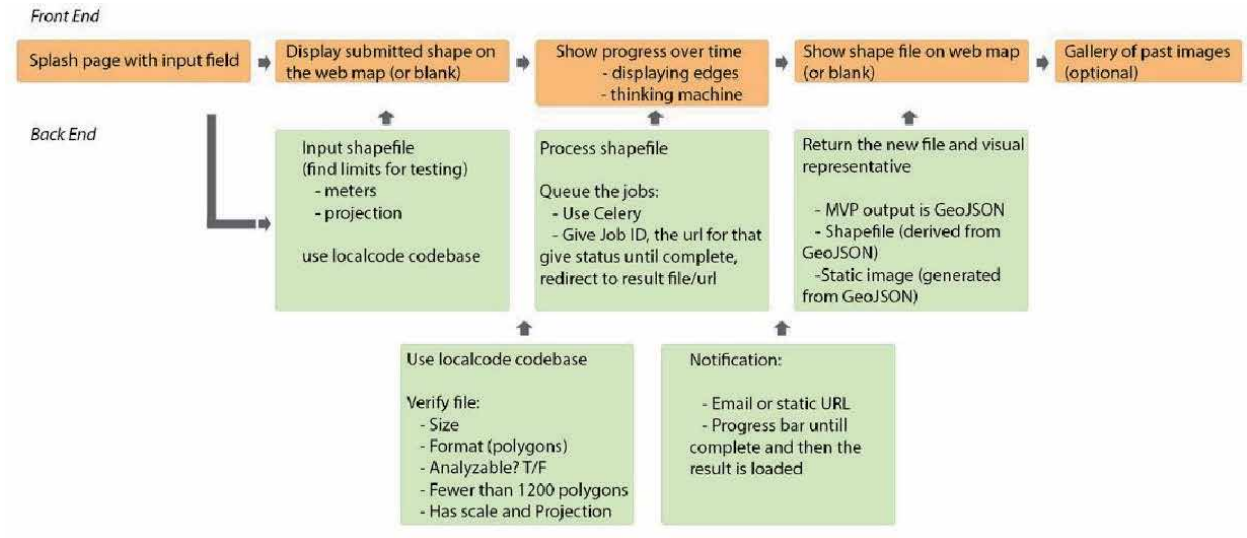

Figure 18.

"Openreblock" design system of processes (figure was created by the author).

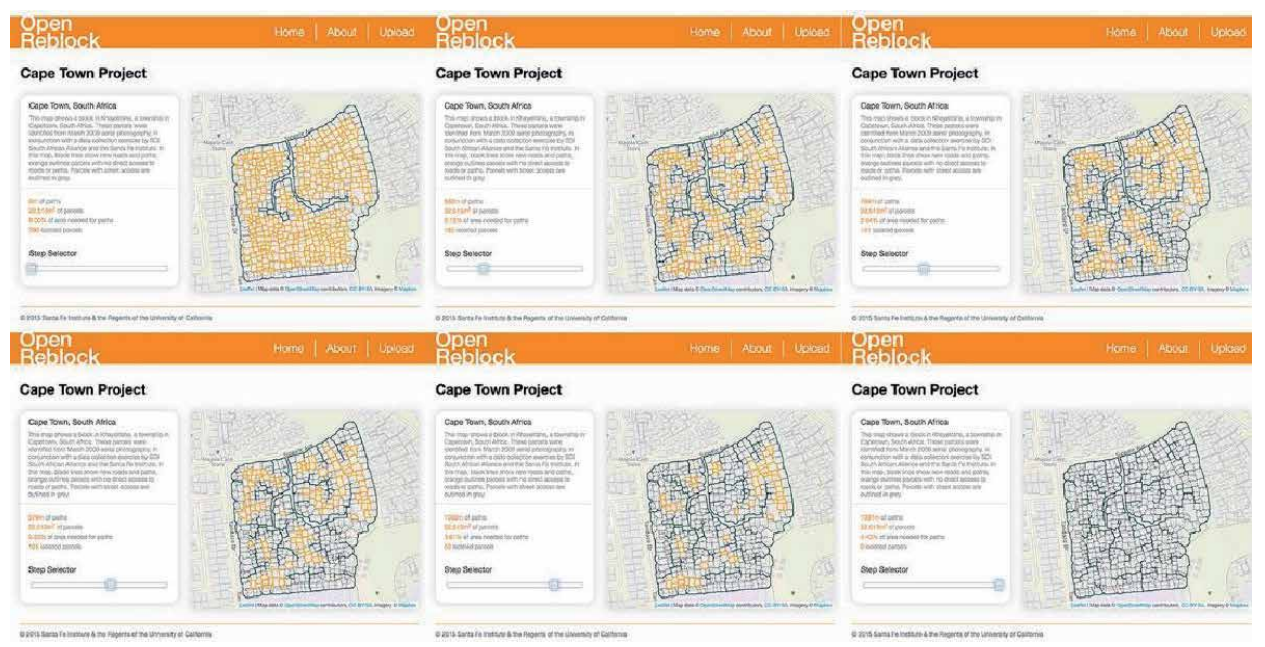

Figure 19.

Cape Town example. Process of "reblocking." New road network is gradually formed (graphic design by Stamen design). 
large amount of time to complete, asynchronous task queue/job queue "Celery" has been utilized to queue the tasks in real-time operation. "Openreblock" front-end processes use "Leaflet" and "Mapbox" libraries for the map display, whereas the back-end processes are built in "Jango" library.

In order to make the process of the calculation interactive, the steps are being displayed during the calculation, so the user can spot the new paths that are being generated gradually during the calculation. The user can also access and download any of the intermediate steps of the process. The algorithm estimates the location of existing paths and associated construction costs for new streets, making discussion, and comparison of alternative plans easy. It produces a new map that allows each home or workplace to have an address and to obtain urban services (Figure 19). Residents can adjust the tool to their needs by prioritizing processes and use the outcome as an alternative proposal for future replanning, in order to oppress the local government to consider their proposal. Users can optimize the process based on their priorities, such as cost minimization, exclusion of certain paths from the calculation, because they clash with landmarks and width of the new road network for circulation convenience. This allowance for customization is key for local resilience to climate change and socioeconomic development.

\section{Conclusions}

Due to the staggering rise of technology, our ability to generate data far exceeds our capacity to comprehend the complexity that is entailed in the process of allocating the right kinds of data, analyzing it and finding meaningful connections between different data sets. As this has become one of the biggest challenges that planners are facing, it is important to employ innovative strategies and attempt to go beyond the conventions in data diagnostics. The core of this paper is devoted to an examination of direct or indirect user participation in understanding and pursuing social cohesion in the urban context.

In recent theoretical and policy debates concerning social correlation with the built environment, human participation has re-emerged as an important asset that could provide insight regarding the dynamics of urban space. In this context of renewal of interest in the local, social interactions, the deployment of notions such as, subjectivity, human scale, and temporality offer a critical review of constrained and narrow-sided methods of visualizing the dynamics of urban space solely from a top-down perspective, that of planners and stakeholders. Beyond its sociopolitical implications, participatory approach in urban planning aims to establish a framework toward a more resilient and sustainable environment that benefits both researchers and citizens. From the researcher's perspective, the ability to visualize and analyze peoples desires and opinions that reflect their background allows for a culturally enhanced database that captures their common aspects and differences as it was demonstrated on the first case study.

The first case study aims to provide a calibrated understanding of the multiple grains of constructed space through top-down and bottom-up methodologies, as well as to offer a tool of visualizing dynamical characteristics of the urban environment. The research balances the traditional census data analysis with more dynamic layers of collective platforms and crowdsourcing. Whichever methodology is considered more or less descriptive of the reality, it is worth examining all the conduits and corridors available to us, by which changes in the urban context are being delivered.

The results of the three surveys were overlapped and weighted in order to produce a series of maps at different scales that visualize gentrification in the Bay Area. Each method described presents certain advantages. The census data analysis provides an 
overview of the context over a significant time span (2000-2012) and helps us understand major socioeconomic shifts. The open data analysis depicts the ephemeral layer of relationships that take place in the urban environment, which is impossible to be described by authoritative data; however, it is more relevant to the actual conditions, revealing user demands through open-source platforms. The third method enriches the process with cultural inputs are captured as data and user personal feedback about ranking the environment of a neighborhood as it currently stands. Looking at urban issues through maps can give us several hints about spatial and social transformations, in which we can think upon, as visualized information provokes feedback, either logical or emotional. Throughout this entire process, we can assess certain findings:

1. Based on the census data analysis, nearly half of the San Francisco Bay Area census tracts are undergoing some form of neighborhood transformation and displacement.

2. Although varied in their approaches, questions and results, one consistent finding across the three methods is that movers in gentrifying tracts were more likely to be higher income, college educated, and younger in age. This came down to depicting certain categories as indicative that the process of gentrification has already been underway: (a) shift in tenure, (b) influx of households interested in urban living, (c) increase in high-income serving amenities such as music clubs, coffee shops, galleries, etc, (d) rise of educational level.

3. The data accumulated from the open data research depict a significant artists' movement regarding art studio rent requests, artwork sale, and creative services in general in the entire Bay Area and especially in San Francisco and Oakland. The San Francisco arts scene has historically overshadowed Oakland; however, in combination with the staggering rise of rent in San Francisco, we can anticipate that the artist movement will intensify in East Bay in a short timeframe.

4. Studying Oakland at a local street view scale, we can assess that the area is undergoing disperse development that presents high contradictions related to infrastructure condition, affordability, and safety. The results from the crowdsourcing survey vary significantly in building block scale; therefore, any sense of continuity of the same character because of proximity is not necessarily a criterion to rely upon (Figures 11-13).

5. Moreover, certain redeveloped areas have uniform functional identity, such as Emeryville, as they present excessive duplication of the most profitable uses (malls, restaurants), while San Francisco and Oakland downtowns present excessive duplication of financial functions (bank district).

6. We notice significant contradictions on the results of the crowed sourced research regarding infrastructure condition, safety, and affordability perception of the participants. Some of the findings depict areas of new development (last 3-4 years) that are yet islanded off because the surrounding area is significantly undermined. However, this contradiction reveals certain dynamics regarding the future, further redevelopment of the area, as well as the areas that accumulate similar features. If we combine the above with the data related to artists' movement and the real estate requests associated with it, we can anticipate that the areas that are currently popular to the artist community will upgrade and the areas that are still undergoing reanesthetization (industrial, abandoned buildings) will follow (Figure 10). 
This new establishment of relationships is replacing almost entirely the previous condition of gradual displacement and gentrification. It evolves rapidly, and although it looks more orderly, visually, as many areas are undergoing significant upgrading, this esthetic ordering might not have a social correlation. Social structure and social stability are inversely proportional to visual order. This condition is known to be establishing in Oakland, which was significantly undermined in the past few years; however, the challenge is not only to identify the problem but also to find the ways to analyze by mapping its characteristics and communicate it visually to its extents. Understanding the shifts of urban space and finding the patterns that drive them is a big challenge. We support that close engagement with users leads us to explore numerous research methods, which have a way of contributing to meaningful connections inside data networks. We find inspiration in the combination of the traditional ways of space categorization by investigating the relationship of home value, income, transportation, etc., with a bottom-up, participative approach in which individuals provide more ephemeral social elements of neighborhoods.

The second case study is a first step in designing a platform that showcases a social and vital problem of undeveloped slum communities. The primary aspect in designing this tool is to understand the problem through the citizens' perspective, resonate it to a wider audience and formulate methods to represent it effectively.

At the moment, "Openreblock" platform computes and visualizes access to essential utilities such as water, energy, and sanitation at a building block level, along with showcasing how the lack of these may relate to risks or disasters faced by entire communities. The potential contribution of this platform could extend beyond a computational and visualization tool, into a powerful decision-making tool used by both policy makers and slum communities alike, with the objective to improve the lives of the communities through design and data, build partnerships with organizations that could bring innovative solutions and impact stakeholders' strategies to become more tailored toward what is important for the communities.

From the citizens perspective, the ability to collect their own data, own the process of development, and reshape the urban fabric prompts the residents to participate in its evolvement and grow conscience and care for their neighborhood.

As the above case studies open the possibility to operate at a fine spatial scale, examining the city, and neighborhoods, block by block and building by building, they provide the context for a more fine-grained understanding of community characteristics, conflicts, and relationships that reveal the heterogeneous characteristics of the urban space. We argue that the key in improving policy-making is engaging community members to collaborate and take advantage of the available information, in order to become more active members in the society and become able to respond with their own creativity and capacity. From the researchers and planners perspective, the key would be to find ways to anticipate the infrastructural requirements of user involvement, come up with new tools and ideas that maximize the potential for cooperation, coordination, and creativity, while diminishing friction. The future goal would be to design for a convergence of trajectories of citizens, stakeholders, researchers, environment, and local authorities. This could be a first step toward the equalization of power and influence between citizens and stakeholders, which could lead in the collaborative construction of urban space and the understanding of the unique challenges that the city faces.

\section{Acknowledgements}

The first case study was initiated in the context of the University of California, Berkeley, during the Master of Architecture Program "Studio One: The Data Made 
Me Do It” 2014-2015, supervised by professor Kyle Steinfeld. The research was continued and concluded by the author at a later stage. The development and design of the digital platform in the second case study is a collaboration between the University of California, Berkeley, and the College of Environmental Design, Stamen Design in San Francisco and the Santa Fe Institute. Contributors from University of Californi, Berkeley, are Nicolas de Monchaux, Carlos Sandoval Olascoaga, Wenzhe Peng, and Eleanna Panagoulia. Design by the Stamen design and technology studio. The source for this site and the topology algorithm can be viewed on GitHub.

\section{Conflict of interest}

The authors declare no conflict of interest.

\section{Author details}

Eleanna Panagoulia

Foster and Partners, London, UK

*Address all correspondence to: eleannapan@gmail.com

IntechOpen

(C) 2019 The Author(s). Licensee IntechOpen. This chapter is distributed under the terms of the Creative Commons Attribution License (http://creativecommons.org/licenses/ by/3.0), which permits unrestricted use, distribution, and reproduction in any medium, provided the original work is properly cited. (cc) BY 


\section{References}

[1] Jacobs J. The Death and Life of Great American Cities. New York: Vintage Books; 1961

[2] Freeman L. Gentrification and displacement: New York City in the 1990s. Journal of the American Planning Association. 2004;70(1):39-52

[3] Alexander C, Ishikawa S, Silverstein M, et al. A Pattern Language. New York: Oxford University Press; 1977

[4] Forer FP, editor. Geometric Approaches to the Nexus of Time, Space and Microprocess: Implementing a Practical Model for Mundane SocioSpatial Systems. New York: Oxford University Press; 1998

[5] Smyth SC, editor. Mining Mobile Trajectories. London: Taylor and Frances; 2001

[6] Salingaros N. Principles of Urban Structure. Amsterdam: Techne Press; 2005

[7] Sassen S. Globalization and its Discontents. New York: New Press; 1998

[8] Sampson J. Great American City: Chicago and the Enduring Neighborhood Effect. Chicago: The University of Chicago Press; 2011

[9] Glass R. London: Aspects of Change. London: MacGibbon \& Kee; 1964

[10] Owens A. Neighborhoods on the rise: A typology of neighborhoods experiencing socioeconomic ascent. Washington DC: City \& Community; 2012

[11] Lees L, Slater T, Wyly E. The Gentrification Reader. Routtledge: Oxon; 2010

[12] Wolch J, Dear M. Malign Neglect, Homelessness in an American City.
San Francisco: Jossey-Bass Publishers; 1993

[13] Batty M. The New Science of Cities. Cambridge, Massachusetts: The MIT Press; 2013

[14] Tufte E. Envisioning Information. Connecticut: Graphics Press LLC; 1990

[15] Corner J. The Agency of Mapping: Speculation Critique and Invention. London: Reaktion Books; 1999

[16] De Monchaux N. Local Code: 3659 Proposals About Data, Design, and the Nature of Cities. New York: Princeton Architectural Press; 2015

[17] Oakland Census Data [Internet]. 2017. Available from: http://data. openoakland.org/ [Accessed: June 2017]

[18] San Francisco Census Data [Internet]. 2014. Available from: http:// www.dof.ca.gov/Reports/Demographic_ Reports/ [Accessed: October 2014]

[19] State of California, Department of Finance [Internet]. 2014. Available from: http://www.dof.ca.gov/Reports/ Demographic_Reports/ [Accessed: October 2014]

[20] United States Census Bureau, Fact Finder [Internet]. 2014. Available from: https://factfinder.census.gov/faces/ nav/jsf/pages/community_facts.xhtml [Accessed: October 2014]

[21] San Francisco Public Services Data [Internet]. 2014. Available from: https:// link-sf.com/ [Accessed: November 2014]

[22] United States Census Bureau [Internet]. 2014. Available from: https:// census.gov/en.html [Accessed: October 2014] 
[23] Craigslist Open Data Platform

[Internet]. 2014. Available from:

https://sfbay.craigslist.org/ [Accessed:

December 2014]

[24] Oakland Crime Postings [Internet]. 2016. Available from: http://oakland. crimespotting.org/ [Accessed:

November 2016]

[25] Amazon Mechanical Turk

[Internet]. 2016. Available from: https:// www.mturk.com [Accessed: November 2016] 


\title{
Chapter 9
}

\section{Urban Sprawl}

\author{
Balamurugan Paramasivam and Illanthirayan Arumugavelu
}

\begin{abstract}
Swift progress in urban areas can pilot to urban sprawl, where new components are urbanized around the external boundaries of urban areas, frequently taking up important farmland. Many tenants want better residence, comfortable space, and calm and safe environment, which they discover in the new suburban growth far separate from the center of the city. This kind of expansion requires the addition of utilities and the transport network, as well as the precautions of services such as education, amusement, medical facilities, and commercial services. A number of Indian cities, for example, have a "Delhi," a "Mumbai," and other cultural-based communities that reflect our multi-cultural people. Historical information said, many Indian immigrants who lived in these neighborhoods were poorly treated and subject to racism and discrimination by the general people. Urbanization is a truth of life in most cities in India and around the world.
\end{abstract}

Keywords: town and city, migration, growth, sprawl, urbanization

\section{Introduction}

The history of urban sprawl is unwritten, and only a small part of the beginning work has been done. The history of urban sprawl dates back from the ancient times of the origin of cities (during what is referred to as the first phase of urbanization in the world). While Gordon and Richardson [1] define urban sprawl as leapfrog development, DiLorenzo [2] defines it as growth with cancer or virus. In the confusion in the definition of urban sprawl, Wilson et al. [3] and Galster et al. [4] state that describing would be more suitable than defining. In this long duration, what was witnessed was the growth of cities from ancestral form to small harbor/ rail-based towns and to the present-day cities with skyscrapers adorning landscapes. By the end of the 20th century, urban growth was rapidly pushing cities further and further out, and the cities were expanding spatially, while in the 21st century, the automobile revolution changed the dominant form of city living. This stretched form of the city with low density at the periphery is sometimes called sprawl. Since sprawl is one name for many situations, there has been no clear consensus regarding what exactly "urban sprawl" is or how it is caused. Although many researchers tried to get bring with descriptions of the idea, the fundamental component of most descriptions and most people's acceptance of sprawl is this: Sprawl is the spread out of an urban area, and it is suburban over more considerable for country land at the fringe of an urban area. Urban sprawl, which is asserted to be carried out for urban growth, is in fact not suitable either for urban growth or rural environments in a real sense. In this sense, since it is carried out in a disorganized and uncontrolled way, it has effects that hinder regional sustainable development [5]. This involves the exchange of open space into various land use purposes, such as housing, building 
industrial estates and health centers, for sustainable living purposes. Al-Kheder et al. [6] explain urban-growth modeling using multitemporal satellite images.

\section{Urbanization}

Urbanization is a metropolitan development that is a response to often less understood implications of technological, economic, social, and political forces and to the physical geography of an area. The pattern of urbanization in India is characterized by a continuous concentration of population and activities in large cities. Kingsley Davis used the term "over-urbanization," "where in urban misery and rural poverty exist side by side with the result that city can hardly be called dynamic" and where inefficient, unproductive informal sector becomes increasingly apparent [7]. Another scholar, Breese, depicts urbanization in India as pseudo urbanization where people arrive in cities not due to urban pull but due to rural push [8].

The considerable economic and livelihood opportunities in urban areas and an increase in accommodating immigrating populations result in greater urbanization. It is never seen as a vulnerability to environmental growth, but it is the accidental urban area and energetic urban growth, or the sprawl that influences the land use of any area that becomes a substance of concern through its habit in the loss of major farming lands. It is very important to study and determine the information and suggestions interrelated with the problem of unexpected urban growth ensuing sprawl.

Urbanization is a global process in which most developing nations experience that has led to the rise of great metropolitans along with slums and squatter. At the same time, a notice concern is also about the exhaustion of natural resources, increasing pollution and environmental hazards apart from the development of urban-rural fringes and suburban divisions, a host of ecological and socioeconomic factors that have become remarkable challenges of the current era. Chandna highlighted these factors [9].

\section{Characteristics of urbanizations}

Urbanization is a universal phenomenon. It is a process of enrich growth in a country's urban inhabitants accompanied by an even huge development in the financial, political, and cultural importance of cities associated with rural areas. In "The Origin and Growth of Urbanization in the World," Davis explains and gives the world growth of population and the way of urbanization and growth stages.

The term "urbanization" illustrates a development in the human population associated with the development of energy and resource consumption and widespread land use. Since the rise of population becomes more enrich, the need for goods and services is often driven by addition rather than just rapid population growth. Urbanization refers to a growth in the percentage of a population living in urban areas of an exact size.

The rapid growth of the population is a result of the sparing scientific and medical knowledge and is the fundamental reason for urban growth and population. However, the rapid development of the population in urban centers is also disturbed by economic development, which is decreasing the percentage of the population engaged in agricultural areas. Structural change in employment, especially the growth of the tertiary (service) sector, has led to an improved number of employments in urban areas. Most service firms need to be central business districts (CBDs) to obtain benefits from close communication with each other. 


\section{Central business district}

The central business district (CBD) is the main part of the city that contains the major commercial streets and main commercial buildings. Throughout history, the Central Business District has been characterized by land classification and land use changes that include residential, commercial, industrial, and administration purposes. These spatial changes have been used to support Central Business District development. However, in the wake of post war decentralization and the growth popularity of polycentric regions in both Europe and the US, much of this work has itself come under criticism. The main force of the criticism proposes that Central Business Districts are now more likely to practice for the development of suburban lifestyles. However, similar developments, such as core city regeneration, propose that CBDs are now at the heartbeat of a more extensive back to the city movement that (re)promotes the pleasant appearance of city area living through residential expansion, delightful cultural districts, and an urban cool cultural social scene.

The beginning of the 21st century, the Central Business District had turned into a discrete area of the metropolitan city and built-in residencies, retail shops, commercial malls, Central universities, recreational, government, financial institutions, health care centers, and culture centers. The urban area is located at workplaces or educational institutions in the CBD for regular movement. This includes students, doctors, academics, government officials and civil servants, business peoples, formers, and financiers. In the current era, the rapid development of residential expansion and the growth of shopping malls have given a new life to the Central Business District. In addition, multi residential buildings, mega-malls with theaters, Kochi Lulu international shopping mall is an example of a business district area as an entertainment and shopping center. City walk malls are also familiar in central business districts in an attempt to make the CBD a $24 \times 7$-hour working destination.

\section{Migration}

Migration is the movement of people from one place to another place for various purposes. Immigrants go away their nation, while migrate peoples enter a country. Migration impacts two nations and places where migrants enter settle. [9] addressed urbanization, migration and economic development and explained the primary stages of urban growth based on the migration of the population and the economic development of a town.

People have so many reasons why they force to move from one nation to another nation. The reasons behind this movement are employment opportunity, economic, education, globalization, and political or environmental condition. Migration is classified as 'push factor' and 'pull factor.' Push factors force people to migrate; for example, unemployment, lack of infrastructure (such as hospital, education institutions, etc.), natural disasters (such as floods, droughts, earthquakes, cyclones, etc.), local conflicts, war, etc. The people get experience of life and move one place which gives them good life. Pull factors attract people from different places, such as better opportunities for education and employment, better health facilities, and various sources of entertainment.

\section{Urban sprawl}

In India, rapid population growth and migration, greater than before urban population and urbanization, is not predictable. Barnes et al. highlight sprawl 
development: its patterns, consequences and measures of particular cities and towns of urbanization [10]. Increasing towns and cities are developed with a change in land use along the national highways, and in the nearby surrounding area of the city, this development occurs outside urban areas such as suburban and urban fringes. Urbanization is a structure of metropolitan city growth that is the reason for social, economic, and political forces and to the physical geography of an area. Some of the reasons for the sprawl contain population growth, urban economy, settlement patterns of infrastructure activities such as the construction of bridges, metal and concrete roads and the provision WiFi using public encouraging development. The direct suggestion of such urban sprawl is the land utilization of the region. Sprawl normally infers some type of expansion with impacts such as loss of farmland, open waste space, and environmentally sensitive habitats. Additionally, sprawl is occasionally equal to the growth of towns or cities. In simple words, as a population in an urban area or a city, the border of the city expands to provide accommodation for growth $[11,12]$. This extension is measured as sprawl. Generally, sprawl occurs on the sub-urban area, at the edge of an urban fringe or along the highways [13].

\section{Effects, impacts and consequences of urban sprawl}

The places of sprawl and the region that is impacted by it are distinct from each other [14]. Urban sprawl takes place at the edge of a town or city, and it might have a direct or indirect force on other parts of the urban area within its administrative boundary or on a nearby city. In general, two adjacent views are taken about the outcome or reflection of sprawl. Urban sprawl may have both positive and negative consequences and impacts; however, negative impacts are often more highlighted, as this is uncontrolled or uncoordinated growth, and eventually, the negative impacts obliterate the positive sides. There are some positive impacts of urban sprawl, such as an increase in economic production, an increase in opportunities for employment, better opportunities and better services creating better living conditions, and better lifestyles. Urban sprawl can extend basic services, infrastructure and social capital, such as transportation, sewer, and water, better educational facilities, and health care facilities, to a larger population. However, since it is an uncontrolled and uncoordinated growth resulting in sprawl, the positive impacts are covered up inviting focus only on the negatives [15].

During the nineteenth and early twentieth centuries, in developed countries, urbanization was created, and it also led to industrialization. The surplus population from the villages was motivated to make a mass movement towards cities because of new job opportunities created there. For the cities too, these migrants provided cheap labor for the newly established factories. Due to the present globalized scenario and opening up of economies, the circumstances are similar in developing countries. The huge concentration of investments in cities attracts a large number of migrants from villages who are looking for employment. This creates a large surplus labor force, and because of this, the wages remain low. Developed and developing nations of the world are different not only in the percentage of people living in urban areas but also in the way in which urban centers are taking place. Most megacities are developing worldwide, urban sprawl is a universal problem, and a significant number of city inhabitants live in slums within the city or in urban centers in poverty and polluted environments. These large settlements are frequently highly polluted due to the shortage of urban sanitation services, including drinking water, drainage, garbage pickup, electricity or paved roads. However, urban areas give life 
for poor people with more employment opportunities and better income to renovate their life compared to rural areas.

Some social welfare societies and environmental welfare and helpers claim that for countries such as India with large land areas, there are too large farmlands and open waste spaces to be concerned about how much land is transformed. They also strain the main benefit of sprawl, which is the delegation of employment to various places in urban areas. Most of the urban centers affected by air pollution based on car culture enable people to commute shorter distances at any time and home. Urban areas construct their own buildings or residential villa like better houses. It is not healthy for people to live in areas with increased densities and smaller meter square of space per individual. Therefore, the better suggestion is for those people to live in larger plots with their own green spaces to go away from city centers and work areas.

\subsection{Ecological impacts}

The percentage of open land space used by each dweller has improved in the last 25 years by two or three times.

\subsection{Atmospheric pollution}

The level of pollution due to motorcar needs can more easily be connected to population densities. Currently, the peoples use their own vehicles for transportation purposes to avoid common transport facilities, and the percentage of usage has rapidly increased. This kind of activity polluted the environment hour's base movement of vehicles.

\subsection{Loss of natural resources}

All spread out directly to the loss of a significant partial resource that is land. Over the years, urban sprawl has openly been given to result in the poverty and decline of natural surroundings such as woodlands, swamp and wildlife habits. It has also reduced open land spaces. Natural resource use has increased. Urban Sprawl guides land-use patterns that are adverse to the development of sustainable transport and increases the use of personal cars, which in turn results in greater than before changes, traffic, rapid use in fuel utilization and air smog. It is in general a hazard to the human environment.

\subsection{Impacts on ecosystem}

In areas where sprawl is not controlled, the concentration of humans in residential and industrial areas of urban sprawl might directly amend urban ecosystem patterns and processes. Urban growth connected with urban sprawl not only reduces the amount of ecosystem, open farmland woodland, and open space. The arrival of urban sprawl into rural areas and land loss may also raise agricultural lands for the purpose of roads, power (tower) lines, and pipelines. This kind of activity disturbs the rural ecosystem.

\subsection{Loss of farmland}

Urban sprawl and urbanization contribute to the loss of farmlands and open spaces. Only in the United States is urban sprawl predicted to consume 7 million acres of farmland, 7 million acres of environmentally sensitive land, and 5 million acres of other lands during the period 2000-2025. Preferred taxation and land 
use policies work in sync to generate economic pressures that force farmers to sale their land to the urban developer. Builders and urban developers are forced to sell land at a low price due to the former economic crises, and the unreasonable prices of farmland often result in far more sales of their land than continuing farming. Additionally, the number of small land parcels of agricultural land is being separated off to create rural residential and industrial development. These small activities guide the loss of a large amount of dynamic farmland each year. The loss of farmland to build up urban sprawl means not only the loss of food sources but also the loss of ecosystems, since farms include plant and animal habitats in woodlots and hedgerows. The presence of farms on the rural landscape provides reimbursement such as green space, urban-rural economic stability, and protection of the traditional rural lifestyle.

\subsection{Lessening of the productivity of city}

It is an economic theory that productivity is much more enhanced with dense development since ideas move quickly when people are in close proximity. However, when jobs move to the suburbs, people follow them. This may reduce productivity in the city, leading to social loss. In addition, authors state that sprawl leads to creating regional imbalances, such as pulling jobs and people further away from poor communities, increasing inequality. Sprawl also creates segregation of rich and poor or social isolation in general. The problem lies not to the people who have moved to the suburbs but rather to the people who have been left behind. The low-income groups are abandoned in the downtown because they cannot afford a car-based lifestyle. The role of transport technology can explain this social fragmentation. The much congested and deteriorated central towns end up being favorable places for crime and social unrest.

\subsection{Increase in temperatures: Creation of urban heat islands}

Due to climatic changes, urban regions can have warmer temperatures than urban areas, resulting in urban heat land. The heat land outcome is caused by two reasons. First, dark surfaces such as road networks and building terraces efficiently absorb heat from sunlight and reradiate it as thermal infrared; these dark surfaces can reach temperatures higher than environmental air. Second, urban regions are moderately split of urban vegetation, particularly trees that would provide shadow and fresh air through ecological action. As urban sprawl, the heat land results increase, both in larger geographic extent and in intensity. This is especially true if the urban pattern and features develop extensive tree-cutting and wide road construction. Two decades of urban climate research: a review of turbulence, exchanges of energy and water, and the urban heat island. Satellite multisensor data analysis of urban surface temperatures and land cover.

\subsection{Deterioration in the air quality}

Atash [12] highlighted the deterioration of urban environments in developing countries. The lifestyle need on automobiles for transportation especially cars forced by sprawl guide to increase in fossil fuel utilization and emissions of greenhouse gases Urban sprawl create to poor air quality by accepting more automobile use, thereby adding more air pollutants such as carbon monoxide, volatile organic carbons, ground-level ozone, carbon dioxide, nitrogen oxides, sulfur dioxide, and microscopic particles. These pollutants can slow plant growth, create air smog and acid rain, cause global warming, and cause serious human health issues. 


\section{Conclusions}

A new growth be it intended or unexpected could begin on waste land or on land that was before used for some other agricultural purpose. In most cases, however, whenever the need arises, it is the outer edge of the city that provides for "boundless" open land because urban areas are usually unbroken. Urban sprawl is a dynamic process. This results in changes and the transformation of urban areas. Urban sprawl means the migration of people from urban rural areas to suburban or urban fringes. It also defined a small village's conversion into a town and city. In India, urban settlement is defined as places having minimum inhabitants of 5000, with at least $75 \%$ of male employees being occupied in secondary and tertiary activities, and the density of the population should be 400 inhabitants per sq. $\mathrm{km}$. Urban sprawl means unexpected, uncontrolled spreading of urban growth into rural areas sharing the border with the outer edge of a city. Urban migration and dwellers have changed the urban environment due to the overpopulation. If the population increases the need for transportation and space for living, all other needs to be provided. The overpopulation and development of unexpected urban settlements have risen to change the urban environment. Different situations are observed to cause sprawl. In almost all cases, the rise in population plays a major role as a main cause. Urban sprawl has been recognized as a problematic aspect of metropolitan growth and development worldwide. The growing concern about the issue is shared among planners, policy makers, environmentalists and people in general.

\section{Author details}

Balamurugan Paramasivam ${ }^{1 *}$ and Illanthirayan Arumugavelu ${ }^{2}$

1 Erode Sengunthar Engineering College, Tamilnadu, India

2 Government Arts College, Salem, Tamilnadu, India

*Address all correspondence to: balamurugan.geo@gmail.com

IntechOpen

(C) 2020 The Author(s). Licensee IntechOpen. This chapter is distributed under the terms of the Creative Commons Attribution License (http://creativecommons.org/licenses/ by/3.0), which permits unrestricted use, distribution, and reproduction in any medium, provided the original work is properly cited. (cc) BY 


\section{References}

[1] Gordon P, Richardson Harry W. Are compact cities a desirable planning goal? American Planning Association. 1997;63(1):95-106

[2] DiLorenzo W. The myth of suburban sprawl. USA Today. 2000;128:54-56

[3] Wilson EH, Hurd JD, Civco D, Arnold CL. Development of a geospatial model to quantify, describe and map urban growth. Remote Sensing of Environment. 2003;86(3):275-285

[4] George G, Royce H, Harold W, Stephen C, Jason F. Wrestling sprawl to the ground: Defining and measuring an elusive concept. Housing Policy Debate. 2001;12(4):681-717

[5] Basudeb B. Analysis of Urban Growth and Sprawl from Remote Sensing Data. Canada: Springer; 2010

[6] Al-Kheder SAM, Wang J, Shan J. Fuzzy inference guided cellular automata urban-growth modeling using multi-temporal satellite images. International Journal of Geographical Information Science. 2008;22(11-12):1271-1293

[7] Kundu A, Basu DN, et al. Urban Development and Urban Research in India. New Delhi: Khama Publishers; 1992. p. 162

[8] Breese EL. The measurement and significance of genotype environment interactions in grasses. Heredity. 1969;24:27-44

[9] Chandna RC. Geography of Population: Concepts, Determinants and Patterns. New Delhi: Kalyani Publishers; 1996

[10] Barnes KB, Morgan JM III, Roberge MC, et al. Sprawl Development: Its Patterns, Consequences and
Measurement. Towson, USA: Towson University; 2001

[11] Diddee J. Indian Medium Towns: An Appraisal of Their Role As Growth Centers. New Delhi: Rawat Publications; 1997

[12] Atash. The deterioration of urban environments in developing countries: Mitigating the air pollution crisis in Tehran. Iran Cities. 2007;24(2007):399-409

[13] Kumar et al. Monitoring urban expansion and land use/land cover changes in Rohtak city using remote sensing and GIS technique. International Journal of Advances in Remote Sensing and GIS. 2012;1(2):186-191

[14] Soffianian A et al. Mapping and analyzing urban expansion using remotely sensed imagery in Isfahan, Iran. World Applied Sciences Journal. 2010;9(12):1370-1378

[15] Weng Q. A remote sensing? GIS evaluation of urban expansion and its impact on surface temperature in the Zhujiang Delta, China. International Journal of Remote Sensing. 2001;22(10):1999-2014 


\title{
Toward Practical Criteria for Analyzing and Designing Urban Blocks
}

\author{
Amir Shakibamanesh and Bita Ebrahimi
}

\begin{abstract}
The streets, blocks, lots, and buildings are the main elements of cities' texture. Surrounded by streets and surrounding the buildings, urban blocks invariably interact with these components dialectically, in that it can connect the network of streets and buildings, hence its significance in urban design. However, affected by unsound formal and spatial changes of urban forms in modern and postmodern eras, space coherence reduction led to a loss of blocks' identity. Therefore, we can barely find a comprehensive functional tool structured on a solid understanding to design this very component of the urban morphology. In this regard, this study seeks to define a practical tool for analyzing and designing this crucial element developing an operational, yet expandable, checklist for urban blocks including various factors, from concepts to indices. All these factors are classified under three main concepts: spatial balance, spatial continuity and integration, and durability. In fact, as a primitive step, this research can enable urban designers to understand urban blocks more effectively and use the framework to assess the current situation and design the future.
\end{abstract}

Keywords: urban morphology, blocks, urban design evaluation criteria

\section{Introduction}

Urban morphology is one of the most important physical approaches to urban form. The term morphology refers to the study of form and deals with shape, form, external structure, or order [1]. Understanding the importance of urban morphology, which involves the design and composition of the urban form and the processes effective in its formation, helps urban designers to recognize the local patterns of development and transformation processes [2]. Referring to the approaches taken by three schools of England, Italy, and France in relation to urban morphology, Moudon states that the typological elements from the perspectives of these three schools of urban morphology focus on three main elements, i.e., street and block, lot, and building [3, p. 7]. Urban block as one of these elements has received little attention compared to other morphological elements.

The formation of this important element took new dimensions after modern times, so that the cities lost their spatial integration due to the construction of single buildings in urban spaces, and as a result, urban context became a collection of amorphous spaces with dispersed neighborhoods and streets and isolated 
applications with disrupted forms, without interconnected urban masses and blocks that could be representative of space [2].

It can be said that urban blocks have the potential to define and create the balance between lots and streets, so that buildings and streets are considered simultaneously and in parallel with each other. Therefore, attempts were made to define factors required for analyzing this element by examining the views and theories related to blocks. To this end, first, the concepts were extracted and then were clustered by examining their interrelationships. Finally, a categorized list of effective factors in design of urban blocks was developed that can be used as a guideline for the design of this essential element.

\section{Urban blocks}

The city block is the fundamental element of physical structure of urban areas [4]. The block is primarily a plot of land defined all around by a multitude of planned and unplanned road and streets [5] and defined by an edge and an interior where the edge is directly connected with the street and is understood as the public realm and the interior is a private zone.

Regarding urban form, Moudon indicates four levels of resolution are commonly recognized, corresponding to the "building/lot," the "street/block," the "city," and the "region" [3].

In a parallel way, it was Conzen who recognized the tripartite division of the townscape, the town plan, or ground plan, comprising street, plots, and block plans of buildings [6].

\section{The role of blocks in the urban spaces}

The urban block must be identified as the most important typological element in the composition of urban spaces [7] because as part of the urban continuum, an urban block is that singular element that is spatially and functionally optimized to support different circumstances of everyday life [7]. Where the urban block is the tool for urban design, the pattern of streets and squares become the result of positioning of the blocks [7]. Also, the size and shape of urban blocks contribute effectively to the formation of the character of the environment [2]. The formation and scope of urban blocks are also effective in determining traffic patterns and visual growth parameters [2].

Additionally, the block faces respond to buildings (the internal load of blocks) and street structure (the external load of blocks). In fact block faces participate in defining the edges and character of the street network; they act as the interface between architectural form and urban form [8].

In fact, the city block facilitates close integration into the surrounding urban structure. It is linked to the network of city streets and building lines, which define it spatially and geometrically. The city block is a continuous closed urban space, accessible from all sides, that ensures the continuity of surrounding structures and exterior urban areas [9].

Therefore, the city block is a spatial system that is extremely complex and flexible and lends itself particularly well to integrating diverse, differentiated modes of behavior, activities, and forms of appropriation [9, p. 22].

\section{Thoughts on urban blocks}

Urban blocks can be traced in a variety of thoughts, and the concepts and factors derived from ideas of this research about the block can be divided into three 
categories: size, dimensions (2D, 3D), and shape; position; and function and meaning. It should be said that each of these categories can have effects on each other, mutually. In the following, spatial qualities which are created by these factors are also discussed. All the factors relate to the urban blocks could be considered in the three categories:

- size, dimensions, and shape;

- position; and

- function and meaning.

\subsection{Size, dimensions, and shape}

\subsubsection{Two-dimensional space}

Many studies have focused on the formal aspects of blocks, especially the size and dimensions of urban blocks, often to achieve optimal sizes for them. Krier [7] who compared and studied different sizes of urban blocks suggested that the sizes of blocks should contribute to integration in the context [2]. Vialard [8] states that such ideas seek to restore a human-scale environment where in buildings and blocks interact closely. In general, in this view, large urban blocks tend to get smaller to achieve the optimum size. One of the effective factors in this regard is the determination of the level of privacy and frontage of buildings, which supports concentrated urban centers [4]. This also induces a sense of transition and transfer between public, semipublic, and private spaces [10].

Conzen [11], Bentley [12], and Jacobs [13] advocate small-sized blocks, because they believe that these blocks enhance physical and visual permeability and enhance public awareness of use options. Siksna [4] supports the sustainability and durability of small urban blocks and in research on the desired size of blocks and the design of blocks in four American cities and also considers the durability and sustainability of "small-block cities" as high.

Talen [10] refers to factors such as the internal connection of blocks and their connectivity, which relates to the relationship between the blocks and the street network. It can be said that very large urban blocks affect connectivity [14]. As Scheer and Petkov [15] state that although these large urban blocks, especially those that include large shopping malls, strengthen the external connection of the blocks with their surrounding environment, they are isolated locally from the environment and have weak internal connections. Maitland [16] considers these major shopping centers as the main factor effective in the separation of blocks and streets. In his opinion, those blocks that contain large shopping centers create privacy in the inner space of the block, rather than at the edges, and though they create footpaths, they limit the connection of these paths to the internal space and weaken or interrupt the pedestrian access to the surrounding area. A similar point can be seen in introverted blocks with cul-de-sacs as a type of POD development, because the cul-de-sacs create autonomous and car-dependent spaces that grow apart from other units in the context and are detached socially and physically from the outside world [2]. Song and Knapp [14] also consider the street intersections, the length of cul-desacs, the block perimeter, and the residential density of blocks as effective on connectivity between neighborhoods.

It is noteworthy that in the close relationship between the street and the block, these patterns require sustainability to evolve so that initial patterns can survive under conditions of change, so one of the factors affecting sustainability is the block 
size. According to Siksna [4] blocks of different sizes can achieve sustainability in block patterns and access networks, but large blocks, although can be largely stable, significantly change the composition of blocks and streets, as if they tend to be disintegrated. Thus, taking into account the corresponding relationship between factors such as the block size, the level and pattern of the access network, and the relationship between them is effective in achieving the desired size. Owens and Southworth [17] state that the street patterns (gridiron, fragmented parallel, wrapped parallel, loops, and cul-de-sac) are effective in creating a variety of urban networks (open and interconnected to closed and discontinuous ones) and believe that changing open and interconnected street patterns into closed and discontinuous ones will separate neighborhoods from their surroundings and thus reduce pedestrian access. According to their study on urban-edge communities, street patterns are related to block sizes (the number of blocks), the degree of connectivity (the number of intersections), and accessibility (the number of access points).

In terms of shape, blocks can take a wide variety of geometric shapes such as triangular, rectangular, square, polygon, ellipse, semicircular, or even circular. However, their main geometric shapes are based on different architectural and urban design frames, design and quality of interior space, and lighting conditions in apartments [9]. Also, "the corners of city blocks can be designed with gaps so that the corner buildings receive adequate light. They can also be completely removed or 'beveled'. Another possibility is creating especially wide or narrow corner buildings" [9, p. 21]. Generally, the geometric shapes of blocks and their corner forms are factors that shape urban block configuration (Figure 1).

\subsubsection{Three-dimensional space}

Talen [10] suggests a minimum distance between the inner space of the block and the street for creating enclosure. In general, enclosure depends on two factors, i.e., the distance between the blocks and the ratio of the block height to the width of the passage. Changes in these proportions and distances resulting from changes in street width, the amount of block setbacks from the edge of the street, and the height of the blocks affect the enclosure of spaces and, in turn, their human scale.
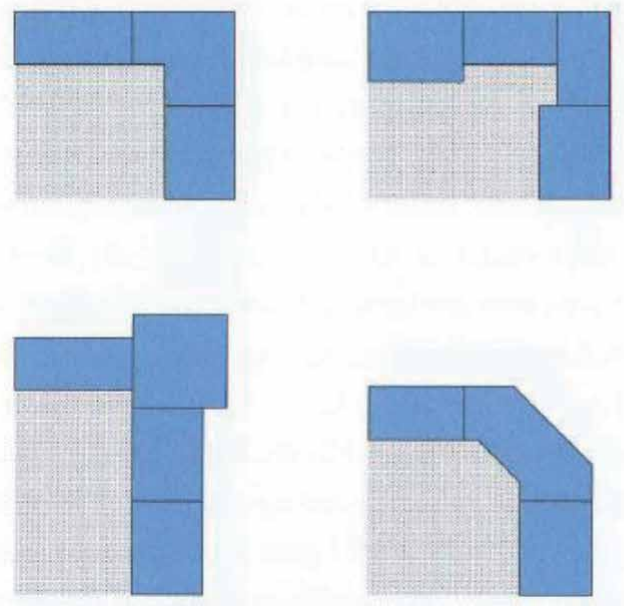
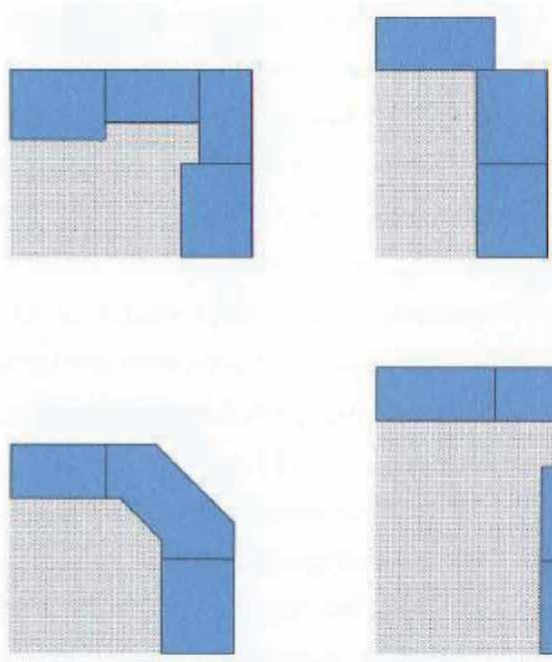

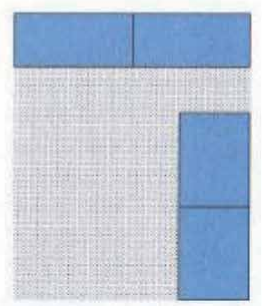

Figure 1.

Samples of block's corner design [9]. 
Martin and March [18] studied the typology of different physical layouts and systematically compared land occupation by building density and its consequences for land occupation, adequate access, create open spaces, and the possibility to enjoy daylight. Therefore, configuration is important, because you can create different configurations with the same density on the land. On the other hand, segregation of urban blocks also affects their layout.

Berghauser Pont and Haupt [19] developed a matrix called "Spacemate," in which a variety of building layouts fit into a block based on various types of densities. This matrix correlates the area of the block, the area of the open space, the ground floor area, and total floor area with different types of development. In general, as Krier [5] suggests, there must be equilibrium between the open space and the building density.

\subsection{Position}

Some scholars believe that the layout of the blocks are defined based on internal arrangement of block components, such as Moudon [20] who defines the layout of the blocks according to the location of the buildings and alleys, based on the observations of progressive evolution of block patterns, land plots, and construction patterns in a residential neighborhood around Alamo Square in San Francisco. Also, according to Conzen, plots in blocks can be taken into three forms: [2] back to back, one front to the main street and the front to the alley and two fronts with a common border on the main street. In fact, the location of plots in blocks and the location of blocks relative to each other represent the relative location of each of these elements relative to other elements and how this affects the spatial configuration and layout of blocks.

In the same way, Boffet and Serra [21] investigated the three principles of proximity, similarity, and good continuation of Gestalt theory and used indicators such as the distance between the gravity centers of buildings, and the geometric indices of buildings including orientation, surface, and elongation, to identify spatial structures within urban blocks. Their study can be used to follow Gestalt theory in the study of the spatial structure between blocks or in a super block. On this scale, Gestalt principles such as proximity, similarity, good continuation, symmetry, and enclosure can be used to understand the alignment of blocks in a superblock as a whole, the location of buildings in block, and spatial configuration of urban blocks and also to evaluate indicators such as distance between gravity centers of blocks, geometric shape influenced by orientation, surface, and elongation.

On the other hand, the other scholars examined the block size based on the location and position of blocks. Talen [10] in her book, City Rules, and Krier [5] in studies on European cities with organic growth state that often central blocks close to the urban core are smaller, more fine-grained, and more complex, but as we move toward areas with lower population densities and with rural behavior, urban blocks gradually become simpler, larger, and longer, changing ultimately to single units with isolated forms in context [2].

\subsection{Function and meaning}

Rossi [22] suggests factors such as continuity of the city reinforced by continuity in time, the underlying structure of the city as a basis for development and adaptation to new uses, and consideration of the city as a repository of collective memory that can be achieved through physical continuity of urban form (via layering of buildings and their deployment in larger and existing urban structures) [8]. 


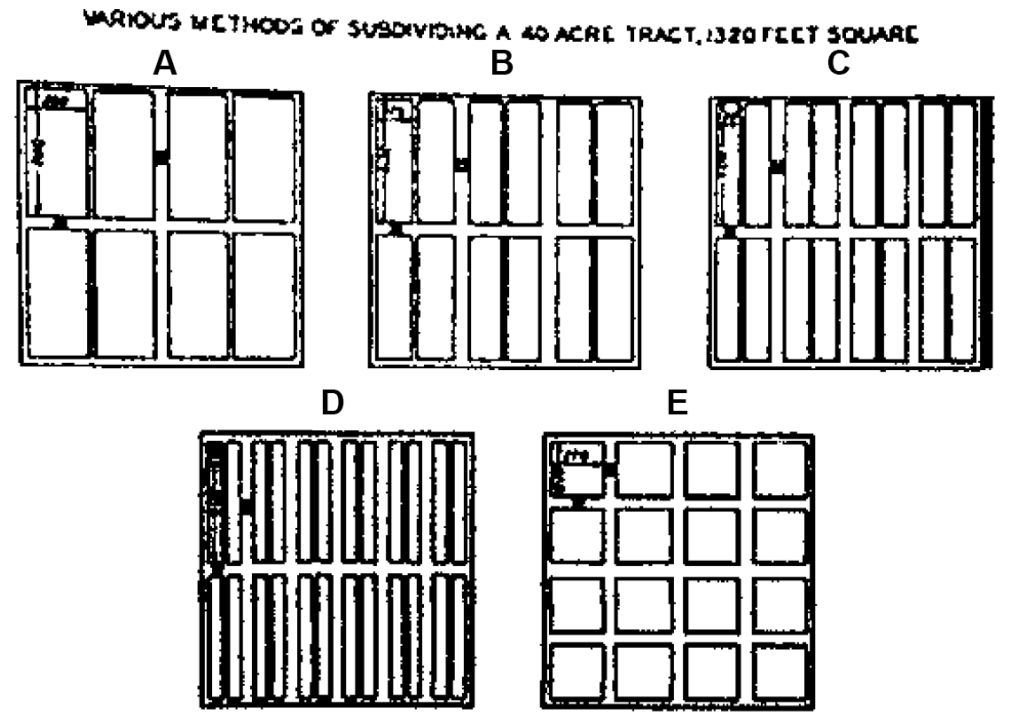

tha ses

Figure 2.

Some possible block arrangements for 40 acre tracts. According to Hoyt's analysis (1933, 431), "A" made sense (i.e., would yield the most aggregate value) where "each square foot is of equal importance." "C" the most common arrangement made sense for residential or apartment use; "1" made sense for commercial use since it has the most street frontage, but it is unrealistic because no subdivision would be composed entirely of commercial lots (Hoyt did not comment on the value of arrangements " $B$ " and " $E$ ") [10].

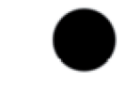

community node

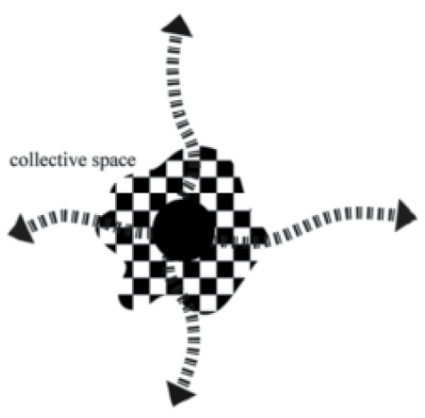

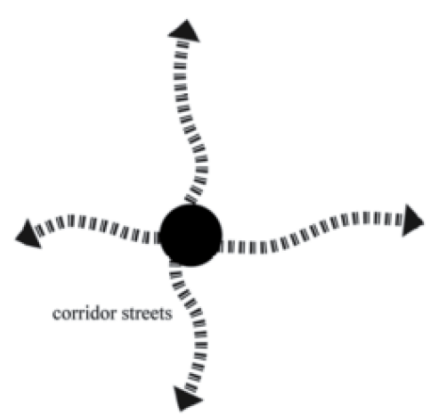

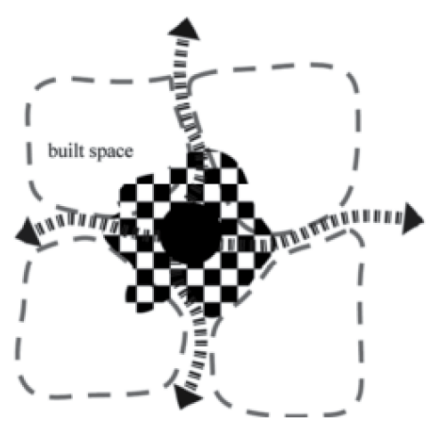

Figure 3.

The urban process of the community block [23, p. 71].

Regarding visual permeability, Bentley [12] stresses the need for front and rear sides for blocks. The front side faces public spaces for more public functions, and the rear side includes activities that have the highest degree of privacy. In this 
regard, a perimeter block type of construction is proposed for blocks that place the private open spaces at the back of the buildings and the public ones in front, distinguishing the internal and external spaces [12].

Hoyt (1933) also refers to a variety of form-based division patterns for urban blocks based on their type of use [10] (Figure 2).

Oikonomou [23], in a research, focuses on the design process of urban blocks to create a community block based on environmental sustainability goals (mobility and accessibility, land use, natural environment, resource management, and economic aspects). Investigating layers of an urban block (street, plot, buildings, and open space) is done taking into account factors such as function; ownership; mixed land use; diversity of buildings; types of open spaces and public facilities; spatial domains and observance of hierarchies in private, semiprivate/semipublic, and public spaces; income and social mixing orientation of buildings based on sunlight; and so on (Figure 3).

Examining and summarizing different perspectives on each of these variables resulted in determining the effects of each block-based variable on spatial qualities (Table 1).

\begin{tabular}{|c|c|c|c|}
\hline Categories & & Variable & Impact \\
\hline \multirow[t]{6}{*}{$\begin{array}{l}\text { Dimension and } \\
\text { size of blocks and } \\
\text { shape }\end{array}$} & $2 \mathrm{D}$ & Size of blocks & $\begin{array}{l}\text { Spatial integration, human scale, } \\
\text { enclosure, physical and visual } \\
\text { permeability, durability }\end{array}$ \\
\hline & & $\begin{array}{l}\text { Geometric shape of the blocks and } \\
\text { their corners }\end{array}$ & Climate, spatial configuration \\
\hline & & Street pattern & Connectivity, permeability \\
\hline & & The amount of privacy and frontage & $\begin{array}{l}\text { Spatial hierarchies, continuity, spatial } \\
\text { integration }\end{array}$ \\
\hline & $3 \mathrm{D}$ & Density & $\begin{array}{l}\text { Spatial configuration, layout, spatial } \\
\text { balance }\end{array}$ \\
\hline & & Enclosure & Human scale, spatial layout \\
\hline \multirow{2}{*}{\multicolumn{2}{|c|}{ Position }} & $\begin{array}{l}\text { Arrangement of buildings in the } \\
\text { block, the location of the buildings, } \\
\text { and alleys }\end{array}$ & Spatial configuration and layout \\
\hline & & $\begin{array}{l}\text { Proximity, similarity, and good } \\
\text { continuation }\end{array}$ & Spatial continuity and integration \\
\hline \multirow{4}{*}{\multicolumn{2}{|c|}{ Function and meaning }} & Block subdivision patterns & Configuration \\
\hline & & Land use & Adaptability, durability, variety \\
\hline & & Access & $\begin{array}{l}\text { Spatial layout, configuration, } \\
\text { connectivity, permeability }\end{array}$ \\
\hline & & Meaning & Memorability, sustainability, durability \\
\hline
\end{tabular}

Sources: Adapted from Krier [5, 7]; Talen [10]; Siksna [4]; Conzen [11]; Jacobs [13]; Maitland [16]; Owens and Southworth [17]; Bürklin and Peterek [9]; Rossi [22]; Moudon [20]; Berghauser Pont and Haupt [19, 25].

Table 1.

The spatial qualities affected by the block-based variables.

\section{Sorting practical concepts: from macro-concepts to indicators}

\subsection{Procedure}

In this section, the findings of the previous section are used to develop a practical checklist of the most important aspects required for the assessment of urban 
blocks. Efforts have been made to extract all these findings in the form of factors without prejudgment and valuation. Since these factors do not have the same semantic and scale levels, the checklist is developed in two main steps:

- first step: the first step is conceptual classification, which is done by connecting factors with similar meanings (Figure 4). Here, similar factors are identified and semantically classified into three groups, distinguished from one another by color (Figure 5); and

- second step: the second step is the scale classification, which is done by defining the hierarchical relationships among the factors of each category in each of the three conceptual groups (Figure 6). Finally, the factors of these groups are placed in three classes, i.e., macro-concepts, concepts, and criteria (Figure 7). In addition, to make the assessment checklist more practical, definitions of indicators are included in the agenda. These indicators have been defined according to different views in the literature (Table 2).

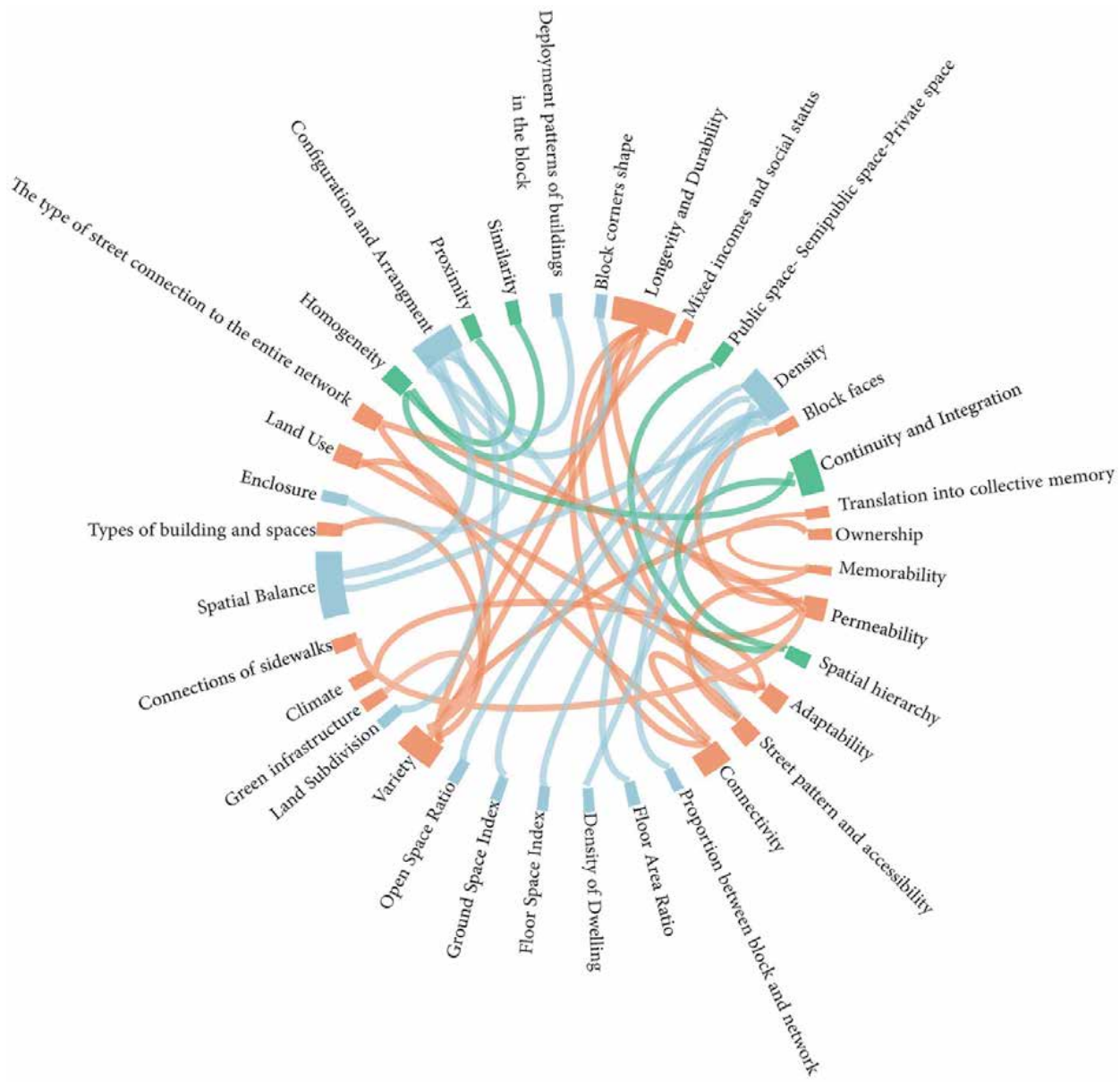

Figure 4 .

The first step: identifying similar factors and their interconnections. 


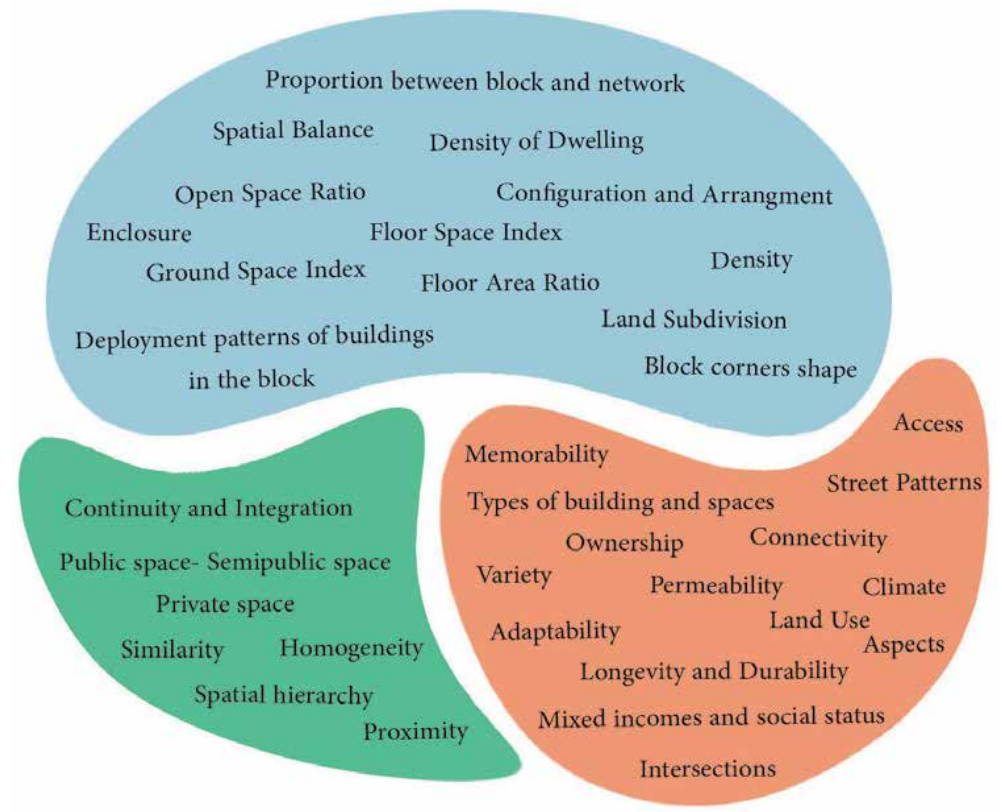

Figure 5 .

The first step: classifying similar factors into three groups.

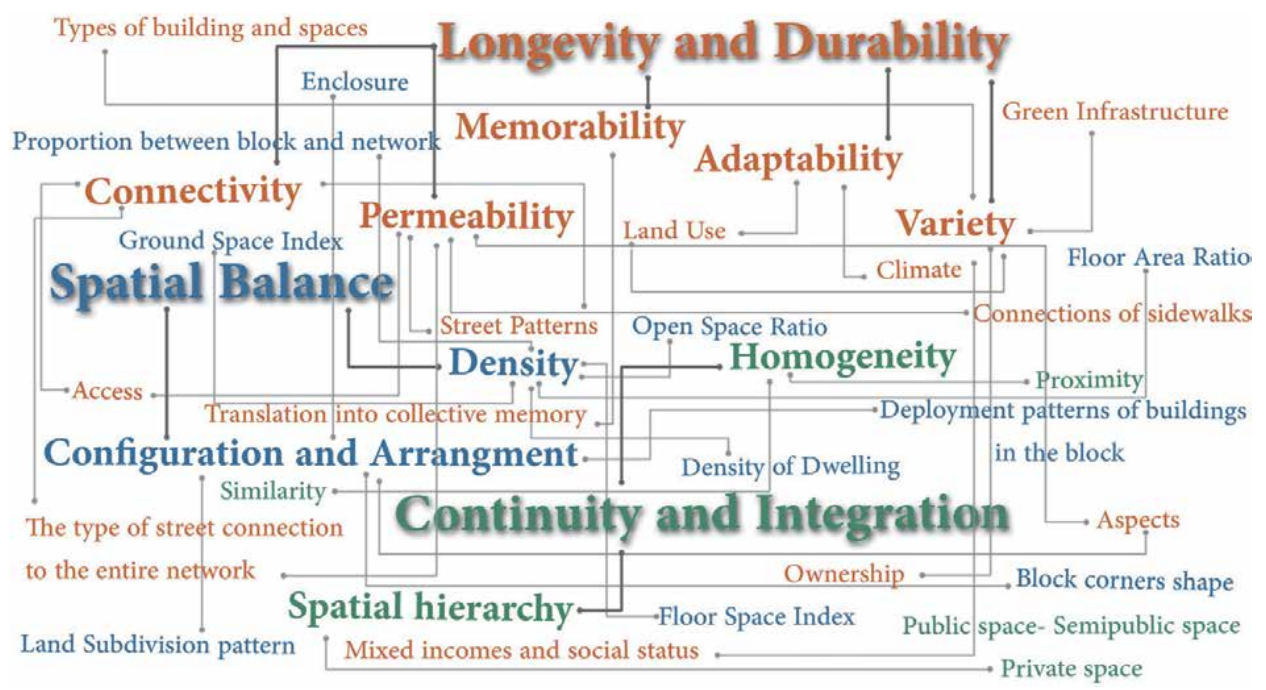

Figure 6.

The second step: hierarchical relationships among the factors of each category in each of the three conceptual groups.

\subsection{Definition of concepts}

\subsubsection{Spatial balance}

According to Rowe and Koetter and Krier, spatial balance can be considered as a lasting interaction between mass and space, in which there is a balance between open space and the density of buildings [5]. 


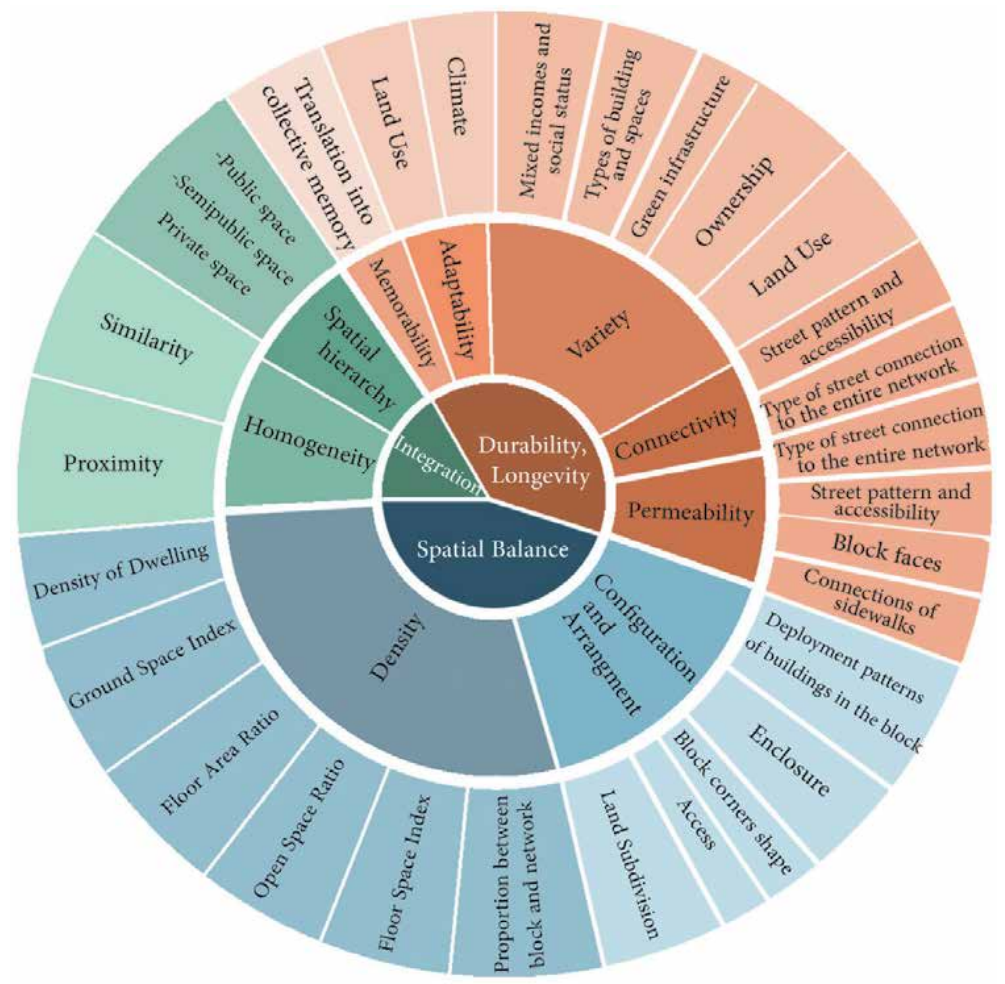

Figure 7.

The second step: grouping factors into three categories and the classification of the factors of each category.

\subsubsection{Configuration and spatial arrangement}

Spatial configuration in architectural and urban studies investigates the relationships among properties of spaces regardless of the assessment of these properties in isolation [24]. Arrangements deal with "where" [10] and are closely related to factors such as dimension and the size of the block and the functions of the buildings in the block [25]. In fact, spatial configuration deals with the way the blocks are arranged next to each other, the configuration of the edge of the blocks [10], and the resulting spatial effects.

\subsubsection{Density}

Martin and March [18] and Berghauser Pont and Haupt [19] define density as land occupation, which is related to the dimensions of the block and the resulting pattern [10] and affects the spatial configuration, though different configurations can be created with the same density. Density has different types including residential density, floor area density, open space density, ground space density, and floor space density.

\subsubsection{Continuity and integration}

Continuity and integration are manifested in the form and the network. Continuity in form can result from observing the principles of Gestalt theory, such as 
Toward Practical Criteria for Analyzing and Designing Urban Blocks

DOI: http://dx.doi.org/10.5772/intechopen.90504

\begin{tabular}{|c|c|c|c|}
\hline Concept & Items & Criteria & Indicators \\
\hline \multirow{17}{*}{$\begin{array}{l}\text { Spatial } \\
\text { balance }\end{array}$} & \multirow{11}{*}{$\begin{array}{l}\text { Configuration } \\
\text { and } \\
\text { arrangement }\end{array}$} & \multirow{2}{*}{$\begin{array}{l}\text { Land subdivision } \\
\text { patterns }\end{array}$} & Geometric shapes of blocks (regular, nonregular) \\
\hline & & & Block edge size \\
\hline & & \multirow{3}{*}{$\begin{array}{l}\text { Deployment } \\
\text { patterns of } \\
\text { buildings in the } \\
\text { block }\end{array}$} & Back to back \\
\hline & & & One side to the street \\
\hline & & & Two sides to the street \\
\hline & & $\begin{array}{l}\text { The form of block } \\
\text { corners }\end{array}$ & Simple, beveled, setback, projected \\
\hline & & \multirow[t]{4}{*}{ Enclosure } & The distance among buildings inside the block \\
\hline & & & $\begin{array}{l}\text { The distance between inside the block and the } \\
\text { street }\end{array}$ \\
\hline & & & The distance between the blocks \\
\hline & & & The ratio of block height to path width \\
\hline & & Access & The number of access points \\
\hline & \multirow[t]{6}{*}{ Density } & Floor space index & $\begin{array}{l}\text { The ratio of total floor area of all stories to the } \\
\text { total area of the block }\end{array}$ \\
\hline & & Open space ratio & $\begin{array}{l}\text { The ratio of unbuilt area to the total area of floors } \\
\text { (the amount of open space in the block) }\end{array}$ \\
\hline & & $\begin{array}{l}\text { Ground space } \\
\text { index }\end{array}$ & $\begin{array}{l}\text { The ratio of plot area (build areas) to the total } \\
\text { block area }\end{array}$ \\
\hline & & Floor area ratio & $\begin{array}{l}\text { The ratio of total floor area of stories to the area } \\
\text { of the plot }\end{array}$ \\
\hline & & Density of dwelling & $\begin{array}{l}\text { The ratio of the block's population to its } \\
\text { residential area }\end{array}$ \\
\hline & & $\begin{array}{l}\text { Block and access } \\
\text { network ratio }\end{array}$ & $\begin{array}{l}\text { The ratio of block area to total surface of } \\
\text { surrounding streets }\end{array}$ \\
\hline \multirow{7}{*}{$\begin{array}{l}\text { Spatial } \\
\text { continuity } \\
\text { and } \\
\text { integration }\end{array}$} & \multirow{3}{*}{$\begin{array}{l}\text { Spatial } \\
\text { hierarchy }\end{array}$} & \multirow{3}{*}{$\begin{array}{l}\text { Public, semipublic, } \\
\text { and private spheres }\end{array}$} & The amount of frontage of buildings \\
\hline & & & $\begin{array}{l}\text { Buildings setback distances (distance from the } \\
\text { street border and the first line of the plot) }\end{array}$ \\
\hline & & & Definition of block sides (back and front) \\
\hline & \multirow[t]{4}{*}{ Homogeneity } & \multirow[t]{3}{*}{ Similarity } & Block orientation \\
\hline & & & Block elongation \\
\hline & & & Block area \\
\hline & & Proximity & $\begin{array}{l}\text { The distances among the blocks' centers of } \\
\text { gravity }\end{array}$ \\
\hline \multirow{5}{*}{$\begin{array}{l}\text { Longevity } \\
\text { and } \\
\text { durability }\end{array}$} & Memorability & $\begin{array}{l}\text { Translation into } \\
\text { collective memory }\end{array}$ & $\begin{array}{l}\text { The existence of buildings with special semantic } \\
\text { dimensions and functions }\end{array}$ \\
\hline & \multirow[t]{4}{*}{ Adaptability } & \multirow[t]{2}{*}{ Land uses } & $\begin{array}{l}\text { Investigating the matrix of adaptability of } \\
\text { different land uses with each other in a block }\end{array}$ \\
\hline & & & $\begin{array}{l}\text { Adaptability between the building and new land } \\
\text { uses overtime }\end{array}$ \\
\hline & & \multirow[t]{2}{*}{ Climate } & $\begin{array}{l}\text { Deployment and orientation of the blocks based } \\
\text { on the sunlight angle }\end{array}$ \\
\hline & & & $\begin{array}{l}\text { The distance between the blocks based on the } \\
\text { amount of shading }\end{array}$ \\
\hline
\end{tabular}




\begin{tabular}{|c|c|c|c|}
\hline Concept & Items & Criteria & Indicators \\
\hline & \multirow[t]{6}{*}{ Variety } & $\begin{array}{l}\text { Mixing of land uses } \\
\text { and activities in the } \\
\text { block }\end{array}$ & $\begin{array}{l}\text { Checking the activity buffer of kindergartens, } \\
\text { schools, libraries, government services, etc. }\end{array}$ \\
\hline & & $\begin{array}{l}\text { The variety of } \\
\text { spaces }\end{array}$ & $\begin{array}{l}\text { The amount of squares, recreational and leisure } \\
\text { spaces, play grounds, parks, etc. }\end{array}$ \\
\hline & & $\begin{array}{l}\text { The variety of } \\
\text { buildings in the } \\
\text { block }\end{array}$ & $\begin{array}{l}\text { Different types of buildings, diversity in } \\
\text { architectural details }\end{array}$ \\
\hline & & $\begin{array}{l}\text { Income and social } \\
\text { status mixing }\end{array}$ & $\begin{array}{l}\text { Combination of independent villas, semi- } \\
\text { independent dwellings, apartment buildings, and } \\
\text { residential complexes }\end{array}$ \\
\hline & & $\begin{array}{l}\text { Green } \\
\text { infrastructure }\end{array}$ & $\begin{array}{l}\text { Green corridors among blocks, vegetation along } \\
\text { the streets, green roofs of buildings }\end{array}$ \\
\hline & & $\begin{array}{l}\text { Mixing of } \\
\text { ownership }\end{array}$ & Public and private \\
\hline & \multirow[t]{5}{*}{ Connectivity } & \multirow{4}{*}{$\begin{array}{l}\text { Street pattern and } \\
\text { accessibility }\end{array}$} & The block's area \\
\hline & & & The number of intersection \\
\hline & & & The number of blocks \\
\hline & & & The number of access points \\
\hline & & $\begin{array}{l}\text { The type of street } \\
\text { connection to the } \\
\text { entire network }\end{array}$ & The number of connections at an intersection \\
\hline & \multirow[t]{9}{*}{ Permeability } & \multirow{4}{*}{$\begin{array}{l}\text { Patterns of streets } \\
\text { and accessibility }\end{array}$} & The blocks' faces \\
\hline & & & The length of cul-de-sacs \\
\hline & & & The number of blocks \\
\hline & & & The number of access points \\
\hline & & \multirow{2}{*}{$\begin{array}{l}\text { The type of street } \\
\text { connection to the } \\
\text { entire network }\end{array}$} & The angle of intersection \\
\hline & & & $\begin{array}{l}\text { The type of street hierarchy (arterial, local, } \\
\text { collector, and distributor) }\end{array}$ \\
\hline & & \multirow{2}{*}{$\begin{array}{l}\text { Connections of } \\
\text { sidewalks }\end{array}$} & Intersection distance \\
\hline & & & Intersection density \\
\hline & & Block faces & Back and front \\
\hline
\end{tabular}

Source: Adapted from: Boffet and Serra [21]; Krier [5, 7]; Carmona [2]; Siksna [4]; Talen [10]; Conzen [11]; Jacobs [13]; Maitland [16]; Song and Knapp [14]; Owens and Southworth [17]; Bürklin and Peterek [9]; Rossi [22]; Moudon [20]; Berghauser Pont and Haupt [19]; Oikonomou [23].

Table 2.

Practical checklist to analyze and design urban blocks.

proximity and similarity, as well as spatial hierarchy in urban spaces. Continuity in the access network is also related to the way pathways are connected to each other [2].

\subsubsection{Spatial hierarchy}

The spatial hierarchy deals with community and privacy. In the transition from public space to private space, at the level of block, frontage of buildings, and in the space between blocks, the block edge plays an important role $[10,26]$. 


\subsubsection{Homogeneity}

The concept of homogeneity here is the same as "the whole" in Gestalt's theory, which belongs to a psychology school dealing with perceptual processes [27]. That is, components in an urban block and the blocks themselves should be put alongside each other in such a way that preserves the nature of blocks and superblocks as a homogeneous whole.

\subsubsection{Longevity and durability}

Durability of urban blocks can be considered as continuity in time, which, of course, requires understanding the underlying structure of the city [22]. Durability can be achieved formally and functionally. Siksna [5] deems the realization of this aspect as dependent on the durability of the formal pattern of blocks that can survive in the conditions of change.

\subsubsection{Memorability}

Memorability refers to the role of urban blocks in shaping the collective memory [22]. According to Moudon [20], this aspect can be seen in the presence of buildings in a block that have specific semantic dimensions by themselves; examples are public and religious buildings. Sometimes, this is also true for the block itself as a whole, because of the social and functional roles it might have. Memorability is one of the factors that cause durability of the block during the time.

\subsubsection{Adaptability}

Sustainable development in relation to urban form is evaluated by the ability to adapt to changes over time [28]. In the late 1970s, architects and urban designers focused on improving the compatibility of the city's form via various uses and functions [8]. What is considered in this chapter is block adaptability resulting from various functions, as well as attention to the adaptability of uses in new developments as stressed by [22]. Also, there is the issue of climate adaptability, which is related to the arrangement of forms of blocks and factors such as sunlight and shading.

\subsubsection{Variety}

Variety refers to the diversity of functions, forms, individuals, and social groups in urban spaces [12]. The existence of this spatial quality in urban blocks and superblocks transforms them into more flexible urban spaces, resulting in higher durability over time.

\subsubsection{Connectivity and permeability}

The concepts of permeability and connectivity are derived from the relationship between the block and the street. The correct definition of this relationship can add to the durability of these two urban elements (blocks and streets) over time. These concepts primarily refer to how the environment is blocked.

In fact, the distinction between permeability and connectivity becomes clearer in practice. Connectivity refers only to the number of connections between blocks (the number of intersections) and is a quantitative concept, while permeability is defined as the way streets interconnect and depends on criteria such as the width of 


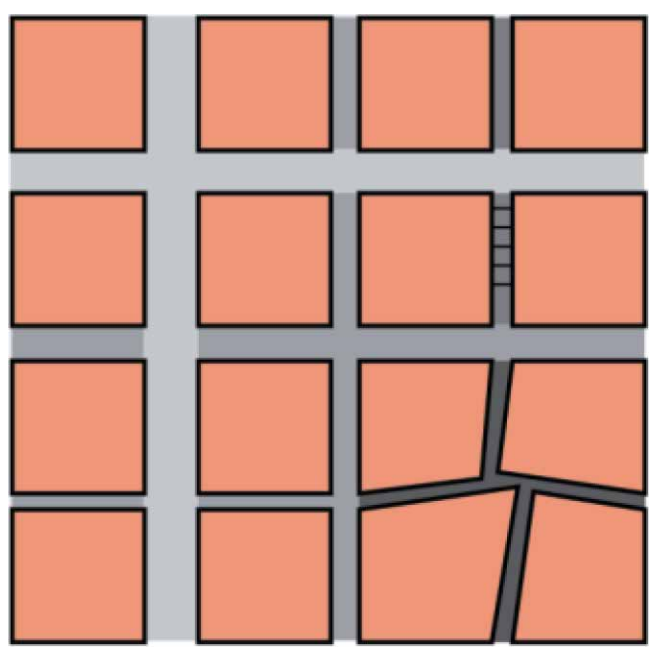

Figure 8.

Distinction between connectivity and permeability: from light gray to dark, streets become less but connectivity remains identical. (source: [29]).

the paths, the access hierarchy, as well as the visual and physical factors that induce a sense of movement (Figure 8).

\section{Discussion}

The checklist is the result of this study, as the first step in this area can be a basis for urban designers to look at urban blocks from a novel viewpoint and provide a suitable basis for the effectiveness of this element in urban design studies. Although this study is the initiator of this endeavor, in future studies it will be possible to develop and complete other factors related to the blocks.

The results show the breadth of the concept of block, hence the complexity of understanding and application of this element in the design of urban spaces, and can develop a comprehensive look at design. Finally, the mediating role of this element can balance other elements of the city.

Spatial balance, continuity and integration, and longevity and durability are macro-concepts of the list that are conceptually and functionally related to other factors and are divided into three categories of concepts, criteria, and indicators. Spatial balance is the relationship between mass and space; therefore, it can include as its subcategories "configuration and arrangement" and density, which are defined in terms of the arrangements of masses in space and the manner in which the space is occupied by masses, respectively. Subsequently, each of these factors subdivides to other factors at a smaller level. If continuity and integration are defined as the existence of the rhythm and order in the form of blocks (at the levels of superblocks, neighborhoods), and the connection in the access network, then it can include the spatial hierarchy (semiprivate, semipublic, and public) and the privacy and homogeneity among the blocks that can be used to create and interconnect such factors.

We have defined durability as capability to last over time, which can be achieved via qualities such as memorability, adaptability (of land uses and climate), diversity, permeability, and connectivity, because memorability transforms the block into collective memory and adaptability helps accepting new or varied land uses for the blocks in their lifetime or adapting to changes made over time, and thus, both 
are in the direction of reaching durability. The third quality, i.e., diversity, is a quality of space that changes urban blocks and superblocks into more flexible spaces via the presence of various social groups, mixed uses, and diverse spaces that in turn help them survive over time.

The concepts of permeability and connectivity represent the relationship between the block and the street. These concepts are primarily related to the arrangement of blocks in the environment, so they can be affected by the size of the block, which, in turn, affects the block's durability [4]. Therefore, it can be concluded that the rate of permeability and connectivity affects the longevity and durability of urban blocks.

\title{
7. Conclusions
}

Designing contemporary urban spaces requires form patterns that can be adapted to different aspects and at the same time address social interactions and encounters. This study was carried based on the concern about the status of blocks in the context of urban design and looked for a way to place the block as a focal point in urban design studies. Different concepts derived from different theories and approaches were clustered, and the interconnections among them were reviewed and defined and ultimately formulated in the form of an evaluation checklist. The checklist includes various form relationships that have a bearing on the social aspects of urban space. It has the potential to be used in the future as a framework for analyzing existing urban blocks and finding their problems in future studies, as well as for structuring new designs, taking into account context characteristics.

\section{Author details}

\author{
Amir Shakibamanesh* and Bita Ebrahimi \\ Department of Urban Planning and Design, School of Architecture and Urban \\ Studies, Art University, Tehran, Iran
}

*Address all correspondence to: shakibamanesh@ut.ac.ir

\section{IntechOpen}

(C) 2020 The Author(s). Licensee IntechOpen. This chapter is distributed under the terms of the Creative Commons Attribution License (http://creativecommons.org/licenses/ by/3.0), which permits unrestricted use, distribution, and reproduction in any medium, provided the original work is properly cited. (c) BY 


\section{References}

[1] Madanipour A. Design of Urban Space: An Inquiry into a Socio-Spatial Process. New York: Wiley Press; 1996

[2] Carmona M. Public Places, Urban Spaces: The Dimensions of Urban Design. Oxford: Architectural Press; 2003

[3] Moudon A. Urban morphology as an emerging interdisciplinary field. Urban Morphology. 1997;1:3-10

[4] Siksna A. The effect of block size and form in North American and Australian city centres. Urban Morphology. 1997;1: 19-33

[5] Krier R. Urban Space. New York: Rizzoli International Publications; 1979

[6] Whitehand J, W R. British urban morphology: The Conzenian tradition. Urban Morphology. 2001;5(2):103-109

[7] Krier L. Urban components. In: Papadakis A, Watson H, editors. New Classicism: Omnibus Edition. New York: Rizzoli; 1990, 1990

[8] Vialard A, Green D. A typology of block-faces [PhD thesis]. Georgia Institute of Technology; 2013

[9] Bürklin T, Michael P. Basics Urban Building Blocks. Birkhäuser Architecture; 2008

[10] Talen E. City Rules: How Regulations Affect Urban Form. Washington, DC: Island Press; 2012

[11] Conzen MRG. Alnwick, Northumberland: A Study in Town-Plan Analysis. Institute of British Geographers Publication. London: George Philip; 1960

[12] Bentley I et al. Responsive Environment: A Manual for Designers. Inc, New Jersey: John Wiley and sons; 1985
[13] Jacobs J. The Death and Life of Great American Cities. New York: Random House; 1961

[14] Song Y, Knaap GJ. Measuring urban form: Is Portland winning the war on sprawl? Journal of the American Planning Association. 2004;70(2): 210-225

[15] Scheer BC, Petkov M. Edge city morphology: A comparison of commercial centers. Journal of the American Planning Association. 1998; 64(3):298-310

[16] Maitland B. Shopping Malls: Planning and Design. London: Construction Press; 1985

[17] Southworth M, Owens PM. The evolving metropolis: Studies of community, neighborhood, and street form at the urban edge. Journal of the American Planning Association. 1993; 59(3):271-287

[18] Martin L. The Grid as generator. In: Martin L, March L, editors. Urban Space and Structures. Cambridge: Cambridge University Press; 1972

[19] Berghauser Pont M, Haupt P. Spacemate: The Spatial Logic of Urban Density. Delft, Holland: Delft University Press; 2002

[20] Moudon AV. Built for Change: Neighborhood Architecture in San Francisco. Cambridge, Mass: MIT Press; 1986

[21] Boffet A, Serra SR, Rocca Serra S, Serra SR. Identification of spatial structures within urban blocks for town characterisation. Proceedings of the 20th International Cartographic Conference. 2001;3:1974-1983

[22] Rossi A. The Architecture of the City. MIT Press; 1966 
[23] Oikonomou M. The urban block as a potential for sustainable urban design.

The Sustainable City X. Transactions on Ecology and the Environment. 2015; 194:69-77

[24] Rismanchain O, Bell S. The application of Space Syntax in studying the structure of the cities. Journal of Fine Arts. 2010;43:49-56

[25] Berghauser Pont M, Haupt P. Spacematrix: Space, Density and Urban Form. Rotterdam: NAI; 2010

[26] Ryan BD. The restructuring of Detroit: City block form change in a shrinking city, 19002000. Urban Design International. 2008;13(3):156-168

[27] Arnheim R. Art and Visual Perception. Berkeley: University of California Press; 1974

[28] Scoffham E, Marat-Mendes T, editors. The 'ground rules' of sustainable urban form. In: Achieving Sustainable Urban Form. Oxford: E \& FN Spon Press; 2000

[29] Marshall S. Streets \& Patterns. Routledge. 2005 



\title{
Adaptive Governance as an Avenue for Delivering Public Purpose in the Wake of Financialization
}

\author{
Corina Shika Kwami and Nick Tyler
}

\begin{abstract}
The demand for infrastructure and utility services is an acute challenge for countries in middle- and low-income countries undergoing high levels of urbanization, demographic shifts, and civil and political reorganization. The demand for utilities occurs alongside a trend toward increased financialization of the local state. A challenge for meeting demand for utility services is the shift toward increased financialization where the delivery of public purpose is challenged. This chapter aims to highlight governing arrangements that aid in understanding how public purpose can be delivered through utilities using the case study of Medellin, Colombia. Through examples of public infrastructure projects and the delivery of water by its utility-company, Empresas Publicas de Medellin, the paper discusses how this company achieved alignment of essential services with public purpose through adaptive governance structures that mitigate adverse effects of financialization and promote the integration of economic, environmental, and social goals. While this case does not propose a transferable model of governance, it highlights arrangements that enable a more mixed, adaptive, and nuanced understanding of how adverse effects associated with total financialization might be abated.
\end{abstract}

Keywords: cities, public-private partnerships, urban development, public purpose, adaptation, entrepreneurial city, governance, sustainability, adaptation

\section{Introduction}

The demand for infrastructure and utility services such as water, energy, gas and public transport in low-and-middle income countries is increasing alongside shifting demographics, the effects of climate change as well as economic, fiscal and political volatility. Most imminently, acute and population growth is occurring in urban areas, and more specifically, in secondary cities where populations are growing at a faster rate compared to other cities. The implication of this growth is that there is greater stress on available resources [1]. These shifts are accompanied by increased demand for infrastructure and utilities for which prompts cities in particular to explore opportunities to create new investment instruments using municipal assets as collateral [2]. This process of financialization is the capacity to create and monetise new asset classes. One effect of this shift is the occurrence of 'corporate neoliberalism' which is described by Crouch as an economy where key industries are dominated by small numbers of large corporations due to the privatisation of public industries and outsourcing public services [3]. This paper will explore the governing arrangements, 
enabling factors and approaches that a city within this complex, social political milieu underwent as an example of where governance of essential services can aid in delivering public purpose. While the paper does not propose a model for utilities, it highlights governing arrangements that place community engagement, stakeholder management and social infrastructure at the heart of delivery.

There is a subset of cities, also described as entrepreneurial cities, that have been able to convert their wealth into freedom from financial market dependence and/or utilise financialization as leverage for more borrowing [2]. The work on entrepreneurial cities is not exclusively limited to cities that have converted wealth into freedom from financial market independence. Jessop and Sum define an entrepreneurial city in capitalist societies as having three properties related to (1) changing forms of competitiveness, (2) changing strategies to promote interurban competitiveness in both economic and extra-economic fields, and (3) entrepreneurial discourses, narratives and self-images [4]. In public utilities' sectors, the entrepreneurial city has come to be associated with reforms in service delivery with privatisation as the most common reform. There have also been cities that have expanded municipally owned water corporations through corporate models that retain an entrepreneurial and local profile in the domain of the public sector [5]. This perspective, is described as "urban entrepreneurialism," is both a response to gaps in revenues and costs, which then drives commercial development alongside delivering public purpose. One explanation for this is the observation that capital mobility, in some ways, pushes urban governments to compete with other urban areas to attract investment and to minimise risk. In the water sector, this shift in cities coincides with political rhetoric towards public-private partnership and infrastructure investment to support development [6].

Given the trends towards corporate neoliberalism, what aspects of governance mitigate the adverse effects of financialization whilst still encouraging investment that is in alignment with public purpose? This paper emerges from a larger body of working examining adaptive governance in the water sector in Medellin, Colombia. This paper showcases governance features that emerge in a city and share characteristics of an entrepreneurial city where financial gains are aligned with public purpose. The background provides information related to pathways for delivering public goods and where a case study on Medellin could contribute a perspective on delivering public purpose through governance. As this case study emerges from a wider piece of work on governance, the methods' section describes the means by which the data was collected, analysed and justifications. The results include literature synthesis on the Medellin and results of interviews on the system for public service delivery. Using this case study to illustrate how a city approaches, the paper discusses the implications of adaptive governance for aligning economic trends with delivery of public purpose. In order to understand the wider context for delivering public goods, the following Section 1.1 discusses different pathways for delivering public goods.

\subsection{Pathways for delivering public goods}

Delivery of public services has taken various forms ranging from state-level provision to various forms of privatisation. From the mid-twentieth century, public-private partnerships (PPP) between a city, regional and/or national government and private entities, facilitated by a multilateral organisation such as the World Bank, marked a shift towards involving the private sector in delivering public goods. The shift often required measures to encourage privatisation, and subsequent financialization of the sector through a form of a public-private partnership between the state and a private provider $[7,8]$. The importance of public purpose has arisen alongside this trend particularly, in identifying ways to meet 
public needs. This pathway has been described as a form of smart urbanism and smart citizenship whereby community participation, commons, and ideals beyond the market account for the right to the city, entitlements, or in order to avoid reversion to pragmatic, instrumental and paternalistic discourses [9]. There one argument that places an importance of context in relation to urban processes and the role of politics in delivering essential services. This originates from an extensive review of 23 case studies which explores how local authorities, SME's, corporations, utility providers and civil society are engaged in creating smart cities and the ways in which urban services are being optimised for public good through information and communication technologies [10].

Understanding the role of the private sector in the wider governance of cities is a critical component of designing a governance system that delivers the kind of output end-users need and want with respect to essential services. In the smart city discourse, this is explored further in an exercise to map stakeholders and vendors from the private sector stakeholders in a smart city showing that to deliver aims in alignment with public purpose, inclusion of the following is critical: openness in the meaning of open participatory communities, balanced approach in terms of the social and technology components, trust in terms of transparency of services and integration [11].

While the PPP is arguably the most common model for public services delivery, the partnership model has a variety of different forms and demonstrate several pathways for delivering public goods. Crouch argues that in the process of privatisation and outsourcing of public services, there has been less competition, political intervention by firms and increased inequality which is in direct contrast to neoliberalism's claims. He coins this term as 'corporate neoliberalism' [3]. While the private sector has had increasing visibility in the delivery of public services, Mazzucato explores in detail the role of the state in delivering public purpose through investment in infrastructure, technology, research and development through patient capital, which in turn enables private sector participation. This model examines the close relationship between the public and private sector of the US and UK historically and articulates pathways for how this might be achieved [12].

\section{Methods}

In reviewing different cases, there is a predominance in the literature on the failure of public-private partnerships (PPP) related to the governance of public utilities. ${ }^{1}$ The literature review identifies PPPs as the dominant theme likely as it is where financialization through reforms over the last three decades have originated,

\footnotetext{
${ }^{1}$ The aim of the wider study from which this chapter is drawn, was to identify a case for further depth where the governing arrangements enabled delivery of public purpose despite wider trends towards financialization. Water was selected as a sector to explore given the debates on water as a human right and its characterization as a public good. Cases reviewed having these different models of service delivery in the water sector in cities such as Cochabamba, Bolivia and Porto Alegre, Brazil as well as other larger cities in Latin America [13], Europe, South Asia, Middle East and Africa [14] that have taken steps to reform the delivery of water through public reform, privatization and/or an evolution towards mixed models of delivery. Other cities reviewed include those such as Istanbul [15], Mumbai [16] and Johannesburg [17] which have experimented with mixed models. Review of these cases highlighted a multi-country study investigation comparing cities 'governance' challenges in the provision of public services in cities of different scales such as Jakarta, Dhaka, Johannesburg, Sao Paulo, Mexico City, Riyadh, Istanbul and Singapore and the ways in which governance enabled or inhibited successful provision [18]. Further in depth case studies included scholarship on Bangalore [19], South Africa [17], the Netherlands WMD [6] and a review of different examples in Sub-Saharan Africa [20].
} 
and thus dominate the governance discussion [7]. There are reviews that show where system change for the performance of water utilities has led to system failure $[21,22]$ and also where there have been successes. Where management models can go further is in incorporating public purpose within the governing arrangements using the utility as a means, albeit public or private, in the design and delivery. Therefore, in selecting a case study, there is a preference for a case that provides substantial evidence for an approach to governance with strong evidence for putting public purpose at the forefront of service delivery.

The well-documented social urbanism model in governance in Medellin [23, 24] provided evidence suggesting the model for water services that places community engagement, stakeholder engagement and social infrastructure. The opportunity to explore this further through stakeholder engagement positioned the Medellin case study as a strong candidate for exploring how this city could employ financialization in the delivery of public purpose.

The method for analysis built on existing literature and uses data from semistructured interviews to identify themes shared by stakeholders within the water system to compare with existing frameworks on adaptive governance $[25,26]$ using Ostrom's perspective on social-ecological systems [27] and Pahl-wostl's understanding of resource governance regimes [28]. Semi-structured interviews related to how stakeholders perceive the system, challenges and opportunities in order to develop an understanding of the system. A qualitative approach with a constructivist epistemological paradigm was employed to account for a diversity of perspectives from stakeholders. Thematic content analysis was chosen because of its demonstrated use for investigating questions where existing data is limited, however, providing a systematic approach for comparison of results with existing theory [29]. This approach is associated with content analysis as a suitable approach for model generation and based on experience in the literature that an open approach to coding using thematic content analysis facilitates theory emerging from the data (grounded theory) [30-32]. This is also useful in having a broad view of themes that can be compared with existing frameworks facilitated when a theory-based approach to coding is applied [30, 33-35].

Sample composition and sizing combined (1) saturation, (2) purposeful sampling, and (3) snowball sampling. To recruit interviewees, contacts with the utility provider, Empresas Publicas de Medellin, the universities (UNM and UCL) and Penca de Sabila, a civil society organisation working closely in water and environmental issues more broadly, provided the first channels for recruiting interviewees. The final sample includes 30 + representatives from municipal authorities, metropolitan area authorities, university experts, utility provider (EPM), members of the different civil society organisations and water user associations. Of these participants, approximately $1 / 3$ of the perspectives were from EPM. This was due to the large scale of the organisational diversity in departments working on issues related to water: water and wastewater, sanitation, infrastructure, planning, payments, regulation, energy-water, finance and business development.

The interview guide was developed in partnership with the national university in Colombia based on Pahl-Wostl's definition of resource governance and refined through a series of pilot interviews. Interviews were coordinated between the researcher and the interviewee and conducted in line with UCL Ethics (Project 814/001). The level of engagement before the meeting ranged from very limited to several informal introductions and conversations leading up to an interview.

A two-pronged approach to coding was conducted to ensure that contextual themes were not ruled out by data exclusively [36]. A data-driven approach was used at first to identify themes or ideas that may be overlooked with the purpose of having a breadth of context for the study as a whole. For data-driven codes, this 
proved consistent with the theory of letting the data speak for itself particularly as there may be features of the system of adaptive governance in Medellin that depart from what the theory predicts $[29,30]$.

This was an iterative process of more than $25+$ drafts of the codebook, then shared with supervisors (2), local partners (2), possible coders (5) and several others. The intent of the codebook evolved from merely reproducing the definitions of the codes of interest to a user-friendly and concise code that could be used to read through the interviews and identify relevant themes. The researcher coded the data-set twice, amending the codebook for improved internal consistency.

Secondary coders were identified and given the codebook. They were encouraged to send any questions ahead of coding to verify the codes and confirm understanding of the task. This varied from informal conversations to an email exchange, where the secondary coder wrote how they interpreted the codebook in plain English. After a coding a sub-sample of the excerpts given, the coders could ask additional questions before continuing to code the sample. Coded excerpts were then compared with the results of the researcher.

To apply an approximate measure for reliability in coding, several examples were consulted [29]. The measure that was best suited to test this was the percentage agreement on presence: percentage of occasions where the researcher and the second coder found information in common.

After coding the interviews using the codebook and comparing results with the other researchers, analysing the coded material was conducted using the percentage agreement on presence. A threshold of $70 \%$ for inter-rater reliability was agreed as the standard.

Percentage agreement on presence $=2$ (number of occasions Coder $\mathrm{A}+$ number of occasions Coder B)/(number of occasions Coder A+ number of occasions Coder B).

Three secondary coders were included to code a percentage of the interviews and yielded the following percentages on agreement [29].

Coder A: .82

Coder B: .77

Coder C: .77

\section{Results}

\subsection{Contextual findings from the literature for the city of Medellin, Colombia}

The following section presents the results of the literature review and the results of the semi-structured interviews related to the governing arrangements. The literature review is meant to highlight contextual factors (geographic, political, social and governance) for understanding how public purpose is delivered through the governance of utilities in the city despite trends towards financialization.

Medellin is the second largest city in Colombia and for centuries was an industrial hub for the country. The city is located in the Aburra Valley and is the capital of the Department of Antioquia. It currently has a population of 2.4 million, and 3.7 in the metropolitan area, which includes 10 municipalities. The city itself has $16 \mathrm{sec}-$ tions, known as communes or comunas which is the smallest administrative units shown in Figure 1. While Medellin is well-known in recent years for its innovation in social and public architecture [23, 37], Medellin boasts a long history of innovative infrastructure, utility development and planning.

Alongside profound events in politics and social transformation in response to demographic changes within the city during the twentieth century, public institutions developed a tradition of including citizens in the process of urban planning, 
using the provision of public services, such as water, as a means to engage in wider articulation of public purpose. This was facilitated by a system of urban governance that begins in the modern period in the 1940s by Sociedad de Mejoras Publicas (SMP), a private organisation, which drove urban planning and development in Medellin. This organisation had a strong influence over the public and private sectors: a relationship that was highly integrated according to Botero Herrera (1996). Through reforms, this entity evolved to become EPM, Medellin's first legally independent utility and single city-owned multi-utility corporation [38]. The entity is public however the boards have a commercial licence to explore the ways in which to improve service reliability and extend infrastructure without government driving decision-making. At the same time, there were/are several programs implemented with city government and utility management which fought business and guilds to pursue programs aimed at wider, long-term public goals [38].

The governance of public services as a means to deliver wider public purpose emerged during the 1950s, with the Medellin Master Plan, which was developed to manage urban development and promote legislation that would impact infrastructure for housing, transport and infrastructure for utilities [38]. Planning for the city was done in an integrated manner by the municipality and with EPM. Several programs involved city-dwellers in the planning and provision of public services including Habilitacion Viviendas, literally meaning "Fitting Out Dwellings" spearheaded integration of new settlements in the city through a series of regulatory processes to obtain legality with utility connections as the point of contact between user and duty-bearer (the state) [38]. Connection to public services such as water was one of several ways these plans had an impact on the city's planning activities. Changing migration patterns related to the conflict, internal issues in Medellin and worsening political and economic conditions during the 1970s intensified the need for engagement between users and city-planning activities [39]. In the 1990s, following a rapidly changing regulatory environment, EPM commercialised, while remaining still the property of the municipality which has raised questions about the future of the company and its objectives of delivering public purpose. While this is a vibrant and active debate, the governance and the role it has played historically

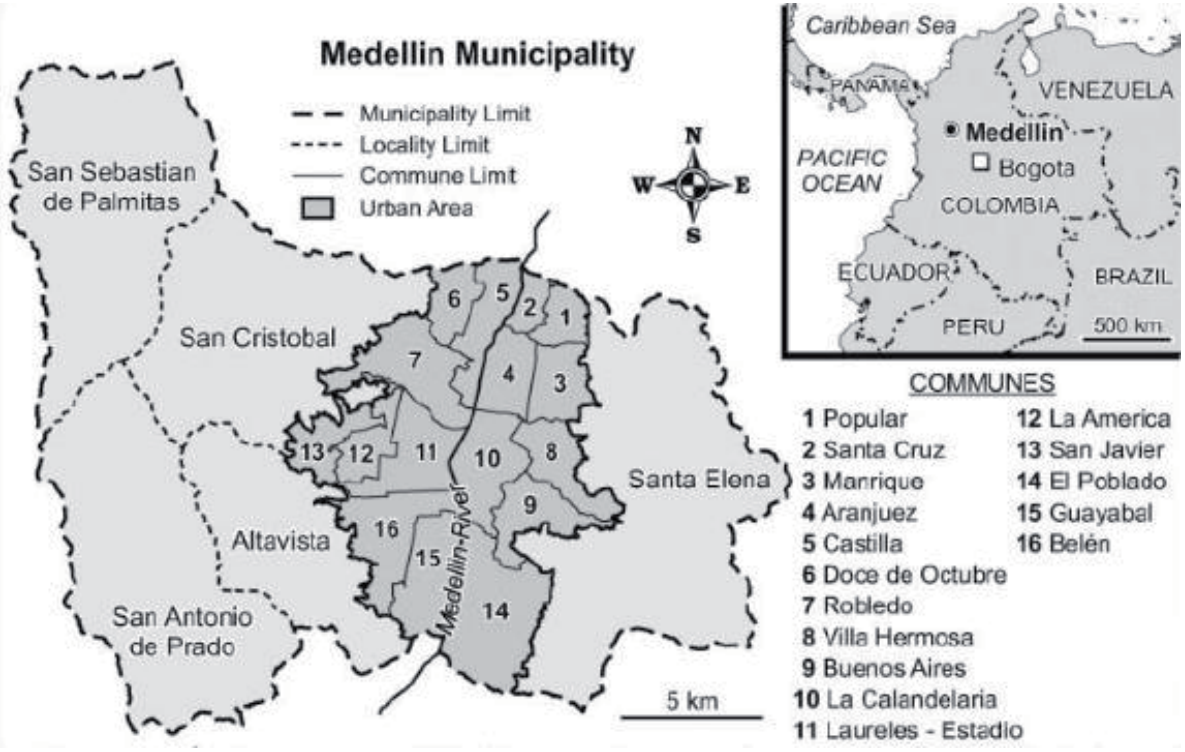

Figure 1.

Medellin municipality, including socio-economic tiers (Furlong [40]). 
orients the discussion towards understanding how EPM is delivering public purpose in the wake of these changes, rather than if/how public purpose can be delivered.

\subsection{The transformation and "the Medellin" miracle}

Descriptions of the transformation that brought the city through decades of conflict include the role of civil society, the multi-utility EPM and public architecture which highlights the role mayors of Medellin who were committed to a vision of public purpose. Success has also been linked to a succession of leaders, namely the city mayors Luis Perez (2001-2003), Sergio Fajardo (2004-2007) and Alonzo Salazar (2008-2011), all highly qualified with a vision of public purpose for the city beyond traditional politics [41-43]. Programs shared similarities with the concept of social urbanism which focused public investment in the city's more deprived areas through high-quality infrastructure and striking architecture [23].

Medellin's transformation garnered international and national recognition. Described as the "Medellin Miracle" particularly in the areas of social urbanism and mobility, there are several features in the Medellin context associated with its "perceived success" which are part of the landscape of an integrated and adaptive society [21]. Success in Medellin from a social perspective is associated with a range of factors: cultural aspects of the entrepreneurial class (Antioquian people with a strong work ethic, Catholic, close-knit community) associated with a strong business elite and a sense of duty, decentralised governance structure of Colombia, public trust, regional pride, high returns on human development, disciplined business culture and well-educated elite that serve in the public sector [33, 44].

Municipal programs have played a significant role in integrating and normalising informal sectors during the transformation of the early 2000s and beyond [23]. These programs emerged in response to barriers such as social inequality, spatial segregation, under/unemployment, social exclusion, weak state control, insufficient provision of essential services and housing density. These programs also existed alongside strong paramilitary and police presence in surrounding areas. This pressure to respond created a dichotomy of investment in social programs to "improve people" and "excessive policing" to "control undesirables" [45].

\subsection{Governance context for Medellin in the wider Colombian political landscape}

There are several features of the governance context in Medellin and Colombia more broadly that should be taken into account. Firstly, Medellin is situated within a national decentralised regime for Colombia, which places responsibility at a national level for policy-setting and decision-making and the duty to implement situated within the remit of the regional and local governing authorities. Secondly, the national Constitution in 1994 and subsequent reforms in public services [46] placed specific regulations about entities that could provide public services (public, private and community-based entities) [47]. This law had several implications, namely that sectors cannot cross-subsidise one another after the 1990s reforms. Thirdly, there is evidence of the role of the multi-utility, EPM, and its implementation of the law as a public service provider at a city level which is where this paper will focus on.

With this context of governance in mind, implementation of monitoring and evaluation activities in Medellin is overseen at a local and metropolitan level by the municipality and Area Metropolitano de Valle de Aburra, the metropolitan authority for 10 municipalities including Medellin. EPM is the primary service provider that covers a wide metropolitan area for service delivery. EPM provides potable water services in 10 municipalities in the Aburra Valley: Medellin, Bello, Envigado, Itagui, La Estrella, Sabaneta, Copacabana, Girardota, Caldas and Barbosa [48]. 
The 3 main governance approaches that reflect a view of having public purpose at the centre of water utility delivery are: the composition of a multi-stakeholder board, profit transfers for social projects in the city and corporate governance that dictate the interaction between the city and the company, EPM. The following section will present synthesis of these governance approaches utilised by EPM and present perceptions of the interviewees through quotes from stakeholders in the water sector. The quotes are examples where stakeholders have helped to shed light on governance approaches. They are perceptions held by the speaker and are triangulated with other speakers' perspectives and literature where relevant. The Discussion will present these findings in light of trends towards financialization, highlighting features that resonate with the entrepreneurial city delivering public purpose.

\subsubsection{Governance approaches}

EPM's board composition is an example where an integrated group of actors from different stakeholders are included within an entity that has a level of independence in its governance.
"The board of EPM is: the mayor, who is the president, with 3 representatives from the municipality, then we have one from the regional governments, from Antioquia, represents the governor, then you have 5 citizens, that represent differ- ent sectors, but two of them are "locals" that are elected by elected by local councils and they have control, responsibility (23:31), and need to provide information to the citizens, but the power of the mayor of Medellin is really important because it is $100 \%$ legal owner. And EPM is a group that provides services in Bogota, Bucaramanga, Cali, everywhere in Colombia, in most of Colombia." - ID21, metropolitan area (urban environmental authority).

This finding was verified in the General Agreement on Corporate Governance (Figure 2) and offers an example of how a governance design at a leadership level can ensure diversity of stakeholders in a decision-making seat of authority. This includes the mayor who is the president, 3 municipal representatives, 1 regional representative, 5 representatives from industrial sectors ( 2 of whom must be private citizens).

The balance may be primarily due to the governance of the company itself, which requires this balance of powers in institutional agreements. Although the extent to which this system could favour the interests of the elite is neither supported nor ruled out by evidence, nonetheless this agreement affords a continuity, despite elections every 4 years.

Another governance feature that shows where the financial success lies - of an entity, as a public company that operates much like a multinational private entity namely in an agreement between the city and company that ensures $30 \%$ of profits transferred from the company to the city annually to fund social projects. This also includes an agreement that the city has sovereignty over decisions of how the city uses the $30 \%$ of the annual profits transferred from the company. One stakeholder describes this saying:

"So EPM is $100 \%$ property of the citizens of Medellin, 100\% property of the municipality and its profits, a percentage, about $30 \%$ of its benefits, goes to the mayor for social investment. So it supports the capacity of the city to solve problems. Not only to provide but also to develop social services and development. That is really important and special and particular to Medellin.” - (Municipal authority, ID21). 


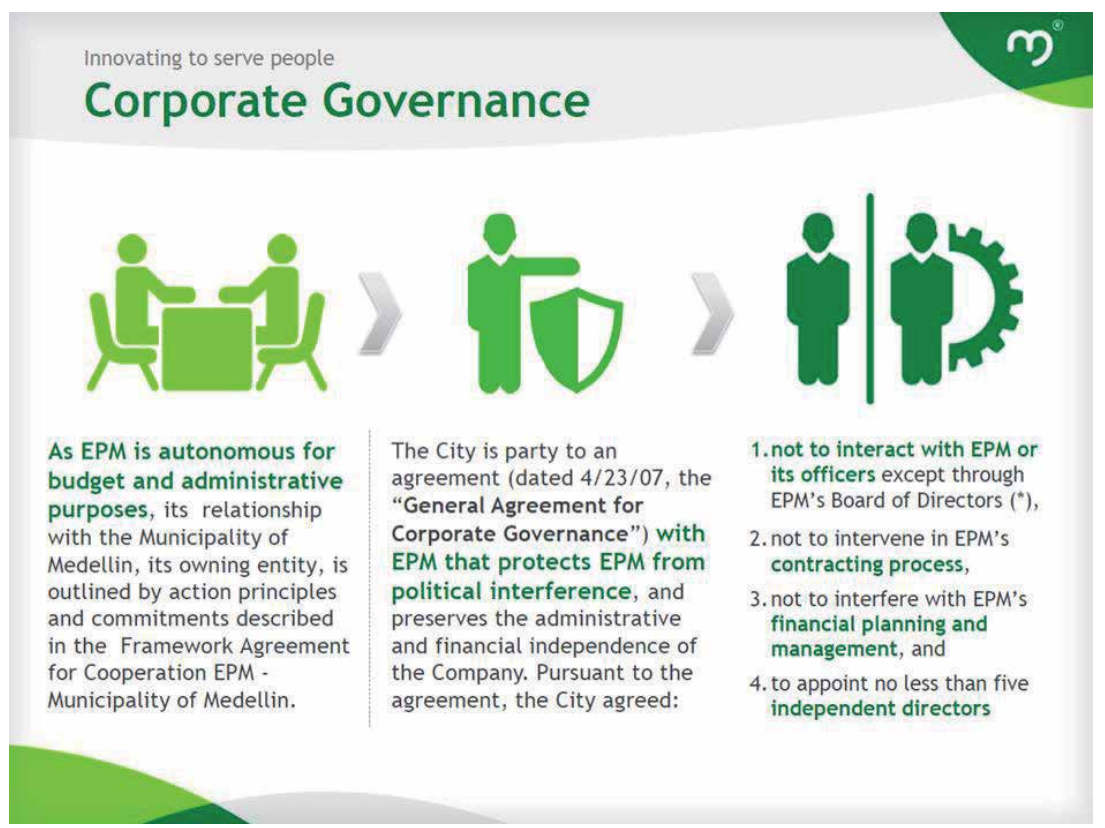

Figure 2.

Corporate governance of EPM (examples from agreement between the City and the company) supplementary material from $I D 1,(E P M, 2016)$.

This quote is included as an example of how the two actors are arranged in efforts to deliver social goods in the city. Contextually, this quote is taken from a conversation related to the role of EPM and the municipality during and after the transformation which included social innovation efforts by the city and EPM.

\subsubsection{Corporate governance and institutional agreements}

There are other examples where institutional agreements between different actors enable the institutions to maintain independence and sovereignty while also working together in an integrated manner. For example, the public service company is technically the property of the municipality but exercises a degree of independence in its business affairs regardless of the political party in power. This means there is autonomy in how the company can conduct its business. However, at the same time, a percentage of profits are transferred annually to the municipality for social projects where the city oversees the spend with guidelines on how to deliver goods for the public. This form of transfer indicates a balance between independence and sovereignty as well as evidence for working together in an integrated manner.

This balance is not one governing arrangement exclusively, but a series of different corporate governance guidelines that govern the company.

This includes governance codes to ensure that the municipality does not interact with the company except through the board, does not intervene in EPM's contracting processes or other aspects of its financial planning and management. The agreement for example stipulates that the City agrees to "appoint no less than 5 independent directors."

The Discussion will discuss these findings and what the governance model for the Medellin case demonstrates, highlighting features that resonate with the entrepreneurial city. 


\section{Discussion}

Each of these governance arrangements seems to raise questions on the boundary between public and private and to what extent public purpose is achieved where the public and private aspects of delivery intersect. The blurring of the lines between public services and privatisation is consistent with a pattern of entrepreneurial states Mazzucato argues have historically had as a characteristic of delivering infrastructure, technology, research and development for long-term public goods [12]. While not a causal relationship from this analysis, there is evidence to suggest an association between this type of system and an adaptive arrangement of actors that can adapt based on needs within the system. The multi-stakeholder board of EPM achieves this by including representation from public, private and non-governmental interests alike, who in having decision-making power at the level of the board can negotiate the provision of services in the city, ensuring that the public purpose that the company was established to fulfil is in balance with its commercial aims. Similarly, the earmarked 30\% profit which is transferred annually from the company to the city reflects a closeness between public and private entities yet with arrangements for how the funds are spent in order to deliver public good. This is one example of several governance arrangements set out by the code of corporate governance which includes autonomy for EPM in terms of budget and administrative purposes. The code also safeguards EPM from political interference such as contracting processes, financial planning and processes as well as appointing independent directors.

The independent nature of governance EPM, in terms of business growth with constraints on earmarked funds for local social projects suggests that this autonomy-within-limits approach ensures that the city can convert its wealth into freedom, whilst ensuring that there are ways in which the market can serve public purpose. Whilst not explored in this research, policy evidence has suggested that because the market and political social context of Medellin is thriving and, on the rise, coupled with the success of EPM's services, that companies like EPM are able to access international loans for expanding infrastructure. While not established as causal, this does suggest that there may be an association between market, public and social stability and increased investment. There are questions around the boundaries of adaptive governance and how far this can be stretched within a system, with further questions about transparency, accountability and conflicts of interest, yet this example allows us to explore further questions from a starting point where the intersection of public and private is a norm.

What goes beyond seemingly mitigating the adverse effects of financialization and encouraging investment, is an ongoing dialogue by the company and the city on how to deliver public purpose. Recall that EPM as a company was founded with the purpose of engaging in planning of the city and ensuring uniform, stable and resilient access to utilities. As the city evolved, there were different demands that the company and city had to respond to. For example, when there was a surge in population growth, EPM and the city collaborated extensively on housing and land-use reform. When public and social cohesion was destroyed, EPM and the remaining civil society worked together to help rebuild the social fabric. And currently, as there is pressure to ensure that the success of the company is in parallel with success in the city. There is widespread debate on what this success in the twenty-first century would mean for the future of Medellin as an entrepreneurial city or as it is described as an 'innovative city.' Perhaps, though the very nature of its innovation and entrepreneurship is in its capacity to have an ongoing dialogue with all parties involved about what that would look like. 


\section{Conclusion}

In reflecting upon the experience of Medellin, the governance of public services is characterised as adaptive and designed in ways that can facilitate delivery of public purpose through utilities despite a trend towards financialization in the public services worldwide. While not the end goal, the composition of the multistakeholder board, 30\% transferred profits annually for social transformation projects and the code of corporate governance serve governing arrangements in place to facilitate a dialogue between the public and private aspects of the system, with a broad base of stakeholders that operate within and across these boundaries.

The strengths of this type of investigation are that it allows for exploring in depth, the contextual background in which these innovative governing arrangements are situated. This type of model also shows the limitations in discerning where boundaries between public and private sector lie in delivery of long-term public goods. While these findings are context specific and not identified as causal, transferability is something that would require further analysis. There are also questions around the boundaries of adaptive governance and how far this can be stretched within a system, with follow on questions about transparency, accountability and conflicts of interest. While this case does not explore these aspects beyond the governance design, this case provides a starting point for future work where the intersection of public and private is a norm.

With these constraints in mind, however, there is scope to position the Medellin example to spur dialogue on how adaptive governance could be explored further in efforts to deliver public purpose in the wake of financialization, and further, how governance might promote processes for achieving aims that go beyond public and private boundaries. Looking beyond Medellin, possible next steps would be to identify synergies with other seemingly entrepreneurial cities and explore more fully under what conditions these features thrive.

\section{Acknowledgements}

Special thanks and support to colleagues Ivan Sarmiento and Peter Brand at the National University in Medellin, Colombia. Julio Davila from the University College London Development Planning Unit. Special thanks to stakeholders from various institutions that provided insights for the interviews including environmental organisations, utilities, urban, metropolitan and regional authorities, civil society, community-based and academic institutions. This research emerges from a $\mathrm{PhD}$ studentship funded by the Transforming the Engineering of Cities Grant by the Engineering Physical Research Council (EP/J017698/1). The views expressed are from the authors only and do not represent a stance from the Council.

\section{Conflict of interest}

No competing interests from any author.

\section{Author contributions}

Dr. Corina Shika Kwami oversaw the planning, obtaining ethical clearance, data collection, analysis of the data and writing of the paper. As it was part of a wider study for a doctorate, Dr. Nick Tyler supervised the work and provided comments at various stages of the written work. 


\section{Author details}

Corina Shika Kwami and Nick Tyler*

Department of Civil, Environmental and Geomatic Engineering, University College London, London, United Kingdom

*Address all correspondence to: n.tyler@ucl.ac.uk

\section{IntechOpen}

(c) 2019 The Author(s). Licensee IntechOpen. This chapter is distributed under the terms of the Creative Commons Attribution License (http://creativecommons.org/licenses/ by/3.0), which permits unrestricted use, distribution, and reproduction in any medium, provided the original work is properly cited. $(\mathrm{cc}) \mathrm{BY}$ 


\section{References}

[1] Roberts BH. Managing Systems of Secondary Cities: Policy Responses in International Development. Cities Alliance, London, UK; 2014. 233 p

[2] Weber R. Selling city futures: The financialization of urban redevelopment policy. Economic Geography. 2010;86(3):251-274

[3] Crouch C. 9. The paradoxes of privatisation and public services outsourcing. The Political Quarterly. 2016;86:156-171

[4] Jessop B, Sum N-L. An Entrepreneurial City in action: Hong Kong's emerging strategies in and for (inter) urban competition. Urban Studies. 2000;37(12):2287-2313. DOI: $10.1080 / 00420980020002814$

[5] Guerrero TA, Furlong K, Arias J. Complicating neoliberalization and decentralization: The non-linear experience of Colombian water supply, 1909-2012. International Journal of Water Resources Development. 2015;32(August):1-17. DOI: 10.1080/07900627.2015.1026434

[6] Furlong K. Water and the entrepreneurial city: The territorial expansion of public utility companies from Colombia and the Netherlands. Geoforum. 2015;58:195-207. Available from: http://linkinghub.elsevier.com/ retrieve/pii/S0016718514002024

[7] Philippe M. Public-private partnerships for urban water utilities: A review of experiences in developing countries. Trends and Policy Options; World Bank. Washington, DC; 2009:8. Available from: https://openknowledge. worldbank.org/handle/10986/2703 License: CC BY 3.0 IGO

[8] Bakker K. Archipielagos and networks: Urbanization and privatization in the south.
The Geographical Journal. 2003;169(4):328-341

[9] Cardullo P, Kitchin R. Smart urbanism and smart citizenship: The neoliberal logic of 'citizen-focused' smart cities in Europe. Environment and Planning C: Politics and Space. 5 August 2019;37:813-830. DOI: 10.1177/0263774X18806508

[10] Karvonen A, Federico Cugurullo FC, editors. Inside Smart Cities Place, Politics and Urban Innovation. 1st ed. London, UK: Routledge; 2018. 304 p

[11] Lytras MD, Anna V, Sarirete A. Clustering smart city services: Perceptions, expectations, responses. Sustainability. 2019;11(6): pp 1-19

[12] Mazzucato M. The Entrepreneurial State: Debunking Public Vs. Private Sector Myths. Vol. 1. London: Anthem Press; 2015

[13] Lobina E, Hall D. Water Privatisation and Restructuring in Latin America. Greenwich, UK: Public Services International Research Unit (PSIRU); 2018. Vol. 442007. Available from: http://www.psiru.org/ reports/2007-09-W-Latam.doc

[14] Bakker KJ. From public to private to ... Mutual? Restructuring water supply governance in England and Wales. Geoforum. 2003;34:292-302

[15] Altinbilek D. Water management in Istanbul. International Journal of Water Resources Development. 2006;22(2):241-253. DOI: $10.1080 / 07900620600709563$

[16] Nallathiga R. Reforming water sector governance and institutions for improving efficiency: The case of Mumbai. International Journal of Regulation and Governance. 2006;6:99-133 
[17] Smith L. Neither public nor private: Unpacking the Johannesburg water corporatization model. Social Policy. 2006;27:1-62. Available from: http:// unrisd.org/unrisd/website/document. nsf/ab82a6805797760f80256b4f005da1a b/79f48a7bdd5ca384c12571d100257095/ \$FILE/LaSmth.pdf

[18] Varis O, Biswas AK, Tortajada C, Lundqvist J. Megacities and water management. International Journal of Water Resources Development. 2006;22(2):377-394

[19] Connors G. When utilities muddle through: Pro-poor governance in Bangalore's public water sector. Environment and Urbanization. 2005;17(1):201-218

[20] Schwartz K. The new public management: The future for reforms in the African water supply and sanitation sector? Utilities Policy. 2008;16:49-58

[21] Baietti A, Kingdom W, van Ginneken M. Characteristics of wellperforming public water utilities. Water Supply Sanit Work Notes. 2006;1. Available from: www.worldbank.org/ watsan

[22] Noll R, Shirley MM, Cowan S. Reforming Urban Water Systems in Developing Countries. Econ Policy Reform Second Stage. Stanford, California USA: Stanford Institute for Economic Policy Research; 2000. pp. 243-289

[23] Davila J, Brand P. Urban Mobility and Poverty, Lessons from Medellin and Soacha, Colombia. Development Planning Unit, UCL and Universidad Nacional de Colombia. London, UK; 2013

[24] Turok I. The seventh world urban forum in Medellin: Lessons for city transformation. Local Economy. 2014;29(6-7):575-578. DOI: $10.1177 / 0269094214547011$

[25] Pahl-Wostl C. The implications of complexity for integrated resources management. Environmental Modelling and Software. 2007;22(5):561-569

[26] Rijke J, Brown R, Zevenbergen C, Ashley R, Farrelly M, Morison P, et al. Fit-for-purpose governance: A framework to make adaptive governance operational. Environmental Science \& Policy. 2012;22:73-84. DOI: 10.1016/j. envsci.2012.06.010

[27] Ostrom E. General framework for Analyzing sustainability of social-ecological systems. Science. 2009;325:35-38

[28] Pahl-Wostl C. A conceptual framework for analysing adaptive capacity and multi-level learning processes in resource governance regimes. Global Environmental Change. 2009;19(3):354-365

[29] Boyatzis RE. In: Boyatzis RE, editor. Transforming Qualitative Information: Thematic Analysis and Code Development. Thousand Oaks, CA; London: Sage; 1998. 184 p

[30] Glaser BG, Strauss AL. The Discovery of Grounded Theory: Strategies for Qualitative Research. Vol. 1. New York, USA: Routledge. 1967. 271p. Available from: http://www. amazon.com/dp/0202302601

[31] Creswell JW. Qualitative Inquiry and Research Design: Choosing among Five Approaches. 2nd ed. Newbury Park, California: Sage Publishing; 2007. 424 p

[32] Lincoln YS, Guba EG. Ethics: The failure of positivist science. In: Lincoln YS, Denzin NK, editors. Turning Points in Qualitative Research: Tying Knots in a Handkerchief. Walnut Creek, CA: Altamira Press; 2003. pp. 219-237

[33] Hameiri S. The trouble with miracles. 2007;19(2):409-441. Available form: https://www.economist. com/the-americas/2014/06/07/ the-trouble-with-miracles 
[34] Denzin NK, Lincoln YS. Editors. The SAGE Handbook of Qualitative Research. Third Edit. Thousand Oaks: Sage Publications, Inc; 20051232 p

[35] Hsieh H-F. Three approaches to qualitative content analysis. Qualitative Health Research. 2005;15(9):1277-1288. DOI: $10.1177 / 1049732305276687$

[36] Braun V, Clarke V. Thematic analysis. Qualitative Research Methods in Mental Health and Psychotherapy. 2012;5(4):53-76. Available from: http:// discovery.ucl.ac.uk/91396/

[37] Brand P, Davila J. Mobility innovation at the urban margins: Medellin Metrocables. City. 2011;15(May):37-41. Available from: http://discovery.ucl.ac.uk/1325728/

[38] Lopez M. Paisajes hidricos urbanso en disputa: agua, poder y fragmentacion urbana en Medellin, Colombia [Internet]. Confiar, Corporacion ecologica penca de Sabila; 2016. Available from: https:// openlibrary.org/books/OL26234923M/ Paisajes_hídricos_urbanos_en_disputa_ agua_poder_y_fragmentación_urbana_ en_Medellín_Colombia

[39] Hylton F. Medellín: The peace of the pacifiers. NACLA Report on the Americas. 2008;41(1):1-6

[40] Furlong K. The dialectics of equity: Consumer citizenship and the extension of water supply in Medellín, Colombia. Annals of the Association of American Geographers. 2013;103(5):1176-1192. DOI: 10.1080/00045608.2013.782599

[41] Fukuyama Francis CS. Half a miracle: Medellin's rebirth is nothing short of astonishing but have the drug lords really been vanquished? Foreign Policy. 2011;(1):26-28. Available from: http:// web.a.ebscohost.com/ehost/ detail/ detail? vid=56\&sid=a212bad69461428b-ad17-92a37687fcf4\%40sessio nmgr4006\&hid $=4214 \&$ bdata $=J m x h b m$ c9ZXMmc210ZT1laG9zdC1saXZl\#AN= $60849592 \& \mathrm{db}=\mathrm{a} 9 \mathrm{~h}$

[42] Mendieta E. Medellín and Bogotá: The global cities of the other globalization. City. 2011;15(2):167-180

[43] Ashoka. The Transformation of Medellín, and the Surprising Company behind it. Forbes, New Jersey; 2014. pp. 1-3. Available from: http://www. forbes. com/sites/ashoka/2014/01/27/ thetransformation-of-medellin-andthesurprising-company-behind-it/

[44] Drummond H, Dizgun J, Keeling DJ. Medellín: A City reborn? Focus on Geography. 2012;55(4):146-154

[45] Tubb D. Narratives of citizenship in Medellín, Colombia. Citizenship Studies. 2013;17(5):627-640. DOI: $10.1080 / 13621025.2013 .818380$

[46] Secretaria. Ley 142 de 1994 Nivel Nacional El regimen de los servicios publicos domiciliarios [Internet]. 1994. Available from: http://www. alcaldiabogota.gov.co/sisjur/normas/ Norma1.jsp?i=2752

[47] Furlong K, Acevedo T, Arias J, Patiño C. 2018. Rethinking water corporatisation: A 'negotiation space' for public and private interests, Colombia. Water Alternatives, Montpellier, France. (1910-2000);11(1):187-208

[48] Revuelta San Martin L. El impacto de las actividades antropicas que se desarrollan en las cuencas abastecedoras sobre la prestacion del servicio de acueducto (EPM) Embalse La. [Internet]. Medellin, Colombia; 2017. Available from: http://slideplayer.es/ slide/10168749/ 



\title{
Sustainable Design in Urban Green Space
}

\author{
Ning Li and Yang Liu
}

\begin{abstract}
As a fundamental part of the urban function, urban green space faced a longterm maintenance requirement. The maintenance of urban green space (i.e., trimming, irrigation, fertilization, pesticide, and plant waste removal) can have environmental impacts, such as energy consumption and greenhouse gas (GHG) emission. This chapter focuses on the adjustment of the plant communities' combinations in urban green space to reduce the environmental impacts in long-term maintenance. The plant communities in urban green spaces are a combination of four plant layers: woodland, shrubs, herbicides, and grassland. In this chapter, we will start to investigate the environmental impacts in the maintenance of urban green space. Then we introduced the quantitative method life cycle assessment (LCA), to quantify the environmental impacts of the maintenance tasks. We analyzed the maintenance environmental impact (MEI) index of 95 plant community samples $(20 \mathrm{~m} \times 20 \mathrm{~m})$ in Zhengzhou (China) through LCA and sorted out the changing curves of the MEI index during the change of the combined amount in each plant layers. Finally, we sorted out the MEI strength of the plant layers and summarized the low MEI plant community model. The low MEI model can save energy consumption and GHG emissions of the maintenance tasks, to contribute to the sustainable development of the urban green space.
\end{abstract}

Keywords: urban green space, plant community maintenance, environmental impact, energy consumption, GHG emissions

\section{The environmental impact in urban green space maintenance}

\subsection{The fast expansion of maintenance workload in urban green space}

The increase of the urban green space leads to the expansion of maintenance workload. During the years 2000-2018, due to the 2.6 times growth of the urban built-up area in China (from 2,152,500 ha to 5,622,500 ha), the urban green space increased from 778,200 ha to $2,921,300$ ha (Figure 1). The dramatical extension of the urban green space increased the maintenance pressure directly. This point can be reflected by the fast increase of the maintenance equipment used in urban green space. Figure 2 shows that the number of maintenance machine increased 5 times between the year 2000 and 2018, from 44,238 to 228,019 in the Chinese city [1].

The functional expansion of urban green spaces has also increased the workload of maintenance. In the past 40 years, the development goal of urban green space in 


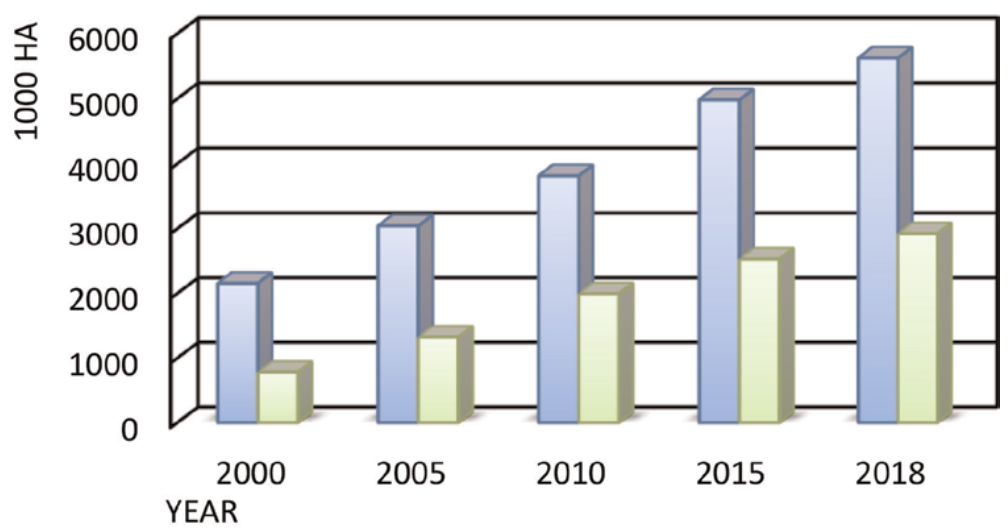

Urban Built-up Area $\square$ Urban Green Space Area

Figure 1.

The increase of urban built-up and green space area in China (2000-2018).

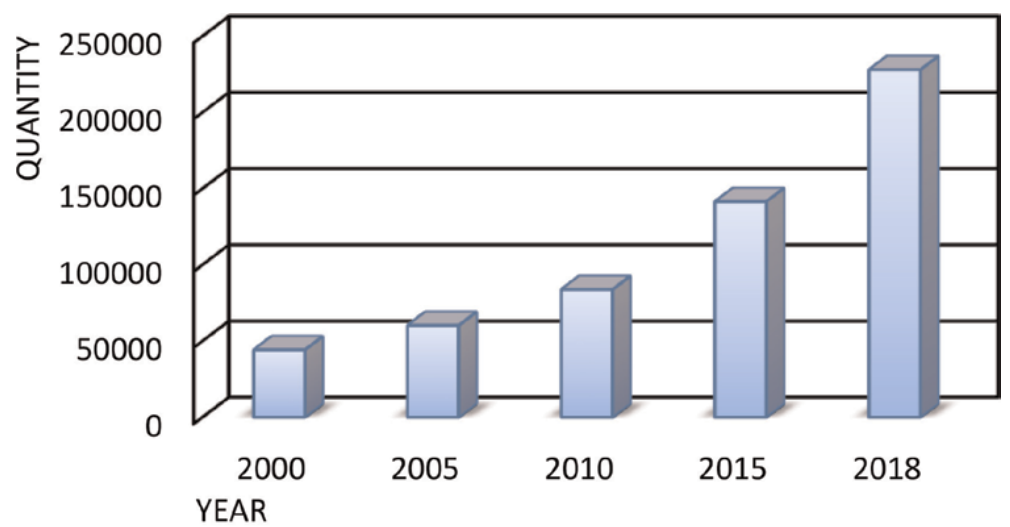

$\square$ Maintenance equipemnt in green space

Figure 2.

The increase of maintenance equipment used in Chinese urban green space (2000-2018).

most parts of the world has changed from "quantity" to "quality" [2]. Take China as an example.

The extensive growth period of the urban green space was from 1990 to 2004. With the intention of the "garden city" proposed by the Ministry of Construction, most cities began to expand the green area and pursue high greening rates [3]. During this period, many urban reservations were filled with woodland and lacked maintenance.

From 2005 to 2014, urban green space growth began to focus on the richness of vertical plant layers. This dramatically increases the maintenance workload. With the goals of the "National Forest City" and "Ecological Garden City" proposed by the State Forestry Administration and the Ministry of Construction, the development of urban green space has turned to forest vegetation as the main body, enriching the vertical plant level to improve ecological functions [4]. Multilevel plant communities require more maintenance tasks to maintain the shape or function of each plant layer than traditional woodland green spaces [5]. During this time, the growing maintenance workload has forced city managers to consider increasing productivity and reducing resource consumption to save on maintenance budgets.

In the year 2015, the General Office of the State Council issued the "Guiding Opinions on Promoting the Construction of Sponge City" [6]. This framework 
aimed to exert the natural ecological functions of the urban green space, to increase the urban eco-securities, such as absorption, infiltration, and sustained release to the rainwater, and decrease the maintenance requirement in simultaneously [7]. That can deliver a clear message that the city managers have to seek a more natural plant combination method to release the maintenance pressure in the future plant community design and management in urban green space.

\subsection{The maintenance tasks in urban green space}

The maintenance tasks in urban green space include trimming, irrigation, fertilization, and pesticide [8]. During the maintenance record in the urban green space in Zhengdong New District (2018, Zhengzhou, China), the annual trimming frequency in woodland, hedge, and grassland was 1-3 times, 6-10 times, and 13-22 times separately; the average irrigation frequency was 30-50 times/year; the fertilization frequency was 2-4 times/year; the centralized pesticide frequency was 2-5 times/year. In addition, it also includes the removal of plant waste after every time of the trimming work.

The maintenance of green space is related to strong labor work and machine input. According to the official regulation of the number of maintenance team in Zhengdong New District, in a total of more than 460 ha urban green area, they totally configured about 900 site conservation workers responsible for daily maintenance $(0.3 \mathrm{ha} /$ per person at $70 \mathrm{ha}$ of CBD area, $0.6 \mathrm{ha} /$ person at other green areas). Besides, the trimming/mowing work is related to the application of power chainsaw, hedge/edge strimmer, and lawn mower. Sprinklers are required for irrigation and pesticide work. Trucks are required for the removal of plant waste and transportation of the maintenance materials.

\subsection{The energy consumption and emission discharge in green space maintenance}

The maintenance work in urban green space includes the consumption of energy resources and the discharge of waste to the environment, with annual cycles [9]. In daily maintenance, most trimming work and plant waste transportation depend on machine use. This machine work mainly consumes fossil energy and emits harmful gases (including $\mathrm{CO}_{2}, \mathrm{NO}_{\mathrm{x}}, \mathrm{CH}_{4}$, etc.) into the atmosphere. Irrigation mainly consumes urban tap water. The fertilizer and pesticide consumed in fertilization and pest control work can produce soil carbon residues. Besides, the trucks responsible for fertilizer transportation and drug spraying also need to consume fossil energy and generate exhaust gas $[10,11]$.

The fossil energy (gasoline, diesel, etc.) consumed in green space maintenance is named direct energy (DE) consumption, which can be converted with standard coal that releases the same amount of heat during combustion. The use of water resource, fertilizer, and pesticide is named indirect energy (IDE) consumption. The IDE consumption also has the equivalent conversion coefficient with the calorific value of standard coal, and ultimately all show the consumption of heat energy $[12,13]$. Among the harmful gases emitted by green space maintenance, greenhouse gases (GHG) have been recognized as the main source of atmospheric pollution, which account for more than $83 \%$ of the total emissions [14]. This energy consumption and exhaust emissions persist with the annual cycle of maintenance tasks.

Although the purpose of maintenance is to provide a safe and healthy development for the green space, which is able to continue the service for the urban public, this long-term human intervention in the green space itself also violates the basic requirements for the sustainable development: maximization of self-renewal and 
minimization of the artificial disturbance [15]. Therefore, reducing the environmental impact caused by maintenance tasks will contribute to the sustainable development of urban green space.

\subsection{The literature review of environmental impact in urban green space maintenance}

Few urban environment assessment systems are mentioned about the environmental impacts of green space maintenance. The University of Florida, in the "Florida-Friendly Landscaping Guidelines," proposed that the maintenance team should sign a contract with the green space owners and enact a detailed working plan before maintenance operations. The working plan should estimate the types of maintenance tasks and detail workload. This is important to improve working efficiency, save maintenance materials, and reduce environmental impacts [16]. The "Sustainable Sites Initiative" (proposed by the US Lady Bird Johnson Wildflower Center and US Botanic Garden) point out that during the complete life cycle of the urban landscape (design, construction, operation, maintenance, and disposal), the maintenance procedure occupied around $10-20 \%$ of the total environmental impact [17].

Some research point out reducing the maintenance workload can decrease the environmental impact and improve the ecological benefits of the green space. Zhao and Liu pointed out that the city managers should reduce the area of grassland and plant more native woodland to improve the adaptability and tolerance of urban green space. Extensive use of wildflowers and meadows can also benefit to the urban wildlife and reduce the maintenance requirement [18]. Guo in the renewable and recyclable landscape research indicated that the self-maintenance green space is able to maximize the utilization of energy and materials and reduce environmental pollution in the use process [19]. Min put forward that the conservation green space is to improve the utilization rate of maintenance resources and energy use and obtain the maximum ecological, environmental, and social benefits [20]. Shu-Hua pointed out that symbiotic cyclic urban landscape architecture should adopt the design of low environmental impact, including the selection of recyclable, lowconsumption, and high-durable building materials, and pay attention to reduce the maintenance material input in the later period [21].

The quantitative study on the environmental impact of urban green space maintenance is limited. After finishing 3 years of urban green space maintenance carbon emission data collection for the three major cities, Seoul, Chuncheon, and Gangneung, Hyun found that the annual increase of urban green space carbon emissions is between 10 and $20 \%$. The average carbon $\left(\mathrm{CO}_{2}\right.$-eq) emissions are $264.9,37.0$, and $67.9 \mathrm{t} / \mathrm{ha} / \mathrm{y}^{-1}$ in Seoul, Chuncheon, and Gangneung, respectively. The annual carbon storage in the three urban green spaces (the amount of $\mathrm{CO}_{2}$-eq) is about $50 \%$ of the respective carbon emissions [22]. Lynch et al. believe that pruning, fertilization, pest control, and other works in green space maintenance can cause heavy carbon discharge. The design phase can directly influence the maintenance workload, such as the time investment, energy, and water consumption in urban green space [23].

\section{Life cycle assessment of the environmental impact}

\subsection{Introducing of LCA}

Life cycle assessment (LCA) is a comprehensive tool for evaluating the environmental impact of products or behaviors. This method can comprehensively analyze 
the potential environmental impact of human behavior from the beginning to the end by collecting the life cycle inventory (LCI) [24]. The LCA method includes four steps (Figure 3): goal and scope definition; analysis of life cycle inventory; environmental impact assessment; and interpretation of results [25]. It is mainly used to quantitatively study the negative environmental impacts (i.e., resource energy consumption and waste discharge) on the LCI list and seek ways to decrease the environmental stress of production or behavior system [26].

\subsection{The development of LCA}

LCA was initially applied primarily to research on resource consumption and environmental impacts of product packaging. In the early 1980s, due to the global energy crisis, environmental problems mainly focused on fossil energy consumption and combustion pollutant emissions, and the life cycle assessment method also entered the stage of academic discussion. At the same time, with the global solid waste problem that emerged from the late 1970s to the mid-1980s, the life cycle method has gradually become a resource analysis tool and has entered the field of scholars. Research at that stage mainly focuses on the assessment method construction, with limited case studies. The earlier LCA research was concentrated in the United States and encouraged by the government [27].

After entering the 1990s, LCA entered a stage of rapid development. In 1990, for the first time, the International Society of Environmental Toxicology and Chemistry (SETAC) hosted an international seminar on LCA. The concept of "life cycle assessment" was first presented at the conference. In the following years, the SETAC hosted and held several academic seminars and conducted extensive research on the theory and methods of life cycle evaluation [28]. Although the current life cycle assessment methodology still has many issues worth studying, the SETAC and the International Standards Organization (ISO) have been actively promoting the international standardization of LCA. The ISO 14040 standard (Environmental Management-Principles and Framework for Life Cycle Assessment) was promulgated on 1997, and the corresponding series of standards ISO 14041 (list analysis), ISO 14042 (impact evaluation), and ISO 14043 (interpretation of impact statements) are also in the following [24]. The standard system has a great improvement to the standardization steps of the LCA concept and the technical framework.

Construction of the LCI database is a vital factor in the development of LCA. LCI database includes the total environmental impact data on every life cycle stage of the upstream product. The LCI database construction starts from the early 1990s.

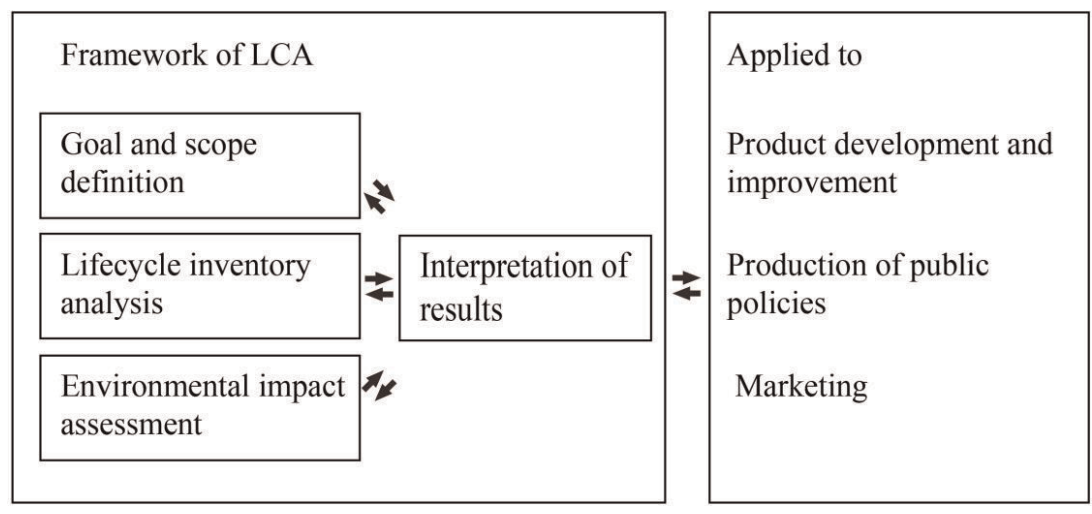

Figure 3.

The framework of LCA [24]. 
Currently the word mainstream database includes "ecoinvent" in Europe and "Chinese life cycle database" (CLCD) in China [26].

\subsection{The quantitative method of LCA}

\subsubsection{The general characterization model of LCA}

Different ecological impact factors have different potential for the same type of environmental impact. Based on a certain ecological impact factor, the relative impact potential could be characterization [29]. Characterization is the main step to quantify the environmental impact intensity, which includes resource and energy consumption and waste discharge:

1. Consumption of resources and energy. Heat consumption is usually taken as a characteristic factor, and the material consumed in the system boundary is converted into a unified heat unit according to their energy consumption coefficients accumulated:

$$
E C_{s}=\sum_{i}^{n} \alpha_{i} \times R C_{i}
$$

In the formula, ECs is the characteristic quantity of resource and energy consumption; take $\mathrm{MJ}$ as a characteristic index. $R C_{i}$ is the consumption of material $i$ in a certain process of the system. $\alpha_{i}$ is the equivalent coefficient of material $i$. At present, GB/T 2589-2008 standard offered majority kinds of materials in coal calorific equivalent coefficient.

2. Waste discharge. At present, a unified equivalent model has been established for the environmental impact of the LCA system on climate warming, environmental acidification, eutrophication, and environmental toxicity. The EIs of an environmental impact factor in the waste generated within the system boundary can be calculated by the following formula:

$$
E I_{s}=\sum_{i}^{n} \beta_{i} \times E C_{i}
$$

In the formula, $E C_{i}$ refers to the emission amount of factor $i$ in waste discharge characteristic factors. $\beta_{i}$ is the equivalent coefficient of factor $i$. The coefficients of factors $\mathrm{CO}_{2}, \mathrm{CH}_{4}$, and $\mathrm{N}_{2} \mathrm{O}$ are 1,21 , and 310, respectively [30].

\subsubsection{Standardization and weighted assessment of LCA characteristic result}

Standardization refers to the ratio between the LCA characteristic quantity of an environmental impact factor and the regional total or average quantity of the factor, with the aim of eliminating the difference in dimension and series of each environmental impact factor. At present, data of energy and resources and emissions of environmental waste per capita in the world in 2000 are mostly used as standardized reference in the field of environment [31]. The calculation process is as follows:

$$
R E_{i}=E_{i} / S_{i(2000)}
$$




\begin{tabular}{lcccc}
\hline $\begin{array}{l}\text { The characterization factors of } \\
\text { environmental impact }\end{array}$ & Unit & $\begin{array}{c}\text { The reference value of } \\
\text { standardization unit/person [32] }\end{array}$ & $\begin{array}{c}\text { Weight } \\
\text { coefficient [33] }\end{array}$ \\
\hline Resource and energy consumption & MJ & $2.59 \times 10^{6}$ & $1.1 \times 10^{-1}$ \\
\hline Global warming potential (GWP) & $\mathrm{kg} \mathrm{CO}_{2}$-e & $6.87 \times 10^{3}$ & $1.2 \times 10^{-1}$ \\
\hline
\end{tabular}

Table 1.

Reference values and weight coefficients of some environmental impact characteristic factors.

In the formula, $R E_{i}$ refers to the standardized result of environmental impact factor $i . E_{i}$ is the LCA characteristic quantity of environmental impact factor $i$, including both EC and EI. $S_{i(2000)}$ refers to the world per capita standardized benchmark of environmental impact factor $i$ in 2000.

The weighted assessment is based on the actual environmental load of each environmental impact factor to determine the weighted coefficient, which is used to revise the standardized results of LCA system:

$$
W E_{s}=\sum_{i}^{n} W_{i} \times R E_{i}
$$

In the formula, WEs is the weighted value of environmental impact within the boundary of the LCA system. $W_{i}$ is the weighted value of environmental impact factor $i$.

Standardized reference values and weight coefficients of two environmental impact factors, resource and energy consumption and climate warming potential (GWP), are shown in Table 1.

\subsection{The application of LCA on ecological research}

In the environmental ecology research, LCA has been widely used in plant nursery, forestry management, and agricultural production. Lazzerini assessed the carbon emissions of two types of nursery plant cultivation (in-pot and on-field) in Tuscany (Italy). Guided by LCA, this study summarized the carbon emissions of farm structure, aboveground structure, input of cultivation, and packaging in nursery cultivation. He pointed out the GHG emission of in-pot cultivation was 7.4$26.5 \mathrm{~kg} \mathrm{CO} 2 / \mathrm{m}^{2} / \mathrm{y}^{-1}$, which was much higher than that of $0.6-1.0 \mathrm{~kg} \mathrm{CO} / \mathrm{m}^{2} / \mathrm{y}^{-1}$ of on-field cultivation [34]. Berg summarized the energy consumption and carbon emissions in Sweden's forestry management process by LCA. The forestry life cycle includes seedling production, silviculture, logging, and haulage to the wood processing plant. In Sweden forestry, the energy consumption (in $\mathrm{m}^{3}$ wood unit) is about $150-200 \mathrm{MJ} / \mathrm{m}^{3} / \mathrm{y}^{-1}$, and the carbon emissions $\left(\mathrm{CO}_{2}\right.$-eq $)$ is about $12.5-17.1 \mathrm{~kg} /$ $\mathrm{m}^{3} / \mathrm{y}^{-1}$. The energy consumption and carbon emissions in logging and transportation are the most obvious, accounting for more than $60 \%$ of the total amount [35]. Ingram used LCA method to study the management carbon footprint of red maple forest during planting. The life cycle of the study included 1-year seedling production and 4-year seedling field management. It was found that the carbon emission $\left(\mathrm{CO}_{2}\right.$-eq $)$ footprints were $2.9 \mathrm{~kg} /$ plant for tube feeding materials and the consumption of fuel and energy was $10.3 \mathrm{~kg} /$ plant during production, at a distance. In $386 \mathrm{~km}$ of transportation, $4.0 \mathrm{~kg} /$ plant and $3.3 \mathrm{~kg} /$ plant in planting and landscape sites, the most carbon emissions were from production to planting, accounting for $17.7 \mathrm{~kg} /$ plant and accounting for $86 \%$ of the total greenhouse gas emissions [36]. Haas et al. assessed the environmental impacts of intensive, extensive, and organic forage management in 18 grasslands in Allgau, Bavaria, and southwestern Germany 
by LCA. The energy consumption of tube feeding was $19.1,8.7$, and $5.9 \mathrm{GJ} / \mathrm{ha}^{-1} \mathrm{y}^{-1}$, respectively, while the greenhouse gas emissions were $9.4,7.0$, and $6.3 \mathrm{t} / \mathrm{ha} / \mathrm{y}^{-1}$, respectively. It was concluded that organic animal husbandry was more environmentally friendly and intensive animal husbandry had a stronger environmental impact [37].

At present, there are few studies on the environmental impact of urban green space using LCA. In 2015, Dr. Ji Yuan-yuan summarized the carbon emission inventory of landscape sites in the production, construction, maintenance, and abandonment stage. She believed that the main consumption material in maintenance stage includes fossil energy, irrigation water, fertilizer, and pesticides [38]. Strohbach and Haase believe that the total carbon emissions per hectare of urban green space in Leipzig (Germany) are about $2.6-4.7 \mathrm{t} / \mathrm{CO}_{2}$ in 50 years after its construction [39].

\section{The LCA of urban green space maintenance}

\subsection{Goal and scope definition}

The purpose of urban green space maintenance is to ensure the realization of landscape services. Therefore, the continuous supply of usability of green

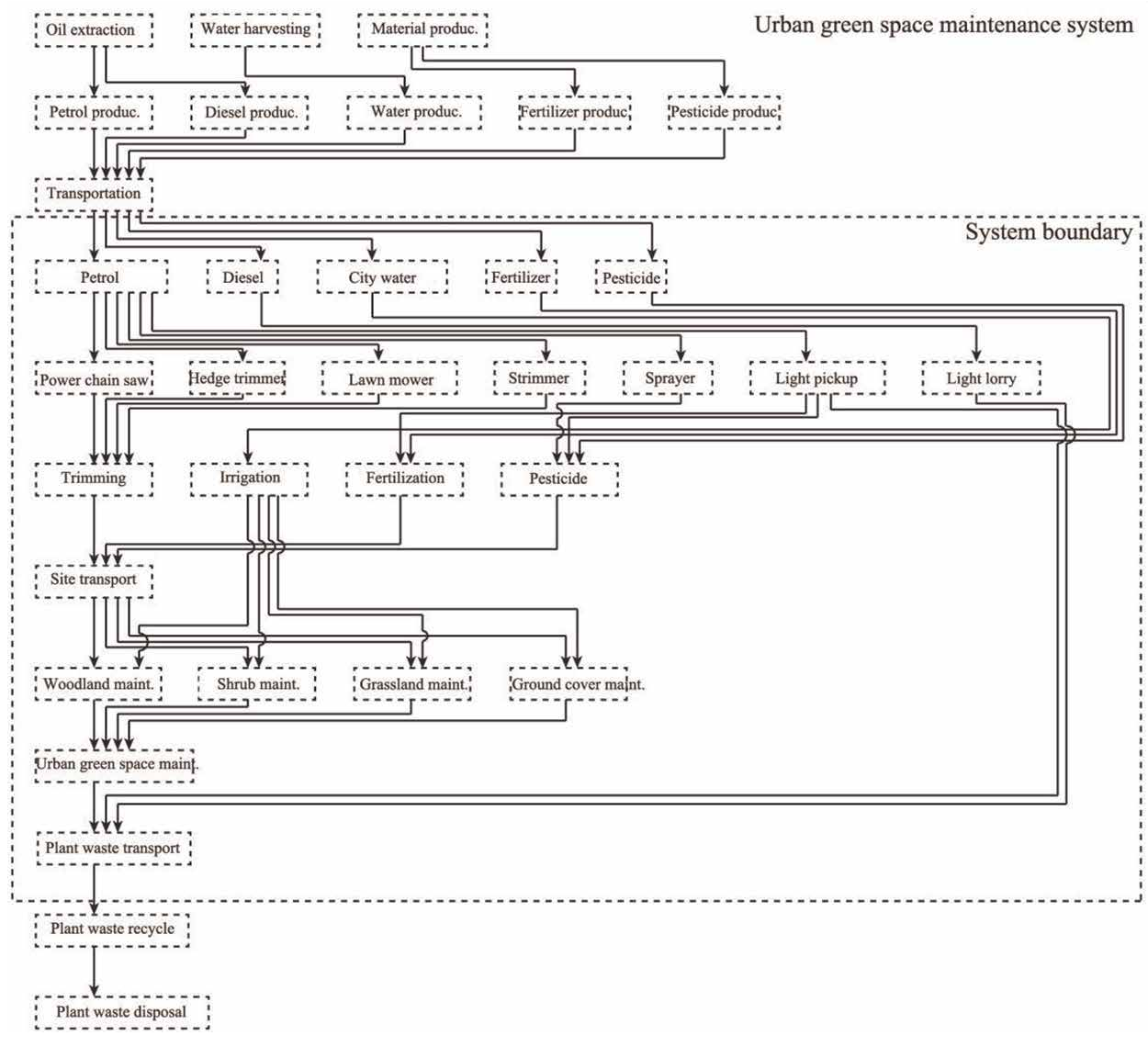

Figure 4 .

The LCA system boundary of urban green space maintenance. 
landscapes that meet the design requirements can be regarded as the "product" of maintenance work. Therefore, the environmental impact of the maintenance tasks can be defined as the goal of the green space maintenance LCA.

The maintenance of green space has long-term and repetitive characteristics. After the completion of the green space, the management work is continuously carried out. Although the content of the maintenance work will change with the growth of plants, the change is not obvious reflected in the annual period. Jiang Shipping divides the green space into three stages: initial age ( $\leq 3$ years), middle age (4-10 years), and mature age ( $>10$ years). It is considered that the annual management content of each stage is repeated [40]. Therefore, in the urban green space LCA evaluation, the life cycle of each stage green space can be carried out annually.

\subsection{System boundary and LCI data collection}

The system boundary is the evaluation scope of the LCA, and the material consumption and waste discharge within the system boundary are the substance list. When conducting LCA evaluation of products or behaviors, the related upstream and downstream processes are very intensive. Some process factors participate in system construction, but the environmental impact on the system is limited, or the environmental impact data is not clear. In order to avoid interference with the accuracy of the evaluation results, these processes are generally excluded from the system boundary. Figure $\mathbf{4}$ is a systematic flowchart of urban green space maintenance. The plant combinations of green space are divided into four layer

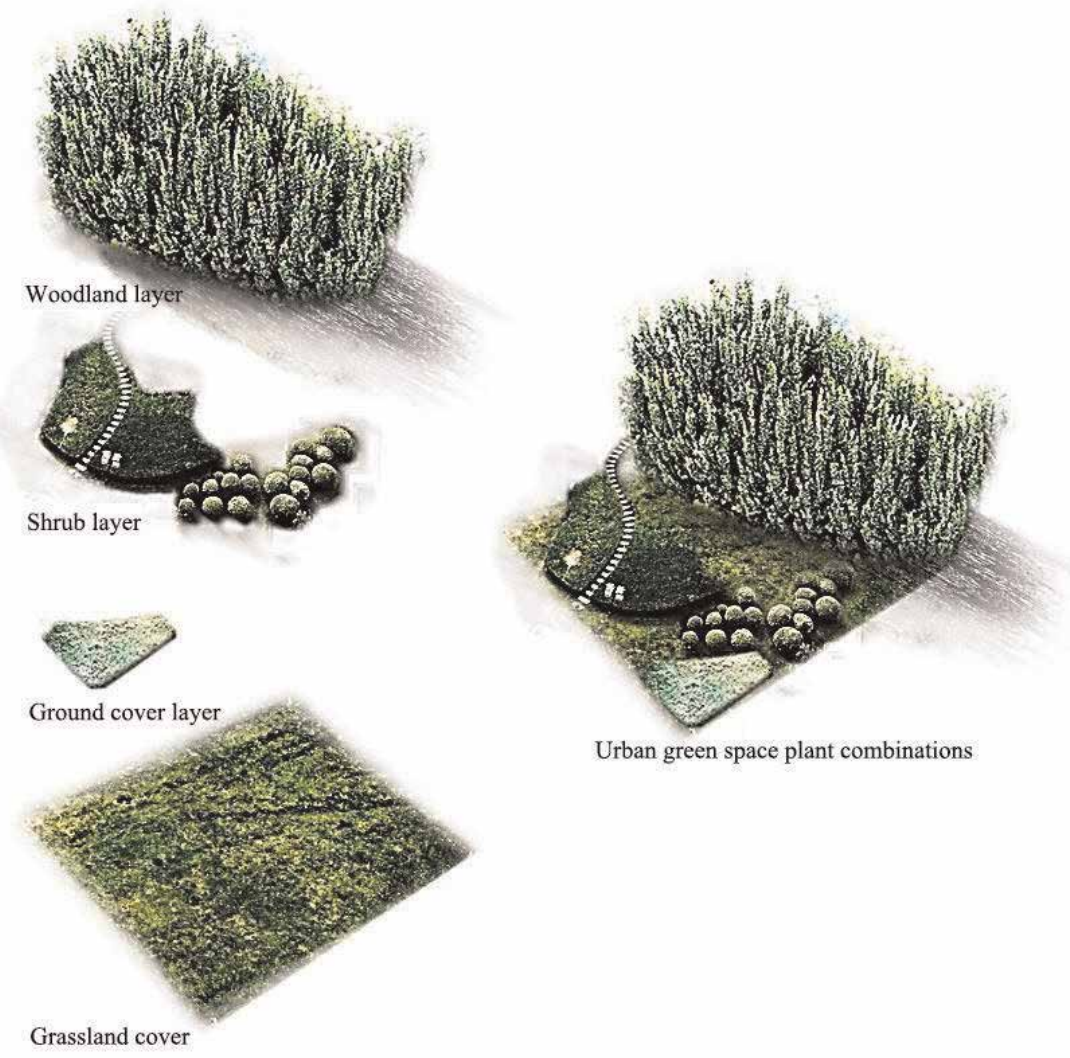

Figure 5 .

The plant combinations in urban green space. 
subsystems of trees, shrubs, ground cover and turf based on the difference in maintenance work (Figure 5).

Figure 4 shows that the upstream of the system mainly contains the production and sales of the maintenance materials. This part of the list can be obtained by referring to the CLCD or by referring to the same LCA evaluation results. However, the upstream data is mostly the market average, and there may be large deviations [41]. In the system downstream, due to the different waste recycle ways taken by the different maintenance teams, the environmental impact list is difficult to obtain. Therefore, The LCA of green space maintenance system mainly includes onsite energy consumption and emissions. The list of this part comes from on-site investigation and has high reliability, which is also a direct reflection of the environmental impact of maintenance.

\subsection{Characterization model of environmental impact in urban green space maintenance}

Based on the general characterization model of LCA, using the equivalent coefficient of energy consumption and global warming potential (GWP) or climate warming potential, we establish an environmental impact characterization model of the maintenance material input and GHG emission inventory:

$$
E C_{g}=\sum_{i}^{n} \alpha_{e i} \times A_{w i}
$$

$E C_{g}$ refers to the characteristic quantity (MJ) of urban green space management resource and energy consumption. $\alpha_{e i}$ represents the resource and energy consumption equivalent coefficient of the species $i$ list in the system. $A_{w i}$ refers to the input amount of the $i$ substance in the system.

The calculation of the $A_{w i}$ value of petrol- and diesel-powered maintenance equipment can be obtained by the following formula:

$$
A_{w i}=\sum_{a}^{n} \frac{M_{w a}}{E_{e a}} \times \beta_{a}
$$

where $a$ is the maintenance equipment associated with the maintenance substance $i$ in the system. $M_{w a}$ refers to the workload of the maintenance equipment within the system boundary. $E_{e a}$ and $\beta_{a}$ represent the working efficiency and fuel consumption per time unit.

The calculation method of the GWP potential $\left(\mathrm{kg} / \mathrm{CO}_{2}\right) E I_{g}$ of urban green space management is as follows:

$$
E I_{g}=\sum_{i}^{n} \alpha_{c i} \times A_{w i}+E I_{e g}
$$

$\alpha_{c i}$ is the GWP equivalent coefficient of the $i$ input in the system. $E I_{e g}$ is the GWP characteristic quantity of the maintenance equipment used in the system boundary, which can be calculated by the following formula:

$$
E I_{e g}=\sum_{a}^{n} \frac{M_{w a}}{E_{e a}} \times\left(A \gamma_{a} \times A \alpha_{c i}+B \gamma_{a} \times B \alpha_{c i}+C \gamma_{a} \times C \alpha_{c i}\right)
$$


$A_{\gamma a}, B_{\gamma a}$ and $C_{\gamma a}$ are the emission amount of climate warming factors $\mathrm{CO}_{2}, \mathrm{CH}_{4}$, and $\mathrm{N}_{2} \mathrm{O}$ in the system boundary, respectively. $A \alpha_{c i}, B \alpha_{c i}$, and $C \alpha_{c i}$ refer to the equivalent coefficient of $\mathrm{CO}_{2}, \mathrm{CH}_{4}$, and $\mathrm{N}_{2} \mathrm{O}$, respectively.

\section{The quantification of environmental impact in urban green space maintenance}

\subsection{Introducing of research area}

The research area of quantification of urban green space maintenance environmental impact was located in Zhengdong New District, Zhengzhou (China). The

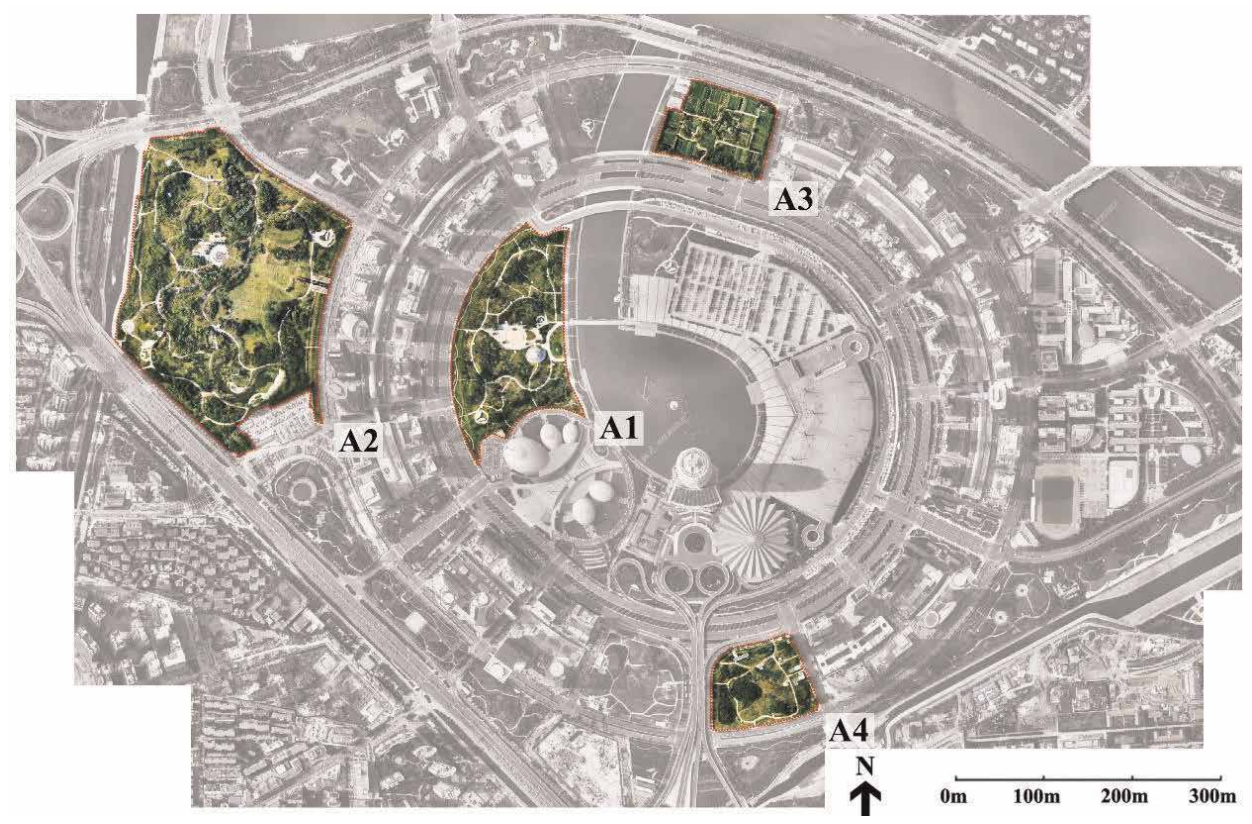

Figure 6.

The research sites in CBD area of city Zhengzhou. Resource: http://map.tianditu.com/
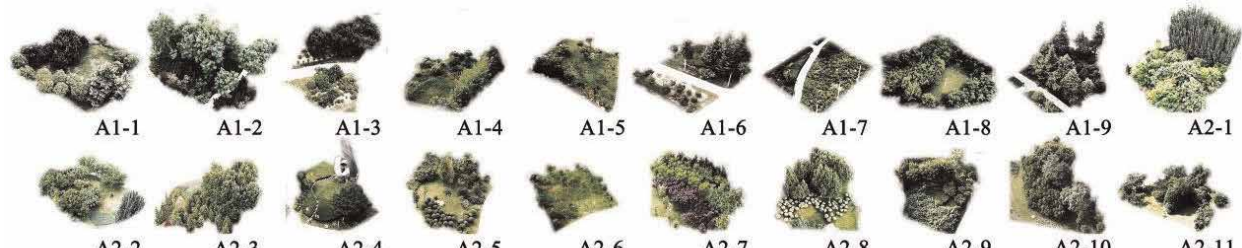

A1-9

A2-1
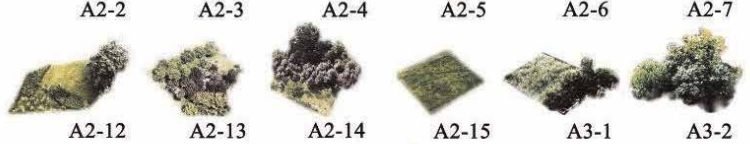

A2-8

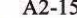

A3-2
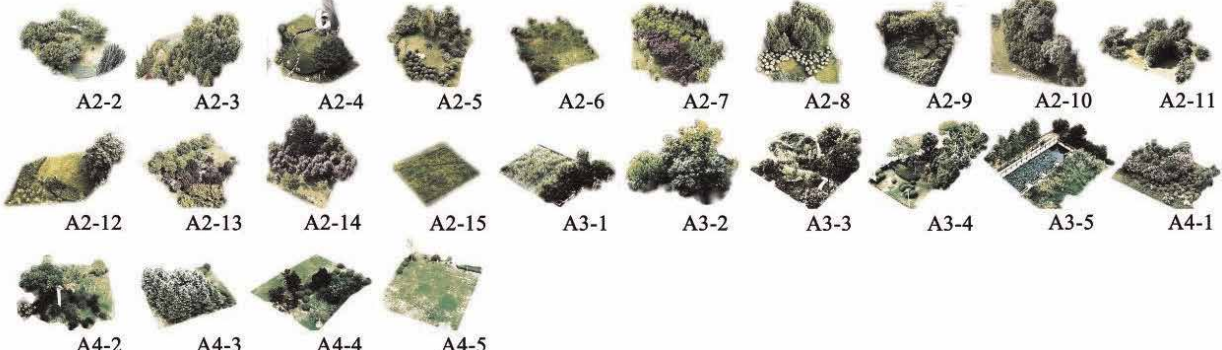

Figure 7.

The sample plots in research sites. 


\begin{tabular}{lccccc}
\hline $\begin{array}{l}\text { Inventory of } \\
\text { maintenance material }\end{array}$ & $\begin{array}{c}\text { Units } \\
(\mathbf{U})\end{array}$ & $\begin{array}{c}\text { Woodland } \\
\left(\mathbf{U} / \mathbf{h a} / \mathbf{y}^{-\mathbf{1}}\right)\end{array}$ & $\begin{array}{c}\text { Shrubs } \\
\left(\mathbf{U} / \mathbf{h a} / \mathbf{y}^{-\mathbf{1}}\right)\end{array}$ & $\begin{array}{c}\text { Ground cover } \\
\left(\mathbf{U} / \mathbf{h a} / \mathbf{y}^{-\mathbf{1}}\right)\end{array}$ & $\begin{array}{c}\text { Grassland } \\
\left(\mathbf{U} / \mathbf{h a} / \mathbf{y}^{-\mathbf{1}}\right)\end{array}$ \\
\hline Petrol & $\mathrm{kg}$ & 0 & $2 \times 10^{1}$ & 0 & $3.6 \times 10^{1}$ \\
\hline Diesel & $\mathrm{kg}$ & $2.1 \times 10^{1}$ & $9.8 \times 10^{1}$ & $3.0 \times 10^{1}$ & $7.1 \times 10^{1}$ \\
\hline City water & $\mathrm{m}^{3}$ & $1.3 \times 10^{4}$ & $1.5 \times 10^{4}$ & $1.3 \times 10^{4}$ & $1.6 \times 10^{4}$ \\
\hline Fertilizer & $\mathrm{kg}$ & $1.4 \times 10^{2}$ & $1.6 \times 10^{2}$ & $1.3 \times 10^{2}$ & $1.5 \times 10^{2}$ \\
\hline Pesticide & $\mathrm{kg}$ & $1.0 \times 10^{1}$ & $2.7 \times 10^{1}$ & $1.1 \times 10^{1}$ & $4.5 \times 10^{1}$ \\
\hline
\end{tabular}

Table 2.

Maintenance material input list in urban green space.

\begin{tabular}{lccccccc}
\hline Equipment type & $\begin{array}{c}\text { Energy } \\
\text { type }\end{array}$ & Unit & $\begin{array}{c}\text { Working } \\
\text { efficiency/unit }\end{array}$ & $\begin{array}{c}\text { Energy } \\
\text { consumption } \\
\text { (kg/unit) }\end{array}$ & \multicolumn{2}{c}{$\begin{array}{c}\text { GHG emission } \\
\text { (kg/unit) }\end{array}$} \\
\hline & & & & & $\mathbf{C O}_{2}$ & $\mathbf{C H}_{4}$ & $\mathrm{~N}_{2} \mathrm{O}$ \\
\hline Hedge strimmer & Petrol & $\mathrm{h}$ & $300 \mathrm{~m}^{2}$ & 0.60 & 1.69 & $8.96 \times 10^{-3}$ & $3.20 \times 10^{-4}$ \\
\hline $\begin{array}{l}\text { Hand-driven } \\
\text { mower }\end{array}$ & Petrol & $\mathrm{h}$ & $300 \mathrm{~m}^{2}$ & 1.50 & 1.80 & $9.10 \times 10^{-2}$ & $9.02 \times 10^{-4}$ \\
\hline Riding mower & Petrol & $\mathrm{h}$ & $2000 \mathrm{~m}^{2}$ & 2.30 & 2.68 & $3.74 \times 10^{-3}$ & $5.40 \times 10^{-4}$ \\
\hline $3 \mathrm{~m}^{3}$ light pickup & Diesel & $\mathrm{h}$ & $20 \mathrm{~km}$ & 1.00 & 3.43 & $8.11 \times 10^{-3}$ & $5.22 \times 10^{-4}$ \\
\hline $5 \mathrm{~m}^{3}$ light lorry & Diesel & $\mathrm{h}$ & $20 \mathrm{~km}$ & 2.60 & 6.20 & $1.81 \times 10^{-3}$ & $9.39 \times 10^{-4}$ \\
\hline
\end{tabular}

Table 3.

Energy consumption and GHG emission inventory of maintenance equipment.

green coverage rate in research area is $49.1 \%$. The construction of green space in the CBD area was completed in 2004, and it is a mature green area. The survey sites are (1) Hongbaihua Park with an area of $106,000 \mathrm{~m}^{2}$; (2) Zhengzhou Forest with an area of $264,000 \mathrm{~m}^{2}$; (3) Zhengdong New District Wetland Park with an area of $44,000 \mathrm{~m}^{2}$; and (4) No. 6 parking lot with an area of $39,000 \mathrm{~m}^{2}$. The plot area is $453,000 \mathrm{~m}^{2}$, accounting for about $60 \%$ of the total urban green area of the CBD (Figure 6). Thirty-four plant community samples of $20 \mathrm{~m} \times 20 \mathrm{~m}$ were set in the research sites (Figure 7).

\subsection{LCI data collection}

The LCI data collection consists of two parts (2017.06-2018.07): (1) plant structure: the area $\left(\mathrm{m}^{2}\right)$ of each plant layer in the sample survey site and the tree layer are calculated by the projected area of the canopy; (2) material input list: annual workload of each plant layer maintenance (trimming, irrigation, fertilization, pesticide, and plant waste removal). Table 2 shows the average amount of maintenance material inputs per ha of urban green space calculated according to the data collected in research samples. Table 3 shows the energy consumption and GHG emission of the maintenance equipment tested in the field.

\subsection{The LCA result of environmental impact in urban green space maintenance}

See Tables 4 and 5 . 


\begin{tabular}{|c|c|c|c|c|c|c|c|}
\hline \multirow{2}{*}{$\begin{array}{l}\text { Environmental } \\
\text { impact factor }\end{array}$} & \multirow{2}{*}{$\begin{array}{l}\text { Plant } \\
\text { layers }\end{array}$} & \multicolumn{6}{|c|}{ Maintenance task } \\
\hline & & Trimming & Irrigation & Fertilization & Pesticide & $\begin{array}{l}\text { Waste } \\
\text { transport }\end{array}$ & Total \\
\hline \multirow{4}{*}{$\begin{array}{l}\text { Resource and } \\
\text { energy } \\
\text { consumption } \\
\left(\mathrm{MJ} / \mathrm{ha} / \mathrm{y}^{-1}\right)\end{array}$} & Woodland & 0 & $3.14 \times 10^{4}$ & $1.13 \times 10^{4}$ & $1.47 \times 10^{3}$ & $9.00 \times 10^{2}$ & $4.51 \times 10^{4}$ \\
\hline & Shrubs & $8.62 \times 10^{2}$ & $3.67 \times 10^{4}$ & $1.25 \times 10^{4}$ & $3.89 \times 10^{3}$ & $4.18 \times 10^{3}$ & $5.81 \times 10^{4}$ \\
\hline & $\begin{array}{l}\text { Ground } \\
\text { cover }\end{array}$ & 0 & $3.29 \times 10^{4}$ & $1.07 \times 10^{4}$ & $1.60 \times 10^{3}$ & $1.29 \times 10^{3}$ & $4.64 \times 10^{4}$ \\
\hline & Grassland & $1.56 \times 10^{3}$ & $4.12 \times 10^{4}$ & $1.19 \times 10^{4}$ & $6.41 \times 10^{3}$ & $3.02 \times 10^{3}$ & $6.41 \times 10^{4}$ \\
\hline \multirow{4}{*}{$\begin{array}{l}\text { GWP potential } \\
\left(\mathrm{kg} \mathrm{CO}_{2}-\mathrm{e} / \mathrm{ha} /\right. \\
\left.\mathrm{y}^{-1}\right)\end{array}$} & Woodland & 0 & $0^{* 1}$ & $2.12 \times 10^{2}$ & 3.61 & $5.29 \mathrm{E}+01$ & $2.68 \times 10^{2}$ \\
\hline & Shrubs & $6.58 \times 10^{1}$ & $0^{* 1}$ & $2.34 \times 10^{2}$ & 9.52 & $2.46 \times 10^{2}$ & $5.56 \times 10^{2}$ \\
\hline & $\begin{array}{l}\text { Ground } \\
\text { cover }\end{array}$ & 0 & $0^{* 1}$ & $2.00 \times 10^{2}$ & 3.92 & $1.13 \times 10^{2}$ & $3.16 \times 10^{2}$ \\
\hline & Grassland & $6.58 \times 10^{1}$ & $0^{* 1}$ & $2.24 \times 10^{2}$ & $1.57 \times 10^{1}$ & $2.67 \times 10^{2}$ & $5.72 \times 10^{2}$ \\
\hline
\end{tabular}

Table 4.

Environmental impact characteristics of each plant layer in mature green space maintenance.

\begin{tabular}{|c|c|c|c|c|c|c|c|}
\hline \multirow{2}{*}{$\begin{array}{l}\text { Plant } \\
\text { layer }\end{array}$} & \multirow{2}{*}{$\begin{array}{l}\text { Environmental } \\
\text { impact factor }\end{array}$} & \multicolumn{6}{|c|}{ Weighted environmental impact index $\left(\mathrm{ha} / \mathrm{y}^{-1}\right)$} \\
\hline & & Trimming & Irrigation & Fertilization & Pesticide & $\begin{array}{c}\text { Waste } \\
\text { transport }\end{array}$ & Total \\
\hline \multirow[t]{3}{*}{ Woodland } & $\begin{array}{l}\text { Resource and } \\
\text { energy } \\
\text { consumption }\end{array}$ & 0 & $1.33 \times 10^{-3}$ & $4.80 \times 10^{-4}$ & $6.26 \times 10^{-5}$ & $3.82 \times 10^{-5}$ & $1.91 \times 10^{-3}$ \\
\hline & GWP potential & 0 & 0 & $3.70 \times 10^{-3}$ & $6.30 \times 10^{-5}$ & $9.24 \times 10^{-4}$ & $4.68 \times 10^{-3}$ \\
\hline & Sum & 0 & $1.33 \times 10^{-3}$ & $4.18 \times 10^{-3}$ & $1.26 \times 10^{-4}$ & $9.62 \times 10^{-4}$ & $6.60 \times 10^{-3}$ \\
\hline \multirow[t]{3}{*}{ Shrubs } & $\begin{array}{l}\text { Resource and } \\
\text { energy } \\
\text { consumption }\end{array}$ & $3.66 \times 10^{-5}$ & $1.56 \times 10^{-3}$ & $5.31 \times 10^{-4}$ & $1.65 \times 10^{-4}$ & $1.78 \times 10^{-4}$ & $2.47 \times 10^{-3}$ \\
\hline & GWP potential & $1.15 \times 10^{-3}$ & 0 & $4.09 \times 10^{-3}$ & $1.66 \times 10^{-4}$ & $4.30 \times 10^{-3}$ & $9.71 \times 10^{-3}$ \\
\hline & Sum & $1.19 \times 10^{-3}$ & $1.56 \times 10^{-3}$ & $4.62 \times 10^{-3}$ & $3.32 \times 10^{-4}$ & $4.48 \times 10^{-3}$ & $1.22 \times 10^{-2}$ \\
\hline \multirow[t]{3}{*}{$\begin{array}{l}\text { Ground } \\
\text { cover }\end{array}$} & $\begin{array}{l}\text { Resource and } \\
\text { energy } \\
\text { consumption }\end{array}$ & 0 & $1.40 \times 10^{-3}$ & $4.53 \times 10^{-4}$ & $6.81 \times 10^{-5}$ & $5.47 \times 10^{-5}$ & $1.97 \times 10^{-3}$ \\
\hline & GWP potential & 0 & 0 & $3.49 \times 10^{-3}$ & $6.85 \times 10^{-5}$ & $1.97 \times 10^{-3}$ & $5.53 \times 10^{-3}$ \\
\hline & Sum & 0 & $1.40 \times 10^{-3}$ & $3.94 \times 10^{-3}$ & $1.37 \times 10^{-4}$ & $2.03 \times 10^{-3}$ & $7.50 \times 10^{-3}$ \\
\hline \multirow[t]{3}{*}{ Grassland } & $\begin{array}{l}\text { Resource and } \\
\text { energy } \\
\text { consumption }\end{array}$ & $6.61 \times 10^{-5}$ & $1.75 \times 10^{-3}$ & $5.07 \times 10^{-4}$ & $2.72 \times 10^{-4}$ & $1.28 \times 10^{-4}$ & $2.72 \times 10^{-3}$ \\
\hline & GWP potential & $1.15 \times 10^{-3}$ & 0 & $3.91 \times 10^{-3}$ & $2.74 \times 10^{-4}$ & $4.67 \times 10^{-3}$ & $1.00 \times 10^{-2}$ \\
\hline & Sum & $1.22 \times 10^{-3}$ & $1.75 \times 10^{-3}$ & $4.41 \times 10^{-3}$ & $5.46 \times 10^{-4}$ & $4.79 \times 10^{-3}$ & $1.27 \times 10^{-2}$ \\
\hline
\end{tabular}

Table 5.

Weighted environmental impact index of each plant layer in mature green space. 


\section{Author details}

Ning $\mathrm{Li}^{1}$ and Yang $\mathrm{Liu}^{2 *}$

1 Henan Agricultural Landscape Planning and Design Institute, Zhengzhou, China

2 College of Forestry, Henan Agricultural University, Zhengzhou, China

*Address all correspondence to: kelivnliu@163.com

\section{IntechOpen}

(C) 2019 The Author(s). Licensee IntechOpen. This chapter is distributed under the terms of the Creative Commons Attribution License (http://creativecommons.org/licenses/ by/3.0), which permits unrestricted use, distribution, and reproduction in any medium, provided the original work is properly cited. (खc) BY 


\section{References}

[1] National Bureau of Statistics. Statistical Yearbook of the Republic of China. 2019

[2] Sun Z. Study of the urban landscape greening sustainable development measures in the conservation-oriented society. Chinese Landscape

Architecture. 2007;9:15-21

[3] Yajun W. Theoretical studies on the ecological garden city planning. Urban Problems. 2007;7:16-20

[4] Yun-Lu Z, Hai-Li G, Xiong LI. Response of urban green space system planning from Garden City to ecological Garden City. Chinese Landscape Architecture. 2017;33(2):71-77

[5] Chen WW. An analysis of problems in the building of ecological Garden City. Urban Planning Forum. 2012;2: 91-96

[6] Ministry of Housing and UrbanRural Development of the People's Republic of China. Sponge City Construction Technical Guide-Low Impact Development Rainwater System Construction. 2015

[7] Wang H, Mei C, Liu J. Systematic construction pattern of the sponge city. Journal of Hydraulic Engineering. 2017; 48(9):1009-1014

[8] Hitchmough J. Plant User Handbook: A Guide to Effective Specifying. 2008

[9] Lindholst AC. Improving contract design and management for urban green-space maintenance through action research. Urban Forestry \& Urban Greening. 2008;7(2):77-91

[10] Khan MY, Russell RL, Welch WA, et al. Impact of algae biofuel on in-use gaseous and particulate emissions from a marine vessel. Energy \& Fuels. 2012; 26(10):6137-6143
[11] Wang X, Qingqiang WU, Zhou J, et al. Life cycle assessment of tomato production in greenhouses. Acta Scientiae Circumstantiae. 2014;34(11): 2940-2947

[12] West TO, Marland G. A synthesis of carbon sequestration, carbon emissions, and net carbon flux in agriculture: Comparing tillage practices in the United States. Agriculture

Ecosystems \& Environment. 2002; 91(1):217-232

[13] National Development And Reform Institute. General principles for calculation of the comprehensive energy consumption: China Energy Research Association Energy Conservation and Enterprise Management Committee Annual Meeting. 2008

[14] Zartman RE, Wester DB, Sosebee RE, et al. Precipitation and mowing effects on highway rights-ofway vegetation height and safety. Landscape \& Ecological Engineering. 2013;9(1):121-129

[15] Wu J. Landscape sustainability science: Ecosystem services and human well-being in changing landscapes. Landscape Ecology. 2013;28(6): 999-1023

[16] Post A, Santana F. Florida-Friendly Landscaping ${ }^{\mathrm{TM}}$ Guidelines Community Associations Can Use to Select a Landscaper and Write an Effective Landscaping Contract. 2014

[17] Center LBJW, Garden USB. The sustainable sites initiative: Guidelines and performance benchmarks. Environmental Policy Collection. 2009

[18] Zhao CJ, Liu XM. The role of urban green space system in Low-Carbon City. Chinese Landscape Architecture. 2010;26(6):23-26 
[19] Guo J. From Renew, Recycle and Reuse to Regeneration of Landscape. 2004

[20] Min LI. On the urban green space system planning theory and method renewal. Journal of Chinese Landscape Architecture. 2002;18(5):17-20

[21] Shu-Hua LI. Symbiosis and Circulation-The basic thought of urban green space construction under lowcarbon economic society. Chinese Landscape Architecture. 2010;26(6): 19-22

[22] Jo HK. Impacts of urban greenspace on offsetting carbon emissions for middle Korea. Journal of Environmental Management. 2002;64(2):115-126

[23] Lynch D, Kirkpatrick C, Dias A. Boise State University landscape applications towards energy conservation. Scholar Works. 2010

[24] Rebitzer G, Ekvall T, Frischknecht R, et al. Life cycle assessment: Part 1: Framework, goal and scope definition, inventory analysis, and applications. Environment International. 2004;30(5):701-720

[25] Klüppel HJ. The revision of ISO standards 14040-3-ISO 14040: Environmental management-Life cycle assessment-Principles and framework-ISO 14044: Environmental management-Life cycle assessmentRequirements and guidelines. International Journal of Life Cycle Assessment. 2005;10(3):165

[26] Wang YT, Wang FC, Hong JL, et al. The development of life cycle assessment theory research in China and analysis of countermeasures. Acta Ecologica Sinica. 2016;36(22):7179-7184

[27] Davies ZG, Edmondson JL, Heinemeyer A, et al. Mapping an urban ecosystem service: Quantifying aboveground carbon storage at a city-wide scale. Journal of Applied Ecology. 2011; 48(5):1125-1134

[28] Cabeza LF, Rincón L, Vilariño V, et al. Life cycle assessment (LCA) and life cycle energy analysis (LCEA) of buildings and the building sector: A review. Renewable \& Sustainable Energy Reviews. 2014;29:394-416

[29] Kaltschmitt M. Life cycle analysis of biofuels under different environmental aspects. Biomass \& Bioenergy. 1997; 12(2):121-134

[30] Ofipcc WGI. Climate change; the physical science basis. Contribution of Working. 2013;43(22):866-871

[31] Sleeswijk AW, van Oers LF, Guinée JB, et al. Normalisation in product life cycle assessment: An LCA of the global and European economic systems in the year 2000. Science of the Total Environment. 2008;390(1): 227-240

[32] Calker KJV, Berentsen PBM, Boer IJMD, et al. An LP-model to analyse economic and ecological sustainability in Dutch dairy farming. General Information. 2003;82(2): 139-160

[33] Pouliot G, Wisner E, Mobley D, et al. Quantification of emission factor uncertainty. Journal of the Air \& Waste Management Association. 2012;62(3): 287-298

[34] Lazzerini G, Lucchetti S, Nicese FP. GHG emissions from the ornamental plant nursery industry: A LCA approach in a nursery district in Central Italy. Journal of Cleaner Production. 2016;112: 4022-4030

[35] Berg S, Lindholm EL. Energy use and environmental impacts of forest operations in Sweden. Journal of Cleaner Production. 2005;1(13):33-42

[36] Ingram DL. Life cycle assessment of a field-grown red maple tree to estimate 
its carbon footprint components.

International Journal of Life Cycle

Assessment. 2012;17(4):453-462

[37] Haas G, Wetterich F, Kopke U.

Comparing intensive, extensified and organic grassland farming in southern Germany by process life cycle assessment. Agriculture Ecosystems \& Environment. 2001;83(1):43-53

[38] Yuan-Yuan JI, Genovese PV, University T A, et al. Research on the carbon emission from the daily use and maintenance on the basis of life cycle of landscape architecture. Landscape Architecture. 2016;9:121-126

[39] Strohbach MW, Haase D. Aboveground carbon storage by urban trees in Leipzig, Germany: Analysis of patterns in a European city. Landscape \& Urban Planning. 2012;1(104):95-104

[40] Jiang SP, Peng YL. Study on maintenance and management for residential planting. Journal of Chinese Landscape Architecture. 2003;19(3): 29-32

[41] Liang L, Chen YQ, Gao WS. Integrated evaluation of circular agriculture system: A life cycle perspective. Environmental Science. 2010;31(11):2795 

Section 2

\section{Lessons from Sustainable Urban Planning and Design - Practical Cases}





\title{
Urban Planning Using a Geospatial Approach: A Case Study of Libya
}

\author{
Bahareh Kalantar, Husam A.H. Al-najjar, \\ Hossein Mojaddadi Rizeei, Maruwan S.A.B. Amazeeq, \\ Mohammed Oludare Idrees, Alfian Abdul Halin \\ and Shattri Mansor
}

\begin{abstract}
Large scale developmental projects firstly require the selection of one or more cities to be developed. In Libya, the selection process is done by selected organizations, which is highly influenced by human judgement that can be inconsiderate of socioeconomic and environmental factors. In this study, we propose an automated selection process, which takes into consideration only the important factors for city (cities) selection. Specifically, a geospatial decision-making tool, free of human bias, is proposed based on the fuzzy overlay (FO) and technique for order performance by similarity to ideal solution (TOPSIS) techniques for development projects in Libya. In this work, a dataset of 17 evaluation criteria (GIS factors) across five urban conditioning factors were prepared. The dataset served as input to the FO model to calculate weights (importance) for each criterion. A support vector machine (SVM) classifier was then trained to refine weights from the FO model. TOPSIS was then applied on the refined results to rank the cities for development. Experimental results indicate promising overall accuracy and kappa statistics. Our findings also show that highest and lowest success rates are 0.94 and 0.79 , respectively, while highest and lowest prediction rates are 0.884 and 0.673 , respectively.
\end{abstract}

Keywords: fuzzy overlay, urban development, TOPSIS, Libya

\section{Introduction}

Rapid population growth and urbanization have caused many problems in the implementation of developmental projects in cities. Haphazard infrastructural project execution that includes disregard in prioritizing city (or cities) selection is also a factor hampering sustainable development practices. Development projects that rely on selected organizations, which in turn rely on human judgment, can lead to unrealistic criteria evaluation, causing delays in project execution [1]. However, the fact remains that continued infrastructure development is unavoidable, especially since urban cities constantly need to evolve and grow to keep up with the times [2].

The selection of a city (or a group of cities) is one of the most important steps for sustainable development. The selection criteria must ensure that the city (cities) has high priority for development and is (are) in line with the needs of the local citizens. 
Moreover, timely selection requires effective planning and analysis and must consider multiple conflicting and disproportionate factors (such as those that have critical socioeconomic and environmental implications to different stakeholders). Urban planning application using remote sensing (RS) and geographical information systems (GIS) is one of the many areas that can be explored for city selection. Such applications would not only eliminate human bias but would also be able to make more objective decisions based on data.

\subsection{Remote sensing and GIS applications in urban planning}

Remote sensing can be applied in different aspects of urban planning such as (but not limited to) urban traffic analysis, urban environment analysis (air and water pollutions), and urban expansion. With recent developments in remote sensing technologies, remote sensing data can be exploited for urban studies. One example is the classification of land use based on high spatial and spectral resolution data such as orthomosaic and elevation images. Multidimensional spatiotemporal data can now be reliably obtained by sensors in different scale ranges and with flexible repetition rates [3].

\subsection{Remote sensing sensors for urban planning}

Medium- to high-resolution satellite imagery can be used by urban planners and land managers to monitor land conditions to support decision-making for sustainable urban development. Remote sensors are able to provide voluminous amounts of data, which can be exploited to produce/update GIS maps or for detection changes in urban land covers. High-resolution satellite sensors available on IKONOS, for example, can collect diverse geospatial data for studying vegetation. The sensors can sense $4 \mathrm{~m}$ resolution multispectral and $1 \mathrm{~m}$ resolution panchromatic, Quickbird imageries with $2.4 \mathrm{~m}$ resolution multispectral and $61 \mathrm{~cm}$ resolution panchromatic, and Worldview-4 imageries with $1.24 \mathrm{~m}$ resolution multispectral and $31 \mathrm{~cm}$ panchromatic. Medium-resolution satellite sensors, available on Landsat-8, Sentinel-2, and SPOT, are also valuable data sources for urban and vegetation change detection from various time periods during the same season, which further supports analyzing any past changes. Analysis of such data can then be used for decision-making and planning for further development of a particular urban area [4].

\subsection{Integration of GIS and remote sensing for urban planning}

Remote sensing data can be integrated with other spatial data to perform various types of full-fledged assessments. GIS techniques can be utilized to integrate the required spatial data and analytic data from various sources, such as field survey data, topographic maps, aerial photographs, and also archived data. The data can be represented as location (i.e., latitude and longitudes) or even as tabular attributes. GIS techniques play a substantial role in the data integration process of multilayer spatial information along with statistical information in various developmental scenarios [5].

\subsection{Methods and approaches for urban planning}

Multi-criteria decision-making (MCDM) is concerned with making a decision by evaluating multiple conflicting criteria. It embodies various methods and procedures where the gist is the formal incorporation of multiple conflicting criteria in 
the analytical process [6]. In the context of GIS, this refers to the spatial decisionmaking process based on GIS data with geolocation tags. Spatial decision-making techniques have been used to solve many GIS problems such as locating solar plants, urban planning, and project construction optimization [7]. Advanced MCDM methods include simple additive weighting (SAW) [8], analytic hierarchy process (AHP) [9], and TOPSIS [10]. Fuzzy set theory and random set theory are also MCDM techniques that incorporate sophisticated algorithms to resolve uncertainty in data [11-14].

TOPSIS is a MCDM technique that deals with real-world problems. It basically ranks criteria on the basis of the shortest distance from the positive ideal solution (PIS) and the farthest distance from the negative ideal solution (NIS) [15]. The work in [2] illustrates the application of a GIS-based MCDM tool for urban infrastructural planning. Awasthi et al. [16] presented a fuzzy TOPSIS method for selecting the best location for an urban distribution center in Canada. Uysal and Tosun [17] proposed a fuzzy TOPSIS-based maintenance management system using 17 criteria categorized under 5 contending parameters. The criteria were deduced from questionnaire feedbacks and interviews administered to company maintenance managers. In addition, Momeni et al. [18] presented a fuzzy TOPSIS-based method for maintenance strategy selection. Baysal et al. [19] developed a two-stage fuzzy method to determine the best sub-municipal projects among a set of proposed projects. The method simplifies the selection process and provides an objective decision outcome for stakeholders. Shelton and Medina [20] presented an integrated method to prioritize transportation projects in Wilmington Area, USA, based on multi-criteria decision support systems, AHP and TOPSIS methods. The process optimally selects the important routes that best serve the interest of the general public.

Based on the literature, TOPSIS has been successfully applied in many fields, producing reasonably accurate results. This study proposes an automated TOPSISbased solution for prioritizing urban projects based on criteria that meet sustainable development. Specifically, this work addresses the following questions on the value of remote sensing (and GIS) to urban planning:

1. Which remotely sensed dataset(s) is (are) useful for urban planning?

2. Which criteria can be derived from remotely sensed data?

3. What are the major factors that need to be considered in urban developments?

From these questions, this study further looks at the automated prioritization of urban projects based on criteria that meet sustainable development practices. The specific objectives are (i) to identify factors that play major roles in urban development and (ii) to develop a geospatial solution based on TOPSIS for prioritizing projects for urban development.

\section{Study area and preparation of the conditioning factors}

This study focuses on Libya, a country in the Maghreb region of North Africa (Figure 1). Libya borders the Mediterranean Sea to the north and Egypt to the east. Along the southeast of Libya is Sudan, Chad. To the south is Niger. Algeria and Tunisia constitute the western border. Libya is the 17th largest nation in the world with a landmass of over $1,759,540 \mathrm{~km}^{2}$. The study area in the northern part of Libya covers six districts, namely, Darnah, Al Jabal Al Akhdar, Benghazi, Al Marj, Al Qubbah, and 

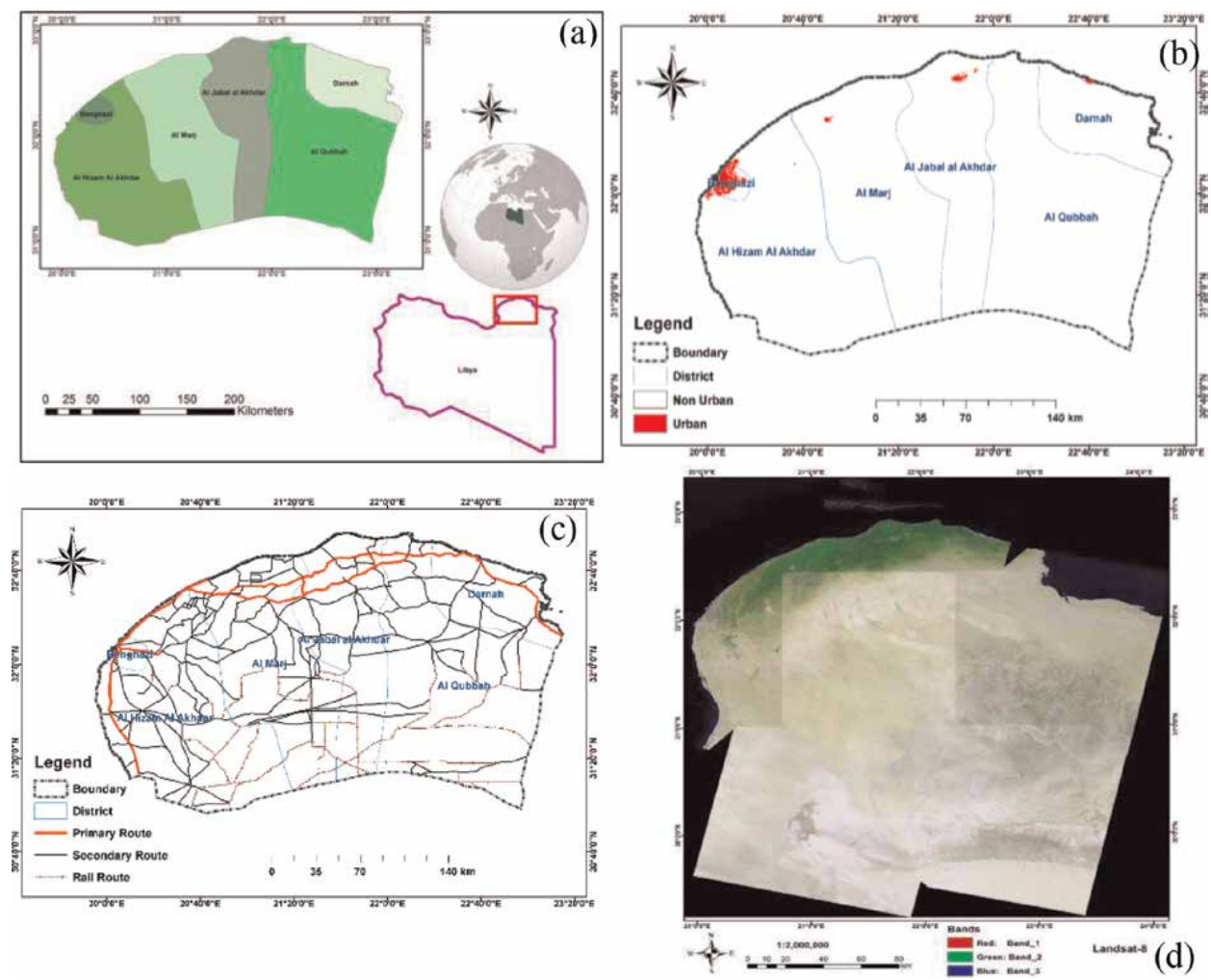

Figure 1.

(a) Map of Libya with northern part highlighted, (b) the location of the urban area, (c) the road networks in the study area, and (d) mosaicked Landsat images.

$\mathrm{Al}$ Hizam Al Akhdar (Figure 1). Libya is geographically bounded between $20^{\circ} 00^{\prime} 00^{\prime \prime}$ $\mathrm{E}$ and $23^{\circ} 30^{\prime} 00^{\prime \prime} \mathrm{E}$ and $31^{\circ} 00^{\prime} 00^{\prime \prime} \mathrm{N}$ and $33^{\circ} 00^{\prime} 00^{\prime \prime} \mathrm{N}$. The climate in Libya is categorized by hot and dry summers with high temperatures. The mean annual temperature in the coastal region ranges from $14.2^{\circ} \mathrm{C}$ (Shahat) to $21.0^{\circ} \mathrm{C}$ (Tripoli Airport) and at stations in the interior region (inland) between $21.3^{\circ} \mathrm{C}$ (Al Qaryat) and (Ghat) $23.4^{\circ} \mathrm{C}$ (1945-2009). Libya is one of the driest countries in the world with mean annual rainfall along the Libyan coast ranging between 140 and $550 \mathrm{~mm}$ and rarely exceeding $50 \mathrm{~mm}$ in the interior regions (1945-2010). December and January are the wettest months with 6 months (October-March) receiving $87.1 \%$ of the total annual precipitation. The majority of rainfall occurs in the winter season with the rainy season beginning in September-October and ends in March-April [21].

\subsection{Data preparation}

The data used in this study include Landsat satellite imagery acquired in the year 2017 with $15 \mathrm{~m}$ resolution panchromatic and $30 \mathrm{~m}$ resolution multispectral, Shuttle Radar Topography Mission (SRTM) digital elevation model (DEM) downloaded from USGS data archive with $30 \mathrm{~m}$ resolution, population density map obtained from GHSL with $250 \mathrm{~m}$ resolution, road network map from Diva-GIS, and MODIS satellite imagery from where the land surface temperature with $0.25^{\circ}$ resolution was derived. Other data include rainfall data at $0.25^{\circ}$, net primary productivity (NPP) at $0.1^{\circ}$, NDVI at $0.1^{\circ}$, and air quality $\left(\mathrm{CO}, \mathrm{NO}_{2}\right)$ at $0.25^{\circ}$ resolution (Table 1$)$. Details of the Landsat data are presented in Table 2. Seven set of images with overlapping areas were acquired between 4 February 2017 and 1 March 2017. In addition, the 
Urban Planning Using a Geospatial Approach: A Case Study of Libya

DOI: http://dx.doi.org/10.5772/intechopen.86355

\begin{tabular}{lcc}
\hline Data & Source & Resolution \\
\hline Landsat satellite imagery & USGS & $30 \mathrm{~m}$ \\
\hline DEM & USGS & $30 \mathrm{~m}$ \\
\hline Population density & GHSL & $250 \mathrm{~m}$ \\
\hline Road network & Diva GIS & $/$ \\
\hline Land surface temperature & MODIS & $0.25^{\circ}$ \\
\hline Rainfall & MODIS & $0.25^{\circ}$ \\
\hline Net primary productivity & MODIS & $0.1^{\circ}$ \\
\hline NDVI & MODIS & $0.1^{\circ}$ \\
\hline Air quality $\left(\mathrm{CO}, \mathrm{NO}_{2}\right)$ & MODIS & $0.25^{\circ}$ \\
\hline
\end{tabular}

Table 1.

Information of the datasets used in the research.

\begin{tabular}{lcccc}
\hline Image ID & Acquisition date & Raw & Path & Cloud cover (\%) \\
\hline Landsat 8 OLI 1 & 1 March 2017 & 38 & 182 & 0.77 \\
\hline Landsat 8 OLI 2 & 13 February 2017 & 39 & 182 & 1.03 \\
\hline Landsat 8 OLI 3 & 4 February 2017 & 38 & 183 & 0.00 \\
\hline Landsat 8 OLI 4 & 4 February 2017 & 37 & 183 & 0.11 \\
\hline Landsat 8 OLI 5 & 4 February 2017 & 39 & 183 & 0.13 \\
\hline Landsat 8 OLI 6 & 19 February 2017 & 37 & 184 & 1.00 \\
\hline Landsat 8 OLI 7 & 19 February 2017 & 38 & 184 & 0.00 \\
\hline
\end{tabular}

Table 2.

Information of the Landsat images.

highest cloud cover was $1.03 \%$, which does not pose a problem for land use information extraction from the study area. Since the images have overlapping areas, they were preprocessed and mosaicked to create one seamless image of the area for effective and efficient processing (Figure 1d).

\subsection{Data preprocessing}

Four preprocessing steps were performed on the Landsat satellite images: (i) Pan-sharpening using a fusion of the panchromatic and multispectral bands for the enhancement of the spatial resolution of multispectral band; (ii) atmospheric correction, which is applied to correct the atmospheric distortion by retrieving surface reflectance and engage topographic correction as well as adjacency effect correction; (iii) radiometric correction, which converts radiance values to the pure surface reflectance to enhance image capability and contrast; and (iv) mosaicking to create one seamless image coverage of the area for effective and efficient processing [22]. The MODIS source data was preprocessed using MODIS Conversion Tool Kit (MCTK). Note that the spatial resolution of the MODIS dataset varied according to the source. However, during the preprocessing, they were resampled to $30 \mathrm{~m}$ to match the DEM and Landsat resolutions.

\subsection{Urban conditioning factor dataset}

In this study, we considered 17 critical urban conditioning factors for selecting the most suitable city or cities for sustainable urban development. The factors are 
grouped into five main categories: (i) topography, (ii) land use and infrastructure, (iii) demography and climate, (iv) vegetation, and (v) air quality.

\subsubsection{Topography}

Topography is a very important consideration for urban development projects [23]. For this study, altitude and slope are the two main factors related to topography. Altitude is important for citing facility because it affects the living conditions as well as breathing behavior. The collected DEM shows that the study area is between -4 and $865 \mathrm{~m}$ above mean sea level (Figure 2a). The slope factor, which ranges from 0 to $14^{\circ}$ (can be classified as almost flat), was also generated

(Figure 2b). Such data is important when estimating cost. For example, any increase in slope will increase the cost of facility installation and maintenance since moving workers, transport vehicles, and machineries will be more difficult (i.e., up and down a slope). Low slope areas also may incur undesirable cost, in the instance of weather anomalies such as dust/sand storms.

\subsubsection{Land use and infrastructure}

Land use and infrastructure are also important considerations for urban projects. Land use information can show human activity patterns, whereas infrastructure can indicate development status in a particular city. The land use of the study area was derived from Landsat images and refined based on Google maps (Figure 2c). In this study we applied the SVM classifier, which was based on object-based image analysis (OBIA) using the ENVI 5.3 software. Training sites for the SVM were collected form all land use classes by stratified random method (i.e., at least 80 sample points for each class) [24]. The area contains five main land use types: (i) irrigated crops, (ii) vegetation, (iii) artificial areas, (iv) bare lands, and (v) waterbodies. Most parts of the study area were bare land (desert), which were predominantly located in the middle and southern parts of the study area. The northern part mostly comprised of irrigated crops and artificial areas, specifically man-made features and urban areas.

Road networks play an important role in the country's economy, serving the people by linking main cities to industrial and commercial sites. In this study, three types of roads, namely, main routes, secondary routes, and trail routes (Figure 2d-f), were considered as factors for city selection. The northern part of the city is supported by main routes (Figure $\mathbf{2 d}$ ). These roads mainly link other cities to Benghazi, which support Benghazi city itself. Main routes span a significant number of kilometers within the study area. The study area also contains several kilometers of secondary routes (Figure $2 \mathbf{e}$ ). Unlike main routes, secondary routes are found in most parts of the study area and in different cities including Benghazi. Secondary routes mainly support transportation of goods and are used for civil construction projects. Finally, trail routes support the rural areas, mainly for transportation of agricultural produce to the markets. The class of roads plays a vital role in selecting a city for development according to the available budget. Cities that can support more people will normally be prioritized for development projects.

Another important factor related to infrastructure is the percentage of built-up areas in a particular city. This is important because cities with many built-up areas indicate little or no space for new projects. On the contrary, cities with fewer builtup areas mean that they are more suitable for new developmental projects. The Normalized Difference Built-up Index (NDBI), which is a quantity of the intensity of urban area from satellite images, was used in this study [25]. The NDBI was initially established regarding the ratio of bands 4 and 5 of TM sensor. However, the NDBI can be adopted on Landsat- 8 data or even any multispectral sensor 
Urban Planning Using a Geospatial Approach: A Case Study of Libya DOI: http://dx.doi.org/10.5772/intechopen.86355

data [26]. It basically extracts the urban areas where there is an upper reflectance in the short-wave infrared band associated to the near-infrared band. The accuracy of built-up areas extracted using NDBI is reported to be around 93\% [27, 28]. We calculate the NDBI (Eq. (1)) based on the work in [27]:

$$
N D B I=\frac{S W I R-N I R}{S W I R+N I R}
$$
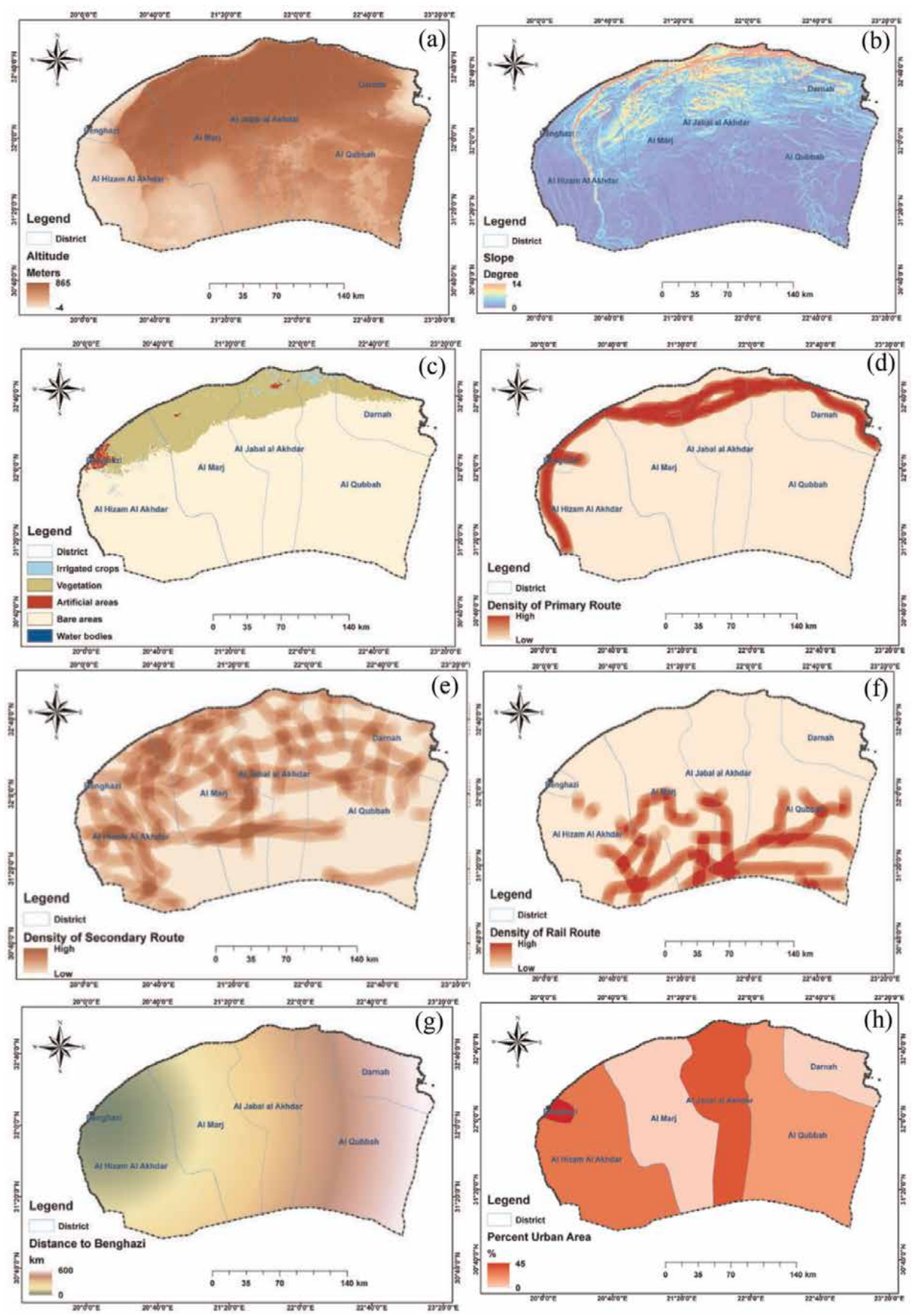

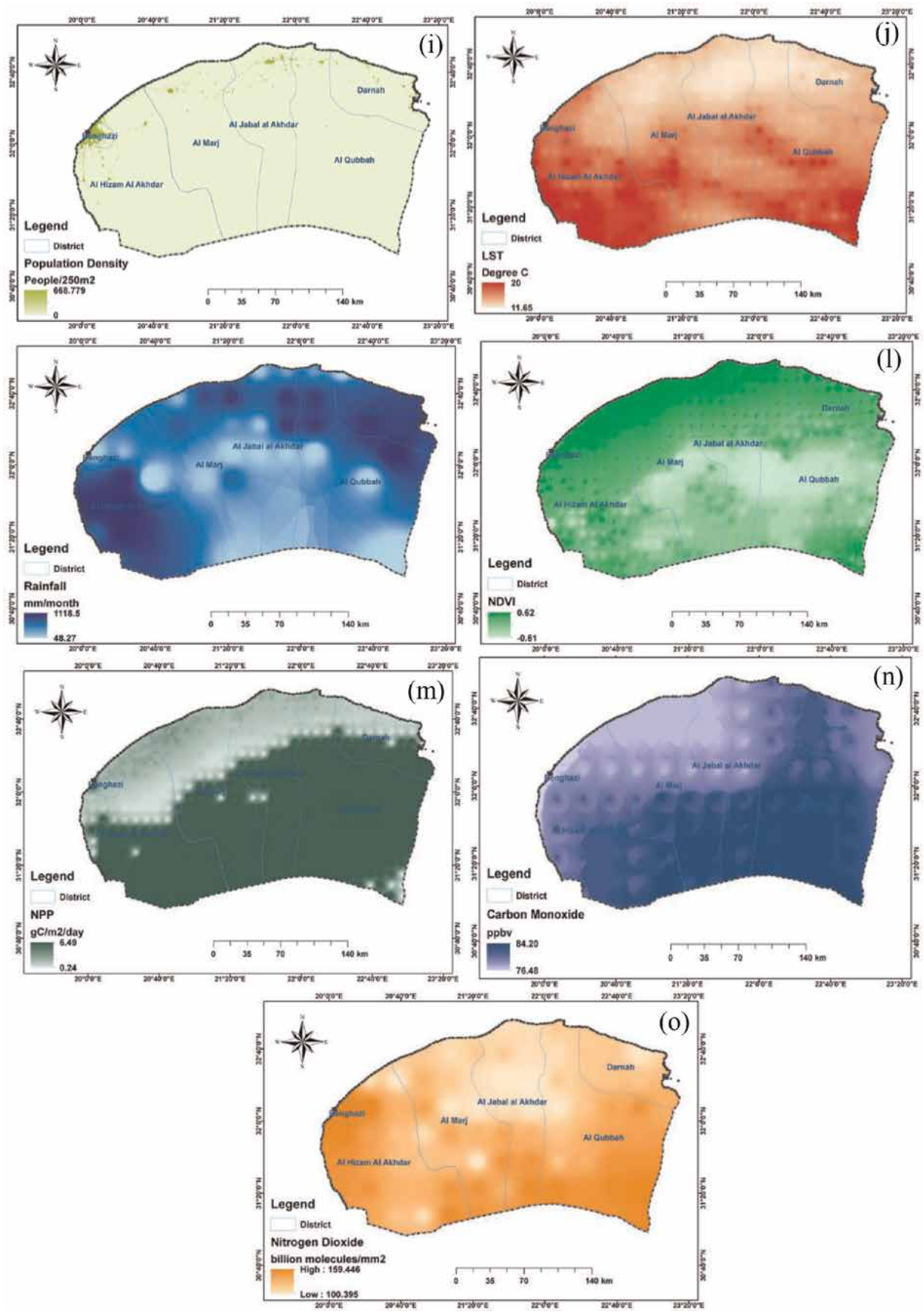

Figure 2.

Elevation criteria: (a) altitude, $(b)$ slope, $(c)$ land use, $(d)$ distance to the primary routes, $(e)$ distance to the secondary routes, $(f)$ distance to the trails, $(g)$ distance to the Benghazi city, $(h)$ percent of urban areas, $(i)$ population density, (j) LST, ( $k$ ) rainfall, (l) NDVI, (m) NPP product, (n) CO concentrations, (o) $\mathrm{NO}_{2}$ concentrations.

SWIR is the short-wave infrared band ranging from 1.57 to $1.65 \mu \mathrm{m}$. NIR is the near-infrared band in the range of $0.85-0.88 \mu \mathrm{m}$. Figure $2 \mathbf{h}$ shows the percentage of built-up areas calculated for each district considered in this work. The largest 
built-up area is found in Benghazi city (>45\%). Some cities though, such as Al Marj and Darnah, have very small of built-up areas that are not detectable through satellite data.

Besides infrastructure factors, distance to the city is also a critical factor. Preferably, a city's location should be as near as possible to the capital or large cities such as Benghazi. This is because it facilitates ease of access to better business opportunities and education. Therefore, in this work, the distance to Benghazi city is one of the important parameters. Specifically, the desired distance to the city should range from 0 to $600 \mathrm{~km}$ (Figure $\mathbf{2 g}$ ) so that cities such as Darnah and $\mathrm{Al}$ Qubbah (which are as far as $400 \mathrm{~km}$ away from Benghazi) are also covered.

\subsubsection{Demography and climate}

An increase in a city's population often leads to an increase in urbanization. Moreover, if the population increase is rapid, urbanization often happens randomly. This can be a major problem for most cities in a developing country. However, proper planning and effective decision-making can mitigate this problem. In this study, the population density (Figure $2 \mathbf{i}$ ) was analyzed. The analysis results indicate that the northern part (mostly around Benghazi city) is most populated with a density of 669 people per $250 \mathrm{~m}$ cell of raster data.

Climate is a factor that also influences the selection of cities for developmental projects. Land surface temperature (LST) and rainfall are two factors considered in this work (Figures $\mathbf{2} \mathbf{j}$ and $\mathbf{3 k}$ ). The LST map shows that the southern part of the study area (mostly desert with no vegetation) has higher surface temperature compared to the northern parts. Another observation from the map reveals that Benghazi has slightly higher temperature than other urbanized areas. In arid regions, people often prefer to settle in areas with low temperature. The average day-night temperature ranges from $11^{\circ}$ to $20^{\circ}$ Centigrade. High temperatures are also observed in the west-southern part, whereas the lowest temperature is found in the northern part of $\mathrm{Al}$ Jabal Al Akhdar cities.

Rainfall, which is another climate factor, is also considered in deciding the location of settlement and development. This is because rainfall frequency and intensity affect the dryness of the cities, the local climate system, as well as agriculture activities. Figure $\mathbf{2 k}$ presents the rainfall intensity of the study area for year 2016 where minimum and maximum rainfall intensities were 48 and $1119 \mathrm{~mm}$ per month, respectively. The central part of the area has less amount of rainfall compared to other areas.

\subsubsection{Vegetation}

Normalized difference vegetation index (NDVI) is an indicator derived from remote sensing satellite data. It is mostly used to monitor vegetation cover over any area on the planet. It serves as a good indicator for vegetation cover of the study area. The presence of abundant vegetation is able to lower the local temperature as well as reduces the negative effects of noise and air pollutants. In the study area, the northern part has higher NDVI compared to the south (Figure 2l).

Larger amounts of vegetation can indicate higher vegetation productivity. Having higher vegetation productivity helps asses the net primary productivity (Figure $\mathbf{2 m}$ ). Plant productivity plays a major role in the global carbon cycle by absorbing some of the carbon dioxide released through coal, oil, and other fossilfuel burning. Large NPP values are found in the southern part of the study area. 


\subsubsection{Air quality}

Air quality directly affects the environment and consequently people's health. In this work, we have considered the $\mathrm{CO}$ and $\mathrm{NO}_{2}$ (Figure $2 \mathbf{n}$ and o) air quality indicators. In 2016, higher $\mathrm{CO}$ and $\mathrm{NO}_{2}$ levels were measured in the southern part of Benghazi. Benghazi city also recorded high levels of these gasses for the year under investigation. The air quality data was extracted from the MODIS source with a resolution of $0.25^{\circ}$. We utilized the ENVI 5.3 software to process the MODIS imagery. However, in order to prepare unprocessed MODIS satellite images for analysis, they must firstly be converted into ENVI format. This was done using the MODIS Conversion Tool Kit.

\section{Modeling process}

This section describes the modeling process, specifically the application of TOPSIS for scheduling and prioritizing the cities for urban development (Figure 3). First, a medium-resolution Landsat-8 satellite image from the study area was acquired and preprocessed. Then, the image was segmented using a multiresolution segmentation algorithm and classified into several classes using object-based image classification. The multiresolution algorithm has three main parameters, namely, scale, shape, and compactness. Since these parameters are data and application dependent, in this study, we had to select them empirically via trial and error. This meant that the best values were determined via visual examination of the segmentation results. After the segmentation process, several attributes were selected and used as class predictors in the classification algorithm. From the spectral attributes, the five bands of the Landsat- 8 image were selected. For spatial attributes, shape index, roundness, compactness, and density were used $[29,30]$. In the classification step, the support vector

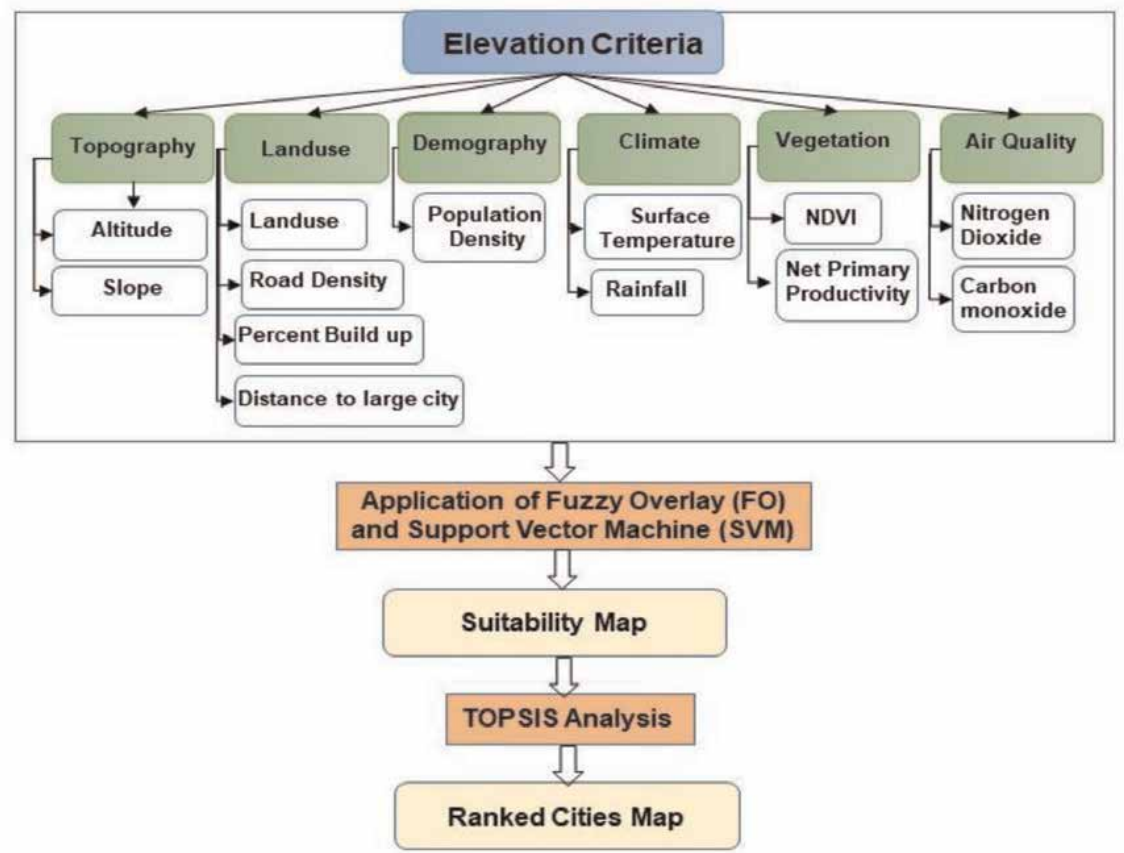

Figure 3.

Flowchart of the methodology implemented in this study. 
machine (SVM) algorithm was used. Although the SVM is a relatively simple binary classifier, it has very good generalization capabilities if properly trained [31, 32].

Several other digital data such as DEM and population density were also obtained from various online sources. The factors used as described in the previous section are widely reported in the literature for selecting urban projects or relevant projects. Fuzzy overlay (FO) analysis was carried out to determine the importance of each parameter to achieving the goal of the study. The SVM classifier was further applied to refine the results obtained from the FO model. Finally, the cities were sorted according to their importance by applying the TOPSIS model on the results of the SVM.

\subsection{Fuzzy overlay and TOPSIS models}

Fuzzy overlay analysis is based on the fuzzy set theory that relies on membership relationship of events to define specific sets or classes [33]. Operationally, FO is similar to overlay analysis but differs in the reclassified values and results from the combination of multiple criteria. It involves problem definition, partitioning into sub-models and determining the significant layers. FO transforms the data to a common scale and defines the likelihood of the data belonging to a specific class, for example, slope values being transformed into the probability of fitting into the favorable suitability set based on a scale of 0 to 1 , expressed in terms of membership [34]. Input raster are not weighted in FO since the transformed values indicate the possibility of membership rather than using ratio scale as with weighted overlay and weighted sum. The equation using fuzzy Gaussian function can be given as [35]

$$
\mu(x)=e^{-f_{i}^{*\left(x-f_{2}\right)^{2}}}
$$

The inputs $f_{i}$ and $f_{2}$ are the spread and the midpoint, respectively. Midpoint can be a user-defined value with a fuzzy membership of 1 . The default is the midpoint of the range of values of the input raster. Spread defines the membership of the Gaussian function. It generally ranges from 0.01 to 1 . Increasing the spread causes the fuzzy membership curve to become steeper. Fuzzy overlay analysis quantifies the possibilities of each cell or location to a specified set based on membership value.

As previously mentioned, the results of FO are refined using the SVM, which develops a linear regression between suitability status and criteria factors. SVM aims to determine an optimal separating hyperplane (maximizing the margin width) between two classes in feature space [36]. The training points near the hyperplane are called support vectors and are utilized for classification once the decision line/surface is obtained. The separating hyperplane is found as follows:

$$
y_{i}\left(w \times x_{i}+b\right) \geq 1-\varepsilon_{i}
$$

where $w$ is the cofficienct vector that defines the hyperplane orientation in the feature space, $b$ is the offset of the hyperplane from the origin, and $\varepsilon_{i}$ is the positive slack variables. The optimal hyperplane is found by solving the following optimization problem $[36,37]$ :

$$
\begin{gathered}
\operatorname{Minimize} \sum_{i=1}^{n} \alpha_{i}-\frac{1}{2} \sum_{i=1}^{n} \sum_{j=1}^{n} \alpha_{i} \alpha_{j} y_{i} y_{j}\left(x_{i} x_{j}\right) \\
\text { subject } \sum_{i=1}^{n} \alpha_{i} y_{i}=0,0 \leq \alpha_{i} \leq C
\end{gathered}
$$


where $\alpha_{i}$ is the Lagrange multiplier and $C$ is the penalty for data classification. The following decision function is applied as follows:

$$
g(x)=\operatorname{sign}
$$

Developed in [38-40], TOPSIS is a multi-criteria decision tool based on the intuition that a selected alternative has the shortest possible geometric distance from the PIS. In other words, the alternative has the longest geometric distance from the NIS [41]. The analysis compares a set of alternatives by assigning weightage to each criterion to compute the geometric distance between possible alternatives to determine the ideal alternative based on the assumption that the criteria uniformly increases or decreases. TOPSIS allows trade-offs between criteria; a poor result in one criterion can be compensated by a good result in another criterion. TOPSIS provides a more realistic model than non-compensatory methods by including or excluding alternative solutions using hard cutoffs. Consider $X_{i j}$ as the inputs for matrix of priorities where there are $i=1, \ldots, m$ alternatives and $j=1, \ldots, n$ criteria. There are six steps associated with the implementation of TOPSIS as follows [42]:

Step 1: Construct the normalized decision matrix calculated using Eq. (6):

$$
r_{i j}=\frac{x_{i j}}{\sqrt{\sum_{i=1}^{m} \sum_{j=1}^{n} x_{i j}^{2}}}
$$

Step 2: Construct the weighted normalized decision matrix using Eq. (7):

$$
v_{i j}=w_{i} r_{i j}, i=1, \ldots, m j=1, \ldots, n
$$

Step 3: The positive and negative ideal solutions are determined by

$$
\begin{aligned}
& A^{+}=\left\{v_{1}^{+}, \ldots, v_{n}^{+}\right\}, \text {where } v_{j}^{+}=\left\{\max \left(v_{i j}\right) \text { if } j \in J ; \min \left(v_{i j}\right) \text { if } j \in J^{\prime}\right\} \\
& A^{-}=\left\{v_{1}^{-}, \ldots, v_{n}^{-}\right\}, \text {where } v_{j}^{*}=\left\{\min \left(v_{i j}\right) \text { if } j \in J ; \min \left(v_{i j}\right) \text { if } j \in J^{\prime}\right\}
\end{aligned}
$$

Step 4: Calculation of separation (positive and negative) measurement using Euclidean distance. Eq. (9) is used to calculate the distance.

$$
S_{i}^{+}=\sqrt{\sum_{j=1}^{n}\left(v_{j}^{+}-v_{i j}\right)^{2}}, S_{i}^{-}=\sqrt{\sum_{j=1}^{n}\left(v_{j}^{-}-v_{i j}\right)^{2},} i=1, \ldots, m
$$

Step 5: Closeness to the ideal solution is calculated using Eq. (10):

$$
C_{i}^{+}=\frac{S_{i}^{-}}{S_{i}^{-}+S_{i}^{+}}, 0<C_{I}^{+}<1, i=1, \ldots, m
$$

Step 6: Ranking alternatives based on closeness to the ideal solution. TOPSIS has been used in different circumstances (e.g., individual and grouping). By applying the TOPSIS model using the results of the FO as input, the cities were sorted according to their importance for proposed urban development projects.

\section{Results and discussion}

According to [43], the most contributing factors to urban suitability are topography, land use and infrastructure, vegetation, demography and climate, and air 
quality. Therefore, these factors should be thoroughly analyzed to discover the most (and the least) suitable area for urbanization. Hence, in this work, 17 detailed factors were analyzed in order to rank each's importance (via weight assignment) for the selection of a city (or cities) for sustainable urban development. Subsequently, a suitability map was generated based on the FO (Figure 4a) method. A continuous scale was used for suitability weightage, which ranges from 0 (less suitable) to 1 (highly suitable). From the generated map, areas indicated as most suitable are located in the northern parts, especially the areas surrounding Benghazi and the northern parts of Al Marj and Al Jabal Al Akhdar. Sole reliance on the generated map, however, does not help much in deciding city development prioritization. As a result, the map was further refined to make it much more distinct for decision-makers. To do this, the map was firstly reclassified into three categorical classes: (i) not suitable, (ii) less suitable, and (iii) highly suitable. This was done using the natural break classification method (Figure 4b) where several samples were selected from the not suitable and highly suitable areas (results of FO) to generate training and testing data. These datasets were then used to train a SVM to classify between the two classes. Table 3 presents the estimated factors and their coefficients. The result indicates that land use, distance to primary route,
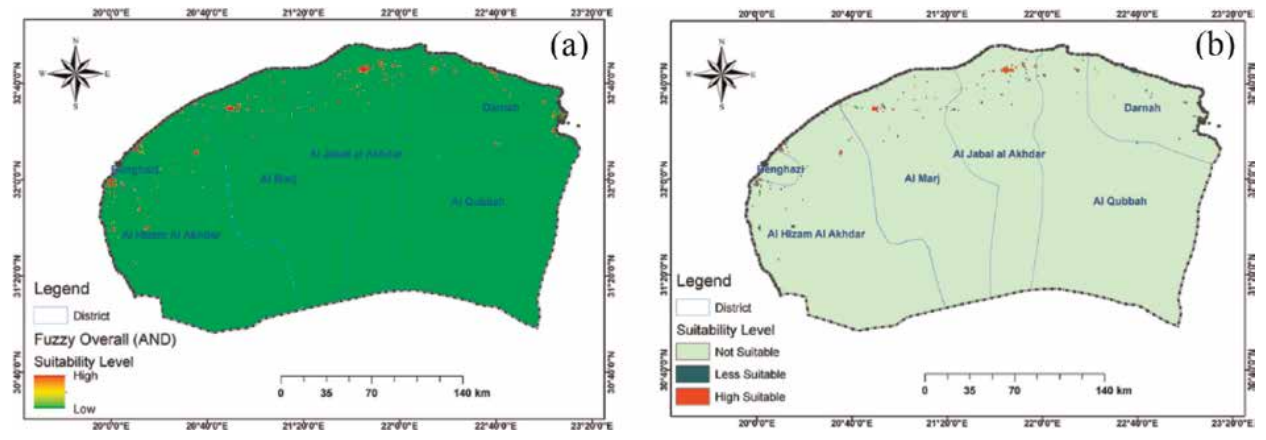

Figure 4.

Results of fuzzy overlay in (a) continuous scale and (b) categorical format.

\begin{tabular}{lcc}
\hline Evaluation criteria & SVM weight & Criteria code \\
\hline Land use & -0.36 & C12 \\
\hline Percent built-up area & 0.97 & C1 \\
\hline NDVI & 2.15 & C10 \\
\hline Altitude & 0.60 & C15 \\
\hline Slope & 0.96 & C7 \\
\hline Distance to primary route & -2.35 & C4 \\
\hline Distance to secondary route & 0.74 & C6 \\
\hline Distance to trail lines & 0.27 & $\mathrm{C} 8$ \\
\hline Distance to capital city & -0.62 & $\mathrm{C} 13$ \\
\hline Population density & 4.88 & $\mathrm{C} 3$ \\
\hline Rainfall & -1.17 & $\mathrm{C} 5$ \\
\hline LST & 0.23 & $\mathrm{C} 11$ \\
\hline NPP & -0.10 & $\mathrm{C} 2$ \\
\hline Carbon monoxide & 1.23 & $\mathrm{C} 14$ \\
\hline Nitrogen dioxide & -1.18 & $\mathrm{C} 9$ \\
\hline
\end{tabular}

Table 3.

List of criteria, estimated coefficient, and their code. 
distance to capital city, rainfall, NPP, and $\mathrm{NO}_{2}$ have negative effects on the suitability level of the selection process. The remaining factors have positive effects. Among the positive factors, population density has the highest effects on the selection process.

Based on the estimated coefficients, the suitability map in Figure 5 was produced. It can be seen that the map reflects the same thing as in the previous suitability map. However, it is clearly more informative for decision-makers. Based on this, the cities were ranked according to their importance using TOPSIS method.

\subsection{TOPSIS analysis}

Table 4 presents the positive ideal, negative ideal, closeness coefficient, and TOPSIS rank for each of the cities being analyzed. According to the closeness coefficients, the ranking order for the cities is as follows:

1. Benghazi

2. Al Jabal Al Akhdar

3. Al Marj

\section{Darnah}

\section{Al Hizam Al Akhdar}

\section{Al Qubbah}

The ranking results were then used to generate a map for final decision-making (Figure 6). Cities with green and light green colors are suggested to be prioritized first for development. More details about the TOPSIS analysis can be found in the Appendices.

Based on the results, the importance of each group of factors was evaluated (Figure 7). The bar chart shows the importance of the standardized factor weights

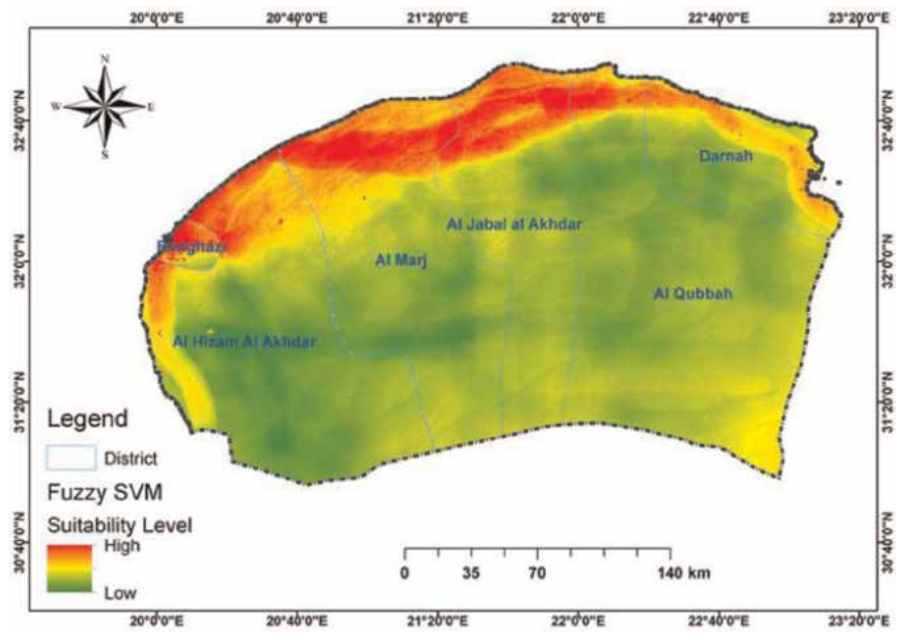

Figure 5 .

FO after refinement with SVM. 
Urban Planning Using a Geospatial Approach: A Case Study of Libya DOI: http://dx.doi.org/10.5772/intechopen.86355

\begin{tabular}{lcccc}
\hline City & A+ & A- & Closeness coefficient & TOPSIS rank \\
\hline Darnah & 2.58 & 1.41 & 0.35 & 4 \\
\hline Al Jabal Al Akhdar & 2.05 & 1.74 & 0.46 & 2 \\
\hline Benghazi & 0.98 & 3.40 & 0.77 & 1 \\
\hline Al Marj & 2.23 & 1.57 & 0.41 & 3 \\
\hline Al Qubbah & 3.13 & 1.08 & 0.25 & 6 \\
\hline Al Hizam Al Akhdar & 2.69 & 1.29 & 0.32 & 5 \\
\hline
\end{tabular}

Table 4.

Ranking of cities on the basis of importance for urban development.

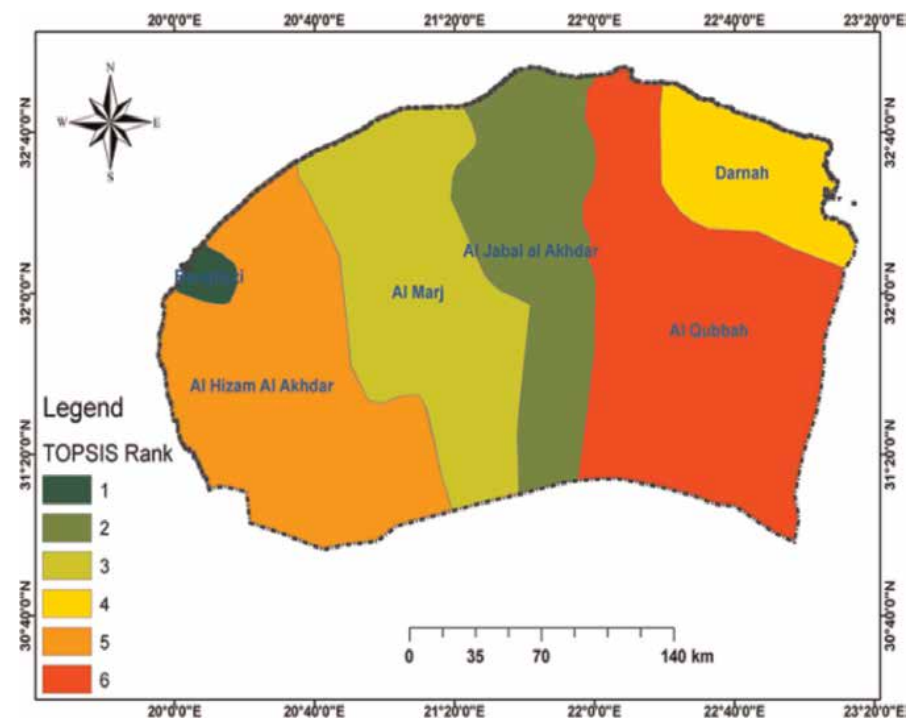

Figure 6.

The map showing the cities' ranks based on TOPSIS.

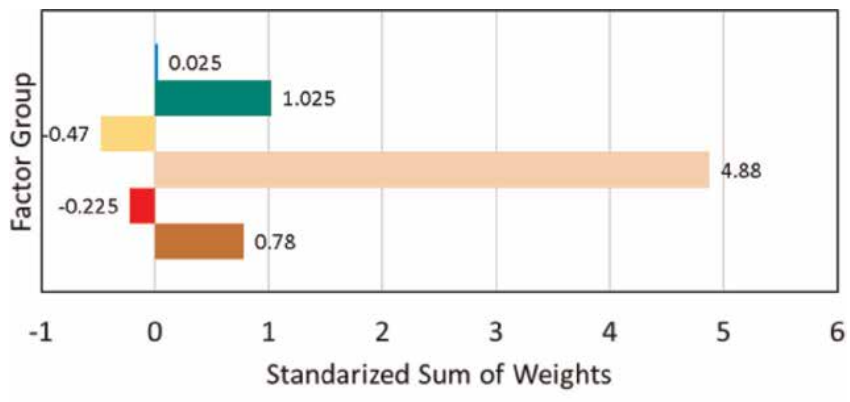

\begin{tabular}{|lc|}
\hline Air Quality & Vegetation \\
Climate & Demography \\
- Landuse and Infrastructure & "Topography \\
\hline
\end{tabular}

Figure 7.

Importance degree of factor groups. 
in each group. Demography and vegetation are the two most influential factors with positive contribution, followed by vegetation and topography. The other factors have negative contribution.

\subsection{Accuracy assessment}

Recall that the refined suitability map was recategorized into the three classes of "not suitable," "less suitable," and "highly suitable," These classes reflect the degree of urban development suitability in the study area. The categorized suitability map can be validated accurately through each class. The continuous refined is suitability map ranging from 0 to 1 . The most suitable areas that range from 0.751 to 1 fall into high suitable class, while the moderate suitable areas for urban development were extracted from 0.401 to 0.751 from the continuous refined suitability map.

\begin{tabular}{lc}
\hline Accuracy metric & Value \\
\hline Correctly classified instances & $1178(78.5 \%)$ \\
\hline Incorrectly classified instances & $322(21.4 \%)$ \\
\hline Kappa statistic & 0.67 \\
\hline
\end{tabular}

Table 5 .

Overall accuracy assessment of SVM modeling.

\begin{tabular}{lcc}
\hline Class & ROC area & PRC area \\
\hline Not suitable & 0.934 & 0.884 \\
\hline Less suitable & 0.799 & 0.60 \\
\hline High suitable & 0.852 & 0.673 \\
\hline Average & 0.861 & 0.719 \\
\hline
\end{tabular}

Table 6.

Accuracy assessment of SVM modeling based on ROC.

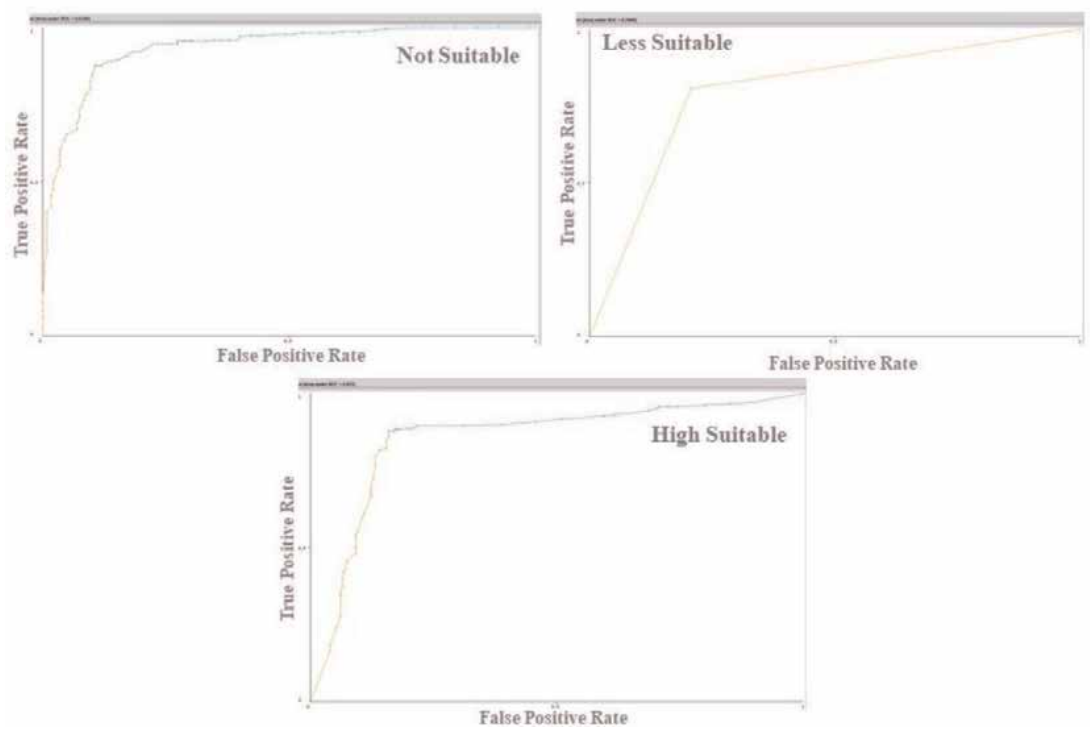

Figure 8.

AUC for the SVM. 
Consequently, the least feasible areas were classified out of 0.001 to 0.40 . The categorized suitability map was then validated based on the same randomly selected samples (Table 5). The SVM model accurately classified 1178 samples, which is about $78.5 \%$ of the total samples tested, which produced kappa index of 0.67 . The kappa index is calculated using Eq. (11) [44]:

$$
K=\frac{P_{C}-P_{\exp }}{1-P_{\exp }}
$$

where $P_{c}$ is the proportion of number of pixels that are correctly classified and is calculated as $\frac{(T P+T N)}{\text { totalnumberofpixels. }}$. $P_{\text {exp }}$ is the expected agreements and is calculated as $\frac{(T P+F N)(T P+F P)+(F P+T N)(F N+T N)}{\sqrt{\text { (totalnumberoftrainingpixels })}}$. Since both the "not suitable" and "highly suitable" classes are important for the final mapping and ranking of the cities, we also evaluated the results using the area under the ROC curve (Table 6), which gives an indication of the global statistical accuracy of the models. If the AUC, which varies from 0.5 to 1 , increases toward 1 , it indicates better performance prediction [45]. The highest and lowest success rates are 0.939 and 0.793 , while the highest and lowest prediction rates are 0.884 and 0.673 , respectively (Figure 8).

\section{Conclusion}

An automated geospatial solution for selecting and ranking cities in Libya for urban development is proposed in this chapter. The suitability map showed that most areas indicated to be suitable are in the northern part of Libya. The results indicate that land use, distance to primary route, distance to large city, rainfall, $\mathrm{NPP}$, and $\mathrm{NO}_{2}$ have negative effects on the level of suitability for the selection process, whereas the other factors have positive effects with population density taking the lead. It is revealed that SVM model accurately classifies 1178 samples, about $78.5 \%$ of the total samples tested which produced kappa statistic of 0.67 . The high-priority city was selected as Benghazi that is followed by Al Jabal Al Akhdar. The results suggest that demography and vegetation are the two most influential factors contributing to the selection of city for development in Libya. This study is limited to analysis of six cities; the procedure developed through this study can be extended to other cities. It is of the opinion that evaluated criteria can be adjusted according to the environment and the current development of the cities. 


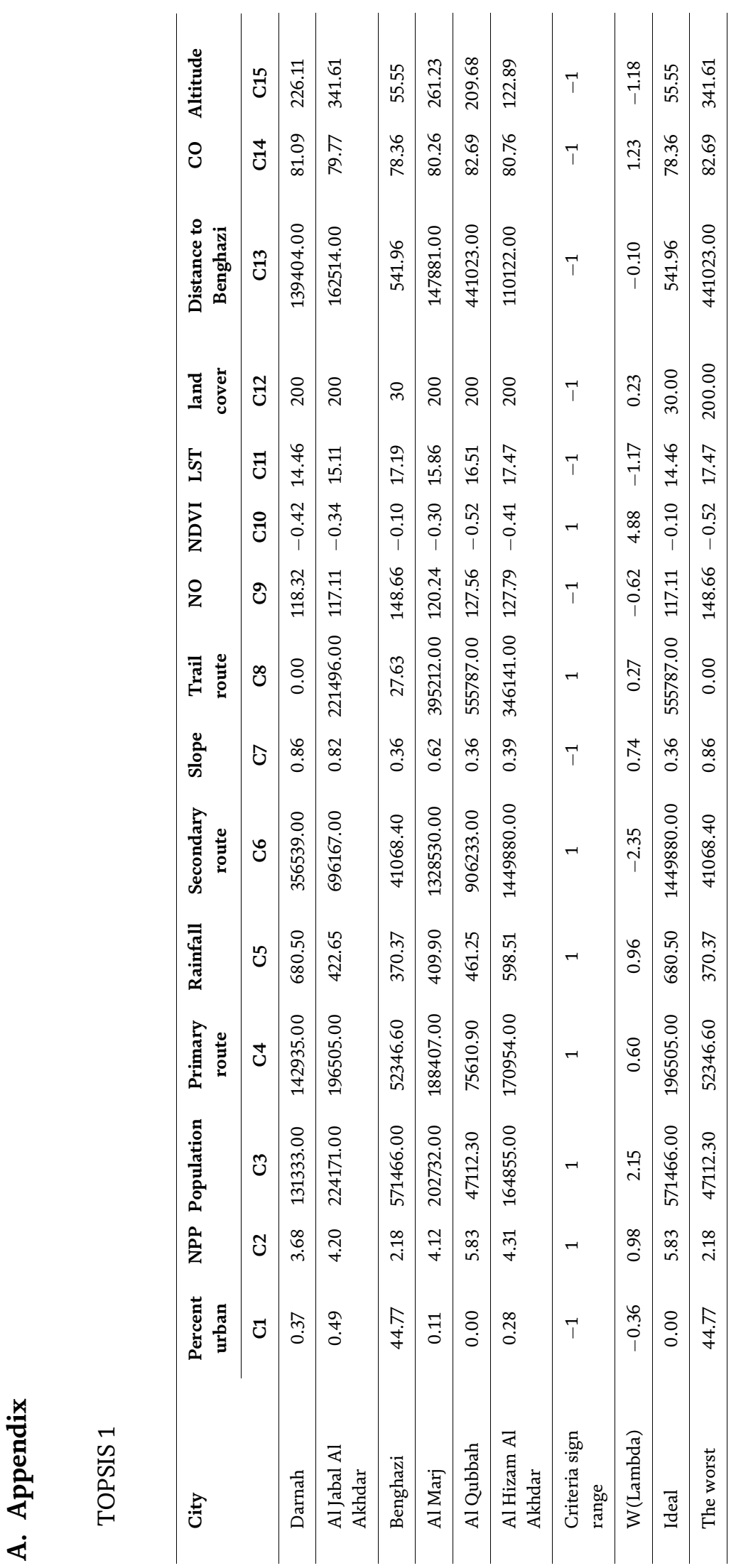




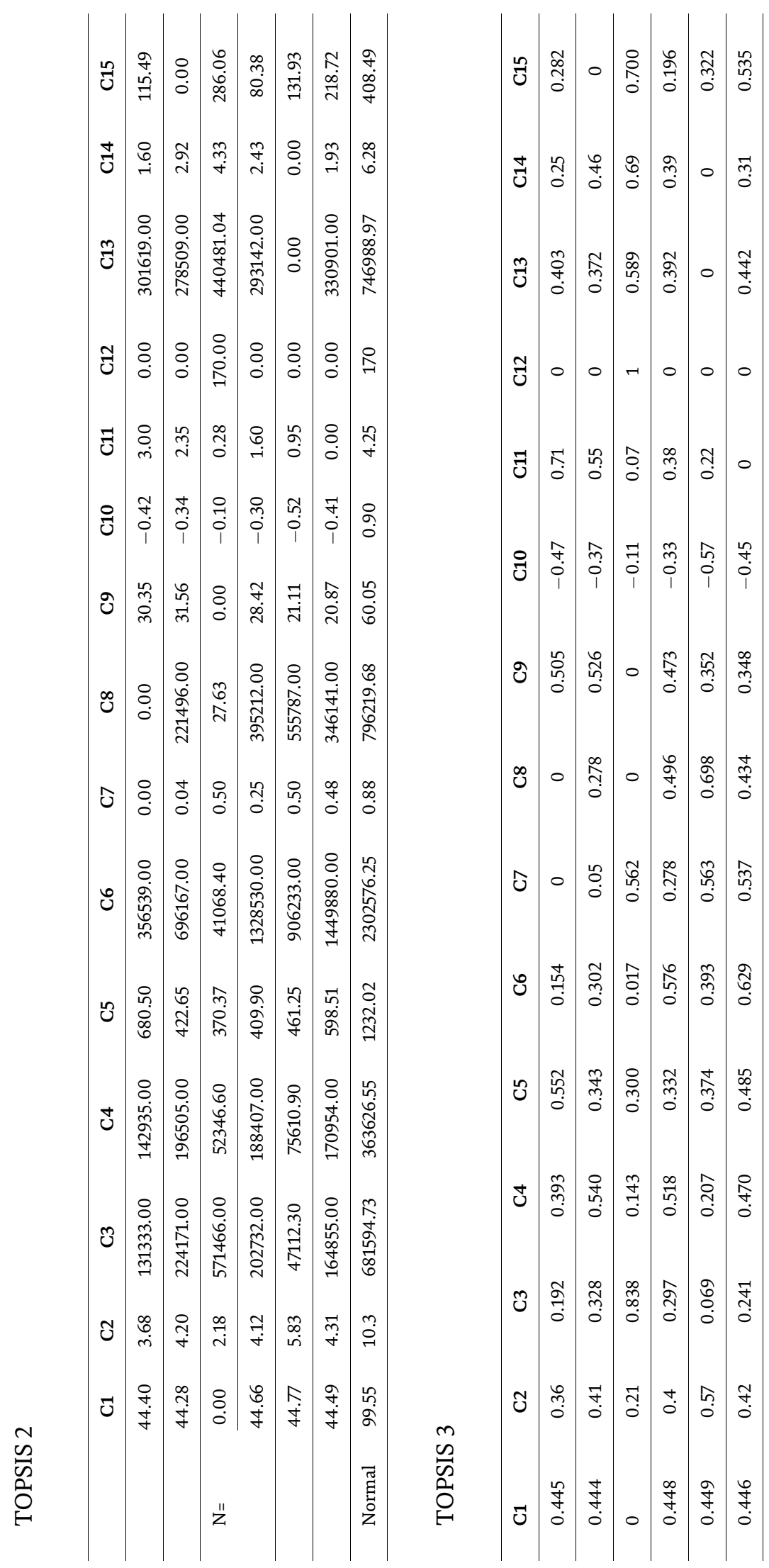




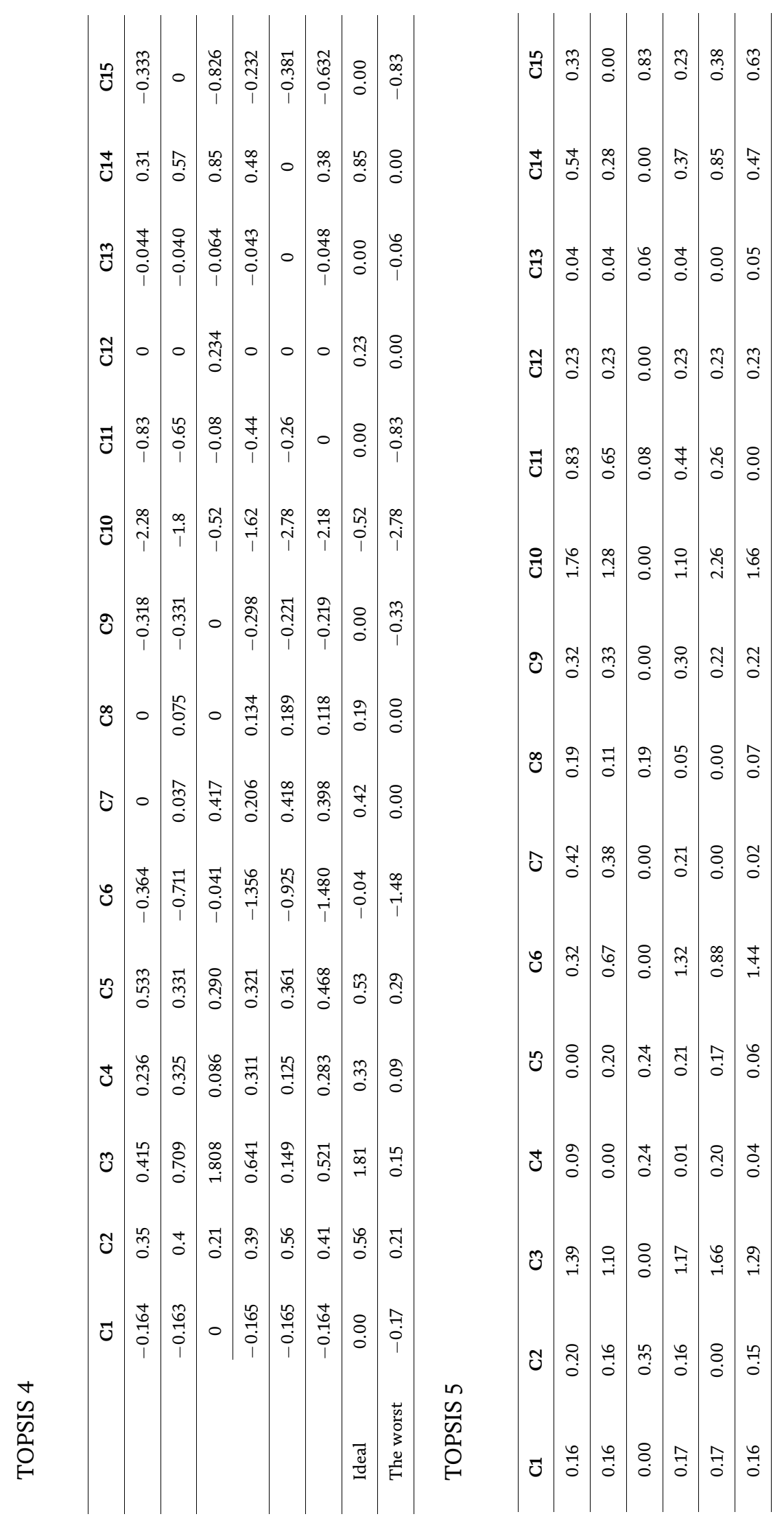




\section{Author details}

Bahareh Kalantar ${ }^{1 *}$, Husam A.H. Al-najjar ${ }^{2}$, Hossein Mojaddadi Rizeei ${ }^{2}$, Maruwan S.A.B. Amazeeq ${ }^{3}$, Mohammed Oludare Idrees ${ }^{3}$, Alfian Abdul Halin ${ }^{4}$ and Shattri Mansor ${ }^{3}$

1 RIKEN Center for Advanced Intelligence Project, Goal-Oriented Technology Research Group, Disaster Resilience Science Team, Tokyo, Japan

2 Centre for Advanced Modelling and Geospatial Information Systems (CAMGIS), Faculty of Engineering and IT, University of Technology Sydney, NSW, Australia

3 Department of Civil Engineering, Faculty of Engineering, Universiti Putra Malaysia, Serdang, Selangor, Malaysia

4 Department of Multimedia, Faculty of Computer Science and Information Technology, Universiti Putra Malaysia, Serdang, Selangor, Malaysia

*Address all correspondence to: bahareh.kalantar@riken.jp

\section{IntechOpen}

(C) 2019 The Author(s). Licensee IntechOpen. This chapter is distributed under the terms of the Creative Commons Attribution License (http://creativecommons.org/licenses/ by/3.0), which permits unrestricted use, distribution, and reproduction in any medium, provided the original work is properly cited. (c) BY 


\section{References}

[1] Juan YK, Roper KO, CastroLacouture D, Ha Kim J. Optimal decision making on urban renewal projects. Management Decision. 2010; 48(2):207-224

[2] Coutinho-Rodrigues J, Simão A, Antunes CH. A GIS-based multicriteria spatial decision support system for planning urban infrastructures. Decision Support Systems. 2011;51(3): 720-726

[3] Mukherjee AB, Krishna AP, Patel N. Application of remote sensing technology, GIS and AHP-TOPSIS model to quantify urban landscape vulnerability to land use transformation. In: Information and Communication Technology for Sustainable Development. Singapore: Springer; 2018. pp. 31-40

[4] Donnay JP, Barnsley MJ, Longley PA, editors. Remote Sensing and Urban Analysis. London: Taylor and Francis; 2001. pp. 3-18

[5] Harris PM, Ventura SJ. The integration of geographic data with remotely sensed imagery to improve classification in an urban area. Photogrammetric Engineering and Remote Sensing. 1995;61(8):993-998

[6] Gandibleux X, editor. Multiple Criteria Optimization: State of the Art Annotated Bibliographic Surveys. Springer Science \& Business Media; 2006;52

[7] Vafaeipour M, Zolfani SH, Varzandeh MHM, Derakhti A, Eshkalag MK. Assessment of regions priority for implementation of solar projects in Iran: New application of a hybrid multicriteria decision making approach. Energy Conversion and Management. 2014;86:653-663

[8] Wang YJ. A fuzzy multi-criteria decision-making model based on simple additive weighting method and relative preference relation. Applied Soft Computing. 2015;30:412-420

[9] Mosadeghi R, Warnken J, Tomlinson $\mathrm{R}$, Mirfenderesk H. Comparison of Fuzzy-AHP and AHP in a spatial multicriteria decision making model for urban land-use planning. Computers, Environment and Urban Systems. 2015; 49:54-65

[10] Abidin MZ, Rusli R, Shariff AM. Technique for Order Performance by Similarity to Ideal Solution (TOPSIS)entropy methodology for inherent safety design decision making tool. Procedia Engineering. 2016;148: 1043-1050

[11] Zarghami M, Szidarovszky F, Ardakanian R. A fuzzy-stochastic OWA model for robust multi-criteria decision making. Fuzzy Optimization and Decision Making. 2008;7(1):1-15

[12] Zhang K, Achari G. Uncertainty propagation in environmental decision making using random sets. Procedia Environmental Sciences. 2010; 2:576-584

[13] Mosadeghi R, Warnken J, Tomlinson R, Mirfenderesk $\mathrm{H}$. Uncertainty analysis in the application of multi-criteria decision-making methods in Australian strategic environmental decisions. Journal of Environmental Planning and Management. 2013;56(8):1097-1124

[14] Montgomery B, Dragićević S, Dujmović J, Schmidt M. A GIS-based Logic Scoring of Preference method for evaluation of land capability and suitability for agriculture. Computers and Electronics in Agriculture. 2016; 124:340-353

[15] Yoon K, Hwang CL. Manufacturing plant location analysis by multiple 
attribute decision making: Part I - Single-plant strategy. International Journal of Production Research. 1985; 23(2):345-359

[16] Awasthi A, Chauhan SS, Omrani H. Application of fuzzy TOPSIS in evaluating sustainable transportation systems. Expert Systems with Applications. 2011;38:12270-12280

[17] Uysal F, Tosun Ö. Fuzzy TOPSISbased computerized maintenance management system selection. Journal of Manufacturing Technology Management. 2012;23(2):212-228

[18] Momeni M, Fathi MR, Zarchi MK, Azizollahi S. A fuzzy TOPSIS-based approach to maintenance strategy selection: A case study. Middle-East Journal of Scientific Research. 2011; 8(3):699-706

[19] Baysal ME, Kaya İ, Kahraman C, Sarucan A, Engin O. A two phased fuzzy methodology for selection among municipal projects. Technological and Economic Development of Economy. 2015;21(3):405-422

[20] Shelton J, Medina M. Integrated multiple-criteria decision-making method to prioritize transportation projects. Transportation Research Record: Journal of the Transportation Research Board. 2010;2174:51-57

[21] Ageena IS. Trends and patterns in the climate of Libya. Thesis submitted in accordance with the requirements of the University of Liverpool for the degree of Doctor of Philosophy. 2013

[22] Mojaddadi Rizeei H, Pradhan B, Saharkhiz MA. Urban object extraction using Dempster Shafer feature-based image analysis from worldview-3 satellite imagery. International Journal of Remote Sensing. 2019;40(3):1092-1119

[23] Kia MB, Pirasteh S, Pradhan B, Mahmud AR, Sulaiman WNA, Moradi A. An artificial neural network model for flood simulation using GIS: Johor River Basin, Malaysia. Environmental Earth Sciences. 2012; 67(1):251-264

[24] Aal-shamkhi AD, Mojaddadi H, Pradhan B, Abdullahi S. Extraction and modeling of urban sprawl development in Karbala City using VHR satellite imagery. In: Spatial Modeling and Assessment of Urban Form. Cham: Springer; 2017. pp. 281-296

[25] Bhatti SS, Tripathi NK. Built-up area extraction using Landsat 8 OLI imagery. GIScience \& Remote Sensing. 2014; 51(4):445-467. DOI: $10.1080 /$ 15481603.2014.939539

[26] Miscellaneous Indices Background. Normalized Difference Built-Up Index (NDBI). Harris Geospatial Solutions. URL: Available from: http://www.ha rrisgeospatial.com/docs/Background OtherIndices.html [Accessed: 27 January 2016]

[27] Zha Y, Gao J, Ni S. Use of normalized difference built-up index in automatically mapping urban areas from TM imagery. International Journal of Remote Sensing. 2003;24(3):583-594

[28] Yang L, Xian G, Klaver JM, Deal B. Urban land-cover change detection through sub-pixel imperviousness mapping using remotely sensed data. Photogrammetric Engineering \& Remote Sensing. 2003;69(9): 1003-1010. DOI: $10.14358 /$ PERS.69.9.1003

[29] Kalantar B, Mansor SB, Shafri HZM, Halin AA. Integration of Template Matching and Object-based Image Analysis for Semi-automatic Oil Palm Tree Counting in UAV Images. In The 37th Asian Conference on Remote

Sensing. 2017

[30] Hamedianfar A, Barakat A, Gibril M. Large-scale urban mapping using integrated geographic objectbased image analysis and artificial bee 
colony optimization from worldview-3 data. International Journal of Remote Sensing. 2019;40(17):1-26

[31] Kalantar B, Mansor SB, Sameen MI, Pradhan B, Shafri HZ. Drone-based land-cover mapping using a fuzzy unordered rule induction algorithm integrated into object-based image analysis. International Journal of Remote Sensing. 2017;38(8-10): 2535-2556

[32] Al-Ruzouq R, Shanableh A, Gibril $\mathrm{BA}$, AL-Mansoori S. Image segmentation parameter selection and ant colony optimization for date palm tree detection and mapping from very-high-spatial-resolution aerial imagery. Remote Sensing. 2018;10(9): 1413

[33] Ahamed TN, Rao KG, Murthy JSR. GIS-based fuzzy membership model for crop-land suitability analysis.

Agricultural Systems. 2000;63(2):75-95

[34] Davis TJ, Keller CP. Modelling uncertainty in natural resource analysis using fuzzy sets and Monte Carlo simulation: Slope stability prediction. International Journal of Geographical Information Science. 2000;11(5): 409-434

[35] Baidya P, Chutia D, Sudhakar S, Goswami C, Goswami J, Saikhom V, et al. Effectiveness of fuzzy overlay function for multi-criteria spatial modeling-A case study on preparation of land resources map for Mawsynram Block of East Khasi Hills District of Meghalaya, India. Journal of Geographic Information System. 2014; 6(06):605

[36] Kalantar B, Pradhan B, Naghibi SA, Motevalli A, Mansor S. Assessment of the effects of training data selection on the landslide susceptibility mapping: A comparison between support vector machine (SVM), logistic regression (LR) and artificial neural networks
(ANN). Geomatics, Natural Hazards and Risk. 2018;9(1):49-69

[37] Pradhan B, Seeni MI, Kalantar B. Performance evaluation and sensitivity analysis of expert-based, statistical, machine learning, and hybrid models for producing landslide susceptibility maps. In: Laser Scanning Applications in Landslide Assessment. Champions: Springer; 2017. pp. 193-232

[38] Hwang CL, Yoon K. Methods for multiple attribute decision making. In: Multiple Attribute Decision Making. Berlin, Heidelberg: Springer; 1981. pp. 58-191

[39] Yoon K. A reconciliation among discrete compromise solutions. Journal of the Operational Research Society. 1987;38(3):277-286

[40] Hwang CL, Lai YJ, Liu TY. A new approach for multiple objective decision making. Computers \& Operations Research. 1993;20(8):889-899

[41] Ertuğrul İ, Karakaşoğlu N. Comparison of fuzzy AHP and fuzzy TOPSIS methods for facility location selection. The International Journal of Advanced Manufacturing Technology. 2008;39(7-8):783-795

[42] Seyedmohammadi J, Sarmadian F, Jafarzadeh AA, Ghorbani MA, Shahbazi F. Application of SAW, TOPSIS and fuzzy TOPSIS models in cultivation priority planning for maize, rapeseed and soybean crops. Geoderma. 2018; 310:178-190

[43] Abdullahi S, Pradhan B, Mojaddadi H. City compactness: Assessing the influence of the growth of residential land use. Journal of Urban Technology. 2018;25(1):21-46

[44] Bui DT, Pradhan B, Lofman O, Revhaug I, Dick OB. Spatial prediction of landslide hazards in Hoa Binh province (Vietnam): A comparative 
Urban Planning Using a Geospatial Approach: A Case Study of Libya DOI: http://dx.doi.org/10.5772/intechopen.86355

assessment of the efficacy of evidential belief functions and fuzzy logic models.

Catena; 2012;96:28-40

[45] Erener A, Düzgün HSB.

Improvement of statistical landslide susceptibility mapping by using spatial and global regression methods in the case of More and Romsdal (Norway).

Landslides. 2010;7(1):55-68 



\title{
Digital Urban Administration Model for a Traditional City (Case Study of Ibadan, Nigeria)
}

\author{
Oluseyi O. Fabiyi
}

\begin{abstract}
Urban administration has been a challenge in the developing economy especially in historical traditional settlements. Growth of these cities often outstrips the capacities of urban managers to administer urban systems coupled with the fact that developments in the older parts and new areas require different strategies. Therefore it is often recommended that digital technologies be adopted to enhance administration of old and new areas in urban settings. The chapter evaluated the challenges of urban administration in Ibadan city, Nigeria from colonial period to recent urban planning systems. It advanced a model of municipal administration in a digital platform for efficient management of Ibadan city. The model is also applicable to any similar cities in the developing economy. The model recommended a replacement paper and maps approach administration to digital approach. The chapter highlighted the deficiency of the current paper and map approach and advanced efficient approach through digital technologies.
\end{abstract}

Keywords: urban administration, spatial data infrastructures, traditional city, digital urban administration, urban systems, physical planning, data sharing

\section{Introduction}

The challenge of urban administration particularly in the traditional urban setting like Ibadan is huge as development of these cities is constrained by many factors. The growth of cities in most less-developed economy often outstrips the capacities of the urban managers [1], coupled with the fact that outdated methods are often used to govern urban areas. The city handlers struggle to manage traditional organic urban systems with very low resources and expertise [2]. Ibadan city had adopted different styles of urban administration ranging from crude traditional approach, colonial administration method, and current post independence arrangement (Fabiyi, 2017, 2006) [3]. During the pre-colonial era, Ibadan had different quarters that were guarded and administered by the warlords or chiefs. The quarter chiefs reported to the central warlord who was an army general or Bashorun, the ultimate ruler of the territory but the Army General of the Yoruba Kingdom. Ibadan remained the military camp of the defunct Oyo Empire until the arrival of colonial government in Nigeria. The institution of colonial administration converted Ibadan city to a district under the administration of a district officer. Later Ibadan city was under the administration of the Ibadan metropolitan authority, which 
superintended planning and urban administration activities in Ibadan city [3]. Under the 1976 Land use Act, the lands in the cities were put under the custodianship of the state executive governors while the custodianship of rural lands were under the control of the local government administration and the chairmen [4] (Fabiyi, 2006). The state governors combine the administration of the state with that of the capital cities, a responsibility that is considered to be too burdensome for a single administration. There were no mayoral platforms or municipal administration to superintend the management of the city. Later in 1991, Ibadan city was fractionated into 11 local government area councils, therefore putting the city under the control of 11 chairmen and Head of Local government Administration (HLA), each of whom controlled a fraction of the city.

The chapter examines issues around the implementation of digital urban administration in Ibadan and proposes a model for a robust digital urban administration in Ibadan city, Nigeria. It suggests organogram, technical arrangement, and training program to ensure successful implementation considering the low resources available for such activity in a developing country like Nigeria. It identified geo databases and Urban Spatial Data Infrastructure as ingredients in achieving sustainable digital urban administration in Ibadan or any similar organic city of a developing economy.

\section{Urban administration's historical antecedents in Ibadan city}

Urban administration according to Fabiyi (2017) is a branch of public administration designated for ordering, re-ordering, regulating, and controlling urban systems and urban land uses for the purpose of human comfort, convenience, urban esthetics or city's branding, and economic and environmental sustainability. Urban administration is quite different from land administration based on the unique pivotal focuses of urban administration, which are: human comfort, convenience, urban esthetics or city branding, and economic and environmental sustainability.

Ibadan had been an urban area before the Colonial Administration, therefore semblance of city administration in Ibadan has been in practice prior to the coming of colonial powers. Ibadan was a military camp of the Oyo Empire, which as governed by the military prowess of Basorun Ogunmola and other successive Generalissimo in the Yoruba empire that dominated major part of the west African subregion in the seventeenth century. During colonial administration government District Officer (DO) was appointed to administer Ibadan city and the authority span Town planning and Environmental health. Paper planning was also introduced by the colonial masters. The suburb in Ibadan known as Gbagi was derived from the establishment of survey beacons by the colonial government, which was known at that time as pegging, and this was the initial approach to introduce prepared plan before implementation on the ground.

Ibadan also benefitted from a different arrangement of urban administration since the colonial era was first introduced in Ibadan. The district officer of the colonial government was in charge of town administration including the health and building sectors. After independence in 1960, Ibadan was the capital city of Western Region and was under the jurisdiction of the regional government of the day.

The regional government established metropolitan authority to control the development of Ibadan city and in 1976, during the local government reforms, Ibadan was the capital of Oyo state and was also under metropolitan authority that was fully in-charge of building and land use zoning in the city. However, subsequent local government reforms during the military era saw Ibadan fractionated 
Figure 1 shows the location of Ibadan city with the 11 local government areas. Fabiyi [5] identified the partitioning of cities into diffesrent local government areas as a major setback to urban administration in Nigeria.

The reform therefore contributed to haphazard developments in Ibadan and limited the capacities of local planning authorities to direct and monitor the development of the city. The reform also brought some form of constraints to the development of Ibadan city. Some attempts to introduce wholistic urban administration in Ibadan was sustainable Ibadan Project (SIP) by UNHabitat in Nigeria. The project was sponsored by the UNHabitat and was one of the three cities in Nigeria selected for the project, which were Ibadan, Enugu, and Kano. The city has benefited different arrangement of the comprehensive Technology assisted city administration such as Ibadan Sustainable project under the auspices of UNDP Suitable city project in 1991.

The project introduced a number of novel initiatives to improve city administration in the ancient city, but was limited because the actors were not allowed to domesticate most of the novel initiatives of the project. After the expiration of the grant project, most of the database created disappeared and the knowledge base gradually filtered away from state service. There was no concrete sustainable plan by this project for continuous learning and transfer of knowledge to the coming generation of civil servants. There was no mechanism to replace or repair system breakdown and obsolete equipment.

There were also different donor-funded projects in Ibadan such as World Bank, UNDP, and DFID among others centered on improving the city management but the knowledge and the data generated often disappeared after the expiration of the project funds.

Ibadan Urban Flood Management Project (IUFMP) was established in 2014 through a credit facility from the World Bank group. The project was a direct response to 2011 flood disaster in Ibadan that carted away millions of Naira properties and damaged many urban infrastructures in Ibadan city. The main goal of the project was to build capacity of Oyo state to respond to incessant urban flooding in Ibadan city that has become persistent for long time. The project (IUFMP) developed a series of master plans, which include Ibadan City master

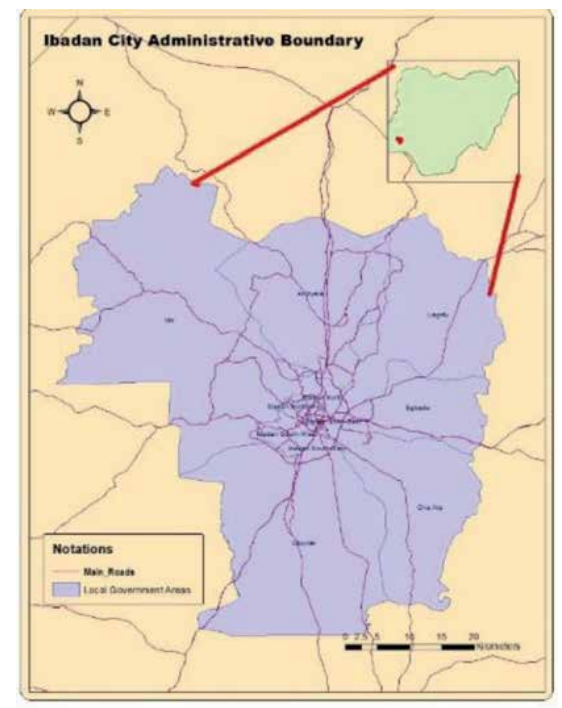

Figure 1.

Administrative map of Ibadan City (source: Author's compilation, Feb 2020). 
plan, Ibadan Flood Risk and Drainage Master Plan, Ibadan Solid waste Master plan, and Ibadan Flood Risks and Early Warning Systems apart from other structural engineering interventions. These instruments produced huge data sets in the spatial data dimension, which have the potential to kick start a holistic urban spatial data infrastructure to drive digital urban administration in Ibadan city. Urban administration in Nigeria has largely been analog and data management had been through paper/hard copy exchanges. Even in many large cities such as Abuja, Lagos, Porthacourt, and Ibadan, building permits are largely done through paper drawings and exchanges of papers. In 2004, digital urban GIS was popularized by Obasanjo Administration with Abuja GIS, which was meant to deliver a robust urban administration to the national capital city. Unfortunately, Abuja GIS promised so much but delivered so little in that it regressed to mere land administration tool that could not respond to the dynamics of the rapidly growing city. Some cities also attempted urban GIS for the purpose of land administration but the huge cost expended on most of these ventures is a far cry from the products and the benefits to the societies. The states that have attempted digital land administration in form of urban GIS include Nasarawa, Kaduna, Lagos, Kano, Kwara, and Rivers among others. It is expected that these attempts at city administrations will help introduce modern mechanisms to city management in such a way that many urban problems would go away; unfortunately, however the challenges are still much in those cities.

The closest to electronic urban administration in few Nigerian cities are land information systems often christened as Urban GIS. The popular Abuja GIS and the similar experiments in Kaduna, Nasarawa, and other states have concentrated on the property titles rather than a comprehensive urban administration through electronic means.

Oyo state government had through World Bank Credit facility developed a Comprehensive Ibadan City Master plan, which also produced a robust digital database of both the existing urban component and proposed development strategies to the year 2036. The digital spatial databases delivered with the development of city master plan provided a start off point to initiate a robust digital urban administration in the city.

\section{Need for digital urban administration in Ibadan: failure of paper administration}

There is rapid growth of population in Ibadan city; in fact it has been adjudged as one of the largest cities in Africa. However, the rapid population growth outpaced housing supply and services delivery in utilities and critical infrastructure. This is evident in the widespread sprawl and slum developments in Ibadan city. Fabiyi (2006) observed that informal sector was topmost among the land use change actors in the city. A number of authors have characterized Ibadan as a city of informal housing and virtual slum (Abumere, 1986; Fabiyi, 1999, 2006, 2016). The brown roof of Ibadan is a display of urban poverty, deteriorating infrastructure, and decrepit housing in this traditional organic city.

The agencies charged with regulating urban developments and housing sector are too overwhelmed to enforce discipline in housing sector and there are no decent alternatives to accommodate the growing poor population. The housing sector is a huge market for prospective investors but there is no reliable database that a rational investor can depend on to provide decent and affordable housing in the city. The growth of Ibadan city is predicated on the need to house the large but very poor population; therefore the city growth does not follow any predefined strategy 
of planned path and is not based on predefined strategic planning. Therefore, urban developments in Ibadan are mostly uncoordinated and unregulated, which make development of slum and squalor settlements common occurrence in most parts of the city. The activities of the land grabbers and unscrupulous land speculators do not encourage real investors in housing in Ibadan because land transactions in Ibadan are notably enshrined in duplicity and fraud. In addition, there are several regulations, laws, bylaws, and edits by the state that govern Urban land administrations but lead to overlaps of functions among states and local government agencies. The consequence is that none of the agencies have the defined operational boundary nor jurisdiction to ensure that the gaps are not exploited by the general public to embark on haphazard developments. The officers responsible for development control do not have the necessary infrastructure to monitor the emergence and ensure compliance of new development to necessary laws and codes in Ibadan central city and suburb.

Informal but spontaneous unplanned developments are very rampant in Ibadan city and make it difficult to provide utilities and infrastructure by agencies of government. The residents are saddled with the responsibility of providing access road, culverts and bridges, drainages and domestic water in their neighborhoods. The provision of these critical infrastructures in the informal and spontaneous residential areas is often in parlous condition and often done with substandard materials.

There are poor or nonexistent base mapping or requisite data for city administration; usually the zonal town planning offices that were expected to verify location of building plan from the office do not have any map to work with and often resort to guess work and local knowledge of the area to approve the building plans rather than use scientific and geospatial methods to verify the appropriateness of the building proposals.

Usually, cities in developed economies do not use prescriptive form of land use such as city master plan and strategic urban plan (see [6]), but rather use marketoriented spot zoning, which is more adaptive and can adjust to the dynamics of city growth and city housing market. The 25-year prescriptive master plan developed for Ibadan city in 2018 is not sensitive to the property market nor adjustable to the orientation of government policies. The plan was due for review and update just six month into the plan adoption.

The land tenure system in Ibadan is best described as chaotic and unregulated. These account for the development of squatter settlements and building in mostly undevelopable lands such as the flood plain and the rocky and inhabitable areas, abandoned sand mines, and under electric cables tension electric cables. Because the land tenure in these areas is not reliable, most developers often build structures that can easily be demolished and evacuated. Another major issue is that because more than $50 \%$ of buildings in Ibadan are from informal sector [7], it is difficult to use the planning and management principles used in the developed economies in Ibadan because the building ownership and characterizations are often different.

Urban administrators and city planners in Ibadan are often caught between two extremes of providing housing for teaming population of urban poor and to maintain efficient and esthetically pleasing city. Therefore, when buildings were marked for demolitions because of contravention of building code, they often refrain from outright demolition of property since there are no alternative accommodations for the building owner who may be too poor to gather resources together to build or hire decent accommodation in a new place.

There is no infrastructure to support digital urban administration in Ibadan city. There is also a barrier of low resources to procure GIS technology and lack of expertise to handle spatial data information in Ibadan city. Most of the civil servants that have acquired some form of training in GIS technology and other 
spatial information could not put the training to use because there is no equipment nor infrastructure to implement spatial data infrastructure. The political will of the government is weak toward the implementation of digital land administration. Effort has been directed toward revenue generation through property taxation and collection of dues from land transactions. Most of the time, the contracts for Urban GIS were awarded to foreign firms and add no value to local capacities. There is no effort to build local capacity of the civil servant to take charge of the land administration. This pointed to the fact that the land administration in the states where it is implemented is not sustainable because the civil servant in the mainstream line ministries is not integrated in the electronic land administration mechanism.

Oyo state also embarked on Oyo GIS, which is basically a land administration platform but the local content is at the pedestrian level, which was basically on data capturing. The civil servants were not trained on rudiments of database management and web applications.

Ibadan city is growing at unprecedented rate due to influx of people and businesses to the already expanding city through natural growth [8]. The influx of national government projects such as the dry port and the modern railway terminals will further accentuate the unprecedented growth of the city. The growth in population and the informal sector in the city further constraints the implementation of a robust urban administration.

The fragmentation of the city into different administrative apparatus in form of 11 local government administrations further makes holistic administration of the city more problematic.

The local government administrations in the 11 local government areas that make Ibadan city are weak and cannot tame the activities of unscrupulous developers in the city. Consequently, the city continues to grow in leaps and bounds but mainly as slums and deleterious housing with a lot of contraventions, contradictions, and infractions.

Just as roads and water pipe networks are critical for the development of the city, the digital urban administration (DUA) is critical for the overall development of a city. The government and the civil servant must see investment in DUA as the brick and mortar for good urban governance in Ibadan city.

\section{Challenges for implementing digital urban administration in Ibadan}

Implementation of Ibadan digital urban administration is constrained by a number of factors, some of which are enumerated as follows:

\subsection{Digital spatial data gap}

Data are critical to urban administration but the technology to support digital data is lacking in the city. There are also problems about the right digital technology, policies, and standards of the generation and the use of spatial data in Nigeria and particularly in Ibadan city. There is a need to acquire, process, and store all the requisite spatial data and distribute among the relevant ministries, department, and agencies (MDAs) and the general public for the purpose of aiding decisionmaking and attaining good governance. The integrity of the spatial data is also critical if a robust urban administration must be achieved in a low-resource city like Ibadan city. When data are shared across organization the integrity of the data may be compromised, the implementation of urban spatial data infrastructure requires the right firewall to prevent the hackers from having access to the 
centralized database, which in this context will enable the different users to have ready access to the servers.

Some agencies of government collect and archive large volumes of spatial data sets and map data but are basically in analog paper format. This accounts for the reason why data sharing among the MDAs is very problematic. There are no spatial data in digital form; most maps and drawings available in Ministry of Lands and Urban Planning are outdated and there are many missing data files in different parts of Ibadan. Unfortunately, the data are often classified and restricted access is only available to selected few members of the public and the line ministries, department, and agencies. To this end, it is difficult to share data among the agencies for decision-making.

\subsection{Poor or no spatial data policy}

Robust data policy is a major ingredient necessary for the implantation of the digital urban administration. Data policy relates to procedures for data collection, data analysis storage and exchange among the MDAs and the general public. It also relates to categorization of data to private and public. There is data hoarding among agencies and protectionism, which thrive in a data policy void that characterize the MDAs. The data policy is important to the distribution of data in this data-green environment. Another problem that militates against data sharing among the agencies of a government is that there is no framework nor policy for data sharing and data release to the public. Currently, Ibadan city has more than 300 layers of digital spatial data made available from different projects and data base creation.

\subsection{Low resources for digital overhaul of electronic spatial governance}

Oyo state is constrained by dwindling resources allocation from the central government and the internally generated revenue is also not encouraging; therefore, competing demand could not allow the state to deploy financial resources for urban administration. The collection of traffic and outdoor advertisement, which have been the primary source of IGR by the local government administration, have been taken over by the state administration in order to beef up revenue generation of the state. Consequently, it is very difficult for the local government administration to have resources to invest in data sharing among the local government. Digital overhaul of governance is often the last project on the list of priorities of government. The government of the state has been struggling to invest in IT and most especially the spatial data infrastructure because the investment outlay cannot guarantee immediate return on investment.

Though the production of Ibadan City master plans and Drainage master plans generated a lot of digital databases for urban administration, the government still needs to invest in ICT infrastructure to enable data sharing and data utilizations. Most of the MDAs are not connected with internet facilities. Therefore, there is need to invest in making internet facilities available to the relevant MDAs to ease the spatial data sharing among the staff.

\subsection{Lack of trained personnel}

The state and the local government administrations have aging personnel who are not conversant with modern technology. Digitization of few maps and documents are taking place in the survey department and physical planning. It is necessary to train the exiting staff in the relevant ministry on the spatial data management and specifically GIS in order to implement robust spatial data infrastructures. 
The training activities need to be carried out to encourage MDAs staff members to embrace the implementation of digital technology and abandon their various analog approaches to land management in different ministries.

The land use decree in Nigeria provided the custodianship of urban land on the governor of their respective state while the rural lands are basically under the purview of local government administration.

\subsection{Outdated equipment and low-capacity facilities}

Reproduction of maps is still done by ammonia printers while cadastral maps are still stored in hard copies. There was an improvement of carting cadasters in a paper-plaited board. Most of the equipment procured in the past were not maintained and they have gathered dust. Some of the computer systems used in the department have $500 \mathrm{Meg}$ RAM while some plotters are not functioning because the ink cartridges are out of stock.

\subsection{Property boundaries are poorly demarcated}

Many survey plans in the city have poor spatial accuracy, while some of them are fake and have no direct bearing to the land in question.

\section{Proposed model for digital urban administration in Ibadan city}

The proposed model for the digital urban administration in Ibadan city is a complete overhaul of the existing system where city administration was fragmented to 11 local government administrations. It is necessary to adopt a single administration body to regulate development activities in Ibadan city and ensure even and ordered development in the city. The model is presented in Figure 2.

Digital urban administration requires a very good spatial data infrastructure with a robust mechanism for data uptake and data sharing among different agencies charged with the responsibilities of regulating developments in the urban area There are four cardinal principles of municipal spatial data infrastructure according to the framework put forward by the World Bank in 2009. This is presented diagrammatically in Figure 2: the proposed Ibadan City Authority will be in charge of

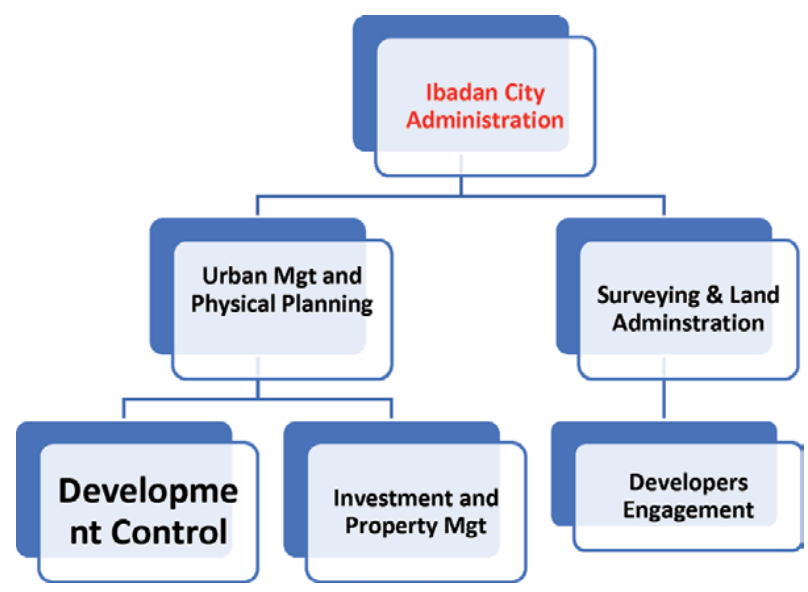

Figure 2.

Model for digital urban administration in Ibadan city (author's compilation). 
administrative structure of the city and will have a city manager who superintends all affairs of the authority.

There shall be two major departments, which include urban management and city planning that shall be in charge of urban infrastructure and physical planning for the city and surveying and land administration department that shall be responsible for land administration in the city.

The urban management and physical planning shall have two subunits including development control unit and investment and property management unit. The survey and land administration shall have a unit that interfaces with the developers in all land transactions and survey.

\subsection{The proposed data sharing platform for digital urban administration}

The model proposed is meant to connect data producing and data consuming agencies together. It is proposed that there should be data sharing arrangement among the ministries, department, and agencies involved in implementing digital urban administration in Ibadan city or any similar city that has traditional outlook. There are three major data nodes or what is referred to as data centers among the various ministries, one of them is the ICT that archives all the data sets and databases of the state and local government. The other node is the physical planning unit of the state that coordinates all the local governments including the 11 local government area councils that make the Ibadan city. The other data node is the surveyor general office that is in charge of land and property title administration of the city.

\subsubsection{Data sharing nodes for Ibadan digital urban administration}

These three data centers will interact with other clienteles on data sharing. The clienteles include the public and other relevant MDAs. For instance the physical planning unit will interact with the zonal town planning offices, which are located in the 11 local government council areas in Ibadan city. It is expected that computer systems and link node would be set up in each of the local council's areas so that they can be used to communicate with these. The Ministry of Land data center will communicate with surveyors' developers and property owners in the city as well as others who are involved in land transactions in the city. There is interconnectedness among these data centers, which will be facilitated by the SDI center or ICT center of the state. It is practically difficult to actualize digital urban administration without a robust urban spatial data infrastructure. USDI will facilitate the spatial data sharing among the organizations and agencies' nodes that are generating and using spatial data in the city. Figure 3 shows the diagrammatic linkages between of data sharing among the relevant MDAs for effective digital urban administration in Ibadan city. The figure shows that urban administration is not limited to land administration in urban area nor urban planning procedures but an amalgamation of several activities across multiple agencies and organizations.

\subsection{Configuration of data centers}

The configuration of each of the data node or data centers is in such a way that they will have public and private component of data archving location. It is expected that the data hubs will maintain their respective data clientiles and will contribute data to the main data center as well as supplying data to its respective consuers. The physical planning data center is patterned as shown in Figure 4. 


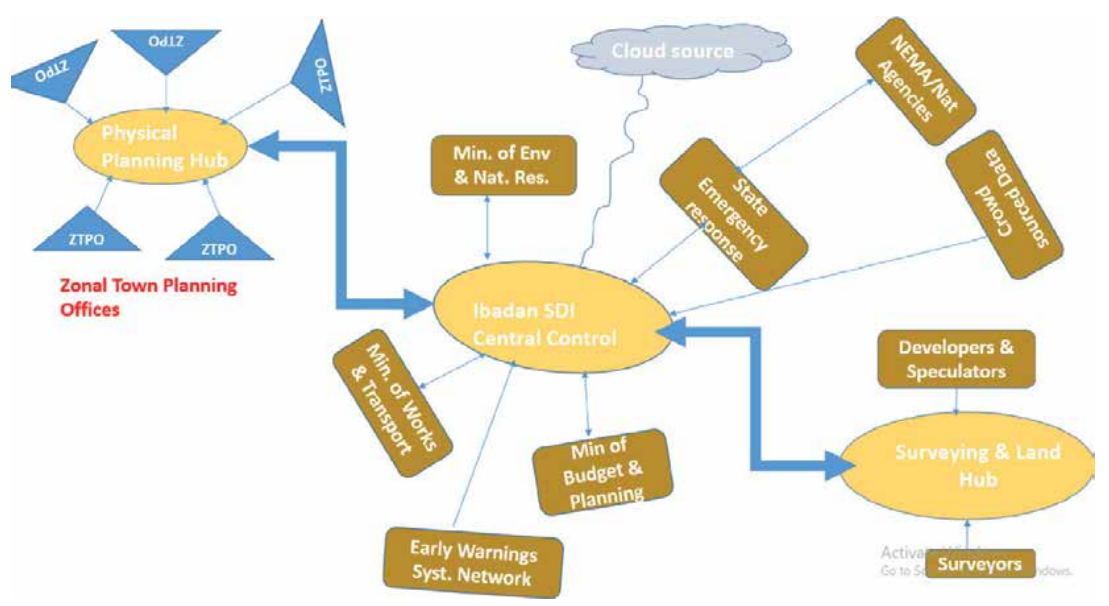

Figure 3.

Proposed urban digital data sharing among relevant stakeholders in Ibadan City (source: author's design, 2019).

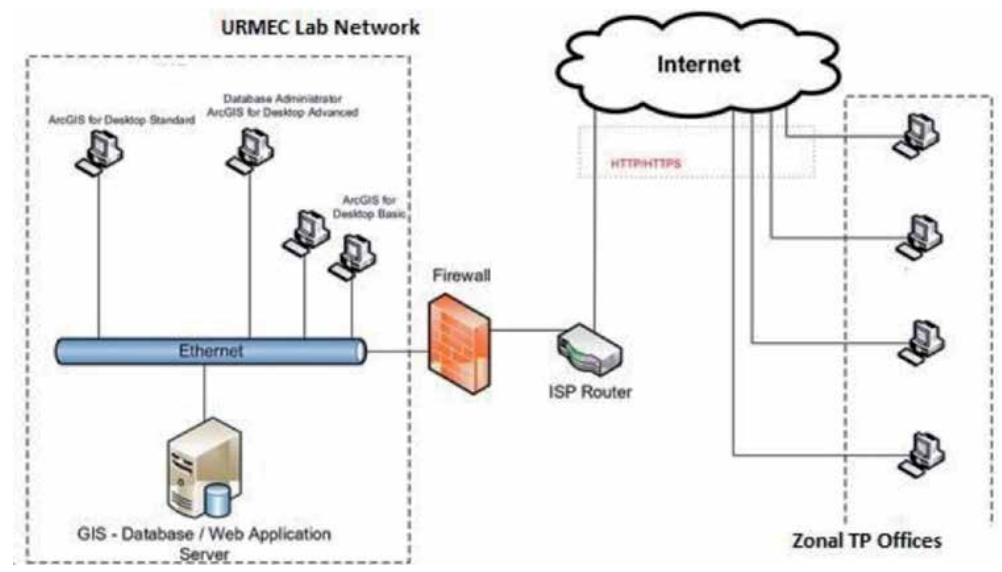

Figure 4.

Data sharing configuration with the physical planning network (source: author's design, 2019).

\subsubsection{Physical planning data center}

The physical planning data distribution configuration prescribes that data will be shared among the Zonal Town planning offices as these are the primary centres for building permits and approval. It is expected that land use plans are regularly developed by the Town Planning unit of the Ministry of Lands. The revised land use proposal plan is stored in the archives and is accessible to the zonal town planners to consult during the application process for building permit by the developers. When the applicant consults the zonal town planner for development activities, the town planners should have access to the updated version of the land use plan of the city to know the prescribed land use for the location. Access will be provided to the zonal Town Planner through security code to the server. When land use has been verified for the intended development and the permit has been granted, the planner should upload the document into the server for archiving georefrencing.

The data center will serve the zonal town planners and the general planners in the private sectors while the Surveyor General data hub will serve the 
developers and the general public that require information on land and land matters.

\subsubsection{Surveyor general office data center}

The configuration of the data center located at the office of the Surveyor General (SG) is indicated in Figure 5. The developers and practicing surveyors will have access to the data archive and also upload spatial data on land matters to the server at the SG office to the data.

The field surveyors will need to collects geodetic datasets from the surveyor general office before they complete their measurement. When the survey exercise is completed, they are expected to send a copy to the archive of the surveyor general for reference.

\subsection{Urban spatial data infrastructure: a major ingredient of digital urban administration}

Urban spatial data infrastructure refers to infrastructure that facilitates the discovery, access, management, distribution rescue, and preservation of digital geospatial resources for urban administration. Just as critical infrastructure such as water supplies and transportation networks among others are critical to the running of the city, the urban spatial data infrastructure is the fulcrum upon which digital urban administration revolves.

Urban spatial data infrastructure is the bedrock of modern urban administration and spatial database is the most critical part of the spatial data infrastructures. Ibadan city has a lot of spatial datasets, which are scattered in different agencies and departments, most of which are often duplicated. The agencies and department are not communicating as regards the spatial datasets while they often become obsolete before they are put to meaningful use. The need to implement digital data sharing arrangement among agencies of government therefore becomes imperative.

It is expected that there will be combined implementation of USDI and DUA together in Ibadan for good urban governance in the city.

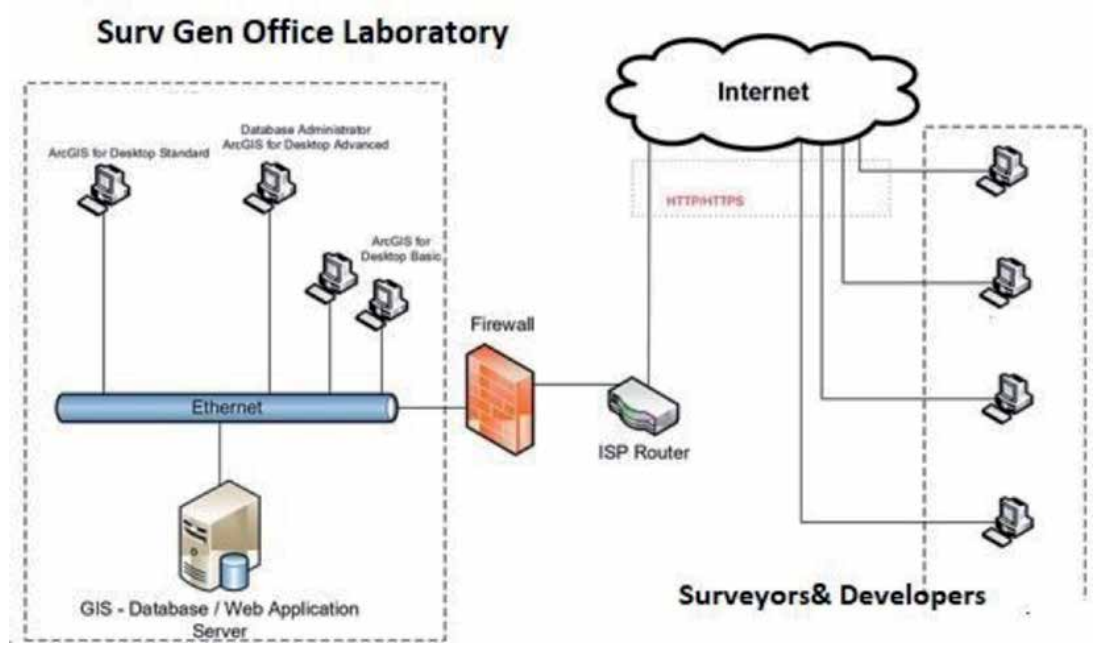

Figure 5.

Data Centre at the Surveying and Land Department (source: author's design, Oct 2019). 


\section{Concluding recommendations}

The rapid development in Ibadan city encourages influx of population into the city and spikes in the housing market. Therefore, it is unlikely that the prescriptive master plan will be able to accommodate the new requirements of the upsurge of the population. However, the spatial database generated by the master plan is a veritable instrument to review and rework the master plan to meet the day-to-day challenges of the city. Planners are overwhelmed and ill prepared to respond to the dynamics of the modern city. Therefore, the current planners need to be trained in modern technics of urban administration and electronic permit systems need to be introduced.

Several attempts were made to introduce urban GIS in Nigerian cities such as Abuja GIS, Lagos GIS, Nasarawa GIS and Kaduna GIS, among others. These attempts were to address land administration and issuance of property titles in cities. It would be expected that comprehensive city management will be possible through the GIS infrastructure put in place. However most of the urban GIS implemented in Nigeria had failed to deliver on holistic urban administration.

Urban spatial data infrastructure is the backbone of digital urban administration, Therefore it is necessary to put in place a robust spatial data infrastructure framework before the implementation of urban GIS. To do otherwise is like putting the cart before the horse. This explains the failure of most of the urban GIS projects in Nigeria.

The model of digital urban administration in Ibadan city requires certain ingredients to operate fully; these are highlighted in the following section.

Training of staff: The MDAs staff required training on the manipulation of data and data sharing in the digital platform. Both the decision-makers, decision uptaker, and the general public as well as data users across different departments in the ministry need training to uptake the digital infrastructure.

Internet connectivity: Internet connection is a major constraint in the developing countries. It is however necessary that the digital urban administration be provided with the internet connectivity for data sharing and data usage. While we proposed on-site data archiving, the trend in the digital community is cloud storage of data.

Sustained investment in technology: There is a need for consistent investment in technology to sustain the digital governance upon which the DUA will operate. What is required is more than one-off investment but a sustained and continuous investment in critical technologies, which will require updating old ones and acquiring new ones to replace obsolete hardware and software.

Change in orientation of key personnel: Paper and analog methods of urban administration have been in practice for long in Ibadan and this encourages unscrupulous practices among the actors in urban systems management. The use of digital urban administration will definitely expose these practices. Therefore, there is possibility of resistance from major players; however, a robust stakeholders' engagement and orientation will help them to embrace new technologies.

The proposed model is expected to ensure smooth implementation of digital urban administration in Ibadan city and can be used in any developing economy. It is meant to address major issues around urban governance in Ibadan city and any other cities with similar conditions. Most cities in less-developed countries need to adopt digital technologies in the management of the city if they want to promote smart cities agenda. There is growing need to achieve inclusive, safe, and resilient cities and the only route to this is to adopt technological innovation for urban management. 
Digital Urban Administration Model for a Traditional City (Case Study of Ibadan, Nigeria) DOI: http://dx.doi.org/10.5772/intechopen.92125

\section{Author details}

Oluseyi O. Fabiyi

Centre for Human Settlements and Sustainable Development, Abuja, Nigeria

*Address all correspondence to: seyifabiyi@yahoo.com

\section{IntechOpen}

(C) 2020 The Author(s). Licensee IntechOpen. This chapter is distributed under the terms of the Creative Commons Attribution License (http://creativecommons.org/licenses/ by/3.0), which permits unrestricted use, distribution, and reproduction in any medium, provided the original work is properly cited. (cc) BY 


\section{References}

[1] Yang X, Lo CP. Modelling urban growth and landscape changes in the Atlanta metropolitan area. International Journal of Geographical Information Science. 2003;17(5):463-488

[2] Oyesiku O. Town and Country Planning Law and Administration in Nigeria. Ibadan, Nigeria: Readings in Urban and Regional Planning Macmillan Nigeria Publishers Limited; 2004. pp. 481-520

[3] Mabogunje AL. Urbanization in Nigeria. UK: University of London Press; 1968. p. 353

[4] Adzandeh EA, Fabiyi OO, Bello YA. Statistical analysis of urban growth in Kano Metropolis, Nigeria. International Journal of Environmental Monitoring and Analysis. 2014;2(1):50-56

[5] Fabiyi OO. Urban space administration in Nigeria: Looking into tomorrow from yesterday. Urban Forum. 2016;28(2):45-68

[6] Wapwera S, Egbu C. Master planning system: Constraints for planning authorities in Jos Metropolis, Nigeria. The Built \& Human Environment Review. 2013;6:61

[7] Fabiyi OO. Analysis of changeagents in urban land use transition; example from Ibadan city, Nigeria. Journal of Environment and Culture. 2007;4(2):43-54

[8] Fabiyi OOJ. Comparative analysis of spatial extent and population sizes of cities in Nigeria: Implications for urban space administration. Journal of Historical Archaeology \& Anthropological Sciences. 2018;7(3):87-95 


\title{
The Rise and Decline of Car Use in Beijing and Shanghai
}

\author{
Yuan Gao, Peter Newman and Jeffrey Kenworthy
}

\begin{abstract}
Chinese cities have primarily evolved around walking, bicycling and public transport with their dense, linear form and mixed land use. The recent urban growth spurt has involved private motorisation, but because of land constraints and not fearing urban density, as in Anglo-Saxon cities, the same dense urbanism has been maintained. This means that automobiles do not easily fit into this traditional fabric and especially the historic walking fabric. Issues like congestion and air quality have become major constraints to further growth. Using Beijing and Shanghai as case studies, the next phase of urban and transport development now appears to be to reduce car use with the dramatic growth in urban rail as in most developed cities in the twenty-first century. This decoupling of car use from economic growth is consistent with other developed cities but is a first for emerging cities, hence the paper aims to explain this pattern from the cultural, political and especially urban fabric perspectives. The application to other Chinese cities and emerging cities is now possible following Beijing and Shanghai's lead.
\end{abstract}

Keywords: car use, rise and decline, urban form, economic factors, cultural and political factors, Beijing, Shanghai

\section{Introduction}

China has undergone rapid urban development with its national urbanisation rate surging from $10.6 \%$ in 1949 to $56.1 \%$ in 2015 [1]. As a result, urban population across the nation has increased by 10.81 million per annum in the period. Personal income, the principal economic driver of private vehicle ownership [2], has remained on a double-digit ${ }^{1}$ high-growth trajectory in most of China since 2001. Urban population growth and economic growth have thus led to growth in private ownership of passenger cars (see Figure 1). ${ }^{2}$ Besides these factors, administrative guidance and political imperatives have also significantly affected the level of automobile ownership in China [3]. However the question in this paper is whether car use is continuing to rise in key cities or whether it is following the trend in developed cities to decouple this from economic growth.

Chinese cities, along with their respective provinces, have increased in car ownership over recent years and now provincially range in car ownership from a meagre 70 per 1000 persons in Gansu up to 209 per 1000 in Beijing (2017 data), with a

\footnotetext{
$\overline{1}$ The growth rate of personal income was actually $8.8 \%$ in 2009.

2 It includes large, medium-, small- and mini-sized passenger cars.
} 


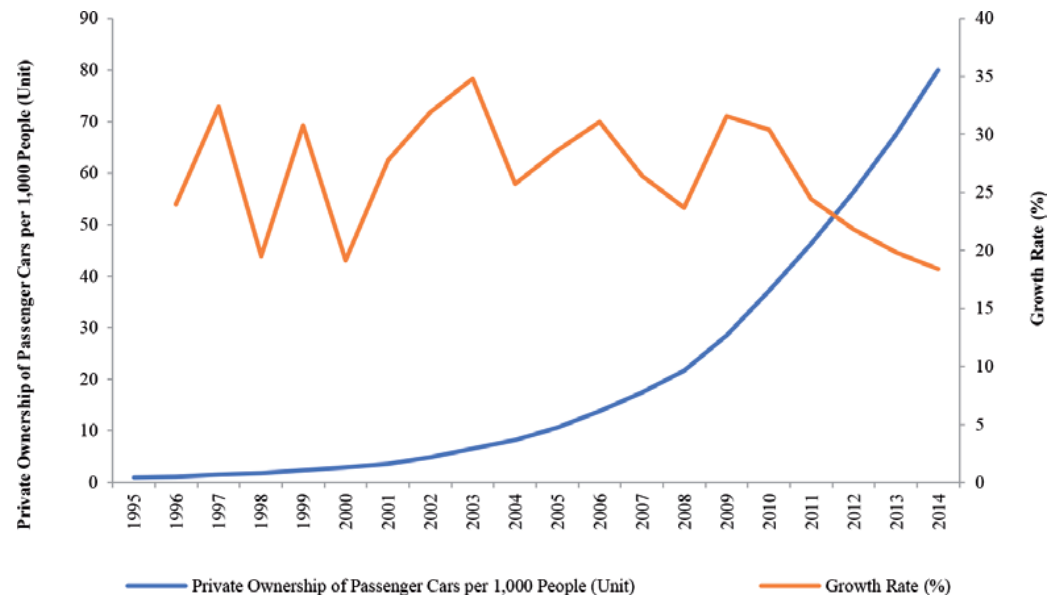

Figure 1.

Private ownership of passenger cars per 1000 people in China (unit) and its annual growth rate (\%) from 1995 to 2014. Source: Compiled based on data provided by [4].

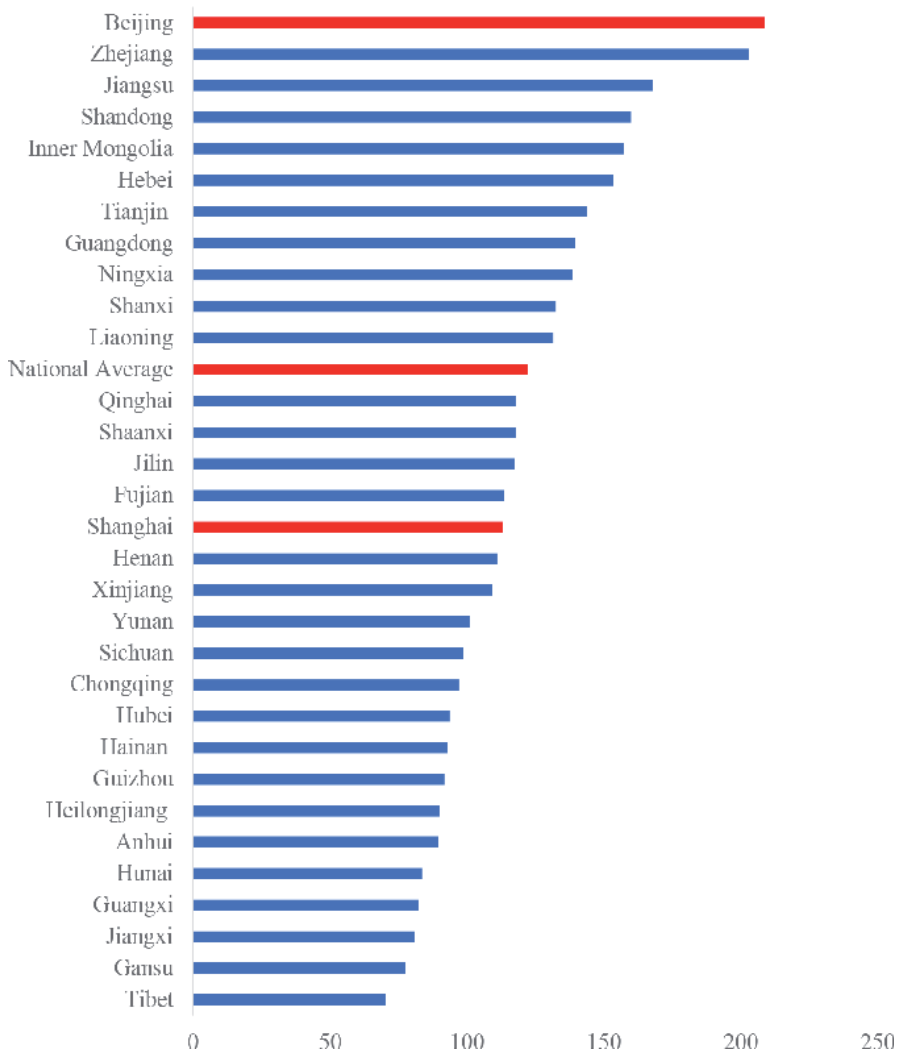

Figure 2.

Private ownership of passenger cars per 1000 people across China in 2017 (unit). Source: Compiled based on data provided by [7].

national average of 122 per 1000 persons (see Figure 2). ${ }^{3}$ This national level of car ownership is less than countries such as Swaziland, El Salvador, Honduras, Guyana and Azerbaijan [5]. These levels are nowhere near the car ownership levels found

\footnotetext{
${ }^{3}$ Beijing and Shanghai are two of the four municipalities directly under the central government. Hence, this comparison is made with other provinces rather than cities.
} 
in cities in more developed countries. For example, in 2005-2006, privately owned cars averaged 640, 647, 522 and 463 cars per 1000 persons in American, Australian, Canadian and European cities respectively [6]. Even between China's two most significant cities, Shanghai and Beijing, the difference is very large (113 compared to 209 cars per 1000 persons, respectively), partly due to Shanghai having implemented car management policies ${ }^{4}$ from 1994.

Thus Chinese provinces and cities, even during what could be called a rampant period of motorisation, had by 2017 not even come close to car ownership rates in more automobile-dependent regions and were even less nationally than in some significantly less developed countries.

Added to this perspective, we now find that recent car ownership growth rates are falling. The question to be addressed in this paper is therefore whether a decline in car use and a structural change is starting to occur in Beijing and Shanghai, like in many developed cities. The paper begins by examining some trends of car use in Beijing and Shanghai. It then tries to explain the reasons why car use is beginning to decline and why this could be happening at an earlier stage of economic development than in developed cities.

\section{The rise and decline of car use in Beijing and Shanghai}

\subsection{Beijing}

Beijing, like all Chinese cities, was dominated by bicycling in the twentieth century and as shown in Figure 3 had over 60\% of daily trips by cycling in 1986, but this quickly was overtaken by a rapid growth in car use; these modes crossed in 2005, and from there a different story emerges that would have been expected in a rapidly emerging global city. Car use begins to plateau in the 2000s and starts declining since 2011. The growth trajectory that then takes over is transit as cycling continues to fall but then plateaus or rises slightly perhaps due to e-bikes as seen in the data below on Shanghai.

The Beijing transit system is shown by mode in Figure 4. The dramatic growth after 2007 that has impacted so strongly on modal share with cars is the role of the metro that continues to grow significantly right through to the most recent data. Beijing was the first city in China to inaugurate metro rail into its transport infrastructure, with the first line opening in 1969 [9]. This development was further pursued and received a promotional boost leading up to the 2008 Olympic Games held in Beijing [10]. The metro has been expanded ever since and has been embraced by the residents of Beijing with a daily patronage of around 9 million using the fast, high-quality system. This follows the rapid expansion of Beijing's metro system from an operational length of $142 \mathrm{~km}$ in 2007 to $555 \mathrm{~km}$ by 2015. Beijing's metro is now the second largest after Shanghai $(588 \mathrm{~km})$ in China $[11,12]$. The metro has become a significant transport mode, though the traditional bus is still the predominant travel choice of public transport. As this is measured in boardings, it would be more favourable to the metro if passenger kilometres were used as bus trips tend to be shorter.

\subsection{Shanghai}

Shanghai transport data are different to Beijing as they include walking as well as e-bikes besides bicycling in the modal split as set out in Figure 5. But like

\footnotetext{
${ }^{4}$ Shanghai has adopted the Singapore-style paid auction system to limit new car registration since 1994. The number of quotas issued to public applicants is less than 10,000 every month. The average bid price soared up to 5040 US Dollars in 2008.
} 


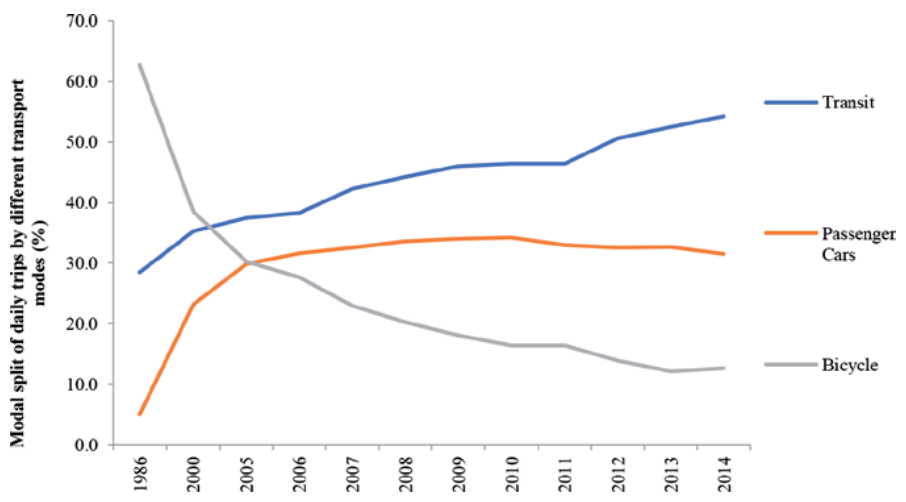

Figure 3.

Model split of daily trips (excluding walking) in Beijing (1986-2014) (\%). Source: Compiled based on data provided by [8].

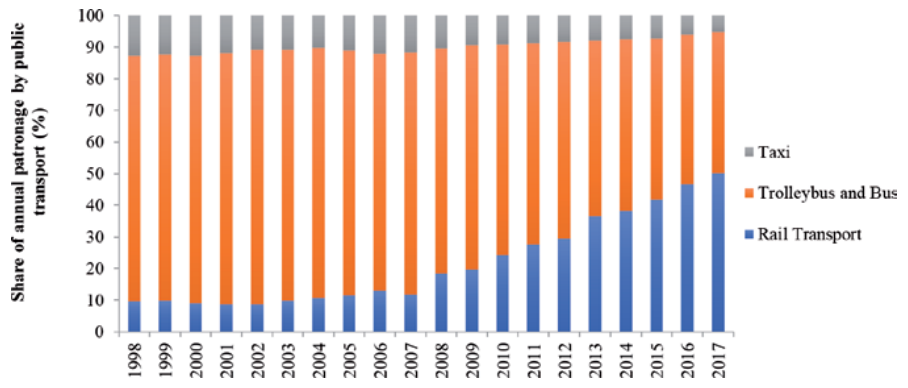

Figure 4 .

Share of annual patronage by different public transit modes in Beijing from 1998 to 2017(\%). Source: Compiled based on data provided by $[13,14]$.

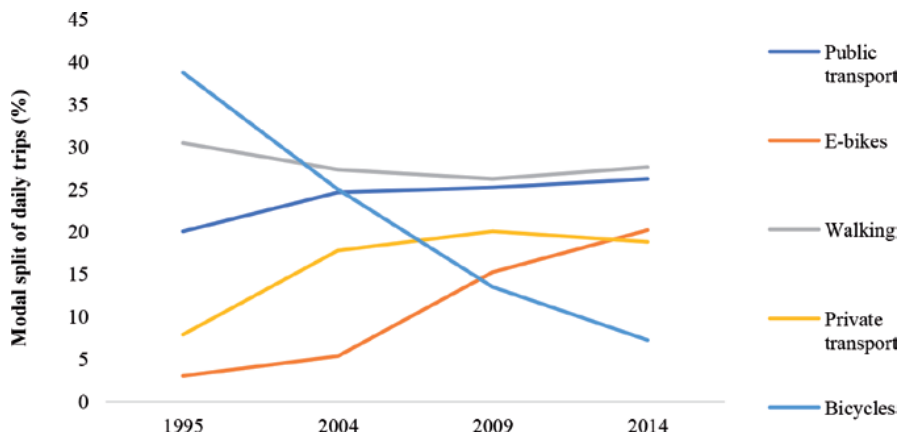

Figure 5.

Modal split of daily trips by different transport modes in the whole city of Shanghai from 1986 to 2010 (\%).

Source: Compiled based on data provided by $[15,16]$.

Beijing, Shanghai was dominated by walking and non-motorized (bicycles and e-bikes) transport in the twentieth century with over $70 \%$ of daily trips by these modes in the 1980s and 1990s. However, as in Beijing, the twenty-first century has seen a dramatic drop in these modes as car use began to grow in Shanghai. Then a plateau in car use began in the 2000s and by 2010 had peaked at less than $20 \%$ of daily trips (even lower than the 34\% in Beijing). Again it would appear that transit has stemmed this car growth, though nonmotorised transport has had more growth in the latest data as well. More interesting, e-bikes have replaced bicycles as the dominant nonmotorised transport modes in China, which was well-known as the "Bicycle Kingdom" in the middle of 1980s. The actual bicycle use per day in 


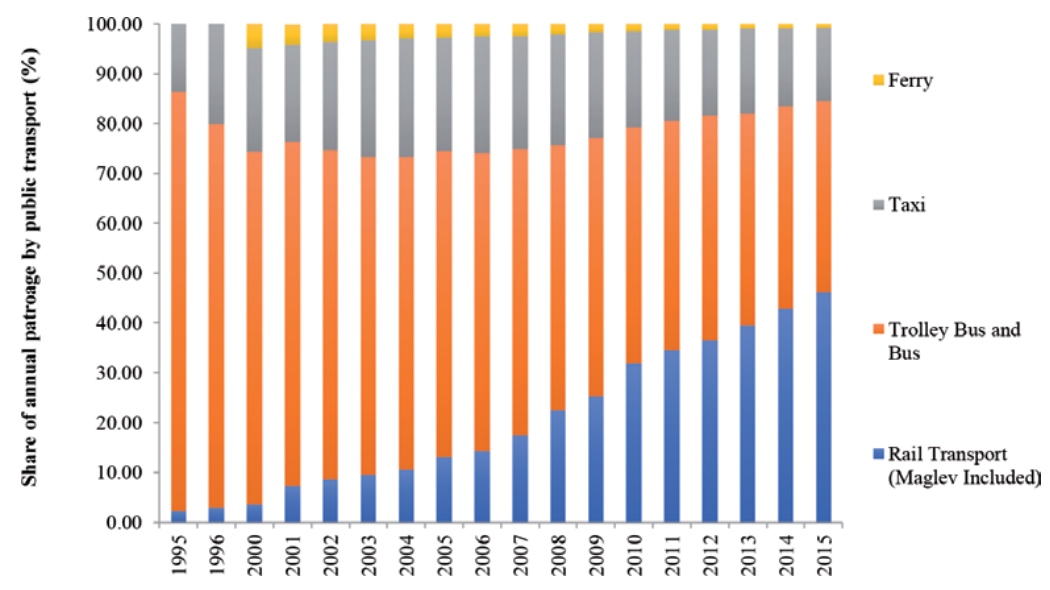

Figure 6.

Share of annual patronage by different public transit modes in Shanghai from 1995 to 2015 (\%). Source: Compiled based on data provided by [17].

Shanghai has decreased 70\% from 2009 to 2014, while there is a sharp increase in actual use of electric bicycles by $68 \%$ during the same period.

Figure 6 sets out the transit data by mode in Shanghai; this again indicates the dramatic growth of the metro. ${ }^{5}$ From the 1970 s through to the beginning of the 1980s, the trolley bus and bus were the main transit modes in Shanghai. The Shanghai metro began in 1993 but was quite small until it was extended for the 2010 Shanghai World Expo. It is now the world's largest rapid transit system by route length and second largest by number of stations with 14 lines and 364 stations and a total length of $588 \mathrm{~km}$. On an average workday, it carries 10 million passengers, while the record patronage was 11.3 million on April 1, 2016.

While private vehicle ownership in both Beijing and Shanghai is still increasing, actual automobile use as measured by modal split has in fact started declining since around 2011. Beijing went further along the automobile path than Shanghai, but both turned dramatically once a quality metro alternative was provided. Shanghai also continues to have a very high walking and nonmotorised component in its transport system (over $50 \%$ of daily trips). Both Beijing and Shanghai have much less private motorisation than would have been expected due to their rapid growth in income like other developed cities in Canada, Australia and America.

\section{Contributors to the decline of car use in Beijing and Shanghai}

\subsection{Economic factors}

Economic factors can play a more significant role in determining automobile ownership compared to actual usage due to differences in land use intensity [18]. However, most models for car use growth still assume it is driven by economic growth, especially in developing economies. Unlike automobile ownership, the actual need for automobile use has been shown to have decoupled from the financial capacity to pay for it; for example, the amount of car driving per unit of real gross domestic product (GDP) significantly declined between 1995 and 2005 in a large sample of world cities $[19,20]$. Taking Beijing as an example, Figure 7, which depicts

\footnotetext{
5 The sharp decrease in daily patronage by trolley bus and bus in the year of 1996 is largely due to the cancellation of monthly pass in 1995 and bus system reform in 1996.
} 


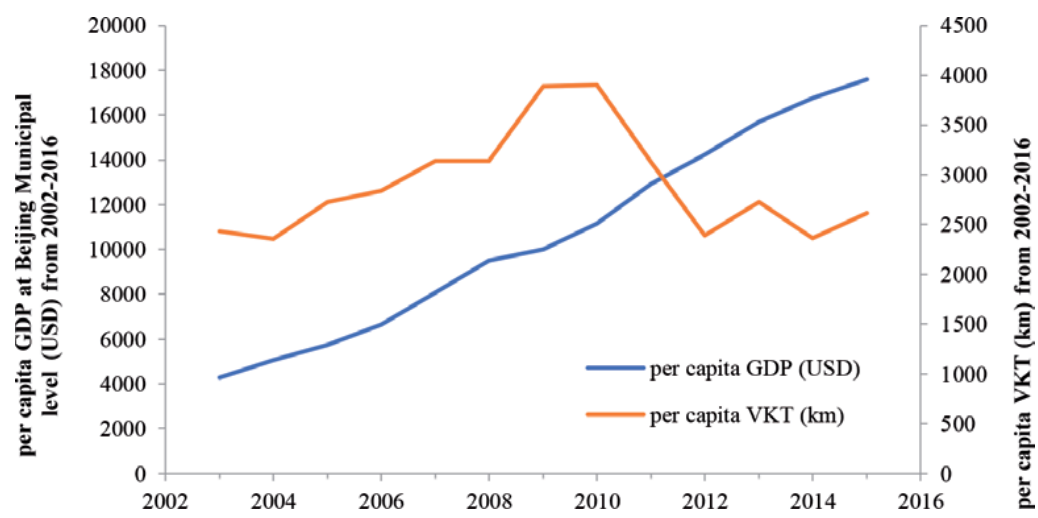

Figure 7.

Comparison of per capita GDP and per capita VKT in Beijing from 2002 to 2016. Source: Compiled based on data provided by $[21,22]$.

the number of passenger cars per 1000 permanent residents, a continuous growth trend is evident in tandem with the ever-increasing per capita GDP at Beijing municipal level. However, the level of private automobile use grows to the inflexion point in 2010 and then starts dropping, despite a continuing improvement in the urban economic performance of Beijing. Furthermore in Beijing, personal income generally decreases from the city centre to the city fringe, whereas the use of the automobile increases in the opposite way. This suggests other factors than economic drivers as set out in other studies [6]. In this paper we will examine cultural, political and urban fabrics as the decoupling seems to have set in well before other cities in terms of GDP levels.

\subsection{Cultural and political factors}

Wealth increases have certainly led to higher levels of car use in most cities over the past 100 years, but the decline in car use setting in needs further explanation. One of the other factors would appear to be a cultural and political intervention that makes other modes more attractive. The increase in public transport in Beijing was made possible largely through the priority, which the government placed on bus and train infrastructure development. This occurred at both a local and national level in accordance with the central government's 12th Five-Year Plan (FYP) (2011-2015). As part of this shift away from the automobile, transportation demand management (TDM) initiatives were also introduced in an effort to further curb the ownership and use of private automobiles across China. These included:

- Restrictions on the operation of private automobiles on certain days throughout the 2008 Olympic Games, based on licence plate end numbers

- Limitations on the number of driving licences made available to the public, a process initiated in 2010

- Since 2011, termination of three pro-car policies designed to help overcome the 2008 global financial crisis (GFC).

As a result of these initiatives, automobile modal split in Beijing plateaued in 2010 before starting a downward trend. This is despite an increase in private automobile ownership in Beijing which would have had the potential to counteract this fall. However, research has shown that for many Chinese urban residents, the automobile 
is seen more as a status symbol than an efficient means of daily transport. The new options now available would appear to be saving time compared to the highly congested road system and the decision to not build more freeways but instead to provide a better public transport option [11].

\subsection{Urban form factors}

Chinese cities have been historically high in density [23] and as will be shown below have been increasing in density. Urban form factors are likely therefore to be a strong explanatory factor in why both Beijing and Shanghai started declining in car use well before they were expected to do so due to usual predictions from income growth.

\subsubsection{Traditional low-rise and high-density urban form and short blocks}

The low-rise, high-density blocks, which characterise China's traditional way of building local neighbourhoods ${ }^{6}$ rather than the western-style low-density and singlefamily detached houses, facilitate the walking-scale environments typical of Chinese cities. In particular, the mixture of residential, commercial and recreational land use within these traditional Chinese communities provides local shops, small public spaces (squares or playgrounds) and other community services. It enables these local areas to cater for their daily necessities within walking distance. The close proximity generated by the short blocks also shortens the pedestrian distance [24]. Finally, this type of urban form helps to facilitate and operate more efficient public transport for these communities. The urban density of the whole city of Beijing and Shanghai is around 50 and 70 persons per hectare in 2005, similar to some European cities and much higher than typical automobile-dependent cities in Canada, Australia and America [25].

\subsubsection{Central square and linear corridor form of urban development}

As well as the organic density of traditional cities, there has been a long commitment to planning the city into a central square and linear corridor. This is known as the imperial-centred and axisymmetric urban form, which is affected by the Doctrine of the Mean ${ }^{7}$ [26]. The Kao Gong $\mathrm{Ji}^{8}$ document presents a city centre based on a square or rectangular shape, a pattern that was developed during the Dynasty of Western Zhou (1046 BC-771 BC) and led to the traditional road grid. This chessboard-like urban form based on small block sizes with multiple route choices is ideally suited to walking which has dominated Chinese urban transport for thousands of years. It also laid the foundation for the later construction and development of efficient public transport corridors across many Chinese cities, and because it was dense and had relatively clear roadways, it was also suitable for the bicycle that grew rapidly in China from the end of the nineteenth century. Then when trams came, they followed these roads and took them further out into longer corridors.

\footnotetext{
${ }^{6}$ Local neighbourhoods in the Chinese context evolved from a quadrangle courtyard (shaped before the establishment of New China), collective compounds (dominated during planned economy before 1978 as a part of social welfare) and commercial residential buildings with entrance guard (popular in the modern economy). It is now mostly enclosed by walls or fences for privacy, security and property rights.

7 The Doctrine of the Mean is one of the Four Books of Confucianism and also regarded as the highest level of moral code and natural law in China.

8 This document records the specification and technology of crafts in Ancient China, playing a significant role in urban planning of Chinese cities, especially the capital cities and political cities.
} 
When this road structure is combined with high density and mixed land uses, as it is in China, it means that the major parts of Chinese cities were fundamentally walking and transit city fabrics [6] and became an entrenched part of how cities were built in the Chinese cultural and political landscape. Automobile fabric only develops where a new kind of urban form is sought further out from the fabric already there and at considerably lower densities. This did not happen very much in China; instead, the city fabrics from the walking and transit eras were rebuilt at much higher density and followed the same corridor-based form into new areas.

\subsubsection{Traditional employment system}

The socialist welfare-oriented housing within walking or cycling distances of work was provided by state-owned sectors under the traditional employment system (the so-called Dan Wei in Chinese) during the period of the planned economy in China. However, the end of this system of nearby housing provision, which came with the 1978 reform and open-up process, largely destroyed what was quite a tight job-housing balance and increased the frequency and distance of the journey to work. However, they did not at any stage build urban fabric that was automobile dependent but continued to build dense, high-rise-based corridors of urban fabric.

\subsubsection{Traditional acceptance of high-density living}

Chinese villages, towns and cities have always been very dense. There are various theories about why density is accepted in some cultures and not others, for example, Anglo-Saxon culture has a long history of anti-density tradition which has been passed on to New World cities [6]. The theories about density in Chinese cities suggest it is a combination of their:

- Military history: The need to have walled cities for security meant that a more urban culture became essential.

- Religion: Confucianism has a strong emphasis on community responsibilities that build networks of close dependence within and between families.

- Economy: The reality of Chinese economic history is that they have built very big centres of economic wealth based on trading textiles, handicrafts and cultural activity that could only work efficiently if it was intensively conducted.

Together these theories suggest that the Chinese economy depended on these big cities that were made of traditional walking city fabric, highly dense and mixed for many centuries, rather than being a set of low-density rural villages based around agriculture.

These various traditions and planning paradigms have resulted in the typical Chinese urban form. The central city of both Beijing and Shanghai is still a very dense urban environment of close to 250 persons per ha (characteristic of walking city fabric). The whole city, together with all its other component parts, is also getting denser despite the "urban sprawl" in outlying areas. The urban density of the whole city is more than 50 persons/ha, which is typical of European transit-oriented regions. The old walking city centres and the transit-oriented linear form of urban development together with dense land use patterns facilitate the development of public transport systems as well as walking and cycling in Beijing and Shanghai. However, especially in the superdense city centres where there is continuous 
rebuilding at higher densities, these areas are becoming more and more unsuitable for cars but at the same time are beyond the affordability of most citizens.

This is not just an issue in Chinese cities as the revival of the walking and transit city fabric in most developed cities is also associated with major issues surrounding equity. The newer urban areas in outlying areas created in the last 20 years to provide more affordable housing are more automobile dependent but are still nothing like the sprawling suburbs of American and Australian cities. These areas in Chinese cities are well served now by fast metro systems as well as having considerably more local services and work; however, they are clearly going to have more car use than the traditional areas and will need to find new ways of dealing with this. For example, the lowest densities are the outer suburbs in Beijing, but even here these are above 25 persons/ha, which is the high end of auto city fabric. These areas do not go down to typical auto city densities of 7-20 persons/ha or so, but they will still need to continue to minimise such areas if they are to keep reducing their car use.

The same kind of urban fabric can be found in both cities examined; the key differences were much higher urban density in some districts of the central city and a more walkable form of urban development in Shanghai compared to Beijing. The urban density of both central cities is similarly more than 200 persons/ha. However, the urban density of the whole city and suburb areas is higher in Shanghai than in Beijing. This is perhaps due to Beijing's scattered urban areas around the ring roads. Some districts of the central city of Shanghai are superdense with more than 600 persons/ha urban density (like Huangpu, Luwan, Jing'an and Hongkou), while the highest urban density in Beijing is around 300 persons/ha. Shanghai's superdense urban form results in the dominance of walking and nonmotorised transport modes in the whole city.

\section{Conclusions}

Beijing and Shanghai are the two most representative cities in China in terms of their political, economic and cultural influences so it is very significant that both are now indicating a peak in car use has happened. This coincides with major investments in public transport that have provided an option surpassing many car use patterns. This has happened despite increasing economic growth and car ownership growth. To explain this needs an understanding of the fabrics that define the city and which are expressions of the cultural and political history of China. Both cities feature Chinese traditional urban fabrics of walking centres with transit linear corridors all with dense, mixed land use patterns that favour public transport and walking and cycling. They can both be termed "emerging transit metropolises" as opposed to the mature transit metropolises such as London and Paris [27]. These areas are also where the major job growth and urban activity are focused and thus private vehicle use has decoupled from wealth and has now peaked in terms of modal split. This paper suggests that this is strongly affected by their walking and transit urban fabrics, which are not built for much car use. More than likely the response will be to continue the peak car use trend and enable Chinese cities to become more and more a model for any other emerging cities that are trying to face up to a future with less automobile dominance in their cities.

\section{Acknowledgements}

This document was produced with the financial support of the Department of Education of Henan Province (Project No. 20B630021) and Zhengzhou University (Project No. 32220525). 


\section{Conflict of interest}

The authors declare no conflict of interests.

\section{Author details}

Yuan Gao* ${ }^{1 *}$ Peter Newman ${ }^{2}$ and Jeffrey Kenworthy $y^{2,3}$

1 School of Politics and Public Administration, Zhengzhou, China

2 Curtin University Sustainability Policy (CUSP) Institute, Curtin University, Perth, Australia

3 Frankfurt University of Applied Sciences, Perth, Australia

*Address all correspondence to: yuan.gao@zzu.edu.cn

IntechOpen

(C) 2020 The Author(s). Licensee IntechOpen. This chapter is distributed under the terms of the Creative Commons Attribution License (http://creativecommons.org/licenses/ by/3.0), which permits unrestricted use, distribution, and reproduction in any medium, provided the original work is properly cited. (cc) BY 


\section{References}

[1] National Bureau of Statistics of the People's Republic of China (NBSC). 2015 Statistical Bulletin on National Economy and Social Development (Chinese Version). 2016. Available from: http://www.stats.gov.cn/tjsj/ zxfb/201602/t20160229_1323991.html [Accessed: 16 March 2016]

[2] Dargay J, Gately D, Sommer M. Vehicle ownership and income growth worldwide: 1960-2030. The Energy Journal. 2007;28(4):143-170

[3] Gao Y, Kenworthy J, Newman P. Growth of a giant: A historical and current perspective on the Chinese automobile industry. World Transport Policy and Practice. 2014;21(2):40-55

[4] National Bureau of Statistics of the People's Republic of China (NBSC). 2015 China Statistical Yearbook. Beijing, China: NBSC; 2016

[5] NationMaster Online Database. Transport > Road > Motor Vehicles per 1000 People: Countries Compared. 2016. Available from: http://www. nationmaster.com/country-info/stats/ Transport/Road/Motor-vehicles-per1000-people [Accessed: 10 May 2016]

[6] Newman P, Kenworthy J. The End of Automobile Dependence: How Cities Are Moving beyond Automobile-Based Planning. Washington DC, WA: Island Press; 2015

[7] National Bureau of Statistics of the People's Republic of China (NBSC). 2019 China Statistical Yearbook. Beijing, China: NBSC; 2018

[8] Beijing Transportation Research Centre (BJTRC). Beijing Transport Annual Reports (Chinese Versions). 2002-2014. Available from: http://www. bjtrc.org.cn/PageLayout/ZLXZ.aspx [Accessed: 11 May 2016]
[9] Beijing Transportation Research Centre (BJTRC). Beijing Transport 2015 Annual Report (Chinese Version). BJTRC, Beijing, China. 2015. Available from: http://www.bjtrc.org.cn/InfoCent er\%255CNewsAttach\%255C2015年北京 交通友展年披_20160303143117631.pdf [Accessed: 11 May 2016]

[10] Strickfaden M, Devlieger P.Empathy through accumulating techné:

Designing and accessible metro. The Design Journal. 2011;14(2):207-229

[11] Gao Y, Newman P, Webster P. Transport transitions in Beijing: From bikes to automobiles to trains. The Journal of Sustainable Mobility. 2015;2(1):11-26

[12] Fan J, Zhang C, Lu K. Statistic and analysis on operational length of urban rail transport in China in 2015 (Chinese version). Urban Rapid Rail Transit. 2016;29(1):1-3

[13] Beijing Transportation Research Centre (BJTRC). Beijing Transport Annual Reports (Chinese Versions). 2002-2016. Available from: http://www. bjtrc.org.cn/PageLayout/ZLXZ.aspx [Accessed: 11 May 2016]

[14] Beijing Transportation Research Centre (BJTRC). Beijing Transport 2015 Annual Report (Chinese Version). BJTRC, Beijing, China. 2017. Available from: http://www.bjtrc.org.cn/InfoCent er\%255CNewsAttach\%255C2015年北京 交通友展年披_20160303143117631.pdf [Accessed: 11 May 2016]

[15] Shanghai City Comprehensive Transportation Planning Institute (SCCTPI). 2010 Shanghai

Comprehensive Transportation Annual Report (Chinese Version). Shanghai, China: SCCTPI; 2011

[16] Lu X, Liu M. Importance of public transport priority in urban cities 
and participation-based motivation

(Chinese version). Urban Management.

2012;5:38-41

[17] Shanghai City Comprehensive Transportation Planning Institute (SCCTPI). Main Achievements of Shanghai Fifth Comprehensive Traffic Survey (Chinese Version). Shanghai, China: SCCTPI; 2015

[18] Newman P, Kenworthy J. The land use-transport connection: An overview. Land Use Policy. 1996;13(1):1-22

[19] Kenworthy J. Decoupling urban car use and metropolitan GDP growth. World Transport Policy and Practice. 2013;19(4):7-21

[20] Newman P, Kosonen L, Kenworthy J. Theory of urban fabrics: Planning the walking, transit and automobile cities for reduced automobile dependence. Town Planning Review. 2016;87(4):429-458. DOI: $10.3828 /$ tpr.2016.28

[21] Beijing Municipal Bureau of Statistics (BJMBS). Beijing Statistical Yearbooks (Chinese Versions). 19822015. Available from: http://www. bjstats.gov.cn/tjsj/ndsj/ [Accessed: 25 April 2016]

[22] Beijing Municipal Bureau of Statistics (BJMBS). 2015 Beijing Statistical Yearbook (Chinese Version). BMBS, Beijing, China. 2016. Available from: http://www.bjstats.gov.cn/ nj/main/2015-tjnj/zk/indexch.htm [Accessed: 25 April 2016]

[23] Kenworthy J, Hu G. Transport and urban form in Chinese cities: An international comparative and policy perspective with implications for sustainable urban transport in China. The Planning Review. 2002;38(151):12-22

[24] Ewing R, Cervero R. Travel and the built environment: A meta-analysis.
Journal of the American Planning

Association. 2010;76(3):265-294

[25] Gao Y, Newman P. Beijing's peak car transition: Hope for emerging cities in the $1.5^{\circ} \mathrm{C}$ agenda. Urban Planning. 2018;3(2):82-93. DOI: 10.17645/ up.v3i2.1246

[26] Sit V. Chinese City and Urbanism: Evolution and Development.

Hackensack, NJ: World Scientific; 2010

[27] Kenworthy JR. Is Automobile Dependence in Emerging Cities an Irresistible Force? Perspectives from São Paulo, Taipei, Prague, Mumbai, Shanghai, Beijing and Guangzhou. Sustainability. 2017;9(11):1953. DOI: 10.3390/su9111953 


\title{
Exploring the Prescriptive and Descriptive Lost Space in the Setting of Urban Fabrics of Kuala Lumpur
}

\author{
Nurul Shakila Khalid
}

\begin{abstract}
Due to the tension of urban uniformity and environmental setting, what emerges in most patterns of use in the city is lost space that usually ignored as insignificant. They emerge as if by accident during the design process, sometimes, the result of negligence or simply a feature of time flow in the city. To understand the phenomenon of lost space, this research seeks to identify the prescriptive and descriptive character of lost space from the local perception in Kuala Lumpur. This research also investigates the varied forces, circumstances, and the mechanisms that are responsible for their production. A qualitative analysis is made on selected parameters in the theory of lost space, activities, accessibility, connectivity, maintenance, and design. The result indicates that there were various new perceptions of descriptive lost space includes economic and social activity as these are an important strategy for maintaining the vitality and robustness of urban space. It is proposed in this paper the need of tools and effective ways of (re)designing a space to be applied in a new context and can act as a resource for urban life by hosting the intervention or alternative uses.
\end{abstract}

Keywords: lost space, urban fabrics, vitality, local perceptions

\section{Introduction}

In most of the cities today, architect, urban designers, city authorities and city makers are faced with the challenge of creating holistic environments in an urban core particularly as collective, unifying and restructuring frameworks for new (re) development [1]. Too often the design's contribution becomes an after the fact cosmetic treatment of spaces that are ill-planned for public use in the first place. The process of urban development treats buildings as isolated objects, not as part of the larger fabric of streets, squares, parks and viable open space, without considering the relationship between buildings and spaces, and deeper understanding of human behavior $[2,3]$. Hence, what emerges in most environmental settings today is unshaped antispace. It is centered on the concept of urbanism as an essential attitude in urban design, favoring the spatially connected public environment over the master planning. This approach knows for making figurative space out of the lost landscape. Here, architects, urban planners, urban environment, and landscape 
architects have a major responsibility to meet the challenge and to reintegrate the lost spaces in the urban core into the democratic urban fabric or identify the most holistic ways for temporary or alternative uses. Chohan (2014) found lost space as the normative essence of urbanity. Prior to the economic manipulation in urbanity that aiming at increasing on mobility, global competition and image marketing to boost economic, all too often tend to homogenize space on consumerist and aestheticized values. If the urban space is poorly defined, the failure of harmonizing with the existing system of public space and fit into its surroundings more effectively created the dilemma of modern urban space.

The restructuring of city centers in particular reflects practices that observe the consolidation of the divided city - space is functionally and economically shared, but subject to an increasing social and cultural segregation.

According to Trancik [4], lost space is a leftover unconstructed landscape. They are the undermanaged areas between districts, buildings, or roads emerge without anyone realizing it until its being done physically on the ground. It is the undesirable urban space that is accidentally formed during the planning stage [5]. In other words, lost space can be seen as an inadequate use of space in urban area, isolated from the walking flow [6-8]. It is abandoned and left area that has lost their functions [9]. Trancik [4] notices that space such as a park can be considered as lost space if space does not serve its intended purpose. Lost space becomes a place when it is given a contextual meaning derived from cultural or regional content [10].

Mobility and communication have increasingly dominated Kuala Lumpur, which has consequently lost much of its cultural meaning and human purpose especially today; the spaces between buildings are rarely designed. The results of this can be seen all around us. The disjointed lacking visual and physical coherence in Kuala Lumpur has resulted to the more utilitarian in their organization, the notion of function was gradually displaces from the external space to the organization of internal space. A building tended to become more of an object, separate from its context.

Under the logic of lost space and how the theoretical understanding contributes to user perception, this research attempts to seek a better understanding towards the local perception of lost space in the urban core areas of Kuala Lumpur and thus to seek the appropriate tools to improve the usability of the space. The aim of this study is to implement a methodology: (i) to define lost space in the context of urban space in Kuala Lumpur, (ii) to identify the factors contributing to lost space, and (iii) to recommend several effective approaches to improve the usability and redesigning lost spaces that have emerged over the last two decades.

For that reasons, 10 respondents were interviewed, as the samples in qualitative research as are often small. Their responses and understandings as the end users help the contribution to design the efficient urban space that incorporates respondents' value meaning.

\section{The model of lost space}

Since 1986, many scholars began to study a particular kind of lost spaces and provided many definitions and suggested several interpretations such as loose space, cracks, vacant, in-between, transitional, liminal, neglected spaces, deteriorated and indeterminate space (Table 1). Trancik [4] first used the term of lost space to describe spaces that are in need of re-design, antispaces, making no positive contribution to the surrounds or users. According to Trancik [4], lost space is a leftover unconstructed landscape or under managed space. It is the undesirable urban space that is accidentally formed during the planning stage [5]. 
Exploring the Prescriptive and Descriptive Lost Space in the Setting of Urban Fabrics... DOI: http://dx.doi.org/10.5772/intechopen.89907

\begin{tabular}{clll}
\hline Year & Scholars & Terms & Definitions \\
\hline 1974 & Sommer & $\begin{array}{l}\text { Tight space, } \\
\text { hard space }\end{array}$ & $\begin{array}{l}\text { Offerings possibilities for different activities, unrelated to the } \\
\text { original designed purpose for a particular space. }\end{array}$ \\
\hline 1986 & $\begin{array}{l}\text { Roger } \\
\text { Trancik }\end{array}$ & Lost space & $\begin{array}{l}\text { Space that makes no positive contributions to the surrounding } \\
\text { and people. }\end{array}$ \\
\hline 1996 & $\begin{array}{l}\text { Loukaitou- } \\
\text { Sideris }\end{array}$ & $\begin{array}{l}\text { Cracks in the } \\
\text { city }\end{array}$ & $\begin{array}{l}\text { Spaces that are abandoned and left deteriorate, which eventually } \\
\text { be filled with trash and human waste. }\end{array}$ \\
\hline 2001 & $\begin{array}{l}\text { Hajer and } \\
\text { Reijndorp }\end{array}$ & $\begin{array}{l}\text { In-between } \\
\text { spaces }\end{array}$ & $\begin{array}{l}\text { As an ephemeral object, a site - yet not only space, but also a } \\
\text { possible future, and disparate activities. }\end{array}$ \\
\hline Franck and & Loose space & $\begin{array}{l}\text { Spaces that only allows certain regulated activities, unrelated to } \\
\text { the original designed purpose for a particular space. }\end{array}$ \\
\hline
\end{tabular}

Table 1.

Definitions of lost space by various scholars.

Lost space can be car parking, the edge of highways which are being planned without maintenance and management, under elevated highways, the base of highrise tower, overhead bridge, abandoned waterfronts, unused sunken plaza, vacated military sites and deteriorated parks [4]. Trancik [4] argues that the blame for creating lost spaces lies squarely with the car, urban renewal, the privatization of public space, the functional separation of uses and the modern movement.

In placing more emphasis, lost spaces or leftover spaces are mostly found in between two buildings, in front, at the sides or at the rear of buildings, and rooftops. These spaces loss their values and meanings, functions, and a sense of belonging. Leftover spaces, usually publicly owned but without any assigned function, are often located right next to spaces with fixed and restricted functions [9]. Examples
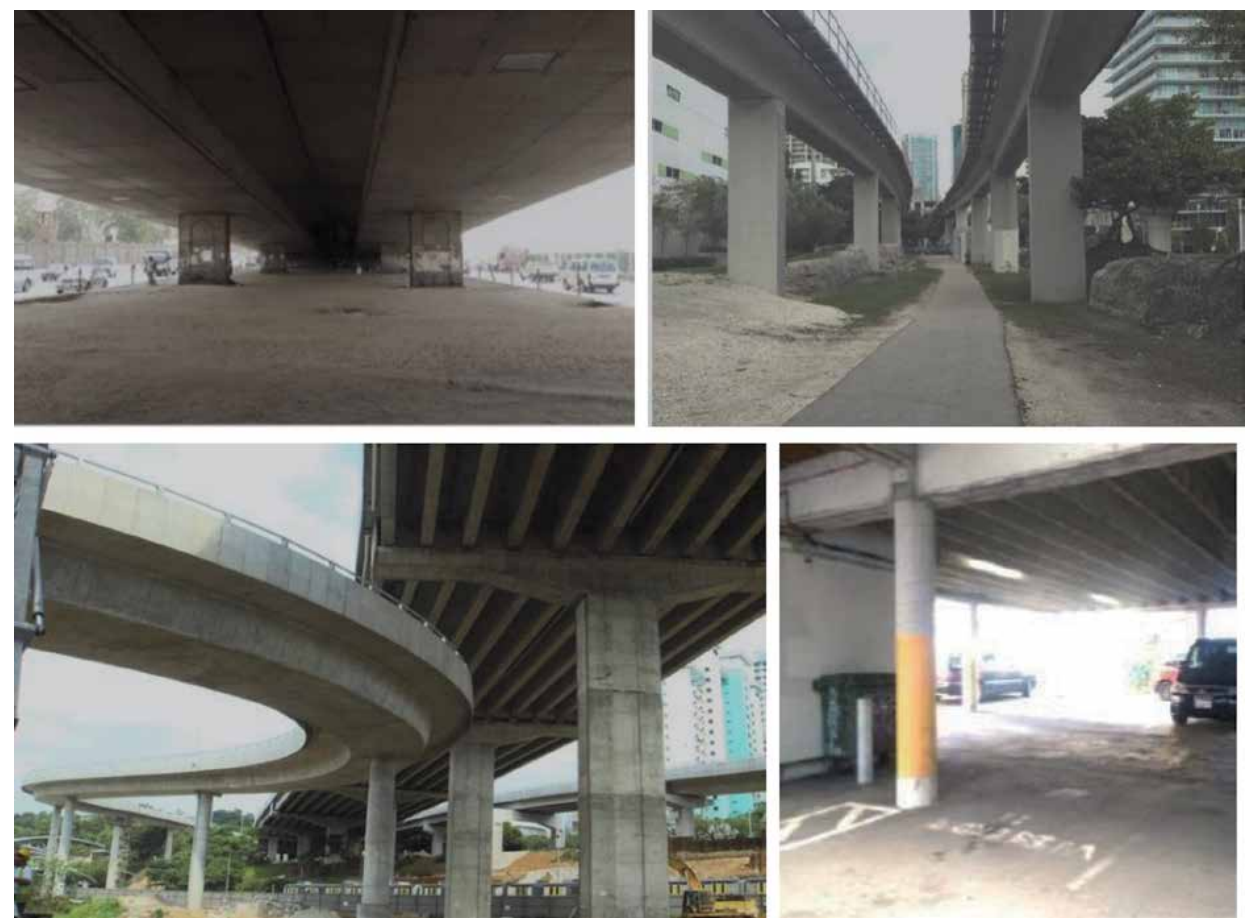

Figure 1.

The examples of underutilized spaces in urban areas accommodate unexpected and unintended activities such as businesses and parking lots. (source: [10]). 
include the spaces under bridges and next to highways. These exist beyond the boundaries of organized social space, having no intended use and often lacking conventionally appealing features, as shown in Figure 1.

Tibbalds [8] argued that the lost space affects the way we experience the city thus contribute to undesirable views, piled with rotting rubbish, covered in graffiti, illegal activities, polluted, unsafe, congested by traffic, full of mediocre and ugly poorly maintained buildings, and populated at night by homeless people living in cardboard boxes. Besides, the unclear territoriality of these spaces acts as physical and psychological barriers making the poor experience among users and disconnected between new and old uses, buildings and activities. What a failure to deal with minor signs of decay within an urban area could bring a rapid spiral of decline. For example, as Malaysia aggressively build the elevated highways as the "efficient" alternative to solve the issues of traffic congestion in major cities, thus affect the aesthetical, ecological, historical, and recreational qualities [11]. The worst phenomenon is the elevated highways disconnect neighborhood until then the urban community feel the marginalization in the development program. Loukaitou-Sideris [3] writes about "Cracks in the City" and define cracks as the "in-between spaces, residual, under-utilized and often deteriorating." The poor management is also to blame for the state of many plazas, car parks, parks and public housing estates, where abandonment and deterioration have filled vacant space with human waste and trash.

What is the best characteristic to describe the factors contributing to lost space? According to Trancik [4], there are four major factors contributing to lost space, which are (i) increasing dependency on the automobile, (ii) modern movement in design, (iii) land use zoning policies, and (iv) unwillingness of urban authorities and designers to assume responsibility for the public realm.

The increasing automobile dependency has caused the city form to change from time to time. Streets are no longer essential urban open spaces for pedestrian use. Open spaces are slowly replaced by highways, thoroughfares, and parking bays which are considered as predominant types of open spaces in the modern urban planning perspectives. These highways, parking bays and similar to it cuts through cities and created huge areas of lost spaces.

The modern movement has created buildings more practical and functional in their organization, spaces between buildings are rarely taken into consideration as architects and planners tend to make the building as a formal object separated from its context. Architects and urban planners in the twentieth century failed to understand the needs and desire of pedestrian towards space [8]. This has resulted in what once used to be an external space of an organization gradually turns into a private internal space of the organization (Peterson, 1980).

\section{Research methodology}

To understand the definition and characteristics of lost space, this study attempts to investigate what and how local people perceived the lost space from their view, experience and understanding. The aim to gather and understand the local perceptions is may help to improve the usability of lost space optimally and also to help the architects, urban planners and local authority to design and plan the space in a more holistic way.

The data were collected through semi-structured interviews who respondents have been selected using snowball sampling who lives or works nearby the study area (refer Figure 2) that covers the area of Perdana Botanical Garden, Jalan Parlimen, Merdeka Square, KL Bird Park, Kompleks Daya Bumi and Masjid Jamek. 


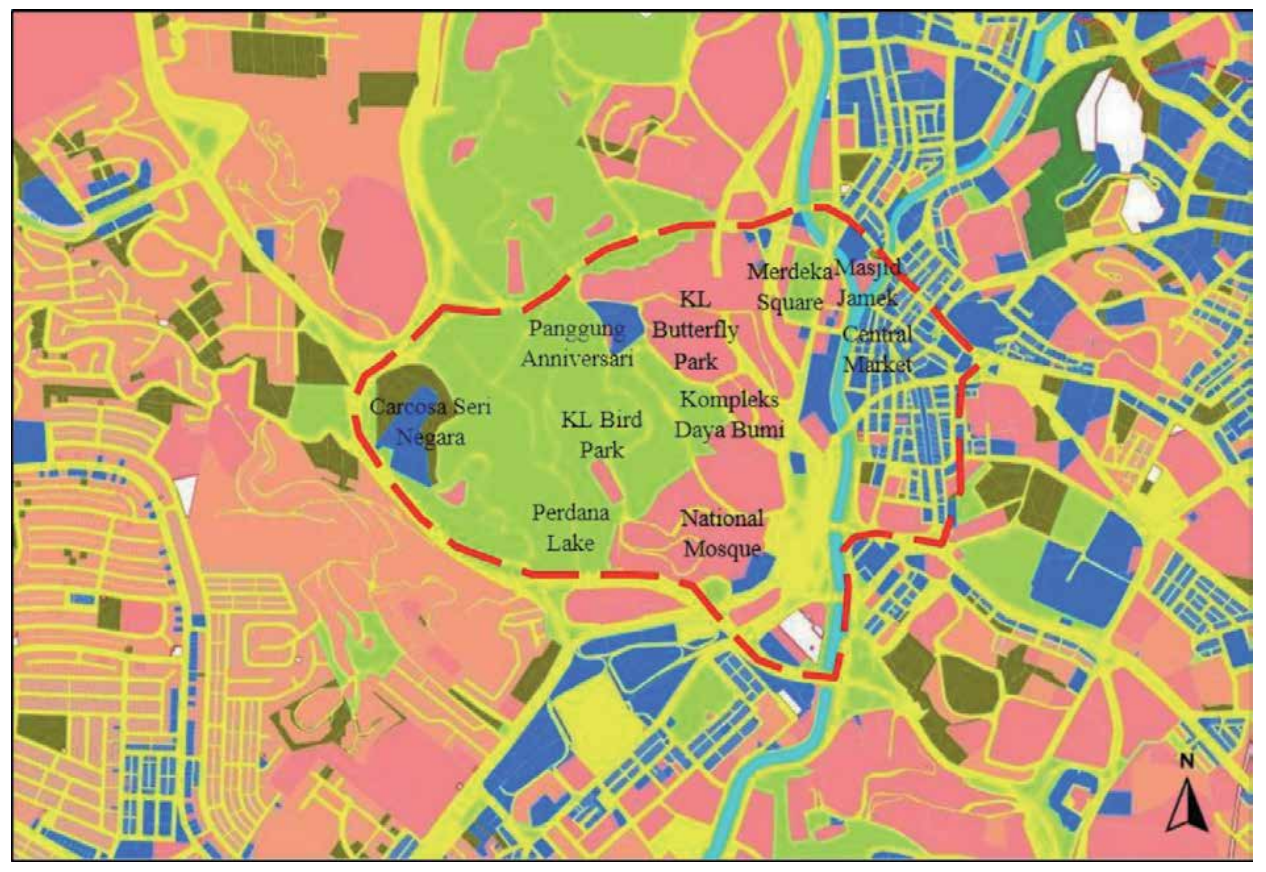

Figure 2.

Urban core areas of Kuala Lumpur have been chosen as a study area including the heritage quarters, urban parks, institutions and major river.

The total of 10 respondents is among direct and indirect stakeholders. The direct stakeholders are professionals such as architects, urban planners, environmentalist, place-maker, contractor and local authority while indirect stakeholders are the local people who are randomly selected during a weekend in the study area such as in Perdana Botanical Garden, Merdeka Square and KL Bird Park - the most visits place. The interviews questions were conducted as non-directive to allow respondents to describe and explain their understanding of the subject matter in their own words and expressions. Every interview session only took approximately about 15-20 minutes. Among the questions to be asked to the professional respondents are, "To what extent do you understand the term of lost space?"; "Do you think there have lost space in Kuala Lumpur?"; "What are the characteristics of the lost space and what improvement can be done in aspect of design to improve the usability of the lost space."

Furthermore, this study utilizes an addition to a base map during the interview session. A tracing paper is overlaid on the base map of Kuala Lumpur (as the study area) and the respondents thus are required to encircle the location of lost space base on their experience and knowledge.

Data collected from the interviews are further analyzed using grounded theory to identify the appropriate characteristics of lost space in Kuala Lumpur. Coding and themes are formulated to analyze the data collected. The findings will be compared with characteristics of prescriptive lost space and thus provide the research with the respondent's understating of lost space in urban areas.

\section{Analysis and discussions}

To understand the phenomenon of lost space in urban areas, this study attempts to investigate the descriptive and prescriptive in the context of lost space. To be 
noted, prescriptive lost space refers to the definitions as explain in the theory of lost space, and using codes and themes to group the definitions, while descriptive refers to local perceptions that may contrast with the definitions by theory. Local respondents only are able to describe the lost space from what they experience and observe. Both descriptive and prescriptive reflects the question how theoretical approach of lost space may differs how local perceive and understand the lost space. Analysis sections were divided into three sections: (i) analysis of relationship between the characteristics of lost space and the built environmental setting, (ii) analysis of characteristics between prescriptive and descriptive lost space, and (iii) analysis of prescriptive vs. descriptive lost space.

\subsection{The relationship between the characteristics of lost space and the setting of built environmental}

In this analysis, the setting of built environment in urban core areas of Kuala Lumpur such as streets, public spaces, parks, government reserve, buildings and parking has its unique characteristics needed in enhancing the quality of urban fabrics. Built environmental settings in the urban areas become a part of city attractiveness elements because of its ability to attract newly-emerging businesses, enhance social interactions among urbanites and improve the landscaping.

The results found that there are three most characteristics mentioned by the respondents; social activity, economic activity and design (Table 2). Cafes, buskers, picnic, exhibitions, music festivals, and other events are types of social activities identified by the respondents. If space was poorly managed and declined either physically, or in the activities (social, cultural and economic) it offers, the vicious cycle of decline may all too easily set in Ref. [12] describe "if people use space less, then there is less incentive to provide new spaces and maintain existing ones. With decline in their maintenance and quality, public spaces are less likely to be used, thereby exacerbating the vicious spiral of decline".

The second characteristic of descriptive lost space as perceived by the selected members of the creative class is economic activities. Retail locations, restaurants, cafés, street food stalls, are some of the economic activities that were identified by the respondents. The third characteristic of descriptive lost space as perceived by end users' is the connectivity. According to the respondents, connectivity refers to the relative location and types of elements in the physical setting. Connectivity also refers to the availability of public transportation in the area. Accessibility, according to the respondents, refers to safety, convenience, and permeability. Some respondents have been denied access to it, prominent among which are the rich, elderly and youth. Exclusion of fear and inability to consume, the most written about being sporting and skateboarding, which is regarded by some as anti-social because of the conflict it creates with other groups. In such places, youth experience problems of safety and security and feelings of exclusion, while what they desire in a public space is social integration, safety and freedom of movement. All these describe failures to manage shared public spaces in a manner that allows their equitable use by all groups without diminishing the welfare of others.

Analysis of characteristics of descriptive lost space is very important as to compare with the characteristics of prescriptive lost space explained in the theory. As an example, the variety of public spaces in Kuala Lumpur such as KL Bird Park, Orchid Garden, Merdeka Square, and Perdana Botanical Garden, includes those that are planned for certain assigned functions; both legally and physically, accommodate other activities as well. It also includes other kinds of spaces currently without assigned functions that accommodate unintended and spontaneous activities. Many of these spaces possess particular features that invite people to appropriate them for 


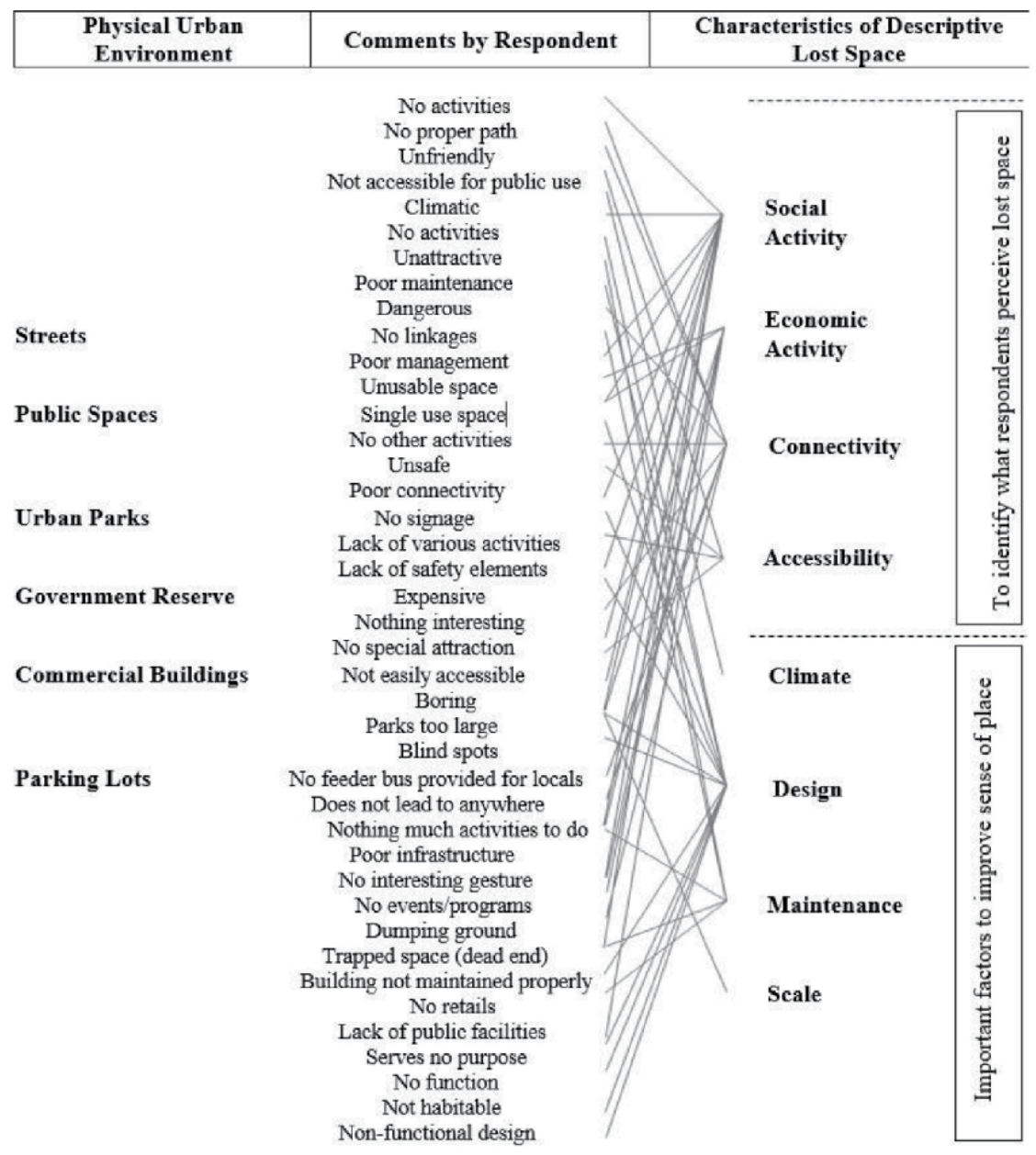

Table 2.

Respondent's comment on the characteristics of descriptive lost space based on the physical urban environment.

their own uses.Three respondents have mentioned that urban core areas of Kuala Lumpur are lacking social and economic activities, connectivity, accessibility and design. The respondents have highlighted that there are no significant attractions or interesting activities that attract people to come. The following comments show how the importance of having a synthetic gesture in an urban area:

“... it is important to have a synthetic gesture to attract density towards an area.

However, in the case of Perdana Botanical Garden and its surrounding, there is no strong attractions that may attract people to visit often. Having the activities alone does not make the area vibrant and liveable. The support by the efficient public transportation and better connectivity helps to contribute the density in the area ...."

The poor physical state of Perdana Botanical Garden seems to rest with the fact that it is rarely clear who should be managing it after it is built, or after it has declined. As a result, it is being neglected, with [13] explaining that more attention needs to be given to such transitional space.

In addition, the study area consists of a large recreational park surrounded by various cultural and eco-tourism areas. However, local people did not find any 
attractions to visit. This brings us to the second characteristic, which is poor in connectivity and accessibility that contributes to lost space as mentioned by the respondent.

\begin{tabular}{|c|c|c|c|c|c|}
\hline & Term & Count & & Term & Count \\
\hline 1 & access & 76 & 36 & Know & 16 \\
\hline 2 & activity & 127 & 37 & poor & 98 \\
\hline 3 & alley & 30 & 38 & landscape & 14 \\
\hline 4 & also & 46 & 39 & lane & 68 \\
\hline 5 & always & 34 & 40 & level & 12 \\
\hline 6 & area & 53 & 41 & like & 37 \\
\hline 7 & around & 28 & 42 & little & 18 \\
\hline 8 & back & 25 & 43 & live & 16 \\
\hline 9 & beautiful & 31 & 44 & look & 17 \\
\hline 10 & better & 39 & 45 & lost & 178 \\
\hline 11 & big & 43 & 46 & lot & 12 \\
\hline 12 & building & 93 & 47 & main & 13 \\
\hline 13 & business & 37 & 48 & make & 18 \\
\hline 14 & called & 32 & 49 & management & 25 \\
\hline 15 & change & 51 & 50 & many & 12 \\
\hline 16 & come & 40 & 51 & massive & 27 \\
\hline 17 & connectivity & 86 & 52 & maybe & 17 \\
\hline 18 & design & 40 & 53 & mean & 13 \\
\hline 19 & different & 38 & 54 & much & 16 \\
\hline 20 & park & 68 & 55 & need & 24 \\
\hline 21 & end & 17 & 56 & negative & 153 \\
\hline 22 & even & 23 & 57 & never & 11 \\
\hline 23 & example & 25 & 58 & new & 12 \\
\hline 24 & fell & 22 & 59 & nice & 10 \\
\hline 25 & garden & 38 & 60 & nobody & 70 \\
\hline 26 & get & 26 & 61 & not & 10 \\
\hline 27 & giving & 20 & 62 & now & 9 \\
\hline 28 & go & 19 & 63 & occupied & 31 \\
\hline 29 & good & 20 & 64 & oh & 17 \\
\hline 30 & got & 27 & 65 & okay & 15 \\
\hline 31 & green & 37 & 66 & old & 18 \\
\hline 32 & hot & 61 & 67 & outside & 23 \\
\hline 33 & huge & 24 & 68 & empty & 133 \\
\hline 34 & invert & 13 & 69 & parking & 71 \\
\hline 35 & just & 16 & 70 & part & 14 \\
\hline
\end{tabular}

Table 3.

The frequent term that mentioned by respondents. 
"I have been living in Kuala Lumpur for 30 years. Very rare I visited the Perdana Botanical Garden. Hardly reachable, unfriendly pathways and bicycle lane, and no public transportation access to the area except the Hop on Hop off Bus, which only caters for the tourists only, make me consider to visit this place".

This can be said that the design of the area also influences people to utilize the space. Two respondents perceived that Perdana Botanical Garden is unsafe due to many reasons such as robbery and vandalism. The massive development around the park especially the new highways and high rise residential contributed to the feeling of unsafe due to the lack of natural surveillance.

\subsection{Characteristics of prescriptive and descriptive lost space}

Most of the respondents expressed the negative perceptions towards the term lost space as defined by the authors in [3, 4, 9]. People are aware of the negative side of the space and the need of redesigning towards the area. This shows that most of the respondents' definitions of lost space are somehow similar to Trancik's [4].

For the descriptive definition of lost space, this study synthesizes the key themes discussed by selected end-users' when asked to define their perceptions of lost space. Provided that, most respondents perceived descriptive lost space as an activity, building, poor, lost, connectivity, empty, and negative (see Table 3). These terms are the most frequently mentioned by the respondents where they were asked how they define the lost space. The respondents were given several photos of lost space as guidance such as the back lane, buildings, corridor, parks, under elevated highways and pathways. The respondents understand what is the definition of lost space by looking at the photos and their answers were almost similar to the definitions by the scholars (see Table 4).

\subsection{Prescriptive vs. descriptive lost space}

In discussing the lost space in Kuala Lumpur, the respondents mentioned Taman Tasik Perdana, streets, roundabout, waterfront, Kompleks Daya Bumi, viaduct of Jalan Kuching - Jalan Tun Perak, and parking space. Examples of each area mentioned by respondents will be discussed in the following section.

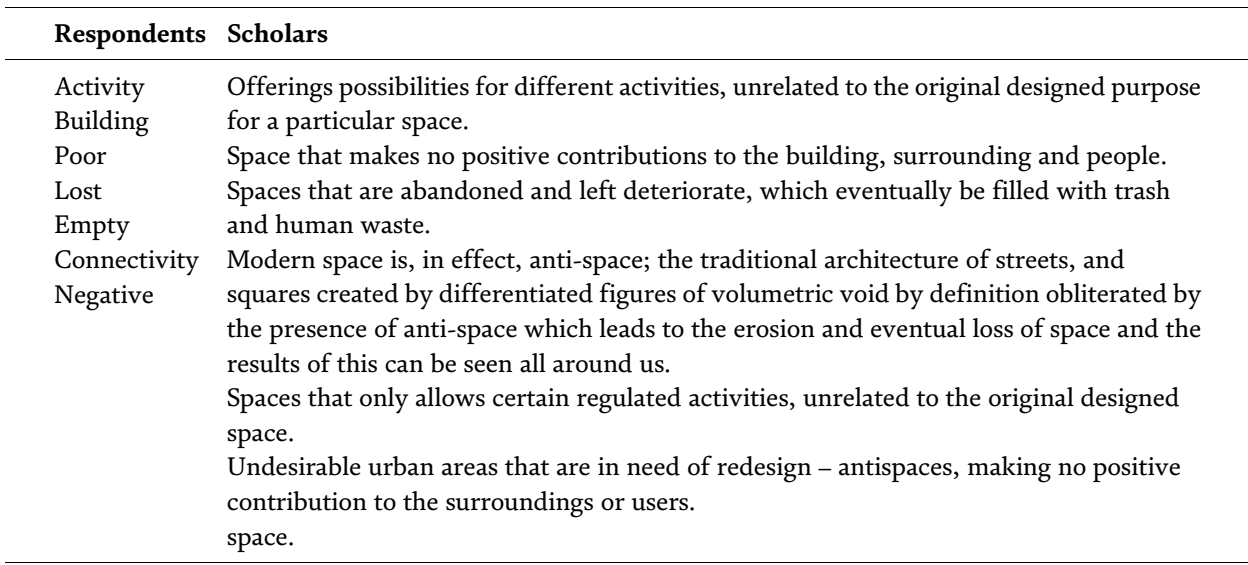

Table 4.

Comparison between respondents' understanding and scholar's definition of lost space. 


\begin{tabular}{|c|c|}
\hline Respondents & Definitions \\
\hline Trancik [4] & $\begin{array}{l}\text { Lost space is the leftover, undesirable urban areas that are in need of redesign- } \\
\text { antispaces, making no positive contribution to the surrounding or users. }\end{array}$ \\
\hline Respondent 01 & Lost space is a wasted space \\
\hline Respondent 02 & Lost space is a space that are uninviting and unconducive \\
\hline Respondent 03 & Lost space is a space that nobody took notice of the space existed \\
\hline Respondent 04 & Lost space is a space that we do not notice it existence, and not being highlighted \\
\hline Respondent 05 & Lost space is a redundant space \\
\hline Respondent 06 & $\begin{array}{l}\text { Lost space is a space that is no longer there, hidden spaces, negative spaces, } \\
\text { Bermuda spaces }\end{array}$ \\
\hline Respondent 07 & Lost space is a space that is not occupied by any program or events \\
\hline Respondent 08 & Lost space is a negative spaces that could be made better for an urban environment \\
\hline Respondent 09 & $\begin{array}{l}\text { Lost space is a space that could be transform for other uses such as economic } \\
\text { benefits or social activities }\end{array}$ \\
\hline Respondent 10 & $\begin{array}{l}\text { Lost space is a place that no activity, no people walk around and nothing been } \\
\text { really taken care of }\end{array}$ \\
\hline
\end{tabular}

Table 5.

Comparison of definition between prescriptive and descriptive of lost space.
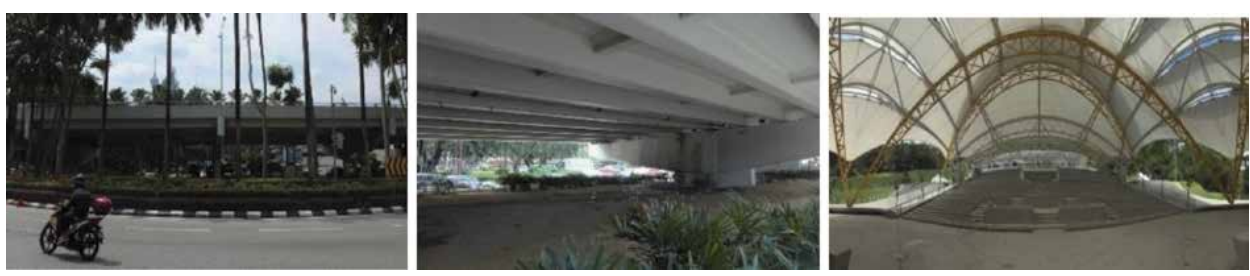

Figure 3.

Lost spaces identified by the respondents include (i) roundabout in Jalan Kuching, Kuala Lumpur; (ii) viaduct of Jalan Kuching - Jalan Tun Perak, and (iii) Panggung Anniversari.
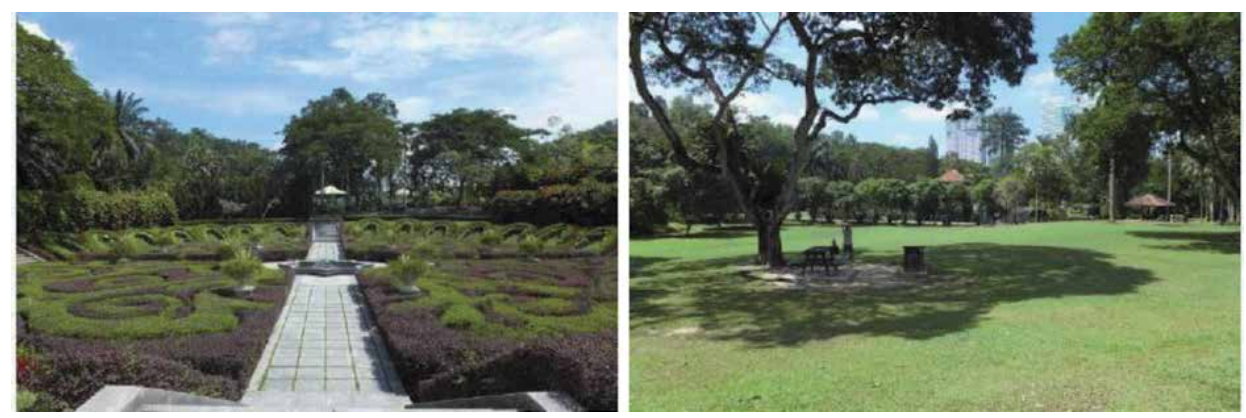

Figure 4.

Respondents highlighted the Perdana botanical garden is well maintained. However, due to the lack of interesting activities, poor connectivity and accessibility, thus contribute to lost space.

For the purpose of determining whether an exact location conforms to the characteristics of prescriptive and or descriptive lost space, these specific areas of Kuala Lumpur mentioned by the respondents were fit into the typologies of prescriptive lost space. Table 5 summarizes the respondents' understanding on lost 
spaces in Kuala Lumpur. The results show that there is the conflict between the characteristics of prescriptive and descriptive of lost space. In fact, the respondents reported that the parking lots are not a lost space because it is a part of public facility. People create loose space through their own actions and behavior [14]. These urban spaces possess physical and social possibilities for looseness, being open to appropriation, but it is people, through their own eyes and understanding, who fulfill these possibilities in social context. From the results, the emergence of a lost space depends upon; people's perspective of the potential within the space, and second, varying degrees of creativity and determination to make use of what is present, with possibility of modifying existing elements or bringing in additional and temporary uses (Figures 3-6).

In further discussing of the definition of lost space, Table 6 below shows the comparison of characteristics between prescriptive and descriptive of lost space. According to the findings, respondents describe the characters of descriptive lost space was divided into fivecategory; activity includes economic and social, connectivity, accessibility, design and maintenance. These five characters of descriptive fit into the typology of prescriptive lost space by Trancik, Loukaitou - Sideris, and

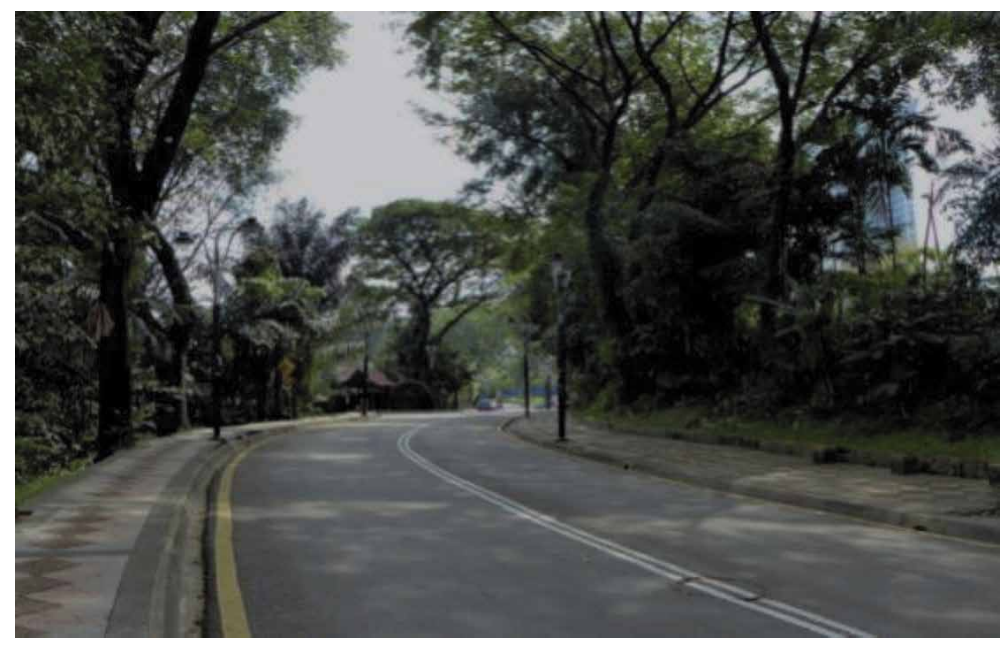

Figure 5.

Jalan Lembah, Kuala Lumpur, a street that found lack of activities and pedestrian infrastructures. A greater variety of streets and land uses stimulate the emergence of loose space.
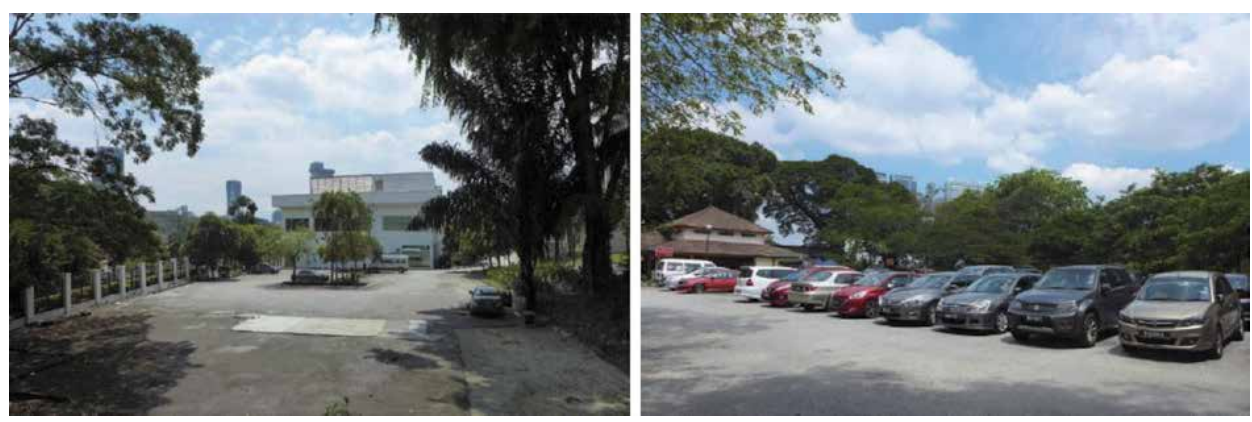

Figure 6.

The vacant lots and abandoned spaces turn into parking lots which has no necessary relation to ownership, size, type of use, or even landscape characters. 


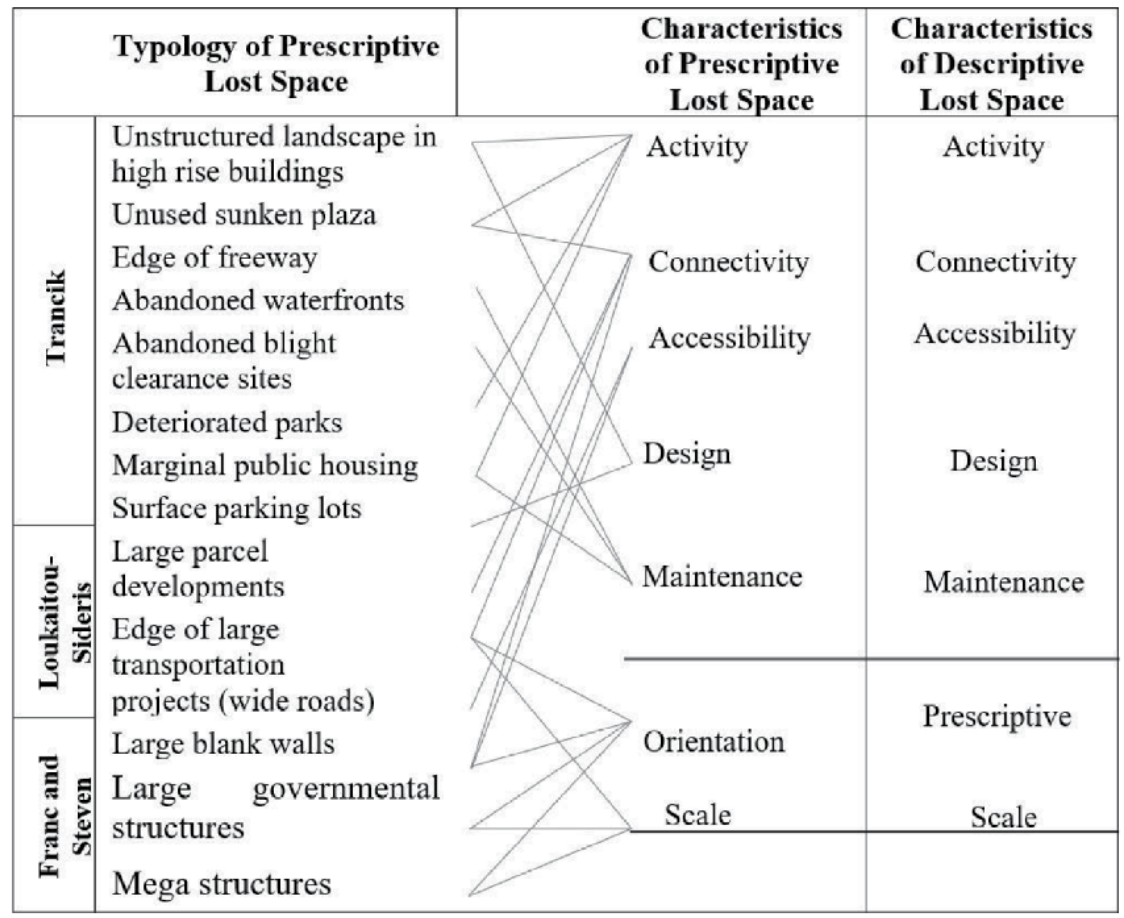

Table 6.

Comparison of characteristics between prescriptive and descriptive of lost space.

Franc and Steven. The activity refers to the activity in unstructured landscape, unused sunken plaza, abandoned blight and deteriorated parks. While for design characters refer to unstructured landscape ad marginal public housing. This thus concerned with the contrasting roles of design normally associated with protecting the community's interest in the environment and with the role of maximizing a developer's profit. For example, the provision of public housing (known as affordable houses in Malaysia) for low and middle-income groups did not take into account wider issues, such as the qualities of the environment which make it both

\begin{tabular}{|c|c|c|c|c|c|c|}
\hline & $\begin{array}{c}\text { Typology of Prescriptive } \\
\text { Lost Space }\end{array}$ & Areas & $\begin{array}{l}\text { Prescriptive } \\
\text { Lost Space }\end{array}$ & $\begin{array}{c}\text { Prescriptive } \\
\text { Characteristics }\end{array}$ & $\begin{array}{l}\text { Descriptive } \\
\text { Lost Space }\end{array}$ & Prescriptive Characteristics \\
\hline \multirow{5}{*}{ 曾 } & Unstructured landscape & $\begin{array}{l}\text { Kompleks Daya } \\
\text { Bumi }\end{array}$ & $\bullet$ & $\begin{array}{l}\text { Activity, connectivity, } \\
\text { accessibility }\end{array}$ & 0 & 1 \\
\hline & Edge of freeway & Jalan Kinabalu & $\bullet$ & $\begin{array}{l}\text { Activity, connectivity, } \\
\text { accessibility }\end{array}$ & - & Activity, connectivity \\
\hline & Abandoned waterfronts & $\begin{array}{l}\text { Along Klang River } \\
\text { and Gombak River }\end{array}$ & - & $\begin{array}{l}\text { Activity, connectivity, } \\
\text { accessibility }\end{array}$ & - & $\begin{array}{l}\text { Activity, connectivity, } \\
\text { accessibility }\end{array}$ \\
\hline & Deteriorated parks & $\begin{array}{l}\text { Taman Tasik } \\
\text { Perdana }\end{array}$ & - & $\begin{array}{l}\text { Activity, connectivity, } \\
\text { maintenance }\end{array}$ & $\bullet$ & $\begin{array}{l}\text { Activity, connectivity, } \\
\text { accessibility, maintenance, } \\
\text { scale }\end{array}$ \\
\hline & Off-street parking & Parking space & 0 & Connectivity & 0 & 2 \\
\hline \multirow[b]{2}{*}{ 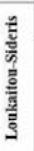 } & Large parcel developments & $\begin{array}{l}\text { Taman Tasik } \\
\text { Perdana }\end{array}$ & 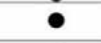 & $\begin{array}{l}\text { Connectivity, } \\
\text { accessibility }\end{array}$ & - & $\begin{array}{l}\text { Activity, connectivity, } \\
\text { accessibility, scale }\end{array}$ \\
\hline & $\begin{array}{l}\text { Edge of large transportation } \\
\text { projects (wide roads) }\end{array}$ & Jalan Kinabalu & ? & Activity, accessibility & - & Activity, accessibility \\
\hline \multirow{3}{*}{ 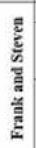 } & Large blank walls & & & & 0 & \\
\hline & $\begin{array}{l}\text { Large governmental } \\
\text { structures }\end{array}$ & & & & 0 & \\
\hline & Mega structures & & & & $\mathrm{O}$ & \\
\hline
\end{tabular}

Table 7.

Comparison between areas of prescriptive and descriptive lost space according to the definitions. 
enjoyable, pleasant, and safe to use throughout a 24 hour day. Housing schemes were based on the home as a defended space not a as a lost space (Table 7).

\section{Notes}

1. Only one respondent highlight the issue of lack of activity in area of Kompleks Daya Bumi.

2. None of the respondent report that the parking areas in KL Historical Zone was lack of connectivity. Most of the respondents indicate that parking are necessary to facilitate their daily life, therefore they assume it as not a lost space. However, one respondent report that due to the single use of the space, it has been caused to be as wastage of space instead of lost.

\section{Conclusion}

Having the understanding on the differences between prescriptive lost space and descriptive lost space, it is apparent that the respondents in this research perceive Kuala Lumpur to be lacking activity, connectivity and accessibility, and therefore, has descriptive lost space potential. The respondents also perceive that more social economic activity would help prevent descriptive lost space, especially if those activities had better connectivity and accessibility with the surrounding.

It is crucial to trigger the relevant bodies' interest by highlighting certain basic principles in planning for a better space design and planning in urban core areas. As conclusion, both political commitment and public investment are required. It is not the planning system per se which is at fault. We need a strong planning system. It is possibly the way that it is operated that needs review. There needs to be greater sensitivity in the application of planning laws to better control over the location of high buildings, infrastructures, public spaces, greater regard for historic areas, better understanding of the organic growth of urban core and a striving for higher quality in building and space design.

Additionally, there has always been a strong relation between commerce and urban public space, and strong exclusionary tendencies among those with management and ownership responsibilities. It is surprising that corporate interests are determined to take responsibility for public spaces when the public sector has often done such a poor job in managing the spaces for which they are responsible, spaces that still make up the large majority of the public realm.

\section{Acknowledgements}

The author gratefully acknowledge the support of Universiti Teknologi MARA, Centre of Studies for Town and Regional Planning and all the anonymous who willingly to participate in the interview. 


\section{Author details}

Nurul Shakila Khalid

Faculty of Architecture, Planning and Surveying, Centre of Studies for Town and Regional Planning, Universiti Teknologi MARA Selangor, Selangor, Malaysia

*Address all correspondence to: sabirah_hilal@yahoo.com

\section{IntechOpen}

(C) 2020 The Author(s). Licensee IntechOpen. This chapter is distributed under the terms of the Creative Commons Attribution License (http://creativecommons.org/licenses/ by/3.0), which permits unrestricted use, distribution, and reproduction in any medium, provided the original work is properly cited. (cc) BY 


\section{References}

[1] Krier R, Rowe C. Urban space. London: Academy Editions; 1979

[2] Carmona M. Contemporary public space: Critique and classification, Part one: Critique. Journal of Urban Design. 2010;15(1):123-148

[3] Loukaitou-Sideris A. Cracks in the city: Addressing the constraints and potentials of urban design. Journal of Urban Design. 1996;1(1):91-103

[4] Trancik R. Finding Lost Space: Theories of Urban Design. New York: Van Nostrand Reinhold; 1986

[5] Sommer R. Tight Spaces: Hard Architecture and how to Humanize it. Old Tappan: Prentice-Hall; 1974

[6] Madani-Pour A, Madani A. Design of Urban Space. 1996. Academy

[7] Montgomery J. Making a city:

Urbanity, vitality and urban design. Journal of Urban Design. 1998;3(1): 93-116

[8] Tibbalds F. Making People-Friendly Towns: Improving the Public Environment in Towns and Cities. London: Spoon Press; 2001

[9] Franck K, Stevens Q. Loose Space: Possibility and Diversity in Urban Life. London: Routledge; 2006

[10] Azhar J, Gjerde M. Re-thinking the role of urban in-between spaces. In: Zuo J, Daniel L, Soebarto V, editors. Fifty Years Later: Revisiting the Role of Architectural Science in Design and Practice: 50th International Conference of the Architectural Science Association 2016. Adelaide: The Architectural Science Association and the University of Adelaide; 2016. pp. 279-288

[11] Anuar MINM, Ahmad R. Elevated highways and its lost spaces: A review of
Kuala Lumpur? s seldom seen. Environment-Behaviour Proceedings Journal. 2017;2(6):279-291

[12] Carmona M, Heath T, Oc T, Tiesdell S. Public Places - Urban Spaces: The Dimension of Urban Design. Oxford: Architectural Press; 2010

[13] Hajer M, Reijnorp A. In Search of New Public Domain. Rotterdam: NAi; 2001

[14] Krier R, Ibelings H, Meuser P, Bodenschatz H. Town Spaces: Contemporary Interpretations in Traditional Urbanism: Krier-KohlArchitects. Basel: Birkhauser; 2006 



\title{
Integrated Approach towards Participatory Development of Urban Neighborhood Spaces: Chennai, India
}

\author{
Abdul Razak Mohamed
}

\begin{abstract}
The social living of the urban households depends on the physical manifestation of spaces arranged to carry out their day-to-day activities of members including children, adult, women, men, old age, and differently able persons. Urban neighborhoods undergo changes in the spaces in house and building, places in a locality, and the overall built form. The city spaces experience transformation in the house spaces and common places, and the built form experienced the residential character change towards commercial and other nonresidential uses in the neighborhood. The impact of the spatial transformation demands to make redevelopment strategies to resolve the conflict between residential and commercial spaces in the neighborhood. So, the need for an integrated approach towards "Participatory Redevelopment" (PRD) of the urban neighborhood becomes a challenge for the city planners. The new planning model on PRD as an integrated approach developed by the author is followed in the redevelopment project hosted by the Corporation of Chennai. The PRD approach used "C-TC-C" model to follow participation as "Collective-Target Centered-Collective". The PRD adopts the approach called the five-pillar system (FPS). These aspects are the main focus of this chapter within the context of T. Nagar, a residential neighborhood transforming into a busy retail commercial market area and residential living and parking spaces situated in the midst of Chennai City, the capital of the Tamil Nadu State in India.
\end{abstract}

Keywords: participatory planning, urban neighborhoods, redevelopment, integrated approach, five-pillar system, collective and target-centered collective participation

\section{Introduction}

Sociologists deal with the society in three ways such as (a) how is the world come about, (b) what way people differ from one social setting to another, and (c) which direction the society move towards the future. The concern is towards the past, present, and future of the society which are very much important in terms of human settlement planning. Before the invention of various methods and approach to socioeconomic and physical planning, it was people-centered planning. Due to the advancement of education, science, and technology, the 
policy makers and planners while making plans for the socioeconomic or environmental development often ignore, neglect, and exclude the people. The advent of globalization and urbanization brought about change in the governance system of the local government transforming from people-centered planning and development (PCPD) to government-centered planning and development (GCPD). The necessity of people's participation in the public spheres of life is an important agenda of spatial planners, academicians, politicians, and policy makers around the world.

The greater transformation is noticed that the public participation is institutionalized by various means such as inclusion of stake holders by conducting meetings and discussion during the planning process. This is evident from the preparation of regional plans, master plans, and urban area-level redevelopment projects by the state and district development agency and urban local government. This chapter highlights two aspects such as (a) theoretical understanding as well as (b) practical experience of the author while doing collaborative work such as (i) the expert from planning school in association with a corporate planning agency and the city local government in preparing redevelopment plan for a transforming retail commercial area from a planned residential area of a metropolitan city.

The chapter draws lessons gained from the practical experience based on the case study from the southern state of India which is Thyagaraya Nagar (T. Nagar) in Chennai City, Tamil Nadu State. The chapter also attempts to bring out the importance of coordination between the corporate sector, local government, and academic institution in preparation for an urban area-level redevelopment planning.

\section{Participatory planning: an overview}

Urbanization trend in India results in diverse problems experienced by urban dwellers such as crowd, congestion, lack of urban infrastructure, proliferation of informal settlements, and unsafe and unsecure living. The innovative method to address these issues that have been gaining popularity is "people participation" in the planning and development of towns and cities. It is appropriate to state that people's participation in urban planning can empower communities which can lead to better planning of urban development programs and projects. This could result in planned development including redevelopment of specific areas of urban centers which leads to sustainable urban development. Sustainable urban development policies should consider (a) balanced development of small, medium, and big urban centers and (b) the cooperation between public and private sector. Future policies on sustainable development should include the aspects such as (a) the balanced development of (i) small and medium towns and (ii) small and large urban centers, (b) the cooperation between public and private sector, and (c) the development of local and community-based strategies. In India, sustainable development has also been widely recognized during 2015 and established institutions at national, state, and local levels. However, there is a need for an extensive research on the methods and approaches followed in different countries and it is essential to know the international experiences. This will be of a valuable tool for clarifying various issues/aspects related to sustainable development and subsequently developing appropriate guidelines.

Historically, in India there is lack of opportunities for the common people towards participation in plan preparation, including elected representatives, private sector and urban local communities in general. Urban local governments at various 
levels are institutionally disintegrated and fragmented, lacking capacity as well as resources. Some countries in the Asia have made progress with regard to participatory urban planning. In India, for example, the central and state governments have adopted a variety of measures to increase people participation and government responsiveness and accountability at different levels. However, in practice, local government autonomy in India is restricted by limited resources [1].

It is appropriate to state that in the Netherlands there has been an increase in the use of regional design-led practices in national indicative planning. However, the link between design and decision-making is not well understood, but to involve the expertise and add the interest of designers in planning have had unclear outcomes. Since decentralization and deregulation became issues in Dutch planning, design is also expected to be made with the political and organizational settings [2]. The debate about the new integrated Environment and Planning Act (Omgevingswet) in the Netherlands. Initially, the government proposed abolishing local land use plans and replacing them with a system of bylaws.

Participatory urban planning process is a viable urban management tool that focuses on (a) mutual partnership and continuous interactions between planners, government officials, elected representatives, and the community for incorporation and convergence of knowledge, skills, and resources to prepare a plan and (b) which people can relate to and can show their interest, can have the feeling of ownership, and can have concern for investment since the decisions directly benefit them.

So, once the plans get implemented which are more sustainable and the process can help the government and people to reduce operation and maintenance costs as well as the local stakes generate ownership on the planning and development.

The growth and expansion of cities in India experienced an imbalance in the development of infrastructure in the periphery/peri-urban areas of the cities. Suburbanization of an urban area could generate migration between the city and its suburb. People's migration decisions can be associated with migrant age, stage of life, economic condition, employment situation, race, sex, education, distance to the destination, and other variables [3]. There is a strong difference between the peri-urban areas of developing countries characterized by pollution of land and waterways, poverty, and informal settlement and those of developed nations of Europe characterized by low levels of mobility, economic performance, landscape integrity, and environmental quality. Within both the developed and developing world, one must recognize the different nature of the territory and the variety of peri-urban areas it contains [4]. Peri-urban areas have enormous potential to play a positive role in enhancing urban sustainability at different levels. This is because cities in all countries have to face the challenges posed by urban sprawl. As per the United Nations, the population growth and urbanization are projected to add 2.5 billion people to the world's urban population by 2050, with nearly $90 \%$ of the increase concentrated in Asia and Africa [5].

Participatory planning is largely being acknowledged by planners, practitioners, and academicians as the suitable planning approach to overcome the gaps in the existing "top-down" method of planning. Participatory planning is a process wherein the local communities address the professional urban planners about their developmental needs and about the potential resources of the region, which can be used. Planners work together to produce plans of the settlement that address the identified priorities of the people at local level.

\section{Participatory planning and planning profession in India}

In India, the practice of Master Plan Approach was generated during the Third Five Year Plan (1961-1966), when the central government provided full financial 
assistance to the state governments to set up town planning departments. The creation of town planning departments is meant for preparation of Comprehensive Master Plans for the fast-growing cities and towns. This was supported by a legislative framework based on the Model Law formulated by Town and Country Planning Organization (TCPO). The need for master plan has been clearly defined in various town planning acts of the states and other relevant legislations. Basically, it is a statutory instrument for controlling, directing, and promoting the sound and rational development and/or redevelopment of urban areas with a view to achieving maximum economic, social, and aesthetic benefits.

Urban planning conventionally has been viewed as land use planning through Master Plan Approach or Development Plan Approach following the zoning regulations, the development control regulations, and bylaws which are the legal tools of intervention in urban development, creating exclusions of the people and their needs and aspirations. In India the local governments gain importance when the country enacted the 73rd and the 74th Constitutional Amendment Act (CAA), in 1992. This amendment targeted at a redistribution of powers to enable local bodies which are closer to local issues to respond more quickly and efficiently. However, the practices in participatory planning in Indian cities become disjointed and failed to implement decentralization processes. The people involvement and participative planning in India is collaborative between the government and citizen towards the development of their local areas. According to the World Bank, participatory planning is "a process that convenes a broad base of key stakeholders, on an interactive basis, in order to generate a diagnosis of the existing situation and develop strategies to solve jointly identified problems." Urban planning needs an overview of the situation and public interest that must lead the decision-making. It has been demonstrated that the state alone can deliver this and that markets cannot. In the past, the city of Chennai in Tamil Nadu state has been at the forefront of the innovative planning ideas. It is the time city planners get proactive and regain their cutting-edge thinking [6].

The regional planning approach followed in Indian cities carry rich historical legacy and geographical diversity. They offer an array of economic and cultural profile. The urbanization process in India has resulted in the development of urban conurbations or polycentric urban agglomeration and metropolitization. The Urban and Regional Development Plan Formulation and Implementation (URDPFI) Guidelines of 2014 acknowledge the symbiotic relationship of the rural and urban areas and emphasize on the regional planning approaches as a guide for future development. This approach will maintain a rural-urban continuum and facilitate regional hierarchy by integrating and strengthening the urban centers and surrounding rural areas.

People participation in urban governance has become a concern for many in recent times in developing countries. Many examples and methodologies towards people participation in development and governance have been evolved and upscaled in the last two decades. However, most of the efforts have been used in the rural development planning contexts, whereas very few in urban contexts in India. The existing legal framework of urban planning and governance in small and medium municipalities does not support people participation. The efforts from civil society organizations to promote people participation in urban planning are also very limited due to a variety of reasons [7].

Participation has always been a concern in development practice, particularly since the 1960s. In the early years, many practitioners worked with communities at a local level as individuals or in small groups. During the 1980s, the focus on participation was upscaled. This was reflected in the introduction of decentralized planning and the creation of participatory institutionalized structures through the 
74th Constitutional Amendment Act of 1992, along with other larger economic reforms initiated in the early 1990s [8].

Spatial planning is an important aspect of any planned development. It is vital for provision of serviced land and lying down of infrastructure further to which "development" takes place. Spatial plans are prepared in the form of Master Plans, Development Plans, Area Development Plans, and Comprehensive Development Plans in India. It is appreciated by many of the planning practitioners that urban areas and the rural settlements should be considered in totality for planning at the district and regional level. Several states in India also have their Town and Country Planning departments for undertaking spatial planning; such exercises for rural settlements have altogether been absent.

Out of about 7933 urban settlements in India, only 3892 qualify to be classified as census towns by the Census of India. From 2001 to 2011, the urban population of India has increased major contribution which was by inclusion of large rural settlements as urban settlements in 2011. Such census towns in India attract migration from surrounding villages, serving as nodal centers or market places and also as centers of socioeconomic activities. The gram panchayat areas surrounding the settlements are used for agriculture, grazing, mining, resource collection, and a variety of other uses. Environmental concerns are also rapidly gaining importance on account of increasing pressure on land and other resources. Planned development is intricately linked with socioeconomic development including poverty alleviation. The need for spatial planning in gram panchayat areas can therefore hardly be over emphasized.

While the Ministry of Urban Development has released the Urban and Regional Development Plan Formulation and Implementation Guidelines, similar guidelines for spatial planning in gram panchayat areas are lacking. The present document is prepared to serve as the guidelines for planned spatial development in gram panchayat areas.

The recent thrust of the Government of India to upgrade urban infrastructure and basic services through a comprehensive program (Jawaharlal Nehru National Urban Renewal Mission (JNNURM) and Urban Infrastructure Development Scheme for Small and Medium Towns), by developing City Development Plans (CDPs) through a community consultative process, is step forward in endorsing and recognizing participatory method of urban planning as a precursor to any sustainable city development strategy.

\section{Participatory planning: a collaborative venture}

The driving force of town planning in India today is towards people and technology centered rather than the conventional government and finance centered. The transformation from centralized to decentralized system of town planning in India is institutionalized and demands more on objective learning environment rather than the subjective learning environment in the town planning schools. The innovation in education system is a must to cope with the tremendous change in the aspirations of modern society, greater access to better information and communication technology, and high-powered infrastructure facilities and services in cities. The provision approach (the government sector project planning) vs production approach (the private sector project implementation) towards building city infrastructure and rebuilding neighborhoods becomes evident in the city planning approaches in India.

Conventionally government-based town planning practices avail support of academics in making development plans/master plans for towns and cities. Later the practice changed into consultative groups making plans with management agenda. 
The shift was evident from the academic-based planning practice to corporate sector both as national- and international-based making of plans for cities and towns. But the implementation part of the plans is with the government. The planning education play an important role in importing knowledge, training, research, and consultancy work in the field of town and country planning and development. In practice, the emergence of local and multinational corporate sectors venture into preparation of development plans/master plans is due to the slow growth of academic and learning environment in planning schools in India. Also the organizational climate in planning schools in India both in terms of administrative and academic activities changes the planning practice as corporate and academic collaborative activities. The joint ventures, that is, the academics joint with the corporate sector and practice planning profession as consultative mode is more prevalent in India. This is evident from the program implementation of the Jawaharlal Nehru National Urban Renewal Mission such as preparation of city development plans and detailed project reports for many cities in India.

Participatory planning in the wake of globalization and invention of information and communication technology that facilitates the people involvement in planning is easy as well as saves time and cost. The creation of opportunity by the planning agencies and local government towards public participation is essential and important. In this process the planning education should integrate the people collaborative efforts in educational exercises as well as take actions towards local area development. In this regard the following sections state the practical experience in doing collaborative urban and regional planning exercises.

\section{Collaborative planning project: $T$. Nagar redevelopment plan-experiences}

Understanding society is an important step towards formulating and undertaking measures to direct growth and change in the physical form and social harmony. Consultative process recognizes the importance of creating opportunities and facilitates the people to involve and participate in the planning and development of their local area.

The urban redevelopment is a process of controlled development of urban activities in an area which is experiencing growth and change in a haphazard manner in terms of land use, infrastructure availability, vehicle movement, and community activities. The redevelopment strategies set for the area could follow either retaining the structure and functional character of the area or creating a multifunctional character which is set forth by the market force, planning and design norms, and community interest. The existing structure and functions of buildings and streets with the movement of people and vehicles where the residential buildings and roads and streets attract to house trade and commercial activities result in congestion, crowd, environmental destruction, social tensions, etc. The redevelopment efforts should focus on the physical form and patterns of the area, the social, economic, and environmental concern of the community living in it. So the consultative process is important and considered to understand the social acceptance and responsibility of the local community in the redevelopment.

\subsection{Innovation in planning profession}

The corporate sector and academic sector involvement in making a redevelopment plan for T. Nagar, Chennai, is a very new attempt and first of its kind in India. In academic language as per Anna University, Chennai, the university-industry 
collaboration in demanding and doing social-oriented innovative development plan for the redevelopment of an area in a city is a new chapter in the history of the university-industry collaborative planning. Here to mention that, my experience with the corporate sector JLL in association with TOWNLAND Consultants from Hong Kong is very unique and encouraged to initiate the participatory planning in preparing a redevelopment plan for T. Nagar as Social Development Expert. The motivating factor from my side and the JLL team regional head and other members are my students of M. Plan Housing and urban planning during 1994-1996 Session (from the School of Planning and Architecture (SPA), New Delhi, where I was a faculty member in the Urban Planning Dept from 1990 to 2003). As per the invitation from the team on seeking to work as a team member in the project, it was a unique experience in involving many stages of the project to specifically devise a new method of conducting the consultative meetings at various stages. It is by evolving "Makers-Users Centered Approach" (MUCA) to the consultative process [9].

\subsection{T. Nagar: a residential area to retail business place in Chennai City}

Until the early 1900s, the villages to the west of Mount Road of Chennai City formed a part of Chengalpattu District. A residential suburb was conceived in the middle of this reclaimed land by the Justice Party government of the Raja of Panagal; a park was developed at the center of this new locality and was named, in honor of the then Chief Minister, as Panagal Park. Soon afterwards, the Pondy Bazaar began to make its existence. The broad roads in this new locality were treelined, as were other parts of the city, and were named after stalwarts in the ruling Justice Party then. Nalli's showroom was the first prominent shop to establish in the area during the year 1935. From the 1950s onwards, Thyagaraya Nagar has steadily risen as the most preferred shopping centers in Chennai city. The place is an important center for shopping and entertainment and also a major hub for the intracity bus service.

T. Nagar is a foremost commercial hub in the city of Chennai. Chennai City is the capital of the Tamil Nadu State (Figure 1). T. Nagar is located in the southern precincts of the city and has been named after a distinguished leader, P. Thyagaraya, of the Tamil Nadu State. The adjoining regions of T. Nagar include Teynampet, West Mambalam, and Azeez Nagar. In fact, the place has been referred by many as East Mambalam.

T. Nagar provides some of the best shopping centers, business establishments, accommodation, and other commercial enterprises. The location of T. Nagar is shown in Figure 2. Apart from being an important center for shopping and entertainment, T. Nagar is also a major hub for the intracity bus service. Historically, it was planned as residential neighborhood with roads and streets radiating from Panagal Park for the movement of the residents and developed into an exclusive shopping area which attracts visitors from various parts of the country for shopping. T. Nagar has shed its original character and has huge stand-alone shopping centers as well as a sizeable informal business sector. This has paved way for the present traffic and congestion problems. Despite better bus and rail facilities, people see a lack of integration especially when the pedestrians face problems to move around. The shopping during festivals, like Deepavali (during November), Navaratri (during October), Ramzan, Bakrid, and Pongal (during January), brings additional traffic and people movement to the area due to the heavy discounts and reductions offered by dealers. So far, all development projects have looked primarily at traffic improvement and were implemented on a piecemeal basis.

T. Nagar area have three major parks like Natesan Park, Panagal Park, and Jeeva Park as major green and lung spaces in the locality. Due to the vibrant residential 


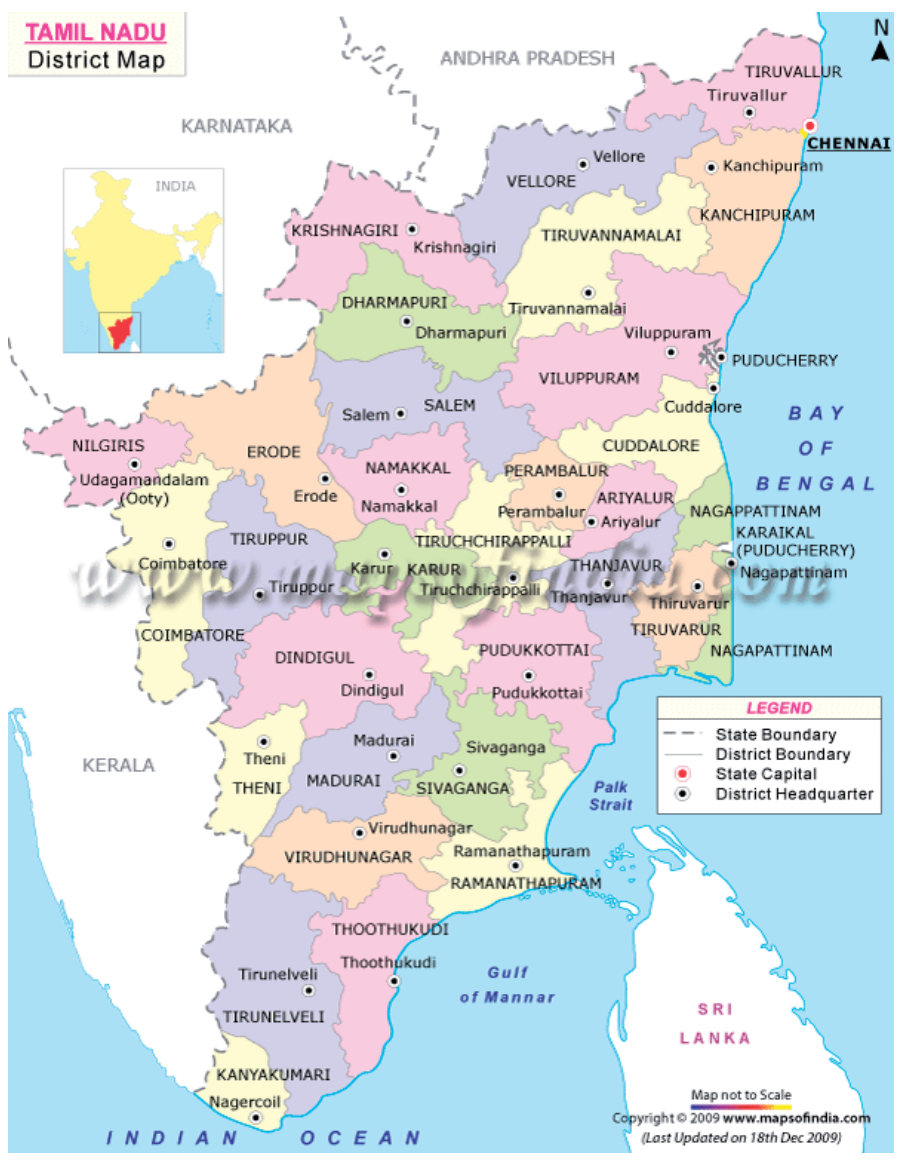

Figure 1.

Location of Chennai in Tamil Nadu.

T . Nagar - Major Parks and Open Spaces

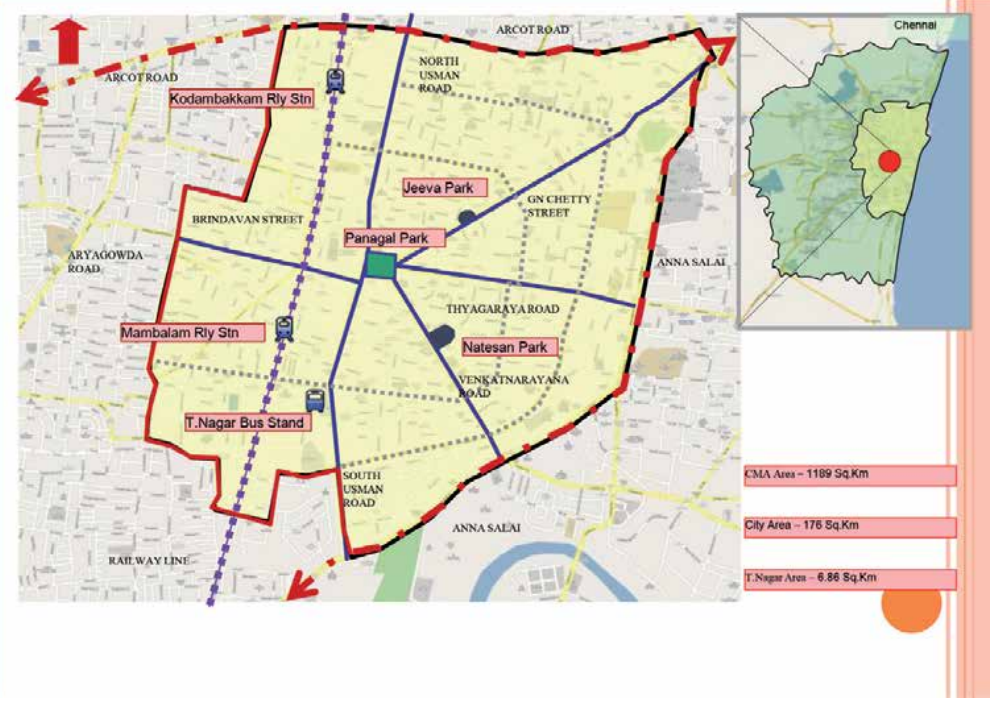

Figure 2.

Location of T. Nagar in Chennai. 
and commercial activity in T. Nagar, there is a presence of good number of banks, healthcare units, and renowned schools.

\subsection{T. Nagar redevelopment strategies}

The redevelopment plan follows strictly the concept of inclusive planning, on land and building acquisition. Inclusive strategy is used to the redevelopment of buildings, streets, foot paths, parks, market streets, bus stand, flyover, and public places including the inclusion of street venders and business activities. Placemaking, walkability, a sense of open realm, and raising tress are considered as very important elements of redevelopment plan. The methodology followed in the preparation of redevelopment plan showing the different stages of consultation meeting conducted is shown in Figure 3.

Placemaking has been for years at the forefront of redevelopment projects in (sub) urban city centers, particularly the USA. The core objective of this planning principle is to create memorable public places that have character and spaces that make people want to stay and visit again and again. The public realm in many city centers had over the years been taken up by traffic and commercial uses and been efficiently designed around the flow of cars. Placemaking is not just about pedestrians staking back a claim on the public realm but moreover about how to create spaces that entice people to interact, to meet others, to enjoy the outdoors, and to feel part of a community. Different aspects of implementing placemaking are, e.g.: walkability-is ensured through the re-establishment of pedestrian-friendly pavements and public spaces, walkable block distance, and building orientation and landscaping to enhance shading and ensure comfort for the pedestrian. A safe, open realm-a well-lit, open public space is essential to reduce crime and further encourage the growth of a strong community. Introduction of more trees and low
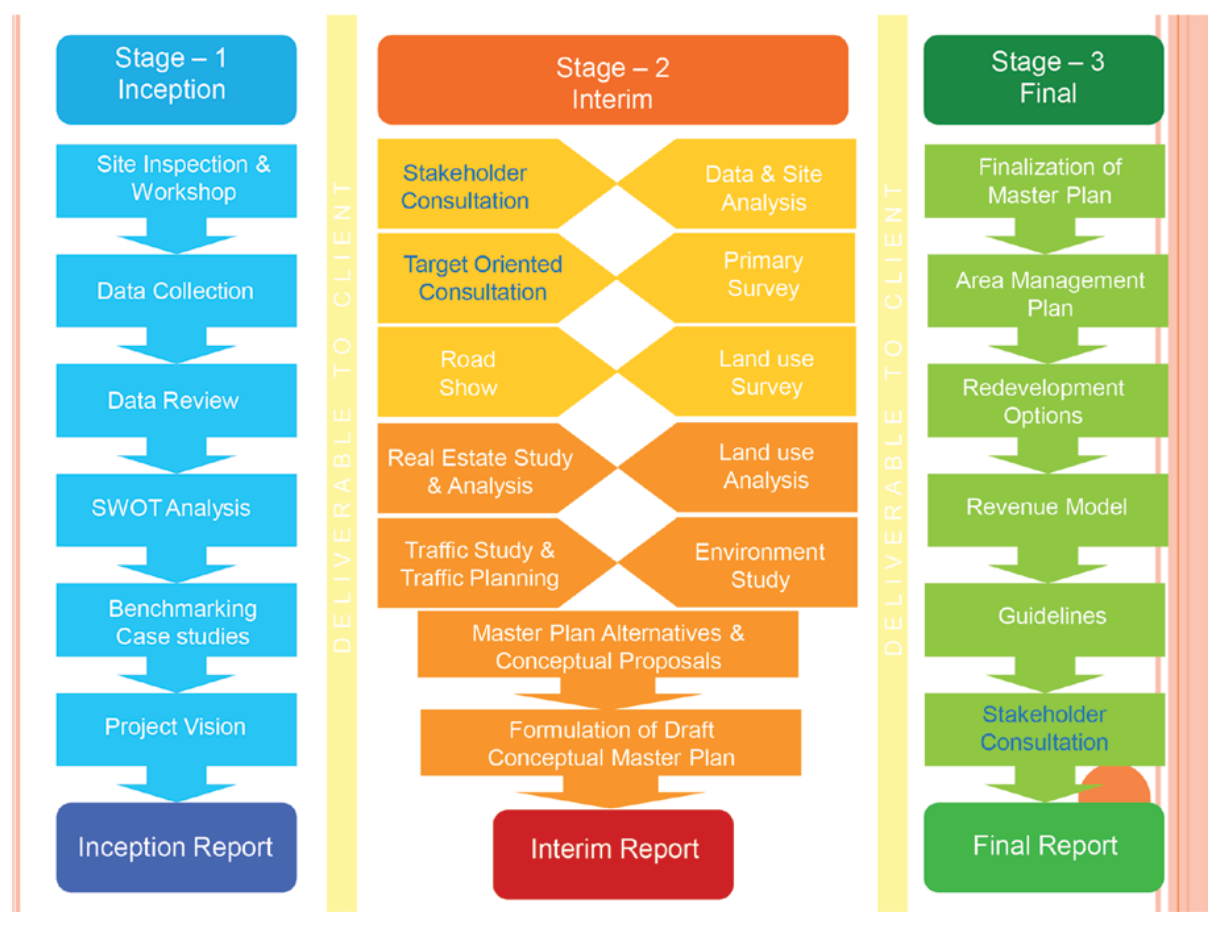

Figure 3.

The consultation stages in the overall methodology of the project. 
shrubs-a well-designed landscaped environment is envisaged to add to the physical beauty of the area and to extend the tree cover, which will encourage residents and visitors to walking instead of using motorized transportation.

Places for interaction through strategically placed points of convergence-the original urban design ensures that pedestrian pathways and key development nodes are laid out in such a way that will create a number of points of convergence, like the Panagal Park. These open spaces are not being used to their full potential at the moment. By improving their design, accessibility, and visibility, T. Nagar shall have a wider range of type of spaces and activities to offer to its residents and visitors alike.

\subsection{Consultative process of T. Nagar redevelopment plan}

Various stakeholders that play a key role in planning area have been identified. This has been done in consultation with TNUIFSL. Mapping of regional stakeholders and exploring potential of a collaborative effort in planning and development have ensured local ownership and sustenance of plan proposals. Consultations with the stakeholders have been carried out regarding each aspect of the study. The consultative process followed is shown in Figure 4. The stakeholders include TNUIFSL, the Corporation of Chennai, the CMDA, the MTC and traffic police, trade owners and T. Nagar area, street hawkers and shoppers of different categories, T. Nagar residents, and other establishment owners. There were three levels of meeting organization which were:

1. Collective consultation (CC) —open consultative meeting to understand the problems and seek the concerns and corrective measures for reducing or solving the problems in general.

2. Target-centered consultation (TOC)—closed to specific groups to address the problems and discuss suitable and alternative solutions and seek consensus.

3. Road show (RS) - open meeting with the shoppers was undertaken on oneto-one basis to understand the problems and best corrective measures.

The consultative process followed in the redevelopment of T. Nagar is a "Makers-Users Centered Approach." "Makers" include the policy makers, planners, and professionals, and the "Users" include the inhabitants; traders, formal and informal; the residents; the customers; the support service providers including tourists; etc. The consultation considered all the stakeholders in the processes of planning for the redevelopment plan in two types using three stages.

The two types of consultation are as follows:

\section{Collective consultation}

\section{Target-centered consultation}

The three stages of consultation can be classified as:

1. First stage is collective consultation.

2. Second stage is target-centered consultation or focused consultation.

3. Third stage again is collective consultation. 
Integrated Approach towards Participatory Development of Urban Neighborhood Spaces... DOI: http://dx.doi.org/10.5772/intechopen.90832

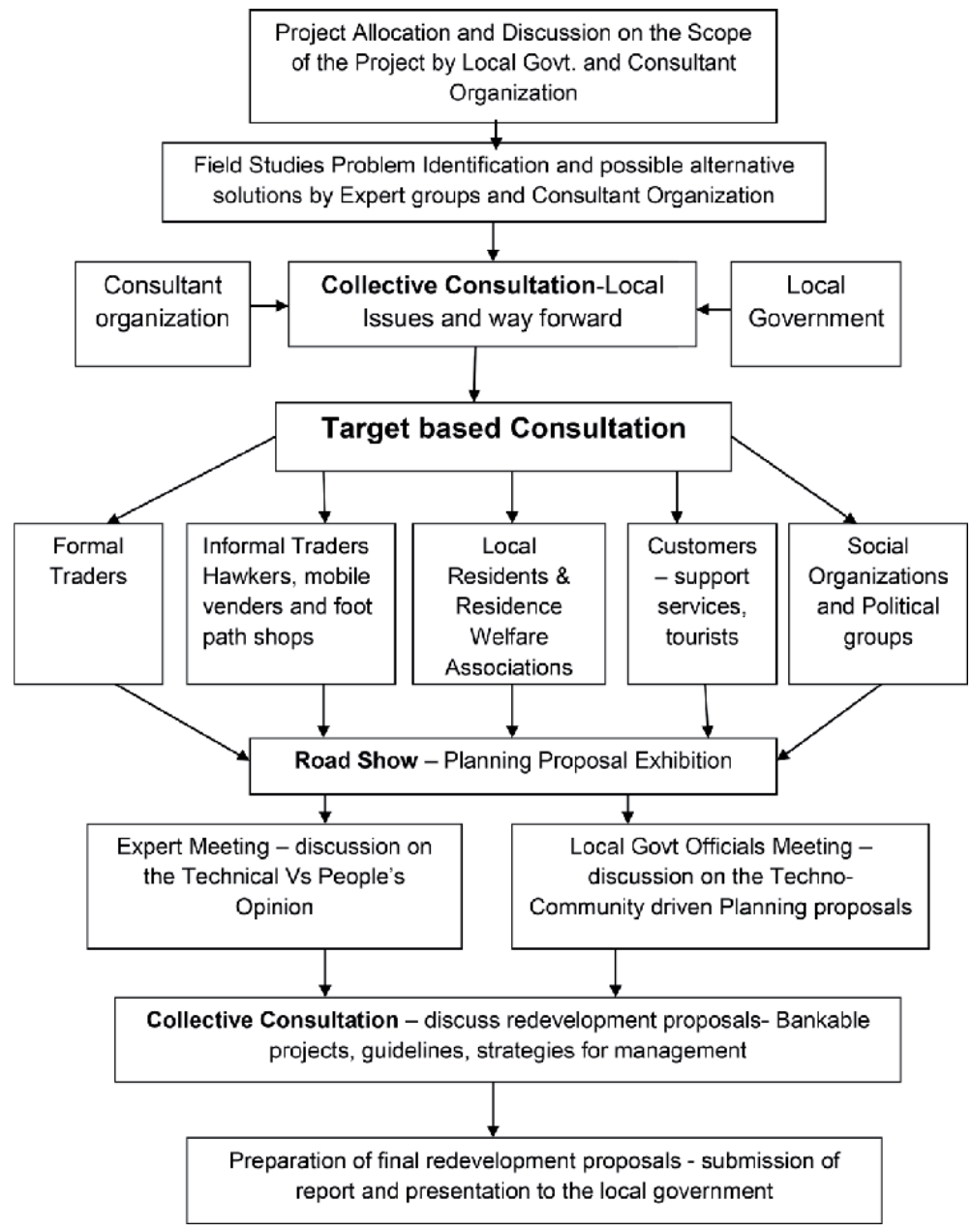

Figure 4.

"Makers-Users Centered Approach" to participatory planning process.

The first stage of the collective consultation has been carried out with all the stakeholders including the makers and users in one platform after the inception stage of the plan. The participants of the meeting (Figure 5) and the group discussion taken are shown in Figure 6.

During the second stage, a series of target-centered consultation has been done (Figure 7) especially with four groups separately such as:

- The residents.

- The formal traders.

- The informal traders or hawkers.

- The social organization and political groups.

- The customers including the support service providers and tourists. A road show was conducted to ascertain their preferences and recommendations. 

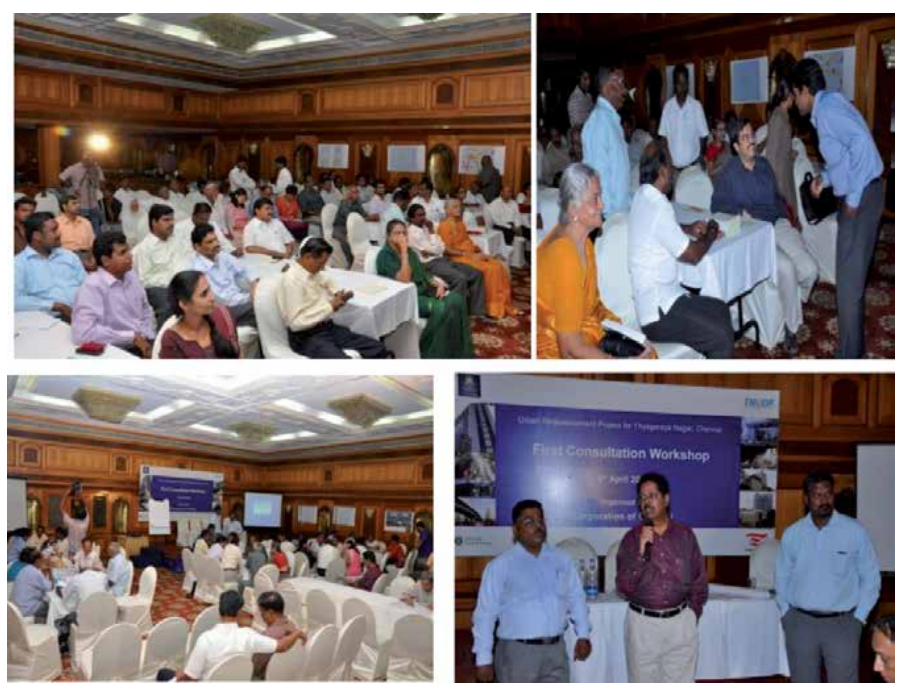

Figure 5.

Participants in the first consultation workshop.

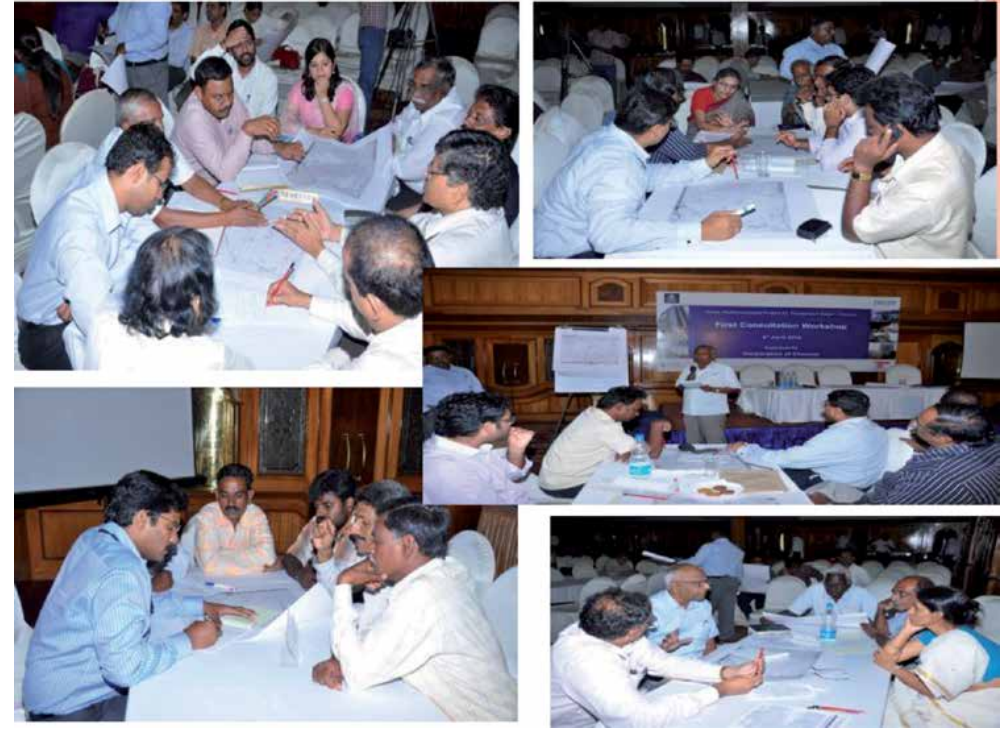

Figure 6.

The group discussion during first consultation workshop on the way forward.

The third stage, a collective consultation that included all the stakeholders, has been carried out to discuss on the redevelopment proposals of T. Nagar with planning guidelines, bankable projects, and strategies for management to facilitate the final report submission.

These consultative meetings have been conducted during the processes of making the redevelopment proposals and incorporated in the final report submission of the project.

The activities during the collective consultative meeting included:

a. Introduction to project by client

b.Presenting aim and objectives of the project by consultant 

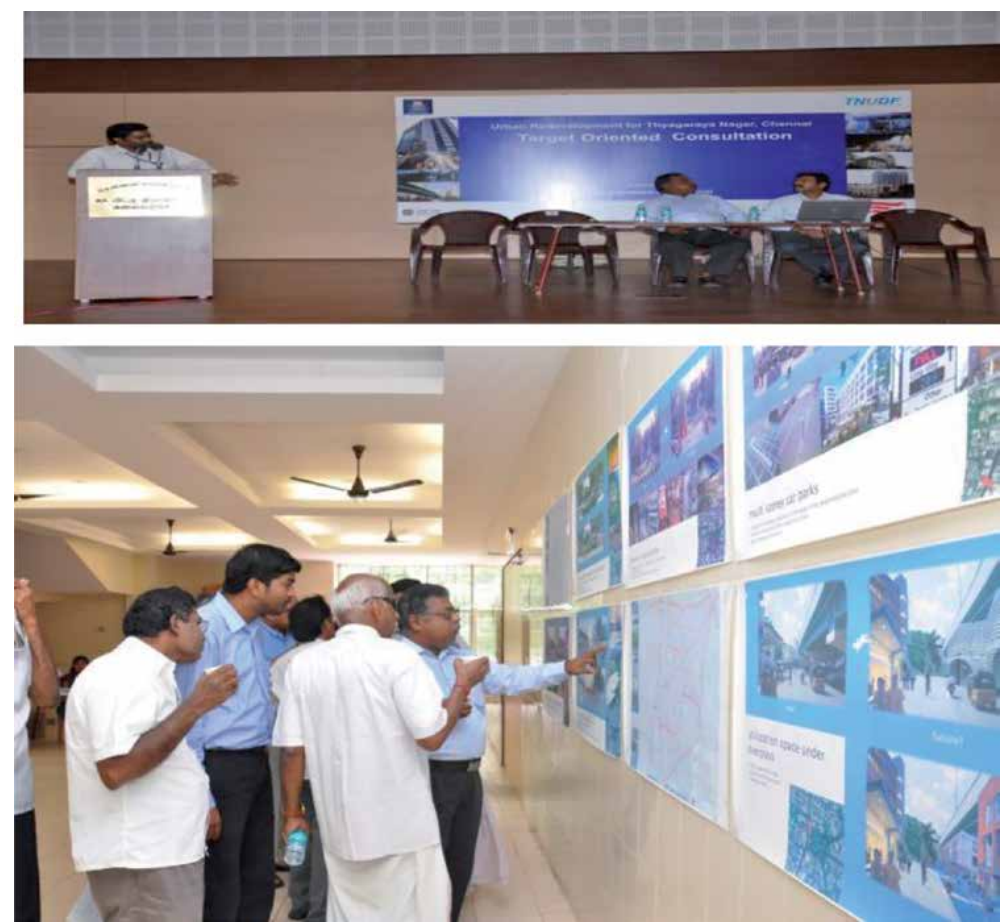

Figure 7.

The participants discuss on the proposal for redevelopment in the target-based consultation meeting.

c. Expression of views by stakeholders on their issues and problems

d.Possible strategies for redevelopment plan by consultant

e. Group discussion on possible solution for different sectors such as housing, transportation, social and recreation, environment, and trade

The activities during the target-centered consultative meeting such as residents, formal traders, and informal traders were conducted separately to focus on their concerned areas, issues, and proposals. The target-based consultative meeting activities include:

a. Presentation on the project with alternative scenario for the redevelopment possibilities

b.Expression on the issues and problems by the participants

c. Question and answer section to discuss the possible planning solutions and management of services

d.Exhibitions with interactive discussions on the alternative planning and design solutions.

e. A structured questionnaire (both in English and Tamil—the local language) was distributed, and the participants were asked to fill up their responses towards their profile, satisfaction level on infrastructure, and preferences on alternative solutions 

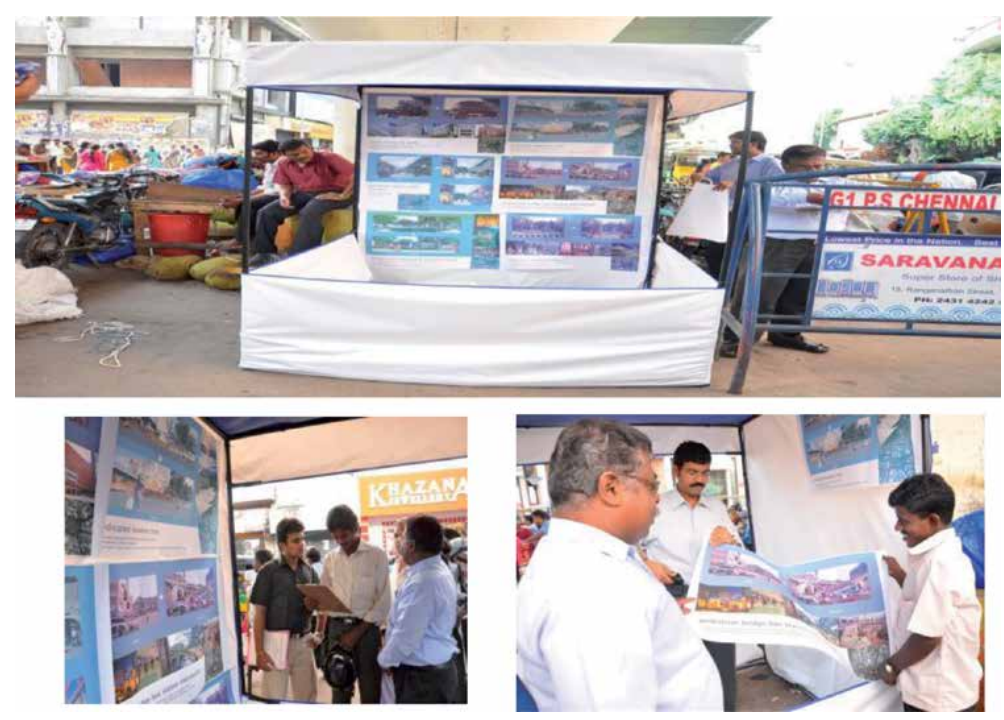

Figure 8.

The road show under the flyover near Pothys.

The customer as target-centered consultation has been done by setting up roadside exhibits on the "T Nagar: Before and After" (Figure 8).

a. Road show with help of a stall—under the bridge near Pothys

b. Exhibits on T. Nagar—bus stand area, Panagal Park area, Pothys area, etc. depicting existing scenario and how it can be transformed in the future

c. A structured questionnaire (both in English and Tamil language) was distributed, and the visitors were asked to fill the same on satisfaction level, preferences towards better facilities and services, etc.

The public consultative meetings of different types and various levels reveal, in true sense, democratic participation of the stakeholders not only as informed but also knowing in advance about the redevelopment initiatives. So this makes it as a participatory redevelopment. The outcome of the consultative meetings and activities helped in drawing attention to evolve the project areas for future development which includes planning and design of infrastructure, environmental improvement, designated space for formal and informal trades activities, improvement of street space, organized parking areas, locating public conveniences, pedestrian areas, public transport arrangement/augmentation, sanitation improvement and management of activities, etc.

\section{Conclusions and future directions}

Planning profession and education needs a paradigm shift from the conventional planning as government-centered delivery of services and facilities to people. It is essential to shift towards people-centered participatory planning and development. Planning profession needs to be seen from the perspective of people engagement in different stages of planning process. Planning education needs to create a teaching and learning environment which involves students and local communities in the planning and local area development. 
The rich tradition of scholarly reflection and debate on the purpose and content of planning education [10] demonstrates educators' concern about providing appropriate skills and knowledge. The theoretical and ideological evolution of the planning agenda-partly driven by practice and partly shaped by academia and research-is clearly reflected in planning education [11]. Most academicians consider the inclusion of new relevant topics that address societal developments vital for ensuring professional relevance and student employability (e.g., $[12,13]$ ). The need for planning integrated with social and economic conditions has been perceived significant enough to spur proposals for a revised "core curriculum" in the USA $[14,15]$ and a comprehensive review of planning education in the UK (Royal Town Planning Institute (RTPI) 2003). It is not only education but also entrepreneurship skills and attitudes that could contribute to the profile of the profession and whether it would be valuable to include such skills in the planning curriculum, i.e., whether entrepreneurship skills represent indeed a missing element in planner's education? Projects involving planning-oriented entrepreneurialism and community involvement are likely to motivate students and provide the excitement many of them seek from a university education [16].

Student-community engagement activity in community planning is essential. This is a subset of university-community engagement and is a point of overlap between such engagement and planning education. Community engagement activity enables students to learn in situ practical skills within live projects, while community partners may benefit from technical know-how and human capital input. Explores the pedagogical design helps to explore the underpinning community engagement activities involving students, as well as the various capacities in which the different participants where students, instructors and community members participate. An alignment of student engagement activities in the planning curriculum with emerging transformative co-learning models of university-community engagement could offer novel opportunities for the discipline of planning and their impact on communities as well as the fields standing in multiversities [17]. In designing teaching activities within the university, the community engagement with a view to understanding the impacts on community participants is important. As impact is unavoidable, it is essential to find out what these impacts are and how they happen, so that in designing teaching activities, harmful consequences are avoided as far as possible (e.g., $[18,19])$.

The multicultural communities living in a "global neighborhood" is a prime example of a major new category that includes a significant presence of nonHispanic whites and blacks along with newer Hispanic and Asian minorities $[20,21]$. The spatial structure of change has implications for the role of spatial proximity and diffusion in contemporary neighborhood racial change. In planning a simple mapping of types of neighborhoods based on their racial/ethnic composition, it could help towards assessing the measures of centralization and adjacency in this metropolitan region. Residential mobility changes over time and brings changes to social structures and cultures of a city [22]. The spatial landscape of an urban area plays an important role in creating inequality among its residents [23].

It is important to consider that planning school is a community and it should promote holistic development and help the learners discover themselves and others as human beings, both graced with life and talents, and be responsible for freely, conscientiously, and creatively nurturing them. The education program should be willing and ready to collaborate with the other members of the planning school community (admin, teaching staff, children, parents, and the local community). The teacher, who is willing to focus on the key areas of approach to the curriculum: imitation, activities in nature, role plan, and planning games. Teachers should have 
a number of teaching hours (to different groups) as well as some in-school preparation time so that the contact hours with the learners are always moments of rich and creative learning.

In India the urban planning approach has experienced that besides top-down approaches, bottom-up perspective in decision-making processes is occurring. Given this fact, it is no longer the question whether the public should be involved but rather with which methods a broader spectrum of citizens can cooperate in planning processes. So, the participatory methods should be evolved aligned with the new characteristics of the contemporary urban settings and utilize the potentials offered by mobile technologies to enhance the citizen participation processes in urban planning.

Urban redevelopment planning should focus on making areas in the cities and towns into better places. The plan should envision a more livable and equitable future for the places where people live, work, play, and connect. The plan should consider what people love about their communities so that the next generation can also enjoy these places. The planners should work to build communities that have minimal impact on the natural environment and provide affordable housing opportunities for all people.

Urban redevelopment planning requires multiple perspectives, including system dynamics and institutional economics approaches as well as traditional urban land use planning. This requires new participatory techniques, and simulation, computation, and games can provide increased opportunities for more diverse inputs and analysis. The planning processes should view the redevelopment area as a complex system with many interconnected parts and consider using computation as a means to enable participation and integration [24].

Community consultation should not be decorative; it should be democratic in its true sense. Community consultation is nowadays just used as a word of fantasy wherein the community has no role to play. This encourages dissatisfaction among the people especially the urban poor, and they lack a feeling of responsibility or ownership of the plan. To support the participatory process, the government must carry out extensive education reforms and empowerment programs in India's school curriculum. Training should be followed up in three levels: state, district, and local. A lot of problems and solutions are tied close to local activities, and the participation of locals becomes significant for its success. Local authorities form the governance closest to the people and play a key role in the promotion of sustainable development. The focus of public participation has thus changed from the implementation of decisions to the nature of decision-making itself [25].

Therefore, it is essential to develop a conceptual framework that allows to explore the formulation of priorities regarding strategic urban redevelopment planning in the context of both the operation of city governance and changes in the external environment. The framework needs to encompass global-local interaction. This involves a number of different stages of participation in urban redevelopment planning. An important dimension will be the interaction between different stakeholders at various stages and the collaborative as well as combined effects in the process of redevelopment planning processes.

Better planning with people makes better neighborhoods, cities and regions, and overall healthy families and communities. Also, participatory planning supports active people and democratic governance. One of the most important factors is to include people throughout planning and from the very beginning, be open enough to allow public debate to shape the plan. This approach allows people to contribute their ideas at the various stages of planning through participatory activities. Participatory planning requires planners to change the way to do urban 


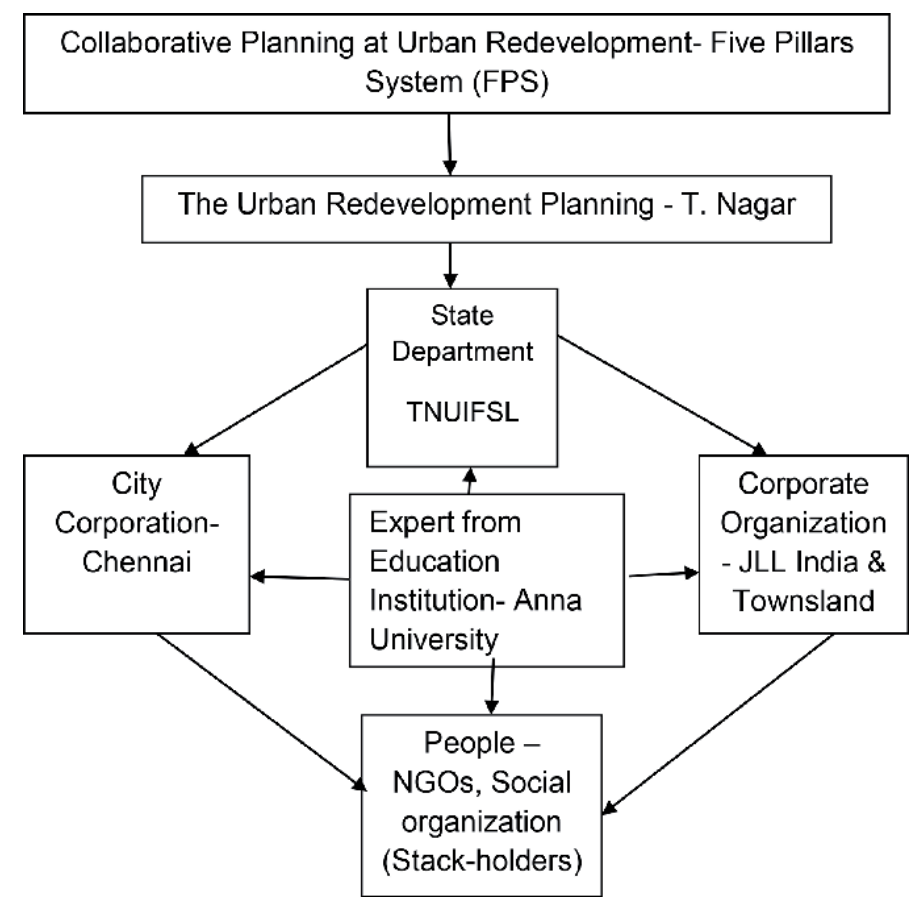

Figure 9.

Five-pillar system (FPS) of participatory planning-urban redevelopment.

redevelopment planning; it gives everyone the opportunity to become an agent of change in their living environment. At the outset, it will create better quality of life and sustainable living in cities, towns, and neighborhood spaces.

In conclusion, the author wanted to stress upon the new methods of participatory planning taking the lesson from the practical experience. The participatory planning at the redevelopment planning follow a collaborative venture and (b) what is followed in the redevelopment of T. Nagar Experience as corporate sectorstate and local government-education institution-stakeholders (C-TC-C) model (Figure 9). This kind of collaboration is interconnecting the five pillars as called as five-pillar system (FPS). The FPS works while the planning education expert as the middle pillar connects with other four pillars to function technically and democratically to make development plans at various levels. Participatory planning is sharing ideas, resources, time, and suitable and sustainable development. Planning process at the urban redevelopment area should make a right choice of collaborative efforts to make livable houses and urban neighborhoods spaces in cities.

\section{Acknowledgement}

The author extends his sincere thanks and gratitude to Anna University, Chennai, for providing the golden opportunity to work as a consultant to JLL India in the collaborative urban redevelopment planning for T. Nagar Project. The author expresses thanks and gratitude to the JLL India for appointing him as the Social Development Expert and to conduct the consultative meetings democratically and complete the project with great success. 


\section{Author details}

Abdul Razak Mohamed

Department of Planning, School of Planning and Architecture,

Vijayawada, Andhra Pradesh, India

*Address all correspondence to: razak@spav.ac.in

\section{IntechOpen}

(C) 2020 The Author(s). Licensee IntechOpen. This chapter is distributed under the terms of the Creative Commons Attribution License (http://creativecommons.org/licenses/ by/3.0), which permits unrestricted use, distribution, and reproduction in any medium, provided the original work is properly cited. (cc) BY 


\section{References}

[1] UN-Habitat Feature/Backgrounder. Participatory urban planning. In: Global Report on Human Settlements 2009, United Nations Human Settlements Programme. P.O. Box 30030, Nairobi 00100, Kenya: UN-HABITAT; 2009

[2] Balz VE. Regional design:

Discretionary approaches to regional planning in The Netherlands. In:

Planning Theory. The Netherlands: Sage Publications; 2017

[3] Ambinakudige S, Parisi D. A spatiotemporal analysis of inter-county migration patterns in the United States. Applied Spatial Analysis and Policy. 2017;10(1):121-137

[4] Forsyth A. Defining suburbs. Journal of Planning Literature. 2012;27(3):270-281

[5] United Nations Department of Economic and Social Affairs-Population Division. World Urbanization Prospects: The 2014 Revision, Highlights. New York: United Nations; 2014

[6] Srivatsan A. What happened to good city planning? Urban Jungle Columns. The Hindu. 2012

[7] PRIA, Society for Participatory Research In Asia. Participatory urban planning participatory innovations from Rajnandgaon and Janjgir, Chhattisgarh. In: Occasional Papers Series-No. 3. New Delhi: Urban Governance; 2008

[8] Kumar A, Prakash P, editors. Public Participation in Planning in India. Delhi: Cambridge Scholars Publishing; 2016

[9] JLL-India. Redevelopment plan for T. Nagar, Chennai. In: Consultancy Project Work. Chennai Municipal Corporation; 2012

[10] Frank AI. CPL 376: Three decades of planning education thought. Journal of Planning Literature. 2006;21(1):15-67
[11] Dalton LC. Weaving the fabric of planning as education. Journal of Planning Education and Research. 2001;20(4):423-436

[12] Cuthbert AR. An agenda for planning education in the nineties: Part I-Flexible production. Australian Planner. 1994a;31(4):206-211

[13] Cuthbert AR. An agenda for planning education in the nineties: Part II-The enduring crisis of planning. Australian Planner. 1994b;32(1):49-55

[14] Castells M. The education of city planners in the information age. Berkeley Planning Journal. 1998;12:25-31

[15] Friedmann J. The core curriculum in planning revisited. Journal of Planning Education and Research. 1996;15(2):89-104

[16] Frank AI. Entrepreneurship and enterprise skills: A missing element of planning education? Planning, Practice \& Research. 2007;22(4):635-648. DOI: 10.1080/02697450701770142

[17] Frank A, Sieh L. Multiversity of the twenty-first century-Examining opportunities for integrating community engagement in planning curricula. Planning Practice \& Research. 2016;31(5):513-532

[18] Schroeder K, Wood CA, Galiardi S, Koehn J. First, do no harm: Ideas for mitigating negative community impacts of short-term study abroad. Journal of Geography. 2009;108(3):141-147

[19] Wood CA, Banks S, Galiardi S, Koehn J, Schroeder K. Community impacts of international servicelearning and study abroad: An analysis of focus groups with program leaders. Journal of Service-Learning \& Civic Engagement. 2011;2:1, 1-23 
[20] Logan JR, Zhang C. Global

neighborhoods: Paths to diversity in the immigrant metropolis. American Journal of Sociology. 2010;115:1069-1109

[21] Zhang W, Logan J. The Emerging Spatial Organization of the Metropolis: Zones of Diversity and Minority Enclaves in Chicago. USA: Springer International Publishing AG; 2017

[22] Oishi S. The psychology of residential mobility: Implications for the self, social relationships, and well-being. Perspective on Psychological Science. 2010;5(1):5-21

[23] Jaret C, Reid LW, Adelman RM. Black-white income inequality and metropolitan socioeconomic structure. Journal of Urban Affairs. 2003;25(3): 305-333

[24] King RA, Rathi S, Sudhira HS. An approach to regional planning in India. International Journal of System of Systems Engineering. 2012;3(2):117-128

[25] Prakash P, Kumar A. Public Participation in Planning in India. New Delhi: Cambridge Scholar Publishing; 2016 


\title{
Assessing the Urban Design Quality of Turkish Cities
}

\author{
Umut Doğan
}

\begin{abstract}
The common characteristic of qualified urban spaces is that they offer an environment enriched with livability criteria, protecting and maintaining the elements of identity and offering flexibility and diversity compatible with the current conditions. Nowadays, the first condition of creating such qualified/successful urban spaces is to reflect the "urban design" processes on the urban spaces. Therefore, the present study aims to discuss the "urban design" quality (the level of success) of the Turkish cities shaped within the scope of urban plans. This discussion was performed using the urban design criteria determining and assessing the actors, which play an effective and relevant role in urban design and planning processes. The fuzzy multi-criteria decision-making (MCDM) method was used. By making use of the results of the present study, the conditions influencing the urban design aspect were re-discussed via current state analysis, and the foundation for a general assessment about the urban design quality of Turkish cities was established.
\end{abstract}

Keywords: urban design, urban design actors, fuzzy logic, multi-criteria decision-making

\section{Introduction}

Urban design is the only multidimensional and multidisciplinary approach aiming to establish functional, esthetic, and safe urban public spaces for the societies. It is one of the planning strategies such as spatial planning, strategic planning, cultural planning, regional development, and economic strategies. Rather than replacing the other planning approaches and implementations, it can be seen to move together with them and consider the subjects from the third dimension [1]. It can be stated that the planning decisions must incorporate the "design" aspect because of this step, in which the spatial theme of the planning decisions at the upper scale comes to the forefront [2]. From this aspect, the design aspect has been defined as making $3 \mathrm{D}$ designs or design policies at the local and city scale when putting the planning decisions into practice $[3,4]$. Hence, it is necessary to focus on the urban design criteria in order to discuss the quality of urban space. The criterion here refers to the criteria determining the success of the design reflecting on the urban space. The main condition for constructing livable and sustainable urban spaces is for the urban design processes to play an active role in planning processes. The main subjects of urban design are to revive social and economic life, using natural sources, esthetic sensitivity, and the pleasure derived from the space. Qualified urban design implementations might contribute to creating livable places with 
a rich and different character. The integration of urban design and urban planning is very important from this aspect. Considering the case of Turkey, there are very important problems in this integration. The main starting point of this study is to discuss the formation of urban space, which is caused by these problems, in terms of specific criteria.

The main objective in the present study is to evaluate the "urban design" quality (the level of success) of the Turkish cities which have been shaped within the scope of urban plans since the proclamation of the republic, over the relevant and effective actors playing a role in the urban design and planning processes. This assessment was performed using a fuzzy multi-criteria decision-making (MCDM) method incorporating the processes emphasized in the flowchart (Figure 1). The results of the present study allow a general discussion about the urban design quality of Turkish cities. The insufficient and negative conditions influencing the

\begin{tabular}{|c|}
\hline Actor Selection \\
\hline 73 specialist actors consisting of \\
urban planners (30), architects \\
(27), and landscape architects \\
(16) experienced in urban design \\
in Turkish cities and playing \\
active roles -working in public, \\
private and NGO bodies \\
\hline
\end{tabular}

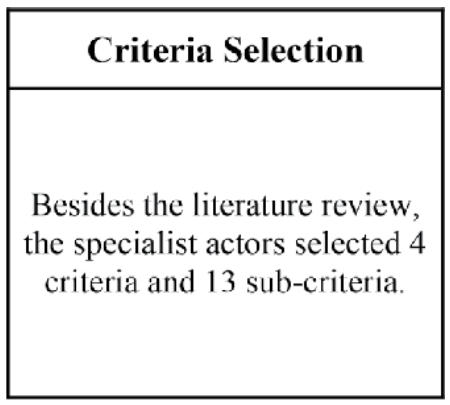

\begin{tabular}{|c|}
\hline Assessing the Turkish Cities by Criteria \\
\hline $\begin{array}{c}\text { The assessments made by the actors were weighed according to the } \\
\text { selected criteria and sub-criteria. }\end{array}$ \\
\hline
\end{tabular}

\begin{tabular}{|c|}
\hline Normalization of Data (Fuzzy Logic) \\
\hline MCA was developed using fuzzy logic. The linear normalization was \\
used together with the fuzzy logic. \\
\hline
\end{tabular}

\begin{tabular}{|c|}
\hline General Assessment - Conclusion \\
\hline 4 criteria were separately assessed according to the results achieved in \\
the way incorporating the sub-criteria.
\end{tabular}

Figure 1.

Methodological diagram of the study. 
urban design aspect were re-discussed over the current state analysis, and infrastructure to guide all the relevant actors was established.

\section{Urban design in the Turkish planning system}

The planning can be described as the process of preparing systematic action plans in order to achieve the desired goals. The plan is defined over two components constituting it. These components are:

- The target to be achieved, which refers to the project.

- The regulations needed for achieving this target, which refer to the instruments.

In planning, which refers to systematically implementing the theoretical knowledge, it is necessary to determine both the target of the plan and the ways to follow in order to achieve the target. Within its widest meaning, the planning has three characteristics:

- It should be a design for the future.

- It should be made for achieving specific targets/objectives.

- It should be a systematic action series.

The planning is to systematically implement theoretical knowledge. It is a process extending from the current time to the future. The main sub-processes are as follows: preparing the research, planning, implementing, monitoring, and assessing $[5,6]$.

Urban planning is defined as a science, art, and discipline aiming to shape the physical development of the cities by considering the social and economic necessities. Besides that, it is also considered to be a way of directing the change of urban areas [7].

The construction and design of the urban built environment are performed with a systematic approach in countries having a national planning system. The urban design should be a part of this system. The core of the planning system is the urban plans prepared at specific levels. Accordingly, the urban plans offer a framework for directing all the construction activities in the cities. The success of the framework offered by these plans depends on their relationship with the urban design in terms of the spatial dimension of the plans. The position of urban design in the planning system of Turkey is controversial. Urban design could not be positioned in Turkey's planning system in the form specified in the literature, being nothing but a technical implementation carried out because of the legal obligations. For this reason, it would be very useful to discuss the concept of planning.

Urban design is a comprehensive and multidimensional concept. In general, it reveals the ways of creating ideas and putting them into practice. All the long-run social, economic, administrative, and spatial change factors related to the use of sources in the habitat are considered within the scope of planning.

In urban science, planning is discussed at four levels: the city, the environmental, the regional, and the national. As for the topic of urban spaces, it can be defined as the process of determining the land use, transportation, and physical structure within a mutual interaction with the social relationship, including the investigation 
of the positions of cities in the region [8]. Urban planning is a comprehensive process with economic, social, and esthetical dimensions, as well as the directing of the physical formation developments. The steps of this complex process are as follows:

- Defining the problem

- Determining the objectives ad targets

- Collecting and constructing the knowledge

- Assessment, synthesis

- Designing the options (suitable plans)

- Assessment

- Feedback and control

- Projecting

- Implementing $[9,10]$.

Since the outcomes of the urban planning processes were different, various assessments were developed. Especially in keeping with the understanding that the city is a multidimensional and complex case, urban planning has shown advancement towards becoming an interdisciplinary and inter-specialty field of implementation. Urban design has an important role in urban planning's process of gaining an identity, and, as one of the peoples' activities of organizing the environment in which they live, it cannot be separated from the planning [10-12]. From this aspect, different actors also play a role together with the components of the planning system in this process. The urban spaces, which are constructed by the sociopolitical dimension, are the spaces in which the discussions and reconciliations between the actors having different interests and expectations occur. The area in which the process occurs defines the participation styles, effects, and activity forms of the actors.

From the aspect of planning and urban design, the main reason for the problems observed in Turkey is the "zoning approach and practice" [13]. Being the main guideline of the legal foundation of the Turkish planning system, Zoning Law Nr.3194 can be summarized as follows: the zoning plans can be defined as the "master plan" and the "implementary development plan"; the "master plan" is the plans prepared in order to lay the foundation of the preparation of the implementary development plans and to show subjects such as general usage types, main region types, future population densities, building density (when necessary), size and principles of the development of various residential areas, transportation systems, and solutions for the problems on the existing maps prepared in accordance with the regional or environmental plans. The "implementary development plan" is, however, drawn up based on the principles of the master plan drawn on the existing maps showing the cadastral statuses, and these plans show the building blocks, the intensity and order of these blocks and roads, and all the implementation steps and information to form the basis of the development implementation programs in detail.

As can be seen here, the zoning planning aiming to achieve a legal document generally defines how a building can be constructed on a parcel, but it falls short as 
a regulation instrument shaping the physical environment. Even though the landuse plan (physical plan) is an important input for managing the quality of the environment, the land-use plan alone without comprehensive urban design plan/ project may not ensure and maintain a high-quality environment $[10,14]$.

From this aspect, the framework offered by the zoning approach and practice is a regulatory system based on high-level accuracy and offering uniformity at the national level. The zoning plan, which is the expression of this framework, is to create and audit the urban built environment qualitatively. In this process, the main auditing subject of the zoning plans is the parcel [15]. This structure, not including the urban design processes but offering a strict frame, may fall short in providing a qualified urban space. Urban planning and urban design are two important phenomena complementing each other. For this reason, excluding the urban design from the planning process prevents the plans from achieving their targets. Hence, urban design should be involved in the entire planning process.

\section{Urban planning and urban design approaches and relations}

The spatial quality of urban spaces in developed countries is better than other countries. The main reason for this is thought to be that the planning system starting from the upper scales moves together with the urban design approaches to the lower scales. Thus, everything in the city that people have contact with is provided using various instruments developed together with the plans. These instruments, playing an important role in shaping the urban space, also show similarity from the aspect of urban design.

For instance, in England, the design codes, design briefs, design guidelines, and development briefs named as supplementary planning guidance are prepared for this purpose. In the USA, however, this process is generally named as design review, and the design auditing instruments such as urban design guideline are prepared. In France, the urban plans (Schéma Directeur master plan) and the "land-use plans" (Plan d'occupationdessols-POS) are not alone considered sufficient for managing the change in the urban space, and therefore the instruments such as "planning zone" (ZAC-Zoned'AménagementConcerte) and "zoning plan” (PAZ-Plan d'Aménagement de Zone) are used [15].

In the different planning approaches and legal regulations worldwide, both the central and local administrations use urban planning and urban design together in ensuring urban quality. Even though the framework offered by the zoning plans in Turkey seems enough from the quantitative aspect, the plans are not sufficient in the process controlling and directing the urban design in different countries, and the urban design instruments are used together with the plans. This is the hint for creating high-quality spaces and a successful outcome [16-18].

Since the nineteenth century, the concept of urban design has been considered in different contexts and scopes within urban planning. In this process, practitioners and theoreticians such as Kevin Lynch, David Mackay, Francis Tibbalds, etc. have offered different definitions. In parallel with the works and discussions of the theoreticians and practitioners, urban design has been conceptualized in an organized fashion (Figure 2).

In this conceptualization, urban design is close to urban planning at a high scale. Besides that, considering urban design as the design of small urban spaces at a low scale, it is close to the esthetic and spatial points of interest of the architecture and arts. Moreover, urban design is interested in the interaction between public and private development and its effect on the form of the city, the relationships between people and locations, movement and urban form, nature, building structure, and the processes providing successful cities and towns $[1,2,19]$. 


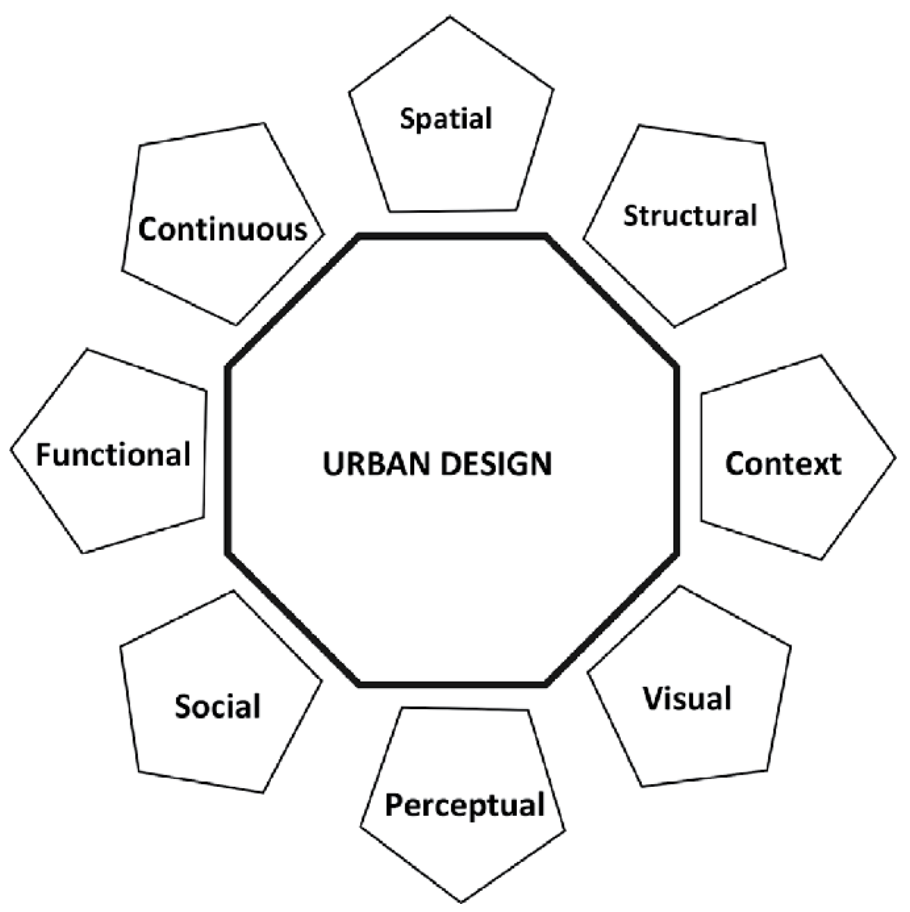

Figure 2.

Conceptualization of the idea of urban design [18].

In this form, one of the most important objectives of urban design is to ensure and maintain quality and character, to integrate the old and new; to protect the natural characteristics of the city, providing new and multidimensional areas; to improve the security, health, and comfort of the city, etc. The environmental quality includes many components such as "esthetic," identity, assessing the vista and natural exposition points and corridors, human scale, comfort in pedestrian transportation, ability of keeping away from the traffic noise, providing public spaces to rest-commune, developing the consciousness of heritage, and reevaluating culture and historical heritage [19].

Summarizing the theoretical frame might significantly contribute to the urban design approach and the organization of the city. In the cities that are in the development process, many of the human scales disappear, the memories of the cities weaken or disappear, and the connections between the city and people rupture. The process of reconciling humans and the city in which they live incorporates a series of tasks starting with planning works, continuing with urban design practices, taking place in the third dimension. From this aspect, the best way of constructing successful and sustainable cities is to think about urban design from the very beginning of the planning and development process.

\section{The actors in urban design processes: authorities and experts}

The physical environment is formed as a result of urban planning and the urban design process. The components of this formation are the appearance of buildings, the relationships between these structures, their locations, densities, spatial sense, landscapes, and pedestrian and vehicle movements. The components of the physical environment are gathered under nine groups: spatial, morphologic, contextual, visual, perceptual, functionality, sustainability, and the design/planning process $[8,20]$. 
This process, designed as multidimensional, is constructed by the actors having different expectations and objectives. In order to understand or perceive the built environment, it is necessary to define key actors, the objectives and targets of these actors, the expectations of them in designing the built environment, and the relationships between the actors [21]. The roles and positions of the actors in urban design may always vary depending on the progression of the process. Although the actors may vary between the parts of the built environment, they continue existing.

It is difficult to define and to clearly describe the actors of urban design. Despite this difficulty arising from diversity and multidimensionality, there also is a consensus on some of the main actors. From this aspect, the actors deciding in the formation of built environment in urban design are divided into four groups: private sector, public sector, public-private cooperation, and society [22]. In other words, they can be described as professionals (urban designers, planners, architects, landscaping architects, etc.), politicians, municipalities (those working at local administration), non-governmental organizations (NGOs), universities, userssociety-urbanites, sponsors, and entrepreneurs/investors. These actors have different specialties and financial and political effects depending on their professional, administrative, capacities, etc. The professional identities in these fields have an interdisciplinary character related to planning, architecture, and landscape architecture. The specific character and professional capabilities of each of the relevant design professions are reflected in the urban design [23]. Besides these professional characters, the other professional groups supporting the process and playing a binding role are the social scientists, lawyers, economists, environmental scientists, and engineers [1].

Within the scope of this study, the evaluations of the most effective actors directly influencing the urban places in the design and implementation phases are discussed. In other words, an analysis was made of the actors having a fundamental

\begin{tabular}{|c|l|c|}
\hline $\begin{array}{c}\text { Number } \\
\text { of Actors }\end{array}$ & Institution & Professional Title \\
\hline 9 & Municipality & Urban planner \\
\hline 3 & $\begin{array}{l}\text { Non Governmental } \\
\text { Organization (NGO) }\end{array}$ & Urban planner \\
\hline 7 & Private & Urban planner \\
\hline 11 & University & Urban planner \\
\hline 7 & Municipality & Architect \\
\hline 3 & $\begin{array}{l}\text { Non Governmental } \\
\text { Organization (NGO) }\end{array}$ & Architect \\
\hline 9 & Private & Architect \\
\hline 8 & University & Architect \\
\hline 4 & Municipality & Landscape architect \\
\hline 2 & $\begin{array}{l}\text { Non Governmental } \\
\text { Organization (NGO) }\end{array}$ & Landscape architect \\
\hline 5 & Private & Landscape architect \\
\hline 5 & University & Landscape architect \\
\hline Total:73 & & \\
\hline
\end{tabular}

Table 1.

Actors selected for the analysis. 
professional identity in the urban design. These are the professionals working in the private sector, public sector, and NGOs. The common character of these professionals is that they have an effective and specialized structure in the field of urban design. From this aspect, the professional titles of these actors were selected to be an urban planner, architect, and landscape architect. Seventy-three professionals following the urban design processes in Turkey and involved in many processes were involved in the analyses. Among these actors, there are 30 urban planners, 27 architects, and 16 landscape architects (Table 1).

Among the selected actors related to the field of urban design, the urban planners are interested in the quality of the built and visual environment, examine the designrelated subjects from theoretical and political aspects, and ensure that they are reflected in the practice. They prepare the projects, which will meet the necessities of future objectives and provide solutions for the problems at different scales. Within the scope of plans, the architects make use of their creativity and implement their original and independent designs. They play a role in the entire project design and implementation process. The landscape architects, however, integrate the physical content, nature, and nature's components with the design by making use of their experience in using the dependence to location/ground and time as an important design element [24]. The decision-makers in this process may significantly vary in terms of person and institution. The effects of powers such as politicians, entrepreneurs, financial institutions, investors, etc. have always been effective on the actors. However, the present study does not involve these powers. It focuses on the evaluations of the main actors about the reflection of design processes on the space.

\section{Assessing the quality of Turkish urban design (level of success) by using a fuzzy logic method}

Determining the "urban design" quality of the Turkish cities which have been designed using urban plans is very important for future urban design approaches. In the following sections of this study, the success level will be determined by making use of the evaluations of the relevant and effective actors. In this analysis to be performed using the fuzzy logic method, the urban design criteria specified in the literature will be taken as a basis. The results of the evaluations will be used in analyzing the Turkish cities which come to the forefront with their planned development, in terms of the urban design criteria, and a general evaluation will be made.

Developed by Zadeh in 1965, fuzzy logic is a method for defining and solving the problems having no exact limits [25]. Besides that, it is generally accepted as a way of thinking and deciding in the way closest to the human's way of thinking. In the study of Yager, McNeill and Thro [26], this method was reported to have various positive characteristics such as simplicity, easiness, robustness, and the use of linguistic variables similar to the human's way of thinking. The multi-criteria decision-making methods are used for defining and solving decision-making problems with multiple criteria and repetitive decision-making processes.

The criteria involved in assessing urban design have different complex relationships. Since the urban design criteria are multifactorial and have various sizes and the criteria could not be expressed in a common way, the analysis of the cities in the present study can be formulated as multi-criteria decision-making [27]. In MCDM methods, the opinions of the main actors are requested, and these opinions are directly utilized. Since the specialists make net evaluations while making a decision, useful results may sometimes not be achieved when comparing complex criteria. For this reason, the fuzzy MCDM allowing an analysis of an interval and presenting the evaluations of the specialists within a range was used in the present study. 


\section{Selection of the evaluation criteria within the scope of urban design}

The common characteristics of qualified/successful urban spaces are to offer livable, dynamic, and different spaces having character and (most importantly) satisfying the people living there. Nowadays, the first step of constructing these qualified/successful urban spaces is to determine and implement the principles of urban design. The urban design criteria are abstract on their own. However, when they are concretized within the process of development, they have significant effects on the city and consequently on the people because they gain an environment for contacting all the senses of people after the concretization.

The most effective part of these urban spaces is the urban public spaces. Urban public spaces cover all the built or natural environments easily accessed by the public and used free of charge. It covers all the streets, squares, roads, residential areas, parks incorporating commercial or public usage areas for the citizens, open areas, and the public or private properties where the society can freely visit at least in the daytime. The urban spaces should be freely accessible for every person and provide the highest urban quality to the urbanites. The most important necessities in public spaces are comfort, relaxation, active/passive participation, exploration, and human needs [28].

Certain urban design criteria are utilized in order to keep the urban space quality at the highest level. These criteria cannot become clear because of the different perspectives of researches and the spatial conditions in different periods. However, there are also certain common points.

According to the analyses made in the literature by various researchers, the criteria constituting the components of high-quality urban spaces are classified in different ways. The physical needs and the need for security, belonging, respect, and existing in a space are the fundamental needs [24, 29]. Another perspective is about the relationship and continuity of the patterns. The integrity and continuity of spatial relationships are crucial. From this aspect, many principles influencing the quality of urban life have been determined [30]. Another approach is that of Kevin Lynch. The criteria he put forward as design criteria are vitality, identity, adaptation, access, diversity, freedom, and domination [31]. In the criteria

discussed by Nasar [32], there are common points besides the differences from the other theoreticians. These criteria were classified as compliance with nature, order, definitiveness, identity, and cleanliness. Similarly, discussing the importance of human scale and the pedestrian- and cyclist-oriented urban design for ensuring the urban quality and the destructive effect of vehicles, Gehl designed the criteria for the livability of urban spaces. These criteria are security, vitality, density, perceptibility, accessibility, and control [33]. From the same perspective, considering that the importance of the urban design criteria arises from livable cities, Llewelyn Davies Yeang also designed certain criteria. These criteria are noise, sound, crowdedness, the material quality of space, presence, function of open and public area, presence of pedestrians, accessibility, service diversity and quality, mass transportation, and security [34].

The criteria selected here are based on the literature review and the participation of a specialist group, which consists of actors playing an effective role in urban design decisions, in Turkey. This group consists of 73 specialist actors (urban planners, architects, and landscape architects). In this approach, the quantitative weight method is used in defining the relative importance of the criteria following the vision of specialists.

Considering the specific conditions of Turkish cities in terms of urban design, the specialists defined the criteria. In the next phase, these criteria were weighted and prioritized. 
The "urban design success criteria," which were defined using the literature review, were asked to every specialist separately in the form of survey. Four main criteria and 13 sub-criteria accepted by all the specialists were accepted in the present study. In the next step, the specialists were asked to prioritize the criteria, and the weights of selected criteria representing their importance in the success level of urban design were determined. In the third step, the design and current status of Turkish cities were analyzed in terms of the selected criteria.

Four main criteria and 13 sub-criteria presented in Tables 2 and 3 were used in analyzing the success level of urban design in Turkey within the scope of this manuscript.

In this parallel, the urban design assessment criteria were defined based on the relevant literature. These criteria are as follows:

1. Urban design quality

a. Character and identity

b. Diversity

c. Readability and definitiveness

d. Continuity, closeness, coverage, and guidance

e. Flexibility

2. Environmental quality

a. Urban built environment's compliance with nature

b. Level of noise

c. Appearance and level of cleanliness

3. Functional quality

a. Pedestrian and non-motorized vehicle access

b. Mass transportation opportunities

c. Urban services

\section{Security}

a. Pedestrian security

b. Balance of daytime-nighttime usage

\subsection{Character and identity}

This can be defined as the "location" and its identity. The character is the quality consisting of the combination of topography, building type, geology, traditional structures, urban texture, and borders. In other words, it can be defined as 


\begin{tabular}{|c|c|c|c|c|}
\hline & Main criteria & & Pairs of sub-criteria & $\begin{array}{c}\text { Specialist } \\
\text { evaluations (\%) }\end{array}$ \\
\hline \multirow{22}{*}{$\begin{array}{l}1^{\text {st }} \text { Main } \\
\text { criterion }\end{array}$} & \multirow{22}{*}{$\begin{array}{l}\text { Quality of Urban } \\
\text { Design }\end{array}$} & $\mathrm{a}$ & Character, identity & 58.7 \\
\hline & & $\mathrm{b}$ & Diversity & 41.3 \\
\hline & & a & Character, identity & 56.7 \\
\hline & & $\mathrm{c}$ & Readability, definitiveness & 43.3 \\
\hline & & a & Character, identity & 42.2 \\
\hline & & $\mathrm{d}$ & Continuity, closeness, coverage, guidance & 57.8 \\
\hline & & a & Character, identity & 40.8 \\
\hline & & $\mathrm{e}$ & Flexibility & 59.2 \\
\hline & & $\mathrm{b}$ & Diversity & 56.6 \\
\hline & & $\mathrm{c}$ & Readability, definitiveness & 43.4 \\
\hline & & & & \\
\hline & & $\mathrm{b}$ & Diversity & 57.5 \\
\hline & & $\mathrm{d}$ & Continuity, closeness, coverage, guidance & 42.5 \\
\hline & & $\mathrm{b}$ & Diversity & 51.2 \\
\hline & & $\mathrm{e}$ & Flexibility & 48.8 \\
\hline & & & & \\
\hline & & c & Readability, definitiveness & 38.8 \\
\hline & & $\mathrm{d}$ & Continuity, closeness, coverage, guidance & 61.2 \\
\hline & & $\mathrm{c}$ & Readability, definitiveness & 46.2 \\
\hline & & e & Flexibility & 53.8 \\
\hline & & $\mathrm{d}$ & Continuity, closeness, coverage, guidance & 46.1 \\
\hline & & $\mathrm{e}$ & Flexibility & 53.9 \\
\hline \multirow{6}{*}{$\begin{array}{l}2^{\text {nd }} \text { Main } \\
\text { criterion }\end{array}$} & \multirow{6}{*}{ Environmental Quality } & a & $\begin{array}{l}\text { Compliance of urban built environment with } \\
\text { the natural environment }\end{array}$ & 87.2 \\
\hline & & $\mathrm{b}$ & Noise level & 12.8 \\
\hline & & a & $\begin{array}{l}\text { Compliance of urban built environment with } \\
\text { the natural environment }\end{array}$ & 85.1 \\
\hline & & $\mathrm{c}$ & Appearance, cleanness level & 14.9 \\
\hline & & $\mathrm{b}$ & Noise level & 42.7 \\
\hline & & $\mathrm{c}$ & Appearance, cleanness level & 57.3 \\
\hline \multirow{6}{*}{$\begin{array}{l}3^{\text {rd }} \text { Main } \\
\text { criterion }\end{array}$} & \multirow{2}{*}{ Functional Quality } & a & Pedestrian and non-motored vehicle access & 80.4 \\
\hline & & $\mathrm{b}$ & Mass transportation options & 19.6 \\
\hline & & $\mathrm{a}$ & Pedestrian and non-motored vehicle access & 72.5 \\
\hline & & $\mathrm{c}$ & Urban services & 27.5 \\
\hline & & $\mathrm{b}$ & Mass transportation options & 41.2 \\
\hline & & $\mathrm{c}$ & Urban services & 58.8 \\
\hline \multirow{2}{*}{$\begin{array}{l}4^{\text {th }} \text { Main } \\
\text { criterion }\end{array}$} & \multirow[b]{2}{*}{ Security } & a & Pedestrian security & 46.6 \\
\hline & & b & $\begin{array}{l}\text { Balance between daytime and nighttime } \\
\text { usages }\end{array}$ & 53.4 \\
\hline
\end{tabular}

Table 2.

Evaluation percentages of assessment criteria and sub-criteria pairs. 
Sustainability in Urban Planning and Design

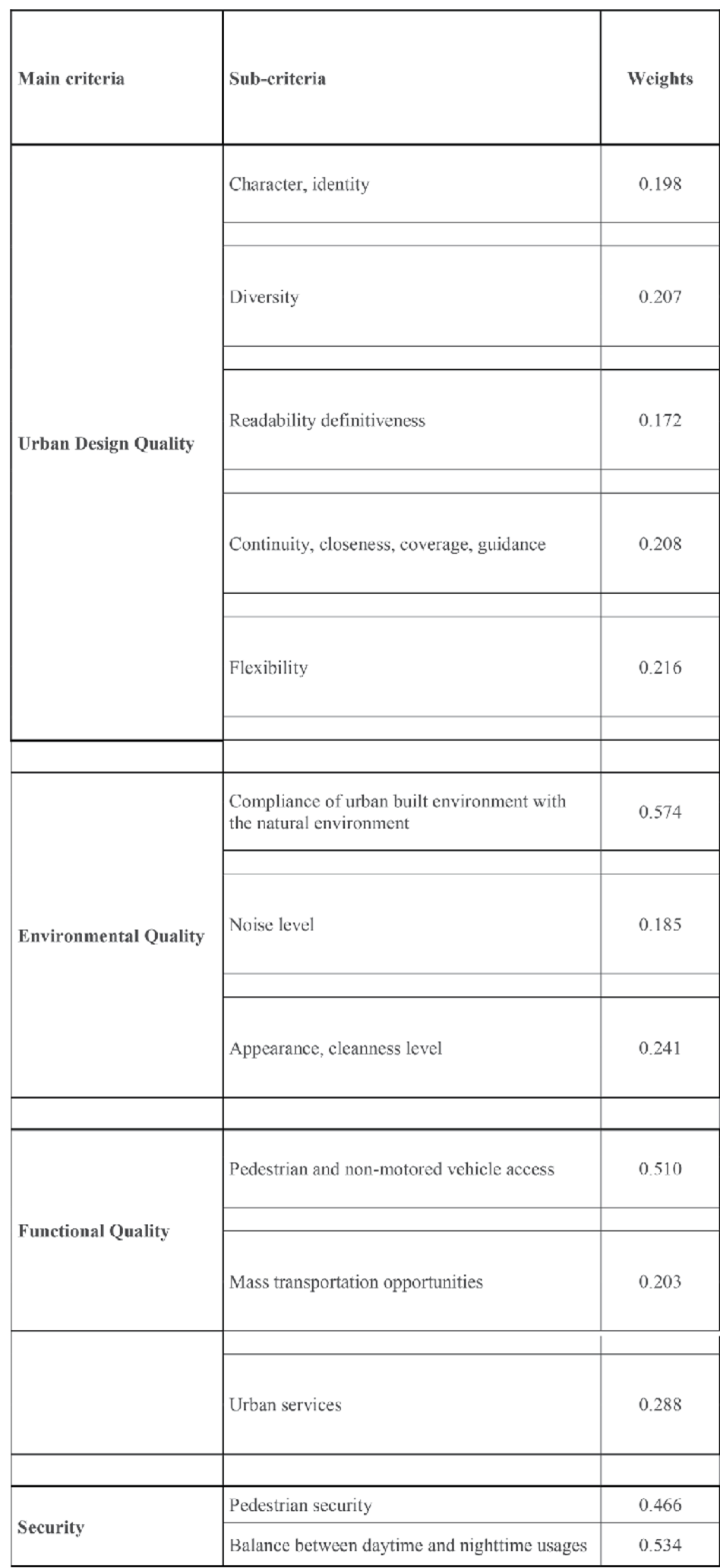

Table 3.

Weights of the sub-criteria. 
improving the townscape and landscape character by supporting and answering the distinguishing/featured texture of the development and culture locally. The positive characteristics and habitats of a location are important for gaining that place a character and a meaningful identity. The landscaping, building types and materials, the structure of local life, and the other characteristics distinguishing the place from the others are the components of that place's character.

\subsection{Diversity}

It can be defined as the mixture of appropriate developments and development of options and differences between the usages in order to create livable places answering local needs. The usages offering diversity indicate how well a place is used, and it supports the economic and social activities in that place. The urban design criteria specified above are meaningful only when concretized. From this aspect, the design policy is an intermediary design instrument between the urban design criteria and the design instruments allowing the implementation of these criteria. The effective design policies do/should focus on how the urban design criteria can be achieved within a specific scope/context.

\subsection{Readability and definitiveness}

It can be defined as assisting the people in finding their way by making use of the definable roads and crossroads. The readability is always neglected; thus, it is very important to strengthen it because, in the design process, it is necessary to consider that not all the people are literate, and they do not get pleasure out of a place in the same way. Women and men, children and adults, visitors and inhabitants, old and young persons, and persons from different cultures perceive and interpret the same location in different ways. For this reason, a frame addressing all the perception styles is important.

\subsection{Continuity, closeness, coverage, and guidance}

It can be defined as improving the continuity of the street fronts and closeness of "places" via the advancements clearly defining the public and private places. The successful urban space is a field closed and defined by structures, buildings, and landscape components. Both relationships between the structures on a street and between street and structures are an indicator of it. The buildings following the general structure lines define the street and strengthen the effect of the street. The advancements following the borders of street fronts might contribute to clearly distinguishing the public and private spaces.

\subsection{Flexibility}

It can be defined as creating advancements answering to the social, technologic, and economic conditions changing in the course of time. The urban spaces should be adaptable for usage at different scales. The most successful spaces are those capable of changing under different conditions. From this aspect, the cities should be able to adapt themselves to the rise and collapse of industries and the change from residential to commercial areas, and the structures and infrastructures should show the same adaptation. Moreover, the spaces should allow diversity in usage under different conditions and in different seasons. 


\subsection{Compliance of urban built environment with the natural environment}

The compliance and integrity of built physical environment with the natural environment are very important for the value added to the quality of life. Rather than ignoring the natural formations, it is necessary to move together with them if possible, and the urban spaces should be created with this integrity. It is the basic objective of sustainability. The quality of the public space depends on its compliance with the local climatic conditions, material, vegetation, lighting, instructions, signs, street furniture, functions, and esthetic qualities.

\subsection{Noise level}

It is one of the important factors of environmental quality in urban spaces. Motor vehicles are among the parameters determining the quality of space because of the production activities of various intensities (such as pedestrian or vehicle).

\subsection{Appearance and cleanliness level}

From the aspect of cleanliness, the rate of use of the urban spaces compatible with the health conditions will always be high. From this aspect, it is a necessity to take measures preventing the dirtiness of urban spaces. It is important to adapt the design processes to space in this context.

\subsection{Access of pedestrian and non-motorized vehicles}

Given the physical environment and the relationship with others, the easiest and most appropriate way of movement is seen to be moving as a "pedestrian." For this reason, the pedestrian movement should be well-organized in order to maintain the urban space life based on the healthy human-human relationship. It is a fundamental necessity to gather the pedestrian movements and flows in an appropriate and meaningful manner and to canalize it to the activities.

\subsection{Mass transportation opportunities}

Walking is the most frequently used method for accessing to the mass transportation vehicles and is one of the traveling modes used by the people between a departure and a destination. In the present study, the walking distance to mass transportation vehicles (busses, taxis, rail-system stops, etc.) was a maximum of $800 \mathrm{~m}$, which is recommended for such studies.

\subsection{Urban services}

One of the most important reasons for the existence of humans in the cities is the services. The presence and quality of administrative, social, educative, recreational, access, etc. services indicate the success level of that city in terms of urban services.

\subsection{Pedestrian security}

It can be defined as developing attractive, safe, non-complex, and effectively functioning roads and public spaces by considering elderly people, children, pregnant women, etc. Besides that, the crime factors are also evaluated within the security. This parameter, which is very important from this aspect, indicates that the presence of a pedestrian in the city depends on the elements of security. 


\subsection{Balance of daytime-nighttime usage}

The cities and especially the city centers should not be designed only for daytime usage. In light of the safety factors, the balance should be established between the daytime and nighttime usages. Especially the city centers isolated from the residential areas turn into desolate and insecure spaces at night. From this aspect, it is important to establish the conditions of safe nighttime usage.

\section{Weighting and method}

The criteria and sub-criteria were selected by the specialists, and then the experienced actors evaluated Turkey before and after the urban planningimplementation processes. The relevant assessment data were obtained. These data include all the information related to the selected criteria and spatial physical environment.

In the next step, fuzzy logic was used, and MCA was developed for preparing and analyzing all the criteria and sub-criteria by using the fuzzy logic method. Since the values obtained from the criteria are expressed in different qualitative and quantitative scales, it was necessary to normalize the data in order to be able to make a comparison. The linear normalization, which is a common approach used in process, MCA, and decision-making problems, was used together with fuzzy logic. The fuzzy theory is based on a fuzziness level (probability) varying between 0.0 and 1.0 and showing a constant increase. The calculation was made using the sigmoidal function specified below:

$$
f\left(x_{i}\right)=\left\{\begin{array}{c}
x=x_{\text {min }}=0 \rightarrow f\left(x_{i)=0}\right. \\
\cdot \quad x_{\text {min }}<x_{i}<x_{\text {max }} \rightarrow f\left(x_{i}\right)=\frac{x-x_{\text {min }}}{x_{\text {max }}-x_{\text {min }}} \\
x=x_{\text {max }} \rightarrow f\left(x_{i)=1}\right.
\end{array}\right.
$$

$X_{i}$-network element $(i=1,2, \ldots, n) ; \mathrm{X}-X_{i}$-between the network elements.

The next step was to determine the importance of the urban design criteria and sub-criteria. The analytical hierarchy process was used for assigning the weights given by 73 specialists (Tables 2-4). The pairwise comparison matrix was used in translating the opinions of specialists into values. As shown in Tables 2-4, the weights of criteria and sub-criteria were calculated using different combination pairs.

The last step of this process is the involvement of weights given by the specialist actors to the sub-criteria and criteria. The method used here was the weighted linear combination (WLC) because it is an analytical approach that can be used in multifeatured decision-making. In the WLC, the combination enabled the application of the weights obtained from the binary combination to the conditions provided by Turkey's urban design approach. The conditions provided by the country were ordered based on the priority number and calculated by summing up the results of every criterion. The higher the score is, the better the relevant criterion is reflected in the urban spaces. The WLC enables an exact balance between various criteria. In other words, even though a criterion has a very bad score, a balance can be established by a higher score from another criterion. WLC was used with GIS and calculated using Eqs. (2) and (3): 


\begin{tabular}{|c|c|c|c|}
\hline Paired Main Criteria & Partial Weights (\%) & Main Criteria & Final Weights \\
\hline Urban Design Quality & 77.2 & \multirow{2}{*}{ Urban Design Quality } & \multirow{2}{*}{0.379} \\
\hline Environmental Quality & 22.8 & & \\
\hline Functional Quality & 31.1 & \multirow{2}{*}{ Environmental Quality } & \multirow{2}{*}{0.222} \\
\hline Urban Design Quality & 68.9 & & \\
\hline Urban Design Quality & 81.2 & \multirow{2}{*}{ Functional Quality } & \multirow{2}{*}{0.257} \\
\hline Security & 18.8 & & \\
\hline Environmental Quality & 69.2 & \multirow{2}{*}{ Security } & \multirow{2}{*}{0.142} \\
\hline Security & 30.8 & & \\
\hline Functional Quality & 58.7 & & \\
\hline Environmental Quality & 41.3 & & \\
\hline Security & 35.8 & & \\
\hline Functional Quality & 64.2 & Total & 1.000 \\
\hline
\end{tabular}

Table 4.

Weights of the main criteria.

$$
S_{k}\left(x_{i}\right)=\sum_{j}^{n} f_{j}^{k}\left(x_{i}\right) w_{k j}
$$

where $j=1,2, \ldots, 9 ; S_{k}\left(X_{i}\right)$ is the element evaluation $X_{I}$ and $\mathrm{j}$ criteria for all sub-criteria $\mathrm{k}$.

$$
T\left(x_{i}\right)=\sum_{j}^{n} S_{k}\left(x_{i}\right) w_{k}
$$

$T\left(x_{i}\right)$ is the evaluation of all criteria for the element $\mathrm{k}$.

\section{Discussing the results by the criteria}

The results obtained for Turkey in terms of the criteria examined for the urban planning and design approach by considering 4 main criteria and 13 sub-criteria are 


\begin{tabular}{|c|c|c|c|c|c|}
\hline & Main criteria & & Sub-criteria & Sub-criteria scores & $\begin{array}{l}\text { Main eriteria } \\
\text { scores }\end{array}$ \\
\hline \multirow{5}{*}{$\begin{array}{l}1^{\text {st }} \text { Main } \\
\text { criterion }\end{array}$} & \multirow{5}{*}{$\begin{array}{l}\text { Urban Design } \\
\text { Quality }\end{array}$} & a & Character, identity & 0.20 & \multirow{5}{*}{0.19} \\
\hline & & b & Diversity & 0.35 & \\
\hline & & $\mathrm{c}$ & Readability definitiveness & 0.15 & \\
\hline & & $\mathrm{d}$ & Continuity, closeness, coverage, guidance & 0.15 & \\
\hline & & e & Flexibility & 0.20 & \\
\hline \multirow{3}{*}{$\begin{array}{c}2^{\text {nd }} \\
\text { Main } \\
\text { criterion }\end{array}$} & \multirow{3}{*}{$\begin{array}{l}\text { Environmental } \\
\text { Quality }\end{array}$} & a & $\begin{array}{l}\text { Compliance of urban built environment with } \\
\text { the natural environment }\end{array}$ & 0.15 & \multirow{3}{*}{0.27} \\
\hline & & b & Noise level & 0.25 & \\
\hline & & $\mathrm{c}$ & Appearance, cleanness level & 0.30 & \\
\hline \multirow{3}{*}{$\begin{array}{l}3^{\text {rd }} \text { Main } \\
\text { criterion }\end{array}$} & \multirow{3}{*}{$\begin{array}{l}\text { Functional } \\
\text { Quality }\end{array}$} & a & Pedestrian and non-motored vehicle access & 0.10 & \multirow{3}{*}{0.25} \\
\hline & & $\mathrm{b}$ & Mass transportation opportunities & 0.25 & \\
\hline & & $\mathrm{c}$ & Urban services & 0.20 & \\
\hline \multirow{2}{*}{$\begin{array}{l}4^{\text {th }} \text { Main } \\
\text { criterion }\end{array}$} & \multirow[b]{2}{*}{ Security } & a & Pedestrian security & 0.15 & \multirow[b]{2}{*}{0.29} \\
\hline & & $\mathrm{b}$ & $\begin{array}{l}\text { Balance between daytime and nighttime } \\
\text { usages }\end{array}$ & 0.10 & \\
\hline
\end{tabular}

Table 5 .

Scores by the main criteria and sub-criteria.

presented in Table 5. All the criteria were scored between 0.000 and 1.000. For all the criteria, the scores closer to 1.000 indicate the high level of success for the criterion, whereas the scores closer to 0.000 indicate failure. In this section, the evaluations are made based on the scores of criteria.

\subsection{First main criterion}

In this criterion aiming to measure the urban design quality of Turkish cities in terms of the physical design, there are five sub-criteria. Constituting the main principles of the physical design in general, the highest score among the five criteria was 0.35 , whereas the lowest one was 0.15 . Since it has a score of 0.35 , "diversity" is the criterion with the highest score, but it is much lower than the intermediate level (0.50). Moreover, the mean score of these five criteria was found to be 0.21 . From this aspect, the score of the main criteria is 0.19 . Given these values, it can be understood that urban design quality is not at a good level in Turkey. All the scores were found to be below 0.35 . There are many problems to solve before Turkish cities can come to the forefront with their planned development. It is an inevitable necessity to reconsider the integrity of planning and design in both planning and designing processes. It is understood from these results that, without considering the identities and characters of the cities, they were either damaged or neglected and not included in the planning and design processes. Rather than emphasizing or enhancing the diversity, an inclination towards stereotyping and monotony has been exhibited. Rather than making the cities more readable and defined, the complexity and irregularity have become the dominant approach. The physical and functional continuity has been destructed by the point regulations. There are many undefined areas. The effects of guidance, coverage, and closeness have decreased. Rather than flexible regulations meeting the current necessities, strict and oldschool implementations have become prominent.

\subsection{Second main criterion}

In this criterion, taking the environmental quality as a basis, there are three subcriteria. None of these sub-criteria could exceed the score of 0.30 (appearance and 
cleanliness). The lowest score was that of "the compliance of the urban built environment with the natural environment" $(0.15)$. Thus, the score of the main criteria is 0.27 . These results indicate that the compliance between Turkish cities' physical environment with their natural environment is at very low levels. Nature has been neglected and deteriorated via urban interventions. But, the results of planning and design procedures integrated with nature are more successful and more important for sustainability. Besides that, as a result of the urban spaces left to the production of motorized vehicles and industrial production, noise pollution is one of the most negative situations. Although it has a higher score than the other sub-criteria, the level of appearance and cleanliness in Turkish cities is much lower than the intermediate level.

\subsection{Third main criterion}

Examining the functional quality of Turkish cities, this criterion has three subcriteria. The highest score belongs to the mass transportation opportunity $(0.25)$, whereas the lowest score belongs to pedestrian and non-motorized vehicle access (0.10). The score of the main criterion is 0.25 . Hence as in the other criteria, the level of success is very low in this criterion. In particular, the score of the criterion "pedestrian and non-motorized vehicle access" is a result of a desperate situation. Turkish cities have been designed for the motorized vehicles, and all the planning-designing processes strengthen this resignation. The pedestrians and non-motorized vehicles are given second priority in the cities. The priority is given to motorized vehicles. It is gradually becoming more difficult to be a pedestrian in the cities. In this parallel, the mass transportation opportunities are limited, and there is a lack of alternatives. In some of the cities, the buses are used only at specific hours. The alternatives (metro, light rail system, sea transportation, train, etc.) do not seem to be a dominant approach yet. The urban services start to fall apart from the city centers. They are relegated to the borders, access to which is difficult. This is one of the reasons why the functional quality of the city centers has decreased.

\subsection{Fourth main criterion}

This criterion examining the security in the cities has two sub-criteria. The scores of these two sub-criteria are very low $(0.10$ and 0.15$)$. The security here is not limited to the statistical values related to crime. The secure presence of pedestrians in the cities was especially taken into consideration. If all the pedestrian groups such as elderly people, children, patients, pregnant women, etc. can securely reach the locations they want, then that city is a secure city. At this point, the other risk factors such as continuity of the road and confliction with the motorized vehicles were evaluated. Besides that, the transformation of cities into insecure and unsafe places after certain hours was considered within the scope of this main criterion. For this reason, the balance between daytime-nighttime usages is important. The urban services supporting the cities and the planningdesigning approach separating the housing from city centers disrupt the balance between daytime-nighttime usages. The cities become deserted and unsafe at night.

\section{Conclusion}

Analyzing the "urban design quality" of countries in terms of various criteria is very difficult because of the depth and multidimensionality of the subject. Within 
the scope of fuzzy logic used in the present study, a multi-criteria method was used. Thirteen sub-criteria and four main criteria were selected, and they were weighted according to the opinions of 73 specialists. All the values were normalized in order to obtain the final order.

The results showed that the urban design quality of the Turkish cities is very low. In these cities coming to the forefront with their planned development from past to present, the negative results have various reasons. However, one of the most important reasons is the lack of an urban design approach that will guide spatial decisions. The urban design approaches do not comply with urban plans. For this reason, the upper scale plans fall short in shaping the spaces or shape them in an unqualified manner.

Within the scope of this study, a general evaluation was made on the urban design approach of Turkey. However, it is believed that similar results would be achieved even if the cities are separately examined. These results indicate that the "urban design" approach shaping the spatial decisions has not been integrated into the planning approach of Turkey. The upper-scale plan approach that does not deal with the urban space has served only for the motorized vehicles, taken the design aspect away from the cities, and reduced the design to a mechanical process.

The present study is important for an understanding of the urban design approach of Turkish cities. The results obtained here can be used in order to define the current problems and to suggest solutions. After determining the problematic criteria, it might contribute to supporting the urban planning decisions aiming to improve the urban design approaches. The problems detected have arisen from the fact that the planning policies giving low importance to the design and implementation processes are still in effect. However, the urban design has become more important from various aspects in the modern planning approaches, and it becomes active together with the planning processes.

In any field, quality is related to a product's ability to solve the targeted problems and meeting the physical, social, and other needs. The quality of the urban design is directly proportional to its ability to meet the vital needs in urban spaces and ensuring urban comfort. Since the concept of quality is a multidimensional concept, the urban design quality should be considered together not only with the functional characteristics of the urban spaces but also with their descriptive characteristics. Urban quality can be achieved with the right urban space design. Increasing, ensuring, or maintaining the quality of spaces, in which humans live and their lives are shaped, affect all the life segments including the culture, economic status, and physical aspects as the components of urban quality. The more perceptible and readable the urban space is and the more complementary the urban components are, the more satisfactory it is for the spatial quality of life and urban quality. In order to increase urban quality, the actors related to urban design should support all the interventions to be made on the urban space with social and economic sustainability. Urban design quality can be achieved with the cooperation of all the actors who play a role in urban design in creating urban space focusing on the targeted design objectives. 


\section{Author details}

\section{Umut Doğan}

Department of City and Regional Planning, Faculty of Architecture, Erciyes University, Kayseri, Turkey

*Address all correspondence to: umutdogan@erciyes.edu.tr

\section{IntechOpen}

(C) 2019 The Author(s). Licensee IntechOpen. This chapter is distributed under the terms of the Creative Commons Attribution License (http://creativecommons.org/licenses/ by/3.0), which permits unrestricted use, distribution, and reproduction in any medium, provided the original work is properly cited. (cc) BY 


\section{References}

[1] Olszewski A, Pudlowski ZJ. Urban Design Training Courses: Leadingby Design, Australia. 2001. Available from: www.eng.monash.edu.au/uicee/gjee/ vo/5nol/o/szewski\&zjp.pdf

[2] Greed C. Definitions and perceptions of urban design. In: Greed C, Roberts M, editors. Introducing Urban Design Interventions and Responses. Longman; 1998. pp. 3-14

[3] Günay B. Kentsel Tasarım Bir Kamu Politikasıdır [Doktora Yeterlik Çalısması]. ODTÜ; 1993

[4] Aydemir S. Planlama ve Planlama Türleri. In: Aydemir S, Aydemir S, Beyazlı S, Ökten N, Öksüz AM, Sancar C, et al., editors. Kentsel Alanların Planlanması ve Tasarımı. Trabzon: Akademi Kitabevi; 2004. pp. 33-40

[5] Freiedman J. Planing in the Public Domain. New Jersey: From Knowledge to Action Princeton Üniversity; 1987

[6] Jaeger JC, Cook NG. Fundamentals of Rock Mechanics. London: Methuen \& Co. Ltd. 1969. p. 513

[7] Keleş R. Urban Regeneration and Related Concepts, UNEP Regional Activity Center, Split. 2004

[8] Tekeli İ. "Her Geçen Gün Geleceği Yeniden Yaratıyor ve Yeniden Kavriyoruz", Geleceği Planlamak, Dünya Şehircilik Günü 24. Ankara: Kolokyum TMMOB Şehir Plancıları Odas1; 2001

[9] Atmaca BS. Kent Planlama ve Kentsel Tasarım Bütünleşmesinin Kentsel Mekanlara Yansıması, Bursa Örneğinde Meydanların İncelenmesi, Mimar SinanÜniversitesi, Fen Bilimleri Enstitüsü Doktora Tezi, _İstanbul. 1994
[10] Aydemir ES. Planlama ve Planlamanın Evrimi. In: Aydemir S, Aydemir S, Beyazlı SD, Ökten N, Öksüz AM, Sancar C, et al., editors. Kentsel Alanların Planlanması ve Tasarımı, Ders Notları No: 54, KTÜ. Müh.Mim. Fak. Mimarlık Bölümü, Trabzon. 1999. pp. 62-91

[11] Sökmen P. Kent Planlamasında Yeni Yönelişler ve Kentsel Tasarım. In: 1. Kentsel Tasarım ve Uygulamalar Sempozyumu, Mimar Sinan Üniversitesi MimarlıkFakültesi Şehir ve Bölge Planlama Bölümü, İstanbul. 1991. pp. 39-42

[12] Türkoğlu K. Kentsel Tasarım'ın Varoluş ve Nitelik Sorunlarında Bugünkü. In: İmarPlanlama ve Uygulama Süreci"nin Rolü, Mimar Sinan Üniversitesi MimarlıkFakültesi Şehir ve Bölge Planlama Bölümü, İstanbul. 1991. pp. 34-42

[13] Türkiye 3194 sayılı İmar Kanunu (Turkey construction zoning law no. 3194)

[14] Vardar A. Kentsel Tasarımın Farklı Çehreleri. Planlama Dergisi, TMMOBSehir Plancıları Odası Yayını. 1997;16:6-13

[15] Ünlü T. Kentsel Mekânda Değişimin Yönetilmesi. Megaron, Y.T.Ü.Mimarlık Fakültesi e-Dergisi. 2006;2(2):63-92

[16] Onaran KS, Sancar FH. Design review in small communities. Environment and Planning B: Planning and Design. 1998;25:539-557

[17] Biddulph MJ. Choices in the design control process. Town and Planning Review. 1998;69:23-48

[18] Carmona M. Controlling urban design. Part 1: Possible renaissance. Journal of Urban Design. 1996;1(1): 47-73 
[19] Madanipour A. Design of Urban Space: An Inquiry into A Social-Spatial Process. England: John Wiley \& Sons (Canada) Ltd.; 1996

[20] Carmona M. Residental Design Policy and Guidance: Content Analytical Basis, Prescription and Regional Emphasis. Planing Practice \& Research. 1999

[21] Knox P, Ozolins P. The Built Environment, Urban Design Reader. 2007

[22] Carmona M, Sieh L. Measuring Quality In Planning: Managing the Performance Process. 2004

[23] Bilsel FC. Kentsel Tasarımda Kuram ve Uygulama. Mimarlık Dergisi. 2001; 302:44

[24] Lang J. Urban Design: The American Experience. New York: Van Nostr and Reinhold; 1994

[25] Paksoy T, Yapıcı Pehlivan N, Özceylan E. Bulanık Küme Teorisi. Ankara: Nobel Yayıncilık; 2013. pp. 195-296

[26] Yager RR, McNeill FM, Thro E. Puzzy logic: A practical approach. AP. Professional. 1994

[27] Zhang X, Xu Z, Liu M. Hesitant trapezoidal fuzzy QUALIFLEX method and its application in the evaluation of green supply chain initiatives. MDPI Journals of Sustainability. 2016;8:952

[28] Carr S, Francis M, Rivlin LG, Stone AM. Public Space. Cambridge: Cambridge University Press; 1992. p. 205

[29] Maslow. A theory of human motivation. Psychological Review. 1943; 50(4):370-396

[30] Alexander C, Silverstein M, Ishikawa S. A Pattern Language. New York: Oxford University Press; 1977
[31] Lynch K. Good City Form. Mass:

MIT Press, Cambridge; 1984

[32] Nasar JL. Perception, cognition and evaluation of urban places. Public Places and Spaces: Human Behavior and Environment: Advances in Theory and Research. 1989;10:31-56

[33] Gehl J. Cities for People.

Washington: Island Press; 2010

[34] Llewelyn Davies Yeang (LYD).

Quality of Place: The North's Residential

Offer, Leeds City Region, London. 2006 


\title{
Jamaican Universities Aiding the Design of an Urban Public Space
}

\author{
Carol Archer, Colette Cunningham-Myrie, \\ Nadine Freeman-Prince, Marvin Reid, Brian Williams \\ and Tamika Royal Thomas
}

\begin{abstract}
Many governments are actively seeking solutions to address the economic crises bedeviling their countries. University/college towns have proven to be successful models of opportunities for attracting investments for economic development while at the same time promoting optimal health outcomes. Harvard, MIT and Newcastle universities provide examples of successful models of universities aiding in spatial design and planning of towns or neighborhoods where they are located to yield sustainable development. The Government of Jamaica has supported the proposal from the University of Technology, Jamaica, (UTech, Jamaica Ja.) to redesign the Papine area in St. Andrew into a university town, given its proximity to the two largest universities in Jamaica, UTech, Ja. and the University of the West Indies (UWI). Both institutions collaborated by using cutting-edge scholarly research and design approaches to propose workable solutions that can promote economic development and healthy lifestyle in an area designated as a university town. The research found that SOPARC was a feasible and reliable instrument for assessing park user variables and associated contextual variables. However, for the proposed design to be executed and maintained, the study recommends establishing a body such as a University District/Town Council with oversight responsibility for planning and land use management of the area.
\end{abstract}

Keywords: urban planning, open public spaces, university town, healthy lifestyles, land use management, participation, redesign

\section{Introduction}

The emerging Development Order for the City of Kingston, Jamaica, which governs the land use planning for the City, denotes the study area as the "Papine University District Local Planning Area." This designation is informed by Jamaica Settlement Strategy: A Review of Experiences and Potentials [1], which denotes a town as having basic infrastructure, such as; a post office, electricity, telephone, piped water and paved roads.

Notwithstanding the official designation, the popular name used by residents and other stakeholders from the area is the Papine University Town. The Papine University Town contains 11 communities extending from the Blue Mountain Range in the north to the Liguanea Plains. See location map in Figure 1. Two of Jamaica's 


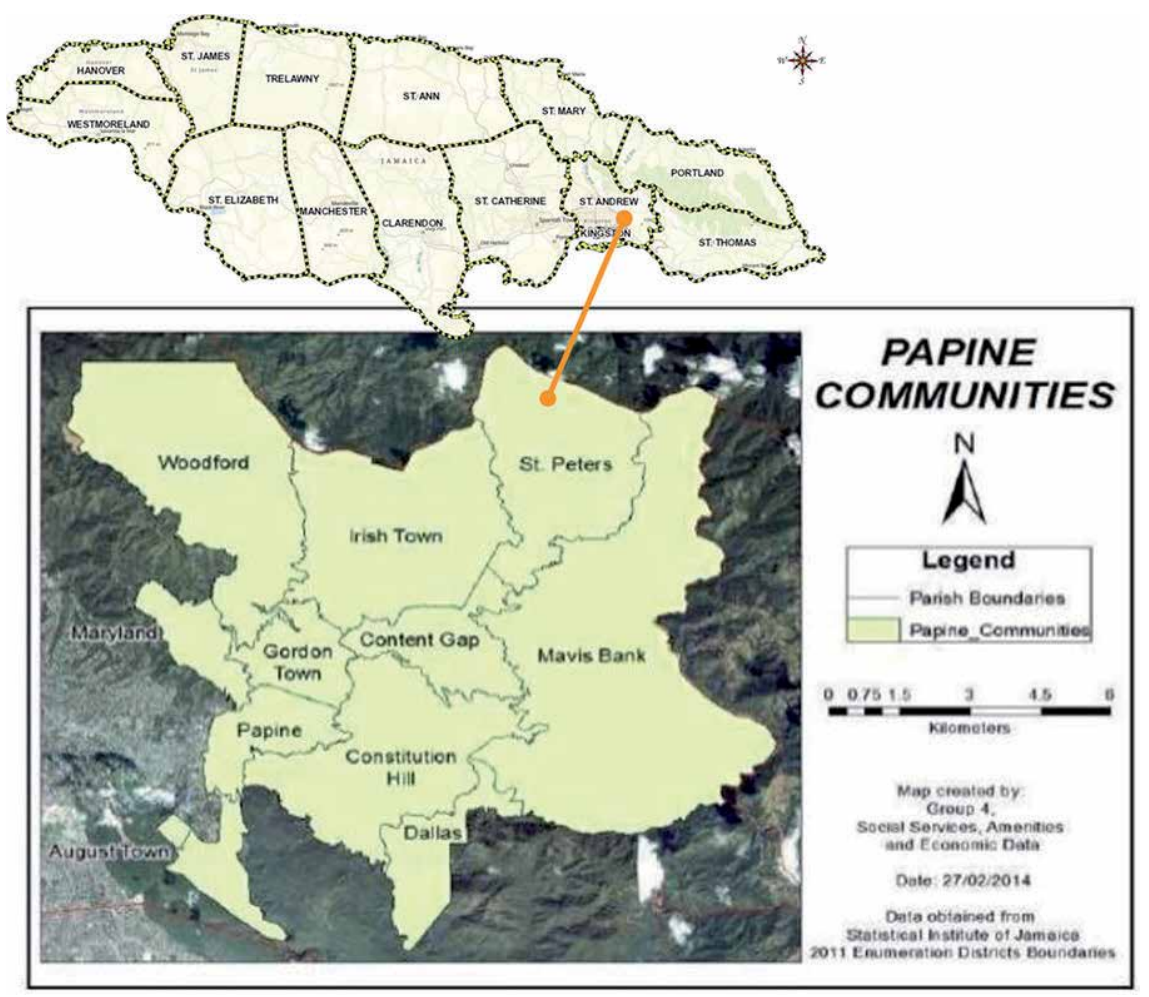

Figure 1.

Location map showing the communities comprising Papine university town.

major institutions of higher learning — the University of Technology, Jamaica and the University of the West Indies, along with other vocational and training institutes are located in the study area. The area also boasts the University Hospital of the West Indies, as well as several other tertiary institutions.

The local planning area is also home to the Royal Botanical Gardens of Hope (Hope Gardens), which today, is the largest public green space in the Kingston Metropolitan Region and home to Jamaica's most popular collection of endemic and exotic botanical collections.

The Papine local planning area is located on the Liguanea Plains within the geological formation of Liguanea and White Limestone. As a result of the rapid and unplanned urbanization and the fact that the land is susceptible to soil erosion and landslides, the area is unable to sustain large scale agricultural activities.

The 2011 current census from the Statistical Institute of Jamaica (STATIN), place the population count for Papine University Town at 23,018 persons. Currently, the area is zoned at 50 habitable rooms per acre. However, with the expanded sewage system, the zoning is proposed at 100 habitable rooms per acre, particularly along the major thoroughfares. Housing developments in the study area consists primarily of single family residential detached type units. Within the past 10 years, there has been an increasing demand for housing for enrolled college students, recent graduates, and young professionals. In 2014, the total student population of the two major institutions was estimated at 25,000. The developers responded to the demand for student housing by constructing apartment and townhouse complexes in the area and on the university campuses. Since it is likely that this trend will continue, there will be the need for additional green open spaces for recreation, basic social interaction, and the promotion of healthy lifestyles. 


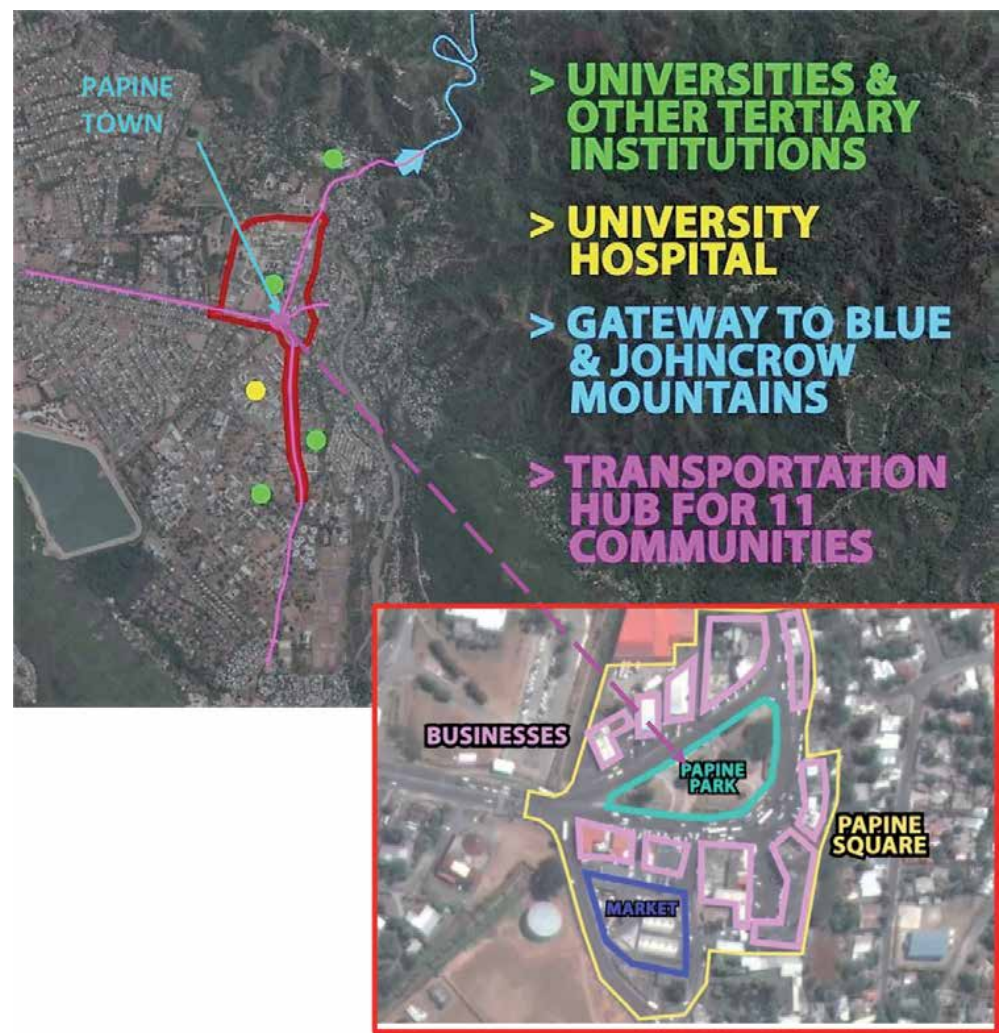

Figure 2.

Satellite image photograph of the areas immediately adjacent to the tertiary institutions (Google map 2012).

In addition to the Royal Hope Botanical Gardens, there are several parks, recreational areas and public open spaces, in varying states of repair, serving the surrounding neighborhoods. The Kingston and St. Andrew Municipal Council is directly responsibility of these open public spaces. The Papine Park is one of the public open spaces serving the communities in the local planning area of the Papine University Town. This public space is also referred to as Papine Square. It occupies approximately $4575 \mathrm{~m}^{2}$ with no perimeter fencing, and uncontrolled pedestrian access from all sides of the park is the norm. It is usually used for recreational purposes, and for group gatherings such as political rallies and cultural concerts or religious meetings. Many people traverse the Park to access the public and private transportation on the roadways that immediately border and/or are within $0.5 \mathrm{~km}$ (Figure 2).

\section{University town concept and characteristics}

History is replete with examples of symbiotic relationship between towns and centers of higher learning. In the past decade, for example, rapid development of university towns has been observed in Mainland China. It is estimated that about 50 university towns have been built in different cities throughout China, primarily to address the issues of economic growth.

Based on an assessment of university towns across the globe, the Hong Kong Planning Department [2] placed the development of these university/college towns into two broad categories - those that evolved organically and those promoted by 
government actions and or direct policies. Towns such as Stanford, Cambridge and Oxford are representatives of the organic evolution model. In these towns, the university graduates remained after completing their studies. Graduates are attracted to areas such as these, because of the availability of jobs in companies that have relocated to the university town to benefit from the synergy of information and technology. These towns have been formed by the establishment of purpose-built campuses for the clustering of universities to achieve objectives such as, relocation and expansion of universities, and promotion of high-tech industries ([2], p. 2).

\subsection{Characteristics of university towns}

The characteristics of a university town, as described by the Hong Kong Planning Department (outlined below), with the exception of the last point, are all applicable to the Papine University Town:

1. nurturing of a number of high-tech companies and activities in the surrounding area;

2. clustering of education, research institutions and start-up companies;

3. occupying a large site area, ranging from a few hundred to a few thousand hectares with a wide range of supporting facilities such as housing, shops, banks, research and development companies, entertainment and exhibition facilities;

4. high degree of facility sharing, including sharing among the, educational institutions the companies and the people living in the town; and

5. attracting talents, intellectual elites, research and development companies and international investments, thus enhancing the town.

Despite having met the requirements, for the most part, the area has not attracted the level of international or local investment in comparison to similar urban areas in the United States or Europe. The economy of a university city or town is closely associated with the university's activity and is highly supported by the whole university structure, which may include university hospitals and clinics, university printing houses, libraries, laboratories, business incubators, student rooms, dining halls, students' unions, student societies, and academic festivities. In some university or college towns, the history of the city or town is often intertwined with the history of the university itself.

A university town plays an important role in defining the urban form and creating a sense of identity for residents and visitors of a country. The university's role in the design and layout of public open space is one way of defining and creating this identity. The university's involvement in the creation of new knowledge, technology and other forms of innovations, through research and development, allows for an environment conducive to learning and growth. Evidently, the University towns, cities or district are important to national development because of the important role these urban forms play in promoting major investments in public space development, public maintenance, and public safety. Universities also influence the shape and direction of the urban expansion because they tend to occupy large tracts of land and depend on services provided by external providers within close proximity.

Research on university towns highlighted the fact that, in the initial, the university and the town failed to work together to address common problems. 
In fact, historical records from North America and Europe suggested that, at best, the relationship between university and residents from surrounding communities was antagonistic. The source of antagonism is the disconnect between scholars in the perceived ivory towers and the inaccessibility of the scholarship to the average residents. Martin et al. [3] in their essay, support the argument that partnerships between universities and community organizations have been either non-existent or unconstructive; this state of affairs being the result of opposing philosophies and practices. They postulate the demand for good governance and participatory democracy worldwide, and the support of this demand by international lending agencies and organizations such as the United Nations has spurred the renaissance for innovative university-community partnerships.

There are several approaches to how universities are engaged in the community development process. The United States Department of Housing and Urban Development (HUD) developed a taxonomy for university/community partnership under broad categories of service learning, service provision, faculty involvement, student volunteerism, community in the classroom, applied research, and major institutional change ([3], p. 4). The activities undertaken by the University of Technology, Jamaica and the University of the West Indies in the Papine area fits squarely with the HUD taxonomy. The students of both universities provide service to the surrounding communities as part of their regular course work. In the design and maintenance of Papine Park, students are able to complete assignments for credit associated with a mandatory course on community development. Furthermore, faculties are assessed annually on their level of engagement in community initiatives in and around the Papine area.

\section{Method}

The University of Technology, Jamaica, through its Faculty of the Built Environment (FOBE), took on the responsibility to prepare architectural designs for the restructuring of the built environment in the local planning area designated as the Papine University Town. The Papine Park, an important landmark and a community hub, is the key target area for the redesign. Baseline data was needed to assess current usage patterns to guide the planning and redesign efforts based on the needs identified by the various stakeholders. A team from the University of the West Indies Tropical Medicine Research Institute (TMRI) was engaged to assist with data collection, using a particular approach. Over the years, the TMRI provided cutting edge, high quality research solutions for developmental needs. The built environment is now the focus of important ongoing collaborative research at UWI by both the Department of Community Health \& Psychiatry and Tropical Medicine Research Institute (TMRI), through the project dubbed Evaluating Qualitative and Quantitative Issues in Physical Activity in Jamaica (EQUIP-JA). The overall goal of EQUIP-JA is to utilize rigorous qualitative and quantitative methodologies to better understand physical activity (PA) patterns in Jamaicans and develop interventions that increase physical activity levels in communities and also provide important data for community and public space designers and planners, as well as prove useful for monitoring and evaluating the investment of public funds in parks. The team from the Tropical Medicine Research Institute employed the SOPARC method which is described below. In addition, the research employed qualitative methods inclusive of questionnaires, focus group interviews and in depth interviews with government officials who have responsibilities for public open space and public works. 


\subsection{System for observing play and recreation in communities (SOPARC)}

A proven reliable and valid direct observation tool employed to assess park usage and conditions is the System for Observing Play and Recreation in Communities (SOPARC) developed by McKenzie et al. [4] in the USA. Though somewhat labor intensive, it is an observational tool that is less intrusive than other data collection strategies and may also be used as a monitoring tool for evaluating changes in park usage patterns and park conditions. Whiting et al. [5] examined the tool as an efficient and effective tool for monitoring park visitation by comparing it with intercept surveys and exit surveys.

UTECH and UWI collaborated on a pilot study to obtain baseline data on current usage patterns and conditions of the Papine Park and assess the reliability and utility of SOPARC as an assessment tool in small-island developing country context.

The SOPARC method, approved by the UTech Ja Research Ethics Committee was employed in the study. It used momentary time sampling techniques that were both systematic and periodic to gain objective observational data on contextual and individual physical activity. The original SOPARC coding forms used by McKenzie et al. [4] were slightly modified by removing the racial categories and adjusting the age group categories.

\subsection{Surveys and interview}

In addition to SOPAC method, face to face interviews were conducted among park users to determine their views and perceptions of the park and to solicit their input on features to be incorporated in the redesign of the park. Although surveys were also administered, it is important to note that the survey was done at a time when both universities and other educational institutions in the area were on summer break, which resulted in limited student participation. Two hundred surveys were administered to persons in the Papine Park over a 3 week period during the months of July and August 2015. The survey included questions on safety in the park, esthetics, accessibility and mobility in and around the park. The researchers collected additional data by way of focus groups interviews with members of citizens associations, business owners along the park, police personnel and other key stakeholders associated with the park. The researchers interviewed key personnel from state agencies who are likely to play a role in the redesign and re-construction of the park. Representatives from the public transportation agency, the agency with responsibility for solid waste management and infrastructure development. These interviews elicit information from the representatives relative to their agencies work plan for the park and their willingness to execute the ideas emanating from the participatory process. The results of these findings were used to inform the redesign of the park.

\subsection{Limitations}

The limitations noted were few. Firstly, data were collected during only 1 week of summer when schools and universities in close proximity to the park were closed. Secondly, the predetermined observation periods may not have captured periods of increased use outside of those timeframes. Thirdly, inter-observer agreement (IOA) scores were not formally calculated during training and may have affected reliability assessment of gender-specific age and activity levels. Despite the limitations, this study has revealed that SOPARC is a reliable assessment tool and effective for providing baseline estimates on the user characteristics of the Papine Park. Reliability for sex-specific age groups and activity levels may be improved by 
ensuring inter- observer agreement (IOA) scores of at least $80 \%$ prior to commencing data collection.

Future observation studies over a longer period and at different times of the year may improve on the representativeness of the data. SOPARC may, therefore, be useful for evaluating changes in user characteristics over time, particularly, if the Papine Park remains a part of the new university town. The Park can be described as a transportation hub. Thirty-one or $27 \%$ of the respondents stated that they use the park for rest and relaxation. During the field survey, several vendors were observed plying their wares in the park. They were selling snacks, beverages, phone cards, fruits, and cigarettes. Regardless of the fact that the Kingston and St. Andrew Corporation, the local authority with responsibility for managing the park, has stipulated that vending is prohibited, this is not strictly enforced.

\section{Analysis}

\subsection{SOPARC analysis and results}

The SOPARC analysis shows that the target areas used most frequently were those nearest to public transportation, where sitting was possible and areas that offered shade. There were limited green spaces in terms of number and size. A number of vendors were observed mainly in the target areas along the western half of the park where there was easy access to parked public transport. However, given that the scan was momentary, it was pre-determined that vending would be coded according to PAL observed rather than type of vending activity. Almost all of the target areas within the park were accessible and usable. Nonetheless, a few areas were empty for each observation period, with the exception of the evening period where all target areas were used by persons (Figure 3).

Significantly, more men than women were observed using the park and the vast majority of users were adults (18-64 years old, 83\%). Of all users, approximately $54 \%$ were observed engaged in sedentary activity viz. sitting, standing or lying down, $39.7 \%$ were walking and only $6.2 \%$ were engaged in vigorousintensity PAL.

Differences were noted in park use according to time of day. There was an increasing trend in use throughout the day, from a low of $15 \%$ of persons observed in the morning period to a high of $38 \%$ in the evenings. Regarding PAL among men, almost $60 \%$ were observed to be sedentary compared with the other PALs. For all females, the proportion observed to be sedentary versus walking was almost equally split ( $47 \%$ vs. $46 \%)$. When the PAL of each sex was examined by period of the day,

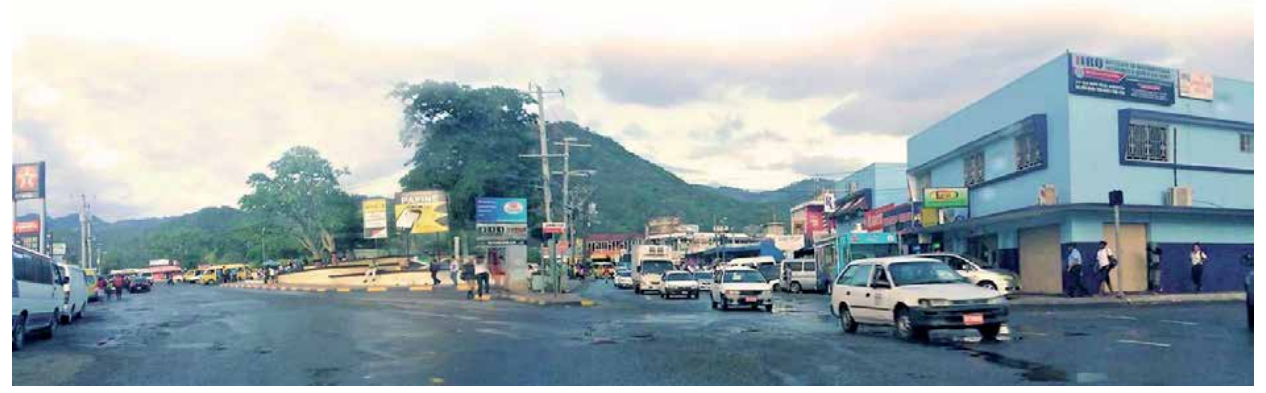

Figure 3.

Photograph showing the northeastern view of the entrance to Papine Park, August 2015 (Source: Author). 
vigorous-intensity activity levels were significantly highest for both sexes in the evening period (Figure 4).

When usage patterns by day of the week were examined, Friday had the highest proportion of use by all users (21\%) with Sunday having the least proportion $(12 \%)$. This difference in proportion over days of the week, was not statistically significant $(p=0.674)$. When usage patterns among females of different age groups were examined, only a minority of seniors (persons $\geq 65$ years old) used the park on any day of the week when compared to females in the lower age group categories $(\mathrm{p}<.001)$. Among men, the 18-64 year old group visited the park at significantly higher levels than the other age groups irrespective of the observation day $(p<.001)$. User counts within age groups for males revealed a statistically significant difference according to the day of the week for adults $(\mathrm{p}<0.001)$ and seniors $(\mathrm{p}=0.002)$ but this difference was not statistical significant for males $<18$ years. For most days, both sexes were engaged in significantly more sedentary activities compared to walking and vigorous-intensity PAL $(\mathrm{p}<.001)$. The exceptions were Saturday and Sunday. However, it was only on Saturday that the difference was significantly higher among females; the highest proportion of women observed walking was 59\% compared to $37 \%$ sedentary and 5\% doing vigorous physical activity $(\mathrm{p}<.001)$ (Figure 5).

The most common activities for each sex in areas scanned where at least one person was observed were walking (F: 57.3\%, M: 47.6\%), sitting (F: 31.6\%, M: 37.8\%) and standing (F: 9.0\%, M: 10.8\%) (Figure 6).

Following on studies conducted by McKenzie and Cohen, the reliability of user count data was assessed by calculating single and average measures intra-class correlations for the variables sex, age and PAL. Data from a total of 261 simultaneous measures were used in the reliability analysis. Inter-observer agreement (IOA) scores for contextual variables were perfect for area accessibility, degree of lighting and presence of organized activity and above $99 \%$ for presence of supervision, provision of equipment and usability. All coefficients met acceptable criteria for reliability assessment ranging from $r=0.87$ to 1.0.

In general, almost all areas of the park were accessible and usable during the observation periods. The target areas used most frequently were those nearest to public transportation, where sitting was possible on concrete seats and ledges and

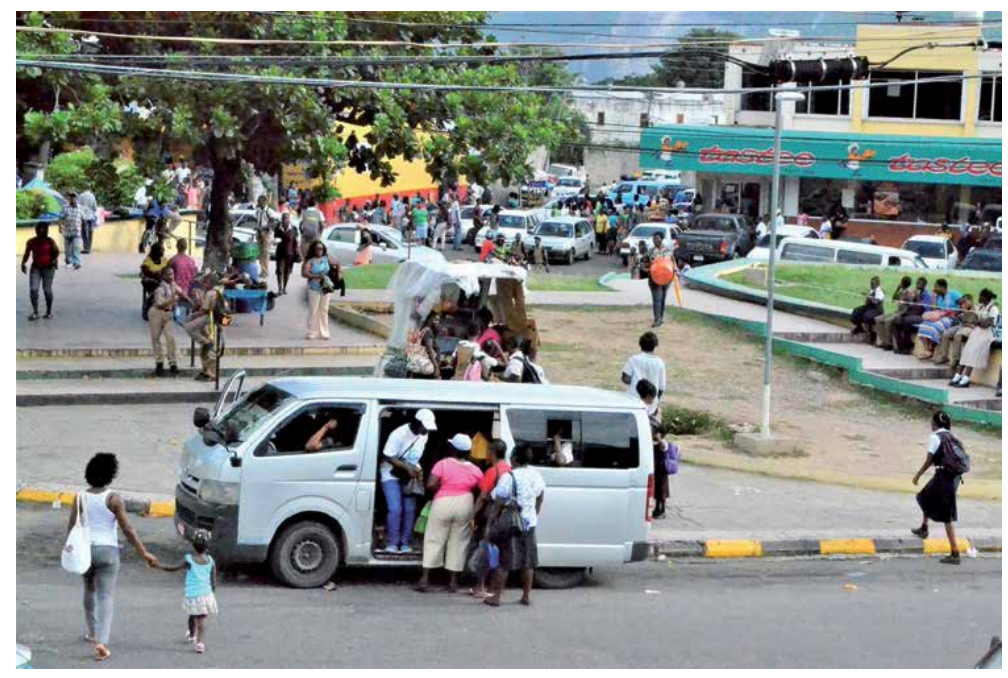

Figure 4 .

Photo of typical evening activities in Papine Square (source: Author). 

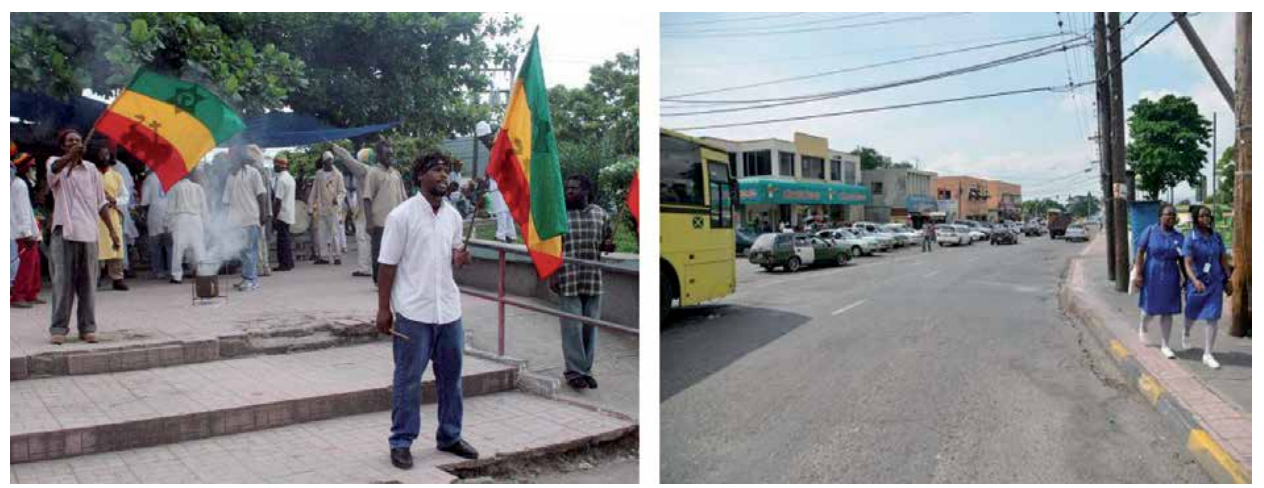

Figure 5.

Photos of Papine Park and surrounding area on a Saturday (source: Author).

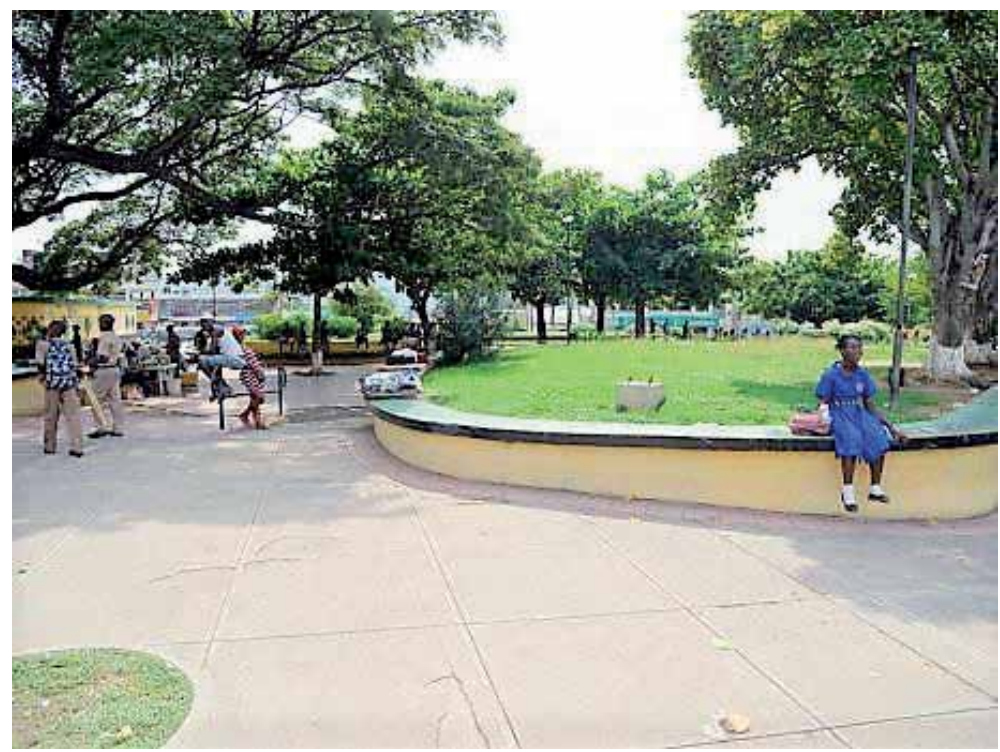

Figure 6.

Photo of Papine Park (source: Author).

near to shaded areas. The observations also revealed significant differences in the use of the park: there was greater use by men versus women and by more adults than seniors or children/teenagers. There was also significantly higher use in the evenings and on Fridays by both sexes. Our results were similar to other studies done using SOPARC.

For most days of the week both sexes were observed to be engaged in sedentary activity in the park, even though activity tended to be more vigorous in the evenings. The possible reason for this is that the Papine Park is more of a square, i.e. a small park/plaza. Hino et al. [6] found that regardless of gender, persons tend to be more sedentary in squares (mean area $\leq 6217 \mathrm{~m}^{2}$ ) than the larger parks, with the possible explanation being that there are fewer walking and running trails. The presence of trails has been associated with higher PALs.

\subsection{Interviews and surveys analysis}

Of the 115 participants interviewed, 41\% (47) were males and 57\% (66) females. While more males were observed in the SOPARC method, using the park, it was 
assumed that more women were represented in the survey because of the likelihood of women to respond to surveys. Majority of those interviewed were between the ages of 20-34. A total of 65 persons fit within this age group. Few senior or persons between the ages of 65-80 were interviewed. Five persons interviewed reported that they were between 65 and 80 years old. Similarly, 17 respondents reported that they were 19 years old or less. This group is identified as the school age population in Jamaica. It is likely that they were represented in small numbers because the survey was conducted in August while most schools were on summer recess.

As it relates to employment status, 71 respondents reported that they were employed, 27 indicated that they were students, 7 were unemployed and 4 retired. One person stated that they are unemployed because of their disability. Two persons did not respond. Based on how the question was posed, it was not clear how many of those employed were "self-employed." While a significant number of the people interviewed reported that they were employed, it is likely that they were in the vicinity of the park as they transitioned between work and home.

The respondents were asked how often they used the park. Thirty-two respondents (28\%) indicated that they used the park every day. Forty-three respondents (37\%) stated that they use the park anywhere from two to five times per day. Thirty-eight respondents indicated that they seldom used the park or use it once in a while. The question on frequency of use did not specify or define the type of use; hence, it is likely that those who walk through to access public transportation or retail stores on either side of the park might not describe this as "using." The study did not highlight any significant difference in the frequency of use based on gender.

\section{Proposed redesign and structure for management and maintenance of Papine Park and Papine}

Proposed design were presented to the stakeholders at community meetings organized by the Papine Area Development Committee, the umbrella organizations representing various civic associations in designated Papine University Town local planning area. There were approximately four meetings to arrive at a final redesign of the Park. Below are artist renditions which incorporated the changes.

To address the issues of safety and security the design incorporated covered bus stops, planting trees and other vegetation for shading from the sun and reducing the heat island effect in the area, solar lighting, and a multi-story pavilion to house a police outpost and information center. The design also included underground parking to accommodate approximately 20 cars. This would remove cars from the roadway and limit traffic congestion in and around the park. This would be supported by the recommendation to re-route traffic via the road way behind the University of Technology. The design also considered designated seated areas for public gatherings and general seating. Based on the analysis of the SOPARC data more than 54\% of the park users were observed to be seated or lying down. Only $6.7 \%$ of the users were involved in vigorous physical activities such as running (Figures 7 and 8).

The leadership of the University of Technology, Jamaica and the University of the West Indies is mindful of the great expectations that are likely to emerge from residents of the surrounding areas. The leadership has also become concerned that elected officials and other decision-makers might become reliant on the universities since their involvement in the planning and development of activities in the Papine Local Planning Area. In several focus group meetings regarding the park design, residents and public officials indicated the need for an appropriate governance/ management structure of the university town. The members of the focus groups interviewed for this project are of the view that an entity should be created with 

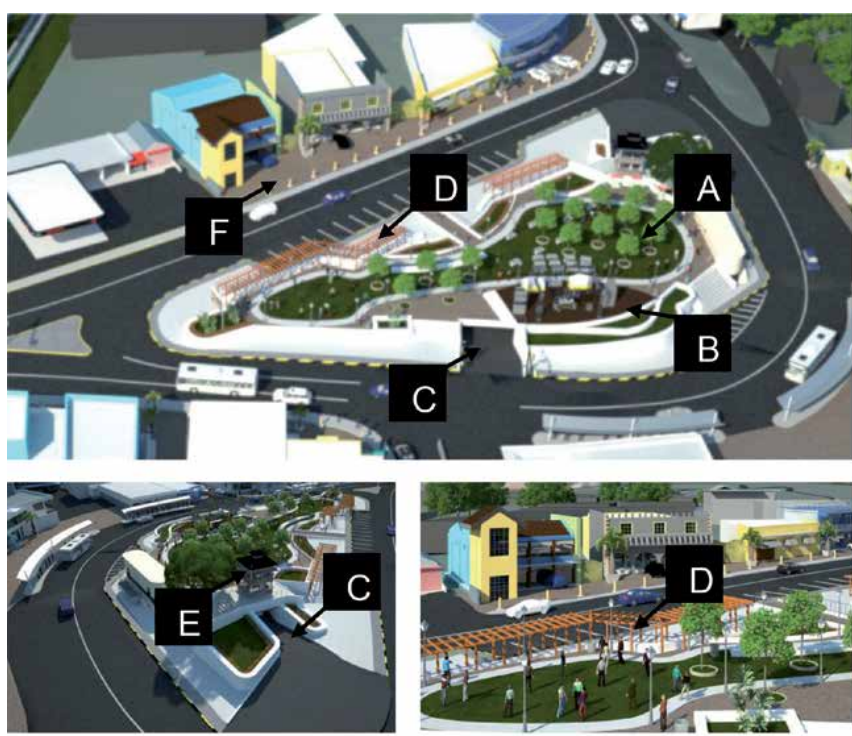

A.

Lighted seating park Area

B.

Stage for events

C.

Underground parking

D.

Covered bus stops

E.

Multi-storey Pavilion Police Outpost Information Center

F.

Ballards to promote pedestrian walkability.

Figure 7.

Artist impression of park proposal.

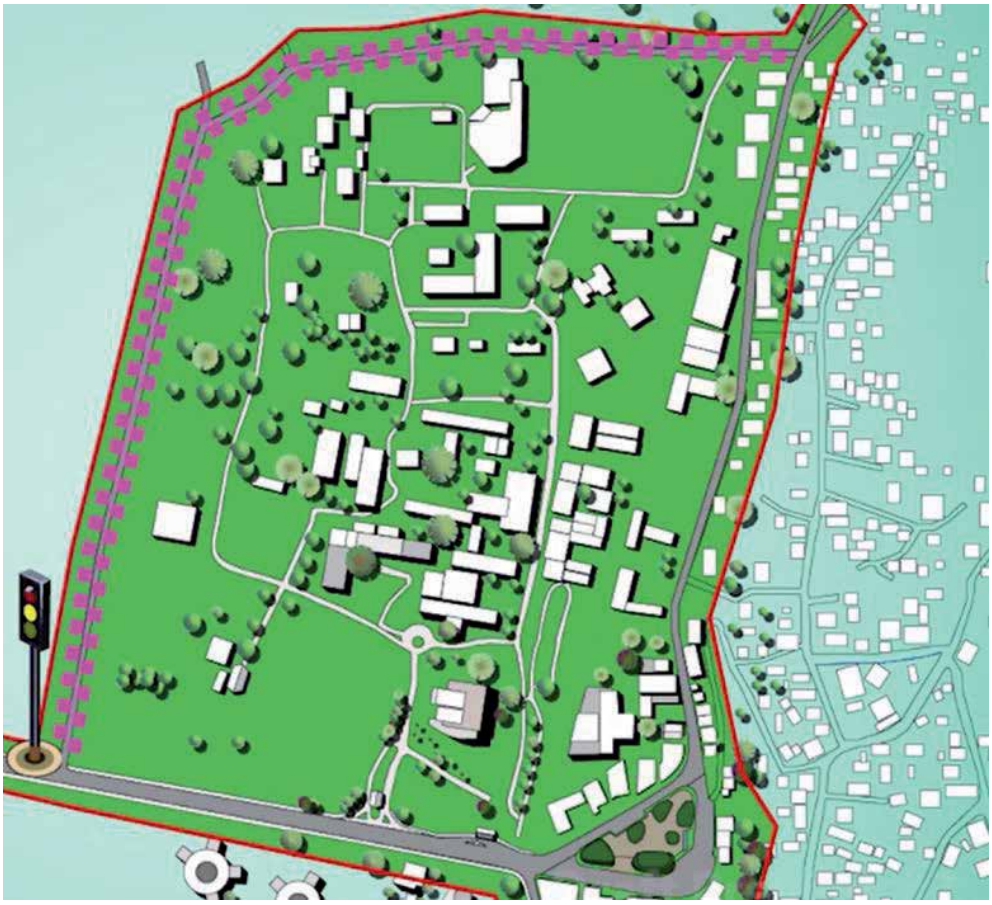

Figure 8.

Showing Papine bypass to ease congestion in Papine Square.

representatives from the relevant stakeholder group to assist with the construction and/or implementation and maintenance of the Papine Park once it is redesigned.

The focus groups believe that for any development to be effective and sustained in the Papine University Town, the establishment of a management structure is critical. The proposed structure is in keeping with the Town Centre Manager concept introduced in 2013 by the Ministry of Local Government and Community 
Development. The concept of Town Centre Manager, while new to Jamaica, has been in existence in Europe and North America for several decades. Andrés et al. [7] postulate that the town center management is more relevant now than before, as growing mega cities compete for prosperity on a global scale. They further noted that in the early days of its development in the United Kingdom, Town Center Management (TCM) was seen primarily as a response to external factors and "a comprehensive response to competitive pressures, which involves development, management and promotion of both public and private areas within town centers, for the benefit of all concerned" (p. 75). More importantly, they are also of the view that the Town Centre Management implies a co-operative rather than confrontational relationship with the private sector and all other stakeholders while striving to retain a local identity. The Government of Jamaica, through the Ministry of Local Government and Community Development, representatives from the University of Technology, and representatives of the civil society are currently in dialog with the local planning authority to establish a town center manager to oversee planning regulatory functions and assist with the management of the Park once it is redesigned.

While Andrés et al. [7] is a major proponent of a structured approach to town center management, Reeve [8], on the other hand, has concerns about the town center structure. He sees this structure being heavily influenced by the private sector or serving mainly its interest. He also argued that in general the management structure for most town centers across Europe are not elected by the people and thus making their accountability to the people questionable. Mindful of Reeve criticism of the town center management structure, based on the responses from the focus groups and surveys, the proposed structure below (see Figure 6) includes a management board with representatives from the political directorate in the form of the Member of Parliament(s) representing the national government and councilors from the local government. In addition, the other proposed members include representatives from the universities, civil society, business interests and other stakeholders. These members would appoint the town center manager and provide oversight for the implementation of development activities in the local planning area designated as The Papine University Town (Figure 9).

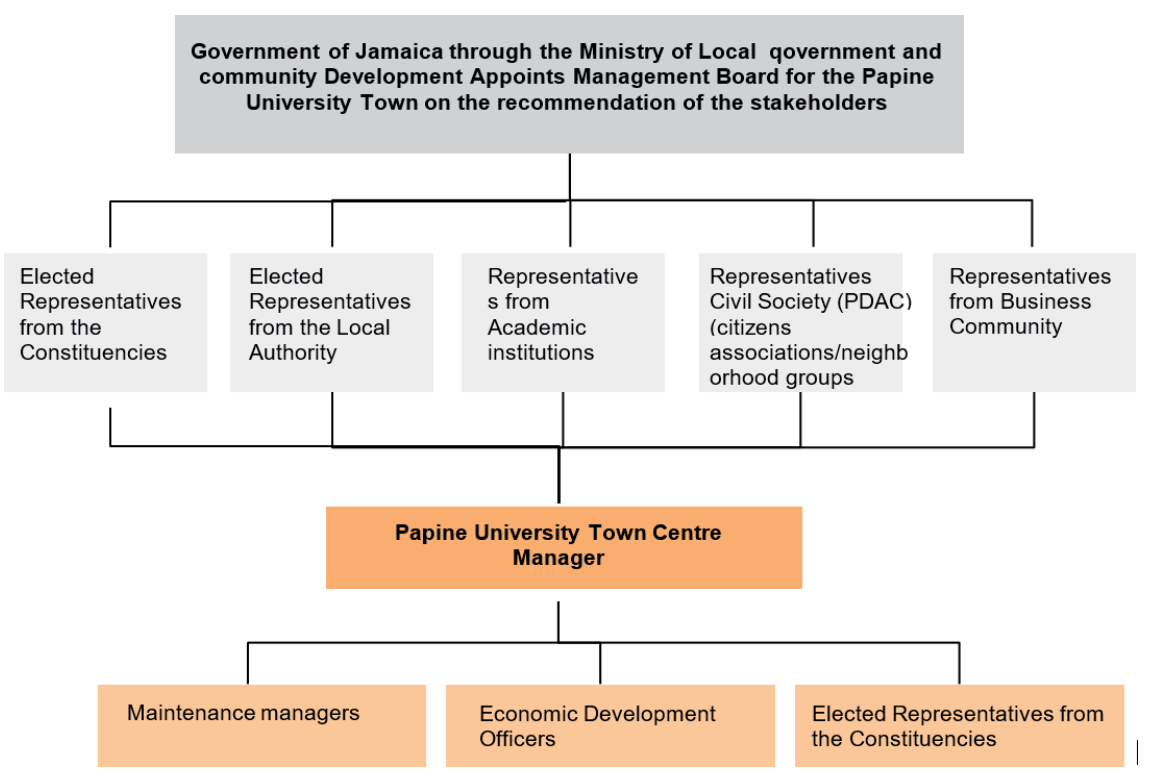

Figure 9.

Proposed structure for the Papine university town local planning area. 


\section{Conclusion}

Activities undertaken by higher education institutions across the globe demonstrates that these institutions are important assets to assist regional, national and local governments with achieving sustainable development, particularly those targeted and measured for the United Nations Sustainable Development Goals 2030. Small Island Developing States such as Jamaica, with limited resources have to rely heavily on higher education institutions to use cutting-edge research and technological advances to provide workable solutions for sustainable development. One of the primary areas that the universities assisted the government was collecting, analyzing, and mapping of data for the area around the Papine Park. The municipal government with responsibility for the management and maintenance of the park now has baseline data on the use of the park. This was the first of its kind for the municipality and for Jamaica in general.

As highlighted above the two universities played a significant role in assisting the government of Jamaica to plan, design, develop an urban public space. In addition, the researchers proposed a new framework to govern and manage the public space and the surrounding neighborhood. The proposed governance framework will help to increase participation of the residents in the decision making process; reduce inequalities; promote sustained, inclusive and sustainable economic growth; improve human health and wellbeing; foster resilience; and protect the environment. This is one of the major commitments of the New Urban Agenda associated with Sustainable Development Goal 11_ “Safe, Inclusive, and Resilient Neighborhoods, Towns and Cities." which Jamaica agreed to. In essence, the redesign and construction of Papine Park as proposed by the university allow Jamaica to demonstrate its commitment to SDG 11.

The proposed design was achieved using the participatory approach which promoted the engagement of a wide cross section of users and potential users of the public park. As a result of the participatory approach used, residents and park users expressed a sense of ownership and belonging and knowledge of how the park should be designed. Safety and crime reduction, inclusiveness, accessibility and environmental sustainability were some of the major consideration voiced by the park users and these concerns were included in the proposed design.

The proposed design also gave due consideration to the multifunctional use of the areas for social interaction and inclusion, human health and well-being, economic exchange and cultural expression. In order for the multi-purpose park to serve future generations, the researchers proposed a governance and management framework that involves the major stakeholders in the decision making process. The involvement of the stakeholders will ensure that the design is implemented to meet the need of the primary users based on their feedback of the design process. 


\section{Author details}

Carol Archer ${ }^{1 *}$, Colette Cunningham-Myrie ${ }^{2}$, Nadine Freeman-Prince ${ }^{1}$, Marvin Reid ${ }^{2}$, Brian Williams ${ }^{1}$ and Tamika Royal Thomas ${ }^{2}$

1 University of Technology, Jamaica

2 University of the West Indies, Jamaica

*Address all correspondence to: carcher@utech.edu.jm

\section{IntechOpen}

(C) 2019 The Author(s). Licensee IntechOpen. This chapter is distributed under the terms of the Creative Commons Attribution License (http://creativecommons.org/licenses/ by/3.0), which permits unrestricted use, distribution, and reproduction in any medium, provided the original work is properly cited. (cc) BY 


\section{References}

[1] McHardy P. Jamaica's Settlement Strategy: A Review of Experiences and Potential. Town Planning Department; 1997

[2] Hong Kong Planning Department. Initial assessment of the development of university town in Hong Kong Jamaica information service. KSAC wants Papine to be university town. Working Paper No. 36. November 2003. Available from: http://www.jamaicaobserver.com/news/ KSAC-wants-Papine-to-be-universityTown_11945084

[3] Martin L. Bridging town and gown through innovative university community partnerships. The Innovation Journal. 2010;10

[4] McKenzie TL, Cohen DA, Sehgal A, Williamson S, Golinelli D. System for observing play and recreation in communities (SOPARC): Reliability and feasibility measures. Journal of Physical Activity \& Health. 2006;3:S208

[5] Whiting RC. Oxford: Studies in the History of a University Town Since 1800. Manchester: Manchester University Press; 1993

[6] Hino AAF, Reis RS, Riberio IC, Parra DC, Brownson RC, Fermino RC. Using observation methods to evaluate public open spaces and physical activity in Brazil. Journal of Physical Activity and Health. 2010;7(Suppl 2):S 146-SS154

[7] Jose Andrés C et al. Town centre management models: A European perspective. International Journal of Urban Policy and Planning. 2008;25(2)

[8] Reeve A. Town centre management: Developing a research agenda in an emerging field. Urban Design International. 2004;9(3):133-150 



\title{
Approaching Urban Design through the Analysis of Structural Differences within Three Neighborhood Typologies in Basra City
}

\author{
Qaaid Al-Saraify and David Grierson
}

\begin{abstract}
Recognizing the importance of physical environments as a major product of an urban design process for the livability of the built environment, this study focuses on urban planning and design characteristics within three different neighborhood typologies of Basra City. The aim of the study is to support future urban developments in the city based on evidences from the association between the current qualities of neighborhood design and the computed walking minutes of residents. These characteristics are determined from reviewed literature in urban design as reliable physical environmental perceived or objectively measured qualities. The methodology of this study describes four steps of analysis such as: (1) the use of the cadastral maps of the case studies as a source of raw information for objective measurement; (2) the use of objective and subjective measures as defining indicators that are utilized from previous studies; (3) the application of defined indicators for the selected neighborhoods through a comparative analysis; and (4) the conducting of statistical analysis to reveal the influence of the defined indicators on the walking. The findings of this study have led to conclusions on the importance of design attributes to future master planning of neighborhoods especially those of the traditional neighborhood, such as the Al-Saymmar neighborhood in Basra city.
\end{abstract}

Keywords: New Urbanism, smart growth, urban design, physical environment, neighborhood planning, walking

\section{Introduction}

New Urbanism and related studies recognize the traditional organization of the built environment as offering more appropriate solutions for a better urban life [1]. In contrast, the modern movement tends to focus on the suburban, automobilebased built environment, with homogenized land use, the diminution of a sense of place and community engagement, and the decline of the role of neighborhood units in the formation of urban environments [2]. The New Urbanism movement adopted certain qualities from traditional neighborhoods that were felt to be particularly positive and reflective of a more compact traditional urban tissue; 
key qualities included mixed land use, housing typologies, grid-like streets, and high densities. New Urbanism often expresses the need to, "rediscover the neighborhoods and sense of community through more human scale development" ([1], p.18), and conceives a better "public transit connectivity", more walking among the community, and an increase in the social experience of a community [1]. Along with that, smart growth trend of urban planning seeks to improve the walkability of existing urban sprawl developments by retrofitting their physical environment [3]. In this regard, Talen explained that the retrofitting of sprawling existing developments is achievable through applying quantitative measures of physical environment that are validated by research. Thus, models of those quantitative models can predict, explain, justify, and achieve potential smart growth. However, she addressed a series of challenges that pertained to smart growth studies including "data sources, geographical scales, aggregation scales and spatial resolution" which all have primarily to do with the research outcomes [3, 4]. Moreover, Hillier [5] argues that architects predominantly rely on normative criteria for design and future developments. Nevertheless, master planning represents a strategic framework that comprises several aspects of a particular location, including its physical, social and economic contexts [6]; thus, it is a reality-pertaining activity as much as normative activity. Evidence-based practice (EBP) within planning has recently emerged as a method to link planning practice to research in order to inform decision makers and professionals within urban planning [7]. Thus, this study both suggests a model to improve the existing neighborhoods and also provides feedback to decision-makers around future developments concerning the current master planning of neighborhoods in Basra city (2010-2035).

It is worth mentioning, that the Master Plan is the only official intervention plan by the government of Basra city. The current Master Plan of Basra city, developed by a local firm, (Snafy company) was approved by government officials in 2015 [8]. The statement and criteria for the current Master Plan of Basra city (2010-2035) recognized a common problem in the significant shortage of both residential units and land for new development. Although the importance of neighborhood as a widely considered planning unit primarily concerned with people's living environment, the existing residential land-use organizations of the current Master Plan applies the 'residential quarter unit' for future developments; this is approximately equal to four neighborhoods. Estimated residents in each quarter total 15,000. The units are classified into three types namely, high, medium, and low density housing units, where each type has a different percentage of the total quantity. Of the total area specified for each residential portion, high-density units will comprise 100units/ha (10\%), medium density will total 45-units/ha (25\%), and low-density will amount to 35 -units/ha (65\%). Furthermore, the structure of the residential quarter includes two commercial centers ( $1 \mathrm{ha})$, retail space ( $1 \mathrm{ha})$, two religious centers (1 ha), health and social centers ( $1 \mathrm{ha})$, seven nurseries ( $2.5 \mathrm{ha})$, four primary schools (2.2 ha), four middle schools (3.8 ha), four secondary schools (4.4 ha), playgrounds (2 ha), local parks (3.5 ha), roads and open spaces (25.2 ha).

With regard to these aspects of the new Master Plan and further design considerations, is the subject of feedback from our study, which will be based on evidence concerning the walking minutes to occupational activities suggested by Al-Saraify and Grierson [9]. To support feedback, this work suggests a quantitative model adopting several urban design measures applicable to the physical environment at neighborhood scale. The authors explore structural and design differences within three neighborhoods of Basra city, namely Al-Saymmar, Al-Mugawlen, and Al-Abassya. Their buildings, streets, land uses, and edges were quantitatively measured to reveal differences with potential impacts on the walking activity of the residents. Moreover, the walking minutes outcomes of the residents are 
based on previous work using Q-GIS software and the Neighbourhood Walking to Occupational Activities NWOA model [9]. Then, the walking outcomes are statistically associated with the urban design qualities to explain the extent to which the differentiation of the physical environments may impact on walking.

\section{Defining the case studies}

The urban form of Basra city was significantly altered by different stages of interventions and this influenced the selecting of the case studies [10]. Also, sociopolitical conditions influence the formation of the urban form of Basra city over three distinct historical stages, including the Ottoman period (before 1916), the British colony and Iraqi Kingdome period (1916-1958), and Republic period (after 1958) [11]. No official planning system was applied after the old fence decayed. The inner organization of the traditional neighborhoods mostly still the same since it was founded before 1916 [12-14]. In the early 1950s Max Lock was hired by the Iraqi government to make the first Master Plan of Basra city [15]. This Masterplan had been embraced the automobile-oriented development, an orthogonal or grid-like or modern planning vision was applied to the city.

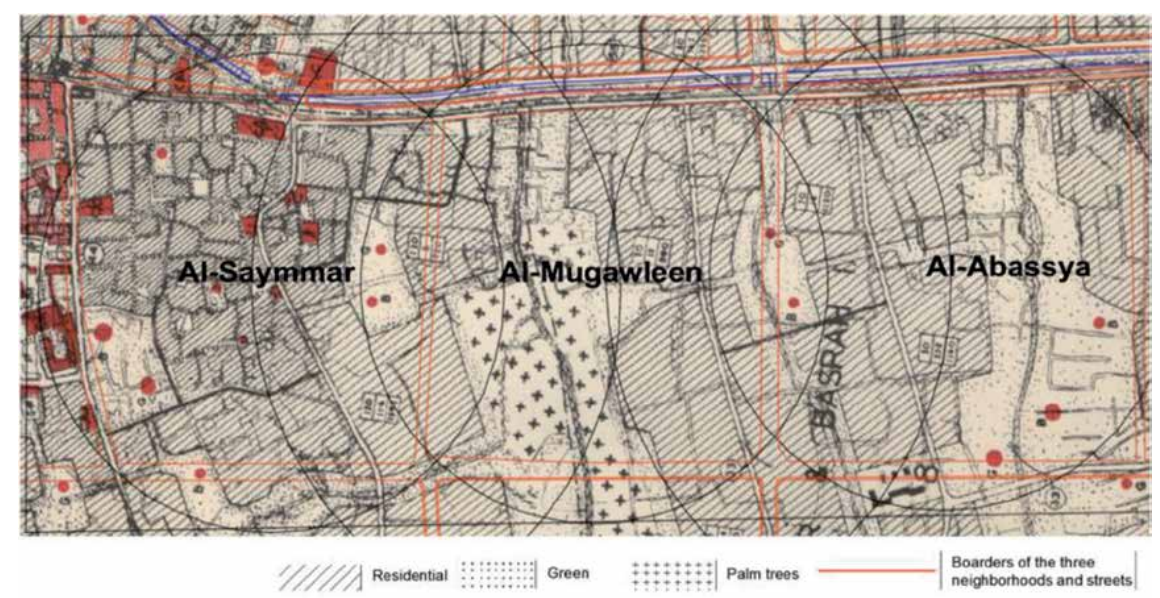

Figure 1.

The current locations of the three neighborhoods located over the master plan of Basra City (authors based on Lock [15]).

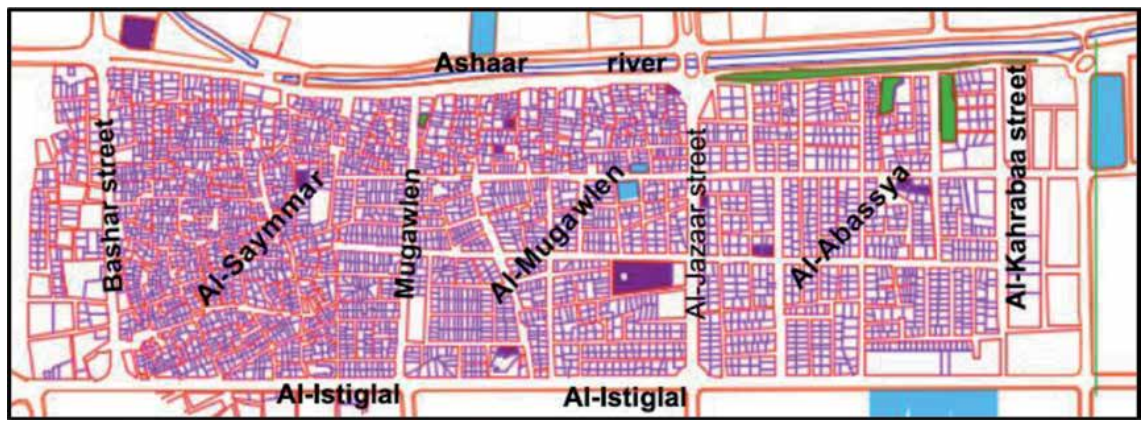

Figure 2.

The targeted three case studies (three neighborhoods of Basra city): [10]. 
Three neighborhoods within Basra are considered by Al-Saraify [10] providing three distinct residential typologies of Basra City with varied potential impact on the physical activity of the residents. A visual comparison between the current status (Figure 1) and the proposed Max Lock's master planning of the three neighborhoods (Figure 2) shows that the interventions have considerably altered the quality of the neighborhoods' built environments. Figure 2 illustrates how land uses of the case studies were planned by Lock, however, the peripheral arterial streets around the neighborhoods imposed gridlines which are mostly now utilized as commercial land use that surrounding the residential blocks of the neighborhoods. Thus, this urban tissue systematically sampled for the application of the defined urban design measures of the physical environment.

Within general consensus, the 'walking distance' offers a standard method to sample neighborhoods in behavioral studies, and the range of walking distance falls somewhere in the range between (0.4) and (0.8) kilometer radius [16, 17]. Similarly, health-built-environment studies depend on measuring Euclidian distance, 15-min radius or 30-min network distance that is $600-\mathrm{m}$ radius [18]. Therefore, this study considers (400-600 $\mathrm{m}$ ), that is, (10-15 $\mathrm{min}$ ), as optimum ranges covering both the spatial definition of the neighborhood and the requirements of active living lifestyle. Accordingly, the sampled neighborhoods accommodate varied urban design qualities which are investigated in this study include; transportation roads, residential area, and commercial destinations. The centers of the selected neighborhoods were utilized to define the minimum $(400-\mathrm{m})$ and maximum $(600-\mathrm{m})$ ranges of the case studies. Moreover, following Al-Saraify [10] the cadastral maps of the three case studies are created depending on the systematic survey of the original maps and data of the government. The satellite images, PDF maps, and orthoimages were obtained from the Basra local government and georeferenced and geometrically corrected (orthorectified). Moreover, the images were spatially correctly located according to its georeferenced coordination points ( $N: 768546, S: 3376180$, UTMWGS 1984, 38 North) into the QGIS free source software by Google. AutoCAD Map 3D was utilized to create a shape file extension (.shp) of the neighborhoods in question that can be added into Q-GIS (Figures 3-5).

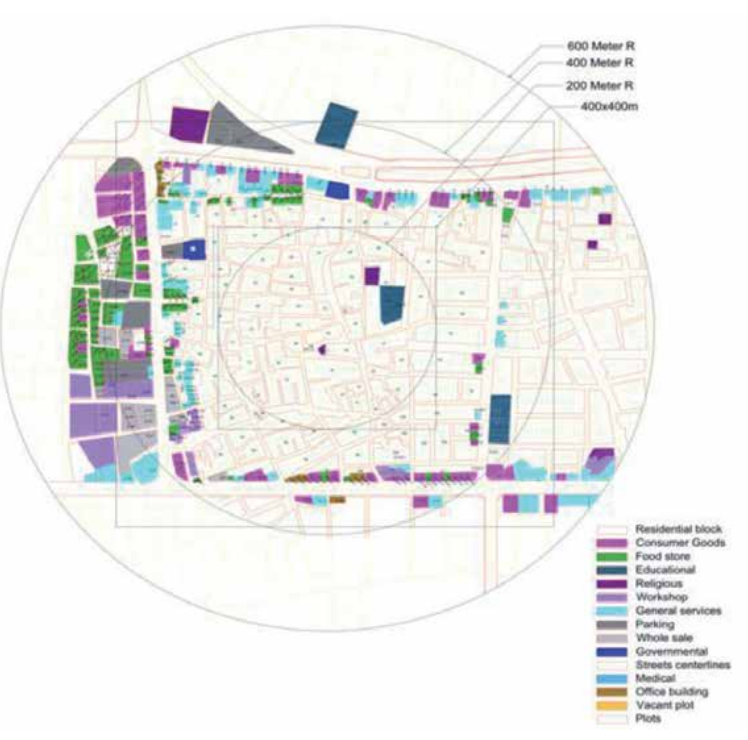

Figure 3.

Al-Saymmar neighborhood cadastral plan: [10].
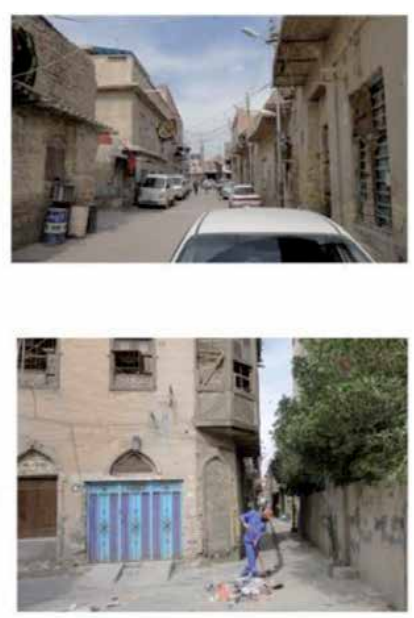

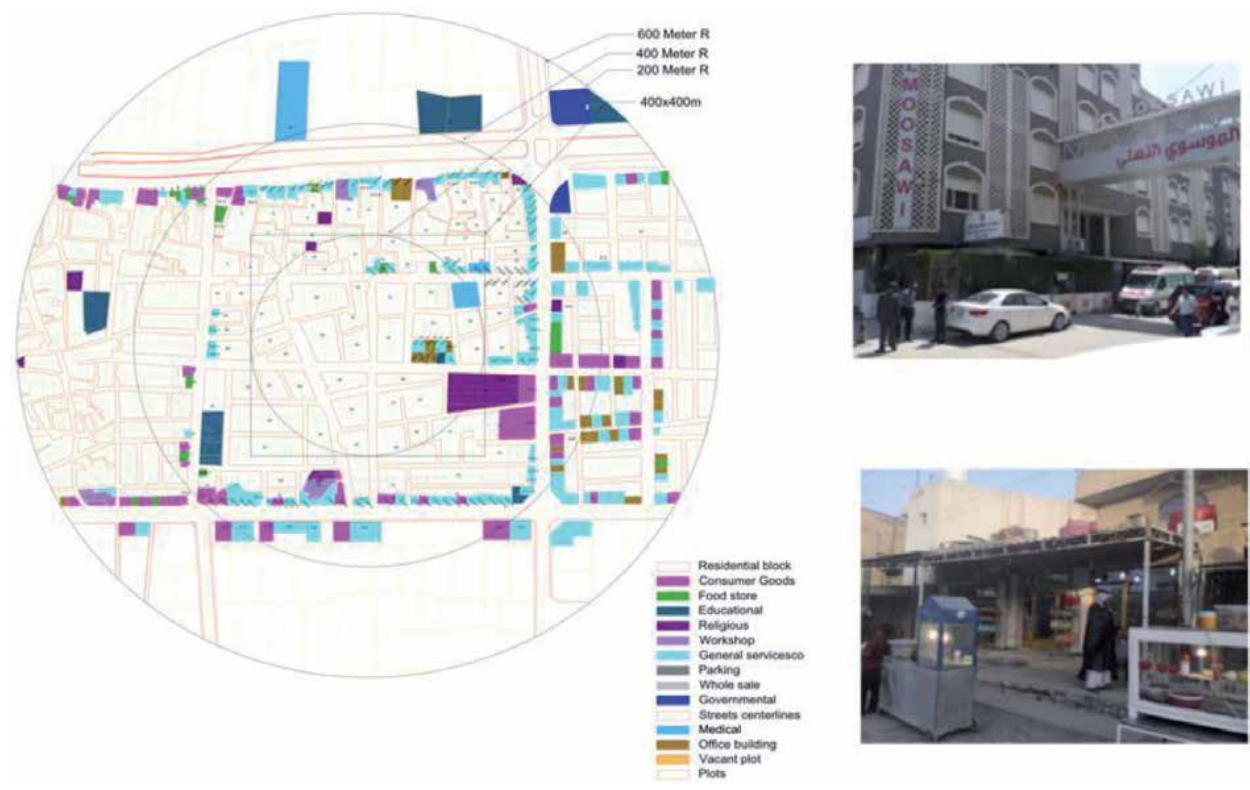

Figure 4.

Al-Mugawleen cadastral neighborhood map: [10].
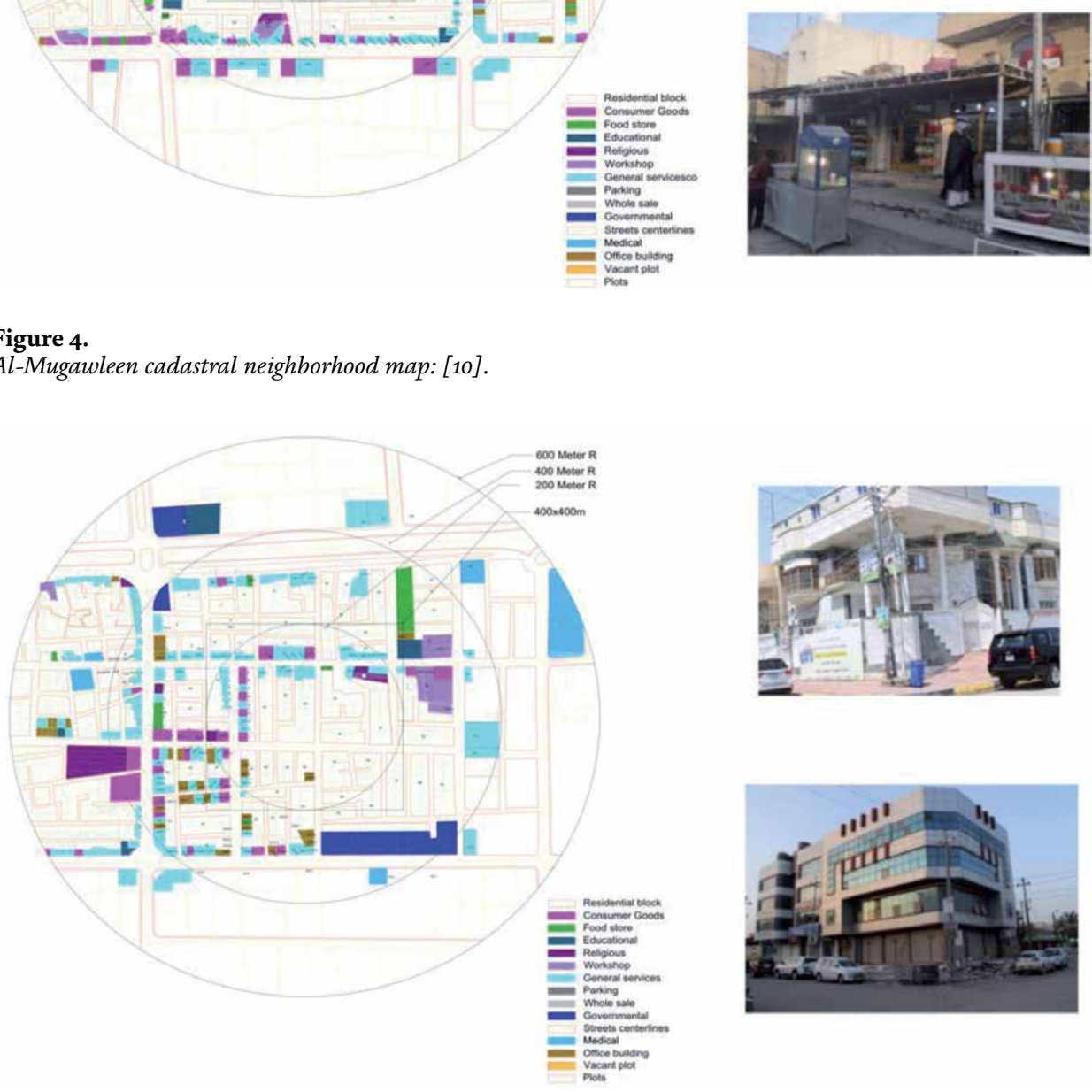

Figure 5.

Al-Abassya cadastral neighborhood map: [10].

\section{Review of the measurement indicators of the urban physical environment}

A proponent study by Cervero and Kockelman, addressed three dimensions that are considered responsible for moving demands of residents in the built environment; these include density, diversity, and design. The so-called '3Ds' represent a general umbrella for the measurement of the physical dimension of the urbanism phenomenon. Their study showed how these three dimensions contributed to an increase in the number of walkable streets in San-Francisco [19]. Regarding the 
issue of density, the intensity of users in urban areas is associated with the concentration of built-up urban developments. Density influences how well human activity and place are related since it influences the availability of urban space. Moudon et al. demonstrated that density and walking are strongly associated and higher density areas are more vibrant and walkable [20]. Although the locations of destinations are defined by the distance factor, the density of the urban area is influenced by locations of activities. This is because the geometrical relationship among components of a higher density area imposes closer distances. Moreover, Frank et al. demonstrated that the residential typologies and their physical layouts could provide a conception of population density. For example, a high-density place could include multi-family housing, apartments, and small residential lots. Moreover, high density is suggested as $>6$ housing units per acre, and low density is defined as $<3$ units per acre, while a medium density falls between these values [21]. Therefore, density could be rather a parametric concept that abstractly defines the neighborhood typology. Although density is a reliable measurement in urban planning, there is no particular level of acceptance concerning density. It shifts according to different factors, such as social and cultural contexts. For example, what could be considered as high density in some Western countries could be seen as low density in China or India.

Eq. (1): Block density equation [21]

$$
\text { Blocks density }=\mathrm{B}_{\text {tot }} / \mathrm{A}_{\text {tot }}
$$

$\mathrm{B}$ is the total area of blocks, includes the open space inside the block and $\mathrm{A}$ is the total area measured by $\mathrm{m}^{2}$.

Eq. (2): Housing unit density equation [21]

$$
\text { Housing density }=\mathrm{H}_{\text {tot }} / \mathrm{A}_{\text {tot }}
$$

$\mathrm{H}$ is the total number of housing units and $\mathrm{A}$ is the total area measured by square hectare.

The mix of land use measure is the degree of difference between the land uses that occupy a certain urban area. In other words, this means the degree of proportionating between different types of land use areas within the total area. Similar to density, the mix of land uses is considered to be associated with the increase of walkers in urban areas. In other words, when a place has diverse facilities or destinations, this will encourage users to walk $[19,21,22]$. The impact of land use diversity on users is manifested in the way in which users associate themselves with their neighborhood or with the wider urban area of the city. This is because it provides them with more opportunities. Also, it facilitates their imagination, in accordance with the notion of a cognitive map, as posited by Kevin Lynch. Thus, diverse land use adds to the experience of people providing more motives and resolutions, which encourage walking. Furthermore, studies used a mix of land use as a criterion of the '3Ds' to probe the quality of place in term of its walkability and transportation, and positive correlations were widely noted among several studies [17, 23-25]. The method to compute land use diversity is addressed by Frank et al. [21]. It adopts a mathematical equation to compute the entropy of land use division to a group of land usages, from a baseline of equality between the different portions [21, 26].

Eq. (3): Land use diversity equation [21]

$$
\text { Land use diversity }=-\frac{\sum_{k} p k \ln p k}{\ln N}
$$


$k$ is an individual category of land use, $p$ is the proportion of total land use, and $N$ is the total number of categories.

The design dimension based on Cervero and Kockelman [19] is the streets connectivity which is considered the third indicator in urban planning studies. It is based on the notion that a greater flow of movement highly depends on how easily people and cars can gain access within/through urban areas. Thus, more accessible attractions require more connectivity of streets and walkways. Their study outlined design dimension as the shape and number of streets and nodes. Streets could be a grid or curve-lined shapes, and the intersections are nodes of four or three legs. Regarding the quality of the streets, studies depend on street design criteria as a parametric measure to assess their contribution in terms of walkability and transportation [17, 20,21]. Connectivity and smaller and denser blocks and streets decrease travel distances and encourage users to walk or cycle. Consequently, they increase place accessibility [27]. New Urbanism supported this finding, proposing that more connected and compacted urban form is generally more accessible and results in lower land consumption. Thus, the pedestrian-oriented areas designed with highly connected streets and a lower ratio of wasted land are not just more walkable but safer. As such these can also be considered as more sustainable areas $[27,28]$. Both streets and intersections are useful tools for engineering urban tissue, which define its key urban characteristics. Moreover, many researchers emphasized the importance of these two components in measuring people's movement $[29,30]$. In this regard, several forms of measurement were addressed by different scholars, such as: (1) the intensity of nodes per area [21, 31]; (2) the external connectivity, which depends on the number of entrances (related to length in $\mathrm{m}$ ) into a certain urban area [32]; and (3) the number of street segments normalized by the number of accommodated intersections [33]. However, the node density was more commonly used among urban planning measures of ecological models.

The density of intersections per area was considered a measure of the streets' network connectivity, whereas the presence of three legs intersections or more indicate a greater connectivity, and thus more accessible place [19, 21]. However, different formulas were applied to measure the density of intersections. The first formula was by urban planners, and depends on the ratio of the aggregated number of three and four legs intersection to the total area in question [34].

Eq. (4): Intersection density equation [19]

$$
\text { Intersections density }=\mathrm{N}_{\text {tot }} / \mathrm{A}_{\text {tot }}
$$

$\mathrm{N}$ is the total number of $\mathrm{T}$ and $\mathrm{X}$ intersections and $\mathrm{A}$ is the total area measured by hectare.

Street density is the total length of streets included in a certain urban area, as normalized by the total area, was considered a measure of connective urban tissue [35-37]. Thus, the denser the streets per area, the more connected, and accessible, the place.

Eq. (5): Street density equation [35, 36]

$$
\text { Street density }=\mathrm{L}_{\text {tot }} / \mathrm{A}_{\text {tot }}
$$

$\mathrm{L}$ is the total length to street segments and $\mathrm{A}$ is the total area measured in hectare units.

Other studies considered other indicators and the text below explains several reliable indicators that were considered in empirical studies and showed considerable association with walking, namely, external connectivity, Pedestrian Catchment 
Area (PCA), pedestrian route directness ratio (PRDR), the clustering coefficient of destinations, the quality of edges, and the enclosure ratio. The external connectivity is the ratio of Ingress/Egress (access) points of the neighborhood to the total length of peripheral streets reveal the extent to which the neighborhood is connected to external urban areas; thus, the greater the distance, the poorer the external connectivity [32].

Eq. (6): External connectivity equation [32]

$$
\text { External connectivity }=\mathrm{L}_{\text {tot }} / \mathrm{E}_{\text {tot }}
$$

$\mathrm{L}$ is the total length of peripheral boundaries of the neighborhood, and $\mathrm{E}$ is the total number of entrances into the neighborhood.

Pedestrian Catchment Area (PCA): The PCA is the accessible area via the street network, assesses the efficiency of the street network to serve certain destinations or built up urban areas within an acceptable Euclidean walking distance, such as a 200,400 , or 800-m radius, from a given point or important facility, like a transport station [37, 38]. Furthermore, the PCA ascertains that, measuring the extent to which the street network serves blocks, demonstrates a certain level of accessibility into the built-up area, as sampled by a circle (e.g., 200-m radius). The center of the circle is hypothetically considered as the pedestrian departure point and a $200-\mathrm{m}$ radius ring is the proposed walkable shed. Thereby, the total accessible built-up area in a 200-m network distance is normalized by the total built-up area inside the circle, indicating the efficiency of the street network defined by the sampling circle. In some research this is referred to the 'Pedshed ratio' [37].

Eq. (7): Pedestrian Catchment Area equation (PCA) [37]

$$
\mathrm{PCA}=\mathrm{AA}_{\text {tot }} / \mathrm{A}_{\text {tot }}
$$

AA is the total accessible area and A is the total built-up area.

Pedestrian route directness ratio (PRDR) concerns the proximity of the distributed destination in the urban area, which was frequently used in accessibility and transportation related research. This involves the distance, either aerial or real, between a resident's house and the destination (calculated in walking distances, e.g., $1 / 4$ mile, $1 / 2$ mile, and 1 mile). This was considered an influential factor in facilitating the activity of users, especially walking to the nearest destinations [17, 22, 23, 39-41]. Moreover, Randal and Baetz [42] developed the pedestrian route directness ratio (PRDR), which is the ratio between the aerial distance and the real distance. It is an expressive formula because it explains the ease or probability to access certain destinations located within a certain distance-range of residences. Thus, the higher ratios (up to 1) represent the best proximate relationships between origin and destination. In this study, the ratio was adopted to express the proximity caused by the street network design, and the number of destinations measure was considered in different measurement levels. The (PRDR) measure was considered on the neighborhood level of measurement, Eq. (8), and the numerical range of this ratio is $\leq 1$. The 1 value represents an optimum relationship that has identical aerial and real distances, whereas a smaller ratio illustrates that the real route is longer than the aerial distance. In streets, network routes relate between two points, the user's departure station and contextual locations or destinations; meanwhile, the Euclidian distance is the aerial distance between the two points. In this study, a certain number of destinations and one origin are defined for each case study, where the origin is the postulated departure point and the destinations are defined by the survey. 
Approaching Urban Design through the Analysis of Structural Differences within Three... DOI: http://dx.doi.org/10.5772/intechopen.87221

Eq. (8): PRDR equation [42]

$(\mathrm{PRDR}=$ Euclidian distance/network length of a route $)$

The clustering coefficient of destinations suggests that people perceive this as more than a single destination because each cluster provides a range of options. Thus, the cluster has a greater chance of meeting users' needs than an individual destination $[22,43]$. Thus, a cluster of destinations is a design process that serves the proximity by compromising the distance and geometrics of destinations; therefore, users maintain a cognitive map of the proximity of their houses to non-residential clusters. However, there is no study that validates any standard measures of a cluster; instead it is simply perceived as a group of destinations proximate to each other to which people take themselves. Each cluster accommodates a bundle of different types of uses instead of single type of land use. The depending bundle criterion was devised by Canter and Tagg, who defined how many clusters could serve a particular urban area [44]. The clustering coefficient is a graph-based measure, developed by Watts and Strogatz, to calculate social networks, which were considered 'small world' networks. If a group of destinations is represented as nodes and a graph was made through connecting the nodes by hypothetical links, then the clustering coefficient is the number of links between all the nodes divided by the total number of links that was postulated as a rational relationship among the nodes. Also, the coefficient represents the degree to which a group of nodes are clustered, by normalizing the number of observed Links to the number of possible Links among the same group of nodes. The implication of a small-world phenomenon, as defined by network theorists Watts and Strogatz [45], to measure the degree of proximities between a group of destinations is promising because there is no equivalent topological measure to represent the relationship among a group of proximate destinations. However, there is no available method to produce a standard measurement of accessibility from this coefficient. In this respect, van der Westhuizen [46] used the ratio of a number of realized links between destinations, normalized by the number of possible links, and reported the significant influence of walking.

Eq. (9): Clustering coefficient equation [46]

$$
\text { Clustering coefficient }=\text { observed links } / \text { possible links }\left(n^{2}-n\right) / 2
$$

The quality of edges: the studies of walking urban areas linked the quality of street edges with the number of walkers. Jacobs in [2] asserted the link between the quality of streets and street life. A street facilitates the interaction between people because it brings them together, even those who do not know each other. In a street, people do their favorite things: walking, watching, sitting, or choosing their favorite viewpoint. A good street has clearly designed edges, geometry and carefully delineated transparency [2]. The block frontage is an important component of block structure, which impacts on human perception, traffic and pedestrian flow [32, 47-49]. In this study, the method to assess the quality of street edges was adopted from Remali et al. [50], and depends on five factors to assess the quality of elevations. These factors are: the "number of visible units accessible from the street (S); visible diversity of function (F); openness to the public street $(\mathrm{O})$; level of maintenance $(\mathrm{M})$; and level of detail and quality of materials (D)". The frontage quality index (SFOMD) method depends on a Likert scale of seven points, starting with (1), which is the lowest score of the assessment, and ending with (7), which the

\footnotetext{
${ }_{1}$ The formula $\left(\mathrm{n}_{2}-\mathrm{n}\right) / 2$ ) to compute the possible number of links amongst $\mathrm{n}$ nodes is addressed by this study because the original reference did not mention this part: (authors).
} 
highest score of the assessment. The computing of the overall index was adopted from Gehl [51] and Hershberger [52], and combines the five indicators by totaling their raw scores. Thereby, the minimum score for the process is five points, which represents the poorest street quality, whereas, the highest score is 35 points which represents the best possible street quality [50].

Enclosure ratio: studies in urban design have developed different ideas on the relationship between human perception and street room. The enclosure notion defines the sense of place in connection with the relationship between street widths and adjacent building heights. From an architectural point of view, Cullen illustrated that enclosure is an important tool that influences the human perception of a place or the "hereness". Accordingly, the quality of enclosure is defined as a highly-required dimension of a streetscape, because the street-building proportions represent the "outdoor room" of walkers. For example, Ewing et al. indicate that building height and other vertical elements are milestones to establishing welldefined outdoor spaces when they are proportionate with the width of the counter space, or street [53].

\section{The measurement process of physical environmental attributes}

The measurement of physical environmental attributes, which were addressed in the previous section, are applied to the case studies and discussed in this section based on the cadastral maps of the three case studies. The raw information concerning the essential structure of the case studies is elicited from cadastral maps which were in AutoCAD and QGIS formats (Figures 3-5), the numerical attributes were entered into an excel sheet and then SPSS software. Then, each individual indicator is computed based on its defined equation and coded in the SPSS based on their initial letters, either on 400-m radius or 600-m radius (Table 1). For example, the density indicator has three variables for each case study; thus, it was measured two times to produce six numerical values for three neighborhoods. The two scales are ( $400-\mathrm{m}$ radius), and (600-m radius). Thus, the codes of the three density variables are DnS1 and DnS2, respectively; this coding is continued for the rest of the independent variables (Table 1). From this, independent variables for measures of the physical environment attributes are produced (Table 2). Twenty-two independent variables were developed in this study, which resulted from the application of the measured physical environment indicators to the case studies.

\subsection{Block and housing units density}

The area of the blocks was computed on the two scales 400-m radius and 600-m radius, and the density equations Eqs. (1) and (2) were applied with the assistance of Excel software. Although the block density indicator is computed on two scales, the housing unit density is computed on one scale. Thus, three independent variables were calculated for the densities, which are labeled as BDnSi $i=1$, and 2 , and HDnS1 (Table 1). Moreover, the block density has been measured on the two scales, for the block density on the 400-m radius scale, the highest density was found in Al-Saymmar (0.71), while in Al-Mugawlen and Al-Abassya differed slightly from (0.65) to (0.67), respectively. Furthermore, the block density on the 600-m radius scale was slightly degraded from Al-Saymmar (0.78) to Al-Mugawlen (0.77) to Al-Abassya (0.72) (Table 2). The intensity of housing units (HDnS1) was measured only on scale (400-m radius); however, a divergence was noted from Al-Saymmar (41.9) to Al-Mugawlen (25) to Al-Abassya (17.25), in light of the single-family housing per hectare (Table 2). 


\begin{tabular}{|l|l|l|l|l|}
\hline Codes & Content & $\begin{array}{l}\mathbf{4 0 0}- \\
\text { m R. }\end{array}$ & $\begin{array}{l}\mathbf{6 0 0 -} \\
\text { m R. }\end{array}$ & Tot. \\
\hline BlkDnSi & Block density (Built-up area) & $\mathrm{x}$ & - & 1 \\
\hline HUDnSi & Housing units density & $\mathrm{x}$ & - & 1 \\
\hline LUDv1Si & $\begin{array}{l}\text { Land use diversity of all commercial land } \\
\text { uses. }\end{array}$ & $\mathrm{x}$ & $\mathrm{x}$ & 2 \\
\hline LUDv2Si & $\begin{array}{l}\text { Land use diversity of the commercial land use } \\
\text { without parking, workshops, and wholesale }\end{array}$ & $\mathrm{x}$ & $\mathrm{x}$ & 2 \\
\hline LUDv3Si & $\begin{array}{l}\text { Land use diversity of all the non-residential } \\
\text { land uses. }\end{array}$ & $\mathrm{x}$ & $\mathrm{x}$ & 2 \\
\hline NodDnSi & Nodes density per hectare & $\mathrm{x}$ & $\mathrm{x}$ & 2 \\
\hline StDnSi & Streets length per hectare & $\mathrm{x}$ & $\mathrm{x}$ & 2 \\
\hline ExtCnS1 & External connectivity & $\mathrm{x}$ & - & 1 \\
\hline PCAS2 & Pedestrian catchment area & $\mathrm{x}$ & - & 1 \\
\hline PRDRSi & Pedestrian route directness ratio (PRDR) & - & $\mathrm{x}$ & 1 \\
\hline ClsCofSi & Clustering coefficient & $\mathrm{x}$ & $\mathrm{x}$ & 2 \\
\hline SFOMDS1 & Quality of edges & $\mathrm{x}$ & - & 3 \\
\hline EnRS1 & Enclosure ratio & $\mathrm{x}$ & - & 3 \\
\hline
\end{tabular}

$\mathrm{i}$ : stands for the two scales

Table 1.

The measurement indicators of the physical environment attributes.

\begin{tabular}{|l|l|l|l|l|l|l|l|}
\hline & & \multicolumn{2}{|c|}{ Al-Saymmar } & \multicolumn{2}{l|}{ Al-Mugawlen } & \multicolumn{2}{l|}{ Al-Abassya } \\
\hline & Unite & $\mathrm{S1}^{\star}$ & $\mathrm{S} 2^{\star}$ & $\mathrm{S} 1$ & $\mathrm{~S} 2$ & $\mathrm{~S} 1$ & $\mathrm{~S} 2$ \\
\hline BIkDSi & ratio & .71 & .67 & .65 & .66 & .67 & .58 \\
\hline HouDnSi & U/hctr & 41.9 & - & 25 & - & 17.25 & - \\
\hline LUDv1Si & degree & .94 & .94 & .70 & .75 & .79 & .73 \\
\hline LUDv2Si & degree & .98 & .97 & .67 & .76 & .68 & .76 \\
\hline LUDv3Si & degree & .39 & .45 & .57 & .63 & .52 & .63 \\
\hline NoDnSi & no./hctr & 4.16 & 3.36 & 2.89 & 3.33 & 2.03 & 1.8 \\
\hline StDnSi & Length/hctr & 387 & 346 & 324 & 368 & 267 & 250 \\
\hline ExCnS1 & no./L. & - & - & - & - & - & - \\
\hline PCAS1 & \% & 61.67 & - & 73.18 & - & 70.4 & - \\
\hline PRDRSi & ratio & .71 & .75 & .77 & .79 & .72 & .76 \\
\hline CIsCofSi & ratio & .05 & .04 & .04 & .03 & .05 & .04 \\
\hline SFOMDS1M & Likert & 21 & - & 27 & - & 30 & - \\
\hline SFOMDS1C & Likert & 20 & - & 23 & - & 27 & - \\
\hline SFOMDS1CS & Likert & 15 & - & 22 & - & 25 & - \\
\hline EnRS1M & ratio & 2.9 & - & 2.7 & - & 2.7 & - \\
\hline EnRS1C & ratio & 1 & - & 1.7 & - & 1.3 & - \\
\hline EnRS1CS & ratio & 1.1 & - & 1.7 & - & .93 & - \\
\hline S1: 400-meter radius & & & & & & \\
S2: 600-meter radius & & & & & & & \\
\hline
\end{tabular}

Table 2.

The computed indicators of the physical environment attributes.

\subsection{Mixed land use}

The diversity of land use was computed by the entropy equation Eq. (3) and the variables used for that purpose were the different land uses measured by the area. From this, the equation was applied with the assistance of MATLAB software and the categories of land use, for instance, the retail shops and workshops, were 
entered as a variable of the equation (X1, X2, ..., Xi) in the MATLAB format. Additionally, because the land use categories are not unified across the three case studies, they could have different nature of influence on residents' lives. This study considers different combinations of land uses, or different type-based bundles. The first bundle involved all the commercial land uses, the second bundle involved the retail shops, which are the commercial land use without parking, workshops, and wholesale, and the third bundle included all the non-residential land uses, which are the commercial plus the civic buildings, such as mosques. Moreover, this indicator was applied to the two scales; 400-m radius, and 600-m radius. Thus, six independent variables were calculated for the land use diversity, which were labeled as LUDiv1S1, LUDiv1S2, LUDiv2S1, LUDiv2S2, LUDiv3S1, and LUDiv3S2, (Table 1). In terms of the commercial land use variable (LUDiv1S1), on a 400-m radius scale, the degree of diversity demonstrated a significant difference between the Al-Saymmar neighborhood (0.94) and the Al-Mugawlen and Al-Abassya neighborhoods, (0.7, and 0.79), respectively.

Moreover, the same variables, on a 600-m radius scale, had approximately a similar pattern of variance among the three case studies $(0.94,0.75$, and 0.73$)$, respectively. In terms of the variable for commercial land use without parking, workshops and wholesale (LUDiv2S1), on a 400-m radius scale the degree of diversity adequately differed between Al-Saymmar (0.98) and the other two neighborhoods, Al-Mugawlen and Al-Abassya, (0.67, and 0.68), respectively. Moreover, the same variable, on a 600-m radius scale, showed an approximately similar pattern of variance among the three case studies; Al-Saymmar brought about a 0.97 degree of variance, whereas, Al-Mugawlen and Al-Abassya each brought about 0.76 degree. In terms of the non-residential land use variable (LUDiv3S1), on scale 400-m radius, the degree of diversity adequately differed between Al-Saymmar (0.39) and the other two neighborhoods (0.56, and 0.52) for Al-Mugawlen and Al-Abassya, respectively. Moreover, the same variable, on a 600-m radius scale, had approximately shown a similar pattern of variance among the three case studies: Al-Saymmar brought about (0.45) degree of variance, whereas Al-Mugawlen and Al-Abassya each brought about (0.63) degree (Table 2). Thus, the land use diversity of Al-Saymmar, as measured by the six variables (Table 2), is significantly different from the other two case studies, namely the Al-Mugawlen and Al-Abassya neighborhoods.

\subsection{Streets connectivity}

The QGIS software was used to compute the number of segments, length of each segment, and number of nodes, and these were transferred to an Excel sheet. Moreover, the streets' segments are represented as polyline between two adjacent nodes, or from a node to a dead-end street. The nodes are either X-intersection or $\mathrm{T}$-intersection types. This procedure is conducted twice, on a $400-\mathrm{m}$ radius scale and on scale 600-m radius. In this study, four indicators defined the connectivity, namely: intersections density, street intensity, link-node ratio, and external connectivity. Moreover, each indicator was applied to two scales, (400- and 600-m); however, the external connectivity was only applied to the 400 -m radius scale because the 600-m radius scale did not define neighborhood boundaries, but instead the walking ranges. Thus, the total number of variables for this indicator is five namely, NodDnSi i = 1, 2, StDnSi, ExtConS1 (Table 1). Moreover, three equations were used to compute these indicators Eqs. (4)-(6).

The intensity of nodes (NodDnS1) on the 400-m radius scale in the Al-Saymmar neighborhood was (4.16), which is approximately double the number in for both Al-Mugawlen and Al-Abassya (2.89, and 2.03), respectively. Moreover, the node density (NodDnS2) on a 600-m radius scale showed a decline in the node intensity 
per hectare, from Al-Saymmar (3.36) to Al-Mugawlen (2.33) to Al-Abassya (1.8), (Table 2). The intensity of street lengths (StDnS1) on a 400-m radius scale showed a significant reduction in total street lengths, from $387 \mathrm{~m} / \mathrm{ha}$ for Al-Saymmar to $324 \mathrm{~m} /$ ha for Al-Mugawlen and $267 \mathrm{~m} /$ ha for Al-Abassya. However, the intensity of street lengths (StDnS2) on a 600-m radius scale was the highest in Al-Mugawlen 368 at $\mathrm{m} / \mathrm{ha}$, while Al-Saymmar was slightly lower at $346 \mathrm{~m} / \mathrm{ha}$, and Al-Abassya illustrated the lowest street density in terms of length at $250 \mathrm{~m} / \mathrm{ha}$ (Table 2). The external connectivity (ExtConS1) on a 400-m radius scale demonstrated an adequate reduction in the number of entrances per mile length, while the Al-Saymmar neighborhood showed the highest score with 28.1 entrance/mile, and the Al-Mugawlen neighborhood showed a moderate score at 20 entrance/mile; meanwhile, the lowest score was in the Al-Abassya neighborhood at 16 entrance/ mile (Table 2).

\subsection{Pedestrian catchment area (PCA)}

To apply the PCA indicator, the center of each case study is the center of the 400-m radius, as sampled in the cadastral maps. Every single block was considered a destination that needs to be accessed from the center of the neighborhood within 10 min of walk along the street network. The QGIS Road-Graph tool was utilized to measure the shortest network distance between two spatial points, which are the center of the case study and each individual block falls within the 400-m radius. After the adjustment of the human speed to $5 \mathrm{~km} / \mathrm{h}$, only the blocks within a 10 -min walk were considered in determining the total accessible area in each neighborhood. Thus, the accessible blocks in $\leq 10 \mathrm{~min}$ were added up, and the resulting total accessible block area was represented as percentage area out of the total block area within a 400-m radius. Thus, only one independent variable was noted in applying this indicator, PCAS1 (Table 1). Therefore, the PCA variable illustrates that, in the Al-Saymmar neighborhood, out of $356,135 \mathrm{~m}^{2}$ of built-up area, there was $219,635 \mathrm{~m}^{2}$ of accessible area in 10-min of network walking within the 400 -m radius area; this is $61.67 \%$ of the total built-up area. In the Al-Mugawlen neighborhood, out of $326,500 \mathrm{~m}^{2}$ of built-up area, there was $219,635 \mathrm{~m}^{2}$ of accessible area in 10-min of network walking within a $400-\mathrm{m}$ radius area; this is $73.18 \%$ of the total built-up area. In Al-Abassya neighborhood, out of $333,600 \mathrm{~m}^{2}$ of built-up area, there was $2235,600 \mathrm{~m}^{2}$ of accessible area in a 10 -min network walk within the 400 -m radius area; this is $70.4 \%$ of the total built-up area (Table 2 ).

\subsection{Pedestrian route directness ratio (PRDR)}

To apply the PRDR indicator, the center of each case study is the center of the 400-m radius, as sampled in the cadastral maps. The retailers are those that inhabitants want to access from the center of the neighborhood in 10 min of walk along street networks. In this regard, the shapefile maps were generated to create the blocks, blocks centroids, and streets networks on the 400-m radius and the 600-m scale. The QGIS Road-Graph tool was utilized to measure the shortest network distance between two spatial points, which are the center of the case study and each individual retailer within the 400-m radius and the 600-m radius. Moreover, because the indicator concerns how well the street network is connected between the destinations and residents' houses, this study designed an approach to test the PRDR for 16 destinations within each case study on each scale. The approach divided the circles of the two scales into 16 sectors then the intersection point of the radiuses with the circles (for the 400-m and the 600-m radiuses) are defined; from this, the nearest destination to those points are considered to compute the 
indicator. Thus, two independent variables were addressed by the PRDR, which were labeled: PRDRS1, PRDRS2 (Table 1). Then, the specified PRDR equation Eq. (8) was utilized to compute the indicators, which must be $\leq 1$. A value of 1 represents an optimum relationship that has identical aerial and real distances; whereas, the smaller ratio illustrates that the real route is longer than the aerial distance. In other words, the street network route distance between the two points relates the user's departure station to the location of a contextual destination; thus, the shorter distance indicates the more accessible destination. The PRDR for the 16 destinations of each case study were averaged to determine how well the destinations of each case study are served by the street network. The PRDRS1 on the 400-m radius scale slightly differed among the three neighborhoods, at $0.73,0.77$, and 0.72 for Al-Saymmar, Al-Mugawlen, and Al-Abassya neighborhoods, respectively. Also, it illustrated similar differences for the $600-\mathrm{m}$ radius scale, at $0.76,0.79$, and 0.76 for Al-Saymmar, Al-Mugawlen, and Al-Abassya neighborhoods, respectively (Table 2).

\subsection{Clustering coefficient}

The clustering coefficient indicator of the physical environment is measured by applying the equation of the clustering Eq. (9), and the major two components to run the equation are the observed number of links among the destinations and the possible number of links. However, there was no clear explanation about how to measure these two components in the reviewed literature; therefore, the criteria to measure these two components are designed by this study. In this regard, the first component of this equation is the observed links between destinations. It considered $5 \mathrm{~min}$ as the maximum walking distance between two destinations, which is a 200-m length. Thus, each destination has a potential relationship with all other destination in the 200-m radius. The reason for such an assumption is because, if the distance between every two destinations is not a complete journey for the walker but rather a sub-journey, then the minimum distances mean a better relationship. Based on this criterion, each destination was defined as a center and a straight line was drawn to all other adjacent destinations in the $200-\mathrm{m}$ radius. The required information was elicited from the cadastral maps with the assistance of AutoCAD 3D map software; in this regard, the shapefile maps were generated to both the links and the destinations on the 400-m radius and 600-m radius scales. From this, the layers were added into QGIS software. The resulting total number of links was considered the observed links (numerator). The second component is the possible number of links, even if they did not exist, between the destinations; for this purpose, the equation used was: the number of possible links $=\left(n^{2}-n\right) / 2$ (denominator), Eq. (9), where $\mathrm{n}$ is the total number of destinations. Thus, two independent variables resulted from this indicator, on the $400-\mathrm{m}$ radius and $600-\mathrm{m}$ radius scales. The two variables were labeled as ClsCofS1, ClsCofS2 (Table 1). Thereafter, on the 400-m radius scale, the clustering coefficient variable CICS1, indicated that the Al-Saymmar and Al-Abassya neighborhoods were identical, at 0.05 for each. Meanwhile, Al-Mugawlen was slightly different at 0.04 . Moreover, on the 600 -m radius scale, the clustering coefficient variable CICS2, indicated that the Al-Saymmar and Al-Abassya neighborhoods are identical at 0.04 for each. Finally, Al-Mugawlen was slightly different at 0.03 (Table 2).

\subsection{Edges assessment}

The method to assess the quality of street edges was adopted the frontage quality index (SFOMD) [50]: p.108. It depends on a Likert scale of seven points, starting with (1), which is the lowest score of the assessment, and ending with (7), which 


\begin{tabular}{|l|l|l|l|l|l|l|l|l|l|}
\hline Factors & \multicolumn{3}{|c|}{ Al-Saymmar streets } & \multicolumn{3}{|c|}{ Al-Mugawlen } & \multicolumn{3}{|c|}{ Al-Abassya } \\
\hline & $\mathrm{M}^{*}$ & $\mathrm{C}^{*}$ & Col $^{*}$ & $\mathrm{M}$ & $\mathrm{C}$ & $\mathrm{Col}$ & $\mathrm{M}$ & $\mathrm{C}$ & $\mathrm{Col}$ \\
\hline $\mathrm{S}$ & 6 & 4 & 3 & 6 & 5 & 4 & 6 & 6 & 5 \\
\hline $\mathrm{F}$ & 5 & 4 & 3 & 6 & 4 & 4 & 6 & 5 & 5 \\
\hline $\mathrm{O}$ & 4 & 3 & 3 & 5 & 4 & 4 & 6 & 5 & 5 \\
\hline $\mathrm{M}$ & 1 & 4 & 4 & 6 & 5 & 5 & 6 & 6 & 5 \\
\hline $\mathrm{D}$ & 5 & 5 & 5 & 6 & 5 & 5 & 6 & 5 & 5 \\
\hline $\begin{array}{l}\text { Total } \\
\text { scores }\end{array}$ & 21 & 20 & 15 & 27 & 23 & 22 & 30 & 27 & 25 \\
\hline
\end{tabular}

$\mathrm{M}^{*}$ : main, $\mathrm{C}^{*}$ : Collector and Col*: Col-de-sac

Table 3.

SFOMD index, analysis of the edges.

is the highest score. The application of the method depends on observations is conducted by a specialist team and criteria based sampling of the urban tissue. The computation of the overall index concerning the quality of the area was adopted from Gehl [51] and Hershberger and Clements [52], which combines the five indicators by totaling their raw scores. Therefore, the minimum score of the process is five points which represents the poorest quality streets, whereas, the highest score is 35 points, which represents the best possible quality. Thus, one independent variable was developed in terms of the edges assessment, namely: The Frontage quality index (SFOMDS1) on the 400-m radius scale (Table 1). Moreover, the principle of sampling the streets is an important issue to avoid bias and to validate the generalization of the results, therefore, this study depends on the selection of three streets segments based on the hierarchal level of the street. From the hierarchical street levels, they define the main street, a connector street, and a cul-de-sac from each case study. The information of the survey was transferred into Excel-sheets for the purpose of analysis. The individual survey sheets were summarized (Table 3). Accordingly, three variables were developed from this analysis, which were: the Frontage quality index of the main street (SFMODS1M), the Frontage quality index of the Connecting street (SFMODS1C), and the Frontage quality index of the Colde-sac (SFMODS1CS) (Table 1).

The SFOMD index in Al-Saymmar neighborhood demonstrated the lowest levels of frontage quality, at 21, 20, and 15 points for the variables SFOMDS1M, SFOMDS1C, SFOMDS1CS, respectively. The SFOMD index in Al-Mugawlen neighborhood demonstrated moderate levels of frontage quality, at 27, 23, and 22 points for the variables SFOMDS1M, SFOMDS1C, SFOMDS1CS, respectively. Finally, the SFOMD index in Al-Abassya neighborhood demonstrated the highest levels of frontage quality, at 30, 27, and 27 points for the variables SFOMDS1M, SFOMDS1C, SFOMDS1CS, respectively, (Tables 2 and 3). Therefore, the value of the SFOMD index increased in parallel with the increased grid structure among the street typologies. For example, the red level of the SFOMD index, brought about different scores across the three neighborhoods, 21, 27, and 30, for Al-Saymmar, Al-Mugawlen, and Al-Abassya respectively (Table 2).

\subsection{Enclosure ratio}

The enclosure ratio was measured for the sampled streets in Figures 6-8, Thus, three independent variables resulted from applying the enclosure indicator on the 400-m radius scale; these were coded as EnRBS1M, EnRBS1C and EnRBS1CS 

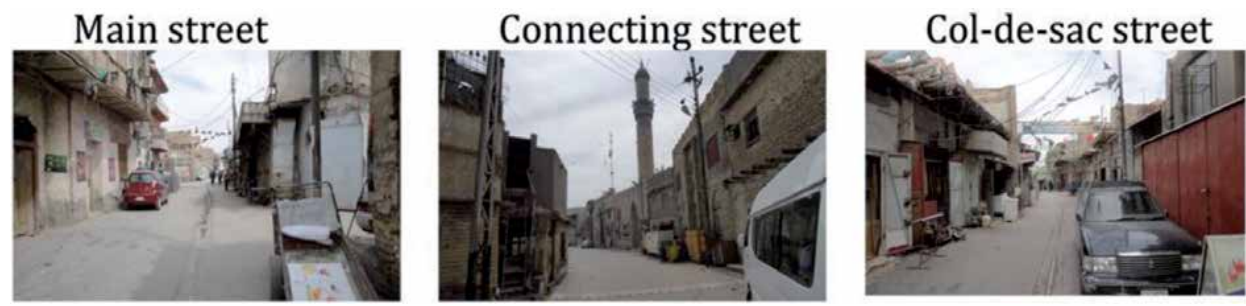

Figure 6.

Al-Saymmar edges assessment.
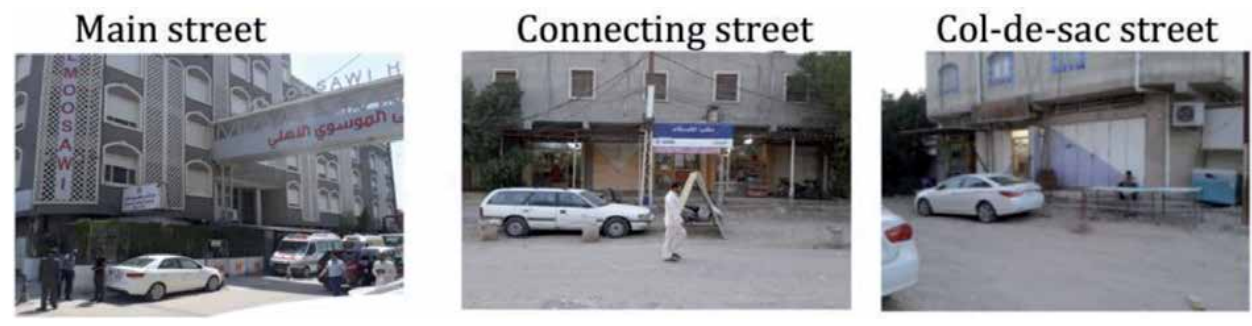

Figure 7 .

Al-Mugawlen edges assessment.
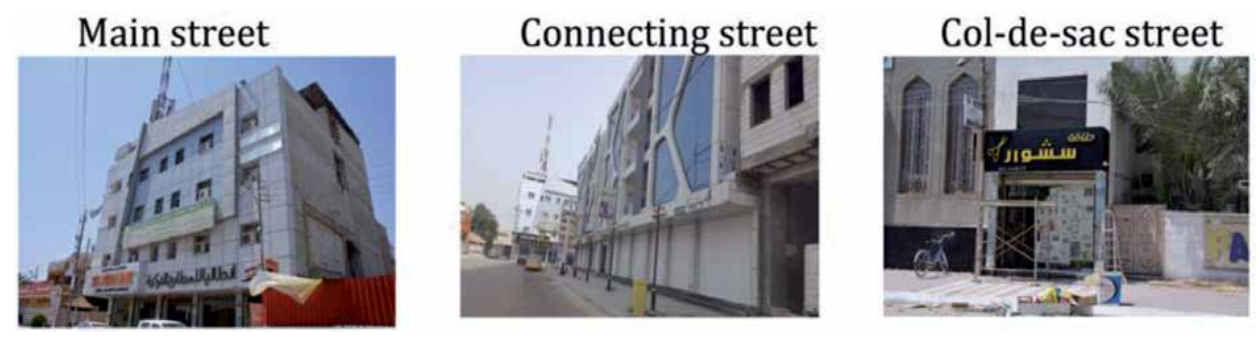

Figure 8.

Al-Abassya edges assessment.

(Table 1). The variables required to apply the indicator are the width of the street and the heights of the adjacent buildings, which were measured directly in this study. Then, the function of the indicator was applied to the sections of all the sampled streets segments. In terms of the main streets (EnRBS1M), the three case studies have a broadly similar value of enclosure ratios, at 2.9, 2.7, and 2.7, for Al-Saymmar, Al-Mugawlen, and Al-Abassya, respectively. In terms of the Connecting streets with the green level of betweenness (EnRBS1C), the highest score was noted with the Al-Mugawlen neighborhood (1.7); Al-Abassya showed a moderate enclosure ratio level (1.3), and the lowest level was noticed within Al-Saymmar (1). In terms of the local streets and the blue level of betweenness (EnRBS1CS), the highest score was noted within the Al-Mugawlen neighborhood (1.7); Al-Saymmar showed a moderate enclosure ratio level (1.1), and the lowest level was noticed with Al-Saymmar (0.93) (Table 2).

\section{The statistical analysis}

The statistical analysis examines the extent to which the indicators of the physical environment are able to explain the variance among the walking outcomes of 
the individuals. The measured attributes of the physical environment were tested in terms of their predictability for the walking minutes. Thus, their variables are considered predictors $(\mathrm{X})$, which need to be tested in terms of their predictability for the walking minutes (Y). In other words, this analysis tests whether the walking outcome variables can be individually predicted by the measured attributes of the physical environment. For such a purpose, the hierarchal regression analysis was chosen because of its flexibility to enter predictors in a split block with extra predictors. Moreover, the $p$-value $(<0.05)$ indicates the significance of the models, while the determination coefficient $\left(R^{2}\right)$ explain the potential of the predictors to explain the variance of the outcomes. The hierarchical regression analyses were run to test the predictability of the physical environment indicators, which were individually tested with the walking minutes in one model for each indicator to determine the effect significance of the predictor on the outcome variable ( $p$-value) and the $\left(R^{2}\right)$. Moreover, the SPSS software was utilized for the conducting all the required statistical analysis in this study.

\subsection{Findings}

The Block density, the predictability of the model was significant $(F(173,1)=$ $16.989, p<0.001, R^{2}=0.089$ ). Thus, the singular model was able to explain $8.9 \%$ of the variance of the total walking minutes. Also, the test shows that the higher walking behavior outcome score was associated with higher block densities $(b=11.817$, $p<0.001)$. In term of Housing Units density, the predictability of the model was significant $\left(F(173,1)=26.231, p<0.001, R^{2}=0.132\right)$. Thus, the model was able to explain $13.2 \%$ of the variances of the total walking minutes. It was showed that the higher scores for walking behavior outcomes were associated with higher housing units densities $(b=0.040, p<0.001)$.

Diversity of all commercial land use on a $400-\mathrm{m}$ radius scale; the predictability of the model was significant $\left(F(173,1)=11.145, p<0.001, R^{2}=0.061\right)$. Thus, the singular model was able to explain $6.1 \%$ of the variances of the total walking minutes. Furthermore, the higher walking behavior outcome scores were associated with a higher diversity of all commercial land uses $(b=2.478, p<0.001)$. Regarding the commercial land use without parking, wholesale, and workshops variable on a 400-m radius scale, the predictability of the model was significant $\left(F(173,1)=20.176, p<.001, R^{2}=0.104\right)$. Thus, the model was able to explain $10.4 \%$ of the variances of the total walking minutes. Furthermore, the higher scores of walking behavior outcomes were associated with the higher diversity of commercial land use without parking, wholesale, and workshops $(b=2.390$, $p<0.001$ ). In term of the diversity of the non-residential land use on a $400-\mathrm{m}$ radius scale, the predictability of the model was significant with the total walking minutes $\left(F(173,1)=13.947, p<0.001, R^{2}=0.075\right)$. Thus, the model was able to explain $7.5 \%$ of the variances of the total walking minutes. Also, the higher of walking behavior outcomes scores were associated with a lower diversity of nonresidential land use $(b=-3.390, p<0.001)$.

Regarding the connectivity indicators; the node (streets intersections) intensity on both scales 400-m and 600-m radius, the predictability of the model was significant $\left(F(173,1)=26.940, p<0.001, R^{2}=0.135\right)$ and $(F(173,1)=18.678$, $\left.p<0.001, R^{2}=0.097\right)$, respectively. Thus, the models were able to explain 13.5 and $9.7 \%$ of the variances of the total walking minutes on the two scales, respectively. However, the higher walking behavior outcome scores were associated with the higher node intensities only on the 400-m radius scale in terms of the total walking minutes $(b=0.573, p<0.001)$. In term of the street intensity on $400-\mathrm{m}$ and $600-\mathrm{m}$ radius scales, the predictability of the two models was significant for the total 
walking minutes $\left(F(173,1)=27.071, p<0.001, R^{2}=0.135\right)$ and $(F(173,1)=13.331$, $p<0.001, R^{2}=0.072$ ), respectively. Also, the models were able to explain, 13.5 and $7.2 \%$ of the variances of the total walking minutes, respectively. Moreover, the higher walking behavior outcome scores were associated with a higher street intensity on a 400 -m radius scale $(b=0.009, p<0.001)$ and on a 600 -m radius scale $(b=0.005, p=0.001)$.

The Pedestrian Catchment Area (PCA) on a 400-m radius scale; The predictability of the model was significant with the total walking minutes $(F(173,1)=$ $\left.14.914, p<0.001, R^{2}=0.079\right)$. Also, the singular model was able to explain $7.9 \%$ of the variances of the total walking minutes. Furthermore, the higher walking behavior outcome scores were associated with the lower value of the Pedestrian Catchment Area $(b=-0.059, p<0.001)$. Also, Pedestrian Route Directness Ratio (PRDRS1 and 2) on 400-m and 600-m radius scale; the predictability of the two models was nonsignificant for the total walking minutes were $(F(173,1)=0.301$, $\left.p>0.05, R^{2}=0.002\right)$ and $\left(F(173,1)=0.142, p>0.05, R^{2}=0.001\right)$. Similarly, the models were inconsiderably explained the variances of the total walking minutes, at 0.2 and $0.1 \%$, respectively. Also, the higher walking behavior outcome scores were not associated with the Pedestrian Route Directness Ratio $(b=1.231, p>0.05)$.

Regarding the Clustering coefficient of destinations on a 400-m and 600-m radius scales, the predictability of the two models were nonsignificant for the total walking minutes $\left(F(173,1)=0.142, p>0.05, R^{2}=0.001\right)$ and $(F(173,1)=2.288, p>0.05$, $\left.R^{2}=0.019\right)$. Also, the models were able to explain, 0.1 and $1.9 \%$ on the two scales, respectively.

Frontage quality index of the streets on the 400-m radius scale: the predictability of the three models of the main, Connecting and col-de-sac streets was significant for the total walking minutes $\left(F(173,1)=26.427, p<0.001, R^{2}=0.133\right),(F(173,1)=$ 26.586, $\left.p<0.001, R^{2}=0.133\right)$ and $\left(F(164,9)=4.374, p>0.05, R^{2}=0.211\right)$, respectively. However, the higher walking minutes were marginally associated with the lower frontage quality index of the main, the connecting and the col-de-sac streets $(b=-0.110, p<0.001),(b=-0.145, p<0.001)$ and $(b=-0.097, p<0.001)$, respectively. Regarding the enclosure ratio of the streets on the 400-m radius scale, the predictability of the three models of the main and Connecting streets was significant for the total walking minutes $\left(F(173,1)=20.840, p<0.001, R^{2}=0.108\right)$, $\left(F(173,1)=49.636, p<0.001, R^{2}=0.223\right)$, respectively. While, in term Enclosure ratio of the col-de-sac street on the 400 -m radius scale, the predictability of the model was not significant for the total walking minutes $(F(173,1)=0.428, p>0.05$, $\left.R^{2}=0.002\right)$. However, the higher walking minutes were marginally associated with the lower frontage quality index of the main, the connecting and the col-de-sac streets $(b=3.720, p<0.001),(b=-0.615, p<0.05)$ and $(b=0.103, p>0.05)$, respectively.

\section{Conclusions}

In terms of optimizing livability through neighborhood sizes, the feedback from this study challenges the 25.02 ha suggested by the current Master Plan. Instead, it proposes 50.24 ha, which denotes a 400-m radius, or 10-min walking; that is based supported by other relevant urban planning literature. The walking outcomes and accessible amenities within a 10-min walk were highly associated and found to enhance pedestrian activity. In terms of the percentage ratio of retail space, the findings from this study disagree with the suggested proportion of $\sim 1 \%$. Instead, we propose that mixed types of commercial and retail activity should occupy up to $10 \%$ of the total land use. The findings suggest that the ratio should be separated 
into: food shops $(\sim 5 \%)$; consumer goods shops, selling items such as appliances or clothes $(\sim 2.5 \%)$; and general services, such as barbers, coffee shops, or maintenance workshops $(\sim 2.5 \%)$. In terms of health and religious centers, this study agrees with the Master Plan's proposed approximate proportion of $<1 \%$ for each. Meanwhile, open space was specified into playgrounds, local parks, roads and open spaces, and this study agrees with the approximate amount of $30 \%$ suggested by the Master Plan. However, more walking was observed in the traditional neighborhood (Al-Saymmar), which accommodates more and smaller open spaces. In terms of housing, the evidence from this study suggests $50 \%$ for the single-family housing residential typology; therefore it challenges the suggested high ratio of low-density housing within the Master Plan. Finally, no feedback is offered in terms of educational land use, since this depends upon relevant standardizations.

For other planning and design criteria, the indicators applied by this study suggest that the planning of new neighborhoods should, not only be confined to defining the densities and types of land use, but should also consider the topologic relationships, and streetscapes design, as these are important influences on walking. In this respect, further suggestions, in the form of both qualitative and quantitative recommendations, were made by this study. Based on evidence, the recommendations mostly focused on the organization of traditional neighborhoods (Al-Saymmar), which are considered more pedestrian-friendly environments than the more modern developments (Al-Mugawleen and Al-Abassya) because the increase in walking minutes were significantly associated with the higher scores in urban planning and design indicators tested. However, modern neighborhoods were found to be better in other respects than traditional neighborhoods; for example, commercial growth within the center of modern neighborhoods was far greater than in traditional neighborhoods, as was the permeability, and straightness of edges.

\section{Author details}

Qaaid Al-Saraify $^{1 *}$ and David Grierson ${ }^{2}$

1 The Department of Architecture, The University of Basra, Basrah, Iraq

2 The Department of Architecture, University of Strathclyde, Glasgow, UK

*Address all correspondence to: qaaid.alsaraify@gmail.com

IntechOpen

(C) 2020 The Author(s). Licensee IntechOpen. This chapter is distributed under the terms of the Creative Commons Attribution License (http://creativecommons.org/licenses/ by/3.0), which permits unrestricted use, distribution, and reproduction in any medium, provided the original work is properly cited. (cc) BY 


\section{References}

[1] PWK D, PIJ T. New Urbanisms: From Neo-Traditional Neighbourhoods to New Regionalism. In: Theme Cities: Solutions for Urban Problems. New York: Springer; 2015. pp. 17-61

[2] Jacobs J. The Death and Life of Great American Cities. New York: Vintage books; 1961

[3] Talen E. Sprawl retrofit: Sustainable urban form in unsustainable places. Environment and Planning. B, Planning \& Design. 2011;38(6):952-978

[4] Talen E. Retrofitting Sprawl: Addressing Seventy Years of Failed Urban Form. Athens: University of Georgia Press; 2015

[5] Hillier B. Space is the machine: A configurational theory of architecture. London, United Kingdom: Space Syntax; 2007. p. 47

[6] Space CABE. Open Space strategies best practice guidance. Commission for Architecture and the Built Environment and the Greater London Authority. 2009

[7] Krizek K, Forysth A, Slotterback $\mathrm{CS}$. Is there a role for evidence-based practice in urban planning and policy? Planning Theory and Practice. 2009;10(4):459-478

[8] Basra LGo. The master plan of Basra city unpublished. 2015

[9] Al-Saraify Q, Grierson D. Walking to occupational activities within three neighbourhoods in Basra city. Open House International. 2019;44(1):53-61

[10] Al-Saraify Q. Walking to

Occupational Activities in Basra City: Developing and testing an ecological model to support evidence-based feedback in neighbourhood planning [thesis]. Unpublished: University of Strathclyde; 2018
[11] Marr P. The Modern History of Iraq. UK: Hachette; 2017

[12] Wilson AT. Loyalties: Mesopotamia, 1914-17: A Personal and Historical Record. London: Oxford University Press; 1930

[13] Longrigg S. The decline of the west in the Middle East: An alternative view. International Affairs (Royal Institute of International Affairs 1944). 1953;29(3):326-339

[14] Khattab AA. Basra city: A study in urban geography: School of Oriental and African Studies. University of London; 1972

[15] Lock M. Municipality of Basra Survey \& Plan, 1st ed. London: Millbrook Press; 1956

[16] Moudon AV, Lee C, Cheadle AD, Garvin C, Johnson D, Schmid TL, et al. Operational definitions of walkable neighborhood: Theoretical and empirical insights. Journal of Physical Activity and Health. 2006;3(s1):S99-S117

[17] Lee C, Moudon AV, Courbois J-YP. Built environment and behavior: Spatial sampling using parcel data. Annals of Epidemiology. 2006;16(5):387-394

[18] Lovasi GS, Neckerman KM, Quinn JW, Weiss CC, Rundle A. Effect of individual or neighborhood disadvantage on the association between neighborhood walkability and body mass index. The American Journal of Public Health. 2009;99(2):279-284

[19] Cervero R, Kockelman K. Travel demand and the 3Ds: Density, diversity, and design. Transportation Research Part D: Transport and Environment. 1997;2(3):199-219

[20] Moudon AV, Lee C, Cheadle AD, Garvin C, Johnson DB, Schmid TL, et al. 
Attributes of environments supporting walking. American Journal of Health Promotion. 2007;21(5):448-459

[21] Frank LD, Schmid TL, Sallis JF, Chapman J, Saelens BE. Linking objectively measured physical activity with objectively measured urban form: Findings from SMARTRAQ. American Journal of Preventive Medicine. 2005;28(2):117-125

[22] Handy SL, Clifton KJ. Evaluating neighborhood accessibility:

Possibilities and practicalities. Journal of Transportation and Statistics. 2001;4(2/3):67-78

[23] Burke M, Brown A. Distances people walk for transport. Road \& Transport Research: A Journal of Australian and New Zealand Research and Practice. 2007;16(3):16

[24] Handy S. Urban form and pedestrian choices: Study of Austin neighborhoods. Transportation Research Record: Journal of the Transportation Research Board. 1996;1552:135-144

[25] McCormack GR, Giles-Corti B, Bulsara $\mathrm{M}$. The relationship between destination proximity, destination mix and physical activity behaviors. Preventive Medicine. 2008;46(1):33-40

[26] Leslie E, Coffee N, Frank L, Owen N, Bauman A, Hugo G. Walkability of local communities: Using geographic information systems to objectively assess relevant environmental attributes. Health and Place. 2007;13(1):111-122

[27] Duany A, Plater-Zyberk E, Speck J. Suburban Nation: The Rise of Sprawl and the Decline of the American Dream. New York: North Point Press; 2001

[28] Calthorpe P. The Next American Metropolis: Ecology, Community, and the American Dream. New York: Princeton Architectural Press; 1993
[29] Handy SL, Boarnet MG, Ewing $\mathrm{R}$, Killingsworth RE. How the built environment affects physical activity: Views from urban planning. American Journal of Preventive Medicine. 2002;23(2):64-73

[30] Peponis J, Allen D, French S, Scoppa M, Brown J, editors. Street connectivity and urban density. In: 6th International Space Syntax Symposium; 2007

[31] Frank LD, Engelke P. Multiple impacts of the built environment on public health: Walkable places and the exposure to air pollution. International Regional Science Review. 2005;28(2):193-216

[32] Song Y, Knaap G-J. Measuring urban form: Is Portland winning the war on sprawl? Journal of the American Planning Association. 2004;70(2):210-225

[33] Handy S, Paterson RG, Butler K. Planning for street connectivity: Getting from here to there. 2003

[34] Frank LD, Sallis JF, Saelens BE, Leary L, Cain K, Conway TL, et al. The development of a walkability index: Application to the neighborhood quality of life study. British Journal of Sports Medicine. 2010;44(13):924-933

[35] Handy SL, Niemeier DA. Measuring accessibility: An exploration of issues and alternatives. Environment and Planning A. 1997;29(7):1175-1194

[36] Handy SL. Understanding the link between urban form and nonwork travel behavior. Journal of Planning Education and Research. 1996;15(3):183-198

[37] Remali AM, Porta S, Romice O Correlating street quality, street life and street centrality in Tripoli, Libya. The past, present and future of high streets; 2014

[38] Schlossberg M. From TIGER to audit instruments: Measuring 
neighborhood walkability with street data based on geographic information systems. Transportation Research Record: Journal of the transportation research board. 1982;2006:48-56

[39] Cerin E, Leslie E, du Toit L, Owen N, Frank LD. Destinations that matter: Associations with walking for transport. Health and Place. 2007;13(3):713-724

[40] Lee C, Moudon AV. Correlates of walking for transportation or recreation purposes. Journal of Physical Activity and Health. 2006;3(s1):S77-S98

[41] Lee C, Moudon AV. The 3Ds+ R: Quantifying land use and urban form correlates of walking. Transportation Research Part D: Transport and Environment. 2006;11(3):204-215

[42] Randall TA, Baetz BW. Evaluating pedestrian connectivity for suburban sustainability. Journal of Urban Planning and Development. 2001;127(1):1-15

[43] Moudon AV, Hess PM. Suburban clusters. Journal of the

American Planning Association. 2000;66(3):243-264

[44] Canter D, Tagg SK. Distance estimation in cities. Environment and Behavior. 1975;7(1):59-80

[45] Watts DJ, Strogatz SH. Collective dynamics of 'small-world'networks. Nature. 1998;393(6684):440-452

[46] Van der Westhuizen DL. Concepts of space and place neighborhood access, pedestrian movement, and physical activity in Detroit: Implications for urban design and research. University of Michigan; 2010

[47] Carmona M. Public Places, Urban Spaces: The Dimensions of Urban Design. Burlington: Elsevier; 2010

[48] Montgomery J. Making a city: Urbanity, vitality and urban design. Journal of Urban Design. 1998;3(1):93-116

[49] Moudon A, Hess P, Snyder M, Stanilov K. Effects of site design on pedestrian travel in mixed-use, medium-density environments. Transportation Research Record: Journal of the Transportation Research Board. 1997;1578:48-55

[50] Remali AM, Porta S, Romice O, Abudib H, Vaughan L. Street quality, street life, street centrality. Suburban Urbanities: Suburbs and the life of the high street: UCL Press; 2015. pp. 104-129

[51] Gehl J. Public Spaces and Public Life in Perth: Report for the Government of Western Australia and the City of Perth. Curtin University Research Publications; 1994. Available from: http://hdl.handle. net/20.500.11937/15502

[52] Hershberger RG. Architecture and meaning. Journal of Aesthetic Education. 1 Oct 1970;4(4):37-55

[53] Ewing R, Handy S, Brownson RC, Clemente O, Winston E. Identifying and measuring urban design qualities related to walkability. Journal of Physical Activity and Health. 2006;3(s1):S223-S240 


\title{
Chapter 21
}

\section{Lessons from Baghdad City Conformation and Essence}

\author{
Haider J.E. Al-Saaidy
}

\begin{abstract}
This chapter aims to address the emergence of Baghdad and the phases of its morphology and transformation. The first era began with the Round City; this originated the first nucleus that later formed Baghdad. The historical parts of most Middle Eastern old cities usually occupy polar places in relation to the rest of their city zones. These historical centres can give a city its own identity and embody exceptional urban assets, if carefully maintained and managed. In this chapter, there are two significant periods, the Abbasid Empire and post-Abbasid Empire. One of the main concerns is the conflict between two trends, old fabric as a traditional pattern and modern thoughts and, consequently, how that could affect in formulating the development plan.
\end{abstract}

Keywords: urban design, historical urban perspective, development plan, street characteristics, old fabric, modern trend

\section{Introduction}

Since the beginning of the last century until today, Baghdad in Iraq has remained one of the more unstable cities in the world. Political unrest and wars have played a crucial role in its development. Nevertheless, as the capital of the Islamic Empire for more than 500 years, Baghdad has a vibrant historical fabric and some of the most critical historical sites. However, despite the range of academic and consultancy studies conducted throughout the last 100 years, the city has not received the care that it requires. Social and political unrest and wars have prevented successive regimes from implementing preservation projects, and because of this, Baghdad has lost significant parts of its precious and valuable historical fabric. Although more focus has been paid to the oldest part of Baghdad, this does not underestimate the importance of the modern era and the subsequent growth of the city. The methods to recognise and examine different aspects of the city are varied, although these can broadly be considered under two key foci. The first method of the study concerns advanced programmes, for which computing systems have been developed and tested to examine and analyse the spatial configuration of the urban environment. The second method studies the interrelationship between the people and their surrounding spaces, which particularly relates to the city's street life and social interactions. The current chapter addresses the configurational processes of the emergence of Baghdad. 


\section{A historical perspective of Baghdad City}

Iraq, in general, is one of the wealthiest countries due to its oil revenue; unfortunately, it is also considered a developing country due to issues on all levels, including its architecture, urban design, and planning. This consideration is also based on the magnitude of problems that Iraqi people continue to live with. Notwithstanding, Baghdad is a central destination, both as an administrative capital and as a place that represents a new opportunity for people from other regions of Iraq to secure jobs and experience better livelihoods than those afforded elsewhere in the country [1]. Baghdad is the capital of the Republic of Iraq and considered a significant metropolitan city with a population of approximately 6.77 million people. The city is divided into two regions by the Tigris River, namely Rusafa and Karkh, in an arid zone at $33^{\circ}$ $20 \mathrm{~N}$ latitude and $44^{\circ} 23 \mathrm{E}$ longitude [2, 3]. Since its foundation in $762 \mathrm{AD}$ by Caliph Al-Mansur, Baghdad became an attractive location for surrounding foreign powers. Therefore, its history not only witnessed frequent war and domination but also saw the development of a unique variety of various cultures. Based on archaeological evidence, Baghdad's site was occupied by several peoples before the Arab conquest of Mesopotamia in 637 AD. Furthermore, excavations by the famous Michaux Stone, which was founded by a French physician in 1870, discovered that a Babylonian town called 'Bak-da-du' occupied the place of Baghdad as far back as the twelfth century BC. Moreover, due to its strategic location along the banks of the Tigris, it represented an attractive location as the new capital for the Abbasid Caliphate [4].

\subsection{Baghdad during the Abbasid Empire}

In $800 \mathrm{AD}$, only four decades after its establishment, Baghdad became a metropolis of more than 300,000 inhabitants. As the capital of the Abbasid Caliphate that stretched from present-day Algeria to Pakistan, Baghdad was the centre of economic and political power in the Islamic world, unrivalled in its artistic, scientific, and cultural achievements [5]. Le Strange refers to Baghdad by describing some of the monuments and historical features that belong to the Abbasid period. The city was characterised by several features: the old wall of the Eastern city with its four gates, the Mustansiriya College as the first school at that time, as well as mosques and holy shrines [6]. Le Strange states that the topography of Baghdad changed due to the shift of the riverbed and the watercourse and canals that constituted its essential features. The primary task of Le Strange was to achieve and prepare a map of old Baghdad and to reconstruct its fundamental elements by tracing the topography of the city in detail. Although it is difficult to access Le Strange's map directly from the primary source, it is still possible to see that Baghdad's character has changed dramatically, particularly within the old fabric of the city [6]. The historical view of Baghdad reflected its general character as the seat of the Abbasid Caliphate. It was a significant kernel in the emergence of the current city; moreover, cultural, religious, and economic influences provided the essential defining characteristics of the city since the construction of the Round City in 1445/762 [7].

The Tigris River, on which Baghdad stands, experienced a multi-faceted transformation in its physical and cultural environment, which resulted from natural and political factors and comprehensive development plans. In the old city, Baghdad's numerous urban features embody different historical periods. The transformation from the Round City to an organic pattern reflected its local physical and socioeconomic characteristics. Currently, the old urban fabric, particularly within Rusafa and Karkh which are located in the city centre of Baghdad, face severe disintegration. This has created segregation as a result of the implementation of unrestricted planning policies and has led to the dramatic loss of Baghdad's heritage, historical architecture, 

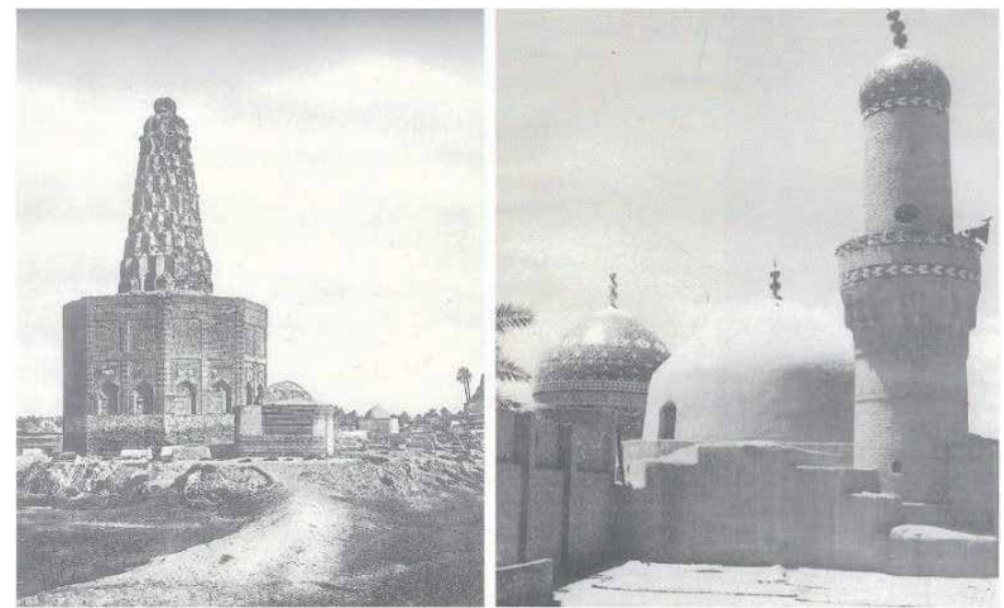

Figure 1.

Zumarrad Khatun's Tomb 1202 AD (left) and Karkhi Mosque 1215 AD (right). Source: ([9], pp. 312-315). All rights reserved for Al-Warrak Publishing Ltd., London, UK.

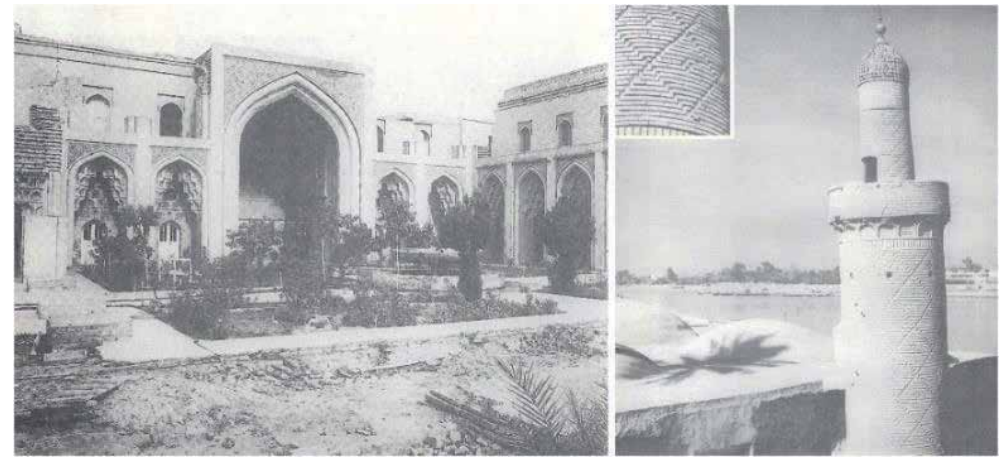

Figure 2.

Sharaibiya Madrasa 1226 AD (left), Qumriya Mosque 1228 AD (right). Source: ([9], pp. 305-311). All rights reserved for Al-Warrak Publishing Ltd., London, UK.

and the identity of its old urban fabric [8]. According to Fathi, the Abbasid period (1152-1258) is immortalised by significant historical monuments and prominent features, such as Zumarrad Khatun's Tomb (1202) and Karkhi Mosque (1215) (Figure 1), Sharaibiya Madrasa (1226) and Qumriya Mosque (1228) (Figure 2), and Mustansiriya (1234) and Sahrawardi's Mosque (1234) (Figure 3) [4]. These monuments and features have played a crucial role in orienting the city network and its traditional neighbourhoods. Furthermore, they have provided indispensable public places for inhabitants throughout history. When tracing an old map, it is possible to recognise the city routes which started and ended at one of these urban points, most notably mosques. Besides its historical buildings, the organic pattern of the street network is another character of the old sector of Baghdad. The importance of Baghdad's inheritance can be studied synchronically and diachronically, including the characteristics of the network and its street edges. Between 762 and 775 AD, Al-Mansur built the Round City of Baghdad (also known as Madinat al-Salam, City of Peace) on the west side of the Tigris between the locations known today as Kadhimiya and Karkh. Gradually, the Abbasid Empire was weakened by internal conflict, which allowed for other surrounding countries to invade Baghdad during various periods of its history, such as the Persian Buwaihids in 946-1055 AD and the Turkish Seljuqs in 1055-1152 AD (Figure 4). 

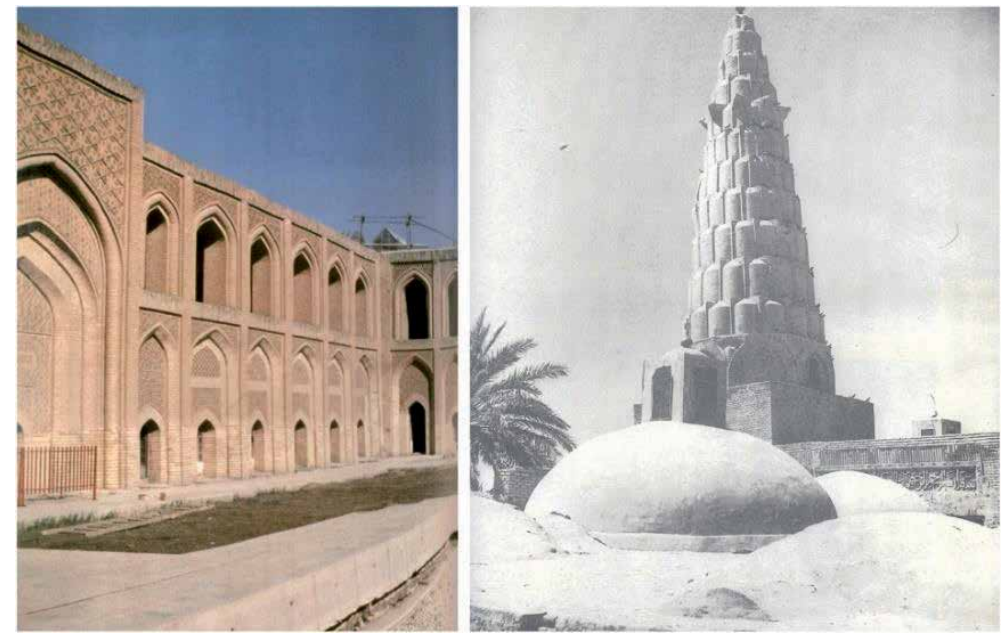

Figure 3.

Mustansiriya 1234 AD (left), Sahrawardi's Mosque 1234 AD (right). Source: ([9], pp. 305-311). All rights reserved for Al-Warrak Publishing Ltd., London, UK.

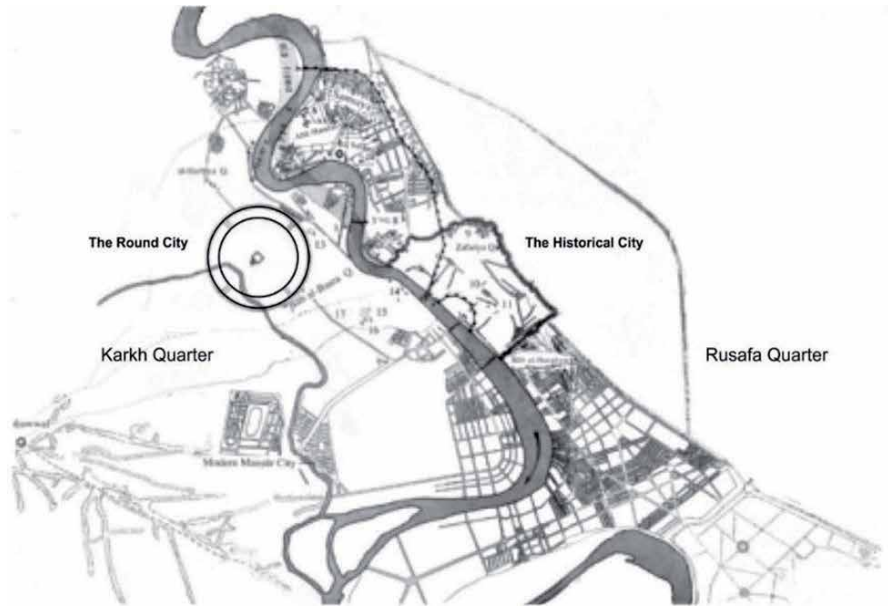

Figure 4 .

Baghdad's morphology at the end of the Abbasid Empire. Source: Based on ([8], p. 81).

The Round City emerged as a kernel of Baghdad; moreover, it continued for three centuries. The city was characterised by a significant pattern, which entailed symmetric streets surrounded by geometrical residential blocks beside three walls with four gates. The wall was used to separate the public and private spaces by the third inner wall and to divide the city into private houses and open courtyards, including the governmental buildings, such as the palace and the mosque. Furthermore, essential buildings inside the Round City comprised the Caliphate's Palace and the mosque, while Al-Hasani states that other sectors were allocated for inhabitants but did not offer gardens, recreation space, or statues [8] (Figure 5). Unfortunately, the Round City disappeared without a clear reason, and nothing remains except for the carved marble of the Khasaki Mosque, which some historians believe belonged to the Mosque of Mansur [4]. At this stage, the city started to expand beyond its wall as a result of limited space, and more public facilities were required due to its increasing population [8]. Allawi states that two systems shape the Arabic Islamic city. The first is the square system; this has a 

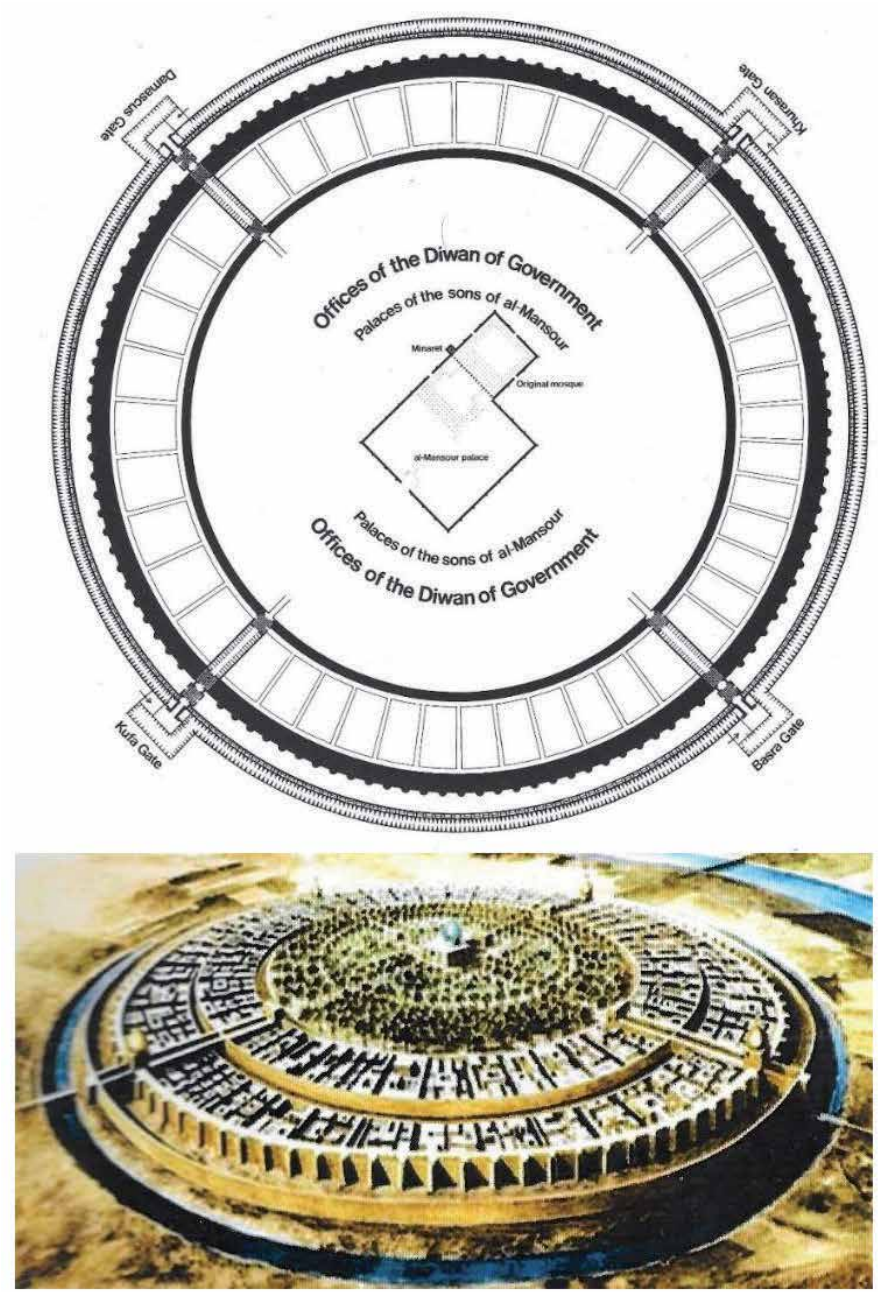

Figure 5.

The Round City. Plan of al-Mansour's Baghdad as originally built. Surrounded by an outer trench and two circular walls and described by historians as the most elaborate fortress city of medieval times (top). Source: ([10], p. 84). Fictive image of the Round City (bottom). Source: ([11], p. 14).

square as its central unit, followed by four surrounding square units. It is generally believed that the five square arrangements denoted the quarters of religious, military, and urban entities. The second system is hexagonal and was known as a system of Asba (sevenths) [12].

Baghdad's Round City plan was described as a turning point in the development of the Islamic city in terms of its urban form and society. This saw a shift from dependent military settlements and expanded tribute collections to investments in private plantations, urban developments, and industrial production. Moreover, the design of the Round City of Baghdad can be discernible as an astrological schema and thus cannot be separated from astrology [12]. Allawi states that Baghdad was created by adopting a stereographic projection of the equator and the Tropics of Cancer and Capricorn where the vertical axis refers to the meridian and the horizontal to the equinoctial line (Figure 5). It is important to note that the decline of the Abbasid Empire in Baghdad did not necessarily simultaneously affect urban life; instead, 'this paradox can probably be explained by the nature of the social structure that arose within the framework of Islam' ([12], p. 70). 


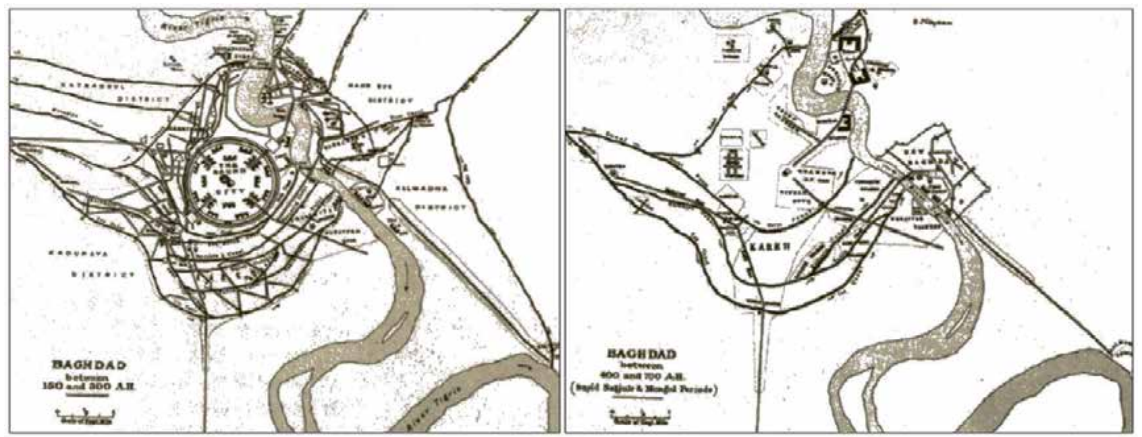

Figure 6.

A general plan of Baghdad during the earlier period between the years 767 and $917 A D$ (left), during the later period between the years 1017 and 1317 AD (right). Source: ([4], p. 4). The Round City disappeared, and little remains today, except for the carved marbles of the Khasaki Mosque. At the end of the Abbasid Empire, Baghdad City had moved entirely to the east bank of the Tigris River. A new era started after this extraordinary move. Later, this site became the central location for the growth and expansion of Baghdad City. Some remarkable features and historical elements remain resistant to change but will not last forever. Moreover, some no longer exist for different reasons. The current study addresses this phenomenon.

A fundamental transformation occurred in the relationship among the city's components; these included the 'Islamic art, architecture, and urban forms first developed under conditions of rapid change and military expansion. They became an expression of the newly settled conditions of Islamic social life' ([12], p. 71). Following the demise of the Round City, and during the new Abbasid Empire, Baghdad moved to the east bank of the Tigris River (shown as the left image in Figure 6). The assets of Baghdad today belong to this historical period of the city with its significant monuments and organic street pattern (Figure 13). Otherwise, the urban areas that settled outside the historical zone were designed according to a modern scheme and a modernist ideology.

\subsection{Baghdad and post-Abbasid Empire: city pattern}

After the Abbasid period, Baghdad was captured by many foreign countries, which left their mark in the urban fabric of the city through the contribution of several prominent buildings that still exist today. Most of those features responded to the existing traditional fabric at that time. Five major occupations manifested their own influences on the historical area of Baghdad, namely, Mongol Hulagu, Jalayirid, Persian Safavids, Ottoman, and the British invasion. In Mongol Hulagu Period (1258-1338), Fathi confirms that, during the Mongol invasion from 1258 to 1338, a significant number of features emerged within Baghdad, such as the minaret of the Caliph's Mosque (1289) and the Aquli Mosque (1328) (Figures 7 and 8) [4]. At the end of the Abbasid Empire and at the start of a new era, Baghdad had moved entirely from the east bank of the Tigris River to the present-day Al-Rusafa. This represented the second major growth period after the Round City (Figure 9).

Since the Abbasid Caliphate and throughout the Ottoman Empire, the level of the growth and development was restricted and only dealt with specific buildings, for example, mosques, schools, and khans. In Jalayirid Period (1338-1411), Fathi states that the next period was occupied by the Jalayirid era (1338-1411), which was responsible for constructing two significant buildings, the Mirjan Mosque (1356) and the Mirjan Khan (1359) (Figure 10) [4]. However, this period saw no drastic changes to the city's shape through its city planning and urban morphology. 


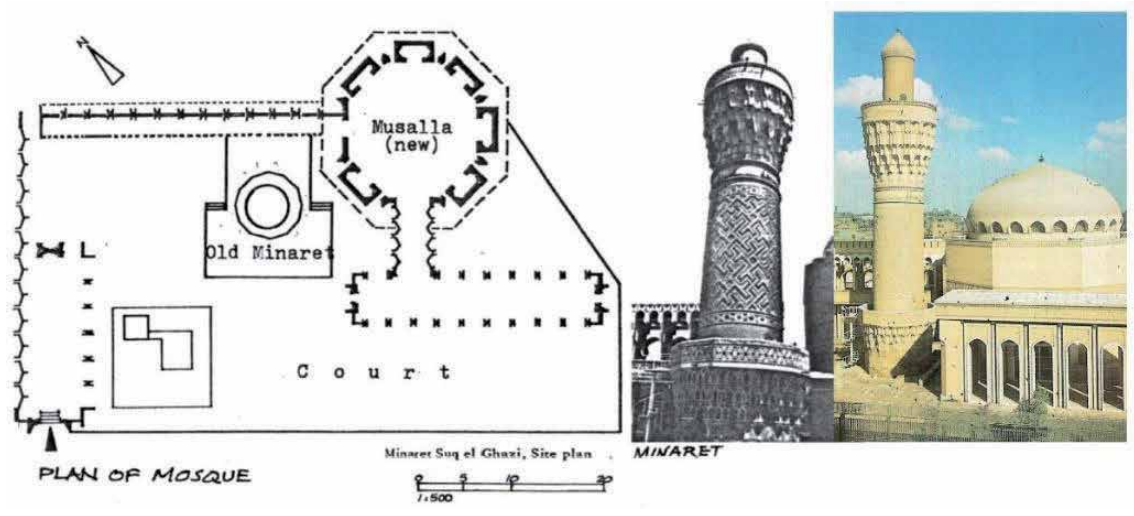

Figure 7

Caliph's Mosque (1289). Sources: ([13], p. 350, [14], pp. 23-24, [10], p. 48).
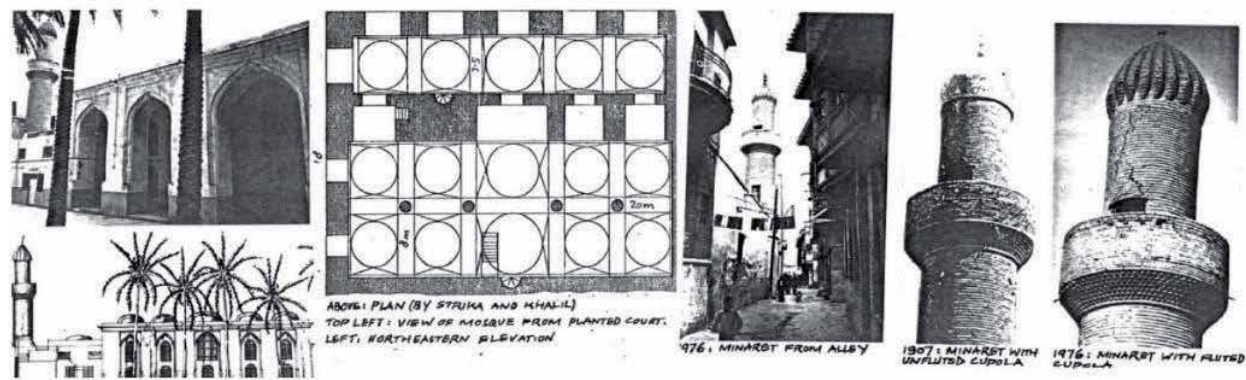

Figure 8.

Aquli Mosque (1328). Source: ([13], pp. 188-189).

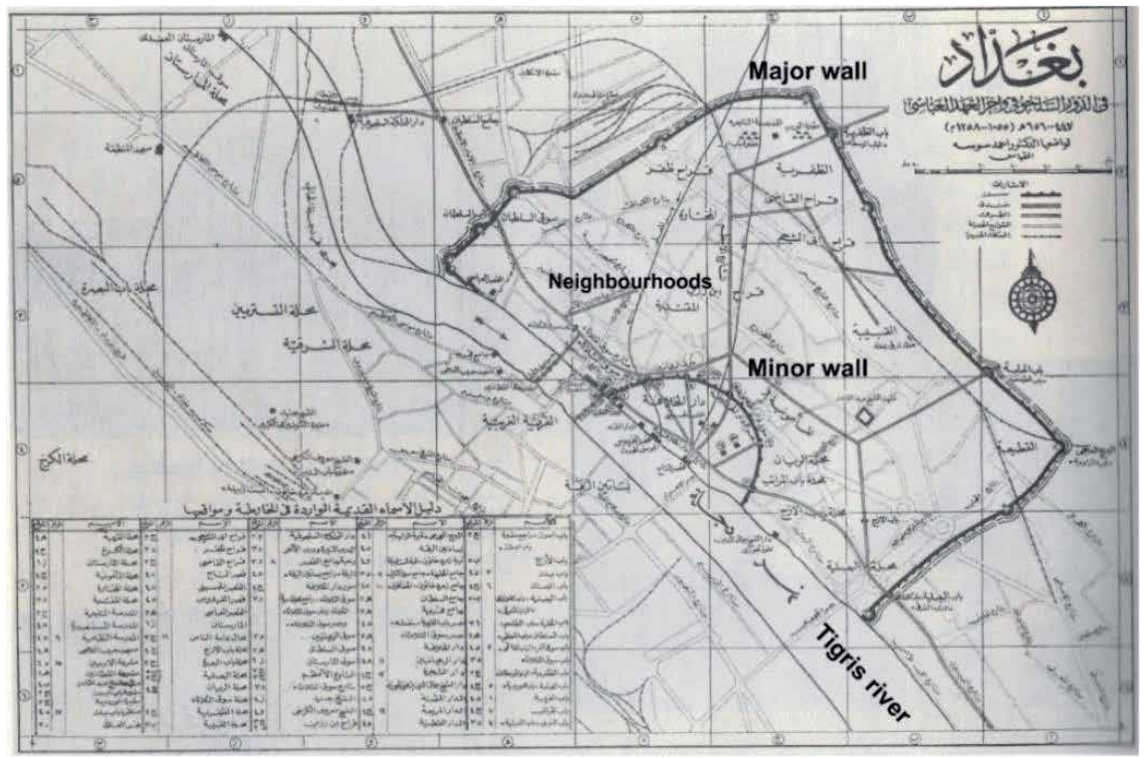

Figure 9.

Baghdad at the end of the Abbasid Caliphate (1055-1258). Source: ([9], p. 59). All rights reserved for Al-Warrak Publishing Ltd., London, UK. 

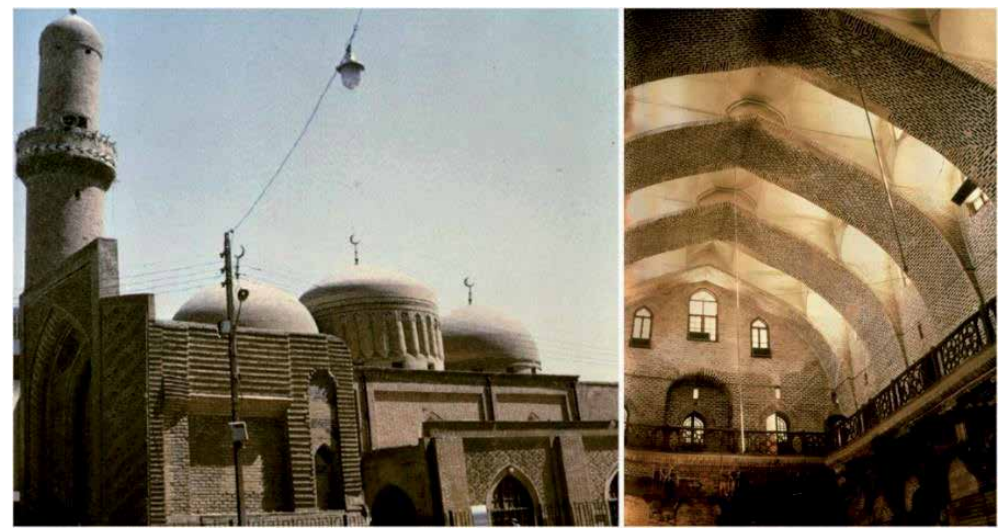

Figure 10.

Mirjan Mosque 1356 AD (left) and Mirjan khan 1359 AD (right). Source: ([4], pp. 40-41).
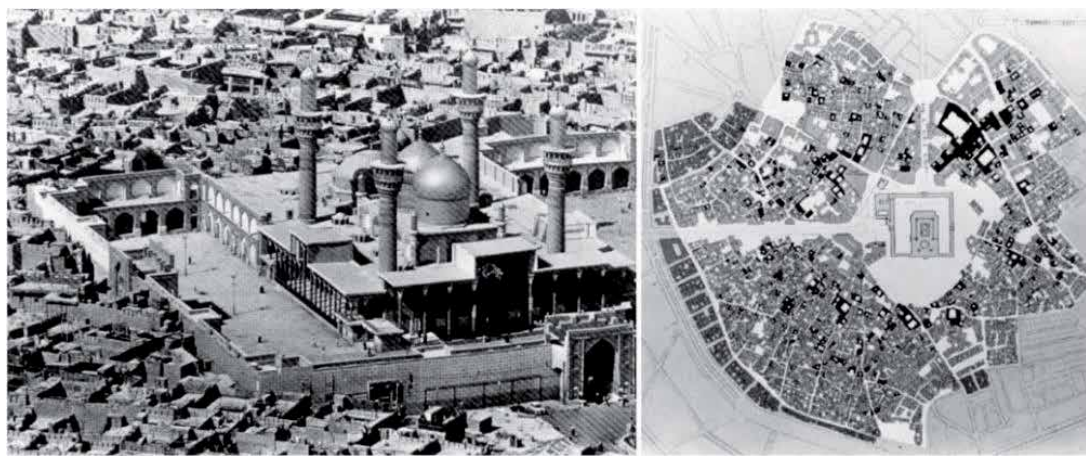

Figure 11.

The Golden Mosque of Kadhimain that was built in 1515 AD. Source: ([15], pp. 148-149).

The Persian Safavid Period (1508-1638), it had a more architectural influence on the city's fabric through the erection of buildings that were characterised by high craftsmanship and impressive monuments, such as the Golden Mosque of Kadhimain that was built in 1515 [4]. This holy shrine was the first development to the north of the walled city and later became the most prominent settlement outside the oldest area of Baghdad. This era saw the same characteristic organic pattern that typified the surrounding neighbourhoods, besides the zigzagged network, which was analogous to the oldest part of Baghdad (Figure 11).

The Ottoman period (1638-1917) represented a long-term period of occupation by a foreign government that controlled both Iraq generally and Baghdad particularly. The period lasted about three centuries (1638-1917) and saw the neglect of the city; this led to a reduction in the value of its urban context and historical monuments. However, some significant features survived, such as Gailani Mosque (1534-1638) (Figure 12), Imam al-Aadham Mosque (1681), Zurur Khan (1534); Khasaki Mosque (1658); Hussain Pasha Mosque (1684); Sarai Mosque (1704); Alia Madrasa (1726); Ahmadiyya Mosque (1796), and the Souk Area (1802) [2, 4]. Like the earlier periods, the number of individual monuments increased during the Ottoman era; these features were built within the same area of the walled city and surrounded by traditional neighbourhoods (called Mahallas). At the level of the city planning, the central development during this period was to open a new street that cuts through the city from the north to the south; this became known as Al-Rasheed Street. From the maps in Figure 13, it can be seen that the city was not subjected 

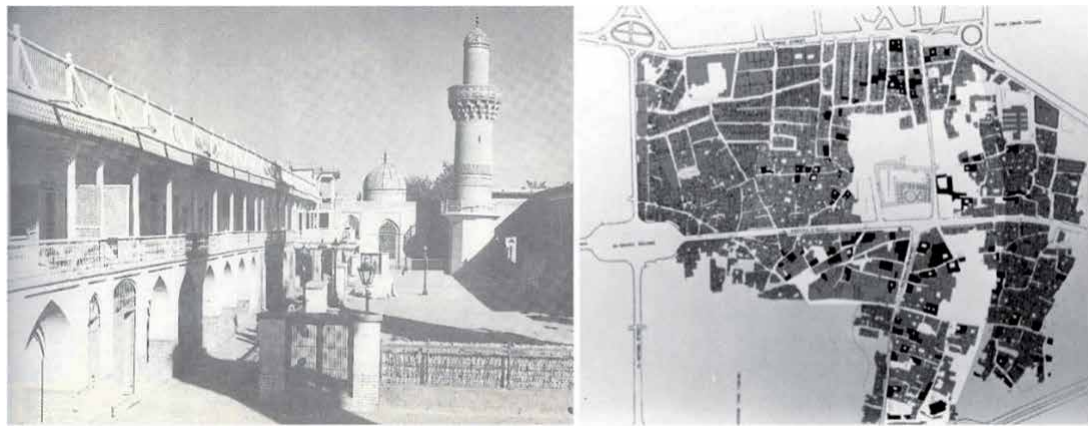

Figure 12.

Gailani Mosque (1534-1638 AD). Source: ([15], p. 150); ([9], p. 318). All rights reserved for Al-Warrak Publishing Ltd., London, UK.
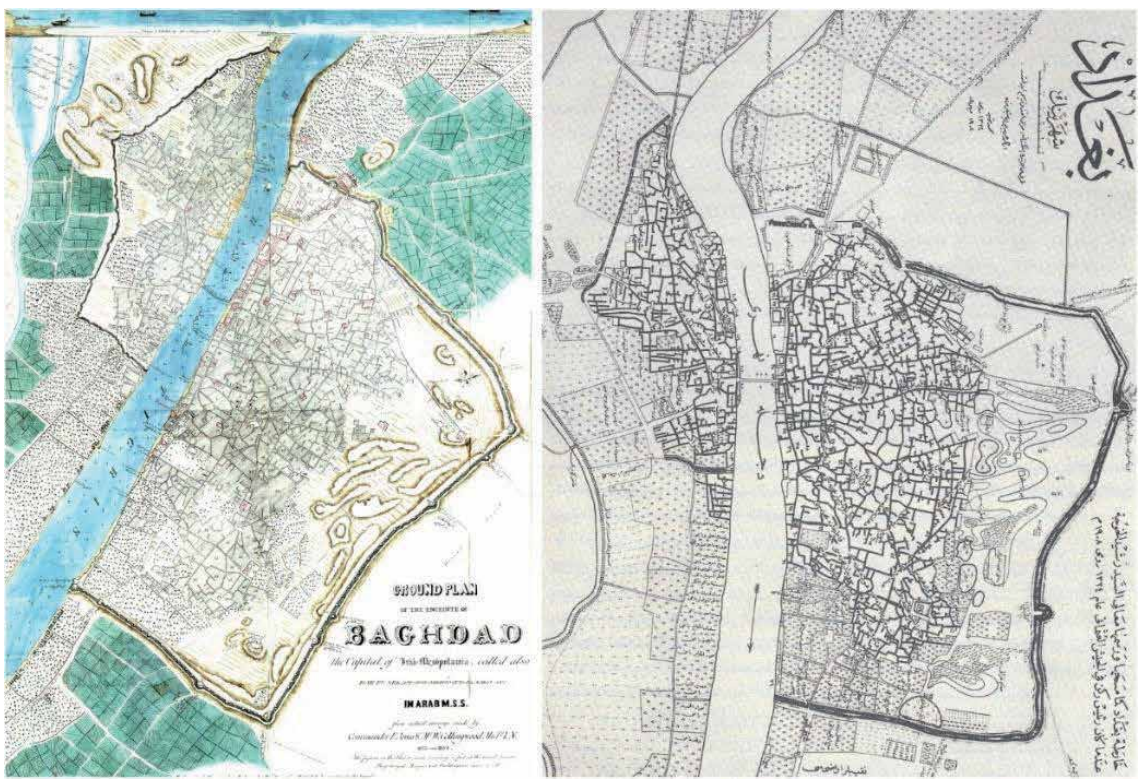

Figure 13.

Baghdad 1854 AD (left) and 1908 AD (right). Source: ([9], pp. 88-430). All rights reserved for Al-Warrak Publishing Ltd., London, UK.

to any central shift in its neighbourhoods and street pattern, except Al-Rasheed Street. The neighbourhood, or mahalla, could be defined as the primary unit in the development and orientation of the street network, which thus formulated significant integration between the two spatial entities, namely, spaces and buildings. According to Al-Ashab, the 'period 1869-1920 can be virtually considered as a forerunner of subsequent morphological phases. It is a transitional phase between the "medieval" and "modern" periods in the urban history of Mesopotamia. It is thus logical to begin the study of the structural evolution and a pattern of the present city with this period' ([16], p. 207).

The British period (1917-1932) and monarchy system until 1958 can be divided into two stages; the first is when Mesopotamia was occupied by Britain from 1917 to 1921 and then subjected to the British mandate from 1920 to 1932; it later became independent in 1932. From 1932 to 1958 , the country was governed by a monarchy. Following these radical changes, 14 July 1958 saw the announcement of a new era for the Iraqi Republic, which formed the second stage. In 1918, the British contributed 
to the dramatic transformation of the style of buildings and introduced new functions to the urban design of Baghdad and other regions of Iraq. Although some public buildings affected the main character of Baghdad, they were considered a new feature among its old urban fabric, particularly with regard to their form and function. Nevertheless, there was an attempt to make these buildings sympathetic to the existing atmosphere by adopting local materials and local historical and cultural metaphors [4]. One noteworthy development in the vocabulary of this period was the use of new terms and classifications to study the structure of the city. Moreover, these new definitions were adopted in the planning and design of new neighbourhoods that were located outside the old town of Baghdad. Furthermore, Al-Ashab argues that the term 'function' cannot be used precisely as an urban definition in Iraq as the term was developed from studies on British towns and therefore signifies meanings that relate to a different context [16]. According to Al-Ashab, 'the definition of urban status in Iraq seems to lie in the acquisition of certain administrative, commercial and religious functions, embodied in the morphological features of al-Sarai (the main administrative complex), bazaar and Friday mosque' ([16], pp. 82-83). Furthermore, during the British period, a new system to number the city via Mahallas was introduced, when the house owner was given a unique number to denote an exact and unmistakable address. The central trend of development in this period was to shift from inward to outward, not only in terms of the typology of the traditional house but also with regard to the city's pattern. One further fundamental transformation was to remove the city wall entirely (Figure 14).

This brief review of the critical stages of planning, urban and architecture, in Baghdad aims to create a general picture of the emergence of the city. Throughout

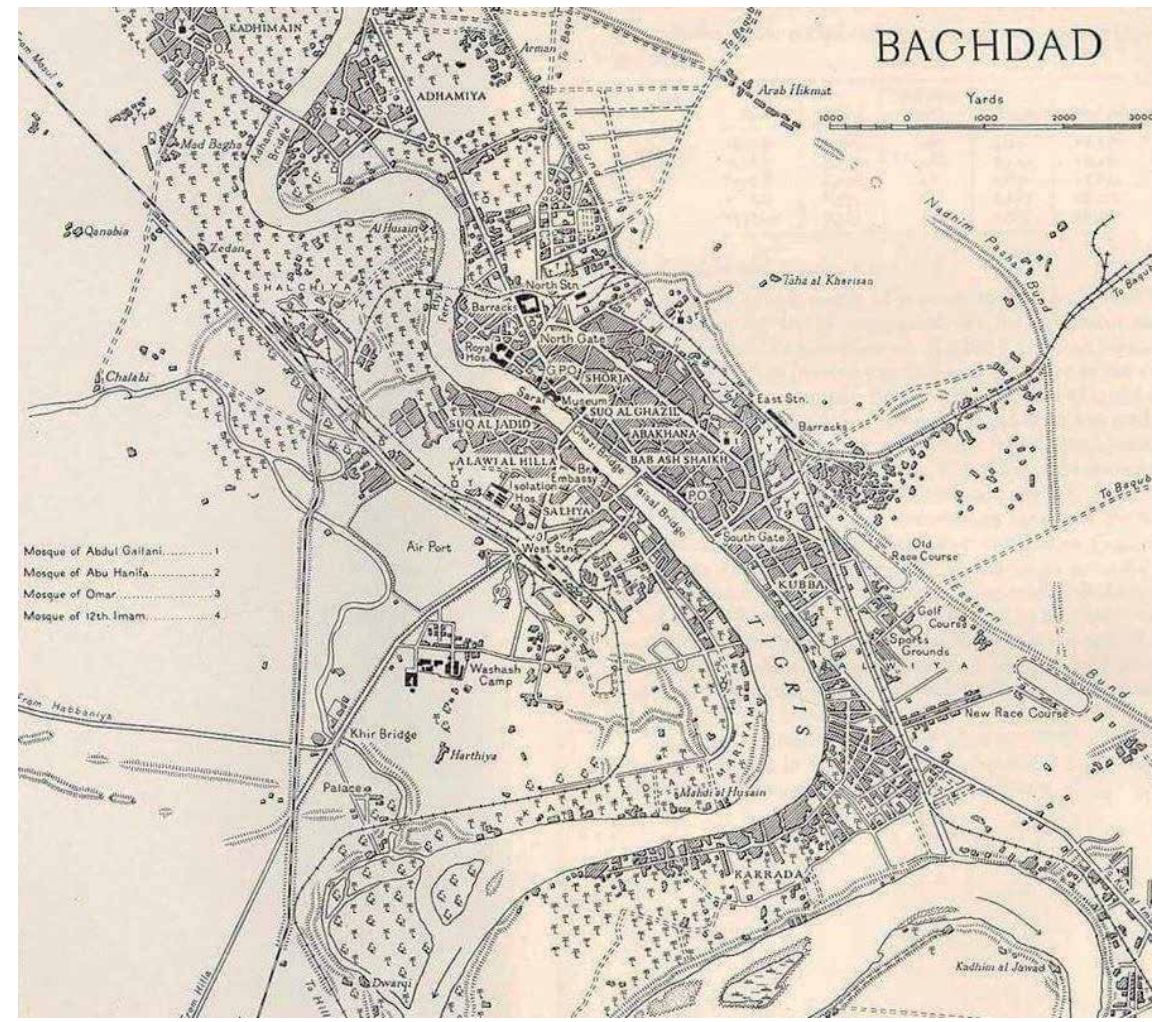

Figure 14.

A plan of Baghdad during and after the British period. Source: [17]. 

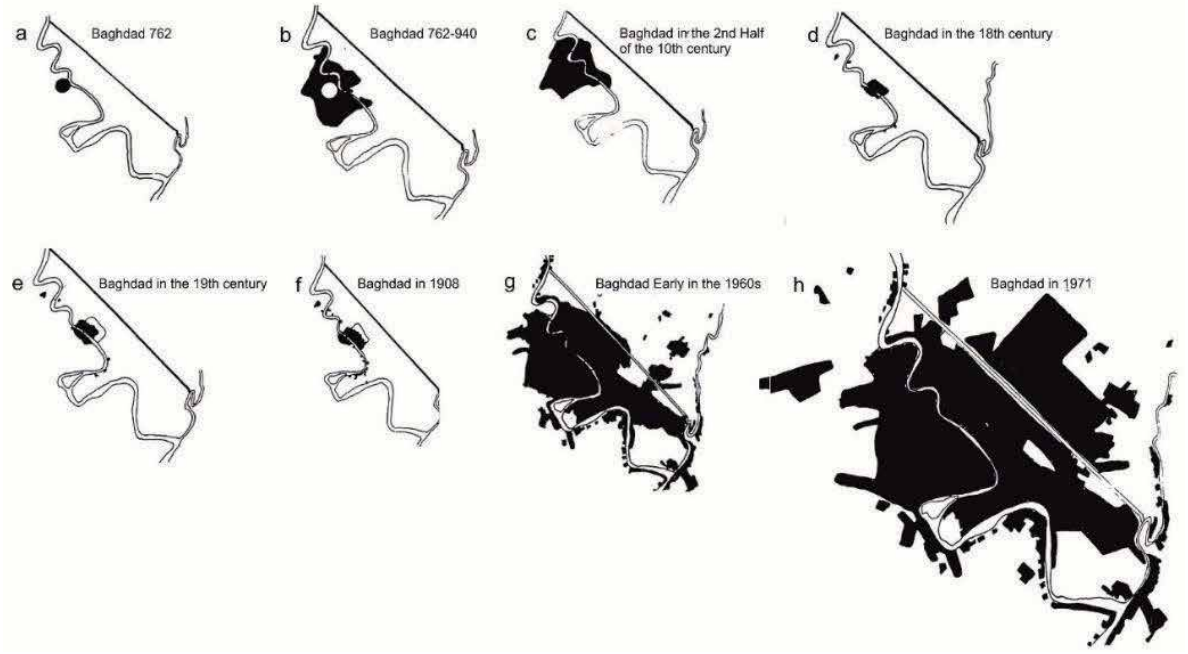

Figure 15.

The growth of Baghdad. Source: ([16], p. 141).

this history, most decision-making was subject to a top-down approach, issued from authorities, and with limited consideration for community needs or social lives. Moreover, there were no sharp, separated lines between these periods of foreign occupation; instead, some continued by adopting similar themes and principles in managing the city. This characteristic also reflects the next phase of Baghdad. In the modern period since 1958, as the capital city of Iraq since 1958, Baghdad adopted significant comprehensive development, whether in the oldest parts or outside the remaining wall. Within the outer areas, and beyond the oldest district of the city, Baghdad extended widely in a semicircular shape, which considered the traditional zone as the centre and thus the starting base for expansion and development (Figure 15).

The 8-year war between Iraq and Iran (1980-1988) clearly influenced the progress of development projects, particularly in Baghdad. In addition, statesponsored projects' progress slowed, particularly those related to Baghdad's city centre; for instance, this affected the substantial project to develop Haifa Street on the Karkh side (1981-1985) [3]. Baghdad's city centre could be characterised as a compact urban structure within the historic fabric, which has a predominantly organic pattern compared with other regions of the city, which seem less compact [3]. Besides the accelerated horizontal expansion of the city, the transformation from the inward (courtyard) to the outward house is the second substantial change in the neighbourhood design prototype. In considering the traditional oldest pattern, the home is the smallest generative unit which cumulatively and spontaneously works with other houses to create al-Mahallas (quarters). In turn, this process leads to the generation of additional urban elements, such as streets and sahahs (squares). In the modern pattern, pre-planned schemes and usebased zoning were the primary tools in designing new neighbourhoods across Baghdad. In this regard, Marshall confirms that the 'land use zones and roads, in a modernist urban structure, [are] represented separately as nodes and links, but in a traditional urban street network, the streets themselves are significant spatial entities' ([18], p. 112). The primary concerns in the traditional area involve not only individual elements (historical and heritage monuments) but also the whole organic fabric of the old city of Baghdad. 


\section{Baghdad development plan}

Before the 1950s, city planning in Iraq had never been well considered; however, in the 1950s the planning firms of Doxiadis Associates (Greek), Minoprio and Spencely, and P. W. McFarlane (both British) prepared general master plans for Baghdad and several other cities in Iraq. Modernisation was therefore supported by a strong European influence; although these developments were slow, they were inescapable and, for many people, acceptable. However, they often led to the destruction of many elegant buildings, such as mosques and bazaars. Al-Rasheed Street is an example of a path which cuts its way remorselessly through an organic pattern and affected outstanding historic buildings. Thus, the emphasis of modern ideology and the adoption of use-based zoning was another concern for the existing urban area [16]. In 1955, the Iraqi government, represented by the Iraq Development Board, asked Doxiadis' firm to prepare a housing programme for Baghdad. Arguably, it was their first large-scale project outside of Greece and solidified the reputation of the firm in this period within the Middle East [19]. Based on the economic policy of Iraq, the National Housing Program was conceived as a long-term territorial plan in an attempt to shape the physical environment. The first phase was to address some urgent needs through a 5-year plan, called 'Basic Foundation Program'. Its aim was to (1) satisfy the most urgent needs, (2) organise the public services concerned with housing and settlements, and (3) create a suitable framework for the further development of all complicated activities [19].

The primary role for Doxiadis Company, as international experts on housing and urban development, was to provide a vital steppingstone for development [20]. An essential motivation in studying the city is to develop a sound understanding of the background of the city life cycle. Since the beginning of the twentieth century, Baghdad has experienced dramatic transformation in its morphological and urban context by changing the rules from the Ottoman invasion to the British occupation. In 1921, during the period of the monarchy, Baghdad became the capital of the new nation; since then, the city has grown substantially in two dimensions, namely, urbanisation and population. Iraq gained its independence in 1931, and since this date, the population of Baghdad has increased dramatically to approximately half a million, and the city has expanded out of the central areas, represented by Rusafa on the east bank of the Tigris river, Karkh on the west bank, and Kadhimiya and Adhamiya towards the north. Regarding the old Baghdad areas, the city has expanded widely in two directions, namely, to the Adhamiya region in the northwest and towards Diyala in the southwest [20]. Doxiadis master plan of Baghdad was based on the concept of linear expansion, namely, 'Dynapolis, meaning a dynamic city' (Figure 16).

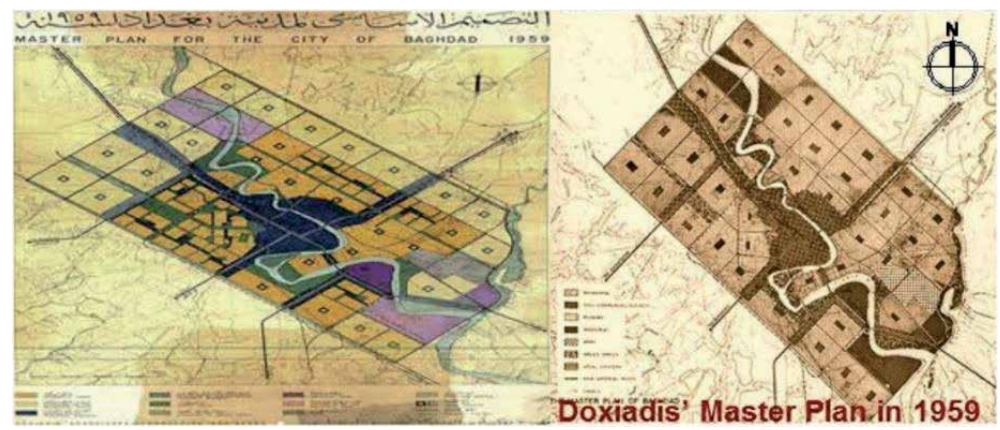

Figure 16.

The Doxiadis' master plan of Baghdad in 1959. Source: ([21], p. 4), referring to the mayoralty of Baghdad. 
The Board supervised the construction of several vital projects, not only in Baghdad but also in other regions of the country. This included dams, irrigation and drainage systems, bridges, roads, factories, power plants, housing, schools, hospitals, and public buildings [20]. Moreover, Doxiadis's vision was embodied in its publication entitled Ekistics, which emphasised a stable and scientific version of urbanism, developed through apolitical authority; this defined human settlements under a scientific approach. Moreover, Ekistics can be understood as a multidisciplinary approach that involved various sciences, such as economics, geography, sociology, anthropology, and other disciplines. This represented an attempt to reduce the influence of designers' arbitrary self-expression and reconceptualised architecture and planning as rational processes that accommodated human need [20]. Within a modern ideology that coordinated the whole system of knowledge about the physical environment, Doxiadis's vision, through Ekistics's multidisciplinary approach, adopted two aims. The first was to emphasise basic human needs and non-functionalism and to further technological concerns. This would accommodate housing and resource shortages as well as other post-World War II urban impasses. It would achieve this by contributing to reforming in earlier modernist urbanism through refusing the concept of the individual designer. The second aim attempted to reinvent designers and planners as experts in urban development. This recognised the importance of the physical environment in promoting socioeconomic development, and this could be achieved by advancing social restructure through applying the paradigm of the industrialised West through global urbanisation, industrialisation, and socioeconomic modernisation [20]. Moreover, through adopting Doxiadis's aims, the intention of the Iraq Development Board was to establish the architectural symbols of a modern state by sharing the ideal of national identity and pride.

When the Iraq Development Board assigned Doxiadis the task of preparing a new master plan for Baghdad, Baghdad had an old centre, which was represented by its old urban fabric; this later became the location for new businesses. The master plan was supposed to provide a comprehensive framework within which various building projects would be integrated. However, in 1956, a British company, Minoprio and Spencely and P. W. Macfarlane, was also assigned by the Iraqi government to create a master plan. It had proposed a road system to connect the premodern urban fabric core with new river bridges and included outlined zoning principles (Figure 17). In this proposal, the historical area of Baghdad was given four colours classifying land use, and one of these was defined as commercial or business use. However, at that stage of the city, its urban structure conditions were not competent to meet the requirements of the new era.

The city developed along the central axis of the Tigris River; this represented a natural feature in the city that emerged as a central spine in the evolution of Baghdad. The future city was expected to develop bidirectionally along the river axis, constituting a rectangular grid pattern [19]. However, the study of Baghdad's urban history highlights some key paradigms of modern planning and raises significant questions about the formation of the contemporary city. One of the strategies adopted by Doxiadis was 'self-contained urbanism', and this manifested in the planning of some residential areas and the cul-de-sac network in the city [19]. The Iraqi government dealt with the problems of population growth and mass immigration in Baghdad by inviting other European companies, such as the British firm Minoprio, Spencely, and Macfarlane, to develop and prepare comprehensive development plans that considered the old area as a vital part of the city. In 1956, the plan by the British firm was completed; this referred to new land use, the clearance of slum areas, the construction of a rural belt, and the development of transportation systems [19]. 


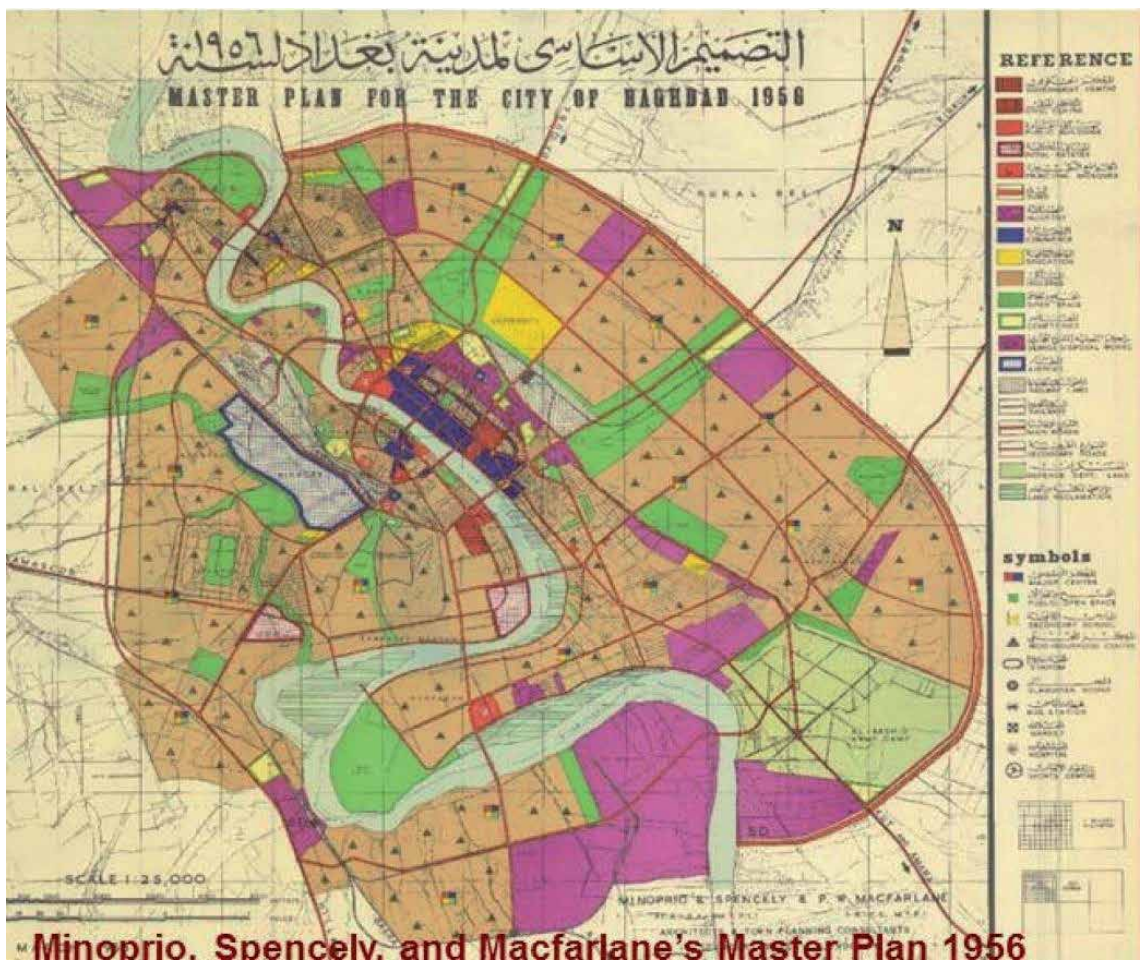

Figure 17.

Minoprio and Spencely and P. W. Macfarlane's master plan of Baghdad in 1956. Source: ([21], p. 4), referring to the mayoralty of Baghdad.

The Tigris River has been a significant feature since the emergence of the original city, also functioning as a central axis of growth. Thus, the ideal population figure suggested by Doxiadis gives maximum limits for Baghdad's expansion, which is defined by an elongated rectangle oriented along the central northwest-southwest axis of the Tigris (Figure 16). Doxiadis's proposed master plan subdivided the existing main roads by using a system of road patterns but also suggested the creation of new networks compatible with a rectilinear pattern. Residential areas were arranged by adopting the same concept of a rectangular grid system [20]. Failing to recognise and neglecting the public's critical role in the old urban dense areas meant the importance of the colourful souks and bazaars and other traditional and historical components were overlooked. However, these embodied the old important urban fabric of Baghdad. The city represented specific social values within its urban context that were characterised by its organic pattern; these aspects represented a big challenge for firms and any comprehensive development plan. Doxiadis Company prepared a detailed documentary study of the old urban fabric in the city centre that included numerous photos, sketches, and detailed analyses of past houses. In an attempt to sidestep much of the old street fabric of Rusafa and Karkh, Doxiadis stipulated that only the future expansion of the commercial and business areas should be recognised according to the rectilinear grid of master plan.

Theoretically, Doxiadis demonstrated greater sensitivity and interest in the old urban fabric than the actual plan that was implemented, which saw the opening of a different set of two main longitudinal thoroughfares, namely, Al Jumhuriya and Haifa. Both modern streets produced a colossal loss when extensive areas of the historical and cultural environment, and irreplaceable features such as mosques, souks, schools, and houses were destroyed [20]. Baghdad was a rapidly growing city 
that gave considerable scope for the development of a physical environment that met people's needs and to promote the quality of living conditions. Road, rail, water, and air transportations were a fundamental aim in developing Baghdad and were considered an appropriate advanced network system to further support urban development projects [22]. The map of the master plan prepared by Doxiadis deliberately avoided extending and imposing the same rectilinear grid on the old city centre. This was a significant dimension in recognising the value of the old fabric and its vitality and to retain these as essential features of Baghdad [23]. On the one hand, greater sensitivity towards the old city centre and an attempt to optimise the relationship between the old core and its surroundings were needed, while, on the other hand, the relationship among the components of the old fabric itself was also essential.

Thus, the historical zone of Baghdad represented a serious urban issue that needed to be appropriately considered. Dealing with this type of urban fabric meant treating it with sensitivity, not only as an ancient area but also in consideration of what it meant to many people. Therefore, the city's characteristics were reflected in its old context for both inhabitants and visitors and bore witness to the city's and inhabitants' deep history and its multilayered vision. In the mid-1960s, the Iraqi government asked Polservice, a Polish planning team, to replan the city and prepare a proposal for a Comprehensive Development Plan for Baghdad to be achieved by 2000. Accordingly, three zones were suggested: greater Baghdad, the inner city, and Baghdad's suburban zone. Also, Polservice organised the city centre by proposing eight secondary sub-centres. This attempted to reduce the pressure on the current city centre through the non-centralisation of activities and services. One of its accomplishments was the establishment of a hierarchy, from the residential quarter to the district and its neighbourhoods (Figure 18).

The company determined the area for the civic centre and offered a proposal to establish a space, situated between Khulafa Street to the west, King Ghazi to the east, Al-Kilani Street to the south, and Al-Wathbah Square to the north. Also, the company suggested a new division for the city centre by creating a central business district (CBD) and a central region. The developmental study offered the first ring road as the boundary of the city centre, which started from the north side of

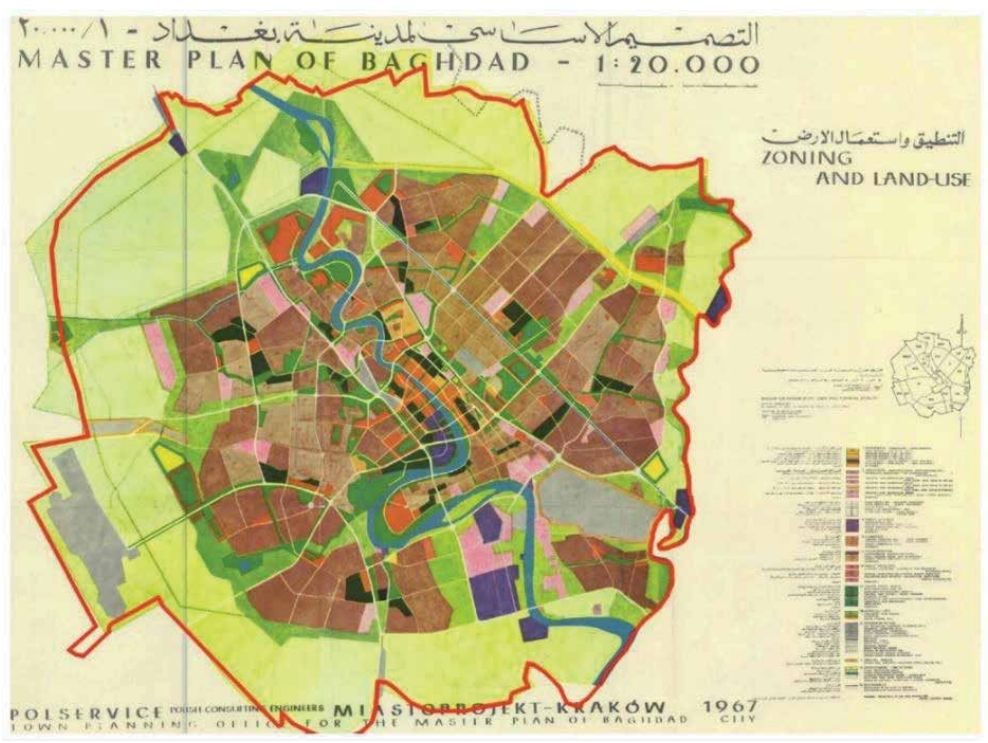

Figure 18.

Polservice's master plan of Baghdad in 1967. Source: [21], Referring to the mayoralty of Baghdad. 
14th July Road and the Muhammad Qasim Freeway. The study stated that the new centre of Baghdad would cover an area of approximately 1.700 hectares. According to Al-Akkam, 'the proposals of the study (Comprehensive Development Plan of Polservice, 1973) pointed to complaints about the city centre regarding a lack of commercial, cultural and recreational opportunities' ([3], p. 61). More recently, after 2003, several firms identified new opportunities when the Iraqi government launched a comprehensive programme to prepare development plans for different Iraqi cities, including Baghdad. The big challenge in the capital was to fill the gap between the former master plan, in terms of what had already been implemented, and the new one. Moreover, addressing important developments helped to establish whether they responded to the prior master plan. Khatib and Alami prepared the general master plan of Baghdad, which identified different aspects of the dramatic changes in city growth since 1967.

One of the primary concerns about the comprehensive development plan was, for example, the old part of Baghdad which was defined by use-based zoning. The origin of the traditional city arose spontaneously, rather than through the mechanism of land use or zoning. This represented a critical point within the urban development projects. The network pattern and layout of the buildings in the area were complicated; therefore, there was a need to prepare specific criteria and regulations to protect the identity of old Baghdad as well as recognise the contemporary ambitions of the new city. The complexity of the network in the old part is not declared today, but many related studies and projects refer to it in different ways. In this respect, Al-Rahmani states that land use was incompatible and inappropriate, due to the greater population in the old quarters. Moreover, there was no integration between old and new developments. Many old areas had been demolished and replaced by new developments on the pretext that they were modern and thus compatible with the needs of a contemporary era. However, the result was unsuccessful as far as functionality and compatibility were concerned [15].

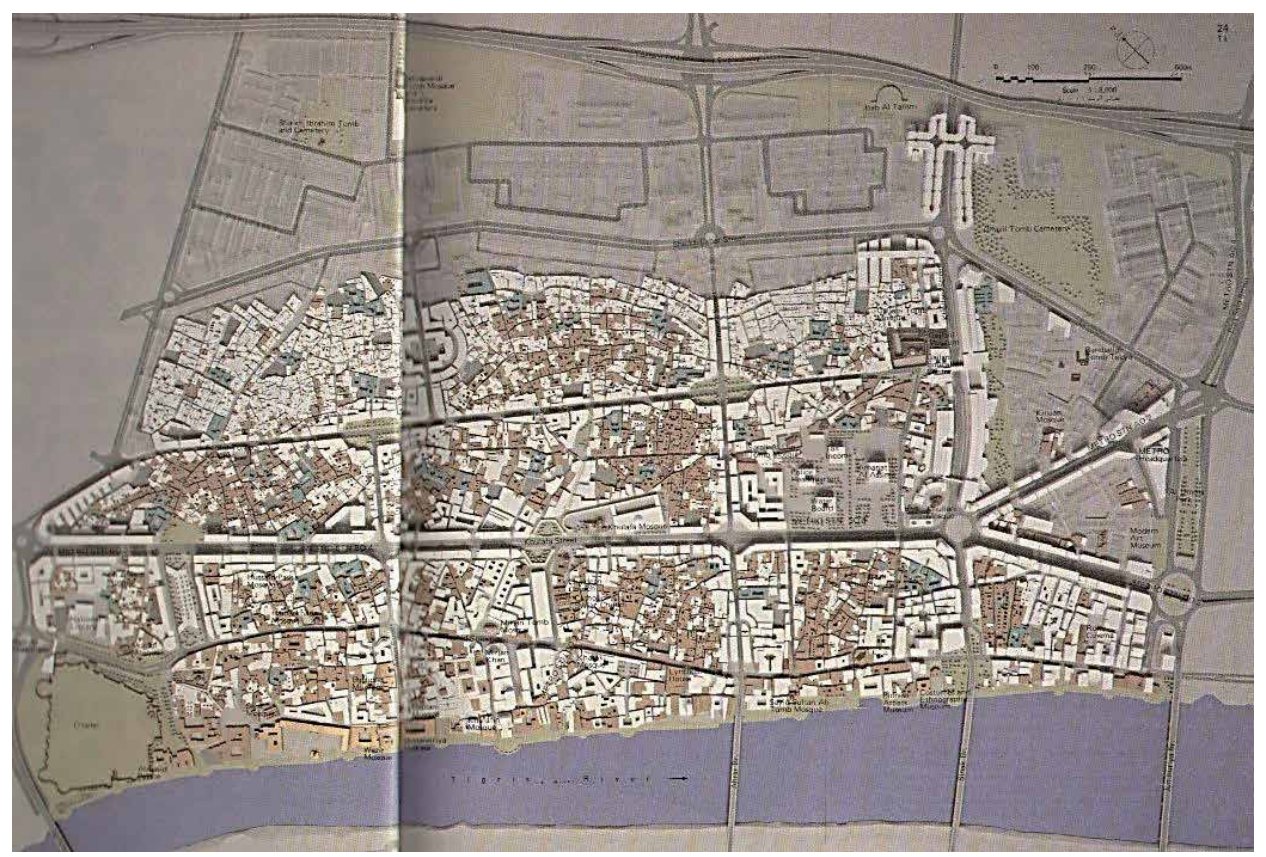

Figure 19.

Study on the conservation and redevelopment of the historical centre of Baghdad City, Rusafa. Source: Mayoralty of Baghdad ([14], pp. 23-24). 
Besides its comprehensive development plan, Baghdad also witnessed other development processes. These were related to the historical area of the city and included both Rusafa and Karkh. The first attempt to conserve and redevelop the historical centre of Rusafa started in 1983 by JCP Inc. from Japan and in association with a consultant group. The study was important because it dealt with different levels of development that covered comprehensive analyses, the urban structure, conservation plans, and urban design schemes. However, the implementation programme unfortunately stumbled (Figure 19). This study focused on the street level and the key characteristics that formed both its opposite edges, thus promoting the historical spines of the city and the traditional environment of Baghdadian people (Figure 20). The study presented the implementation of the proposed structure plan that consisted of three levels; primary action up to 1990, secondary action up to 1995 , and tertiary action up to 2000 . Despite a significant programme

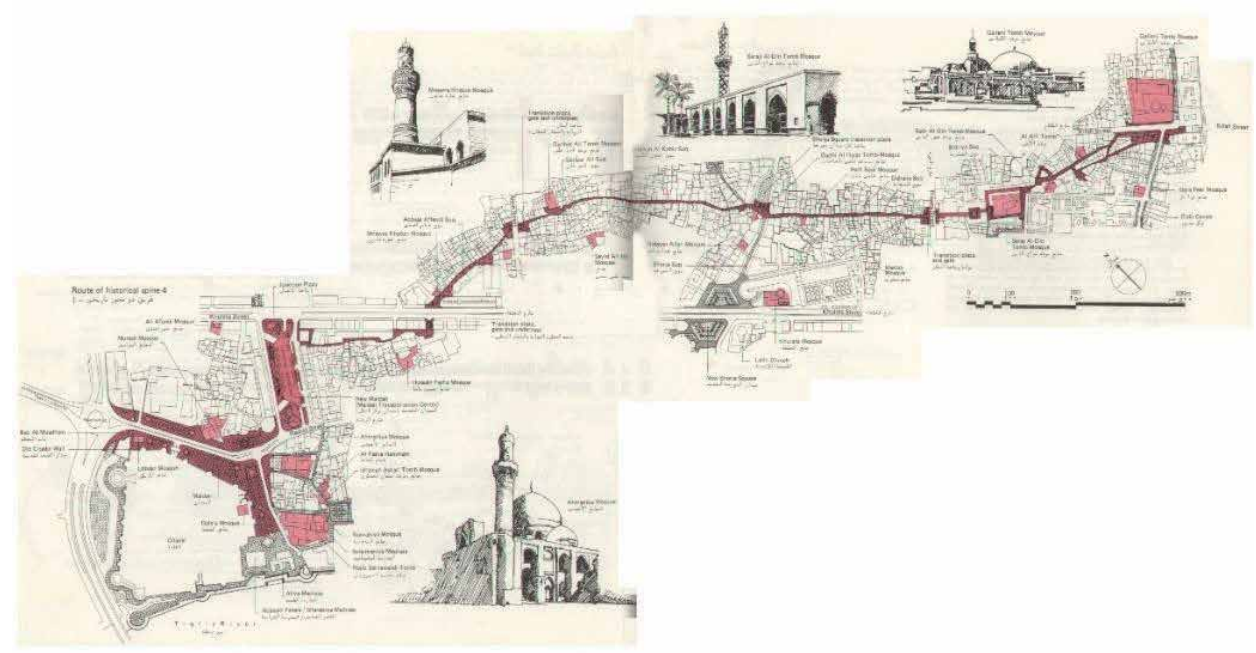

Figure 20.

A historical route in the study on conservation and redevelopment of the historical centre of Baghdad City, Rusafa. Source: Mayoralty of Baghdad ([14], pp. 49-50).

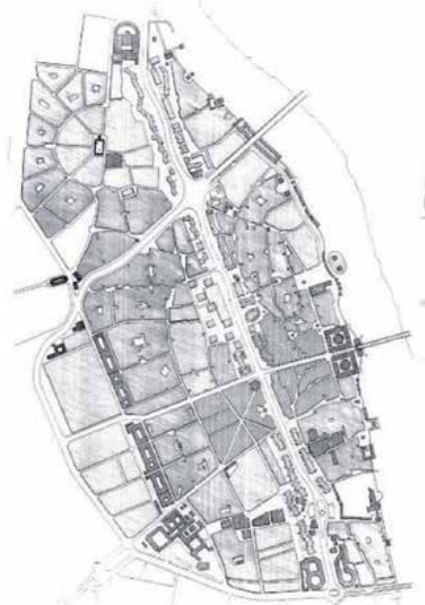

Urban Design Concept A

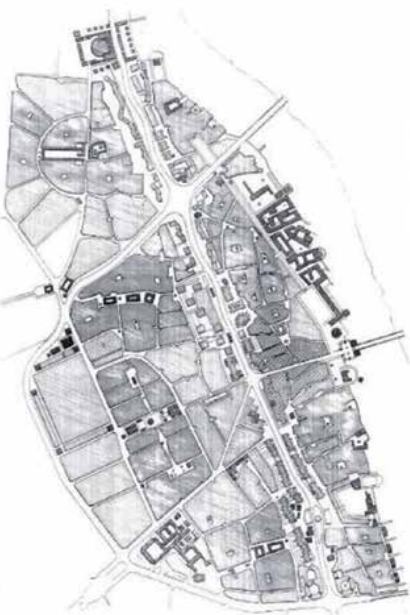

Urban Design Concept B

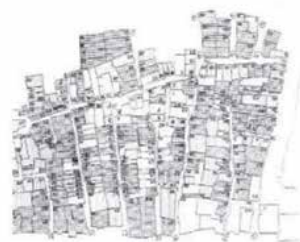

Neighbourhood

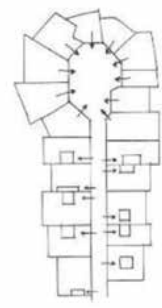

Street

Figure 21.

Al Karkh development. Source: Mayoralty of Baghdad, Alousi ([24], p. 86, 101, 370-371). 
of implementation, none of the actions took place as recorded. Instead, historical parts are still suffering from neglect today, while individual monuments and the street network have similarly been ignored. The Al-Karkh region is the second historical area of Baghdad; this saw a significant development plan in 1982 which was prepared by Alousi Associates and Reinick Consultants, who were from Dublin in Ireland, with Parsons Brown Consulting Engineers, from Bristol in England. Unlike the previous comprehensive plan, this study dealt with an existing traditional area where the street and plot pattern were complicated (Figure 21); thus, the study's aims were not pursued. Haifa Street saw one of the main changes where adjacent high-rise residential buildings were constructed on both sides of the street. Even though these projects were designed to address the historical areas of Baghdad, none of their aims were fully achieved. After 2003, the Mayoralty of Baghdad contracted with local bureaux to study and analyse traditional parts of Baghdad; Al-Rasheed Street in the Al-Rusafa quarter and the Al-Karkh quarter were the main two renovation projects. The primary concerns about these urban renewal plans were the administrative policy and the implementation phases.

\section{The essence of Baghdad}

The essential morphological pattern and structure of the old city in Rusafa remained, in general, unchanged until the first decade of the twentieth century [4]. The main architectural and urban context character of old Baghdad could be typified as a series of spatial patterns and a hierarchy that was based on introversion. The nature of the environment with its socioreligious and socio-climatic dimensions seemed to have experienced fewer typological changes than stylistic ones. This means that the typical scheme of traditional residential areas in Baghdad continued to depend on the concept of the internal courtyard and the inward-facing direction. The non-adoption of rigid space-use corroboration and the increasingly needed formal and aesthetic considerations meant that form, particularly in domestic architecture, was much more important than function, which was mostly stereotyped and multipurpose [4]. In comparison, the modern design gave as much priority to its functional dimensions and use patterns. However, medieval Islamic cities, such as Baghdad, were defensive and inward-oriented in their overall design and through their organic urban fabric.

Moreover, the city was surrounded by a wall which held gates that lead to the heart of the city where many self-contained residential quarters, called Mahallas, were located; these faced the main routes into the countryside. The main character of the old city in Rusafa could be seen through the pedestrian labyrinth of narrow alleyways which amassed together and led to inward-looking courtyard houses. Meanwhile, the centre of the city was covered by significant buildings, such as the Friday Mosque, souks, Khans, hammams, and coffee-houses. The commercial souk sector was situated in the heart of the city, the 'Medina', and often included huge areas with complex networks which led to specific markets, khans, and workshops. Each type of work was situated according to a distinct functional hierarchy, which was based on the needs of merchants, guilds, artisans, and craftworkers. Baghdad exhibited an atmosphere of spontaneity and informality which was represented by its old urban fabric and historic buildings and some of its limited cultural activities [4].

The essential element in the old urban fabric of this ultradense context was a local variant of a central courtyard hosh, meaning house. The traditional Baghdadi house was characterised by an introverted habitat with solid brick walls that directly faced the street with one access door. Furthermore, shanashils were the main feature of the street; these carved wood projections, with railings and 
windows, were used for lighting and viewing $[25,26]$. During the Ottoman occupation, essential changes occurred in several major typological transformations. The housing regulations were issued following the Ottoman occupation of Baghdad and continue today; however, these rules were subjected to three phases. The first phase began in 1869 and continued until the First World War; this was initiated by the Ottoman period under the Tanzimat reforms in Iraq. The second phase started with the monarchy of Iraq and continued throughout the colonial and independent period. The final stage commenced with the revolution of 1958, which saw Iraq shift from a monarchy to a republic. It is important to note that the third phase has also passed through several transitions since 1958.

The first phase witnessed the Ottoman invasion, and its urban and physical form reflected the typical characteristics of Islamic cities through quarters, mosques, bazaars, and other several public institutions. This was also echoed in the character of the traditional house with its courtyard and inward direction [27]. Moreover, the first modernisation that took place in Baghdad occurred during the reign of Midhat Pasha, who was a governor of the Baghdad Vilayet. He ordered the demolishment of the wall of Rusafa and invested its materials in the construction of many significant public buildings. He also prompted the introduction of modern municipal services besides new roads. In 1915, during the same Ottoman period, German engineers established the first railway line, which connected Baghdad and Europe. This coincided with the use of new materials, such as steel, and was later adopted by local masons [28]. The successive occupation of Baghdad finally included the British in 1918; this marked a significant turning point in Iraq's modern history, not only in Baghdad but also in other Iraqi cities. At this stage, a considerable number of public buildings were constructed that affected the main character of Baghdad and its urban context.

In the mid-1950s, the Iraq Development Board invited well-known architects to contribute to a set of projects that aimed to develop the urban structure of the city and to meet a new standard of function. These architects included Frank Lloyd Wright, Le Corbusier, Alvar Aalto, Walter Gropius, and Doxiadis Associates, as well as Captain Philip Hirst, Ellen Jawdat, Hans Muller, Platinov, and Adler and partners [28]. The value of historical detail lies in its importance in sustaining a national architecture; such detail occupies a wide area in the city centre of Baghdad. Traditional detail is not limited to houses but also includes various urban components and networks. The benefit of such features is that historical buildings can not only be saved but also invested in through their housing of different types of activities, not just as museums [29]. Allen states that traditional areas aim to educate the public about the importance of the historical regions (as an endangered urban area) of Baghdad, including its residential zones [30]. This attempts to activate the conservation of ancient and irreplaceable architecture.

The modern city of Baghdad includes four historical areas, namely, Rusafa, Karkh, Adhamiya, and Kadhimiya (Figure 14). These areas stand in the remains of four interspace townships and are surrounded by contemporary urban features that include modern buildings, extensive public squares, and an orthogonal network. The four inherent sectors are a vital resource of expression of a past traditional period and provide a cultural and historical chain that could be continued for future generations [4]. Between 1869 and 1872, governor Midhat Pasha attempted to implement a transport system in the old urban fabric. The city wall was partially demolished to open the first entrance at Karkh for a horse-drawn tram. However, urban expansion remained within the same range of the historical city. Between 1915 and 1917, German engineers established a new street to reach between the North Door (Bab Al Mu'adham) and the South Door (Bab Kulwadha), namely, New Street and the present-day Al-Rasheed Street. However, the modern machinery of urban development generally endured sluggish progress when dealing with Baghdad [26]. 
The existing old fabric, which included a network system, historical neighbourhoods, and heritage buildings, faced the ideology of modernisation, which led to the creation of a new urban morphology within a current traditional structure. This was achieved either by reconfiguration or by removing old structures. Selforganisation was the central concept in the configuration of the old fabric; in contrast, the new urban context relied on planning. Consequently, the two different patterns occurred and led to an interrupted urban pattern which reflected a lack of continuity, coherence, and integration with the surrounding environment [8]. The characteristics embodied in the urban context of Baghdad were (1) the quality of use and the nature of urban space, which was based on different spatial concepts, urban patterns, and building typologies, and (2) specified markets along with public buildings and the river frontage which provided defined and active public spaces [8]. According to Al-Hasani, Baghdad's urban space can be classified under two typologies based on its accessibility and the relationship between privacy and publicity. These two topologies are traditional-surviving spaces and modern-emerging spaces, the latter of which is divided into hybrid urban spaces and entire modern urban spaces [8]. In the same context, Al-Hasani states that urban space revitalisation strategies could be based on space hierarchies and could focus on managing the integration between urban morphologies and contemporary needs [8]. In the past, Baghdad integrated its various urban patterns in order to reduce ambivalence towards the transformation process which historically tended to be continuous and subject to self-organised acts. It was achieved by creating the smallest urban form cells that dealt with hierarchy, land use, and building rules and enhanced human activities by concentrating more on the hierarchy space and accessibility [8].

\subsection{Street characteristics}

Its contemporary streets represent one of the components of the comprehensive plan of Baghdad. However, the street basically follows the same principles of new urbanism under the term of modernity. New roads are wide and long in comparison with traditional ones; they tend to span more than 3 kilometres with tall buildings on both sides and are far removed from the human scale. In addition to this, these new streets replaced the demolished previous, irreplaceable traditional fabric, which included souks, houses, and mosques. Moreover, the massive gap that emerged between the old urban structure and the new urban context under the same terms, westernisation and modernization, cannot be readily ignored [26]. Rasheed Street is one of the oldest streets that cut through the historic central areas to link the north and south of ancient Baghdad and runs parallel to the Tigris River. It was begun by the Turks in 1915 but was completed by the British in 1918 . Its width is varied where the maximum is about 40 metres, including 10 metres of commercial development on either side. It is almost 3.8 kilometres in length [31]. The importance of Al-Rasheed Street comes from the characteristics of the adjacent buildings and their distinctive architectural style.

Porticos, with various facade styles, constitute Al-Rasheed Street; it adopts human-scale dimensions and has an integrated, harmonious architectural unity. Such environmental elements give enough protection for pedestrians against undesirable climates. The street reflects a cohesive alignment of buildings which contains the highest diversity in elevation, and its characteristics represent different types of architecture [32]. Therefore, Al-Rasheed Street reflects a panorama that vividly portrays the long history of buildings and the evolution of architectural patterns. Although crucial events occurred throughout the life of Al-Rasheed Street, each event tells its own story [32]. Al-Haidary states that there is a lack of important construction legislation and conservation monitor programmes for planning and 

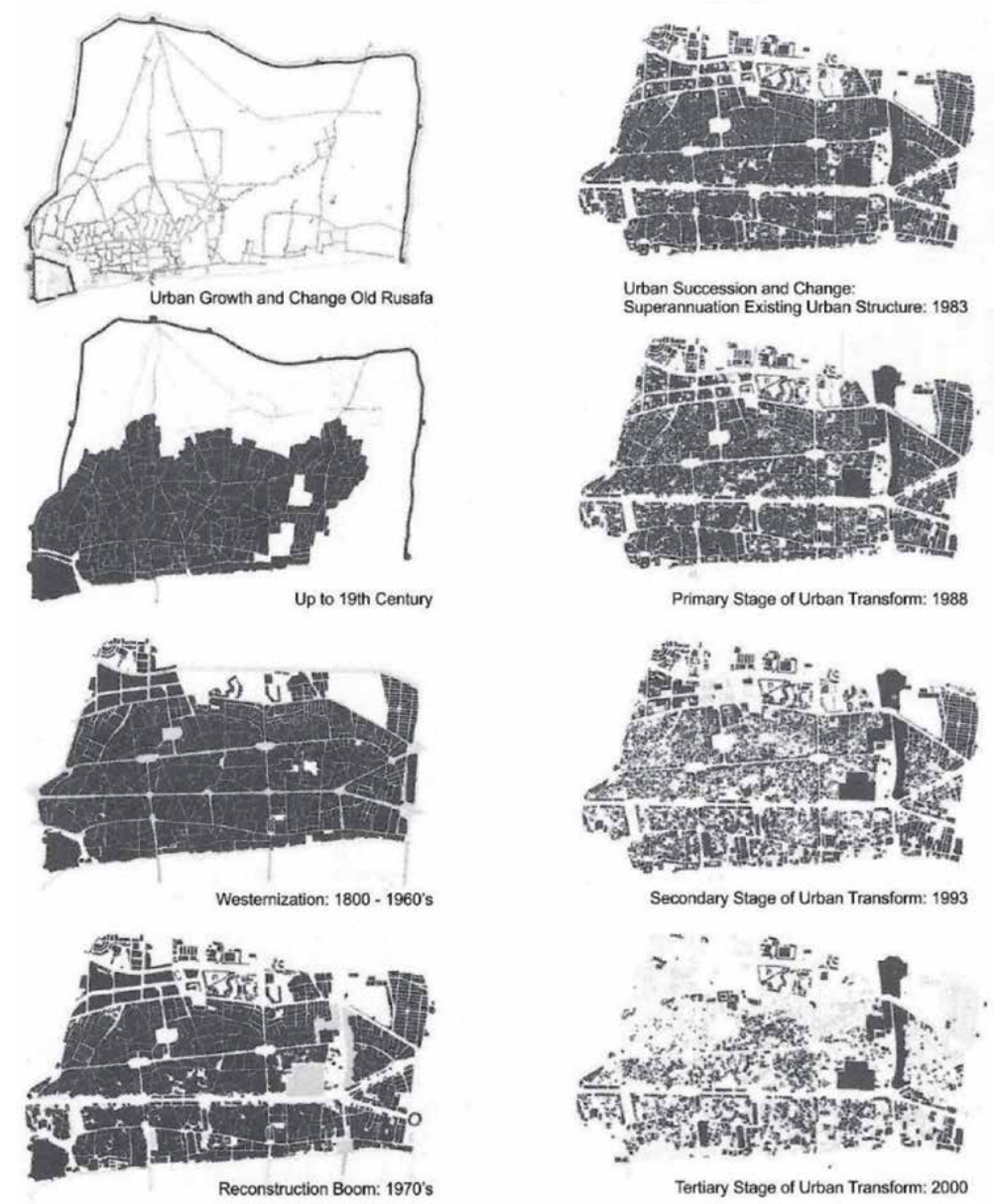

Figure 22.

Urban space transformation in Baghdad. Source: ([33], p. 107) based on [14].

urban design and a similar lack of commitment to restrict initiatives to ensure they adapt to traditional patterns. Concentrating more on the maintenance and restoration of significant heritage buildings within their urban context can be considered an essential factor that positively affects the old urban fabric, for example, Kifah Street, which, in 1936, was orientated through Rusafa. Its width is 50 metres, which includes 15 metres for commercial development on both sides, while its length is about 3.2 kilometres. Unfortunately, this new route also caused severe damage in the traditional urban area of Rusafa. The third street was Al Jumhuriya Street, which in 1954 passed through Rusafa [31] (Figure 22).

The drastic changes in the urban spatial structure of the city affected the streetscape in terms of the street's edges. It developed a new definition of the relationship between private and public, while priority was given to the motorisedbased scale rather than the human scale. To a large extent, this newly defined relationship led to the adoption of new behaviours and social interactions that responded to the street's edge (Figure 23). Adopting a fine-scale classification by analysing the street pattern seems to be a more efficient means of recognising the urban characteristics of streets over large-scale classifications. There is a definite pattern of activity about the classification process of compound parameters, which increase in an area or within defined spatial dimensions. In contrast, large-scale 


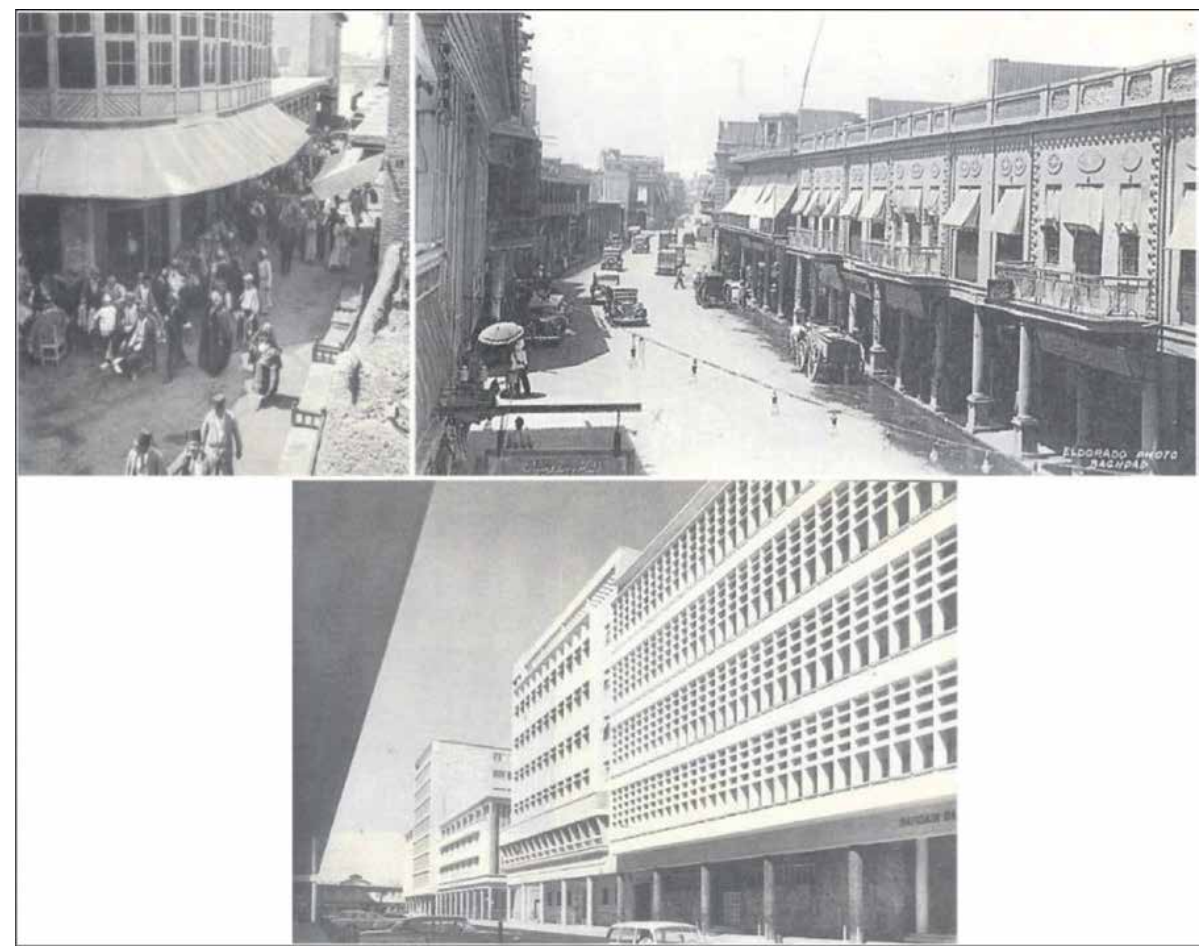

Figure 23.

The historic area of Baghdad witnessed an extraordinary change in the spatial structure of its street edges. Source: ([10], pp. 260, 349-350) all rights reserved for Al-Warrak Publishing Ltd., London, UK.

classification is affected by minimum or single parameters, and this can refer to the comprehensive analysis method of streets, which are likely to be irrelevant in creating distinctive urban characteristics for the whole city. The entire spectrum when distinguishing the urban attributes of streets tends to seek difference rather than similarity [31]. Overall, in terms of its morphological dimensions, the main characteristics of Baghdad Street would be the level of difference and disparity between the original and modern streets. Both types, historical and modern, are subject to two different generative systems: spontaneous (bottom-up approach) and pre-planned (top-down procedure).

\subsection{The old fabric and the modern trend}

Hillier argues that there is apparently fear of doing anything in a historical part of a city, except to retain the old street system. However, the old street network emerged by incremental dynamic processes over time that reflected the growth and change through different generations. Each generation tended to partially modify street networks to better meet their needs [34]. Al-Haidary highlights that 'the city for man, and in the city's philosophy the general should precede the individual, that is, the society's requirements should come before the personal desire, and the city's identity has to be preserved, and it can be expanded via green and red veins' ([32], p. 71). Regarding the old urban fabric in Baghdad, Alobaydi and Rashid state that, since its establishment as the capital of the Abbasid Empire to the end of Ottoman occupation in 1917, the city was characterised by spontaneous urban growth. Their key findings at the diachronic level are that the core of the old city of Baghdad manifested a robust correlation with its commercial centre until the 1940s when modernist developments were undertaken throughout the city. Also, before the 
1940s, the nature of the relationship between the social dimensions and economic factors in the old patterns of Baghdad expressed a mutual correlation. Later, the relationship was subjected to a considerable number of modifications that were instigated by comprehensive and modern development projects [35].

Apart from the degree of implementation and quality, a considerable number of plans were conducted to maintain the old areas and the historical urban form of the city. However, serious practical steps were needed, such as setting laws, regulations, guidelines, and financial resources and raising the level of awareness among communities about their own heritage. Moreover, where existing buildings from the modern era become part of the urban context of the city, any attempt to deal with these buildings is achieved by composing a bridge between modernisation and heritage via a thoughtful conversion with the old environment. This enables such initiatives to be viable, dynamic, and resilient; they have the potential to involve development process with remaining historic essences that have heritage value [32]. The prevalent character of Baghdad becomes the scope of neglect for the old fabric, whether as an individual building or as a network system. The deficiency of infrastructure and unhygienic conditions, irregularity, and the lack of maintenance can lead to the exploitation of an area for various unregulated purposes. In Baghdad, this resulted in chaos and the loss of priority in sustaining the meaning of civilised life, particularly in the old regions of the city, such as Rusafa and Karkh. Thus, the importance of preservation and maintenance should be considered, not only for individual units, such as houses or public buildings, but also for the urban fabric in general which represents a vital network system [32].

The old urban fabric and its morphologies were, formally or informally, influenced by the wave of modernism and replaced later by the new urban context, which resulted in the loss of the relationship between built forms and streets [36]. The urban renewal operation that took place as a part of a comprehensive development plan in Baghdad critically recognised the old urban fabric and determined an efficient process to preserve this vital sector of the city. Two dimensions identify any attempt to develop old areas: firstly, the entirely or partially neglected area of the old urban fabric, and secondly, the direct or indirect reliance on foreign technicians to deal with national heritage and historical, cultural dimensions that shaped the urban context of the old sector of Baghdad [32]. Most of the traditional urban areas have modest conditions and qualities but are still considered an attractive destination. However, the main concern is for functional transformation, which leads to topological depth alteration and can change morphological patterns in an old urban structure. The revolution against what humanity has produced through its long-rooted history has led to unpredictable and unsatisfactory results, with modernism at the forefront of such results [37]. Hall argues for maintaining beneficial, comforting old buildings and communities from 'the bomb' of urban renewal, where not all new ideas and objects are necessarily desirable nor all old thoughts and developments substandard [38]. Cities, however, have many places and sometimes only a few historic buildings or a cluster of outstanding features which merit preservation. These buildings and elements within their own context afford continuity with the past and lend diversity to cities.

Kropf argues that 'the degradation of neglect is reinforced by the active effacement caused by the replacement of old by new buildings which share few of the characteristics of the former. The cumulative effect is that the historical and regional character of the town is being eroded' ([39], p. 721). According to Cullen, the history of a city involves several historical layers, where most cities are constructed on old foundations, and their fabric exhibits evidence of different periods in their architectural and urban patterns and in the diverse accidents which are recorded and conserved by various layers of history [40]. The relationship between 
the old fabric and the trends of modern urbanism in Baghdad is the foremost priority in defining spatial affiliation and in dealing with the city's significant cultural and historical heritage. It is possible to identify two essential perspectives that determine the relationship of the oldest urban area of Baghdad to the contemporary urban progress of the city. The first is the vertical perspective, which stands for the modernisation of the city centre itself and its adoption of the modern ideology. The second is the horizontal perspective, which addresses the extended urban areas that are adjacent to the traditional centre of Baghdad. This relationship, however, could include the fine scale of the city in examining the ability of the street to promote social interaction as a public space for people. Furthermore, different interfacing patterns could also be performed in the street.

\subsection{The dialectic between traditional and modern thoughts}

Since the end of the Second World War, the rapid growth of Baghdad was partially uncontrolled, whether in the oldest zone or the surrounding regions. The built-up area increased from a mere 6 square kilometres in the first decade of the nineteenth century to about 240 square kilometres in 1970; this will be extended in the future unless there will be more thoughtful planning. This has since been achieved since starting the study. The more significant diffusion of Western ideas and the concept of modernity and technology coincided with the colonial and independent phases of Iraq that attempted to instil reform and development. The aim was to open up Iraq to the capitalist global economy by adopting Western patterns of society and their physical environments. In this respect, giving more attention to the central region of Baghdad is needed, meaning that the management of these traditional areas must be thoughtful and methodical in order to improve inhabitants' quality of life and to promote urban sustainability [27].

The influence of such rapid growth on the old fabric was overwhelming during the last three decades of the twentieth century. The growth of urbanisation generally led to an increase in demand for more physical environments, which severely damaged the old urban fabric of the Rusafa area. In contrast to Baghdad, a considerable number of other countries with ancient regions intentionally affected urban expansion outside the boundary of their historical regions [4]. The debate between modernity and identity in the scope of architecture has always been raised, whether by specialists or the public. To a large extent, the concept of Westernisation is evidenced by modernisation and modernity [41]. Thus, historical debates between the two sides (modernisation/Westernisation and traditional/East) should be reviewed in view of their conflict and their influence on the loss of Iraqi identity. The concept of cross-cultural references would be a more efficient way to drive an active role in reshaping and configuring both imported concepts and local objectives in the interaction between different cultures and counties or societies. This could be considered a healthier transformation in the interrelationship and exchange of experiences among communities [41].

Reviewing the brief archaeology of firms that worked in Iraq, Doxiadis prepared the development plan for Baghdad in 1958; the concept adopted was to keep the compact pattern of the traditional central area and to construct new adjacent streets. However, these plans were not largely realised although some housing projects and an Army Canal were carried out [41]. Despite the storming of the Middle East by modernity, particularly in relation to lifestyle, architecture, urban design, and planning, the traditional themes still gave a sense of balance with their socio-climatic traditional components. However, in the 1970s, Polservice designed traffic networks for Baghdad that disregarded the old urban fabric in the city centre [41]. A significant disadvantage in urban space is caused by the intersection between the historic fabric 
and the power of market orientation. Also, the tendency towards augmentation regardless of the historical and cultural environment generally leads to the creation of a vacant area, which mediates between two contradictory contexts in terms of history, culture, and urban structure. The old fabric of the city splits into different sectors through creating new urban spaces that unfortunately work as segregation perimeters. The loss of system regulation, control, and monitors on urban development plans, besides the level of bureaucracy and administrative systems, collectively led to more devastation for traditional buildings and street patterns [8].

Reshaping the city to reflect the Iraqi identity entails a major preliminary survey and the first administrative framing of its heritage. However, a considerable number of architects tended to pervert such legacies by using modern techniques in design, materials, and construction within the framework of traditional Arab architecture. This procedure has been adopted many times by architects trying to gain acceptance for their designs [41]. Accordingly, some attempts have been made to employ a local, traditional vocabulary in decorating new buildings in order to reduce the disparity and develop a new iconographical strategy. However, according to Pieri, 'public architecture neglected the fact that identity is a matter of sedimentation and not of decision: under the pretext of reviving the past Arab and Mesopotamian grandeur as the foundation of a newly built collective identity' ([41], p. 36). The Iraqi identity, in general, belongs to the history of ancient civilisations where part of its artefacts emerged as a fertile and fundamental basis for the nation that is undergoing a revival in the modern era.

Considering the old area in Baghdad, urban public space can be described through monuments, which include emblematic statements that carry a new iconography through the synthesis of a national repertory with a modern style. The notion of value in the old fabric of the city seems to be on the opposite side to highrise buildings, which demonstrate inconsistency with the surrounding horizontal environment, particularly around the central area of Baghdad. The moment that the new European style emerged under the terms modernisation and Westernisation, Baghdad no longer remained a typical Arab-Islamic city. Al-Haidary asserts that modernisation and the implementation of rapid, dramatic changes by increasing economic growth and population sizes resulted in unregulated buildings in the old urban fabric of Baghdad [32]. Pieri refers to urban identity as a language with a syntax that is composed of both built and natural and tangible and intangible realities. Thus, architectural themes have their own exclusive urban character [41].

Despite the paradox that the old urban fabric and its characteristics belong to its historical roots, its ability to survive within new urban developments is considered significant in so many countries. The old structure in a city offers unique opportunities to deal with its urban components to promote and develop an urban environment that meets human need throughout its social, economic, and environmental qualities ([42], cited in Al-Akkam 2012). Moreover, Pieri states that 'to preserve a balance between material layouts and collective memory, urban form and content, it becomes imperative to study the materiality of the built environment or urban design in its various contexts. Architecture and urban planning belong to cultural systems of representation and are part of long-term durability. Tradition should be a laboratory of collective memory so that it becomes easier to conceive of architecture and urban planning as societal choices' ([43], p. 20).

The urban and architectural history of Baghdad should be taken into consideration as part of global urban heritage. From this point of view, Baghdad faces a significant challenge to the reconstruction of the old part of the city. According to Pieri, this challenge must be settled for the long term, not only for urban and architectural patterns but also for the people who live in the city [43]. Mohammed Makiy calls this a micro-vision which plays a significant role in softening the 
aggressiveness of large-scale developments, where the ideology of the human scale provides a guiding route. The debate of the modern movement has often taken place in architectural reviews as one of the crucial transformation points in the history of architecture. The theme of reductionism is a modern ideology; nostalgia for the city's past and the characteristics of humanity has become one of the most critical issues in contemporary architectural writings, conservation projects, and the maintenance of the architectural history of the city, both on the level of structural scope or urban design. Therefore, there is a need to move from 'the rationalised modernist views that deconstructed so many towns and cities in the 20th Century' to meet the desire and 'need to unpack and reconstitute the synoptic art of city-making that was substantially lost during the so-called machine age of the 20th Century' ([44], p. 8).

\section{Deriving the urban gap}

A cross-reading of the literature concerning the emergence and development of Baghdad to the present-day helps to outline the research gap. The awareness of the value of heritage and history, particularly in the oldest sector of the city, has increasingly become an essential kernel for the emergence and diversity of ideas, which help to maintain and develop this part of the city. The characteristics of the old area reflect a considerable number of criteria, such as limited travel distances, lower car dependence, and greater opportunities for people to walk. These encourage community life with better surveillance that enhances public safety [45]. Thus, these characteristics, particularly in the old fabric of the city, underpin the quality of social life by reducing motorised-based use, minimising external pollution, concentrating activities, adopting multimodal street networks, mixing land use, enabling high occupancy rates, and highlighting the value of heritage and cultural elements. Another incentive is to help forge a relationship between the old centre and the city that reflects the concept of a living museum, based on real, coexisting life. A living museum explicitly offers positive opportunities at all levels, such as entertainment, culture and historical experiences, economic support, and social activities; it provides an attractive location for people and helps to underpin tourism ([46], p. 368, [47]).

The city centre of Baghdad is a 'mosaic of memory' that contains unique features, whether related to its physical dimensions or collective memory. The traditional core has varied characteristics, which consist of many activities and ancient architectural components as well as a complex urban fabric [3]. The functional definition of the street is subject to the top-down approach to authority, even in the historical area of Baghdad that originally came from a long-established bottom-up approach. Shamsuddin and Ujang state that streets in an urban context are places of economic and social significance; great cities are often identified by their main streets, and the nature of these streets reflects the image of the city. Furthermore, one of the key functions of the street is to convey the main characteristics of a city and its particular identity. A street can represent the general perception of a city's character, identity, and image due to its bonding with individual experiences [48].

For fine-scale approaches, particularly in historic towns, the priority is the human scale, which is typified by the enclosure of spaces that are shaped by the boundary of buildings. The thoroughness of the building pattern combined with the design of the spaces is essential to give a sense of identity. In contrast, isolationism and introversion become the main features of modernist buildings. The influence of the modern wave was not only witnessed on the public space but also on the social and cultural meaning of space, where human aspects were not fully considered. Four objectives were identified by Gehl with respect to the human dimension, 
and these are as follows: firstly, 'lively, safe, sustainable, and healthy cities'; secondly, a city's ability to invite individuals to walk through as the sign of a coherent structure; thirdly, a 'short walking distance, attractive public spaces, and a variety of urban functions'; and finally, the city offering an invitation to walk and cycle which form a natural and integrated element of daily routines and a non-negotiable part of a unified health policy ([37], pp. 6-7).

Therefore, transformations in the behavioural system can occur rapidly in comparison to alterations in buildings and the urban context. Although this does not deny the role of the built environment and its influence on the community, the rate of change seems more explicit in human behaviour than in physical surroundings. For example, specific historical areas or buildings continue to exist as before, while each generation has their own experiences in an urban environment. Gehl and Svarre pose many questions about public life in a city. These questions are based on the relationship of people to urban spaces and their interactions with the surrounding environment and other people. The fundamental questions posed are 'how many' regarding quantitative data related to people and their activities. The second question is 'who', which gathers knowledge about people's behaviours in the public space. 'Where' is the third question that addresses 'where people are expected to go and to stay'. The final question concerns whether the city can generally provide specific knowledge of the type of activities undertaken [49].

\section{Conclusion}

This chapter addressed the emergence of Baghdad and the stages of its morphology and transformation. The oldest periods began with the Round City; this created the first nucleus that later formed Baghdad. The city then moved from the west to the east riverbank of the Tigris. Moreover, the main historical characteristics of the urban structure survived until the British occupation in 1917. The physical environment was typified by two fundamental urban components: street network and Mahallas (traditional neighbourhoods). These two elements have a close interrelationship and an overlapping pattern. Spontaneity follows the bottom-up approach, where the community manages its own built environment; this is derived from the order and regulation that informed the norms and values of inhabitants and their beliefs.

Morphologically, the historical region of Baghdad was distinguished by an organic pattern for both the street network and its built units. Moreover, the street pattern was also subject to a series of definitions according to the degree of privacy and other functions. This chapter highlighted the main points that differentiate the historical pattern of the city and the modern era. Those points were considered under four main headings: (1) the essence of Baghdad City, (2) its streets' characteristics, (3) the old fabric and modern trends, and (4) the dialectic between traditional and modern concepts. Modern areas in Baghdad follow the top-down approach to generate neighbourhoods that are distinct from the fine-scale or micro level of street life. However, this mainly depends on the expectations of future programmes through predetermined land use. Due to the new strategies and regulations introduced by master plans, the urban structure of Baghdad drastically changed, not only in the centre but also in the surrounding regions. One of the main aspects of these transformations in the urban structure is its street life and how might people respond to the street edge and how their social interactions are influenced. Furthermore, this impacts the underlying system in terms of its street pattern and the network characteristics, including the centrality value. 


\section{Acknowledgements}

First, I would like to express my gratitude to my supervisor Professor Sergio Porta and his thoughtful guidance through this chapter. His experience in urban design, public space design, spatial analysis, urban regeneration, and adaptive urbanism had a significant effect on the formulation of the chapter.

\section{Author details}

Haider J.E. Al-Saaidy ${ }^{1,2}$

1 Department of Architecture, University of Strathclyde, Glasgow, United Kingdom

2 Department of Architectural Engineering, University of Technology, Baghdad, Iraq

*Address all correspondence to: haiderjasim2000@gmail.com;

haider.al-saaidy@strath.ac.uk

\section{IntechOpen}

(C) 2020 The Author(s). Licensee IntechOpen. This chapter is distributed under the terms of the Creative Commons Attribution License (http://creativecommons.org/licenses/ by/3.0), which permits unrestricted use, distribution, and reproduction in any medium, provided the original work is properly cited. (cc) BY 


\section{References}

[1] Fernea RA. Land reform and ecology in Postrevolutionary Iraq. Economic Development and Cultural Change. 1969;17(3):356-381

[2] Nooraddin H. Globalization and the search for modern local architecture: Learning from Baghdad. In:

Elshishatawi Y, editor. Planning Middle Eastern Cities: An Urban Kaleidoscope In a Globalizing World. London: Routledge; 2004. pp. 59-84

[3] Al-Akkam AJ. Towards environmentally sustainable urban regeneration: A framework for Baghdad City Centre. Journal of Sustainable Development. 2012;5(9):58

[4] Fathi I. The Architectural Heritage of Baghdad. Exhibition Catalogue. London: Iraqi Cultural Centre Gallery; 1979

[5] Bosker M, Buringh E, van Zanden J. From Baghdad to London: Unraveling urban development in Europe, the Middle East, and North Africa, 8001800. The Review of Economics and Statistics. 2013;95(4):1418-1437

[6] Le Strange G. Baghdad during the Abbasid caliphate. A topographical summary, with a notice of the contemporary Arabic and Persian authorities. The Journal of the Royal Asiatic Society of Great Britain and Ireland. 1900;33(2):349-351

[7] Gilli-elewy H. Al-awādi al-ğāmia: A contemporary account of the Mongol conquest of Baghdad, 656/1258.

Arabica. 2011;58(5):353-371

[8] Al-Hasani MK. Urban space

transformation in Old City of Baghdadintegration and management. Megaron. 2012;7:79-90

[9] Makiya M. Baghdad. London, UK: Al-Warrak; 2005
[10] Makiya K. Post-Islamic Classicism: A Visual Essay on the Architecture of Mohamed Makiya. London, UK: Al Saqi; 1990

[11] Al Waily TAH. Baghdad 21st Century-the Historical City. 1st ed. Amman, Jordan: Adib Books; 2017

[12] Allawi I. Some evolutionary and cosmological aspects to early Islamic town planning. In: Sevcenko MB, editor. Theories and Principles of Design in the Architecture of Islamic Societies. Cambridge, Massachusetts: The Aga Khan Program for Islamic Architecture; 1988. pp. 57-72

[13] Fethi I. Urban Conservation in Iraq: The Case for Protecting the Cultural Heritage of Iraq with Special Reference to Baghdad Including a Comprehensive Inventory of its Areas and Buildings of Historic or Architectural Interest. Sheffield, UK: University of Sheffield; 1977

[14] Bianca S, Yamada S, Fethi I, Lombardi G. Rusafa: Study on Conservation and Redevelopment of Historical Centre of Baghdad City. Baghdad, Iraq: JCP JP, Architects and Consulting Engineers; 1984

[15] Al-Rahmani SF. Principles for Urban Renewal in Iraq: A Study to Develop Town Planning Principles for the Renewal of the Iraqi Cities with Particular Reference to Baghdad Central Area. Manchester, UK: University of Manchester; 1986

[16] Al-Ashab KH. The Urban Geography of Baghdad. Newcastle, UK: University of Newcastle Upon Tyne; 1974

[17] R.S.GIS.U, cartographer The Georeferencing Aerial Imagery: The official letter, No.: 1578, Date: 01/11/2017; 2017 
[18] Marshall S. Streets and patterns. .

Dawsonera, editor. New York: Spon; 2005

[19] Theodosis L. “containing” Baghdad: Constantinos Doxiadis'program for a developing nation. DC PAPERS, revista de crítica y teoría de la arquitectura. 2008;(1):167-172

[20] Pyla P. Back to the future: Doxiadis's plans for Baghdad. Journal of Planning History. 2008;7(1):3-19

[21] Alobaydi DM. A Study of the Urban Morphological Process of Baghdad: Implications and Guidelines for Urban Design and Planning in Middle Eastern Cities. Kansas, US: Faculty of the University of Kansas; 2017

[22] Ghazoul K. Baghdad Comprehensive Transportation Study: Project Overview 1983. Report No.: 0860501132

[23] Hammadi IA, Mesbah S, Mahar K, editors. Transportation Network Design Using GIS-Based DSS: Baghdad Metro Case Study. Recent Advances in Systems Engineering and Applied Mathematics, Selected Papers from the WSEAS Conferences in Istanbul, Turkey, May 27-30; 2008

[24] Alousi M. Al Karkh Development. Baghdad, Iraq: Mayoralty of Baghdad; 1982

[25] Al-Azzawi S. Daily impact of climate on the pattern of urban family life: Indigenous courtyard houses of Baghdad regions of the hot-dry climates part I: Daily shifts or daily movements in summer. Renewable Energy. 1996;8(1):289-294

[26] Pieri C. Urbanism in Bagdad before the planning: A codification between the fates of the arbitrary and urgent needs. DC PAPERS, revista de crítica y teoría de la arquitectura. 1920-1950;2008(1):266-271
[27] Raouf LAN. Housing in postrevolutionary Iraq. International Journal of Urban and Regional Research. 1984;8(3):332-353

[28] Fethi I. Contemporary Architecture in Baghdad: Its Roots and Transition.

Baghdad: Process: Architecture, Medinat al Salaam; 1979; 1983. p. 58

[29] Goodwin FG. Traditional houses in Baghdad (book review). Journal of the Royal Asiatic Society. 1985;117(1):91

[30] Allen T. Traditional Houses in Baghdad (Book Review). Vol. 38. 1984. pp. 777-778

[31] Al-Akkam AJ. Urban characteristics: The classification of commercial street in Baghdad City. Emirates Journal for Engineering Research. 2011;16(2):49-65

[32] Al-Haidary A. Vanishing point: The abatement of tradition and new architectural development in Baghdad's historic centers over the past century. Contemporary Arab Affairs. 2009;2(1):38-66

[33] Al Chalabi MR. Encyclopedia of Iraqi Architecture: A Documentation of Architecture and Architects. Baghdad, Iraq: Semaa; 2016

[34] Hillier B. Specifically architectural theory: A partial account of the ascent from building as cultural transmission to architecture as theoretical concretion. Harvard Architecture Review. 1993;9:8-27

[35] Alobaydi D, Rashid M, editors. Evolving Syntactic Structures of Baghdad-Introducing 'transect' as a Way to Study Morphological Evolution. The 10th Space Syntax Symposium (SSS10) from 13 to 17 July 2015. London, UK: University College London, Bloomsbury; 2015 
[36] Can I, Heath T. In-between spaces and social interaction: A morphological analysis of Izmir using space syntax. Journal of Housing and the Built Environment. 2015;31:1-19

[37] Gehl J. Cities for People.

Washington: Island Press; 2010

[38] Hall ET. The Hidden Dimension. New York, USA: Doubleday; 1966

[39] Kropf KS. An alternative approach to zoning in France: Typology, historical character and development control. European Planning Studies. 1996;4(6):717-737

[40] Cullen G. The Concise Townscape. Dawsonera, editor. London, Boston: Butterworth Heinemann; 1961

[41] Pieri C. Modernity and its posts in constructing an Arab capital: Baghdad's urban space and architecture. Review of Middle East Studies. 2008;42(1/2):32-39

[42] Voisey H, Beuermann C, Sverdrup LA, O'Riordan T. The political significance of local agenda 21: The early stages of some European experience.

The International Journal of Justice and Sustainability. 1996;1(1)

[43] Pieri C, editor. Baghdad 1921-1958. Reflections on history as a "strategy of vigilance". In: World Congress for Middle-Eastern Studies; 2005-06. Amman, Jordan: Al-Nashra; 2005 Available from: shttps://halshs.archivesouvertes.fr/halshs-00941214/document; https://halshs.archives-ouvertes.fr/ halshs-00941214/file/_3_PIERI-_2006_ BRIIFS.pdf

[44] Evans BM, McDonald F. In: Evans BM, Frank McDonald J, editors. Space, Place, Life: Learning from Place 1. Abingdon, Oxon: Routledge; 2011

[45] Chen H, Jia B, Lau B. Sustainable urban form for Chinese compact cities: Challenges of a rapid urbanized economy. Habitat International. 2008;32(1):28-40

[46] Lynch K. Good City Form. Cambridge, Mass, London: MIT Press; 1984

[47] Blunkett D. Practice Progress and Value-Learning Communities: Assessing the Value They Add. LCN Learning City Network - the UK Network; 1998

[48] Shamsuddin S, Ujang N. Making places: The role of attachment in creating the sense of place for traditional streets in Malaysia. Habitat International. 2008;32(3):399-409

[49] Gehl J, Svarre B. How to Study Public Life. USA: Island Press; 2013 



\title{
Urban Social Sustainability - Case Study; Gellerupparken-Denmark
}

\author{
Amjad Almusaed and Asaad Almssad
}

\begin{abstract}
Urban social sustainability represents a more specific part of urban development. Citizen involvement is a vital element of any future urban social development and helps to maintain the vision of human and diverse cities because it provides vibrant and sustainable cities in which everyone has a seat and can speak. Gellerupparken, as something new, also meets all five criteria for when an area is a ghetto during a given year. The criteria generally consist of income, ethnic origin, level of education, crime, and employment. The study's aim is to present an objective means, to the reactivation of a passive multicultural zone in Aarhus city of Denmark to integrate it in the social life city by using the appreciative inquiry method by an introduction of new city functions. The study will assume the effect of sustainability in an urban social area, in a case study using the application of the pedagogical method, namely, the "appreciative inquiry" method.
\end{abstract}

Keywords: urban social sustainability, attractive public space, space activation

\section{Introduction}

Developing sustainable cities is currently one of the greatest global challenges. Cities face a wide range of social, environmental, and economic challenges that require change. The majority of Western cities possess unique cultural and architectural qualities, strong social inclusion forces, and exceptional economic development opportunities. Cities are centers of knowledge and sources of growth and innovation [1]. As the population influx places new demands on the physical structures, residents, and city management, the need to think across disciplines and sectors arises. At this stage, the use of analytical interpretation is required, which is a sophisticated analysis that inputs evidence for all parameters involved in the investigation process [2]. The keynote speaker "Jan Gehl's" message was that human beings can only achieve sustainable urban development if we start with the people living in cities. A human being can build high-rise buildings with green roofs, green walls, and high-energy efficiency [3], but that does not necessarily mean that the cities are pleasant to live in [4]. Green sustainability, as a broad concept, must have a strong social element [5]. Additionally, Gehl pointed out that if many children reside in a big city-and you see them in the urban space-it is often an excellent city to live in, a livable city $[3,6]$. According to an article published by Emma Lauridsen, there are now 29 residential areas in Denmark that meet the new ghetto criteria, which is eight more than last year. Three of the areas are located in the municipality of Aarhus, which are the same as last year, namely, Gellerupparken or “Toveshøj, Bispehaven," and "Skovgårdsparken.” One of the 
new features of this year's ghetto list is that both Gellerupparken or “Toveshøj” and "Bispehaven" are on a whole new list of "hard ghettos." A hard ghetto area is defined as a residential area that has been on the ghetto list for the past 4 years. It also entails a requirement to submit a development plan by June 1 of the next year that shows how the residential area should meet the need to reduce the proportion of public housing to a maximum of $40 \%$ [7]. It is necessary to develop a concept for improving the formation of public spaces, taking into account the complexity of the influential factors. In scientific studies, only certain aspects of this problem are considered. The urban area is the territory where the interaction between space and the person takes place, where the person's spatial behavior is formed, and this largely depends on how the person relates to this place, whether it is emotionally attractive to him.

The city becomes not just buildings, roads, parks, fences, abandoned corners, water pipes, and cable networks, but it grows as an especial interaction among citizens, contacts, social relationships, direct, and indirect communication interactions [8]. Social sustainability revolves around the human factor as a crucial prerequisite for a sustainable city and a sustainable society. The government's sustainability strategy thus describes the concept in terms of everyone participating in social development and possessing real equal opportunities, regardless of background [9]. Focused and sustained work on social sustainability helps to ensure diversity, democracy, and equality in our cities. As urban settlements have grown, the visual environment has become more monotonous and typical (the country has been faced with the task of solving the housing problem). The quality of public space-its architecture, equipment, design, as well as its level of accessibility and openness to the different needs of the residents-has a direct impact on the number of users and the quality of life in the city $[9,10]$. Therefore, its features can affect residents' activation. To identify the relationship between the forms of activities favored by city residents and the features of public spaces in which they are undertaken, a binary classification has been made. The first approach divides activity spaces into formal and informal ones, while the second one categorizes the different needs of their users according to their age and physical abilities. Every effort should be made to integrate all groups, irrespective of their social and economic situation, age, gender, cultural background, and physical skills, and find a place for them in urban public spaces. Sports and recreation, thanks to the values they bring, can be a handy tool for social inclusion and integration. The design of physically activating public spaces should also constitute an expression of these values [11].

The current unsatisfactory ecological and esthetic state of many objects in the urban environment reduces the social efficiency of city spaces, which requires professional intervention, especially in the process of forming the subject-spatial environment of actively exploited public spaces [12]. They represent the nodes of the most significant social and communication activity of the population. Such spaces include, first of all, urban squares, which are quite diverse in their functional purpose. As the city develops, their existing spatial and spatial structure becomes less effective in terms of providing a comfortable, ecological environment with positive esthetic characteristics [13]. An urban area for people should be livable, safe, attractive, sustainable, and healthy [14]. This is a city where people often want to be on the street and spend time outside the home and office, where most residents can move freely on foot or by bicycle and other environmentally friendly vehicles, and where it is pleasant and comfortable to be at any time of the day. Classification and operative analysis are the leading instrumental procedures used to determine the critical thinking model, which places expectations into requests to detect whether a given right is factual or untrue [15]. Based on this concept, it is necessary to identify several criteria for a successful and high-quality public space and to lay the foundation of our research and future architectural projects: 
Urban Social Sustainability - Case Study; Gellerupparken-Denmark

DOI: http://dx.doi.org/10.5772/intechopen.93124

- Pedestrian friendliness

- Visual appeal

- Original atmosphere

- The appearance of positive emotions and desire to linger in visitors

- Sociality: orientation to different user groups, a variety of social groups, activities, modes of use, functions

- Open access for all, inclusiveness

- Rich symbolic content

Buildings are profane elements that give rise to social spaces, time as an "event" in the mythological sense. Therefore, space is not exclusively the physical extension but rather the sacred place in which the individual manifests and updates itself.

\subsection{Why is participative important?}

A participatory or participatory approach implies that experts in public spaces are architects, designers, and their end users, residents. All of them may have a different experience in using the place, habits, needs, and ideas about how this place should be, and these ideas do not always coincide with the vision of the designer. This raises some difficulties: it takes time and effort to determine how each space function, by whom and at what time of day it is in demand, what kind of people are there, and what their needs are and how they imagine the future of this space [16]. The collected data are analyzed, and project proposals are created on their basis. Despite the additional cost of time and resources, the participatory approach has several essential advantages. First, inclusion of the end user in the design process from the very beginning increases the sustainability of the project: it is more likely that people will feel a personal connection with the place and maintain it in good condition - this reduces the risk of vandalism. Second, the joint creative process helps people get to know each other, establish good neighborly relations, and form local communities $[17,18]$. Third, in joint design, its participants begin to better understand the decisions that are made; they have an understanding of how the object will be used. In the long run, such projects strengthen the personal connection of people with a city or district: when people know that the city is developing with their participation and taking into account their needs and interests and when they feel a part of the local community, their perception of the whole city changes for the better-activating public space by creating public space to be more attractive. Examples of attractive spaces can be amazing gardens, squares, and museums, as well as monumental heritage buildings, which attract the public through their history but also by what they represent in memory of the city. Unfortunately, however, aggressive or rather desolate spaces are found by the present researchers because of many buildings left in comparison, which are not renovated or not restored.

A sustainable city is socially linked by the fact that there are democratic spaces where people can meet, regardless of social, economic, and cultural backgrounds, and which provide the opportunity for development and accessibility for all citizens of the city [19]. When a city has many offerings for both everyday life and when something unusual happens, it becomes more vibrant and attractive-this can 
also help increase the quality of life of the citizens of the city. In addition, a socially sustainable city opens up the possibility that citizens' health is supported in the form of urban spaces designed for physical activity and socializing [20]. For residents, this can help improve health but also cohesion between people who might not otherwise meet. Concurrently, an urban and residential area must be perceived as sufficiently safe and attractive that there is a healthy and natural exchange with the surroundings and that different people want to visit, stay, and settle there. Social sustainability means creating the necessary framework in the city for vulnerable groups, both in the city space itself or in the form of hostels and housing for vulnerable groups [21]. The socially sustainable city prevents the exclusion of the city's communities and ensures that the foundations of social action for vulnerable citizens are present.

\section{Gellerupparken zone (case study)}

\subsection{Area description}

Gellerupparken is part of the large suburban carpet that surrounds old Aarhus. Its characteristics are the major roads that frame individual neighborhoods in the suburbs. The suburban environment is lost and looser, the orientation of the landscape is weak, and the sense of place is the same [22]. Gellerupparken is characterized by either having an arbitrary landscape between buildings or by having a landscape that is growing and is entirely out of proportion to the buildings. It appears as a densely packed landscape area with far too many small blind pockets and dark hooks. Figure 1 shows the location of Gellerupparken in Aarhus city.

\subsection{Integration of “Gellerupparken” on a large green area}

Human beings have always wanted to shape nature and to be surrounded by the elements of nature (trees, shrubs, grasses, rocks, water, etc.), to harmonize them and to integrate them into the created artificial environment, which has marked the culture and traditions of the people concerned [23]. Aarhus is the country's second largest city, representing a reliable and positively charged magnet for tourists and residents from all over the region, and it neither can nor should be changed, but Gellerupparken could develop into another positive flagship in the area. Today, Gellerupparken is highly dominated by housing, and there is not much to look for other than the residents. The residents, who have at least one reason to be in the area, are looking for more life and activity over a broad front. Despite the blocks

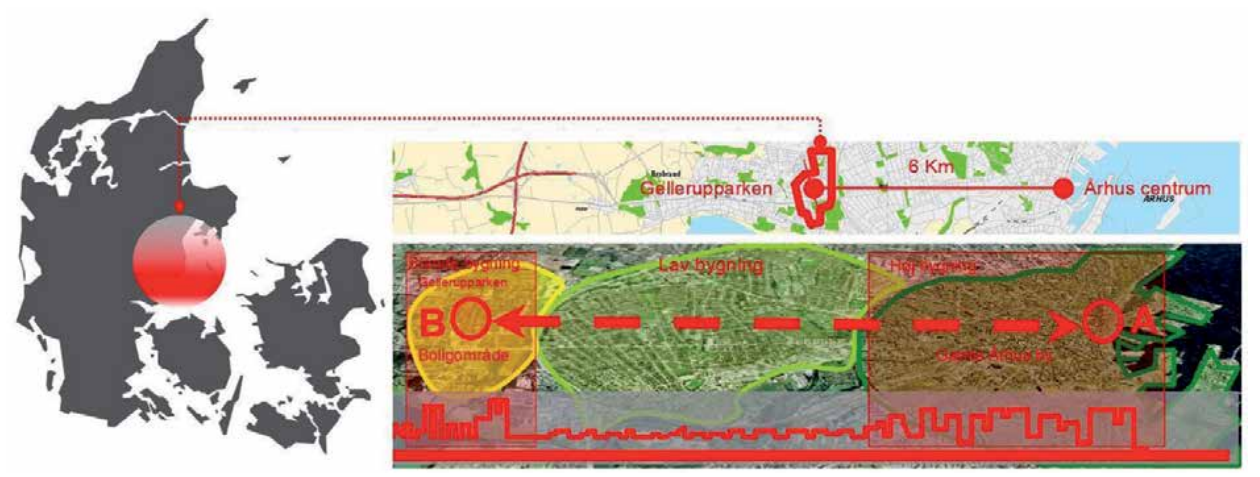

Figure 1.

Gellerupparken in Aarhus city and placing in Denmark. 
of flats, Gellerupparken and the surrounding area is a very scenic area with a lake (perhaps with an upcoming bathing beach) and hill scenery. There is a tremendous voluntary commitment and a wide range of different associations and organizations. Additionally, two large and very diverse shopping centers could be conceived into a larger urban life-oriented whole. However, most importantly, like other residential areas, Gellerupparken has the highest strength of being an area characterized by so many different nationalities, languages, ethnicities, cultures, and religions. Diversity and diversity seen as a resource are the area's distinctive features (see Figure 2). The potentials are thus presented to create an attractive district, where both a resident and a visitor can have many unique experiences.

\subsection{Gellerupparken: The area's many strengths_-The budding potentials}

Approximately 7000 people live in Gellerupparken alone and approximately 20,000 in the whole of Aarhus West, which corresponds to a medium-sized Danish city [23]. In cities of this population size, there are far more shops, education, entertainment and entertainment than in western Aarhus, and it is, therefore, reasonable to assume that there will be more urban-like activities in this area. Such development should not be seen as an attempt to compete with Aarhus, but the offers and activities in the Gellerupparken must represent a new and exciting addition to Aarhus. Gellerupparken must utilize its strength by being one of Denmark's largest multiethnic boroughs, and this distinctive character must be exploited and made a landmark. Among immigrants and refugees in general, there is a great desire to establish themselves as independent entrepreneurs, which is also the case in Gellerupparken, where there has been a surprisingly large amount of courage and creativity in terms of entrepreneurship. There is also a tendency for entrepreneurs in Gellerupparken and the surrounding area to start spreading across several business areas so that businesses other than pizzerias and green merchants are also established. It has also been proven that a strength of this area is its different ethnic background than Danish, which can facilitate beneficial collaborations with suppliers in the country of origin.
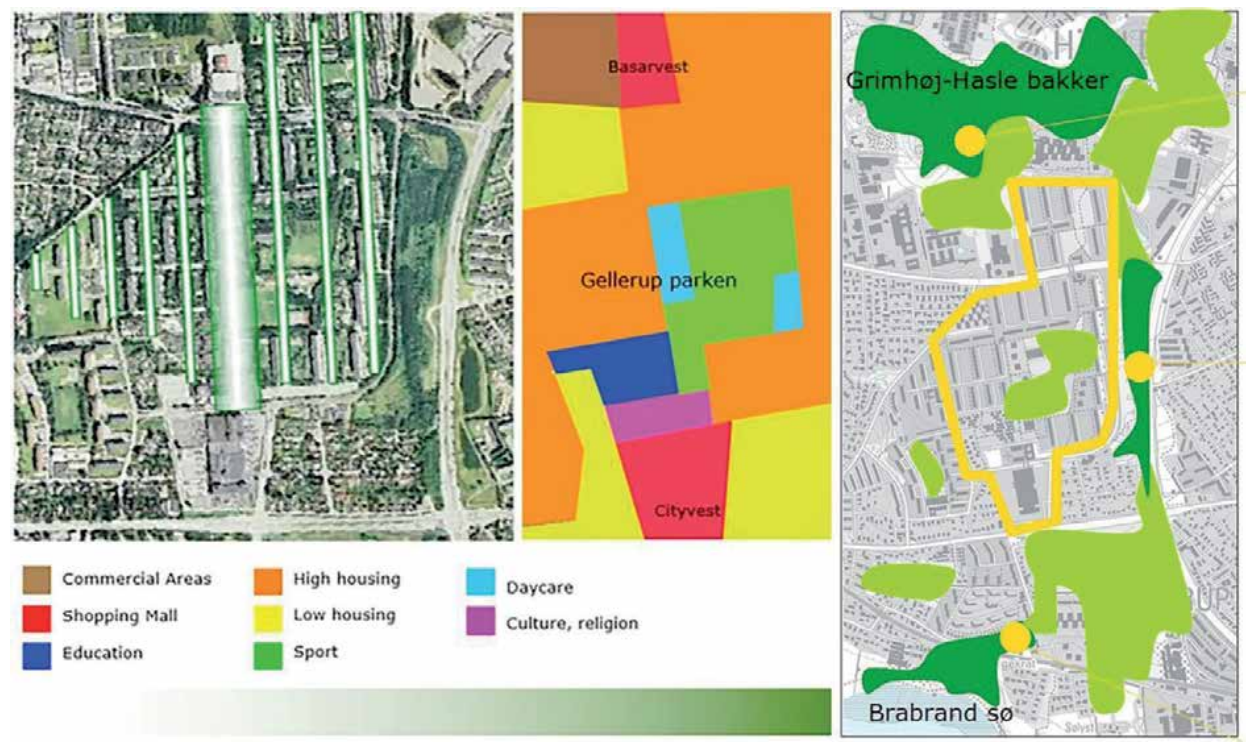

Figure 2.

Gellerupparken design, directions, functions, and scale. 


\section{Description of the problem}

It is essential to ensure social diversity in public residential areas so that citizens with economic, social or integration challenges do not concentrate to a large extent in specific areas or neighborhoods [24]. Therefore, efforts have been made for several years to ensure a better balance in the so-called exposed residential areas, where such imbalance is a reality. The intention of this process, through outreach, is to listen to how the civic groups representing the area believe that a citizen involvement process must take place, partly because they feel invited to have an opinion regarding this issue and partly so that they can see that they have a real impact on how a debate about urban development develops. The experience gained from this process is gathered in a recommendation for how a future process towards a citizen-involved process of urban development can look for Gellerupparken and its surrounding areas. The process must also result in a series of instructions for several specific projects that will be supported and with which people are willing to proceed. A significant factor for a successful strategy to improve the future of citizens in vulnerable residential areas is the involvement of local citizens and local anchoring of the process [25]. It is only possible to find the right strategy by asking the citizens, after which it is only possible to implement the strategy by continuing to involve, motivate, and support the local population. Therefore, it is essential for the implementation of improvements in the housing area that citizens become engaged and motivated to take responsibility for the process, a process that will be new to a large part of the citizens with different ethnic backgrounds in the area and therefore a process with significant challenges, which is very crucial for the effectiveness and sustainability of the change.

\section{The investigative method}

In recent years, in the public debate on urban development and citizen involvement, there seems to be growing doubt as to whether the efforts to date will adequately respond to the challenges that are increasingly faced by larger cities. The criticism herein often focuses on existing efforts being reactive in the sense that they typically focus on solving acute problems, whereby the area's resources are often ignored, and the long-term development perspective fades [26]. It is clear from this debate that this tradition need-/problem-based approach to urban development often has several unintended adverse side effects, whereby efforts often create clients rather than active citizens - thus increasing reliance on external assistance in the district. According to McKnight [27], development assistance based on external assistance is a central part of this negative spiral, because local institutions and organizations are thereby pacified and lose functionality, which means that the district gradually loses its power of action and attracts resourceful citizens. With this in mind, it is therefore essential in urban development to allow the district to revitalize itself "from the inside" through local institutions and organizations actively using their existing resources and anchoring in the area to create quality of life and increase the attractiveness of the area. In this context, this process must take place in an autonomous manner for which the area's institutions are responsible - thus assuming ownership_for its creation. From empirical results, it is a central and well-documented point [27]. The above information is a necessity if the desired development process is to achieve sustainability that goes beyond consultancy assistance. If this is to be successful, then the development process must use an optic with a radically different focus than the problem-oriented approach. In this situation, the resource-based approach to urban development 
(asset-based community development) is one of the most well-founded [26].

Suggestions have been proposed for a development methodology that addresses the above issues as well as potentials, such as the method developed by McKnight [27]. Based on comparative studies of urban development methodologies-and their success rates - the following starting point for urban development is employed:

Communities and boroughs can create development themselves by identifying and utilizing existing (but often unrecognized) resources in new ways. This process requires the borough's actors explicitly focus on finding — and using — the area's resources [26, 27].

Thus, according to [26], the resource-based approach to urban development can be summarized in the description below [28]:

- ABCD is an asset-based approach that uses methods to draw out strengths and successes in a community's shared history as its starting point for change (as in appreciative inquiry).

- Among all the assets that exist in the community, ABCD pays particular attention to the assets inherent in social relationships, as evidenced in formal and informal associations and networks (recognized in research on social capital).

- ABCD's community-driven approach is in keeping with the principles and practice of participatory approaches development where active participation and empowerment (and prevention of disempowerment) are the basis of practice.

- $\mathrm{ABCD}$ is a strategy directed towards sustainable economic development that is community-driven. The reference to community economic development theory is therefore relevant to ABCD strategy.

- $\mathrm{ABCD}$, as a strategy for sustainable economic development, relies on linkages between community-level actors and macrolevel actors in public and private sectors. In fostering these linkages, $\mathrm{ABCD}$ also fosters active citizenship engagement to ensure access to public goods and services and to ensure the accountability of local government. It, therefore, contributes to and benefits from a strengthened civil society.

\subsection{Appreciative inquiry model}

Practical work on urban development from this perspective is based on several methodologies that are defined based on the above basic thinking. In this context, a particularly useful tool must be highlighted, which exemplifies the above starting point and thus can be used in development processes to promote resource-based development. One method of involving and engaging the citizen is, according to the American example, to apply a method called appreciative inquiry. The strength of this approach is that it is based on existing resources and potentials. All areas have positive sides and potentials, but it is often necessary to tend to overlook them and focus on the problems instead. People will naturally feel far more committed and eager to take responsibility if they are met with recognition and an attitude that they are a resource rather than a problem. Simultaneously, an appreciative and curious study of local citizens' experiences and opinions about the area will encourage far more participation than a laid back expert attitude. The proposal for a strategy to improve exposed residential areas, therefore, derives solely from the ideas, wishes, and narratives of citizens who either live or work in the area. Citizens have been asked several times and in many different ways about their perception of the 
area and possible proposals for change in the future. No strategy has been adopted without the support of citizens, and it has always been possible to come up with amendments to both the primary strategy and the most concrete sub-proposals. Amendments, new ideas, and criticisms have been taken seriously and attempted to be incorporated. This approach has slowed down the process, but a human being cannot think that it can be avoided in any way-nor the future process.

Another aspect of the recognizable approach is that it encourages seeing opportunities, allowing the process participants to talk about hopes and dreams for the future. People's need to be recognized and heard, as well as the ability to imagine the best possible imaginable, releases a tremendous amount of energy when given room for it, an energy that is all too often lost in rapid decision-making and political power struggles. This brief presentation of the methodological approach is intended as part of the proposal for a strategy for the development of vulnerable residential areas. It is used extensively in Gellerupparken and other residential areas, and it is no doubt that an appreciative and positive approach will awaken people's desire to participate, which is an invaluable resource. Without citizens' involvement and local roots, development cannot be reversed. Additionally, as a basis for this answer, proposals for change lie in the establishment of close cooperation between book associations, business, and local authorities, which will be discussed in more detail later.

Appreciative inquiry (AI) — or friendly conversation —is a critical methodology in resource-based urban development. It is a transformative approach to change that focuses on collaboration and identifying and working with the positive aspects of organizations, or communities, rather than the problems [29]. This method is based on several research findings, all of which demonstrate that our notions about the future are mainly decisive for our present actions. Therefore, it is essential to focus on strengths and successes as a basis for development rather than problems and shortcomings [30]. What the appreciative approach seeks is to achieve the transformation of a culture from one that sees itself in largely negative terms, and moreover, is, therefore, inclined to become locked into its contrary construction of itself-to one that sees itself as having within it the capacity to enrich and enhance the quality of life of all its stakeholders-and therefore move towards this appreciative construction of itself [30]. AI as a development methodology is, thus, as illustrated below, in sharp contrast to traditional problem-/need-oriented perspectives in terms of the resource-oriented starting point. Table 1 shows the explicative board based on the "release recognition" model.

The world-renowned Imagine Chicago project (see: www.imaginechicago.org) is an inspiring example of how AI and the resource-based approach have been used to revitalize Chicago neighborhoods characterized by ghetto education through the

\begin{tabular}{|c|c|c|}
\hline & Problem and lack of thinking & Resource and value thinking \\
\hline Focus & $\begin{array}{l}\text { Attention to problems, errors, and } \\
\text { shortcomings }\end{array}$ & Attention to resources, values, and dreams \\
\hline Intention & To solve the problem & Creating the future \\
\hline Method & $\begin{array}{l}\text { - Problem identification } \\
\text { - Cause analysis } \\
\text { - Solutions } \\
\text { - Action plan }\end{array}$ & $\begin{array}{l}\text { - Identify the successful and valuable } \\
\text { - Creating images of a desirable future } \\
\text { - Create common images of an achievable } \\
\text { future } \\
\text { - Initiate the process to realize the time } \\
\text { picture }\end{array}$ \\
\hline
\end{tabular}

Table 1.

An explicative board based on the "release recognition" model. 
application of the above principles. The experience of this project, which exemplifies the resource-based approach, has attracted international attention and points to the efforts of the future. With the above starting point, innovative research and international experience seem to be promising with respect to working with citizeninvolving processes in Gellerupparken and the surrounding area. This means that we see citizen involvement as citizen-driven development processes. In this perspective, the successful citizen engagement process will have two significant benefits:

- In terms of yield, the process metaphorically described results in answers to important questions from the citizens of the area. Thus, the process makes a positive difference in the lives of citizens. Furthermore, this difference must be sufficiently significant that the citizens themselves will take responsibility for the continued sustainability of the result.

- Process wise: Through the process, the involved parties increase their acting competence and position, so that they are strengthened with respect to similar processes in the future.

This understanding is basically in harmony with the city of Aarhus model of citizen involvement:

1. Citizen involvement must be based on the values of the Aarhus municipality.

2. Citizen involvement is a mandatory consideration in the initial phase of a task.

3. Citizens have a minimum right to be heard.

4. If an existing plan is changed, it must state why the "agreement" is being changed.

5. Citizens must have real opportunities to participate.

6. The private involvement in the development of the municipality or local areas must be promoted.

7. Cooperation with councils, associations, and organizations must be maintained and developed.

8. Processes, methods, and professional competence must be continually evaluated and developed.

The understanding of citizen involvement on which this report is based can, based on the Aarhus model, be understood as an effort to explain and translate points 5-7 into a concrete basis for action. We strive to develop methods to create real citizen-driven processes, whereby, through interaction with local actors, we establish a self-sustaining practice that continuously promotes the development of local areas. This endeavor requires that, concerning the Aarhus model, we must perceive citizen involvement in a broader perspective. Generally, citizen involvement is perceived as a means of achieving a given content goal. However, this understanding does not include any focus on building the capacity of citizens to be able to handle similar challenges in the local area independently in the future. Ultimately, the development process itself does not then necessarily create more active citizens.

In contrast, development processes in which this aspect is not considered, as pointed out in the above section, entail significant risks for citizens to be positioned 
as clients. With this starting point, we, therefore, consider citizen involvement as a process with a dual objective; a result must be created that is an answer to an essential question of the citizens. Simultaneously, the process must develop the trading skills of the parties involved. This understanding is translated into the following procedure for adjacent writing.

\subsection{Development of action}

Initially, the process is aimed at engaging in dialog with the various actors who must be seen as part of the area's residents and associations. The goal here is to embrace as broadly as possible to ensure that no one is excluded from this new trust-building process. Our entry into these conversations is partly through existing networks and partly through outreach work. The purpose of the conversations is as follows:

A. Creating mutual trust, which in this context is understood as follows: the people to whom we talk should feel that we have a genuine interest in listening to what they have to say about the area and what dreams they have for the future.

B. They are creating and exploring opportunities for citizen involvement processes based on the good experiences of citizen involvement processes of resource persons ${ }^{1}$. As previously pointed out, this focus is essential to ensure that recommendations for future processes are based on structures and processes that have proven sustainable in the area rather than general normative directions.

To ensure these results, the conversations are structured as appreciating interviews. This implies that the focus of the conversation is focused on resources and success based on the assumption that there may be a significant trader's potential. We are investigating what works are doing well to be able to extend these processes even more in the future. With this starting point, the following interview guide is constructed, on which the interviews are based.

\subsection{Interview action guide}

What have you experienced contributing to creating successful citizen engagement processes?

- What was crucial to the success of the process?

- What resources contributed?

What have you experienced creating a process that people feel invited to join?

- What in the past has been particularly effective in getting residents to speak?

- How did you ensure that everyone experienced being heard?

- What have you experienced in creating a trust?

\footnotetext{
1 The term "resource person" is used to describe the interviewed persons. The designation emphasizes that these individuals have only been selected to participate because they constitute an essential resource in the area in terms of their knowledge of the area as well as their experience in citizen involvement processes.
} 
How can we use these good experiences to create successful citizen engagement processes in the future?

An integral part of the discussions is also an explicit focus on which actors and groups resource persons find important to involve in the process. In this way, the individual interview generates, so to speak, the next as we subsequently contact the said persons and groups and invite them to participate in the interviews. Alongside the interview process, two meetings are held with city representatives, which are also designed around the above structure. Finally, a joint day is held for citizens, associations and organizations in the Gellerupparken area.

\subsection{The data required}

In total, hundreds of qualitative interviews, as well as a group interview, have been conducted through the interview process. In the following section, the central themes from the qualitative interviews are presented. An interpretation of the conducted interviews is based on the themes below, on which the interviews were structured.

- Factors that help to create successful citizen engagement processes

- Factors that create a process that people feel invited to join

- From good experiences to citizen involvement processes in the future

\section{Factors that help to create successful citizen engagement processes}

Broadly speaking, two key themes from the experience of the resource persons seem to be crucial to the successful citizen engagement process. First and foremost, the subject of the process is concrete and relevant. Second, the process itself is completed with strong local anchorage in the area.

\subsection{A specific and relevant topic}

Throughout the interviews, it is pointed out that successful citizen engagement processes are characterized by their being perceived as concrete and relevant to the participants. This means that the topic is not abstract but is based on the daily lives and interests of the citizens. This point is reflected in the observation of the consistent emphasis that residents of the area come to meetings largely because of specific matters that interest them. Thus, the focus of successful processes is directed towards themes that have a significant influence on the daily life of the residents. The question in this context is, of course, what is contained in the specific and relevant process. This question seems to be answered from another perspective. Citizens will greatly assess participation in the process based on whether they can acquire a real, visible, and noticeable benefit from it in their daily lives. The following topics are, by extension, highlighted as particularly appealing:

- Health: How can we live healthily?

- Family: How can we create well-functioning families?

- Leisure time: How can we ensure that children and young people have active leisure time?

- Relationships: How can we create new relationships with each other? 
To conclude the interview process, a joint day was held in the Nordgård School hall. Citizens, associations, networks, and organizations in the area were invited. During the day, the following questions were examined: What important questions about the area will help us get closer to our hopes and dreams for the area, are we concerned? The above focus on "the close" topics are supported here by the questions raised by the participants in a future day as crucial for the future of Gellerupparken.

\subsection{A process of rooting in the area}

In addition to the abovementioned thematic themes, the interviewees pointed to several procedural issues that they perceived as crucial for the initiated processes to gain a foothold in the area. Here, the interviewees point to the following factors as crucial:

- That is, a particular desire is taken from the citizens. Several of the interviewees emphasized that it is essential that the specific wishes of the citizens trigger the initiated processes. Throughout the process, this means that the citizens are willing to take ownership of the process. This is highlighted as particularly important as the interviewees feel that external actors are continually seeking to initiate a large number of projects in the area. The consequences of these well-intentioned projects are general project fatigue, and local players in the area lose the courage to engage.

- As the resources of the citizens are providing a basis, as an essential success factor, it is emphasized that the strengths of the citizens are based on whether they feel at home. People would very much like to participate and contribute if they are allowed to use the skills they possess.

- Existing structures based on existing structures. You gain a lot by connecting to existing structures in the area. It is ethnic associations and formal and informal networks that form an essential part of the social structure of the area. The involvement of these structures is crucial, as the networks partly possess significant resources that can be used to create development in the area. Furthermore, networks have more or less influence as opinion-makers. The assumption of starting from existing structures also highlights the advantageous links to existing activities and offers in this area as well as places where people are already arriving.

\section{Factors that create a process that people feel invited to join}

In citizen engagement processes, it is essential that people have the experience that they are welcome to participate as well as experience that their participation is significant. This phenomenon is reflected in the following section, where resource persons point to the following factors as crucial.

\subsection{Knowledge required for the investigation process}

To ensure participation in the citizen involvement processes, the citizens must be aware of the possibility of participation [24]. In this context, the interviewees focus on several areas they perceive as crucial for ensuring connection to the respective processes. In general, written communication is emphasized only as an enterprise when it is linked to local resources. This can be, for example, through pamphlets distributed 
by staff at the health and local center or library. Likewise, the residential magazine, The Spellbook, can be highlighted as an information channel that, in the interviewees' opinion, reaches out to many residents and creates a dialog. Finally, there is also good experience in communicating through notices in the rises. Additionally, immigrant television is mentioned as a medium that has an impact on the area. With the above exceptions, the interviewees' experiences fundamentally deviate from the use of broadly written communication as the core communication strategy. This means that it is generally considered most productive to avoid traditional broadcasts of information leaflets, etc. In line with this assertion, the use of quantitative questionnaires is also not recommended. Conversely, it is emphasized that successful communication in the area requires time and effort over some time so that people can adjust to any eventuality. Interviewees' experiences indicate that using direct face-to-face contact is most effective. This is best established by seeking out key people and spreading the message through the word-of-mouth method of their network. The same method applies to established associations and institutions in the area, which already have citizens' trust. In addition to oral communication through the area's many formal and informal networks, direct outreach work is also highlighted as active. This can be done by tuning doorbells, talking to people in their hallways, as well as by making themselves visible/known in the local area and making face-to-face contact with people, e.g., by standing in front of the City West or Bazaar West. This direct personal contact is experienced as alpha and omega for establishing trust in communication. It is the experience of the resource persons that the residents appreciate this direct contact and significantly want to participate in the dialog when it takes place in this way. The value of personal contact is also reflected in the fact that several resource persons point out how several associations have been successful in reaching out to people rather than vice versa. For example, table tennis has been set up in the library, and footballs have been brought into the community hall.

\subsection{A progressive investigate process (everyone is heard)}

An essential theme about citizen engagement processes is whether the citizens feel invited to participate in them. A key prerequisite for this is, according to the resource persons, that citizens understand what the process is about. Here, direct contact also proves crucial. Concerning activities for young people under the auspices of the association, this means in particular that the actors must assume some form of a supervisory role. The guidance counselor takes the young ones by the hand and accompanies them to the association for the first time. The parents are invited; they are presented to the coach and the association. The possibilities that exist in the associations, how an association works, and the applicable rules are explained so there is no fear of the unknown. In this context, the importance of the direct meeting between the association and the young person is again emphasized with a focus on the concrete benefits of being active in associations. Concerning any language barriers, it is pointed out that the use of interpreters is a significant factor that enables the participation of groups of citizens who have difficulties with Danish. This institution allows the involvement of people who would otherwise have said nothing. Furthermore, good experiences with the involvement of bilingual resource persons with immigrant backgrounds are highlighted as necessary for contact with citizens. They are good at outreach and have their fingers on the pulse of what is occurring.

Part of the strategy is to transform some homes into different types of occupations. For example, the ground floor of a residential look could be arranged for small shops, cafes, or workshops, which may create some new jobs. However, first and foremost, it will soften the massive housing block and create a whole new social life (see Figure 3). Another way in which the housing blocks could be used 


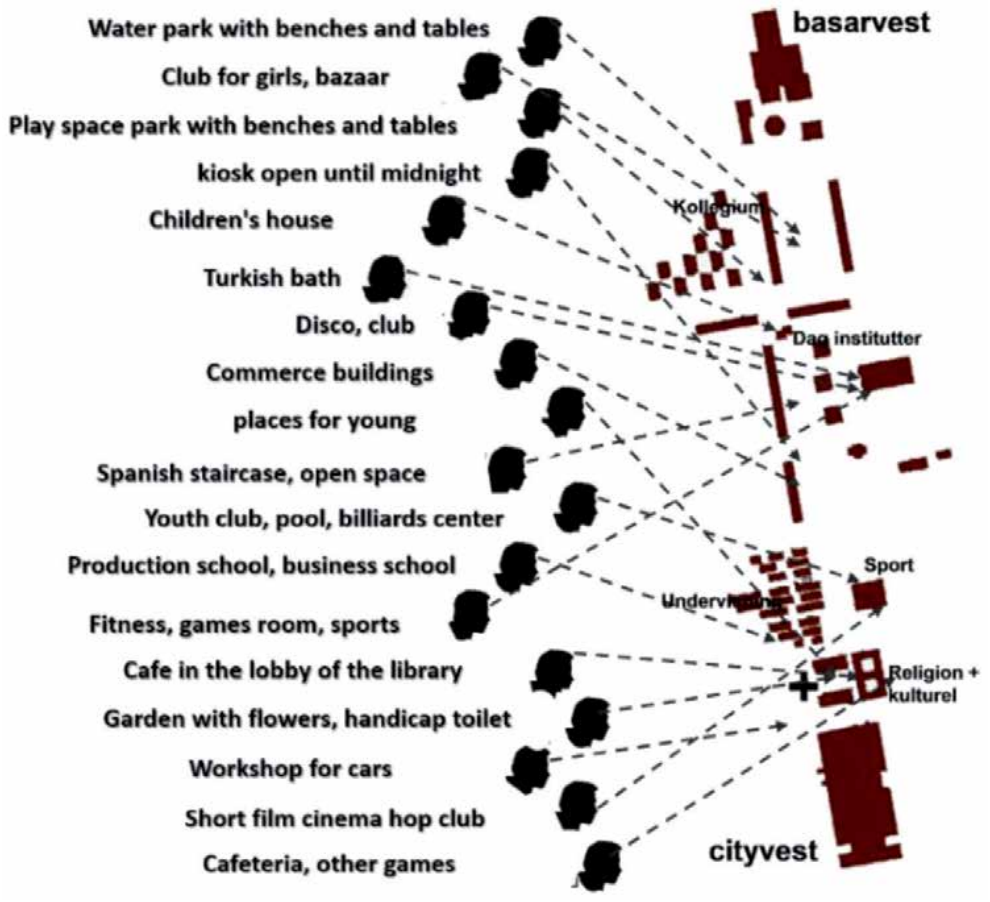

Figure 3.

Concrete ideas of inhabitants with indication of the potential position.

to attract other citizens is to furnish luxury apartments or hotel rooms on the upper floors with views of the city and the lake. In the long term, luxury holiday stays in Gellerupparken could be arranged with bathing and sailing on Lake Brabrand, as well as food and culture from all over the world. The idea of making a hotel in Gellerupparken has met with great optimism from both the "Brabrand Business Association" and the "Brabrand Housing Association.” There are several larger companies in the area, which also have branches and employees from many other countries. These companies could benefit significantly from the proximity of a high standard hotel with a burgeoning international business and research environment.

\subsection{Confidence in the process}

Resource people emphasize, in light of the above, that it is essential that citizens have the necessary confidence in the process. In this context, this can be observed as the belief that the process ultimately results in something good. The most important factor for gaining the trust of citizens in the area is by showing that, through their dedicated work, you are passionate about doing good for the people.

\section{Results}

\subsection{An attractive Gellerupparken district by activating the urban area}

Residents from the urban zone desire more opportunities for activities and social gathering, especially in the evening hours, when Bazar West and City Vest are closed. These two very different shopping centers provide the framework for a large part of the social life in the district. The requirements are as follows: 
Urban Social Sustainability - Case Study; Gellerupparken-Denmark

DOI: http://dx.doi.org/10.5772/intechopen.93124

- A pedestrian street in the middle of Gellerupparken

- Many enjoyable activities for the citizens in the area

- Gain better knowledge and more relationships with outside citizens

Urban zones evolved through dialog in several different contexts. They must have the courage to dream and see opportunities: a strategy to control and regulate citizens' opportunities to settle wherever they want. Through physical and social changes in the residential areas, which build on the citizens own ideas and commitment, the residential areas must be changed so that they become better places to live and move to both for residents and others. Public spaces are also useful as sleeping areas because they create new scenarios for spending time in the area, make it multifunctional, and make living there more intense and exciting. To solve the problem of alienation, the dullness and uniformity of the urban environment must be addressed by saturating it with colors, events, and emotions, creating places for communication and interaction with others and thereby helping to expand the network of acquaintances among neighbors. Thus, instead of a city for cars, it must assume a new understanding like a city for people. Additionally, public spaces solve the monocentric problem: when there are leisure opportunities right next to the house, there is no need to search for them in the city center. Simultaneously, it attracts the interest of residents of other parts of the city and tourists to the district, subsequently attracting investments in the form of small businesses. The idea is to transform the requirement for a functional space into an attractive and activate urban space, where the following table shows the meaning of the two concepts (see Table 2).

\subsection{New urban creation by the courage to dream and comprehend opportunities}

In Denmark, there is a particular risk that increasing population segregation will have severe consequences for the development of society. Some residential areas have such high concentrations of contact beneficiaries and people with ethnic minority backgrounds that they are almost small isolated communities. A strategy to reverse this tendency may, in various ways, be an attempt to control and regulate citizens' opportunities to settle wherever they want. This strategy will, of course, be able to change a certain percentage of the population composition in the exposed housing areas, but for the many children and young people who will continue to grow up without knowing any ethnic Danes, without knowing someone who has a Danish education and perhaps without knowing anyone who has had a job for a long time, this strategy will not suffice. Children and young people, who make up

\begin{tabular}{ll}
\hline Attractive urban space & Functional urban space \\
\hline I like public spaces in Gellerupparken & I feel safe \\
\hline It is so beautiful & I can find the way easily \\
\hline It excites me & I can use urban furniture safely \\
\hline It relaxes me & The urban open spaces are excellent \\
\hline I feel exactly that I am in my home & I can enjoy my time in green areas \\
\hline The city gives me a good temperament & I can access all the spaces in a wheelchair \\
\hline
\end{tabular}

Table 2.

The different understandings of functional and attractive urban spaces. 
approximately $40 \%$ of the residents in the exposed housing areas, need to be a focus when designing a strategy against ghetto isolation. These many children and young people must feel that Danish society takes them and their future seriously and wants to give them more than a hand in their efforts to become better at Danish, attain an education and secure a job. Through physical and social changes in the residential areas, which are based on the citizens' ideas and commitment, the residential areas must be changed so that they become better places to live and move for both residents and others. Based on stories and ideas from the citizens of Gellerupparken, this chapter will present a strategy to improve the future of residential areas, which aims to make Gellerupparken an attractive district for the people who live, work, and move into the area and for all others. Outside people may never have been to Gellerupparken but nevertheless have a negative image of the residential area. For a long time, our group has worked and stayed in the area and talked to many of the area's residents and fire souls. The principal idea is to exert a determined effort to make the residential area attractive neighborhoods with far more activities and functions, which are based as much as possible on the area's distinctive character and the citizens' initiative. Researchers believe that this strategy will positively impact residents' everyday lives and views of themselves, but it is equally important that the neighbors of Gellerupparken and all other citizens in the area will observe a changed and attractive neighborhood. BL has already shown an interest in investing in the transformation of housing into, for example, commercial premises, public service functions, or cultural purposes. In this chapter some of the suggestions will be presented received by the research group from the citizens of Gellerupparken concerning how to create more urban life in the residential area. A strategy for improving exposed residential areas must be broad and multifaceted, but it must simultaneously also be carried out in the right way to obtain the best possible effect. It must be believed that it is essential to examine the resources and positive aspects of the residential areas and allow them to serve as the basis for a process of change.

\subsection{New city life in the residential area}

The exposed residential areas are typically located just outside major cities: cities with lots of life, rides, functions, activity, and diversity. Many people are attracted to the city in connection with either work or leisure. They meet in the city, get to know new people, have fun relaxing, or take advantage of the city's numerous opportunities for shopping, education, and work, among others, and the existing vegetation, geology, and topography all engage in recreating a part of a unique microclimate for every site [31]. It is in the city you are social and show who you are. In an area where there is nothing but housing and very few city's features and opportunities, a man is private, himself, and has no reason to leave home unless it is to leave the area. Figure 4 embodies an architect vision of creation activating areas in the north part of "Gellerupparken." This is where inhabitants spend their free time but typically not with new people.

By drawing inspiration from the pulse, energy, and life of the city, residential areas can be made more attractive and given an identity that will affect both the residents and citizens living nearby. It is far from only the commercial part of the city, which is interesting and which can create positive development as a concept [32]. An increasing number of educational institutions, culture, and arts, as well as alternative venues and social spaces adapted to different age groups, genders, and interests must also be wholeheartedly devoted. How can it be, for example, that in Aarhus you will find cafes that make money by standing out from the crowd with hookahs and Persian rugs? In many residential areas with a very diverse resident mix, much more can be done to create a different atmosphere of security and togetherness 
derived from the residents' own countries of origin. For example, a coffee shop could be made with coffee and tea from all over the world (see Figure 5).

The city's many spaces in the form of parks and squares provide intensity and security that is lacking in the residential areas, where there is often too much space between blocks because nothing is invited to stay. The whole city needs to be brought into play, not just the demarcated residential area. The residential areas must be opened up both physically and mentally to become attractive, welcoming and part of a larger whole. The residential area must be able to offer more than just one dwelling. The features and opportunities must be made visible and make the residential area a place where citizens of the city center and other suburbs can also experience something different and exciting (see Figure 6).

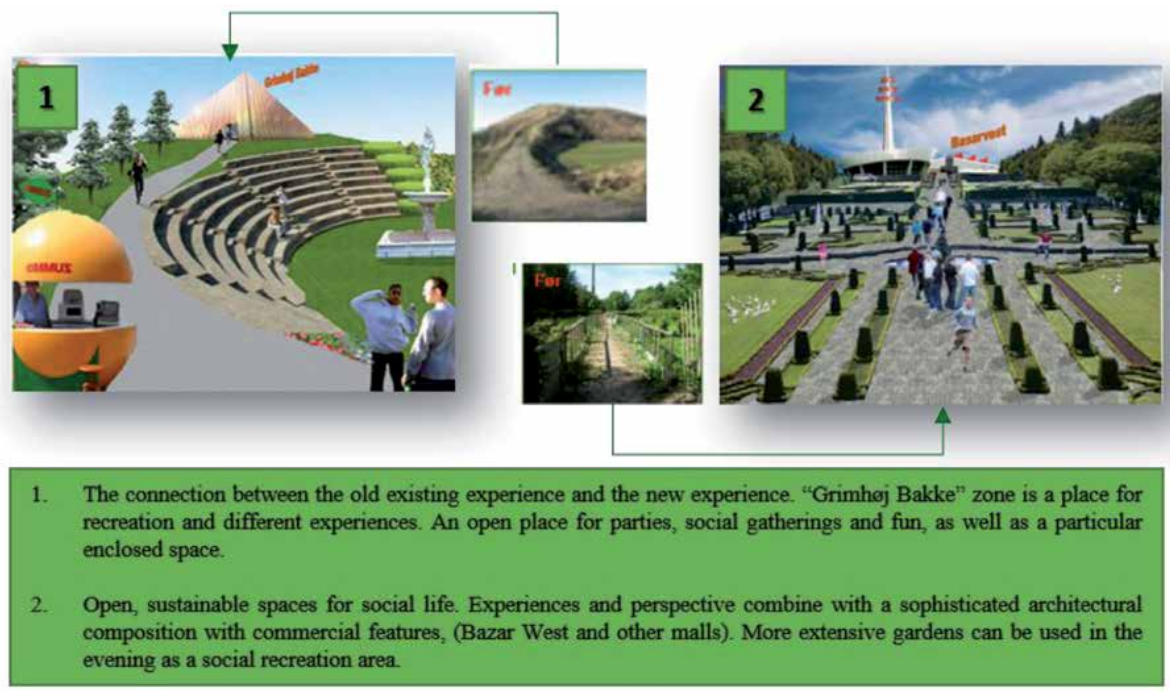

Figure 4.

An architect's imagination of creation activating areas in the north part of "Gellerupparken."

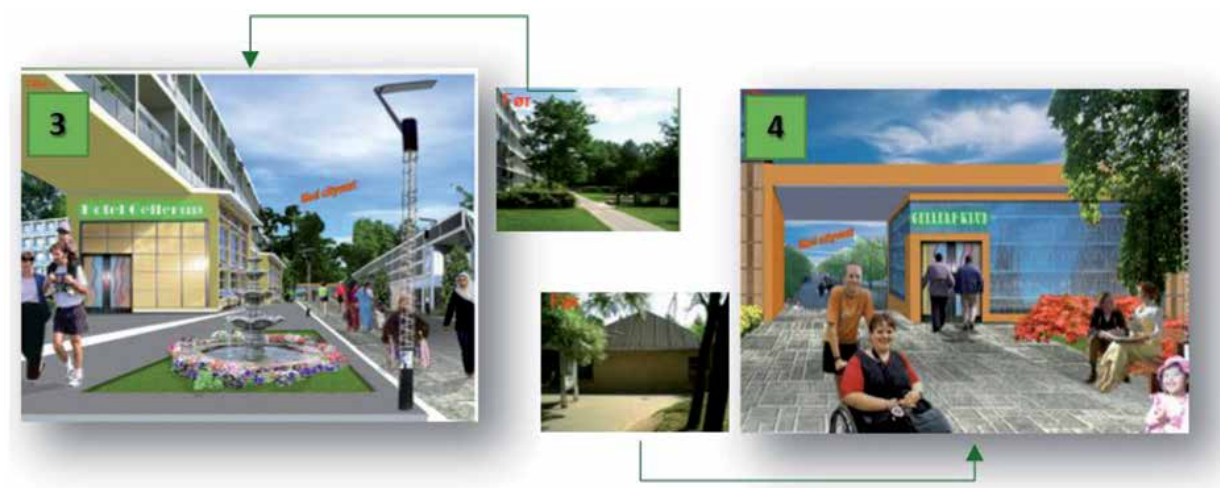

3. The connection between pedestrian zone and green open space. The area opens with a high functional corridor and invites, for example, tourists to an exciting stroll. The walk-through can house tourist functions and administrative buildings while also serving as a transitional space between the pedestrian street facing the city vest and the green recreation area leading to the Bazaar West.

4. Transit rooms for young people. Here they can meet and form social communities, a meeting place for youth with new opportunities and creative ideas. Here the stairs lead to City West via the pedestrian zone.

Figure 5.

An architect's imagination of creation activating areas in the central part of "Gellerupparken." 


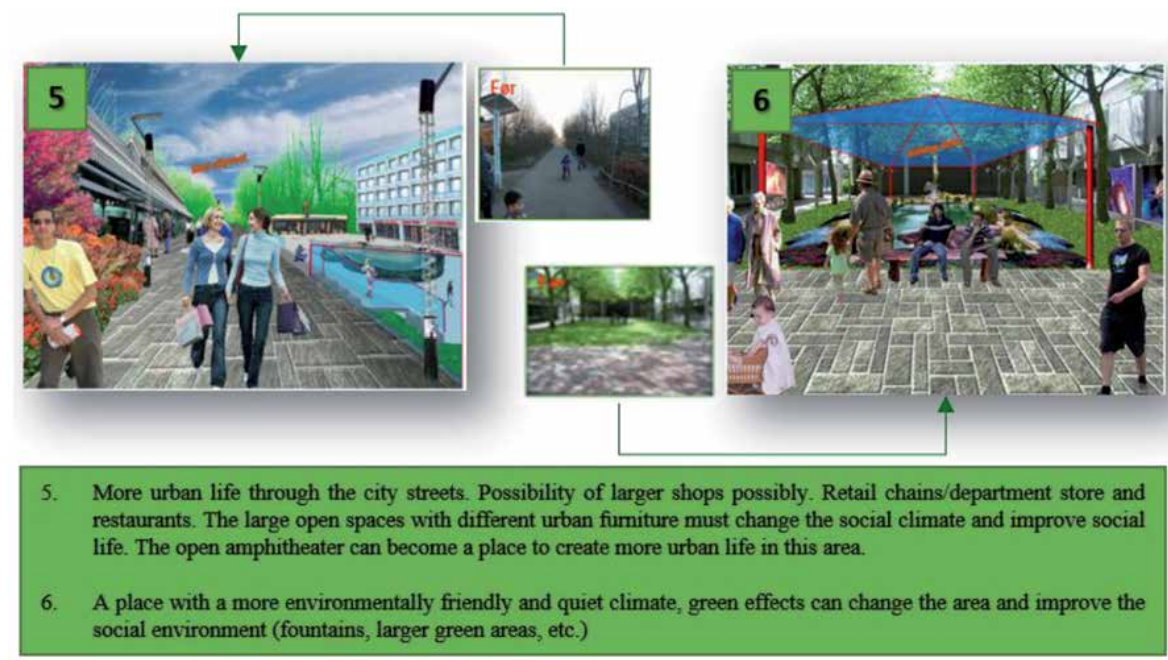

Figure 6.

An architect's imagination of creation activating areas in the significant part of "Gellerupparken."

Diversity and diversity are and will become even more of the future's most valuable resources and potentials for development and innovation. Companies that live by innovation know that a mixed staff is crucial to the company's ability to think in new and creative ways. In residential areas with a more significant proportion of citizens with different backgrounds than Danish, there is excellent potential for establishing networks for the development of new ideas. In this context, devising several specific suggestions on how to create more urban life in residential areas is required. This will be based on Gellerupparken and the opportunities for change offered in this area.

\subsection{New “Gellerupparken” pedestrian axis with attractive urban spaces}

There is a desire from several local citizens, housing, and business associations for more opportunities for activities and social interactions, especially in the evening hours when Bazar West and City West are closed. These two very different shopping centers provide the framework for much of the social life in the district, but after 10 p.m., they are closed. When the centers close, it is almost impossible to just buy a cup of coffee without having to go to Aarhus C. An obvious place for these city life activities is on the stretch between City West and Bazar West, where there is already a well-traveled footpath, but another location could also provide the same result. These thoughts of more urban life have led to the idea of developing a pedestrian street in the middle of Gellerupparken, which on the one hand can create life and activity for the citizens of the area, but on the other hand, it can attract people from the outside. In this way, there are several enjoyable activities available to the citizens of the area, which is especially important in the evening hours, where for many people there is a kind of void. Furthermore, it will be possible for citizens in the area to gain better knowledge and additional relationships with outside citizens and vice versa. As the idea has evolved through dialog in several different contexts, a working group has emerged that is still growing. In particular, some voluntary architects have shown great interest, and they have been of great help in the idea of development and visualization of the group's and citizens' proposals for urban development. The citizens who have been presented with the idea have welcomed it and have shown a great desire to contribute their suggestions and wishes. The urban area is not comparable to the area in Aarhus. It is more about creating a basis for life and security, squares, squares, shops, and cafes in selected sections, perhaps a concept 
area, association rooms, workshops, and institutions, among others. The proposal is intended as a holistic and pervasive effort over a long period, bringing citizens, housing associations, local associations, business, and public bodies together, with the common goal of creating more urban life both physically and socially. However, it is also an obvious opportunity to start with something slightly smaller and perhaps to bet on one of the following concrete proposals. Green open spaces promote a sustainable development process [33]. In this area, the elderly and the young can meet and get to know each other better. Together, they can harness the potential of the area. Moreover, a hub, a city street, can be established. Around this are placed several functions (public and private). These features can be established and rented out on different terms. Our mission is to improve the business and social life of Gellerupparken, generate a more functional and urban area, and develop a more attractive connection along with the new Gellerupparken pedestrian axis.

A better connection between the two only commercial centers in the district could create a whole new area, where people from the more traditional Danish shopping center City West will feel more invited to experience more of the district and perhaps meet at a cafe midway with some of the residents or other merchants from the more Middle Eastern Inspired Bazar West (see Figure 7). This shopping center is seen as a way in which the area's closure can be broken. Some traffic already exists on the path between the two commercial centers, but more area needs to be opened up so that more outsiders acquire an interest in what is happening between the housing blocks. In addition to housing, there are several other features of the line that are proliferating and need more and new premises and facilities. There is a school, a sports hall, a local center, a resident's house, and a library, which has already been expanded with numerous side features such as health information with midwives and dentists, public information, a job corner, and a contact point for young people, among others. Furthermore, in the area around the bazaar, there are
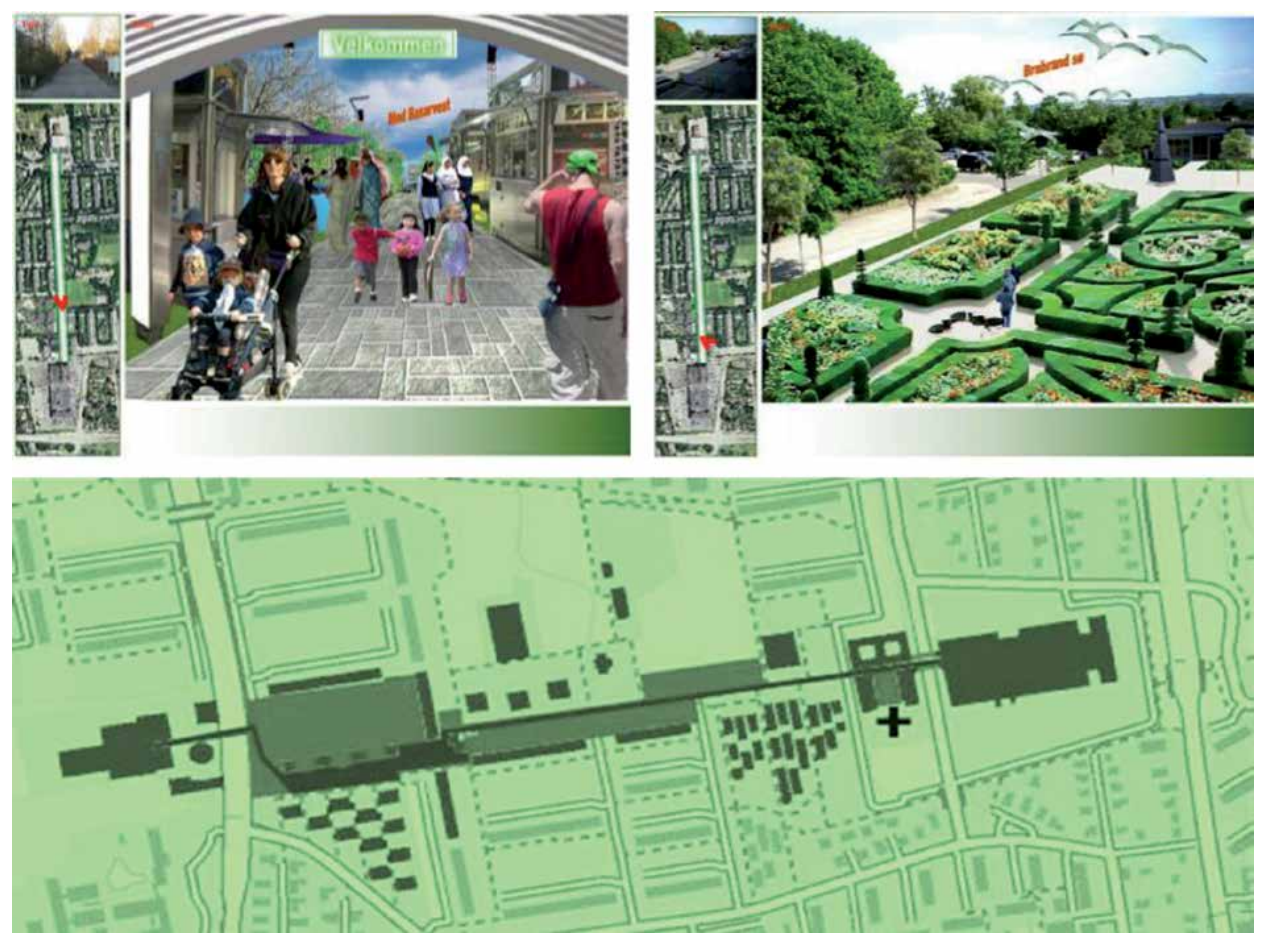

Figure 7.

An overview of a new pedestrian axis with open activity space potentials. 
a large number of companies with a total of approximately 4000 employees. This business area has the potential to develop in the future, and more exciting urban life could contribute positively to this development. There are endless opportunities and synergies in creating a common strategy for residential, commercial, and urban areas. Here, a small selection of the wishes and ideas that have emerged in dialog with the citizens is presented. There is broad support for establishing several places with the opportunity for friendly and entertaining leisure activities. The appendices present the answers to this question, illustrating the opportunities in the area and encourage people to dream and think differently.

\subsection{New educational offerings in the residential area}

Another part of the strategy is to place both existing and new public functions in the area so that more people who do not live in the area enter the area daily, such as educational institutions.

One of the main reasons many of the residents of vulnerable residential areas do not have a job is that they have no education or leave school very early. Some explanations for the lack of education are that the young people in vulnerable housing areas lack knowledge about the available modes of education and someone to tell them what it is like to study. Many young people do not know anyone with a more extended education and, therefore, do not have anyone to ask for advice. Education becomes something foreign and unknown. When neither family nor friends have experience with the education system, it is difficult for the young person to hold onto an education in which everything is foreign and new. It is very likely to open up a new group of young people in education if they can choose the student life without having to altogether leave the safe and familiar environment in the housing area. This phenomenon also applies to a host of other public functions. However, it must be pointed out that further research of the subject is required to answer whether integration is improved by allowing residents in the exposed housing areas to stay more within the area-some researchers will think the opposite.

\subsubsection{Why not try it out?}

The research, therefore, proposes that several relevant educational institutions can be placed in residential areas, thereby increasing young people's knowledge of education and reducing fear. One could imagine many forms of education that could be advantageously placed in exposed residential areas. In particular, there are new opportunities in investing in programs that have an international character. It could be an international high school specializing in languages and foreign cultures. One could also imagine that a department of the School of Business for International Trade, Export, and Entrepreneurship could find a new target group in Gellerupparken.

\section{Prospects for the future}

First and foremost, it is expected that the citizens of residential areas will benefit from a strategy that aims for more urban life, as it will be more interesting to live in a neighborhood with more amenities and a more expansive social life. Next, the place identity will change so that citizens acquire a more favorable impression of their area. In the longer term, there is tremendous potential in making residential areas such as Gellerupparken a neighborhood with attractive offers for residents, visitors, and tourists, on the one hand, and students, researchers, and business, on the other hand. The greater urban life created in Gellerupparken can make it a gathering point 


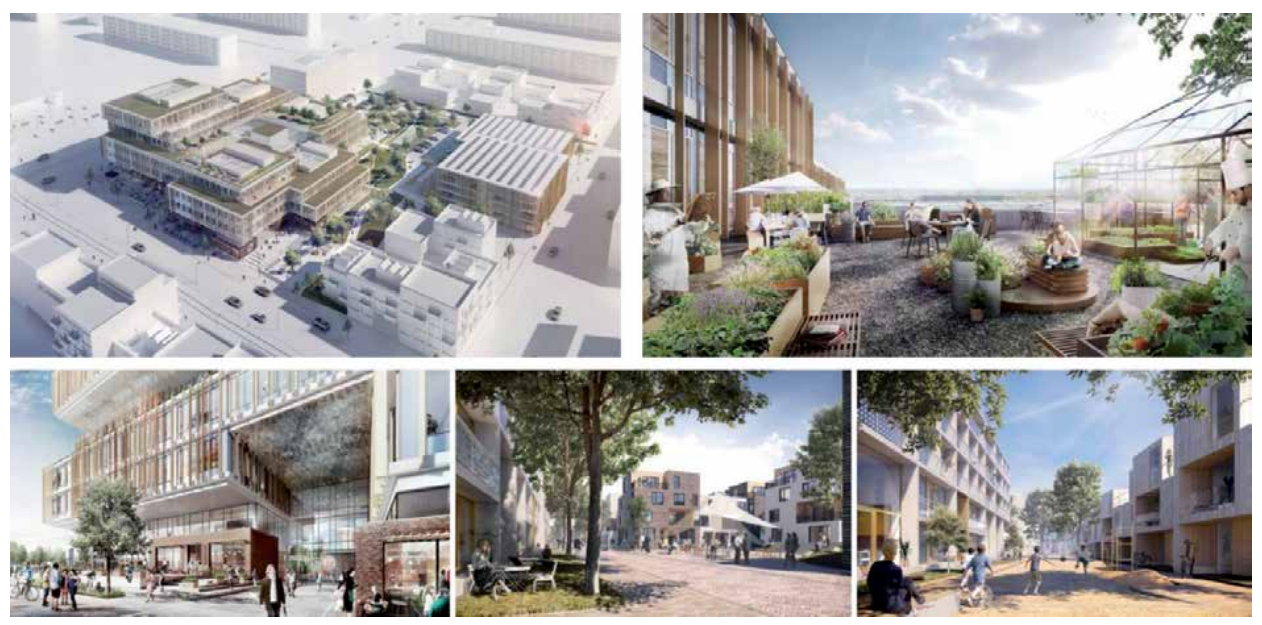

Figure 8.

Views of Gellerupparken imagined by a group of architect companies.

in Denmark for trade and exchange abroad. In connection with the business park and an upcoming hotel for business travelers, a particularly attractive college could be implemented, focusing mainly on international students. It is required to envision an environment where companies, educational institutions, business associations, and housing associations work together to create several exciting educational and internships across all nationalities and utilize the many contacts it will provide to the world. Much can be done to create more favorable conditions for businesses and educators in the area, including various kinds of modern facilities such as suitable cheap premises, IT, and quick access to the highway [34]. Additionally, companies could assume a particular form of the social contract, where, for example, the housing association provides premises, parking, canteen arrangement, and other features for the company to create new jobs or internships for citizens of the local area (see Figure 8). Furthermore, contracts can be made with students at colleges, which offer several benefits towards assuming greater social responsibility for the area by, for example, offering homework help, legal aid, help with job applications, etc. It is crucial to create positive stories about the district, highlight the successes, and build on the area's unique characteristics and potentials, which in the long term will make Gellerupparken an attraction and thus give its citizens the pride that comes with living in an area that is known for something special.

Thus, an integrated approach to design is essential, which includes a detailed, comprehensive study of the territory; work in an interdisciplinary team consisting of architects, city planners, sociologists, anthropologists, and other specialists; and, finally, "participativeness" in the form of the participation of local residents in the research process and design, taking into account their interests and needs. The creation of an objective sustainable public space requires recognition of the significance of the space, such as follows:

- Space as practice: the most important side of Heidegger's specialty, of "beingin-the-world," is the practical one. Therefore, each individual is capable of producing spaces daily, depending on the concrete situations they encounter, culture, and predisposition [35].

- Space as a possibility: the hermeneutics of space developed by Heidegger in "Sein und Zeit" is an attempt to escape the classic alternative objective space/ subjective space. 
- Space as an event: depending on the activities it encompasses, the character of a public space can be changed-a place of revolts, place of ceremonies, place of democratic meeting, etc. [36].

- Space is considered to be the limited three-dimensional space in which all objects are located and in which all events take place.

\section{Conclusion}

An attractive public space becomes an essential issue in the city design process, where the requirement to create high-quality public spaces does not boil down to ordinary beautification, as is often understood by the city administration and developers. Based on qualitative interviews with resource persons in the area, the following themes can be highlighted as crucial for creating successful citizen engagement processes. Fundamentally, it is crucial for participation that the subject of the process is concrete and relevant. Here, it is the close things that count.

Furthermore, people must have the experience that they are welcome to participate as well as experience that their participation is significant. Resource people emphasize that, in light of the above, it is essential that citizens have the fundamental confidence that the process will lead to a real and noticeable result. Furthermore, emphasizing the resources of the citizens involved is a critical success factor. The resource persons consistently point out that these elements can be ensured by the process being rooted in the local structures and based on the area's resources. For such a goal to be realized in Gellerupparken, it will be essential to create a framework that ensures that actors in as well as outside the area are involved in resourcebased interaction with each other. The development of improvement courses for these parties is proposed to create a holistic and robust process in the area. These experiences indicate that, concerning the efforts of external teams, the focus shifts from the subject of the process to instead supporting the process itself. The ultimate goal is that the parties involved build up competencies that generally increase the area's capacity to independently create a development. The aim of this type of development process is thus to create a framework in which the local actors develop independent acting skills by working on themes that they find essential.

\section{Author details}

Amjad Almusaed $^{1 *}$ and Asaad Almssad ${ }^{2}$

1 Architectural Engineering Department, Jonkoping University, Sweden

2 Karlstad University, Sweden

*Address all correspondence to: a.amjad@archcrea-institute.org

IntechOpen

(C) 2020 The Author(s). Licensee IntechOpen. This chapter is distributed under the terms of the Creative Commons Attribution License (http://creativecommons.org/licenses/ by/3.0), which permits unrestricted use, distribution, and reproduction in any medium, provided the original work is properly cited. (cc) BY 


\section{References}

[1] Almusaed A, Almssad A. Introductory chapter: Overview of sustainable cities, theory and practices, sustainable cities. In: Almusaed A, Almssad A, editors. Authenticity, Ambition and Dream. London, UK: IntechOpen; 2018. DOI: 10.5772/ intechopen.82632

[2] Almusaeda A, Almssad A. Analytical interpretation of energy efficiency concepts in the housing design process from hot climate. Journal of Building Engineering. 2019;21:254-266

[3] Gehl J. From downfall to the renaissance of the life in public spaces. In: Fourth Annual Pedestrian Conference Proceedings. Washington, D.C.: U.S. Government Printing Office; 1984. pp. 219-227

[4] Gehl J. Cities for People. Washington/Covelo/London: Island Press; 2010. pp. 23-26

[5] Nicola D, Glen B, Sinéad P, Caroline B. The Social Dimension of Sustainable Development. United States: Wiley InterScience; 2011. DOI: 10.1002/SD.417. Available from: www. interscience.wiley.com

[6] Aleksandra D, Thanos V, Viera J. Liveable open public space-From flaneur to cyborg. In: CyberParks-The Interface between People, Places and Technology. London, UK: Springer Open; 2019. pp. 38-49

[7] Lauridsen EK. NY liste: Her er Aarhus' almindelige og hårde ghettoområder. Stiftedetiderne. 2018

[8] Almusaed A, Almssad A.

Introductory chapter: Housing policy matters. In: Almusaed A, Almssad A, editors. Housing. London, UK: IntechOpen; 2018. DOI: 10.5772/ intechopen.81622. Available from: https://www.intechopen.com/books/ housing/introductory-chapter-housingpolicy-matters

[9] Cuthill M. Strengthening the 'Social' in Sustainable Development: Developing a Conceptual Framework for Social Sustainability in a Rapid Growth Region in Australia. United States: Wiley online; 2009

[10] Bounds M. Urban Social Theory: City, Self, and Society. South Melbourne (VIC): Oxford University Press; 2004

[11] Kostrzewska M. Activity in urban environment. In: Kostrzewska M, editor. 2017 IOP Conference Series: Materials Science and Engineering. Vol. 245. 2017. p. 052074

[12] Guerrero AM, et al. Achieving the promise of integration in socialecological research: A review and prospectus. Ecology and Society. 2018;23(3):38. DOI: 10.5751/ ES-10232-230338

[13] Keeler B et al. Social-ecological and technological factors moderate the value of urban nature. Nature Sustainability. 2019;2:29-38

[14] Giebler JV, Liedtke C, Wallbaum H, Schaller S. Accounting for the social dimension of sustainability: Experiences from the biotechnology industry.

Business Strategy and the Environment. 2006;15:334-346

[15] Almusaed A, Almssad A.

Environmental reply to vernacular habitat conformation from a vast area of Scandinavia. Renewable and Sustainable Energy Reviews. 2015;48:825-834

[16] Savini F, Aalbers MB. The de-contextualization of land use planning through financialisation: Urban redevelopment in Milan. European Urban and Regional Studies. 2016;23(4):878-894 
[17] Watson S. City Publics: The (Dis) Enchantments of Urban Encounters. London: Routledge; 2006

[18] Pugalis L, Bentley G. Place-based development strategies: Possibilities, dilemmas and ongoing debates. Local Economy. 2014;29(4-5):561-572

[19] Islam B, Chaham A, Nadia F. Towards smart, sustainable cities: A review of the role digital citizen participation could play in advancing social sustainability. Sustainable Cities and Society. 2019;50:10162

[20] Zhou H et al. Social inequalities in neighborhood visual walkability: Using street view imagery and deep learning technologies to facilitate healthy city planning. Sustainable Cities and Society. 2019;50:101605

[21] Burton E. The compact city: Just or just compact? A preliminary analysis. Urban Studies. 2000;37(11):1969-2001

[22] Stephenson J. The cultural value model: An integrated approach to values in landscapes. Landscape and Urban Planning. 2008;84(2):127-139

[23] Almusaed A. Introductory chapter: A general reading process on landscape architecture, landscape architecture. In: Almusaed A, editor. The Sense of Places, Models and Applications. London, UK: IntechOpen; 2018. DOI: 10.5772/ intechopen.77971. Available from: https://www.intechopen.com/books/ landscape-architecture-the-senseof-places-models-and-applications/ introductory-chapter-a-generalreading-process-on-landscapearchitecture

[24] Van Loon, J., S. Oosterlynck and M.B. Aalbers (2018) Governing Urban Development in the Low Countries. United States: SAGE Journals

[25] Ferilli G, Sacco PL, Tavano Blessi G, Forbici S. Power to the people: When culture works as a social catalyst in urban regeneration processes (and when it does not). European Planning Studies. 2016;24(11):1-18

[26] Mathie A, Cunningham G. Assetbased community development-An overview. In: ABCD Workshop, Organized by Synergies; 21 February 2002; Bangkok, Thailand. 2002

[27] McKnight JL, Kretzman JP. Building Communication from Inside Out:

A Path toward Finding and Mobilizing a Community's Asset. Chicago: ACTA Publications; 1993

[28] What is Asset-Based Community Development (ABCD). Available from: http://www. neighborhoodtransformation.net/ [Accessed: 18 December 2019]

[29] Virginia S, Elaine B, Athena S. Place of the sanctuary: An appreciative inquiry approach to discovering how communities support breastfeeding and parenting. International Breastfeeding Journal. 2019;14:25

[30] Elliott R, Fischer CT, Rennie DL. Evolving guidelines for publication of qualitative research studies in psychology and related fields. British Journal of Clinical Psychology. 1999;38:215

[31] Almusaed A. Biophilic and Bioclimatic Architecture, Analytical Therapy for the Next Generation of Passive Sustainable Architecture. London, Dordrecht, Heidelberg, New York: Springer; 2011. p. 265. DOI: 10.1007/978-1-84996-534-7

[32] Fei $\mathrm{M}$ et al. The spatial coupling effect between urban public transport and commercial complexes: A network centrality perspective. Sustainable Cities and Society. 2019;50:101645

[33] Baker S, Mehmood A. Social innovation and the governance of 
Urban Social Sustainability - Case Study; Gellerupparken-Denmark

DOI: http://dx.doi.org/10.5772/intechopen.93124

sustainable places. Local Environment:

The International Journal of Justice and

Sustainability. 2015;20(3):321-334

[34] Barot S et al. Urban ecology, stakeholders and the future of ecology. Science of the Total Environment. 2019;667:475-484

[35] Almusaed A. Urban biophilic theories upon reconstructions process for Basrah city in Iraq. In: Conference: PLEA (Passive and Low Energy Architecture). Vol. 4. Ahmedabad, Gujarat, India; 2014

[36] Nicola D, Glen B, Sinéad P, Caroline B. The social dimension of sustainable development: Defining urban social sustainability. Sustainable Development. 2011;19(5):289-300 



\title{
Urban Design, Space Economy and Survival in the City: Exploring Women's World of Work in Kumasi, Ghana
}

\author{
Ebenezer Owusu-Sekyere and Samuel Twumasi Amoah
}

\begin{abstract}
The nature of urban economic design in Kumasi, Ghana, is often reflective of neoliberal economic policies prescribed by Bretton Woods institutions during the economic reforms of the 1980s. The economic structure, which is characterized by uncertainties of formal jobs, has triggered people's ingenuity to engage in novel occupations. One economic activity that has gained popularity in Kumasi is vending of roasted traditional food (RTF) by women. This chapter explores how women have used vending of RTF to overcome years of acute austerity in the "paid" job market. It concentrates on the economic, spatial, and social networks that sustain this informal activity. Drawing on multiple data sources, the results confirm how the structure of the city space has consigned RTF vendors to obscurity, yet their activities are responding to the economic realities of time-increasing urbanization, limited job opportunities, and accumulation of poverty. As a survival strategy, the vendors have developed social connections with clients and made their place comfortable in order to claim their rightful place in the urban space economy. We conclude that given their contributions, the vendors must be appreciated as agents of change and part of the urban system.
\end{abstract}

Keywords: city, informality, roasted food, survival, women

\section{Introduction}

In the last three decades, the common discourse binding together cities in Ghana has been shrinking public welfare system and disintegration of formal job markets [1, 2]. As Thieme [3] remarks, "this has suspended and/or reshaped work opportunities for many in the potentially working population, particularly women." The many years of acute confluence of austerity have had profound implications on both psychosocial and economic make-up of women and other marginalized groups in Ghana such that their daily experiences and encounters are characterized by uncertainties and prolonged periods of desperation [2, 4]. Although Ghana has recently experienced remarkable economic growth [5], this has not translated into sufficient job creation, thereby creating a niche for the informal sector which is estimated to provide approximately $70 \%$ of jobs for women who are trapped in perpetual poverty [6]. 
Characteristically in many Ghanaian cities, vending of roasted traditional foods (RTF) has increasingly become a socially and economically constituted process that mediates how majority of women deal with livelihood challenges $[6,7]$. This perspective highlights the important role informality plays in developing economies. Even with visible evidence, the sector is generally presented as a marginalize sector of the urban economy and suggest that only market-led economic solutions can offer job opportunities and enhance quality of life [8-11]. As Chen [7] observes, such scholars perceive the informal economy as a barrier to full participation in national economies and a hindrance to long-term development and poverty reduction [12]. Meanwhile, research has revealed that the informal economy can reach higher level of organization, change the economic configuration of cities and increase the organization of labor across local, regional and global scales $[11,13,14]$.

Approaches to studying urban informal livelihood have been increasing over time $[6,7,15]$. Asiedu and Agyei-Mensah [16], for instance, focused on migrants' engagement in informal economic activities within urban settings highlighting on their survivalist strategies. Wrigley-Asante [15], expanded the knowledge base of informality in Ghana from the feminist perspective by focusing on how young female internal migrants move from rural areas to urban centers to change their life circumstances. Owusu-Sekyere et al. [17] examined the implications of informal street trading for urban governance in Kumasi. Specifically, they highlighted the daily struggles between city managers and street traders and the various strategies adopted by city authorities to decongest the streets of informal traders. Writing on informalization in Ghana, Oteng-Ababio [6], explored the complexities, degree of organizations and embedded potentials in selected informal worlds of work involving women in Agbogbloshie who engage in waste recycling.

Whilst the literature highlights the variety of activities in the informal economic sector, RTF has not attracted particular attention. Meanwhile the sector has long history of economic significance in Ghana. It provides jobs and serves as linkages between rural agriculture and the modern urban economy $[3,18]$. The economic significance notwithstanding, researchers on RTF in Ghana have concentrated on quality issues, safety requirements and regulations $[18,19]$. This research focuses on how women in Kumasi, Ghana have used vending of RTF to navigate precarious urban job environments to lunch themselves sustainable employment. The objective is to contribute to current scholarly discourse on informality by highlighting the creative enterprises of women who engage in RTF in urban Ghana, often excluded from growth and development potentials and 'trapped in external dependencies' $[6,20,21]$. The rest of the study is organized as follows: the next section discusses the theoretical debates on the subject while the methodology of the study is briefly outlined subsequently. The research results are subsequently presented and discussed. The paper concludes by stressing the significance of the informal sector in the overall urban economy.

\subsection{Urban design and the genesis of informality}

In general terms, the concept of urban design connotes the art of making a place safe, comfortable and inviting places for people. It includes the way places look, work and feel. It also includes the connections between places and buildings, the character of the built environment and the processes used for ensuring successful cities among others $[8,22]$. On the other hand, evolution of informality in Ghana has a long history. Chronological explanations credit Keith Hart-A British anthropologist to have used the term for the first time to characterize unaccounted employment opportunities in the world of work [6,23]. Hart studied how uneducated and inexperienced migrants from Northern Ghana who could not find wage 
employment in Accra negotiated a living by engaging low-income and unregulated livelihood activities [7]. Theoretically, the debate on the informal sector has been dominated by three schools of thought: the dualist, structuralist and legalistic. The dualist school was first popularized by International Labor Organization (ILO) in the 1970s. They argue that there are two types of urban economies; the poor/ informally/unemployed and the rich/formally employed. They indicate that the informal sector of the economy involves small-scale production, family ownership, labor intensive techniques and mainly produce goods and create employment and income for the poor [18]. Conversely, the formal sector is characterized by largescale production, incorporation, and the use of capital intensive technology. The ILO concludes that the informal sector mainly articulates small-scale performance and is somehow isolated from the formal sector.

The structuralist school of thought does not discount the arguments of the dualist [7]. They contend however, that formal and informal sectors are linked to one another and that the informal sector is subordinate to the formal sector. They argue that the informal sector is an integral component of total national economies, rather than the thinking that they are a marginal appendage to them [24]. This by implication means that there is a mutual corporation between the two: the informal sector supply inputs, finished goods or services either through direct transactions or via sub-contracting arrangements while the formal enterprises hire wage workers under informal employment relations as a way of reducing labor costs [7]. While the symbiotic relationship, according to the structuralist has been beneficial, the formal economy always enjoys a dominant power relationship over the informal economy [24].

The legalist argue that the popularity of the informal sector in developing economies is due to unclear and fragmented institutional and legal structures guiding the business environment. This situation restricts fair participation in the formal political and economic systems [25]. They argue that difficulties in obtaining a business license, hiring employees, knowing and complying with applicable government rules and regulations, obtaining a loan, paying taxes, enforcing a contract, and so forth have compelled many businesses to join the informal sector where there is little or no enforcement of business laws.

The three schools have provided insights for better understanding of the popularity of informality. Ghana's informal sector started gaining popularity between 1970 s and 1980s, a period characterized by general economic decline. The declining real wages and employment resulted in large scale poverty in the urban centers [26]. The years of economic decline was followed by structural adjustments which required cutbacks in government spending and public sector downsizing in general, resulting in increased unemployment in the formal sector [25]. The wide-spread economic restructuring which resulted in the formal sector's inability to generate jobs pushed many into the informal sector. Other scholars [27, 28] also argue that the popularity of the informal sector activities is due to the urban bias and labor related policies where planning was deliberately urban centered to the detriment of rural areas. This deliberate policy meant that leaders devoted the vast majority of resources towards urban development to the determinant of rural areas with direct support from development agencies and international financial institutions. The effects of such decisions were the migration of the youth to the urban centers that were not sufficiently prepared to provide formal jobs for the new urban dwellers.

\section{Study context and methodology}

The study was conducted in the Kumasi, a city whose interconnectedness with informal activities has been well documented (Figure 1). 


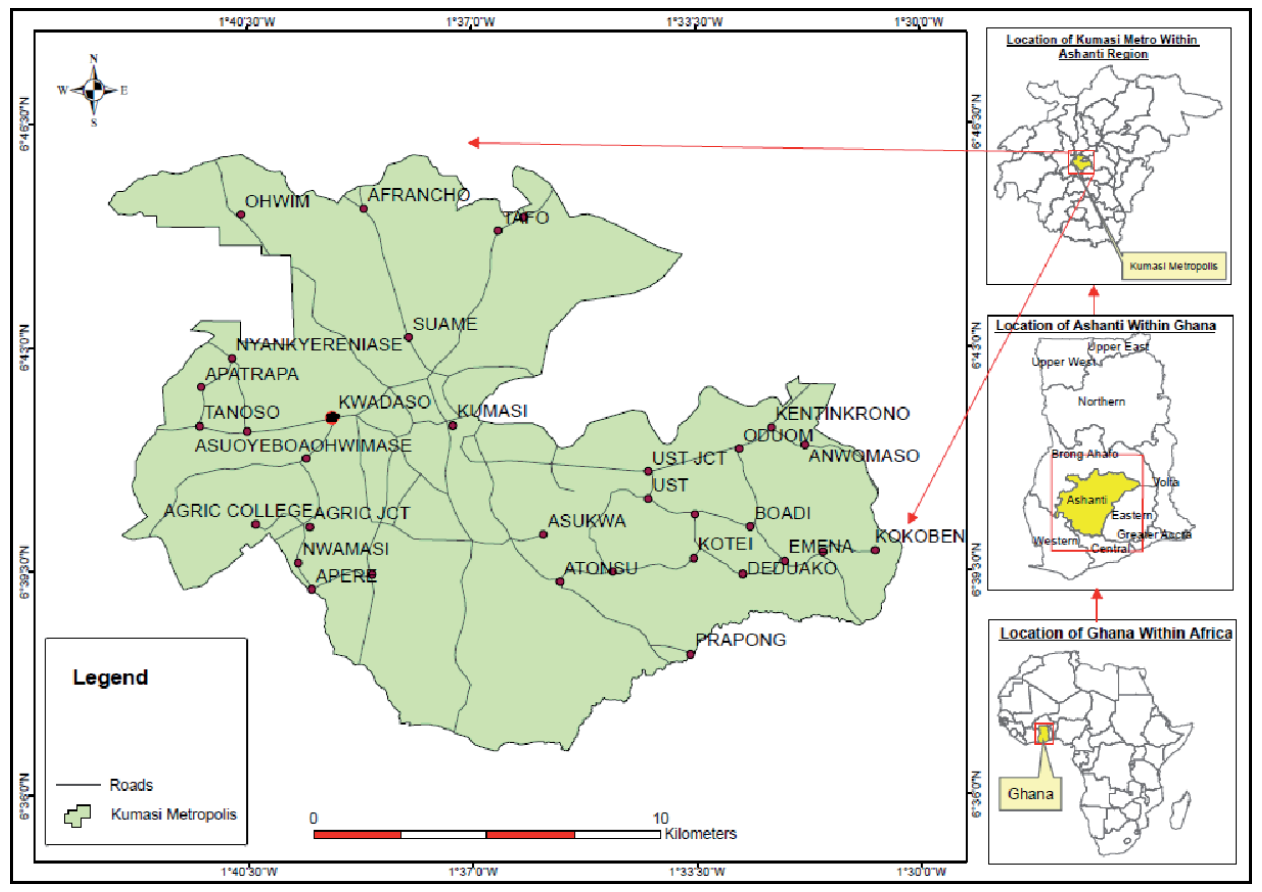

Figure 1.

Map of Ghana showing the study area.

Again the city was selected because its central location, vibrant market, rich culture and history, makes it the first choice destination for migrants not only from Ghana, but also from neighboring countries such as Mali, Burkina Faso, Niger and Togo [5, 29]. While informal food vendors in Kumasi can be classified into major groups, this study concentrate vendors of RTF and were fixed to specific locations such as pavements, verandahs and frontage of stores. They were chosen because the preliminary survey showed that their constant specific location was significant for business survival.

Previous studies revealed that Kumasi-With a population of approximately 218,172 in 1960 had its population increased more than tenfold of 50 years. As at the end of 2010, Kumasi had a population of over 2,022,919, representing an annual growth rate of 5.4\% [5], which is one of the highest recorded in the sub-region [30]. This phenomenal growth of the population has resulted in escalation in the number of people without formal employment. A national occupational structure survey explicitly shows that overall, the informal sector provides about $76.9 \%$ of most employment [5]. Again, there is female dominance in the informal jobs than male counterparts. Similarly, the economically not active population (not employed, not seeking nor available for work) shows that female proportions are higher than those of males for all age groups, ranging from $50.3 \%$ for the $15-19$ years age group to as high as $70.7 \%$ among the $35-39$ years age group. These economic indicators according to the Ghana statistical service, may have accounted for higher numbers of informality in the city.

\subsection{Data collection and analysis}

Data for the study was collected from five principal hotspots in Kumasi where women who sell RTF are common. The selected locations were the Bank street; the Fuler street, Prempeh the 2nd street and Pampaso. Two of the sites, Pampaso 
and Fuler Street connect the two most important trading centers in the West African sub-region-Kejetia and Kumasi Central Market while the Bank Street and Prempeh 2nd Street houses corporate entities in the city. The selected locations are estimated to have approximately 2000 women (by conservative estimates) earning a living directly from selling RTF [5].

The field work involved the use of qualitative research methods and incorporates in-depth interviews and firsthand observations of RTF vending as livelihood strategy. The in-depth interviews involved the use of a semi-structured interview guide. Similar to the scholarly work of Asiedu and Agyei-Mensah [16], the authors conducted a reconnaissance survey prior to the in-depth interviews to familiarize themselves with the nature of RTF vending in the selected study sites. The reconnaissance survey allowed for gained insights into their modus operandi, power relations and others, and also helped in the careful planning such that the field records that were going to be obtained remained focused and systematic in order to generate comparable data sets to aid the analysis. Based on purposive sampling technique, the first set of interviews were conducted with the president and the public relations officer from the Traditional Caterers Association. The Association was selected because it served as the mouthpiece of traditional caterers. Among the issues that were probed included economic, political and social factors influencing their working conditions, local challenges and institutions that hinder their activities.

Secondly, face-to-face interviews were held with a sample of 55 RTF. The inclusion criteria were: must sell RTF; must have been in business for more than 5 years; must have been at present location for more than 5 years and must be a member of the caterers association. The face-to-face interview approach was adopted because of the traders' busy schedule and limited educational accomplishment. Some of the issues that were interrogated in the interviews included but not limited to socioeconomic characteristics, business locational characteristics, the conduct of the food roasting business and economic outcomes, relationship with other stakeholders in the food industry and so on.

Finally, Six Key informant interviews with officials from Food and Drugs Authority; Environmental Health and Sanitation Units; Metropolitan Assembly; Ghana Tourism Authority and Environmental Protection Agency among others. The main issues that were explored included policy development and implementation on RTF, relationship with RTF, enforcement of rules and what alternative plans they have, bearing in mind RTF was not going away and that it constituted a major source of livelihood for the majority of the people. A team of 8 trained researchers who were familiar with terrain and eloquent in the local language including the author conducted the face-to-face interviews. The data collection process started in October and ended in December 2018. On average, each interview section lasted between one and two hours in length, mostly when the interviewee's responses were seen to have reached saturation point and were no longer yielding novel insights, became redundant and were only reinforcing previously collected data.

The responses were recorded with the interviewee's consent and approval and later thematically analyzed and incorporated in the general discussions. These did not only give valuable insights into their raison dêtre and livelihood strategies of the respondents but provided information regarding their personal experiences and life stories. The analytic focus on livelihoods, along with macro-economic forces and the wider policy context for the Kumasi's urban space economy, allowed for a deeper understanding of the multiple dimensions of their activities, and the strategies of the working poor in improving their lives. 


\section{Results}

\subsection{Surviving in the urban economic space}

Majority of women who participated in the study were between the ages of 25 and 56 with a mean of 36 years. Approximately $60 \%$ have not had formal of education; $30 \%$ had completed basic education with the remaining $10 \%$ completing secondary education. The results compliments available literature $[15,31]$ who observed that women who mostly are not literate enough engage in informal trading. The field evidence further showed that RTF vendors operated through experiences of uncertainty and survived through smart improvisation, frugal innovation and creative calculation of the benefits of that livelihood choice. The evidence revealed that vending of RTF required relatively little capital to start. RTF vendor with 17 years of experience explained how she started the business:

"After securing the place, I went for unusable pan from the house and filled with
sand and charcoal which I purchased on credit worth GHS 5.00 (USD 1.00 at
2018 exchange rate). I also bought ten fingers of plantain at GHS 10.00 (USD
2.00 ) also on credit. So as I worked, I also repay and pick on credit again. So that
is how I have gotten to where I am today", she concluded.

The narrative provides a snapshot of the responses of the research participants. About $70 \%$ of RTF vendors recounted how with little difficulty, they could identify the best location and within few days they had taken off. Insightfully, all RTF vendors used personal or family funds as start-up of their enterprises and these funds were paid back as profits were made. None of the RTF vendors considered borrowing funds from financial institutions due to excessive bureaucratic procedures, high interest rate and the lack of collateral security. Their joyful narratives, which depicted images of hope and happiness, explicitly highlighted emotional intensity of the business prospects. The findings indicate that majority (over 90\%) of the respondents indicated there were in the business because the opportunity of greener pastures, often associated with urbanization [25] had eluded them. The drive in the business was to make more money on the basis of which they can lay claim to decent life. For instance Ante Yaa, a vendor of RTF with 15 years of experience narrated some of the factors fostering her pursuit and survival in the business:

\footnotetext{
"This is the job that has kept me alive since my mother died. The profit I make here is able to keep me going the whole year. The reason is that this RTF does not easily go waste and therefore I am able sell anytime of the day".
}

Unlike the other informal activities that are often described as a stepping stone for a more permanent job [32], RTF vending was seen as a permanent job with long-term gains. This was evidenced from the enthusiasm and the responses given by respondents. For instance, Eno Srwaa as she is affectionately called by her clients intimated:

"I should leave this job and go where. This is what I have done to take care of my three children. The first child is a nurse, the second is a teacher and the last will complete school this year (referring to 2018)".

Fofie expressed similar sentiments, recalling how she took over from her late grandmother in 1985 when she was just 15 years. She believes she is obligated to protect the place for his children: 
Urban Design, Space Economy and Survival in the City: Exploring Women's World of Work... DOI: http://dx.doi.org/10.5772/intechopen.89673

\begin{abstract}
I recollect memories of early morning rush as customers troop in... I remember Mondays and Thursdays when fresh plantain typically arrives from the village; when buyers will queue and will be putting pressure on grandma to serve them. I vividly remember how these customers will go through the roasted plantain to make the best choice. I also remember all the advice grandma used to give me as I help her serve the customers. My brother, I cannot leave this job. Grandma's ghost will even punish me. Now, it is my turn to protect this business and hand it over to Cynthia my daughter who I am training. It is good business and provides our daily bread.
\end{abstract}

The interactions, interviews and participant observations revealed the RTF business was an immense source of hope and treasured occupation for mostly middle - to - aged women in particular, with some conspicuously scaling-up the prosperity ladder. These findings confirm earlier studies by Hart [23] who argued that informality is mostly the exclusive occupational province women in cities of developing countries have adopted to leap off the poverty train [6].

\title{
3.2 Dynamics of RTF industry
}

Understanding the dynamics of the RTF industry by situating it in the broader livelihood options within the urban setting was essential in achieving the study objective. The study revealed that the type RTF vended depended on the season of the year which also influenced the availability 'raw material'. Table 1 shows the cycle of most common RTF and the period of the year.

The Interviews revealed how RTF vendors employed season-based strategies and social resources as building blocks to legitimize and create economic spaces by trading in agricultural products. The RTF vendors gave account of how they plan their trade according to the season of the year which also determines availability of fresh food. Ante Yaa indicated that though she roast yams and plantain throughout the year. However, she indicated she mostly roasts yam between August and December while plantain roasting was at its peak between December and March the following year. The research also showed that by May, plantain and yam had gone to the lean season and maize harvesting also begins. The research revealed that between May and August, women who previously roasted yam and plantain move to sell maize.

During the analysis, yams and plantain stood out as the most lucrative among the four commonly roasted. The interviews also revealed that the vendors were better positioned to understand, communicate and respond to directly, positively and confidently the needs of the suppliers. The vendors had also built some sort of social relationship with the food suppliers based on trust such that they (vendors) are able to pre-finance the farming activities of the suppliers. In such instance, the 'sponsor' becomes the first option receiver of the harvested products. In situations of bumper harvested the sponsor determines who else is given the second chance to buy. This situation has created a network between the rural economy where food

\begin{tabular}{ll}
\hline Type of RTF & Period of availability \\
\hline Yam & August-December \\
\hline Plantain & December-March \\
\hline Maize & May-August \\
\hline Cocoyam & April-July \\
\hline
\end{tabular}

Table 1.

Roasted traditional food circle in Kumasi. 
supplies originate and the urban economy which serves as the final destination of the rural products. These embedded social capital and networks provided benefits such as information, influence and the gaining of advantage over other poorly organized informal activities.

Achiaa, a 43 year old RTF vendor narrated how she supports the farmers every year:

\begin{abstract}
"Apart from money, I also give inputs such as cutlasses, fertilizers and protective shoes. Though these things are supposed to be factored when prizing the goods but I give them out for free. I have therefore won their trust and so I am always the first to be supplied after harvesting. The advantage is that in lean seasons when the farm produce are not easy to get and the few available ones are expensive, you can still count on them for supplies", she concluded.
\end{abstract}

From the narratives extracted, the vendor's business practices-Vending RTF can significantly affect the lives of participants and provoke unusual transformations in both the rural and economies. In particular, the social networking offers yet another opportunity for a more bias discourse on informality. The analysis so far shows that informal vending has the ability to potentiate, empower and help in poverty reduction. For this reason, the study tends to concur with Hart that the continuous neglect of the "economic activities of the informal section of the labor force reflects a large gap in public policy and a lack of appreciation of the economic realities of most citizens [23]. Insightfully, it was observed that all the research participants were engaged in other multiple livelihoods to earn additional income. The additional income was from the sale of items such as bottled/sachet water, grilled salted fish (locally called Kobi) and peanuts. The research revealed that eating the RTF with Kobi and peanuts gives a good taste in the mouth.

\title{
3.3 Locating RTF within the urban space
}

Operationally, the RTF business was observed to be quite pervasive and spatially defined. The business was more intense at junctions of busy roads; along on pavements; lorry terminals and the frontages of multinational establishments. These spaces congregated large segments of the society with diverse socio-economic background. Locational negotiations skills was in sync with what Lefebvre [33] calls "the music of the city". This is because the choice of location depended on the availability of potential customers and immediacy of social interactions [34]. As argued by Lefebvre [33] the interaction between RTF vendors, customers and city authorities resembles the rhythms of daily life which he explains to mean "the differing speeds and interaction between pedestrian and automobile traffic, the comings and goings of customers... which required patient observation and reflection". It was observed RTF vendors exhibited artistry traits of vigilance but benefited a lot from the general disorder at those locations. Within the chaos each RTF vendor makes the frantic efforts to be the first to sight an on-coming 'client'. Typically, potential client were courted with all kinds of gestures. These gestures were observed to have been learned and rehearsed over and over again as business progresses. In the face-to-face interviews, a vendor had this say:

"I have chosen to roast my food on the pavements leading to the Stanbic Bank because of the huge numbers of people who pass through this area during the day. You know this is where all the big banks are located. Apart from serving the people who come do business with the banks, I also serve the bank officials in their offices. Most the 'big men' use the roasted plantain as 'fill-ins' as they wait for the real meal for lunch". 
In another face-to-face interview, a vendor who wishes to be called Sarah opined;

\begin{abstract}
"You know roasted plantain is called 'Kofi Brokeman"' and therefore most of my customers are people who are at the lower level of the economic ladder and cannot patronise normal restaurant meals. They are the people who walk on the streets a lot so when you don't choose a correct location where they could easily spot you, your daily sales might dwindle. It is for this reason that I have chosen to roast my food at the KMA traffic light. Besides selling to passers-by, I also sell to passengers in moving vehicles when the traffic light turns red", she concluded.
\end{abstract}

These few responses provide a snapshot of how by sheer dint of determination and experience, the food vendors were able to determine the locational advantage of their business.

The researcher further observed that beyond selling at specific locations, some of the food vendors have also hired the services of porters who service patrons in specific offices and shops located distant away from the location where the food was prepared. As a way of protecting their business locational advantage the traders had developed all kinds of skills to keep their place of work. Notable among these were the use tents with inscriptions and the perpetual mounting of traditional stoves that are used in the roasting business. Some more resource endowed food vendors occasionally provided what they called 'small-small tips' to night security of the nearby multinational companies to extend their night services till they (food vendors) come to work in the next morning. The interaction with the RTF vendors revealed that some have also registered the location with city authorities to keep the place as long as the State has or the rightful owner had not requested to put the space to another use.

From all indications, the choice of a particular location was influenced by myriad of factors including availability of potential customers and non-payment of rental charges. It is also important to note that having a fixed location also which results in high sales. Adwoa Yeboah narrated;

\title{
"As for me, all my customers know that I am here so when they want to buy roasted yam or plantain, they walk straight to me. I have been here for almost twelve years and therefore here is where I always want to be".
}

It is imperative to realize at this juncture that a good location was very important for the survival and sustenance of these RTF vendors in Kumasi. These findings are similar to studies by Mitullah [35], who observed that vendors in West Africa often negotiate with friends who have already been allocated spaces by local authorities at strategic locations so they can also benefit from such client base. Similarly, GSS [5] also found that vendors operate at strategic locations close to clients. This means that access to trading space and rights of access were very important factors that influenced the survival and livelihood activities in the city.

\subsection{Making money in the urban space}

The profit margins made by RTF vendors depended on the location, the type and size of RTF. The findings revealed that an average size of a finger of plantain for example, costs GHS 2.00 (50 cents at 2018 exchange rate), while sliced one costs between GHS 1.00 and GHS 1.50. There were many instances when the prices either went above or below the average prices. The price fluctuations depended

\footnotetext{
${ }^{1}$ A name inspired by its affordability and affordability
} 
on the period of the year and the availability of raw material. It was observed that on a good day, RTF vendor could earn an average income of about GHS 120.00 a figure above the daily minimum wage of GHS 10.00. These figures were based on estimates because the food vendors did not keep proper records on sales and qua revenues that accrued from their transactions. This figure represents about 10 times the average income of most formal workers in Ghana as reported by [5]. Table 2 presents estimates of daily sale reported by food vendors.

All the study participants agreed that it was not easy to sell on the street. However, it was far better than many of the casual jobs in town. Knowledge of the volume of sales is relevant for efficient planning and appreciation of the contribution of street trade. Indeed, keeping record can help in developing appropriate policies that can lead to the overall development of the national economy.

\subsection{Relationship with urban space managers}

Policy terrain concerning the urban space economy in Kumasi is regulated by different State institutions mandated to ensure that the goals of inclusive governance that seeks to promote all interest including participatory democracy and the promotion of all livelihood activities that lift people out of poverty are promoted [25]. Ghana's urban policy [36], enjoins city authorities to maintain urban economic spaces consistent with the aspirations and development needs of the people. In this context, policies on urban economic space are expected to be adopted and translated into programs and projects that respond to the needs of the people and effectively implemented to achieve objectives and targets towards the improvement of the quality of life of the generality of the urban population. Apart from the Ghana's urban policy, in 2012, the Public Health Act was revised to consolidate the laws relating to public health to ensure food safety and protect the population [37]. Prior to that, the existing legislations on food safety were scattered in bits and pieces in numerous national institutions. Table 3 summarizes some of the functions of these ministries, departments and agencies in the food vending industry.

Though the list is not exhaustive, it nonetheless depicts how these State institutions are assigned responsibilities of facilitating the establishment of sectorial policies; and guard their implementation and compliance. The experience so far indicates that these policies, though well intentioned, are not well coordinated at the Ministerial levels as each institution acts independently. A key informant at the Kumasi Metropolitan Assembly explained in the interview section that the policies and responsibilities of the State as explained in Table 3 also places responsibilities on RTF vendors. Among other things, the food vendors were expected to use of protective clothing; undergo regular medical screening and training on food hygiene and safety. Again, the food vendors were expected to keep records of their daily sales for the purposes of tax assessment and payment.

In-depth interviews with officers from Food and Drug Authority and the Environmental Health Unit revealed these outfits had not been able to organize

\begin{tabular}{ll}
\hline Typology & Estimated daily sales \\
\hline $\begin{array}{l}\text { Roasted yam or } \\
\text { plantain }\end{array}$ & $\begin{array}{l}\text { "For me, selling RTF is a good business. I can sell GHS 500.00 a day especially on a market } \\
\text { day. Even the day sales is not good I can sell GHS 200.00". }\end{array}$ \\
\hline Roasted corn or & "Every day I am able to sell about GHS 200.00. Every month I am able to send my parents \\
cocoyam & $\begin{array}{l}\text { about GHS 100.00 That is what they using to take care of my other siblings' education in the } \\
\text { village". }\end{array}$ \\
\hline
\end{tabular}

Table 2.

Estimated daily sales of street traders. 
Urban Design, Space Economy and Survival in the City: Exploring Women's World of Work... DOI: http://dx.doi.org/10.5772/intechopen.89673

\begin{tabular}{|c|c|}
\hline Agency & Responsibilities \\
\hline $\begin{array}{l}\text { Food and Drugs } \\
\text { authority }\end{array}$ & $\begin{array}{l}\text { Has the overall regulatory authority mandate to regulate the food industry. Has } \\
\text { the responsibility for providing policy direction and proposing law reform for } \\
\text { the food and beverage industry. They also carry out training sessions to educate } \\
\text { street food vendors on food hygiene and safety }\end{array}$ \\
\hline $\begin{array}{l}\text { Environmental health } \\
\text { and sanitation units }\end{array}$ & $\begin{array}{l}\text { They are tasked with the oversight responsibility of protecting public health } \\
\text { at the local level. They also conduct food premises inspections and monitor } \\
\text { medical examination status of food vendors as part of their work. }\end{array}$ \\
\hline $\begin{array}{l}\text { Municipal, } \\
\text { metropolitan and } \\
\text { district assemblies }\end{array}$ & $\begin{array}{l}\text { Local authorities and have legal mandate to enact bye-laws regarding food } \\
\text { hygiene and safety. They also carry out education and training sessions for food } \\
\text { vendors across the country and their efforts in this regard are complemented by } \\
\text { the Ghana Traditional Caterers Association-A union of food vendors in Ghana. }\end{array}$ \\
\hline $\begin{array}{l}\text { Ghana tourism } \\
\text { authority }\end{array}$ & $\begin{array}{l}\text { They are mandated to register and inspect catering enterprises They also carry } \\
\text { out education and training sessions for food vendors across the country and } \\
\text { their efforts }\end{array}$ \\
\hline $\begin{array}{l}\text { Environmental } \\
\text { Protection Agency }\end{array}$ & $\begin{array}{l}\text { Together with the Environmental Health and Sanitation Units and Municipal, } \\
\text { Metropolitan and District Assemblies, they are tasked with the oversight } \\
\text { responsibility of protecting public health at the local level and also conduct food } \\
\text { premises inspections and monitor medical examination status of food vendors } \\
\text { as part of their work. }\end{array}$ \\
\hline $\begin{array}{l}\text { Ghana traditional } \\
\text { caterers association }\end{array}$ & $\begin{array}{l}\text { It has the sole responsibility of registering members and organizes capacity } \\
\text { building workshops for their members from time to time on food hygiene and } \\
\text { safety }\end{array}$ \\
\hline Criminal code & $\begin{array}{l}\text { The Code provides the standards for the sale of food and drugs and related } \\
\text { matters. The Code criminalizes the sale of unwholesome food and sale of food } \\
\text { under insanitary conditions and provides the respective penalties for culprits. }\end{array}$ \\
\hline MOF & $\begin{array}{l}\text { Responsible for release of funds based on approved budgets and also ensuring } \\
\text { that adequate budgetary allocations are made available by relevant state } \\
\text { institutions. }\end{array}$ \\
\hline
\end{tabular}

Table 3.

Institutional responsibilities towards food vending in Ghana.

workshops for street vendors in Kumasi, a situation all interviewees blamed on increasing numbers of RTF in the Metropolis in the face chronic under funding. Interestingly, these agencies could not estimate the number of women engaged RTF in the city meanwhile, availability of accurate data is a sine qua non for effective policy planning and implementation. Further probe revealed that the State institutions were ill-equipped, in terms of human resource capacity and other logistics to ensure effective monitoring of all RTF vendors within their jurisdiction. It therefore came as no surprise that almost all the RTF vendors had not followed the requirement for so many years and have not been sanctioned too. As indicated by one RTF vendor who also had five female assistants who help in the business:

"I cannot remember anytime an officer came here for inspection. Though I know I need to go for regular health check, but because of the charges I have not gone for the past six years. After all, if you do not go, nobody will arrest you".

These sentiments were shared by all research participants in the RTF industry. As indicated by Asantewaa, a 45 year old roasted corn seller:

"Since I started this business, nobody has told me what to do. I do not need anybody to tell me to keep my environment clean. This people (referring to city authorities) 
all they know is tax. If you do not pay then they will cease your things", she concluded.

Another 53 year old vendor corroborated the narratives of Asantewaa:

"I use to be a member of the Traditional Caterers Association but since 2009, I have not attended any of the workshops they organize because I realize those of us the city authorities know are the ones they have been chasing for tax and those who don't go, nobody worries them. Since I stopped, nobody has come to ask me of tax".

The responses and field observations suggest that the only interaction that occurs regular between city authorities and the RTF vendors is in the area of tax collection. Insightfully, the study revealed that unlike other informal vendors who are constantly evicted from the streets of Kumasi (see Owusu-Sekyere et al. [17]), the RTF vendors laid claim to their business location without harassment though without any proper documentations. The empirical evidence revealed a disjuncture between expectation of policy implementation on the city's space management and food vendors' appreciation the laws governing their operations.

\section{Discussion}

The results points to the fact that RTF vending infers a constant search for opportunities outside formal employment. It assumes a continuous management of the complexities associated with living and working beyond formal institutional norms [3]. The analysis of the field evidence confirms that vending of RTF as economic activity has a long history in the Ghanaian economy but the realities of the times-Increasing urbanization, lack of job opportunities and accumulation of poverty in Ghanaian cities appear to be changing the dynamics [38]. The occupation has become a competitive arena not because of the increasing number of people involved but because it has become the mainstream economic activity for a large section of the urban population, particularly women. The occupation, just as any informal activity is witnessing a new wave of complexity, unpredictability and culture sensitivity which has necessitated the need to adopt new methodological and conceptual approach particularly in terms of sourcing for continuous supply of raw material and competing for customers [28].

So far the analysis points to the fact that RTF is no longer a preserve for the poor but a popular delicacy for both the rich and the poor. Again, the significance of RTF vending is its significance in the normal food value chain. The results confirms that the sector plays an important role in employment creation by providing incomes to unskilled and semi-skilled workers who otherwise would be unemployed. Studies have shown that in Africa the sector provides $50-75 \%$ of employment [39], and 72\% of non-agricultural employment [26, 40]. Chen [7] estimated that $93 \%$ of new jobs created in sub-Saharan Africa during the 1990s were in the informal sector while nearly $90 \%$ of the labor force in Ghana comes from the sector [26]. Despite the overwhelming contributions the sector makes to the overall GDP, it still remains in the shadows of the formal economy. The sector does get the needed recognition in the national development discourse. In many instances, RTF vendors suffer side-lining and aggressions from city authorities. What is more, they do not have the needed collateral to attract the needed funding that could boost their operations and enhance their output. They are also not protected by the large portions of the labor law in Ghana partly because they are 
not unionized. Though the Traditional Caterers Association is supposed to articulate their interest in national development discourse, the research revealed that this voluntary organization lacks the teeth to bite, a situation that was also espoused by the UN-HABITAT in 2013 [22].

The results from the analysis provides the basis for a proper conceptualization of the significance of the informal sector. The evidence overwhelmingly suggests that the informal food vendors' motivations are based on their lived experiences in the city and the economic stature and social responsibility. From the results, it can be seen that RTF vending was a normal and familiar activity, not deviant and somehow unnatural as posited by Simon in 2015 [41]. It is for this reason that [41], theorizes that the frequent connection between informality and poverty as too naive and in need of unloading. The findings therefore indicates that any policy intervention for the informal sector that is premised on only the survivalist perspective can potentially generate uninformed - and ultimately misleading and misguided-Policy [6, 42]. To understand and appreciate the importance of informal food vending in the urban space economy, Carmody and Owusu [43] and Myers [12], suggest that it is important to seek a more ontological approach that can explore and elaborate on its complexities.

\section{Conclusion and recommendation}

This article locates the possibilities for rethinking and researching urban employment through the analytical frame of informality, drawing from qualitative research conducted in Kumasi. It draws on how over the last three decades, women in urban Ghana have used vending of RTF as a means to lunch themselves sustainable jobs. From the findings, selling RTF can no longer be described as just a 'survival activity' for a few marginalized people in the city but a means of contributing to the overall national income. This is because for majority of them, their daily incomes were far higher than that of the legally set minimum wage by the State. For the RTF vendors, they are engaged in a full time job by using their creative entrepreneurial skills and responding uniquely to the void of state provision of equal opportunities and access to basic urban employment.

The overall findings blur, complicate and raise legitimate questions about earlier propositions that the all informal sector activities only mops up excess or entrenched workers. Rather, the study has revealed that the sector is a vibrant and entrepreneurial part of the economy which can stimulate economic growth and job creation. This paper therefore argues that employment in the informal sector is no longer a journey, but has become the destination for many. Based on the findings the paper recommends that there is the need to establish an enabling environment and supportive regulatory framework that can accommodate informal sector workers. Such a framework can incorporate the sense of grassroots organization in which case informal enterprises can be represented at all levels of national development. That framework can strengthen the Traditional Caterers Association such that they can have the power and ability to lobby and influence decisions on behalf of members. As a matter of urgency, it is proposed that the Government need to unequivocally recognize and admit the importance of the informal sector and find ways to encourage its growth, though not at the expense of the formal sector. Indeed the greatest strength and advantage will be to establish a symbiotic relationship between the informal and formal sectors so they can work to complement each other. It is believed that this dualism that can lead the urban economy to the 'promise land' of prosperity. 


\section{Acknowledgements}

We are grateful to staff of Kumasi Metropolitan Assembly and the anonymous reviewers and the editors of the journal for their great and constructive comments.

\section{Conflict of interest}

None declared.

\section{Author details}

Ebenezer Owusu-Sekyere ${ }^{1 *}$ and Samuel Twumasi Amoah ${ }^{2}$

1 Department of Development Studies, University for Development Studies, Ghana

2 Department of Environment and Resource Studies, University for Development Studies, Ghana

*Address all correspondence to: osekyere@uds.edu.gh

\section{IntechOpen}

(C) 2020 The Author(s). Licensee IntechOpen. This chapter is distributed under the terms of the Creative Commons Attribution License (http://creativecommons.org/licenses/ by/3.0), which permits unrestricted use, distribution, and reproduction in any medium, provided the original work is properly cited. (cc) BY 
Urban Design, Space Economy and Survival in the City: Exploring Women's World of Work... DOI: http://dx.doi.org/10.5772/intechopen.89673

\section{References}

[1] Harvey D. Rebel Cities: From the Right to the City to the Urban Revolution. London: Verso; 2012

[2] Honwana L. The Time of Youth: Work, Social Change and Politics in Africa. Hartford, CT: Kumarian Press; 2012

[3] Thieme T. The hustle economy: Informality, uncertainty and the geographies of getting by. Progress in Human Geography. 2017;42(4):529-548

[4] Dhillon N, Yousef T. Inclusion: The 100 Million Youth Challenge. Middle East Youth Initiative. Dubai School of Government. 2007. Available from: http://www.meyi [Accessed: 10 March 2017]

[5] Ghana Statistical Service (GSS). 2010 Population and Housing Census: Summary Report of Final Results. Accra: Ghana Statistical Service; 2012

[6] Oteng-Ababio M. Crossing conceptual boundaries: Re-envisioning coordination and collaboration among women for sustainable livelihoods in Ghana. Local Environment. 2018;23(18):1-19

[7] Chen MA. The Informal Economy: Definitions, Theories and Policies; WIEGO Working Paper No 1; 2012

[8] UNEP. Cities: Investing in Energy and Resource Efficiency. Geneva: United Nations Environment Programme; 2011

[9] Brand U. Green economy-The next oxymoron? No lessons learned from failures of implementing sustainable development. GAIA-Ecological Perspectives for Science and Society. 2012;21:28-32

[10] Brockington D. A radically conservative vision? The challenge of UNEP's towards a green economy.
Development and Change.

2012;43:409-422

[11] Simon D. Climate and

environmental change and the potential for greening African cities. Local Economy. 2013;28:203-217

[12] Myers G. Urban Environments in Africa: A Critical Analysis of Environmental Politics. Bristol: Policy Press; 2016

[13] Herod A, Pickren G, Rainnie A, McGrath CS. Global destruction networks, labour and waste. Journal of Economic Geography. 2014;14:421-441

[14] Grant R, Oteng-Ababio M. The global transformation of materials and the emergence of informal 'Urban Mining' in Accra, Ghana. Africa Today. 2016;62(4):3-20

[15] Wrigley-Asante C. Accra turns lives around: Female migrant traders and their empowerment experiences in Accra, Ghana. Multidisciplinary Journal of Gender Studies. 2014;3(2):341-367

[16] Asiedu A, Agyei-Mensah S. Traders on the run: Activities of street vendors in the Accra metropolitan area, Ghana. Norwegian Journal of Geography. 2008;62(3):191-202

[17] Owusu-Sekyere E, Twumasi SA, Teng-Zeng F. Tug of war: street trading and city governance in Kumasi, Ghana. Development in Practice. 2016;26(7):906-919

[18] International Labor Organization (ILO). Women and Men in the Informal Economy: A Statistical Picture. Geneva: ILO; 2002

[19] ISSER. Ghana Social Development Outlook. Accra: University of Ghana; 2012 
[20] Scholz A. Don't Turn Out the Lights: Entrepreneurship in Rural Saskatchewan. University of Saskatchewan Council for Community Development. Saskatoon, Saskatchewan: University Extension Press; 2000

[21] Kulke E, Staffeld R. Informal production systems-The role of the informal economy in the plastic recycling and processing industry in Dhaka. Die Erde. 2009;140(1):25-43

[22] UN-HABITAT. State of Women in Cities 2012-2013: Gender and the Prosperity of Cities. Nairobi: UN-Habitat; 2013

[23] Hart K. Bureaucratic from and the informal economy. In: Guha-

Khasnobis B, Kanbur R, Ostrom E, editors. Linking the Formal and Informal Economy: Concepts and Policies. Oxford: Oxford University Press; 2006. pp. 21-35

[24] Ngiba CN, Dickinson D, Whittaker L, Beswick C. Dynamics of trade between the formal sector and informal traders: The case of fruit and vegetable sellers at Natalspruit market, Ekurhuleni. South African Journal of Economic and Management Sciences. 2009;4:462-474

[25] Obeng-Odoom F. The informal sector in Ghana under siege. Journal of Developing Societies. 2011;27(3, 4): 355-392

[26] African Union. Study on the informal sector in Africa. In: Sixth Ordinary Session of the Labor and Social Affairs Commission of the African Union, Addis Ababa. 2008

[27] Lipton M. Why Poor People Stay Poor: Urban Bias in World Development. Boston: Harvard University Press; 1977

[28] Schneider F, Klingrnair R. Shadow Economies Around the World: What do we Know? University of Link
Department of Economics Working Paper, No.0403; 2004

[29] Anyima-Ackah J. AMA versus traders and hawkers-What questions are raised? In: The Ghanaian Times 2005. The Ghanaian Times Newspaper; 31 Aug 2005

[30] Owusu-Sekyere E. Scavenging for wealth or death? Exploring the health risk associated with waste scavenging in Kumasi. Ghana Journal of Geography. 2014;6:63-80

[31] Awumbila M, Ardayfio-Schandorf E, et al. Norwegian Journal of Geography. 2008;52(3):171-179

[32] Agarwal S, Attah M, Apt N. Bearing the weight: The Kayayoo, Ghana's working girl child. International Social Work. 1997;40(3):245-265

[33] Lefebvre H. Writings on Cities.

Translated by Eleonore Kofman and

Elizabeth Lebas. Oxford: Blackwell; 1996

[34] Crotty M. Strategic visibility and the production of day-labor spaces:

A case study from the San Diego metropolitan area. Urban Affairs Review. 2018;54(3):593-631

[35] Mitullah WV. Street Vending in African cities: A Synthesis of Empirical Findings from Kenya, Cote d' Ivoire, Ghana, Zimbabwe, Uganda and South Africa. Background Paper for the 2005 World Development Report; 2004

[36] Osumanu IK, Nyaaba AJ, Tuu NG, Owusu-Sekyere E. From patches of villages to a municipality: Time, space, and expansion of Wa, Ghana. Urban Forum. 2018;30:57-74

[37] Public Health Act. Act 851. 2012. Available from: faolexl.fao.org [Accessed: 24 October 2018]

[38] Monney I, Dramani JB, Aruna A, Tenkorang AG, Osei-Poku F. Health and 
Urban Design, Space Economy and Survival in the City: Exploring Women's World of Work... DOI: $h t t p: / / d x$.doi.org/10.5772/intechopen.89673

safety in high-risk work environments:

A study of fuel service stations in

Ghana. Journal of Environmental and

Occupational Science. 2015;4(3):133

[39] Habitat UN. Global Report

on Human Settlements 2003: The

Challenge of Slums. Nairobi, Kenya: UN

Habitat; 2003

[40] Verick S. The Impact of

Globalization on the Informal Sector

in Africa. Economic and Social Policy

Division. Addis Ababa: UNECA; 2008

[41] Simon D. Uncertain times, contested resources: Discursive practices and lived realities in African urban environments. City. 2015;19:216-238

[42] Lucci P. Leaving No One Behind: Improving Data to Monitor Progress in Slum Areas. Development Progress (blog post). 2014. Available from: http://www.development [Accessed: 29 August 2018]

[43] Carmody P, Owusu F.

Neoliberalism, urbanization and change in Africa: The political economy of heterotopias. Journal of African

Development. 2016;18(18):61-73 



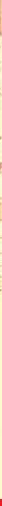

\section{Edited by Amjad Almusaed, Asaad Almssad and Linh Truong - Hong}

This book has been prepared to embody the major and efficient applications of the different duties and the role of sustainability in urban planning and design, by a new reading of the city structure and composition, as well as offering a solid and clear concept for this kind of science. The book aims to illustrate various theories and methods of the treatment of the modern ideas of metropolitan life. The book is divided into two parts and contains 23 chapters.

\section{IntechOpen}
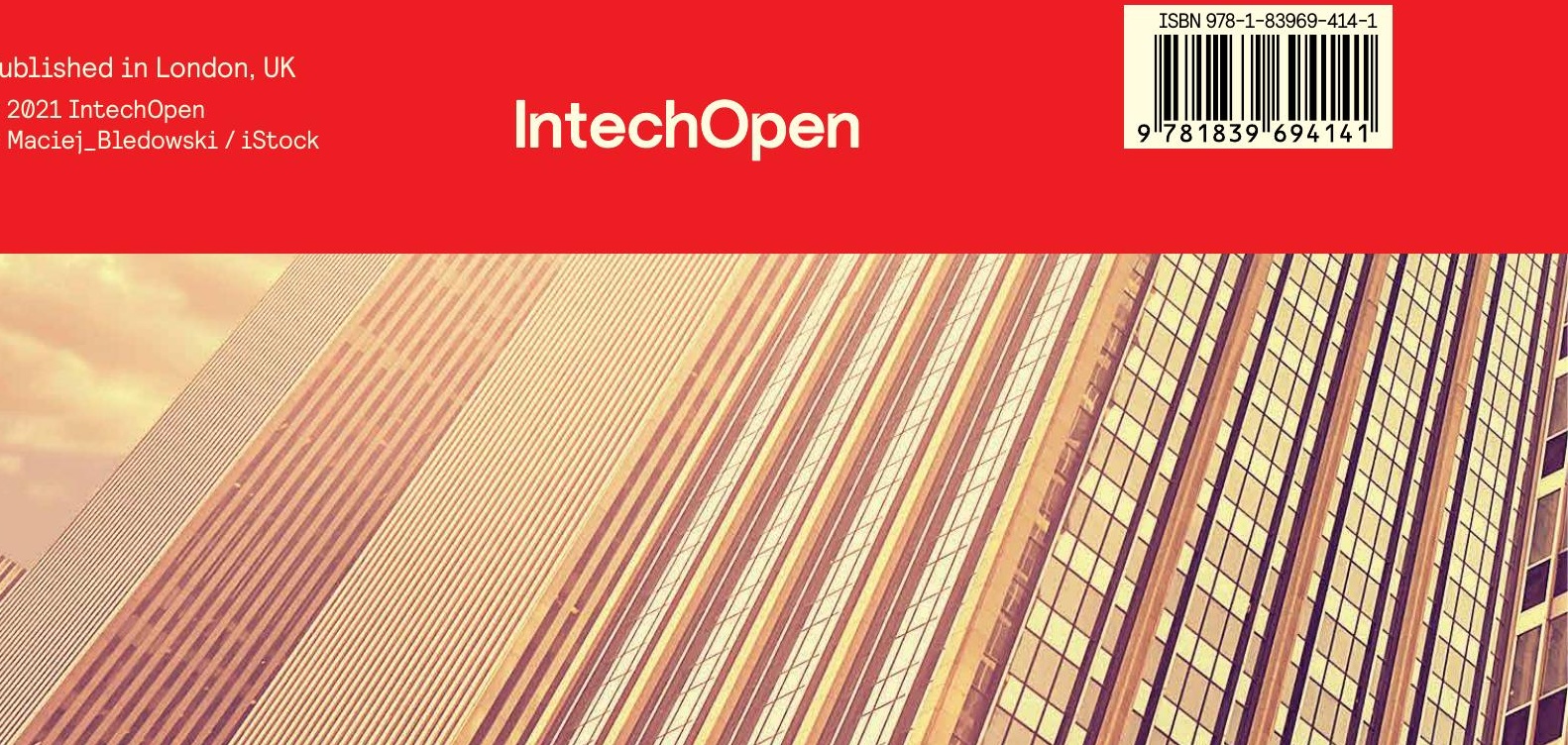